UNIVERSIDADE DE BRASÍLIA

FACULDADE DE TECNOLOGIA

DEPARTAMENTO DE ENGENHARIA MECÂNICA

CARACTERIZAÇÃO REOLÓGICA DE FLUIDOS COMPLEXOS EM CISALHAMENTO LINEAR E TUBO CAPILAR

NUNO JORGE SOUSA DIAS

ORIENTADOR: FRANCISCO RICARDO DA CUNHA

TESE DE DOUTORADO EM CIÊNCIAS MECÂNICAS

PUBLICAÇÃO: ENM.TD - 022 A/2014

BRASÍLIA/DF: NOVEMBRO - 2014 

UNIVERSIDADE DE BRASÍLIA

FACULDADE DE TECNOLOGIA

DEPARTAMENTO DE ENGENHARIA MECÂNICA

\section{CARACTERIZAÇÃO REOLÓGICA DE FLUIDOS COMPLEXOS EM CISALHAMENTO LINEAR E TUBO CAPILAR}

NUNO JORGE SOUSA DIAS

TESE DE DOUTORADO SUBMETIDA AO DEPARTAMENTO DE ENGENHARIA MECÂNICA DA FACULDADE DE TECNOLOGIA DA UNIVERSIDADE DE BRASÍLIA, COMO PARTE DOS REQUISITOS NECESSÁRIOS PARA A OBTENÇÃO DO GRAU DE DOUTOR EM CIÊNCIAS MECÂNICAS.

APROVADA POR:

Prof. Francisco Ricardo da Cunha, PhD (ENM-UnB)

(Orientador)

Prof. Hector Daniel Ceniceros, PhD (UCSB/USA)

(Examinador Externo)

Prof. Márcio da Silveira Carvalho, PhD (PUC/RJ)

(Examinador Externo) 
Prof. Rafael Gabler Gontijo, PhD (ENM-UnB)

(Examinador Interno)

Prof. Taygoara Felamingo de Oliveira, PhD (ENM-UnB)

(Examinador Interno)

BRASÍLIA/DF, 17 DE NOVEMBRO DE 2014. 


\section{FICHA CATALOGRÁFICA}

\section{DIAS, NUNO JORGE SOUSA}

Caracterização Reológica de Fluidos Complexos em Cisalhamento Linear

e Tubo Capilar

[Distrito Federal] 2014.

xv, 312 f. : il. ; 30 cm (ENM/FT/UnB, Doutor, Ciências Mecânicas, 2014).

Tese de Doutorado - Universidade de Brasília.

Faculdade de Tecnologia.

Departamento de Engenharia Mecânica.
1. Reologia
2. Microestrutura
3. Emulsões $\mathrm{O} / \mathrm{A}$
4. Ferrofluido
I. $\mathrm{ENM} / \mathrm{FT} / \mathrm{UnB}$
II. TD $22 / 14$.

CDU 532:62

\section{REFERÊNCIA BIBLIOGRÁFICA}

DIAS, N. J. S. (2014). Caracterização Reológica de Fluidos Complexos em Cisalhamento Linear e Tubo Capilar. Tese de Doutorado em Ciências Mecânicas, Publicação ENM.TD - 022A/2014, Departamento de Engenharia Mecânica, Universidade de Brasília, Brasília, DF, 312 f.

\section{CESSÃO DE DIREITOS}

NOME DO AUTOR: Nuno Jorge Sousa Dias.

TÍTUlO DA TESE DE DOUTORADO: Caracterização Reológica de Fluidos Complexos em Cisalhamento Linear e Tubo Capilar.

GRAU / ANO: Doutor / 2014

É concedida à Universidade de Brasília permissão para reproduzir cópias desta dissertação de mestrado e para emprestar ou vender tais cópias somente para propósitos acadêmicos e científicos. O autor reserva outros direitos de publicação e nenhuma parte desta dissertação de mestrado pode ser reproduzida sem a autorização por escrito do autor.

Nuno Jorge Sousa Dias

e-mail: njsdias@gmail.com 


\section{DEDICATÓRIA}

"Dedico este trabalho a meus pais e irmã que sempre me apoiaram com suas palavaras de incentivo e de calma, mesmo estando longe de casa." 


\section{AGRADECIMENTOS}

Agradeço ao meu orientador, Prof. Francisco Ricardo da Cunha, pelos seus ensinamentos que fortaleceram o meu conhecimento e crescimento profissional. Agradeço também por ter acreditado em mim e por me ter adotado nesta jornada de 4 anos, estando sempre atento a ajudar-me a superar qualquer dificuldade, tanto profissional como pessoal.

Aos Profs. Gustavo Abade, Taygoara Felamingo de Oliveira, Yuri Sobral e Roseany Lopes agradeço pelas discussões de diversos assuntos relevantes para este trabalho.

Agradeço a todos os amigos do grupo Vortex pela amizade e companheirismo e pelos momentos que me ajudaram a ultrapassar as diversas dificuldades cotidianas.

Agradeço ao aluno Yuri Zeniti Sinzato, recém chegado ao grupo Vortex, pela sua preciosa colaboração.

Agradeço a minha namorada Michele Souza Marques pelo seu apoio emocional, paciência e compreensão.

"O conhecimento é em si mesmo o poder."

Francis Bacon (1561-1626)

"O professor tem sucesso no momento em que seu aluno se torna original."

Lane Cooper (1875-1959)

"Um professor influencia a eternidade: ele não pode jamais dizer onde termina a sua influência."

Henry Brooks Adams (1838-1918) 


\title{
RESUMO
}

\section{CARACTERIZAÇÃO REOLÓGICA DE FLUIDOS COMPLEXOS EM CI- SALHAMENTO LINEAR E TUBO CAPILAR}

\author{
Autor: Nuno Jorge Sousa Dias \\ Orientador: Francisco Ricardo da Cunha \\ Programa de Pós-graduação em Ciências Mecânicas \\ Brasília, Novembro de 2014
}

Nesta tese as principais contribuições são referentes às medidas de viscosidade aparente e efetiva de emulsões diluídas e concentradas para diferentes razões de viscosidade gota-fluido base sujeitas a cisalhamento simples e oscilatório e em escoamento em tubo capilar. Estudos experimentais em reologia de emulsões com moderadas e altas razões de viscosidade foram muito pouco explorados na literatura. Em adição, investigase o comportamento reológico de uma suspensão coloidal magnética em cisalhamento permanente e oscilatório medindo-se a viscosidade da suspensão em função do campo magnético e da taxa de cisalhamento adimensional para uma fração volumétrica de 3,9\%. Investiga-se também a tensão aplicada crítica (ou residual) do fluido magnético em função do número de capilaridade magnético. Novamente esses estudos são ainda incipientes na atual literatura.

Este estudo começa pela abordagem teórica de escoamento de emulsões em tubo. A viscosidade do fluido é ajustada por modelos típicos de fluidos newtonianos generalizados. Neste caso é dada atenção ao escoamento da emulsão pela região central do tubo, considerando uma região livre de partículas adjacente à parede do tubo. As expressões obtidas de viscosidade intrínseca são adimensionalizadas pela viscosidade do fluido base da suspensão em função da espessura da camada livre de gotas. Estuda-se o efeito da dimensão da camada livre de gotas na reologia de suspensões.

Devido a formação de uma possível camada limite de gotas adjacente à parede do tubo capilar é proposto um modelo teórico para entender do ponto de vista físico os mecanismos de migração-difusão que podem levar à formação dessa camada. O 
desenvolvimento da camada livre de gotas é estudado, em regiões de parede, por um modelo que considera interações hidrodinâmicas partícula-partícula e partícula-parede em emulsões de baixa fração volumétrica e alta razão de viscosidade. O problema é tratado como sendo um problema semi-infinito. É obtida uma equação de transporte para a fração volumétrica que considera a velocidade de cisalhamento, a velocidade de advecção na direção normal do escoamento e um termo de difusão hidrodinâmica para regimes diluídos e pequenas deformações. Por meio de uma solução assintótica para regiões mais próxima à parede é obtida uma expressão para prever a espessura da camada livre de gotas. É de se referir que a previsão da espessura dessa camada por este modelo é comparada com o modelo de escoamento em tubo capilar em função de dados experimentais obtidos pelas medidas do escoamento unidirecional em tubo capilar. Os resultados dos modelos são idênticos para emulsões diluídas em altas razões de viscosidade.

A tensão interfacial é um parâmetro fundamental para o cálculo do número de capilaridade. Pelo estudo da variação da tensão interfacial com o aumento da concentração de surfactantes sabe-se qual é a concentração acima da qual a tensão interfacial atinge o seu valor de saturação. A tensão interfacial é medida entre o óleo mineral e o fluido base. Observa-se que a tensão superficial diminui com o aumento da quantidade de glicerina no fluido base. Os resultados adimensionais estão de acordo com a equação de Szyszkowski. Verifica-se um decréscimo da tensão interfacial com o aumento da concentração de surfactante. A tensão interfacial apresenta um tempo de equilíbrio em torno de $600 \mathrm{~s}$. Estes resultados foram ajustados pelo modelo de Cross. Os resultados experimentais mostram que o surfactante Tween80 precisa de uma menor concentração para diminuir a tensão interfacial mas o surfactante Span80 permite atingir menores tensões interfaciais.

A análise reológica é realizada com emulsões de gotas de óleo mineral dispersas em um líquido base composto de uma mistura de água e glicerina para se atingir diferentes condições de razões de viscosidade da emulsão. As emulsões são caracterizadas por microscopia óptica de forma a avaliar o índice de polidispersidade. São analisadas emulsões de diferentes razões de viscosidade $(2,5,10$ e 20) com diferentes frações 
volumétricas $(2 \%, 5 \%, 20 \%, 40 \%)$. A reologia destas emulsões é analisada em função de parâmetros adimensionais, como o número de capilaridade que considera o raio médio da gota e a tensão interfacial da emulsão.

A reologia das emulsões de diferentes razões de viscosidade (2, 5, 10 e 20) com diferentes frações volumétricas $(2 \%, 5 \%, 20 \%, 40 \%)$ é estudada pelo escoamento unidirecional em tubo capilar. Para medir a pressão do escoamento em função da vazão imposta, são calibradas membranas de um transdutor de pressão com um manômetro digital. Nesses experimentos mede-se a viscosidade aparente da emulsão, calculada com propriedades avaliadas na parede do capilar, como também a viscosidade intrínseca ou efetiva baseada na Lei de Poiseuille. Todas as emulsões apresentaram efeito pseudoplástico em função do aumento do número de capilaridade. Os resultados mostram que a viscosidade das emulsões de altas frações volumétricas aumenta com a diminuição da razão de viscosidade, devido ao aumento da viscosidade do fluido base. No entanto, quando a viscosidade é adimensionalizada pela viscosidade do fluido base esta mostra a tendência de aumentar com a razão de viscosidade.

As emulsões estudadas pelo escoamento em tubo capilar são também analisadas em escoamento linear (simples) por um reômetro de discos. O reômetro é equipado com um sistema de controle inteligente do espaçamento de fluido entre os discos e o controle de temperatura é feito com um sistema Peltier. Os ensaios são realizados em cisalhamento linear permanente. A viscosidade aparente e efetiva das emulsões é analisada em função do número de capilaridade, da fração volumétrica e da razão de viscosidade. Os resultados mostram que a viscosidade da emulsão apresenta um comportamento pseudo-plástico para as maiores frações volumétricas e menores razões de viscosidade. No entanto, os resultados da presente tese indicam que mesmo em frações volumétricas moderada (20\%), para razões de viscosidade em torno de 10 a emulsão apresenta um comportamento próximo ao diluído já que as deformações entre gotas não produzem deformações comparáveis aquelas produzidas pelo cisalhamento atuando em uma gota isolada.

Os resultados experimentais do escoamento simples e em tubo capilar são comparados 
com modelos teóricos que prevêm a viscosidade aparente da emulsão. Os dados experimentais estão em concordância com os modelos teóricos para emulsões diluídas em altas razões de viscosidade.

As emulsões de maior fração volumétrica $(50 \%, 60 \%$ e $70 \%)$ de diferentes razões de viscosidade (10 e 20) são estudadas em cisalhamento linear e em cisalhamento oscilatório. Os resultados em cisalhamento linear mostram um maior efeito pseudo-plástico na emulsão de maior fração volumétrica. No cisalhamento oscilatório investiga-se regimes de viscoelasticidade linear e não-linear do comportamento dos módulos viscoso e elástico da emulsão em função da deformação para uma fração volumétrica 50\%, 60\% e 70\% e razão de viscosidade 10 e 20. Observa-se que o comportamento elástico típico de sólidos aparece com o aumento da fração volumétrica e da razão de viscosidade em deformações menores que 0,01. Com o aumento da razão de viscosidade para a fração volumétrica de $70 \%$ o efeito elástico típico de sólido é mais destacado.

A reologia do ferrofluido é estudada em cisalhamento simples e oscilatório em função do campo magnético e do número de capilaridade magnético. Observa-se o comportamento pseudo-plástico quando as tensões de cisalhamento viscosas começam a romper (ou degradar) as estruturas de agregados e cadeias inicialmente formadas pela aplicação do campo. Verifica-se o efeito magnetoviscoso, que representa o aumento da viscosidade com o aumento da intensidade do campo magnético devido à formação de um maior número de agregados. Em cisalhamento oscilatório observa-se que o fluido magnético apresenta um comportamento elástico típico de sólidos com o aumento do campo magnético. A função de relaxação do fluido magnético para um campo magnético constante, que é medida pelo software que acompanha o reômetro, é obtida após a interrupção da deformação. Observa-se que quanto maior é a deformação maior é o tempo para que a função de relaxação atinja o seu valor de equilíbrio. A tensão residual é analisada em função da taxa de cisalhamento. Observa-se que a tensão residual aumenta com a diminuição da taxa de cisalhamento devido as estruturas formadas pela aplicação do campo magnético estarem próximas da sua configuração inicial. Verificase que o tempo para que a tensão residual atinja o equilíbrio aumenta com a taxa de cisalhamento devido à microestrutura do ferrofluido se distanciar da sua configuração 
de equilíbrio. Os resultados da tensão residual são ajustados pelo modelo típico de um fluido de Maxwell, pelo qual se calculou o tempo de relaxação. As medidas de tensão crítica são de importância para o cálculo do número de capilaridade magnético. Observa-se um aumento da tensão crítica e da viscosidade crítica com o campo magnético, para intensidades de campo magnético maior do que $24 \mathrm{kA} / \mathrm{m}$. 


\title{
ABSTRACT \\ CHARACTERIZATION RHEOLOGICAL OF COMPLEX FLUIDS IN LI- NEAR SHEAR AND CAPILLARY TUBE
}

\author{
Author: Nuno Jorge Sousa Dias \\ Supervisor: Francisco Ricardo da Cunha \\ Programa de Pós-graduação em Ciências Mecânicas \\ Brasília, November of 2014
}

In this thesis the main contributions are the measures of effective and apparent viscosity of dilute and concentrated emulsions for various viscosity ratio between droplets and continuum liquid phase. The rheology of the emulsions is studied by simple shear and pressure-driven flow in horizontal capillary tube. Experimental studies in rheology of emulsions with moderate and high viscosity ratios have been rarely explored in the literature. In addition, we investigate the rheological behavior of a colloidal magnetic suspension by simple and oscillatory shear. The concentration of magnetic suspension is $3,9 \% \mathrm{~V} / \mathrm{V}$. The viscosity of the suspension is measured for various magnetic fields and shear rates. We also measured the critical applied stress (or residual) of the magnetic fluid for different capillary numbers. Again these studies are still scarce in the current literature.

This study begins with the theoretical approach of emulsions in a tube flow. The viscosity of the fluid is adjusted by typical generalized Newtonian fluid model. In this case attention is given to the flow of the emulsion through the central region of the tube. In this situation a droplet-free layer appears near the wall of the tube. The expressions obtained for intrinsic viscosity depends of the droplet-free layer thickness. This intrinsic viscosity is made dimensionless with the viscosity of continuum liquid phase. A theoretical study is done about the effect of the size of the free layer in the emulsion rheology.

A model is proposed to understand, from a physical point of view, the mechanics of diffusion-migration that can lead to the formation of the deep-layer near the tube 
wall. The model is developed for low concentration and high viscosity ratio emulsions in the wall region and considers hydrodynamic interactions between drop-drop and drop-wall. The problem is treated as a semi-infinite problem. A transport equation for the volume fraction that considers the shear speed, the speed of advection in the normal direction of flow and a term of hydrodynamic diffusion for dilute systems and small deformation regimes is obtained. For an asymptotic solution for the nearest wall regions an expression is obtained to predict the thickness of the drop-free layer. It should be noted that the prediction of the thickness layer by this model is compared with that of the theoretical model of the emulsion pressure driven flow in a capillary tube. Experimental data of the unidirectional flow capillary tube are the inputs of these two models. The models give the same results for the low concentration and high viscosity ratio emulsions.

The interfacial tension is a fundamental parameter for calculating the capillary number. By studying the variation in the interfacial tension with the concentration of surfactants is known which is the concentration above which the interfacial tension reaches its saturation value. The interfacial tension is measured between the mineral oil and the continuum liquid phase. It is observed that the surface tension decreases with increasing amount of glycerin in the continuum liquid phase. The dimensionless results are in agreement with the Szyszkowski's model. There is a linear decrease of the interfacial tension with increasing surfactant concentration. The permanent regime of the interfacial tension is around $600 \mathrm{~s}$. These results were fitted by the Cross model. Experimental results shows that Tween 80 surfactant requires a lower concentration to reduce the interfacial tension but the Span 80 surfactant achieves lower interfacial tensions.

The rheological analysis is performed with emulsion of mineral oil droplets dispersed in a continuum liquid phase composed of a mixture of water and glycerin. This procedure allows change the viscosity ratio of the emulsion. The microstructure of the emulsions of different viscosity ratios $(2,5,10$ and 20$)$ with different volume fractions $(2 \% 5 \%$, $20 \%, 40 \%$ ) is analyzed by optical microscopy to evaluate the polydispersity index. This task is essential to obtain the capillary number which is a function of the droplet 
radius and of the interfacial tension.

The rheology of the emulsions of different ratios of viscosity $(2,5,10$ and 20) with different volume fractions $(2 \%, 5 \%, 20 \%, 40 \%)$ was studied by a unidirectional flow through a capillary tube. To measure the pressure imposed by a flow rate, the membranes of the pressure transducer are calibrated with a digital pressure manometer. In these experiments the apparent viscosity of the emulsion and the effective or intrinsic viscosity based on Poiseuille's law are evaluated with experimental data. All emulsions exhibited a shear thinning effect due to the increased capillary number. The results show that the viscosity of the emulsions of greater volume fraction increases with decreasing viscosity ratio due to the increased viscosity of the continuum liquid phase. However, when the viscosity is made dimensionless with the viscosity of the continuum liquid phase, it shows a tendency to increase with the viscosity ratio.

The emulsions studied by flow in capillary tube are also analyzed by a simple shear on a rheometer with parallel discs. The rheometer is equipped with an intelligent control system of the fluid spacing between the discs and the temperature control is done with a Peltier system. The experiments are performed with linear shear rate. The apparent and effective viscosity of emulsions is analyzed in terms of the capillary number, the volume fraction and the viscosity ratio. The results show a shear thinning behavior for emulsions with larger volume fraction. However, the results indicates that even a moderate volume fractions $(20 \%)$ for viscosity ratio about 10 the emulsion shows a behavior close to dilute. In this case the deformation due to the drop interactions as not strong than that produced by shear on an isolated drop.

The experimental results from the simple shear and the capillary flow are compared with theoretical models that predict the apparent viscosity of the emulsion. The experimental data are in agreement with the theoretical models for diluted emulsions at high viscosity ratios. Outside of the dilute regime the models give results lower than experimental data.

Emulsions of higher volume fraction $(50 \%, 60 \%$ and $70 \%)$ of different viscosity ratios 
(10 and 20) are studied in simple shear and oscillatory shear. The results show that the shear thinning effect is more intense in the emulsion of largest volume fraction. In the oscillatory shear the linear and non linear viscoelastic region are investigated by analyzing the behavior of the storage and loss modulus as a function of strain. It is observed that the elastic behavior typical of the solids appears with increasing volume fraction and viscosity ratio at deformations lower than 0.01 . With the increase of the viscosity ratio to the volume fraction of $70 \%$ the elastic effect of the solids is most prominent.

The rheology of a ferrofluid is studied in simple and oscillatory shear as a function of magnetic field and the magnetic capillary number. Is is observed that the shear thinning behavior starts when the vorticity created by viscous shear stresses begin to break (or degrade) the structures of clusters and chains initially formed by the application of the magnetic field. There is a magnetoviscosity effect which represents an increase of viscosity with increasing magnetic field strength due to the formation of a greater number of aggregates. In the oscillatory shear it is observed that the magnetic fluid has a typical solid elastic behavior increasing the magnetic field. The function of the relaxation of the magnetic fluid to a constant magnetic field, which is measured by the software accompanying the rheometer is obtained after interruption of the deformation. It is observed that the higher the strain the higher the time for the function of the relaxation to reach its equilibrium value. The residual stress is analyzed as a function of shear rate. It is observed that the residual stress increases with decreasing shear rate because the structures formed by the application of the magnetic field are close to its initial configuration. It observed that the time for the residual stress to reach equilibrium increases with the shear rate due to the microstructure of the ferrofluid to move away from its equilibrium configuration. The results of the residual stress are adjusted by a typical Maxwell fluid model. With that model the relaxation time is obtained. Measures of yield stress are of importance to the calculation of the magnetic capillary number. It is observed an increase in the yield stress and the yield viscosity with the magnetic field for magnetic field intensities greater than $24 \mathrm{kA} / \mathrm{m}$. 


\section{Sumário}

Lista de Simbolos xliv

1 INTRODUÇÃO 1

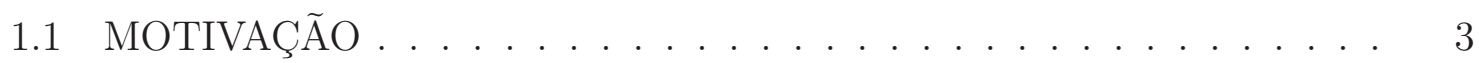

1.2 REVISÃO BIBLIOGRÁFICA . . . . . . . . . . . . . . . 7

1.2 .1 Emulsões . . . . . . . . . . . . . . . . . . . 8

1.2.2 Difusão de Gotas devido a Cisalhamento . . . . . . . . . . . . . 14

1.2.3 Fluidos Magnéticos . . . . . . . . . . . . . . . . . . 21

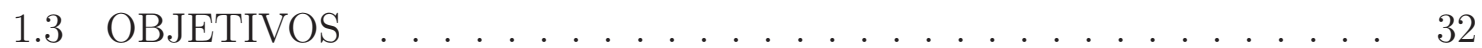

1.3.1 Objetivos Específicos . . . . . . . . . . . . 35

2 FUNDAMENTAÇÃO TEÓRICA 40

2.1 CONCEITOS DE REOLOGIA . . . . . . . . . . . . . . . 40

2.2 EQUAÇÕES GOVERNANTES PARA ESCOAMENTO DE FLUIDOS 50

2.3 ESCOAMENTO DE COUETTE ENTRE DISCOS PLANOS . . . . . . 53

2.4 ESCOAMENTO EM TUBO CAPILAR . . . . . . . . . . . 55

2.4.1 Condição de Unidirecionalidade . . . . . . . . . . . . . . . 57

2.4.2 Viscosímetro Capilar . . . . . . . . . . . . . . . . . 58

2.4.3 ESCOAMENTO DO FLUIDO TIPO BINGHNAM EM TUBO CAPILAR ....................... 61

2.5 ESCOAMENTO DE EMULSÃO PELA REGIÃO CENTRAL DO TUBO CAPILAR .......................... 65

2.5.1 Escoamento de Fluido Viscoso pela Região Central do Tubo Capilar 66

2.5.2 Escoamento de Fluido Não Newtoniano pela Região Central do Tubo Capilar . . . . . . . . . . . . . . . . . . . 70 
2.5.3 Escoamento de Emulsão de Alta Razão de Viscosidade e Baixa Fração Volumétrica pela Região Central do Tubo Capilar . . . . 76

\section{EMULSÕES DILUÍDAS DE ALTAS RAZÕES DE VISCOSIDADE FLUIDO-GOTA $\quad 82$}

3.1 Tensor de Tensões . . . . . . . . . . . . . . . . . . . . . . . 84

3.1.1 Escoamento de Emulsão Diluída de Altas Razões de Viscosidade em Tubo Capilar . . . . . . . . . . . . . . . . 87

3.2 Solução Numérica do Escoamento de Emulsões Diluídas de Alta Razão de Viscosidade . . . . . . . . . . . . . . . . . . . . . . . 89

3.2.1 Discussão dos Resultados do Modelo para Escoamento de Emulsão Diluída com Altas Razões de Viscosidade . . . . . . . . . . 92

3.2.2 Viscosidade de Emulsão Diluída de Altas Razões de Viscosidade em Cisalhamento Permanente . . . . . . . . . . . . . . . . 94

3.3 MODELO PARA MIGRAÇÃO DE PARTÍCULAS DE UMA SUSPENSÃO EM CISALHAMENTO . . . . . . . . . . . . . . . . . . 95

3.3.1 Modelo de Migração Induzido por Cisalhamento . . . . . . . . . 97

3.3.2 Modelo de Difusão Hidrodinâmico Induzido por Deformação . . 98

3.3.3 Adimensionalização e Definição do Problema . . . . . . . . . . . 99

3.4 SOLUÇÃO ASSINTÓTICA EM REGIME PERMANENTE PARA REGIÕES DE PAREDE . . . . . . . . . . . . . . . . . . . 101

3.5 SOLUÇÃO POR MÉTODO DE SIMILARIDADE . . . . . . . . . . . . 104

4 APARATO EXPERIMENTAL E INSTRUMENTAÇÃO 107

4.1 Reômetro . . . . . . . . . . . . . . . . 107

4.2 Bancada para Estudo de Escoamento Quadrático . . . . . . . . . . . . 112

4.3 Microscópio . . . . . . . . . . . . . . . . . . . . . . . . 115

4.4 Tensiômetro . . . . . . . . . . . . . . . . . . . . 117

4.5 Densímetro . . . . . . . . . . . . . . . . . . . . 121

4.6 Agitador Mecânico e Magnético . . . . . . . . . . . . . . . . . . . . . . 122

5 MEDIÇÕES DE TENSÃO INTERFACIAL 124

5.1 Forma Generalizada da Equação de Young-Laplace para o Salto de Tensões Interfacial na Presença de Surfactantes . . . . . . . . . . . . . . 125 
5.2 Salto de Tensões numa Interface com Tensão Interfacial Isotrópica . 127

5.3 Medidas da Tensão Interfacial . . . . . . . . . . . . . . . . . . . 128

5.4 Equação de Adsorção de Gibbs . . . . . . . . . . . . . . . . . . . . . 131

5.5 Dependência da tensão interfacial com o tempo . . . . . . . . . . . 132

6 SİNTESE DE EMULSÕES 139

6.1 Metodologia de Síntese de Emulsões do Presente Trabalho . . . . . . . 146

7 RESULTADOS DA CARACTERIZAÇÃO DO FLUIDO BASE E DAS EMULSÕES 149

7.1 CARACTERIZAÇÃO DO FLUIDO BASE DAS EMULSÕES . . . . . 149

7.2 CARACTERIZAÇÃO DAS EMULSÕES: MASSA ESPECÍFICA E MICROESTRUTURA . . . . . . . . . . . . . . . . 150

7.3 CISALHAMENTO LINEAR EM REGIME PERMANENTE . . . . . . 161

7.3.1 Ensaios de uma emulsão com razão de viscosidade 2 . . . . . . . 164

7.3.2 Ensaios da Emulsão com razão de viscosidade 5 . . . . . . . . 169

7.3.3 Ensaios da Emulsão com razão de viscosidade 10 . . . . . . . . 172

7.3.4 Ensaios da Emulsão com razão de viscosidade de $\lambda=20$. . . . 175

7.4 ESCOAMENTO NO INTERIOR DO TUBO CAPILAR DE SEÇÃO CIRCULAR . . . . . . . . . . . . . . . . 180

7.4.1 Ensaios de uma emulsão com razão de viscosidade 2 . . . . . . . 181

7.4.2 Ensaios da Emulsão com razão de viscosidade 5 . . . . . . . . 186

7.4.3 Ensaios da Emulsão com razão de viscosidade 10 . . . . . . . . 191

7.4.4 Emulsão de $\lambda=20 \ldots \ldots$. . . . . . . . . . . . . . . . . . . .

7.5 Comparação entre a Viscosidade da Parede e a Viscosidade Intrínseca . 203

7.6 Conclusões: Microestrutura e Cisalhamento . . . . . . . . . . . . . . . 204

8 COMPARAÇÕES DOS RESULTADOS EXPERIMENTAIS COM TEORIAS E OUTROS AUTORES 209

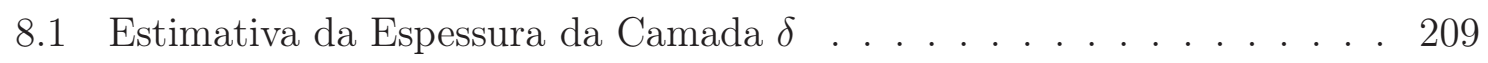

8.2 Comparação dos dados experimentais obtidos em cisalhamento simples com modelos teóricos . . . . . . . . . . . . . . . . . . . . . . . . 212

8.3 Comparação dos dados experimentais obtidos pelo escoamento em tubo capilar com modelos teóricos . . . . . . . . . . . . . . . . . 220 
8.4 Comparação dos dados experimentais com outros trabalhos . . . . . . . 223

8.4.1 Experimentos realizados em Reômetros . . . . . . . . . . . . . 224

9 VISCOELASTICIDADE $\quad 228$

9.1 Escoamentos para capturar Propriedades Viscoelásticas . . . . . . . . . 230

9.1.1 Cisalhamento Oscilatório em Pequena Amplitude (SAOS) . . . . 230

9.1.2 Resultados Experimentais . . . . . . . . . . . . . . 232

10 REOLOGIA DE FLUIDOS MAGNÉTICOS EM CISALHAMENTO PERMANENTE E TRANSIENTE 239

10.1 Fundamentação Teórica . . . . . . . . . . . . . . . . . 239

10.2 Resultados Experimentais . . . . . . . . . . . . . . . . 244

10.2.1 Experimentos de Cisalhamento Permanente de Fluido Magnético 247

10.2.2 Experimentos de Cisalhamento Transiente de Fluido Magnético 250

11 CONCLUSÕES $\quad 261$

REFERÊNCIAS BIBLIOGRÁFICAS $\quad 269$

$\begin{array}{ll}\text { APÊNDICES } & 280\end{array}$

A MICROESTRUTURA DAS EMULSÕES 281

A.1 Emulsões $\lambda=2 \ldots \ldots \ldots \ldots \ldots$. . . . . . . . . . . . . . . . . . . . . .

A.2 Emulsões $\lambda=5 \ldots \ldots \ldots \ldots \ldots \ldots$. . . . . . . . . . . . . . . . . .

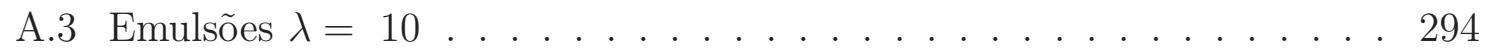

A.4 Emulsões $\lambda=20 \ldots \ldots \ldots \ldots$. . . . . . . . . . . . . . . . . .

B Teoria de Escoamento de Emulsão de Alta Razão de Viscosidade em $\begin{array}{ll}\text { Tubos } & 306\end{array}$

C Teoria de Escoamento de Emulsões de Alta Razão de Viscosidade em $\begin{array}{ll}\text { Cisalhamento Simples } & 307\end{array}$

$\begin{array}{ll}\text { D Cálculo de Incertezas } & 311\end{array}$

D.1 Incerteza da Viscosidade obtida em Cisalhamento Linear . . . . . . . . 311

D.2 Incerteza da Viscosidade obtida no Escoamento em Tubo Capilar . . . 311 


\section{Lista de Tabelas}

4.1 Constantes de Calibração das Membranas . . . . . . . . . . . . . . 113

5.1 Tensão interfacial entre óleo mineral e o fluido base variando a fração volumétrica de glicerina. . . . . . . . . . . . . . . . . . . 129

5.2 Valores extrapolados de tensão interfacial para $\phi>0,7 \ldots \ldots$. . . . 129

5.3 Constantes referentes à correlação empírica de Cross. . . . . . . . . . . 133

5.4 Constante referentes a cada surfactante. . . . . . . . . . . . . . . . 137

7.1 Propriedades das misturas Água-Glicerina. . . . . . . . . . . . . . . . . 149

7.2 Massa Específica $\left[\mathrm{kg} / \mathrm{m}^{3}\right] \ldots \ldots \ldots \ldots \ldots \ldots$

7.3 Polidispersidade das Emulsões $\sigma / \bar{d}$. . . . . . . . . . . . . . 156

7.4 Categorização dos diâmetros de gotas das emulsão com $\lambda=2$. . . . . 157

7.5 Categorização dos diâmetros de gotas das emulsão com $\lambda=5$. . . . . 158

7.6 Categorização dos diâmetros de gotas das emulsão com $\lambda=10$. . . . 159

7.7 Categorização dos diâmetros de gotas das emulsão com $\lambda=20 . \quad$. . . 160

7.8 Variação da viscosidade $\eta_{\infty} / \eta_{b}$ em função da fração volumétrica e da razão de viscosidade . . . . . . . . . . . . . . . . . . . . . . . 179

7.9 Variação da viscosidade aparente em altos números de capilaridade adimensionalizada pela viscosidade do fluido base em função da fração volumétrica e da razão de viscosidade . . . . . . . . . . . . . . . . . . . . 202

7.10 Variação da viscosidade aparente em altos números de capilaridade em função da fração volumétrica e da razão de viscosidade . . . . . . . . . 202

7.11 Comparação entre a viscosidade da parede, intrínseca e de Taylor adimensionalizada pela viscosiade do fluido base, para diferentes emulsões de $\mathrm{O} / \mathrm{A}$ em cisalhamento quadrático. . . . . . . . . . . . . . . 204

7.12 Comparação da viscosidade para diferentes $\lambda$ e $\phi$ para número de capilaridade idênticos em cisalhamento simples. . . . . . . . . . . . . 207 
7.13 Comparação da viscosidade adimensional pela viscosidade de cada fluido base para diferentes $\lambda$ e $\phi$ para número de capilaridade idênticos em cisalhamento simples. . . . . . . . . . . . . . . . . 207

7.14 Comparação da viscosidade para diferentes $\lambda$ e $\phi$ para número de capilaridade idênticos em cisalhamento quadrático. . . . . . . . . . . 207

7.15 Comparação da viscosidade adimensional pela viscosidade de cada fluido base para diferentes $\lambda$ e $\phi$ para número de capilaridade idênticos em cisalhamento quadrático. . . . . . . . . . . . . . . . . 207

7.16 Comparação da viscosidade aparente obtida em cisalhamento simples e pelo escoamento em tubo capilar para a mesma taxa de cisalhamento. . 208

8.1 Predição da Espessura da Camada $\delta$ em cisalhamento quadrático (eq. 8.1) e simples (eq. 8.4) . . . . . . . . . . . . . . . 211

8.2 Taxa de Cisalhamento correspondente ao número de capilaridade da tab.

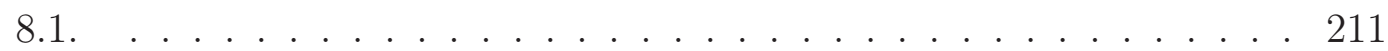

8.3 Comparação entre a viscosidade adimensional obtida em cisalhamento linear (reômetro) com a predição pela expressão de Taylor. . . . . . . . 213

8.4 Comparação entre a viscosidade adimensional obtida em cisalhamento linear (reômetro) com a predição pela expressão Krieger-Dougherty para a emulsão de $\lambda=20$ e $\dot{\gamma}=200 s^{-1} \ldots \ldots \ldots$. . . . . . . . . . 213

8.5 Comparação entre resultados numéricos de Loewenberg e Hinch (1996) com os resultados experimentais da presente tese para $C a=0,20$. . . 220

8.6 Comparação entre a viscosidade adimensional obtida em cisalhamento quadrático (capilar) com a predição pela expressão de Taylor. . . . . . 222

9.1 Ponto crítico $\left(G^{\prime}=G^{\prime \prime}\right)$ para as emulsões analisadas. . . . . . . . . 237 


\section{Lista de Figuras}

1.1 Partículas magnéticas cobertas com surfactantes. Odenbach, (2003) . .

1.2 A força magnética proveniente de um electroíman aplicada a um ferrofluido é forte o suficiente para puxar o fluido contra o campo gravitacional da Terra e formar instabilidades características ("spikes"),

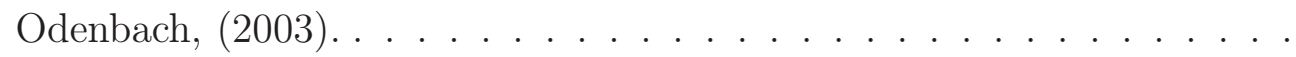

1.3 Raio-X de um tecido com tumor após ser aplicado o fármaco guiado com um campo magnético. As nanopartículas são visíveis no sistema vascular do tumor (Alexiou et al., (2006)) . . . . . . . . . . . .

1.4 Amortecedor e malha porosa metálica. . . . . . . . . . . . . . . .

1.5 Rolamento magnetohidroestatico axial. estator (esquerda), zoom do estator com o ferrofluido (centro), rolamento montado (direita) . . . . . .

2.1 Definição de Meio Contínuo . . . . . . . . . . . . . . . . .

2.2 Escoamento em cisalhamento simples representado pela adição dos efeitos de deformação e de rotação . . . . . . . . . . . . . . . . . .

2.3 Variação da viscosidade em função da taxa de cisalhamento para uma poliacrilamida. •Resultado experimental obtido na presente tese, - Ajuste pelo modelo de Cross. . . . . . . . . . . . . . . . . . .

2.4 Modelo Power-Law: Parâmetros: $\mathrm{m}=50$. Legenda $-\mathrm{n}=1$ (Newtoniano) ; - - n=0,5 (pseudoplástico) ; - - n=1,5 (dilatante). . . . . . . . .

2.5 Modelo Power-Law: Parâmetros: $\mathrm{m}=50$. Legenda: - $\mathrm{n}=1$ (Newtoniano) ; - - - n=0,5 (psedoplástico) ; - - n n=1,5 (dilatante) . . . . . . .

2.6 Modelos para fluidos pseudo-plásticos. Legenda: - - Cross $(\lambda=10,0$, $a=2,0, n=0,1) ;$ Carreau-Yassuda $(m=10,0, n=3) \ldots 48$

2.7 Modelos Viscoplásticos: — Casson ; - - Bingham . . . . . . . . . . . . 49

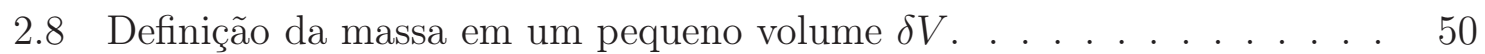


2.9 Escoamento entre disco com movimento de rotação e disco estacionário. $R$ : raio do disco móvel $; \delta$ : região de fluido teste $($ gap $) . \ldots . . . . .54$

2.10 Escoamento em tubo. Legenda: $R$ : raio do tubo ; $L$ : comprimento do tubo; $u(r)$ : perfil de velocidade completamente desenvolvido . . . . . .

2.11 Escoamento de fluido Newtoniano adjacente a parede do capilar com concentração de partículas na região central do capilar. $L$ : comprimento do capilar; $R$ : raio do capilar ; $R_{C}$ : raio da região de escoamento da suspensão ; $R_{\delta}$ : raio da região de escoamento de fluido Newtoniano . .

2.12 Influência do gradiente de pressão na viscosidade intrínseca adimensionalizada pela viscosidade do fluido de Bingham. Constantes: $R=250 \mu \mathrm{m}$ , $\tau_{0}=100 P a$. Legenda: $-G=1000 \mathrm{~Pa} / \mathrm{m},-\cdot-G=3000 \mathrm{~Pa} / \mathrm{m},-$ - $G=5000 \mathrm{~Pa} / \mathrm{m}, \quad \ldots G=10000 \mathrm{~Pa} / \mathrm{m} \ldots \ldots . . .$.

2.13 Influência da tensão de cisalhamento crítica do fluido de Bingham na viscosidade intrínseca adimensionalizada pela viscosidade do fluido de Bingham. Constantes: $R=250 \mu \mathrm{m}, \delta=50 \mu \mathrm{m}, G=5000 \mathrm{~Pa} / \mathrm{m} . \quad \ldots$

2.14 Micrografia do escoamento de glóbulos vermelhos em microvasos de diferentes diâmetros obtida na Escola de Medicina de Yale (Cunha e Lowenberg (1999)). Em a) e b) as hemácias se deslocam enfileiradas apresentando uma deformação na direção do escoamento. Aqui a dimensão do microvaso é menor que a dimensão da hemácia $(6-8 \mu m)$. Em c) e d) o microvaso tem dimensão $12-20 \mu \mathrm{m}$. Neste caso observa-se a formação de uma camada de plasma adjacente à parede e as células. A interação entre as células passa a ser relevante e o escoamento perde a axissimetria passando a ser tridimensional. . . . . . . . . . . . . . .

2.15 Influência da camada $\delta$ na viscosidade intrínseca no caso em que $\eta_{\delta}=$ $1 \times 10^{-3}$ Pa.s, $\eta_{C}=4 \times 10^{-3}$ Pa.s. Diminuição da viscosidade intrínseca com o aumento da região $\delta$. Fluido que escoa adjacente à parede do tubo age como se fosse um lubrificante. Legenda: $--\delta=1,-\frac{-}{-} \delta=3$, $\ldots \delta=5,-\delta=7 \ldots \ldots \ldots \ldots \ldots$

2.16 Influência da camada $\delta$ no platô da viscosidade intrínseca no caso em que $\eta_{\delta}=1 \times 10^{-3}$ Pa.s, $\eta_{C}=4 \times 10^{-3}$ Pa.s e $\delta$ é: $1,0,3,0,5,0,7,0$, 10,0 20,0 e 30,0 $\mu \mathrm{m}$. Neste caso o $R=300 \mu \mathrm{m} . \ldots \ldots$ 
2.17 Influência de $\phi$ na viscosidade intrínseca. A fração volumétrica variou de $0,02-0,5$. A região livre de partícula foi mantida constante $(\delta=7 \mu \mathrm{m})$ e $k=5 / 2$. Legenda: $-\phi=0,02 ;-\cdots \phi=0,05 ;-\longrightarrow \phi=0,1$; $\cdots \phi=0,3 ;-\cdot-\phi=0,5$

2.18 Aumento Linear da viscosidade com o aumento da concentração para o caso em que $R=300 \mu m$ e $\delta=7 \mu m \ldots \ldots \ldots$

2.19 Influência do gradiente de pressão $(G)$ na viscosidade intrínseca. A viscosidade diminui com o aumento de $G$. Esse efeito é notório quando $R>60 \mu m$. Legenda: $-G=1,0 ;--G=1,5 ; \cdots G=2,0$; - - $G=2,5$. Constantes do modelo: $\phi=0,20, n=0,5$ e $\delta=7 \mu m$, $k=5 / 2$.

2.20 Influência de $\phi$ na viscosidade intrínseca. A viscosidade aumenta com a concentração de partículas. Esse efeito é notório quando $R>60 \mu \mathrm{m}$. Legenda: $-\phi=0,05 ; \cdots \phi=0,1 ; \cdots \phi=0,3 ;-\cdots \phi=0,5$ Constantes do modelo: $G=1,5, n=0,5$ e $\delta=7 \mu m, k=5 / 2 \ldots .$.

2.21 Influência da espessura $\delta$ na viscosidade para $R=60 \mu \mathrm{m}$. Constantes: $G=1,5, \phi=0,2, n=0,5$. Diminuição da viscosidade com o aumento de $\delta$ (ação de lubrificante)

2.22 Influência de $n$ na viscosidade intrínseca. Quando $n \rightarrow 1$ mais afinante se torna o fluido. $n$ variou de $0,2-1,0$ para valor constante de $G=1,5$, $\phi=0,2$ e $\delta=7 \mu m$.

2.23 Influência do parâmetro $n$ na viscosidade intrínseca para quando $R=$ $300 \mu \mathrm{m}$. Quanto maior for $1 / n(n \rightarrow 0)$ a viscosidade tende a estabilizar em um valor indicando o valor absoluto do efeito pseudo-plástico do fluido. 76

2.24 Influência da razão de viscosidade na viscosidade intrínseca. Observase que a viscosidade intrínseca se manteve constante para os valores as diferentes razões de viscosidade $(\lambda=1,2,3,4)$. O valor da máxima viscosidade é para o tubo de raio $220 \mu \mathrm{m}$. Constantes: $\phi=0,03$, $\delta=7 \mu m, G=1,5, n=0,5$. Legenda: $-\lambda=1,-\longrightarrow \lambda=2,-\cdots$ $\lambda=3, \cdot . . \lambda=4 \ldots \ldots \ldots \ldots \ldots$ 
2.25 Influência da fração volumétrica na viscosidade intrínseca. A máxima viscosidade foi de 4,69 para a fração volumétrica 0,05 no raio de $230 \mu \mathrm{m}$. A mínima viscosidade foi de 4,37 para a fração volumétrica 0,01 no raio de 210. Constantes: $\lambda=3, \delta=7 \mu m, G=1,5, n=0,5$. Legenda: $-\phi=0,01,-\cdots \phi=0,02--\phi=0,03, \cdots \phi=0,04$,

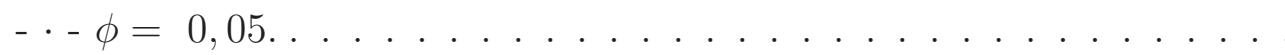

2.26 Influência da razão de viscosidade na viscosidade intrínseca. Para todos as razãoes de viscosidade a máxima viscosidade se verificou em raios em torno de $90 \mu \mathrm{m}$. Constantes: $\phi=0,2, \delta=7 \mu m, G=1,5$. Legenda: $-\lambda=5,--\lambda=10,-\cdots \lambda=20, \cdots \lambda=50$

2.27 Influência da fração volumétrica na viscosidade intrínseca. Para $\phi=$ 0,1 a viscosidade máxima $(1,45)$ se verificou para $R=46 \mu \mathrm{m}$. Para $\phi=0,3$ a viscosidade máxima $(3,25)$ se verificou para $R=146 \mu m$. Constantes: $\lambda=20, \delta=7 \mu m, G=1,5, n=0,5$. Legenda: $-\phi=0,1$, $\multimap-\phi=0,15,-\longrightarrow \phi=0,2, \cdots \phi=0,25, \cdots \phi=0,3 \ldots \ldots$

2.28 Variação do ponto de máxima viscosidade com o aumento da fração volumétrica para diferentes raios. Verifica-se um aumento linear da viscosidade com a fração volumétrica. Legenda: • Dados obtidos pela fig. $2.27,-\left(\eta_{i} / \eta_{\delta}\right)_{\max }=0,632+0,0178 R \ldots \ldots \ldots$

3.1 Microestutura da emulsão de $\phi=40 \%$ e $\lambda=2$. As gotas da emulsão apresentam elevada deformação na direção do cisalhamento. Imagem obtida pelo Microscópio BX51 da Olympus no Laboratório de Microhidrodinâmica e Reologia de Fluidos Complexos (Univ. de Brasília) durante o cisalhamento simples de Couette entre placas planas. . . . . . .

3.2 Microestutura da emulsão de $\phi=40 \%$ e $\lambda=20$. As gotas da emulsão pouco se deformam. Apresentam uma configuração de fileira na direção principal do escoamento. Imagem obtida pelo Microscópio BX51 da Olympus no Laboratório de Microhidrodinâmica e Reologia de Fluidos Complexos (Univ. de Brasília) durante o cisalhamento simples de Couette entre placas planas. . . . . . . . . . . . . . . . 
3.3 Influência da razão de viscosidade na viscosidade efetiva para diferentes frações volumétricas. Pelos resultados nota-se que o aumento da razão de viscosidade pouco afeta a viscosidade efetiva. Legenda: $-\cdot-\lambda=10$, $\cdots \lambda=20,---\lambda=30,-\div \times \lambda=40-\lambda=50 \ldots \ldots$

3.4 Influência da razão de viscosidade na viscosidade efetiva para diferentes valores do parâmetro $\epsilon$. Com o aumento de $\epsilon$ maior é a intensidade do escoamento. Isso faz com que a viscosidade efetiva atinga um platô para valores de $\epsilon \geq 2$. Legenda: - - $\lambda=5,--\lambda=10,-\cdots \quad \lambda=20$, $--\lambda=30, \cdots \lambda=40,-\lambda=50 \ldots \ldots \ldots$

3.5 Saturação da viscosidade efetiva com o aumento da razão de viscosidade. 94

3.6 Aproximação da primeira derivada pelo esquema de diferenças finitas forward de $O\left((\Delta y)^{2}\right)$ é representativo da solução analítica da eq. 3.67.

Para este caso os parâmetros físicos foram: $P e=5,0, C a=0,5, \lambda=10,0102$

3.7 Influência do número de capilaridade no perfil de $\widetilde{\phi}$. Constantes: $P e=$ $5,0, \lambda=10,0, \phi_{\infty}=10,0$. Legenda: $-C a=0,01,-\longrightarrow C a=0,05$, — $C a=0.1, \ldots C a=0,5 \ldots \ldots \ldots$

3.8 Influência da razão de viscosidade $(\lambda)$ na formação da camada livre de $\operatorname{gotas}(\widetilde{\delta})$. O modelo prevê o aumento de $\widetilde{\delta}$ com o aumento de $\lambda . . .104$

4.1 Reômetro MCR 301 da Anton Paar: Esta figura destaca a ferramenta de trabalho rotativa e o disco imóvel cuja temperatura é controlada pelo sistema Peltier e sobre o qual se posiciona a amostra do fluido. . . . . . 109

4.2 Sistema Peltier do Reômetro MCR301 da Anton-Paar. . . . . . . . . . 110

4.3 Fonte para geração de campo magnético na seção de teste da amostra; Banho Térmico . . . . . . . . . . . . . . . . . . . 110

4.4 Sistemas de filtros de óleo (os dois filtros da esquerda), desumidificador (braço branco horizontal central) e filtro de partículas(filtro da extrema

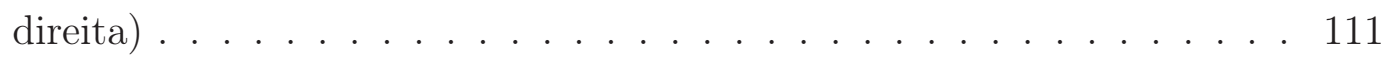

4.5 Bancada para estudo de escoamento em tubo capilar constituída por: manômetro digital, seringa de vidro, transdutor de pressão,tubo capilar de vidro e bomba de seringa. . . . . . . . . . . . . . . . . . 114

4.6 Seringa B-D YALE $10 \mathrm{ml}$;Tubo Capilar com diâmetro interno de 1000 $\mu \mathrm{m}$ 
4.7 Transdutor e Membrana(22) (VALIDYNE) . . . . . . . . . . . 115

4.8 Microscópio Olympus BX51 com câmera UC30 e ampliação ocular é 10X As lentes disponíveis têm apliação de 2X,5X,10X,20X e 50X. . . . . . . 116

4.9 Emulsão analisada por microscópio óptico. . . . . . . . . . . . . . . . . 117

4.10 Gota de um líquido A imersa em um líquido B, formada na ponta de um capilar. Note que a gota se encontra no volume crítico, no qual a tensão interfacial não é mais capaz de balancear a força gravitacional. Imagem retirada de Lautrup,$(2011) \ldots \ldots$

4.11 Tensiômetro TVT2 - Lauda. Formação da gota na extremidade do capilar.118

4.12 Capilar reto e reverso. . . . . . . . . . . . . . . . . . . 119

4.13 Tensão Interfacial $\left(\tau_{s}\right)$ da água destilada-ar. As medições foram feitas a $T=24^{\circ} \mathrm{C}$. Em cada realização foi avaliada a tensão interfacial de 5 gotas de água. A tensão interfacial média foi de $71,11[\mathrm{mN} / \mathrm{m}]$. . . . . 120

4.14 Densímetro Anton Paar modelo DMA38 . . . . . . . . . . . . . . . . . 121

4.15 Chapa Aquecedora FISATOM . . . . . . . . . . . . . . . . . . . . . 122

4.16 Homogeneizador e Misturador. . . . . . . . . . . . . . . . . . . . . 123

5.1 (a) Interface entre dois fluidos imiscíveis; (b) Detalhe de uma aresta da interface . . . . . . . . . . . . . . . . 126

5.2 Tensão interfacial normalizada em função da fração volumétrica de glicerina. As constantes obtidas foram: $A=-0,22, B=8,55$. Dados experimentais, $\triangle$ Valores extrapolados,- Equação de Szyszkowski (eq. 5.2). Encarte: Índice de refração da mistura de água destilada e glicerina em função da fração volumétrica de glicerina. o Dados experimentais, Glycerine Producers Association (1963) . . . . . . . . . . . . . . 130

5.3 Tensão interfacial normalizada em função da razão de viscosidade entre o óleo mineral e o fluido base. As constantes obtidas foram: $A=-0,130$, $B=-6,837$. Dados experimentais, $\triangle$ Valores extrapolados,- Equação de Szyszkowski modificada 5.20 . . . . . . . . . . . . . . . . . . . . 130

5.4 Tensão interfacial em função do tempo de formação da gota na presença de surfactante Tween 80. As medidas foram feitas em temperatura controlada de $25^{\circ} \mathrm{C}$. - Correlação de Cross. $\Delta \phi=1,5 \times 10^{-6}, \nabla \phi=$ $2,5 \times 10^{-6}, \nabla \phi=5 \times 10^{-6}, \diamond \phi=1 \times 10^{-5} \ldots \ldots \ldots 134$ 
5.5 Tensão interfacial em função do tempo de formação da gota na presença de surfactante Span 80. As medidas foram feitas em temperatura controlada de $25^{\circ} \mathrm{C}$. - Correlação de Cross. $\quad \phi=5 \times 10^{-5}, \circ \phi=$ $1 \times 10^{-4}, \boldsymbol{\Delta} \phi=2 \times 10^{-4}, \bullet \phi=5 \times 10^{-4} \ldots \ldots \ldots \ldots$

5.6 Tensão interfacial de equilíbrio em função da concentração de Tween 80. Note que a tensão interfacial para água pura não aparece. - - Ajuste (5.32) . O encarte da figura mostra detalhe da tensão interfacial para concentrações muito baixas. - Ajuste (Eq. 5.33). As medidas foram feitas em temperatura controlada de $25^{\circ} \mathrm{C}$. Tween 80. $\phi_{c}=5,0 \times 10^{-6} .135$

5.7 Tensão interfacial de equilíbrio em função da concentração de Span 80. Note que a tensão interfacial para água pura não aparece. - - Ajuste (5.32). O encarte da figura mostra detalhe da tensão interfacial para concentrações muito baixas, com o eixo horizontal em escala linear. Ajuste (Eq. 5.33). As medidas foram feitas em temperatura controlada de $25^{\circ}$ C. $\bullet$ Span $80 . \phi_{c}=5,3 \times 10^{-4} \ldots \ldots \ldots \ldots \ldots$

5.8 Tempo de equilíbrio em função da concentração. • Dados experimentais. - Ajuste (eq. 5.34). - - $\phi_{c}$.

6.1 Representação da orientação das moléculas de surfactantes em uma gota de óleo rodeada por água. . . . . . . . . . . . . . . . . . . . . 141

6.2 Emulsão gerada por agitação mecânica. . . . . . . . . . . . . . . . . . . 142

7.1 Variação da viscosidade da mistura Água-Glicerina. Os dados foram ajustados com um polinômio de segundo grau $\left(a_{1}+a_{2} \phi+a_{3} \phi^{2}\right)$ com os coeficientes: $a_{1}=0,11, a_{2}=0,012, a_{3}=0,00083$. A viscosidade $\eta_{0}$ é referente à viscosidade da água destilada.

7.2 Imagem da Microestrutura da Emulsão $\lambda=2$ e $\phi=2 \%$. . . . . . . . 152

7.3 Distribuição de Tamanho de Gota e Frequência Relativa típica de uma emulsão $(\lambda=2$ e $\phi=2 \%)$.

7.4 Regime Permanente atingido em $t=150 \mathrm{~s}$ para uma emulsão de $\phi=$ $40 \%$ e $\lambda=2$ sujeita a $\dot{\gamma}=5 s^{-1}$. O valor da viscosidade obtido foi $\eta=0,73 \pm 0,0084$ Pa.s . . . . . . . . . . . . 162 
7.5 Regime Permanente atingido em $t=126 \mathrm{~s}$ para uma emulsão de $\phi=$ $40 \%$ e $\lambda=5$ sujeita a $\dot{\gamma}=5 s^{-1}$. O valor da viscosidade obtido foi $\eta=0,40 \pm 0,0094$ Pa.s . . . . . . . . . . . . . 162

7.6 Viscosidade de uma emulsão de $\phi=40 \%$ e $\lambda=10$ sujeita a $\dot{\gamma}=$ $5 s^{-1}$. Durante o tempo experimental a emulsão não apresentou regime transiente da viscosidade. $\mathrm{O}$ valor da viscosidade obtido foi de $\eta=0,181 \pm 0,011$ Pa.s . . . . . . . . . . . . 163

7.7 Viscosidade de uma emulsão de $\phi=40 \%$ e $\lambda=20$ sujeita a $\dot{\gamma}=$ $5 s^{-1}$. Durante o tempo experimental a emulsão não apresentou regime transiente da viscosidade. O valor da viscosidade obtido foi de $\eta=0,089 \pm 0,0011$ Pa.s.

7.8 Variação da viscosidade em função da $C a$ para $\lambda=2$ e $\phi=2 \%$.O número de capilaridade foi calculado por $C a=\left(\eta \dot{\gamma} \delta_{R}\right) / \tau_{s}$ em que $\delta_{R}=0,4 m m$ é a distância entre os discos do reômetro e $\tau_{s}=0,028 \mathrm{~N} / \mathrm{m}$ é a tensão interfacial. $---\eta / \eta_{b}=0,9 \pm 0,072 \ldots \ldots 166$

7.9 Variação da viscosidade em função da $C a$ para $\lambda=2$ e $\phi=5 \%$. O número de capilaridade foi calculado por $C a=\left(\eta \dot{\gamma} \delta_{R}\right) / \tau_{s}$ em que $\delta_{R}=0,4 m m$ é a distância entre os discos do reômetro e $\tau_{s}=0,028 \mathrm{~N} / \mathrm{m}$ é a tensão interfacial. $--\eta / \eta_{b}=1,02 \pm 0,17 \ldots \ldots 7$

7.10 Variação da viscosidade em função da $C a$ para $\lambda=2$ e $\phi=20 \%$. O número de capilaridade foi calculado por $C a=\left(\eta \dot{\gamma} \delta_{R}\right) / \tau_{s}$ em que $\delta_{R}=0,4 \mathrm{~mm}$ é a distância entre os discos do reômetro e $\tau_{s}=0,028 \mathrm{~N} / \mathrm{m}$ é a tensão interfacial. $--\eta \eta / \eta_{b}=1,16 \pm 0,059 \ldots \ldots 7$. . . . . 167

7.11 Variação da viscosidade em função da $C a$ para $\lambda=2$ e $\phi=40 \%$. O número de capilaridade foi calculado por $C a=\left(\eta \dot{\gamma} \delta_{R}\right) / \tau_{s}$ em que $\delta_{R}=0,4 m m$ é a distância entre os discos do reômetro e $\tau_{s}=0,028 \mathrm{~N} / \mathrm{m}$ é a tensão interfacial. -Modelo Carreau-Yasuda (eq. 2.11) $\eta_{\infty} / \eta_{b}=$ $1,0, \eta_{0} / \eta_{b}=19,0, \alpha=0,21, n=-2,11, a=0,49$.

7.12 Aumento da viscosidade com a fração volumétrica $-\eta_{\infty} / \eta_{b}=(1-\phi)^{-n}$ em que $n=2,49$. Dado experimentais para $C a \approx 0,2$ e $\lambda=2$.Encarte:

- Ajuste pela expressão da viscosidade de Taylor. 168 
7.13 Variação da viscosidade em função da $C a$ para $\lambda=5$ e $\phi=2 \%$. O número de capilaridade foi calculado por $C a=\left(\eta \dot{\gamma} \delta_{R}\right) / \tau_{s}$ em que $\delta_{R}=0,4 \mathrm{~mm}$ é a distância entre os discos do reômetro e $\tau_{s}=0,02926 \mathrm{~N} / \mathrm{m}$ é a tensão interfacial. $---\eta / \eta_{b}=0,97 \pm 0,011 \ldots \ldots$. . . . . . 170

7.14 Variação da viscosidade em função da $C a$ para $\lambda=5$ e $\phi=5 \%$. O número de capilaridade foi calculado por $C a=\left(\eta \dot{\gamma} \delta_{R}\right) / \tau_{s}$ em que $\delta_{R}=0,4 \mathrm{~mm}$ é a distância entre os discos do reômetro e $\tau_{s}=0,02926 \mathrm{~N} / \mathrm{m}$ é a tensão interfacial. $--\eta / \eta_{b}=1,04 \pm 0,037 \ldots \ldots$. . . . . 170

7.15 Variação da viscosidade em função da $C a$ para $\lambda=5$ e $\phi=20 \%$. O número de capilaridade foi calculado por $C a=(\eta \dot{\gamma} \delta) / \tau_{s}$ em que $\delta_{R}=0,4 \mathrm{~mm}$ é a distância entre os discos do reômetro e $\tau_{s}=0,02926 \mathrm{~N} / \mathrm{m}$ é a tensão interfacial . - - $\eta / \eta_{b}=2,17 \pm 0,16 \ldots \ldots 171$

7.16 Variação da viscosidade em função da $C a$ para $\lambda=5$ e $\phi=40 \%$. O número de capilaridade foi calculado por $C a=\left(\eta \dot{\gamma} \delta_{R}\right) / \tau_{s}$ em que $\delta_{R}=0,4 \mathrm{~mm}$ é a distância entre os discos do reômetro e $\tau_{s}=0,02926 \mathrm{~N} / \mathrm{m}$ é a tensão interfacial. -Modelo Carreau-Yasuda (eq. 2.11) $\eta_{\infty} / \eta_{b}=$ $0,5, \eta_{0} / \eta_{b}=19,0, \alpha=51,2, n=0,65, a=1,31 \ldots \ldots 17$

7.17 Aumento da viscosidade com a fração volumétrica $-\eta_{\infty} / \eta_{b}=(1-\phi)^{-n}$ em que $n=3,77$. Dados recolhidos para $C a \approx 0,02$ e $\lambda=5$. Encarte: - Ajuste pela expressão da viscosidade de Taylor.

7.18 Variação da viscosidade em função da $C a$ para $\lambda=10$ e $\phi=2 \%$.O número de capilaridade foi calculado por $C a=\left(\eta \dot{\gamma} \delta_{R}\right) / \tau_{s}$ em que $\delta_{R}=0,4 m m$ é a distância entre os discos do reômetro e $\tau_{s}=0,03066 \mathrm{~N} / \mathrm{m}$ é a tensão interfacial. $---\eta / \eta_{b}=0,887 \pm 0,021$.

7.19 Variação da viscosidade em função da $C a$ para $\lambda=10$ e $\phi=5 \%$.O número de capilaridade foi calculado por $C a=\left(\eta \dot{\gamma} \delta_{R}\right) / \tau_{s}$ em que $\delta_{R}=0,4 \mathrm{~mm}$ é a distância entre os discos do reômetro e $\tau_{s}=0,03066 \mathrm{~N} / \mathrm{m}$ é a tensão interfacial. $---\eta / \eta_{b}=1,03 \pm 0,034$.

7.20 Variação da viscosidade em função da $C a$ para $\lambda=10$ e $\phi=20 \% . \mathrm{O}$ número de capilaridade foi calculado por $C a=\left(\eta \dot{\gamma} \delta_{R}\right) / \tau_{s}$ em que $\delta_{R}=0,4 \mathrm{~mm}$ é a distância entre os discos do reômetro e $\tau_{s}=0,03066 \mathrm{~N} / \mathrm{m}$ é a tensão interfacial. $---1,90 \pm 0,191 \ldots$. . . . . . . . . . . 174 
7.21 Variação da viscosidade em função da $C a$ para $\lambda=10$ e $\phi=40 \% . O$ número de capilaridade foi calculado por $C a=\left(\eta \dot{\gamma} \delta_{R}\right) / \tau_{s}$ em que $\delta_{R}=0,4 \mathrm{~mm}$ é a distância entre os discos do reômetro e $\tau_{s}=0,03066 \mathrm{~N} / \mathrm{m}$ é a tensão interfacial. Observa-se uma tendência para formar um platô em $\eta_{\infty} / \eta_{b}=7,58 \pm 1,286 .-\eta / \eta_{b}=5,65 C a^{0,76-1} \ldots \ldots \ldots 174$

7.22 Aumento da viscosidade com a fração volumétrica $-\eta_{\infty} / \eta_{b}=(1-\phi)^{-n}$ em que $n=3,95$. Dados experimentais para $C a \approx 0,04$ e $\lambda=10$. Dados Experimentais para $C a=0,02$ para $\lambda=10$. Encarte: - Ajuste pela expressão da viscosidade de Taylor.

7.23 Variação da viscosidade em função da $C a$ para $\lambda=20$ e $\phi=2 \%$.O número de capilaridade foi calculado por $C a=(\eta \dot{\gamma} \delta) / \tau_{s}$ em que $\delta=0,4 \mathrm{~mm}$ é a distância entre os discos do reômetro e $\tau_{s}=0,03184 \mathrm{~N} / \mathrm{m}$ é a tensão interfacial. $--\eta / \eta_{b}=0,98 \pm 0,040 \ldots \ldots 176$

7.24 Variação da viscosidade em função da $C a$ para $\lambda=20$ e $\phi=5 \% . O$ número de capilaridade foi calculado por $C a=(\eta \dot{\gamma} \delta) / \tau_{s}$ em que $\delta=0,4 \mathrm{~mm}$ é a distância entre os discos do reômetro e $\tau_{s}=0,03184 \mathrm{~N} / \mathrm{m}$ é a tensão interfacial. $---\eta / \eta_{b}=1,03 \pm 0,034$.

7.25 Variação da viscosidade em função da $C a$ para $\lambda=20$ e $\phi=20 \%$.O número de capilaridade foi calculado por $C a=(\eta \dot{\gamma} \delta) / \tau_{s}$ em que $\delta=0,4 \mathrm{~mm}$ é a distância entre os discos do reômetro e $\tau_{s}=0,03184 \mathrm{~N} / \mathrm{m}$ é a tensão interfacial. $---\eta / \eta_{b}=2,03 \pm 0,134$.

7.26 Variação da viscosidade em função da $C a$ para $\lambda=20$ e $\phi=40 \%$.O número de capilaridade foi calculado por $C a=(\eta \dot{\gamma} \delta) / \tau_{s}$ em que $\delta=0,4 \mathrm{~mm}$ é a distância entre os discos do reômetro e $\tau_{s}=0,03184 \mathrm{~N} / \mathrm{m}$ é a tensão interfacial. -Modelo Carreau-Yasuda (eq. 2.11) $\eta_{\infty} / \eta_{b}=$ $1,0, \eta_{0} / \eta_{b}=19,0, \alpha=4 \times 10^{-5}, n=-7,6, a=0,28 \ldots \ldots 178$

7.27 Aumento da viscosidade com a fração volumétrica $-\eta_{\infty} / \eta_{b}=(1-\phi)^{-n}$ em que $n=4,26$. Dados experimentais para $C a \approx 0,01$ e $\lambda=20$. Encarte: - Ajuste pela expressão da viscosidade de Taylor. . . . . . . 178

7.28 Aumento da viscosidade adimensinalizada em altos números de capilaridade para a emulsão de fração volumétrica $40 \%$ com $C a \approx 6 \times 10^{-2}$. . 
7.29 Variação da pressão em função da vazão para $\lambda=2$ e $\phi=2 \%$. Pontos Experimentais ; - Região Linear. A viscosidade efetiva é de 34, $85 \mathrm{cP}$ que adimensionalizada pela viscosidade do fluido base é 0,51 . . . . . . 182

7.30 Variação da viscosidade aparente é $\eta_{w} / \eta_{b}$ com o número de capilaridade avaliado na parede $\left(C a_{w}=\left(\dot{\gamma}_{w} \eta_{w} R\right) / \tau_{s}\right)$ para $\lambda=2$ e $\phi=2 \%$ em que $\tau_{s}=0,028 \mathrm{~N} / \mathrm{m}$. A viscosidade $\eta_{w, \infty} / \eta_{b}=5,44 \pm 2,628$. - Ajuste com modelo de Sisko: $\eta_{w} / \eta_{b}=\eta_{w, \infty} / \eta_{b}+K C a_{w}^{n-1}$, com $K=1.26 \times 10^{-9}$ e $n=-4,62$.

7.31 Variação da pressão em função da vazão para $\lambda=2$ e $\phi=5 \%$. Pontos Experimentais ; - Região Linear da emulsão. A viscosidade efetiva é de $45 c P$ que adimensionalizada pela viscosidade do fluido base é 0,66.

7.32 Variação da viscosidade aparente é $\eta_{w} / \eta_{b}$ com o número de capilaridade avaliado na parede $\left(C a_{w}=\left(\dot{\gamma}_{w} \eta_{w} R\right) / \tau_{s}\right)$ para $\lambda=2$ e $\phi=5 \%$ em que $\tau_{s}=0,028 \mathrm{~N} / \mathrm{m}$. A viscosidade $\eta_{w, \infty} / \eta_{b}=5,81 \pm 1,493$. - Ajuste com modelo de Sisko: $\eta_{w} / \eta_{b}=\eta_{w, \infty} / \eta_{b}+K C a_{w}^{n-1}$, com $K=6,2 \times 10^{-5}$

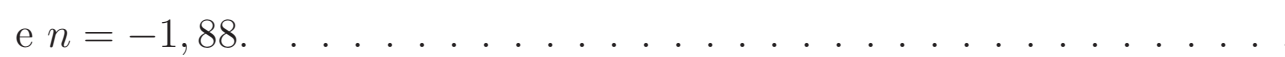

7.33 Variação da pressão em função da vazão para $\lambda=2$ e $\phi=20 \%$. Pontos Experimentais ; - Região Linear da emulsão. A viscosidade efetiva é de 81,32 $c P$ que adimensionalizada pela viscosidade do fluido base é 1,19 .

7.34 Variação da viscosidade aparente é $\eta_{w} / \eta_{b}$ com o número de capilaridade avaliado na parede $\left(C a_{w}=\left(\dot{\gamma}_{w} \eta_{w} R\right) / \tau_{s}\right)$ para $\lambda=2$ e $\phi=20 \%$ em que $\tau_{s}=0,028 \mathrm{~N} / \mathrm{m}$. A viscosidade $\eta_{w, \infty} / \eta_{b}=9,43 \pm 2,557$. - Ajuste com modelo de Sisko: $\eta_{w} / \eta_{b}=\eta_{w, \infty} / \eta_{b}+K C a_{w}^{n-1}$, com $K=1,9 \times 10^{-4}$ e $n=-2,07$.

7.35 Variação da pressão em função da vazão para $\lambda=2$ e $\phi=40 \%$.

Pontos Experimentais ; - Região Linear da emulsão. A viscosidade efetiva é de $204 c P$ que adimensionalizada pela viscosidade do fluido base é 2,98 . 
7.36 Variação da viscosidade aparente é $\eta_{w} / \eta_{b}$ com o número de capilaridade avaliado na parede $\left(C a_{w}=\left(\dot{\gamma}_{w} \eta_{w} R\right) / \tau_{s}\right)$ para $\lambda=2$ e $\phi=40 \%$ em que $\tau_{s}=0,028 \mathrm{~N} / \mathrm{m}$. A viscosidade $\eta_{w, \infty} / \eta_{b}=24,76 \pm 11,329$. - Ajuste com modelo de Sisko: $\eta_{w} / \eta_{b}=\eta_{w, \infty} / \eta_{b}+K C a_{w}^{n-1}$, com $K=4 \times 10^{-5} \mathrm{e}$ $n=-2,63$.

7.37 Aumento da viscosidade intrínseca com a fração volumétrica $-\eta_{\infty} / \eta_{b}=$ $(1-\phi)^{-n}$ em que $n=-2,44$. Dado experimentais para $C a_{w} \approx 5,8 \times 10^{-2}$ e $\lambda=2$. Encarte: - Ajuste pela expressão da viscosidade de Taylor.

7.38 Variação da pressão em função da vazão para $\lambda=5$ e $\phi=2 \%$. Pontos Experimentais ; - Região Linear da emulsão. A viscosidade efetiva é de 15, 2 cP que adimensionalizada pela viscosidade do fluido base é 0,54. 187

7.39 Variação da viscosidade aparente é $\eta_{w} / \eta_{b}$ com o número de capilaridade avaliado na parede $\left(C a_{w}=\left(\dot{\gamma}_{w} \eta_{w} R\right) / \tau_{s}\right)$ para $\lambda=5$ e $\phi=2 \%$ em que $\tau_{s}=0,02926 \mathrm{~N} / \mathrm{m}$. A viscosidade $\eta_{w, \infty} / \eta_{b}=5,80 \pm 2,92$. - Ajuste com modelo de Sisko: $\eta_{w} / \eta_{b}=\eta_{w, \infty} / \eta_{b}+K C a_{w}^{n-1}$, com $K=4 \times 10^{-9} \mathrm{e}$ $n=-3,80$.

7.40 Variação da pressão em função da vazão para $\lambda=5$ e $\phi=5 \%$. Pontos Experimentais ; - Região Linear da emulsão. A viscosidade efetiva é de $29 c P$ que adimensionalizada pela viscosidade do fluido base é 1,02.

7.41 Variação da viscosidade aparente é $\eta_{w} / \eta_{b}$ com o número de capilaridade avaliado na parede $\left(C a_{w}=\left(\dot{\gamma}_{w} \eta_{w} R\right) / \tau_{s}\right)$ para $\lambda=5$ e $\phi=5 \%$ em que $\tau_{s}=0,02926 \mathrm{~N} / \mathrm{m}$. A viscosidade $\eta_{w, \infty} / \eta_{b}=5,57 \pm 2,50$. - Ajuste com modelo de Sisko: $\eta_{w} / \eta_{b}=\eta_{w, \infty} / \eta_{b}+K C a_{w}^{n-1}$, com $K 1.55 \times 10^{-6} \mathrm{e}$ $n=-2,93$.

7.42 Variação da pressão em função da vazão para $\lambda=5$ e $\phi=20 \%$.

Pontos Experimentais ; - Região Linear da emulsão. A viscosidade efetiva é de $38,5 \mathrm{cP}$ que adimensionalizada pela viscosidade do fluido base é 1,37 .

7.43 Variação da viscosidade aparente é $\eta_{w} / \eta_{b}$ com o número de capilaridade avaliado na parede $\left(C a_{w}=\left(\dot{\gamma}_{w} \eta_{w} R\right) / \tau_{s}\right)$ para $\lambda=5$ e $\phi=20 \%$ em que $\operatorname{tau}_{s}=0,02926 \mathrm{~N} / \mathrm{m}$. A viscosidade $\eta_{w, \infty} / \eta_{b}=3,00 \pm 0,70$. Ajuste com modelo de Sisko: $\eta_{w} / \eta_{b}=\eta_{w, \infty} / \eta_{b}+K C a_{w}^{n-1}, \operatorname{com} K=0,7$ e $n=0,31.189$ 
7.44 Variação da pressão em função da vazão para $\lambda=5$ e $\phi=40 \%$. Pontos Experimentais ; - Região Linear da emulsão. A viscosidade efetiva é de $367 c P$ que adimensionalizada pela viscosidade do fluido base é 13,08 .

7.45 Variação da viscosidade aparente é $\eta_{w} / \eta_{b}$ com o número de capilaridade avaliado na parede $\left(C a_{w}=\left(\dot{\gamma}_{w} \eta_{w} R\right) / \tau_{s}\right)$ para $\lambda=5$ e $\phi=40 \%$ em que $\tau_{s}=0,02926 \mathrm{~N} / \mathrm{m}$. A viscosidade $\eta_{w, \infty} / \eta_{b}=55,00 \pm 4,70$. - Ajuste com modelo de Sisko: $\eta_{w} / \eta_{b}=\eta_{w, \infty} / \eta_{b}+K C a_{w}^{n-1}$, com $K=0,09$ e $n=-1,30$.

7.46 Aumento da viscosidade intrínseca com a fração volumétrica $-\eta_{\infty} / \eta_{b}=$ $(1-\phi)^{-n}$ em que $n=-5,26$. Dado experimentais para $C a_{w} \approx 6 \times 10^{-2}$ e $\lambda=5$. Encarte: - Ajuste pela expressão da viscosidade de Taylor. .

7.47 Variação da pressão em função da vazão para $\lambda=10$ e $\phi=2 \%$.

Pontos Experimentais ; - Região Linear da emulsão. A viscosidade efetiva é de $7,6 \mathrm{cP}$ que adimensionalizada pela viscosidade do fluido base é 0,47 .

7.48 Variação da viscosidade aparente é $\eta_{w} / \eta_{b}$ com o número de capilaridade avaliado na parede $\left(C a_{w}=\left(\dot{\gamma}_{w} \eta_{w} R\right) / \tau_{s}\right)$ para $\lambda=10$ e $\phi=2 \%$ em que $\tau_{s}=0,03066 \mathrm{~N} / \mathrm{m}$. A viscosidade $\eta_{w, \infty} / \eta_{b}=4,90 \pm 0,33$. - Ajuste com modelo de Sisko: $\eta_{w} / \eta_{b}=\eta_{w, \infty} / \eta_{b}+K C a_{w}^{n-1}$, com $K=1,12 \times 10^{-7}$ e $n=-2,78$.

7.49 Variação da pressão em função da vazão para $\lambda=10$ e $\phi=5 \%$.

Pontos Experimentais ; - Região Linear da emulsão. A viscosidade efetiva é de $8 c P$ que adimensionalizada pela viscosidade do fluido base é 0,58 .

7.50 Variação da viscosidade aparente é $\eta_{w} / \eta_{b}$ com o número de capilaridade avaliado na parede $\left(C a_{w}=\left(\dot{\gamma}_{w} \eta_{w} R\right) / \tau_{s}\right)$ para $\lambda=10$ e $\phi=5 \%$ em que $\tau_{s}=0,03066 \mathrm{~N} / \mathrm{m}$. A viscosidade $\eta_{w, \infty} / \eta_{b}=5,09 \pm 0,34$. - Ajuste com modelo de Sisko: $\eta_{w} / \eta_{b}=\eta_{w, \infty} / \eta_{b}+K C a_{w}^{n-1}, \operatorname{com} K=9,54 \times 10^{-7}$ e $n=-2,31$. 
7.51 Variação da pressão em função da vazão para $\lambda=10$ e $\phi=20 \%$. Pontos Experimentais ; - Região Linear da emulsão. A viscosidade efetiva é de $16 c P$ que adimensionalizada pela viscosidade do fluido base é 1,17 .

7.52 Variação da viscosidade aparente é $\eta_{w} / \eta_{b}$ com o número de capilaridade avaliado na parede $\left(C a_{w}=\left(\dot{\gamma}_{w} \eta_{w} R\right) / \tau_{s}\right)$ para $\lambda=10$ e $\phi=20 \%$ em que $\tau s=0,03066 \mathrm{~N} / \mathrm{m}$. A viscosidade $\eta_{w, \infty} / \eta_{b}=10,14 \pm 0,38$. A Ajuste com modelo de Sisko: $\eta_{w} / \eta_{b}=\eta_{w, \infty} / \eta_{b}+K C a_{w}^{n-1}$, com $K=1,26 \times 10^{-6}$ e $n=-2,60$.

7.53 Variação da pressão em função da vazão para $\lambda=10$ e $\phi=40 \%$.

Pontos Experimentais ; - Região Linear da emulsão. A viscosidade efetiva é de $81,62 c P$

7.54 Variação da viscosidade aparente é $\eta_{w} / \eta_{b}$ com o número de capilaridade avaliado na parede $\left(C a_{w}=\left(\dot{\gamma}_{w} \eta_{w} R\right) / \tau_{s}\right)$ para $\lambda=10$ e $\phi=40 \%$ em que $\tau_{s}=0,03066 \mathrm{~N} / \mathrm{m}$. A viscosidade $\eta_{w, \infty} / \eta_{b}=30,0 \pm 6,86$. - Ajuste com modelo de Sisko: $\eta_{w} / \eta_{b}=\eta_{w, \infty} / \eta_{b}+K C a_{w}^{n-1}$, com $K=0,12 \mathrm{e}$ $n=-0,68$.

7.55 Aumento da viscosidade intrínseca com a fração volumétrica $-\eta_{\infty} / \eta_{b}=$ $(1-\phi)^{-n}$ em que $n=-4,20$. Dado experimentais para $C a_{w} \approx 3,4 \times 10^{-2}$ e $\lambda=10$. Encarte: - Ajuste pela expressão da viscosidade de Taylor.

7.56 Variação da pressão em função da vazão para $\lambda=20$ e $\phi=2 \%$.

Pontos Experimentais ; - Região Linear da emulsão. A viscosidade efetiva é de $3,5 c P$ que adimensionalizada pela viscosidade do fluido base é 0,47 .

7.57 Variação da viscosidade aparente é $\eta_{w} / \eta_{b}$ com o número de capilaridade avaliado na parede $\left(C a_{w}=\left(\dot{\gamma}_{w} \eta_{w} R\right) / \tau_{s}\right)$ para $\lambda=20$ e $\phi=2 \%$ em que $\tau_{s}=0,03184 \mathrm{~N} / \mathrm{m}$. A viscosidade $\eta_{w, \infty} / \eta_{b}=4,77 \pm 0,33$. - Ajuste com modelo de Sisko: $\eta_{w} / \eta_{b}=\eta_{w, \infty} / \eta_{b}+K C a_{w}^{n-1}$, com $K=2,77 \times 10^{-6}$ e $n=-1,88$. 
7.58 Variação da pressão em função da vazão para $\lambda=20$ e $\phi=5 \%$. Pontos Experimentais ; - Região Linear da emulsão. A viscosidade efetiva é de 4,1 cP que adimensionalizada pela viscosidade do fluido base é 0,55 .

7.59 Variação da viscosidade aparente é $\eta_{w} / \eta_{b}$ com o número de capilaridade avaliado na parede $\left(C a_{w}=\left(\dot{\gamma}_{w} \eta_{w} R\right) / \tau_{s}\right)$ para $\lambda=20$ e $\phi=5 \%$ em que $\tau_{s}=0,03184 \mathrm{~N} / \mathrm{m}$. A viscosidade $\left.\eta_{w, \infty} / \eta_{b}\right)_{\infty}=5,85 \pm 0,65$. - Ajuste com modelo de Sisko: $\eta_{w} / \eta_{b}=\left(\eta_{w} / \eta_{b}\right)_{\infty}+K C a_{w}^{n-1}, \operatorname{com} K=9,61 \times 10^{-12}$ e $n=-4,54$.

7.60 Variação da pressão em função da vazão para $\lambda=20$ e $\phi=20 \%$. Pontos Experimentais ; - Região Linear da emulsão. A viscosidade efetiva é de $7 c P$ que adimensionalizada pela viscosidade do fluido base é 0,94 .

7.61 Variação da viscosidade aparente é $\eta_{w} / \eta_{b}$ com o número de capilaridade avaliado na parede $\left(C a_{w}=\left(\dot{\gamma}_{w} \eta_{w} R\right) / \tau_{s}\right)$ para $\lambda=20$ e $\phi=20 \%$ em que $\tau_{s}=0,03184 \mathrm{~N} / \mathrm{m}$. A viscosidade $\eta_{w, \infty} / \eta_{b}=9,90 \pm 1,09$. A - Ajuste com modelo de Sisko: $\eta_{w} / \eta_{b}=\eta_{w, \infty} / \eta_{b}+K C a_{w}^{n-1}$, com $K=1,69 \times 10^{-9}$ e $n=-3,71$.

7.62 Variação da pressão em função da vazão para $\lambda=20$ e $\phi=40 \%$.

Pontos Experimentais ; - Região Linear da emulsão. A viscosidade efetiva é de $19 c P$ que adimensionalizada pela viscosidade do fluido base é 2,54 .

7.63 Variação da viscosidade aparente é $\eta_{w} / \eta_{b}$ com o número de capilaridade avaliado na parede $\left(C a_{w}=\left(\dot{\gamma}_{w} \eta_{w} R\right) / \tau_{s}\right)$ para $\lambda=20$ e $\phi=40 \%$ em que $\tau_{s}=0,03184 \mathrm{~N} / \mathrm{m} \mathrm{m}$. A viscosidade $\eta_{w, \infty} / \eta_{b}=28,33 \pm 1,36$. - Ajuste com modelo de Sisko: $\eta_{w} / \eta_{b}=\eta_{w, \infty} / \eta_{b}+K C a_{w}^{n-1}$, com $K=1,20 \times 10^{-6}$ e $n=-2,76$.

7.64 Aumento da viscosidade intrínseca com a fração volumétrica $-\eta_{\infty} / \eta_{b}=$ $(1-\phi)^{-n}$ em que $n=-2,82$. Dado experimentais para $C a_{w} \approx 3 \times 10^{-2}$ e $\lambda=20$. Encarte: - Ajuste pela expressão da viscosidade de Taylor. 
8.1 Comparação entre a viscosidade experimental (•) adimensionalizada pela viscosidade do fluido base e a viscosidade teórica de Taylor (- - -, eq. 8.6) para $\phi=2 \%$ em função da razão de viscosidade.

8.2 Comparação entre a viscosidade experimental $(\bullet)$ adimensionalizada pela viscosidade do fluido base e a viscosidade teórica de Taylor (- - - eq. 8.6) para para $\phi=5 \%$ em função da razão de viscosidade. . . . . . . . 214

8.3 Viscosidade experimental adimensionalizada pela viscosidade do fluido base para $\phi=20 \%$ em função da razão de viscosidade. (- - ) Viscosidade teórica de Taylor (eq. 8.6). (•) Viscosidade Experimental da presente tese.

8.4 Variação da viscosidade adimensional com a fracção volumétrica para $\lambda=20$ e $C a \approx 0,020$. A constante obtida para o ajuste dos dois primeiros pontos foi de $K=5 / 2 \ldots \ldots \ldots \ldots$

8.5 Variação da viscosidade aparente em função do número de capilaridade $\left(C a=\eta_{b} \dot{\gamma} \bar{a} / \tau_{s}\right)$ para a fração volumétrica $2 \%$ e razão de viscosidade 20.

- Experimentos da presente tese, - - Eq. 8.8. . . . . . . . . . . 217

8.6 Variação da viscosidade adimensional em função da razão de viscosidade para a emulsão de $\phi=2 \%$ e $C a=\eta_{b} \dot{\gamma} \bar{a} / \tau_{s} \approx 2 \times 10^{-4}$. Experimentos da presente tese. - - - Eq. 8.8. ‥ Eq. 8.5. . . . . . . . . . . . . 218

8.7 Variação da viscosidade no máximo número de capilaridade experimental adimensionalizada pela viscosidade do fluido base em função da razão de viscosidade para a emulsão de $\phi=40 \%$. • Experimento da presente tese. --- Eq. 8.8. . . Eq. 8.5. . . . . . . . . . . . . . .

8.8 Variação da viscosidade aparente com o número de capilaridade $C a_{\lambda}$ para a emulsão de fração volumétrica $2 \%$ e razão de viscosidade 20 . $\eta_{P} / \eta_{b} ; \cdots$ Resultado Teórico da eq. 8.9 e da eq. 8.10 são coincidentes para baixos números de capilaridade.

8.9 Variação da viscosidade aparente com a razão de viscosidade para $C a_{w} \approx$ 0, 02 para a emulsão de fração volumétrica $2 \%$ Resultado Teórico da eq. 8.9 e da eq. 8.10 são coincidentes. 
8.10 Variação da viscosidade aparente em função da taxa de cisalhamento para a emulsão $\mathrm{O} / \mathrm{A}$ de $\lambda=5$. • Jayasuriya et al. (1986) $\phi=15 \% ; \nabla$ Presente Trabalho $\phi=20 \% \ldots \ldots \ldots \ldots$. . . . . . . . .

8.11 Variação da viscosidade aparente com a tensão de cisalhamento para a emulsão $\mathrm{O} / \mathrm{A}$ de $\lambda \approx 5$. • Pal (1992) $\phi=16 \%$ e $0,2 \%$ wt de surfactante $; \Delta$ Presente Trabalho $\phi=20 \% \ldots \ldots \ldots \ldots$

8.12 Variação da viscosidade aparente com a tensão de cisalhamento para a emulsão $\mathrm{O} / \mathrm{A}$ de $\lambda \approx 5$. Pal (1992) $\phi=31 \%$ e $12,8 \%$ wt de surfactante ; $\triangle$ Presente Trabalho $\phi=40 \%$.

9.1 Variação da viscosidade com o aumento da taxa de cisalhamento para emulsões com razão de viscosidade 10 de diferentes frações volumétricas. 234

9.2 Variação dos módulos viscoelásticos $\left(G^{\prime}, G^{\prime \prime}\right)$ em função da deformação $(\gamma)$ da emulsão de $\phi=50 \%$ e $\lambda=10 \mathrm{com} \omega=5 \mathrm{rad} / \mathrm{s} . \quad \gamma<0,01$ : Regime de Viscoelasticidade Linear. $\gamma \geq 0,01$ : Regime de Viscoelasticidade Não-Linear.

9.3 Variação dos módulos viscoelásticos $\left(G^{\prime}, G^{\prime \prime}\right)$ em função da deformação $(\gamma)$ da emulsão de $\phi=60 \%$ e $\lambda=10 \mathrm{com} \omega=5 \mathrm{rad} / \mathrm{s} . \quad \gamma<0,01$ : Regime de Viscoelasticidade Linear. $\gamma \geq 0,01$ : Regime de Viscoelasticidade Não-Linear.

9.4 Variação dos módulos viscoelásticos $\left(G^{\prime}, G^{\prime \prime}\right)$ em função da deformação $(\gamma)$ da emulsão de $\phi=70 \%$ e $\lambda=10 \mathrm{com} \omega=5 \mathrm{rad} / \mathrm{s} . \quad \gamma<0,02$ : Regime de Viscoelasticidade Linear. $\gamma \geq 0,02$ : Regime de Viscoelasticidade Não-Linear. . . . . . . . . . . . . . . . . . . . . . . . . . 236

9.5 Variação dos módulos viscoelásticos $\left(G^{\prime}, G^{\prime \prime}\right)$ em função da deformação $(\gamma)$ da emulsão de $\phi=70 \%$ e $\lambda=20 \mathrm{com} \omega=5 \mathrm{rad} / \mathrm{s} . \gamma<0,022$ : Regime de Viscoelasticidade Linear. $\gamma \geq 0,022$ : Regime de Viscoelasticidade Não-Linear. . . . . . . . . . . . . . . . . . . . . . . . 237

9.6 Módulos viscoelásticos $\left(G^{\prime}, G^{\prime \prime}\right)$ em função da frequência $(\gamma)$ no regime linear $(\gamma=0,006)$ para a emulsão de fração volumétrica $\phi=60 \%$ e $\lambda=10$. 
10.1 Reômetro equipado com os acessórios apropriados para a realização de experimentos com campo magnético. a) Cápsula Magnética. b) Base.

c) Bobinas.

10.2 Influência do campo magnético na viscosidade para uma taxa de cisalhamento constante $\left(10 \mathrm{~s}^{-1}\right)$. Encarte: • $H=0.0 ; \boldsymbol{\square} H=71,28 \mathrm{kA} / \mathrm{m}$. Teste de cisalhamento permanente mostrando o efeito magnetoviscoso do ferrofluido.

10.3 Variação da viscosidade em altas taxas de cisalhamento $\left(\eta_{\infty}\right)$ devido ao aumento da intensidade do campo magnético. Encarte: Perfil de viscosidade com o aumento da taxa de cisalhamento quando a intensidade de campo magnético é constante. • $H=0.0 ; \square H=71,28 k / A m$. A taxa de cisalhamento de saturação da viscosidade foi considerada a mesma para todas as intensidades de campos magnéticos $\left(\dot{\gamma}=120 \mathrm{~s}^{-1}\right)$. . . .

10.4 Influência do aumento da taxa de cisalhamento para uma intensidade constante de campo magnético $(H=123 \mathrm{kA} / \mathrm{m})$. Encarte: Aumento da viscosidade em função do aumento contínuo da intensidade do campo magnético. • $\dot{\gamma}=5 \mathrm{~s}^{-1}$.

10.5 Configurações da microestrutura de um volume típico de fluido magnético com partículas de magnetite: a) Distribuição de partículas na ausência de campo magnético. b) Formação de estruturas de partículas com a aplicação de campo magnético. c) Quebra das estruturas devido ao cisalhamento simples aplicado.

10.6 Influência da deformação $(\gamma)$ no módulo de armazenamento para diferentes intensidades de campo magnético. • $H=0.0 \mathrm{kA} / \mathrm{m} ; * H=$ $8.22 \mathrm{kA} / \mathrm{m} ; 16,13 \mathrm{kA} / \mathrm{m} ; \mathbf{\square} 39,47 \mathrm{kA} / \mathrm{m} ; \boldsymbol{\Delta} 71,28 \mathrm{kA} / \mathrm{m} \ldots .$.

10.7 Influência da deformação $(\gamma)$ em $G^{\prime \prime}$ para diferentes intensidades de campo magnético. • $H=0.0 \mathrm{kA} / \mathrm{m} ; * H=8.22 \mathrm{kA} / \mathrm{m} ; 16,13 \mathrm{kA} / \mathrm{m}$;

- 39, $47 \mathrm{kA} / \mathrm{m} ; \mathbf{\Delta} 71,28 \mathrm{kA} / \mathrm{m} \ldots \ldots \ldots \ldots$

10.8 Função de Relaxação em função do tempo para diferentes degraus de deformação para $H=71,28 \mathrm{~A} / \mathrm{m}$ e $f=0,79 \mathrm{~Hz}(w=5 \mathrm{rad} / \mathrm{s})$. $\gamma=0,01, \circ \gamma=0,05, \gamma=0,1, \diamond \gamma=0,2$, 
10.9 Variação da função de relaxação de equilíbrio com o tempo. Dados ajustados com a função $\Phi_{\infty}=C t^{\alpha}$ em que $k$ e $\alpha$ são constantes de ajuste.253

10.10Configurações da microestrutura de um volume típico de fluido magnético com partículas de magnetite: a) Formação de agregados devido a aplicação de um campo magnético. b) Deformação dos agregados em uma baixa taxa de cisalhamento. c) Relaxação dos agregados após a retirada instantânea da taxa de cisalhamento.

10.11Influência da pré-taxa de cisalhamento $\left(\dot{\gamma}_{p}\right)$ na tensão residual $\left(\tau_{r}\right)$ com campo magnético constante de $71,28 \mathrm{kA} / \mathrm{m} . * \dot{\gamma}_{p}=0,2 \mathrm{~s}^{-1}, \tau_{r}=$ $0,0916 \mathrm{~Pa} ; \boldsymbol{\square} \dot{\gamma}_{p}=0,4 \mathrm{~s}^{-1}, \tau_{r}=0,0582 \mathrm{~Pa} ; \boldsymbol{\Delta} \dot{\gamma}_{p}=0,5 \mathrm{~s}^{-1}, \tau_{r}=$ 0,0265Pa; $\dot{\gamma}_{p}=1,0 s^{-1}, \tau_{r}=0,0$ Pa. - - --Tensão residual. . . . .

10.12Influência da pré taxa de cisalhamento $\left(\dot{\gamma}_{p}\right)$ no tempo de relaxação $\left(t_{r}\right)$ para um campo magnético constante de 71,28 kA/m. * $\dot{\gamma}_{p}=0.2 \mathrm{~s}^{-1}$, $t_{r}=216 \mathrm{~s} ; \boldsymbol{\square} \dot{\gamma}_{p}=0.4 \mathrm{~s}^{-1}, t_{r}=224 \mathrm{~s} ; \boldsymbol{\Delta} \dot{\gamma}_{p}=0.5 \mathrm{~s}^{-1}, t_{r}=232 \mathrm{~s}$; $\boldsymbol{\nabla} \dot{\gamma}_{p}=1.0 \mathrm{~s}^{-1}, t_{r}=280 \mathrm{~s}$. - - - Tempo para o qual a tensão entra em regime permanente. . . . . . . . . . . . . . . 256

10.13Tempo de relaxação em função da pré-taxa de cisalhamento. . . . . . . 257

10.14Tensão de relaxação em função do tempo de relaxação, para uma pré taxa de cisalhamento $\dot{\gamma}=0,5 \mathrm{~s}^{-1}$ com um campo magnético constante de $71,28 \mathrm{kA} / \mathrm{m}$. •Dados Experimentais, -Ajuste $\tau=A \exp (-t / \alpha)$ $(A=80, \alpha=31) \ldots \ldots \ldots \ldots \ldots \ldots$

10.15Aumento linear da tensão crítica com o campo magnético. Encarte: Aumento não linear da viscosidade com o campo magnético refletindo a formação de agregados mesmo nas menores intensidades de campo magnético.

10.16Tensão crítica adimensional pela tensão de cisalhamento quando $H=$ $0.0 \mathrm{kA} / \mathrm{m}$ com o aumento da intensidade do campo magnético adimensional. Encarte: Aumento da viscosidade crítica adimensional $\left(\tilde{\eta}_{0}=\right.$ $\left.\eta_{0} / \eta_{H=0}\right)$ com o aumento da intensidade do campo magnético adimensional 
10.17Variação da saturação da viscosidade adimensional $\left(\tilde{\eta}_{\infty}=\eta_{\infty} / \eta_{H=0}\right)$ em altos números de capilaridade magnético em função da intensidade do campo magnético adimensional. Encarte: Perfil de viscosidade adimensional $\left(\tilde{\eta}=\eta / \eta_{H=0}\right)$ com o aumento do número de capilaridade magnético para constantes campos magnéticos adimensionais. $\bullet H=0.0$; $H=4,07 k / A m \ldots \ldots \ldots \ldots \ldots \ldots$

A.1 Imagem da Microestrutura da Emulsão $\lambda=2$ e $\phi=2 \%$. . . . . . . . 281

A.2 Distribuição de Tamanho de gota para a emulsão $\lambda=2$ e $\phi=2 \%$. Características da microestrutura: $N_{g}=2450, \bar{a}=13,37 \mu m, p=0,286282$

A.3 Frequência Relativa $\left(N_{\text {gint }} /\left(D_{i m_{i n t}} \times N_{\text {gtot }}\right)\right.$ para a emulsão $\lambda=2 \mathrm{e}$ $\phi=2 \%$. Constantes da Log-Normal: $C_{1}=0,035, C_{2}=0,95 \ldots 282$

A.4 Imagem da Microestrutura da Emulsão $\lambda=2$ e $\phi=5 \%$. . . . . . . . 283

A.5 Distribuição de Tamanho de gota para a emulsão $\lambda=2$ e $\phi=5 \%$. Características da microestrutura: $N_{g}=1650, \bar{a}=12,49 \mu \mathrm{m}, p=0,321283$

A.6 Frequência Relativa $\left(N_{\text {gint }} /\left(D_{i m_{i n t}} \times N_{\text {gtot }}\right)\right.$ para a emulsão $\lambda=2 \mathrm{e}$ $\phi=5 \%$. Constantes da Log-Normal: $C_{1}=0,038, C_{2}=1,0 \ldots 284$

A.7 Imagem da Microestrutura da Emulsão $\lambda=2$ e $\phi=20 \%$. . . . . . . . 284

A.8 Distribuição de Tamanho de gota para a emulsão $\lambda=2$ e $\phi=20 \%$. Características da microestrutura: $N_{g}=2555, \bar{a}=12,14 \mu m, p=0,290285$

A.9 Frequência Relativa $\left(N_{\text {gint }} /\left(D_{i m_{i n t}} \times N_{\text {gtot }}\right)\right.$ para a emulsão $\lambda=2 \mathrm{e}$ $\phi=20 \%$. Constantes da Log-Normal: $C_{1}=0,039, C_{2}=0,98 \ldots 285$

A.10 Imagem da Microestrutura da Emulsão $\lambda=2$ e $\phi=40 \%$. . . . . . . . 286

A.11 Distribuição de Tamanho de gota para a emulsão $\lambda=2$ e $\phi=40 \%$. Características da microestrutura: $N_{g}=3570, \bar{a}=14,22 \mu m, p=0,345286$ A.12 Frequência Relativa $\left(N_{\text {gint }} /\left(D_{i m_{i n t}} \times N_{\text {gtot }}\right)\right.$ para a emulsão $\lambda=2 \mathrm{e}$ $\phi=40 \%$. Constantes da Log-Normal: $C_{1}=0,044, C_{2}=0,948 \ldots 287$

A.13 Imagem da Microestrutura da Emulsão $\lambda=5$ e $\phi=2 \%$. . . . . . . . 288

A.14 Distribuição de Tamanho de gota para a emulsão $\lambda=5$ e $\phi=2 \%$.

Características da microestrutura: $N_{g}=1150, \bar{a}=10,00 \mu m, p=0,2987288$

A.15 Frequência Relativa $\left(N_{\text {gint }} /\left(\operatorname{Dim}_{\text {int }} \times N_{\text {gtot }}\right)\right.$ para a emulsão $\lambda=5 \mathrm{e}$ $\phi=2 \%$. Constantes da Log-Normal: $C_{1}=0,05, C_{2}=1,0 \ldots 289$ A.16 Imagem da Microestrutura da Emulsão $\lambda=5$ e $\phi=5 \%$. . . . . . . . 289 
A.17 Distribuição de Tamanho de gota para a emulsão $\lambda=5$ e $\phi=5 \%$. Características da microestrutura: $N_{g}=1385, \bar{a}=9,61 \mu m, p=0,386290$ A.18 Frequência Relativa $\left(N_{\text {gint }} /\left(\operatorname{Dim}_{\text {int }} \times N_{\text {gtot }}\right)\right.$ para a emulsão $\lambda=5 \mathrm{e}$ $\phi=5 \%$. Constantes da Log-Normal: $C_{1}=0,05, C_{2}=1,0 \ldots 290$

A.19 Imagem da Microestrutura da Emulsão $\lambda=5$ e $\phi=20 \%$. . . . . . . 291

A.20 Distribuição de Tamanho de gota para a emulsão $\lambda=5$ e $\phi=20 \%$.

Características da microestrutura: $N_{g}=2320, \bar{a}=11,78 \mu m, p=0,2961291$

A.21 Frequência Relativa $\left(N_{\text {gint }} /\left(D i m_{\text {int }} \times N_{\text {gtot }}\right)\right.$ para a emulsão $\lambda=5 \mathrm{e}$ $\phi=20 \%$. Constantes da Log-Normal: $C_{1}=0,05, C_{2}=1,0 \ldots 292$

A.22 Imagem da Microestrutura da Emulsão $\lambda=5$ e $\phi=40 \%$. . . . . . . 292

A.23 Distribuição de Tamanho de gota para a emulsão $\lambda=5$ e $\phi=40 \%$.

Características da microestrutura: $N_{g}=3115, \bar{a}=11,81 \mu \mathrm{m}, p=0,2762293$

A.24 Frequência Relativa $\left(N_{\text {gint }} /\left(\operatorname{Dim}_{\text {int }} \times N_{\text {gtot }}\right)\right.$ para a emulsão $\lambda=5 \mathrm{e}$ $\phi=40 \%$. Constantes da Log-Normal: $C_{1}=0,05, C_{2}=1,0 \ldots 293$

A.25 Imagem da Microestrutura da Emulsão $\lambda=10$ e $\phi=2 \%$. . . . . . . 294

A.26 Distribuição de Tamanho de gota para a emulsão $\lambda=10$ e $\phi=2 \%$.

Características da microestrutura: $N_{g}=2670, \bar{a}=21,00 \mu m, p=0,30$

A.27 Frequência Relativa $\left(N_{\text {gint }} /\left(\operatorname{Dim}_{\text {int }} \times N_{\text {gtot }}\right)\right.$ para a emulsão $\lambda=10 \mathrm{e}$ $\phi=2 \%$. Constantes da Log-Normal: $C_{1}=0,022, C_{2}=0,92 \ldots 295$

A.28 Imagem da Microestrutura da Emulsão $\lambda=10$ e $\phi=5 \%$. . . . . . . 295

A.29 Distribuição de Tamanho de gota para a emulsão $\lambda=10$ e $\phi=5 \%$.

Características da microestrutura: $N_{g}=1870, \bar{a}=16,00 \mu m, p=0,44$

A.30 Frequência Relativa $\left(N_{\text {gint }} /\left(\operatorname{Dim}_{\text {int }} \times N_{\text {gtot }}\right)\right.$ para a emulsão $\lambda=10 \mathrm{e}$ $\phi=5 \%$. Constantes da Log-Normal: $C_{1}=0,028, C_{2}=0,92 \ldots 296$

A.31 Imagem da Microestrutura da Emulsão $\lambda=10$ e $\phi=20 \%$. . . . . . . 297

A.32 Distribuição de Tamanho de gota para a emulsão $\lambda=10$ e $\phi=20 \%$.

Características da microestrutura: $N_{g}=2440, \bar{a}=17,40 \mu m, p=0,39$

A.33 Frequência Relativa $\left(N_{\text {gint }} /\left(\operatorname{Dim}_{\text {int }} \times N_{\text {gtot }}\right)\right.$ para a emulsão $\lambda=10 \mathrm{e}$ $\phi=20 \%$. Constantes da Log-Normal: $C_{1}=0,028, C_{2}=0,92 \ldots 298$

A.34 Imagem da Microestrutura da Emulsão $\lambda=10$ e $\phi=40 \%$. . . . . . 298

A.35 Distribuição de Tamanho de gota para a emulsão $\lambda=10$ e $\phi=40 \%$.

Características da microestrutura: $N_{g}=2720, \bar{a}=17,00 \mu m, p=0,38$ 
A.36 Frequência Relativa $\left(N_{\text {gint }} /\left(\operatorname{Dim}_{\text {int }} \times N_{\text {gtot }}\right)\right.$ para a emulsão $\lambda=10 \mathrm{e}$ $\phi=40 \%$. Constantes da Log-Normal: $C_{1}=0,028, C_{2}=0,92 \ldots 299$

A.37 Imagem da Microestrutura da Emulsão $\lambda=20$ e $\phi=2 \% \quad \ldots . . .300$

A.38 Distribuição de Tamanho de gota para a emulsão $\lambda=20$ e $\phi=2 \%$.

Características da microestrutura: $N_{g}=4950, \bar{a}=16,39 \mu \mathrm{m}, p=0,274300$

A.39 Frequência Relativa $\left(N_{\text {gint }} /\left(\operatorname{Dim}_{\text {int }} \times N_{\text {gtot }}\right)\right.$ para a emulsão $\lambda=20 \mathrm{e}$ $\phi=2 \%$. Constantes da Log-Normal: $C_{1}=0,033, C_{2}=1,06 \ldots 301$

A.40 Imagem da Microestrutura da Emulsão $\lambda=20$ e $\phi=5 \%$. . . . . . . 301

A.41 Distribuição de Tamanho de gota para a emulsão $\lambda=20$ e $\phi=5 \%$.

Características da microestrutura: $N_{g}=7500, \bar{a}=17,88 \mu m, p=0,270302$

A.42 Frequência Relativa $\left(N_{\text {gint }} /\left(\operatorname{Dim}_{\text {int }} \times N_{\text {gtot }}\right)\right.$ para a emulsão $\lambda=20 \mathrm{e}$ $\phi=5 \%$. Constantes da Log-Normal: $C_{1}=0,035, C_{2}=1,0 \ldots 302$

A.43 Imagem da Microestrutura da Emulsão $\lambda=20$ e $\phi=20 \%$. . . . . . . 303

A.44 Distribuição de Tamanho de gota para a emulsão $\lambda=20$ e $\phi=20 \%$.

Características da microestrutura: $N_{g}=4970, \bar{a}=21,53 \mu \mathrm{m}, p=0,324303$

A.45 Frequência Relativa $\left(N_{\text {gint }} /\left(\operatorname{Dim}_{\text {int }} \times N_{\text {gtot }}\right)\right.$ para a emulsão $\lambda=20 \mathrm{e}$ $\phi=20 \%$. Constantes da Log-Normal: $C_{1}=0,024, C_{2}=0,95 \ldots 304$

A.46 Imagem da Microestrutura da Emulsão $\lambda=20$ e $\phi=40 \%$. . . . . . . 304

A.47 Distribuição de Tamanho de gota para a emulsão $\lambda=20$ e $\phi=40 \%$.

Características da microestrutura: $N_{g}=5000, \bar{a}=21,00 \mu m, p=0,33 \quad 305$

A.48 Frequência Relativa $\left(N_{\text {gint }} /\left(\operatorname{Dim}_{\text {int }} \times N_{\text {gtot }}\right)\right.$ para a emulsão $\lambda=20 \mathrm{e}$ $\phi=40 \%$. Constantes da Log-Normal: $C_{1}=0,026, C_{2}=0,96 \ldots 305$

Módulo Elástico 


\section{Lista de Simbolos}

$\boldsymbol{A} \quad$ Tensor Taxa de Deformação

$\boldsymbol{B}$ Tensor de Forma de Superfície da Gota

$\boldsymbol{b} \quad$ Força de Campo por unidade de massa

$\boldsymbol{D} \quad$ Tensor Taxa de Deformação

$f \quad$ Somatório de Forças

$\boldsymbol{g} \quad$ Vetor Aceleração da Gravidade

I Tensor Identidade

$n \quad$ Vetor normal à superfície

$\boldsymbol{S}_{\alpha} \quad$ Tensor de Tensões na Superfície da Gota

$\Sigma \quad$ Componentes Deviatórios do Tensor de Tensões

$\boldsymbol{\Sigma} \quad$ Tensor de Tensões

$\Sigma^{d} \quad$ Tensor de Tensões oriundo da existência de gotas no fluido

$\Sigma^{N N}$ Contribuição das Tensões de um fluido não-Newtoniano para o Tensor de Tensões

$\boldsymbol{\tau} \quad$ Tensor de Tensões

$\boldsymbol{u} \quad$ Vetor de Velocidade

$\boldsymbol{W}$ Tensor Taxa de Rotação

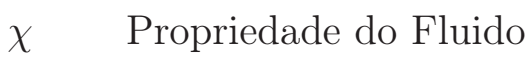

$\delta \quad$ Região Livre de Partículas 
$\dot{\gamma} \quad$ Taxa de Cisalhamento

$\dot{\gamma}_{w} \quad$ Taxa de Cisalhamento na Parede do Capilar

$\eta \quad$ Viscosidade

$\eta_{0} \quad$ Viscosidade em baixas taxas de cisalhamento

$\eta_{\delta} \quad$ Viscosidade na Região Adjacente à Parede do Capilar

$\eta_{\infty} \quad$ Viscosidade em elevadas taxas de cisalhamento

$\eta_{C} \quad$ Viscosidade na Região Central do Capilar

$\eta_{e m} \quad$ Viscosidade da Emulsão

$\eta_{e} \quad$ Viscosidade Efetiva

$\eta_{i} \quad$ Viscosidade Intrínseca

$\eta_{r} \quad$ Viscosidade Relativa

$\hat{e}_{z} \quad$ Vetor unitário na direção longitudinal

$\lambda \quad$ Razão entre a viscosidade da gota e a viscosidade do fluido ambiente

$\mathcal{D} \quad$ Coeficiente de Difusão

$\mathcal{T}$ Torque

$\mu_{B} \quad$ Viscosidade de Blob

$\mu_{T} \quad$ Viscosidade de Taylor

$\omega_{r} \quad$ Velocidade de Rotação

$\phi \quad$ Fração Volumétrica

$\rho \quad$ Massa específica

$\sigma_{r} \quad$ Tempo característico de Relaxação da gota

$\sigma_{x} \quad$ Desvio Padrão

$\tau \quad$ Tensão de Cisalhamento 
$\tau_{s} \quad$ Tensão Superficial

$\tau_{w} \quad$ Tensão de Tensões na Parede do Capilar

A Constante da Lei de Arrhenius

a Raio da Gota

$B \quad$ Constante da Lei de Arrhenius

Ca Número de Capilaridade

d Diâmetro da Gota

De Número de Debora

G Diferença de Pressão na Direção Longitudinal do Escoamento

L Comprimento na direção longitudinal

M Massa Molecular

m Constante do modelo: power-law, Cross, Herschel-Bulkley

$m_{C} \quad$ Massa do Corpo

N Número de Moléculas ou de Gotas

$n \quad$ Constante do modelo: power-law, Cross, Herschel-Bulkley, Carreau-Yassuda $N 1, N 2$ Diferença entre tensões normais

Pe Número de Peclet

Q Vazão

$Q_{P} \quad$ Vazão de Hagen-Poiseuille

$R \quad$ Raio do Tubo

$r \quad$ Distância radial desde o centro do Capilar

$R_{C} \quad$ Região central do Capilar

Re Número de Reynolds 
$S \quad$ Superfície do Volume

T Temperatura

$t \quad$ Tempo

$t_{d} \quad$ Tempo de Deformação

$t_{e} \quad$ Tempo característico do escoamento

$t_{m} \quad$ Tempo característico do material

u Velocidade na direção do escoamento

$u_{\delta} \quad$ Velocidade na Região Adjacente à Parede do Capilar

$u_{\theta} \quad$ Velocidade na direção angular

$u_{C} \quad$ Velocidade na Região Central do Capilar

$u_{\text {med }}$ Velocidade Média

$u_{r} \quad$ Velocidade na direção radial

$u_{z} \quad$ Velocidade na direção longitudinal

V Volume

y $\quad$ Direção Vertical 


\section{INTRODUÇÃO}

A caracterização de fluidos complexos em cisalhamento simples e por escoamento em tubo capilar, em baixo número de Reynolds, é o principal objetivo do presente trabalho. Entenda-se aqui que os fluidos complexos são sistemas que exibem uma relação não linear entre tensão $(\tau)$ e taxa de deformação/taxa de cisalhamento $(\dot{\gamma})$. Nestes sistemas estão incluídos, por exemplo, os polímeros, cristais líquidos, espumas, suspensões de partículas e suspensão de gotas. Neste trabalho são estudadas suspensão de gotas e de partículas rígidas. Estes fluidos podem apresentar estruturas anisotrópicas e consequentemente diferença de tensões normais $\left(N_{1}=\tau_{11}-\tau_{22}, N_{1}=\tau_{22}-\tau_{33}\right)$ ou tensão aplicada/crítica (yield stress). Este tipo de fluido é designado, em geral, por fluido não-Newtoniano. Os fluidos Newtonianos têm uma relação linear entre tensão e taxa de deformação.

Na prática, o que se procura extrair, dentro de outros parâmetros, é a relação da viscosidade dinâmica $(\eta)$ com a taxa de cisalhamento. Na teoria o que se procura é um modelo para o tensor de tensões $(\boldsymbol{\Sigma})$ que relacione o comportamento da microestrutura do fluido com a viscosidade, que é uma propriedade macroscópica do fluido. Neste sentido é interessante que estudos experimentais conectem a microestrutura do fluido com o comportamento reológico.

A microestrutura do fluido pode ser constituída por esferas rígidas (não se deformam), gotas (deformam-se, alinhando-se com o escoamento), macromoléculas poliméricas (possuem uma memória associada às suas propriedades elásticas) e bolhas. As partículas da microestrutura podem ter ainda propriedades que as permitam interagir com forças de um campo externo (ex: campo magnético e elétrico). A superfície das partículas pode ser rugosa alterando localmente o campo de velocidades do escoamento (Cunha e Hinch (1996)). Nesta tese a microestrutura dos fluidos é formada por gotas de fluido Newtoniano e incompressível (emulsões) e por partículas rígidas que interagem com um campo magnético externo (ferrofluido). O estudo de suspensão de partículas, gotas e bolhas em fluidos é de interesse para a mecânica de suspensões, meios porosos, 
fluidização e mecânica dos fluidos interfacial (Kim e Leal (2006)).

A caracterização de suspensões de gotas (emulsão) torna-se relevante uma vez que as propriedades de textura em produtos com finalidade alimentícia e cosmética, estão diretamente relacionadas com a microestrutura da emulsão (Tandros (1994)). Por outro lado, o conhecimento das propriedades das emulsões é relevante para o projeto e seleção de equipamentos de mistura e de bombeamento (Pal (2000b)).

A emulsão apesar de apresentar características de polidispersidade (gotas de diferentes tamanhos) pode ser tratada como sendo um sistema homogêneo seguindo os princípios da Mecânica dos Meios Contínuos, a qual define quantidades médias (velocidade, tensão, taxa de deformação) dentro de um volume característico de dimensão muito menor que a escala externa (i.e. distância entre placas ou discos paralelos, diâmetro do tubo) do escoamento e que contenha um número de partículas suficiente para que as suas propriedades sejam estatisticamente homogêneas (Pal (2001)). Desta forma é possível estudar o comportamento da emulsão levando em consideração a microestrutura do fluido. As emulsões aqui estudadas contêm gotas de tamanho não coloidal (> $1 \mu \mathrm{m})$. Desta forma os efeitos Brownianos que estão associados com a escala molecular são desprezíveis.

No escoamento de suspensões pode existir migração de partículas de regiões de alta para regiões de baixa taxa de cisalhamento. Quando o escoamento acontece no interior de tubos as partículas tendem a se concentrar na região central do escoamento. Este tipo de escoamento é conhecido por escoamento central (em inglês core-flow). A distribuição heterogênea de partículas na direção normal à parede afeta a viscosidade efetiva (Shauly et al. (1998)). Deste ponto de vista, a migração de partículas está relacionada com a reologia de sistemas dispersos tais como emulsões, sangue e suspensões de fibras (Karin e Mason (1967), Nourbakhsh e Mortazavi (2010)). Na literatura são encontrados diversos estudos experimentais e numéricos sobre o tema, em especial para emulsões e escoamento de sangue. Para o último caso é constatado que processos de inflamação podem ocorrer pela ausência de globos vermelhos nas paredes do vaso sanguíneo (Pranay et al. (2012)). Nesta tese o problema da migração hidrodinâmica de partículas é abordado através da equação de transporte a qual faz um balanço entre 
efeitos convectivos e difusivos.

O presente trabalho apresenta o estudo reológico de emulsões de gotas de óleo dispersas em um fluido base cuja viscosidade é alterada pela adição de glicerina, com o intuito de altear a razão de viscosidade da emulsão. A reologia das emulsões é estudada em cisalhamento simples, por um reômetro de discos e pelo escoamento em tubo capilar. Para as maiores frações volumétricas são apresentados resultados do cisalhamento oscilatório referentes ao comportamento dos módulos de viscoelasticidade. Em adição, são apresentados resultados reológicos referentes a uma suspensão de nanopartículas magnéticas sobre a influência da aplicação de um campo magnético externo. A reologia das suspensões de nanopartículas é estudada por

\subsection{MOTIVAÇÃO}

O interesse pelo estudo de sistemas particulados deve-se à sua ampla aplicação teórica e prática. Estes tipos de sistemas são encontrados em diversas aplicações de engenharia. O mais comum é o escoamento em tubo de suspensões tais como resíduos da mineração, pastas, poupas, petróleo e tintas. O estudo apresentado é focado em escoamento de emulsões e de suspensão de partículas rígidas. Nas emulsões, tanto o fluido disperso como o fluido carreador/base têm comportamento Newtoniano. No entanto a presença de gotas no fluido carreador confere a este conjunto um comportamento nãoNewtoniano. Taylor (1932), fez uma extensão do trabalho de Einsten, inicialmente para partículas esféricas rígidas, relacionando a viscosidade efetiva da emulsão $(\eta)$ com gotas que permanecem aproximadamente esféricas (alta tensão superficial) em função da fração volumétrica $(\phi)$ :

$$
\frac{\eta}{\eta_{b}}=1+\frac{5 \lambda+2}{2(\lambda+1)} \phi+\mathcal{O}\left(\phi^{2}\right)
$$

em que $\lambda$ é a razão entre a viscosidade do fluido da gota e do fluido carreador e $\eta_{b}$ é a viscosidade do fluido base. Esta expressão é destinada para regimes em que a $C a \rightarrow 0$. Aqui o número de capilaridade $(C a)$ representa a razão entre as forças do escoamento e as forças interfaciais que atuam sobre a partícula (Saiki et al. (2007)). 
Então o número de capilaridade pode ser interpretado como sendo a razão relativa entre a escala de tempo referente a relaxação da gota $\left(\eta_{g} a / \tau_{s}\right)$ e a escala de tempo referente ao escoamento externo $(1 / \dot{\gamma})$ :

$$
C a=\frac{\eta_{g} a / \tau_{s}}{1 / \dot{\gamma}}
$$

em que $\tau_{s}$ é a tensão superficial da gota, $\eta_{g}$ é a viscosidade da gota e $a$ é o raio da gota. Pela expressão de Taylor observa-se que em regimes diluídos há uma relação linear entre a viscosidade adimensional $\eta / \eta_{b}$ e a fração volumétrica $(\phi)$. É de notar também que quando $\lambda \rightarrow \infty$ a expressão de Taylor recupera a expressão de Einstein para suspensões infinitamente diluídas de partículas esféricas rígidas. Segundo Skartlien et al. (2012), Choi e Schowalter em 1975 observaram uma relação não linear entre a viscosidade efetiva e a fração volumétrica da gota para grandes concentrações, devido às intensas interações entre gotas.

O tempo de deformação da gota pode ser estimado como sendo:

$$
t_{d}=(1+\lambda) \frac{1}{\dot{\gamma}}
$$

Para emulsões de baixas razões de viscosidade a eq. 1.3 depende somente do tempo de escoamento, $1 / \dot{\gamma}$, em que $\dot{\gamma}$ é taxa de cisalhamento do escoamento. Assim o tempo de deformação é da ordem do tempo do escoamento e as gotas se deformam rapidamente. Neste caso, o tempo para que a emulsão atinja o seu regime de deformação permanente é baixo. No entanto, para altas razões de viscosidade o tempo de deformação é dominado pela razão de viscosidade. Assim se a taxa de cisalhamento for baixa, a gota vai demorar muito tempo a se deformar e atingir o seu regime de deformação permanente. Logo é necessário ter a sensibilidade de escolher uma magnitude coerente para a taxa de cisalhamento para evitar tempos de experimento longos.

É de interesse tomar conhecimento quando a emulsão adquire um comportamento não linear. Nesses regimes, o habitual é que a viscosidade da emulsão diminua em função do aumento da taxa de cisalhamento. Esse comportamento é justificado pela deformação da gota na direção do escoamento. Quanto mais alinhada a gota estiver com o esco- 
amento, menor é a variação da viscosidade apresentada pela emulsão. A viscosidade aparente da emulsão depende da fração volumétrica $(\phi)$, da razão de viscosidade entre a gota e o fluido carreador $(\lambda)$, da polidispersidade e do tamanho da gota. Para $\phi \geq 0,3$ a emulsão pode apresentar comportamento de fluido pseudo-plástico (em inglês shear thinning) (Mason (1999)).

A caracterização experimental de emulsões é motivada pela possibilidade de observar regimes críticos de linearidade em função da fração volumétrica, da razão de viscosidade e da taxa de cisalhamento. Estas observações são então confrontadas com teorias. Para o caso da variação da viscosidade com a fração volumétrica pode-se observar quando o regime de Taylor deixa de ser válido. Fora da região linear assiste-se a interação entre gotas e como tal o truncamento da expressão de Taylor não pode ser da ordem $\mathcal{O}\left(\phi^{2}\right)$ (ver eq. 1.1). Em regime de deformação de gotas é de interesse observar a taxa de deformação em função da taxa de cisalhamento e da razão entre viscosidades. No caso da variação da viscosidade com a taxa de cisalhamento é interessante ajustar os dados com modelos por meio de correlações empíricas. Esses modelos podem ser os modelos de fluido não-Newtoniano viscoso (ex: Lei de Potência, Casson, Cross, Carreau-Yassuda, Herschel-Bulkley). No entanto estes modelos não expressam a física envolvida na dinâmica do escoamento de suspensões. Outro ponto de interesse é explorar o aparecimento de efeitos viscoelásticos em emulsões. Nesse sentido é possível observar quando uma emulsão pode ter um comportamento típico elástico de sólido ou de líquido pela avaliação dos módulos de viscoelasticidade em função da fração volumétrica de gotas, da razão de viscosidade e da fracção de surfactante na emulsão.

Os resultados experimentais do escoamento em tubo capilar de emulsões infinitamente diluídas para altas razões de viscosidade podem ser previstos através da teoria de pequenas deformações. De acordo com os estudos publicados sobre reologia de emulsões diluídas, a viscosidade efetiva de uma emulsão é função de três variáveis: fração volumétrica, razão de viscosidade e número de capilaridade (Pal (2003)). Como a fração volumétrica da emulsão é baixa, a dinâmica de deformação da superfície da gota pode ser estudada de forma isolada, não sendo afetada pela presença das gotas restantes. Neste caso a influência do escoamento na deformação da gota pelo aparecimento de tensões na superfície da gota é um efeito local. O somatório das tensões na superfície de 
todas as gotas da emulsão permite sair do meio discreto para o meio contínuo. O tensor de tensões na superfície da gota é então adicionado à equação do movimento contabilizando desta forma a presença de gotas na emulsão. Os resultados experimentais de emulsões são comparados com teorias de pequena deformação para emulsões diluídas e com outros trabalhos experimentais. A motivação é validar as teorias desenvolvidas pelo grupo de pesquisa onde foi desenvolvida a presente tese.

Outro ponto de interesse é estimar a região livre de gotas em escoamento em tubo capilar e comparar com observações experimentais. Para este estudo considera-se primeiramente o escoamento pela região central do tubo capilar (core-flow). Aqui introduz-se a dimensão da região livre de gotas $(\delta)$, adjacente à parede do tubo, e assume-se que a suspensão de gotas escoa preferencialmente no centro do escoamento. A viscosidade intrínseca obtida com as medidas experimentais da vazão em função do gradiente de pressão $(Q(\Delta P))$, através da lei de Hagen-Poiseuille, é inserida em um modelo em que a viscosidade depende de $\delta$. Desta forma é possível prever a espessura de camada livre de gotas.

O modelo de transporte convecção-difusão é um modelo mais robusto para estimar a espessura da região $\delta$. Neste modelo é considerado o regime de pequena deformação de gota, em baixo número de Reynolds $(R e)$. O termo de convecção é composto pela velocidade de cisalhamento na direção preferencial do escoamento e pela velocidade de migração das gotas na direção normal à parede plana. O termo de difusão considera que este efeito é função da concentração espacial de partículas que alteram localmente o campo de velocidades. O interesse neste estudo é estimar a região livre de gotas pelo modelo de convecção-difusão e comparar com o modelo do escoamento da emulsão pela região central do tubo capilar.

Os ferrofluidos são constituídos por nanoparticulas e têm diversas aplicações devido a sua alteração de viscosidade instantânea. Neste sentido nesta tese é realizada a caracterização reológica deste tipo de fluidos em cisalhamento simples e oscilatório explorando a não linearidade do fluido quando sujeito a diferentes taxas de cisalhamento e diferentes intensidades de campo aplicado. 
Esta tese começa por apresentar uma Revisão Bibliográfica sobre estudos relacionados com emulsões, difusão de gotas e fluidos magnéticos. No tema de emulsões foca-se na sua síntese, na proposta de modelos de previsão de viscosidade e em simulações numéricas. Quanto à difusão de gotas os trabalhos destacados referem-se a trabalhos experimentais, teóricos e numéricos. Em fluidos magnéticos abordam-se aplicações práticas e estudos experimentais de caracterização. Em seguida são definidos os Objetivos gerais e específicos da presente tese. A Fundamentação Teórica introduz conceitos relacionados com a caracterização reológica de fluidos e apresenta resultados de escoamento em tubo baseado em modelos de viscosidade. Na sequência é apresentado o tensor de tensões para Emulsões Diluídas de Alta Razão de Viscosidade Fluido-Gota o qual é introduzido na equação da quantidade de movimento que é resolvida numericamente para o escoamento em tubo capilar. Na sequência apresenta-se um modelo para a migração de partículas de uma suspensão em cisalhamento, em regiões próximas a parede, com o intuito de entender quais mecanismos promovem a formação da camada livre de gotas. No capítulo Aparato Experimental e Instrumentação são descritos os equipamentos usados na caracterização reológica de suspensões. A componente experimental desta tese é iniciada pelas Medições de Tensão Interfacial entre o óleo mineral e o fluido base da emulsão. Em seguida é dada uma introdução sobre Sintese de Emulsões que serve como base para a obtenção de emulsões. São apresentados os Resultados da Caracterização do Fluido Base e das Emulsões em escoamento de cisalhamento simples em regime permanente e em tubo capilar. Após os resultados são feitas as Comparações dos Resultados Experimentais com Teorias e outros Autores. Em seguida são apresentados os resultados de Viscoelasticidade realizados em cisalhamento oscilatório. Por fim são apresentados os resultados experimentais da Reologia de Fluidos Magnéticos em Cisalhamento Permanente e Transiente. Na última secção são apresentadas as Conclusões gerais do trabalho e sugestões para trabalhos futuros.

\subsection{REVISÃO BIBLIOGRÁFICA}

O foco deste trabalho é a caracterização reológica de emulsões de diferentes frações volumétricas e razões de viscosidade e de fluidos magnéticos. Este tema é bastante abrangente e como tal a revisão bibliográfica apresentada é um resumo que foca o es- 
sencial para o desenvolvimento do presente estudo. Contudo aborda estudos sobre: a síntese de emulsões, a influência de surfactantes no comportamento macroscópico da emulsão, modelos de viscosidade de emulsões e fatores que contribuem para a migração de gotas em escoamento simples. Por este trabalho introduzir um estudo sobre migração de gotas devido às interações parede-gota e gota-gota uma revisão bibliográfica é apresentada focando em trabalhos experimentais, teóricos e numéricos. A revisão bibliográfica de fluidos magnéticos destaca trabalhos na vertente experimental.

\subsubsection{Emulsões}

A síntese de emulsões está fortemente ligada ao empirismo devido às alterações microestruturais durante o processo. Uma emulsão é constituída por um fluido base, um fluido disperso (gotas) e por surfactantes, cuja função é evitar a coalescência de gotas (contribuindo para a estabilização da emulsão). O tipo de surfactante utilizado na síntese de emulsões é importante, uma vez que está intimamente relacionado com a estrutura química dos fluidos envolvidos no processo.

A importância da influência da concentração de surfactantes na reologia de emulsões foi abordada por Pal (1992). Os autores estudaram emulsões óleo/água (O/A) em que a fase dispersa é composta por petróleo. Destacou que o comportamento não Newtoniano de emulsões com elevada concentração de surfactantes é devido a formação de miscelas (agregados de surfactante). As emulsões com alta concentração de surfactantes exibiram uma tensão crítica (yield stress). O mesmo aconteceu com as emulsões de baixa concentração de surfactante mas com alta concentração de óleo. Na síntese das emulsões foi observado que o aumento da concentração de surfactante faz com que as gotas sejam menores, para a mesma taxa de cisalhamento do homogenizador. Observaram também um aumento de floculação com o aumento da concentração de surfactante.

Em Pal (2000b) são apresentados resultados experimentais relativos à caracterização de emulsões polidispersas do tipo $\mathrm{O} / \mathrm{A}$ em que a fase dispersa é composta por petróleo. Foi observado que para frações volumétricas inferiores a 0,6 a emulsão apresenta com- 
portamento Newtoniano. Para maiores frações volumétricas o comportamento foi de fluido pseudo-plástico (não Newtoniano). Foi observado que o tamanho da gota só tem efeito na viscosidade aparente em emulsões de altas concentrações. O autor associa o aumento da viscosidade com o aumento das interações hidrodinâmicas entre as gotas, com a diminuição do tamanho da gota e com a possibilidade de agregação e floculação de gotas já que a distância entre as mesmas diminui com a diminuição de tamanho das gotas. O número de capilaridade neste trabalho foi da ordem de $10^{-3}$.

A procura de modelos teóricos representativos da viscosidade das emulsões em funções de parâmetros do escoamento é uma vertente em constante desenvolvimento por não existir um modelo definitivo que abranja um grande conjunto de emulsões para um determinado tipo de cisalhamento. Alguns estudos surgem com o intuito de sanar essa lacuna.

Em Tandros (1994) é apresentada uma expressão na forma polinomial para a viscosidade de emulsões concentradas baseado em que quanto maior for a fração volumétrica mais complexa se torna a relação entre a viscosidade relativa e $\phi$.

$$
\eta_{r}=1+k_{1} \phi+k_{2} \phi^{2}+k_{3} \phi^{3}
$$

O polinômio até ao termo de $k_{2}=6,2$, associado com as interações hidrodinâmicas, é suficiente para $\phi<0,2$. Frações volumétricas superiores a 0,2 é necessário termos de maior ordem de $\phi$.

A viscosidade relativa da emulsão pode ser prevista pela equação sugerida por KriegerDougherty no ano de 1959:

$$
\eta_{r}=\left[1-\left(\phi / \phi_{p}\right)\right]^{-[\eta] \phi_{p}}
$$

em que $\eta_{r}$ é a razão entre a viscosidade da emulsão e a viscosidade da fase contínua, $[\eta]$ é a viscosidade intrínseca de valor teórico de 2,5 para esferas rígidas e $\phi_{p}$ é a fração de máximo empacotamento que é igual a 0,64 para um empacotamento randômico e 0,74 para um empacotamento hexagonal semelhante a esferas monodispersas (Barnes 
(1994)). Para uma emulsão polidispersa é esperado um alto valor de $\phi_{p}$ (Barnes (1994)). O valor de $\phi_{p}$ pode ser estimado a partir do gráfico de $\eta^{-1 / 2}$ versus $\phi$ do qual resulta uma reta. A extrapolação de $\eta^{-1 / 2}$ para zero resulta o valor de $\phi_{p}$ (Tandros (1994)).

Danov (2001) no seu trabalho teórico deduziu uma expressão para a viscosidade de uma emulsão diluída. A expressão é baseada na abordagem de que a viscosidade pode ser apurada através do escoamento de cisalhamento simples para baixas taxas de cisalhamento e baixos números de Peclet. Sabendo que o número de Peclet relaciona a escala de tempo do movimento Browniano $\left(a^{2} / D\right.$, em que $D$ é o coeficiente de difusão e $a$ o raio da gota) com a escala de tempo do escoamento $(1 / \dot{\gamma})$, então baixos números de Peclet significa gotas de pequeno tamanho (de poucos mícrometros) ou então baixas taxas de cisalhamento. Analisando o que acontece com uma gota, o autor faz o procedimento comum de média volumétrica para levar em conta todas as gotas da emulsão no volume considerado passando dessa forma para o contexto do continuo. A expressão obtida para a viscosidade depende da fração volumétrica da emulsão e de um parâmetro de mobilidade. Esse parâmetro está relacionado com a viscosidade da gota e do meio onde está inserida, com o coeficiente de difusividade efetivo, que por sua vez depende do coeficiente de difusão do meio e do coeficiente de difusão da superfície da gota, e com a elasticidade da superfície. Os coeficientes de difusão estão relacionados com a fração volumétrica de surfactantes na superfície da gota. A praticidade da sua aplicação é limitada pelo conhecimento dos diversos parâmetros citados. Como a expressão foi obtida para emulsão diluída em que as perturbações do escoamento são exclusivas pela presença de gotas e não pelas interações entre gotas, a expressão pode ser usada por estudos numéricos, através dos quais seja possível obter cada parâmetro citado.

Em Pal (2001) é feita uma revisão dos modelos teóricos para prever a viscosidade de emulsões. Por incluir interações hidrodinâmicas entre gotas existentes em emulsões de relativa fração volumétrica, é destacado os trabalhos de Choi e Schowalter (1975), de Yaron e Gal-Or(1972) e de Phan-Thien e Pham (1997) na condição em que o número de capilaridade tende a zero. Estes modelos preveem que a viscosidade aparente aumente com a fração volumétrica da fase dispersa. O autor elege o modelo de Yaron e Gal-Or (1972) como sendo aquele que se mostrou mais apropriado para prever a viscosidade 
aparente de emulsões de alta fração volumétrica para diferentes $\lambda$.

Pal (2003) propõe uma correlação para a viscosidade de emulsões concentradas que é comparada com resultados experimentais. Uma nova equação para emulsões concentradas é obtida pelo esquema diferencial de Brinkman-Roscoe (1952) assim conhecido na literatura de reologia. Brinkman-Roscoe foram os primeiros a usarem tal esquema para a obtenção da equação da viscosidade para uma suspensão concentrada de esferas rígidas. A equação para emulsões concentradas é obtida pela adição infinitesimal de pequenas quantidades de gotas até ser alcançada a fração volumétrica desejada. Daqui vê-se que a expressão de emulsões concentradas é baseada em uma expressão de concentração inferior obtida pelo esquema diferencial de Brinkman-Roscoe. A expressão de Taylor (1932) é obtida pelas novas expressões quando o número de capilaridade tende a zero. Quando a $C a$ tende a infinito obtém-se a equação de Frankel e Acrivos (1970). $\mathrm{Na}$ equação de Frankel e Acrivos quando $\lambda$ tende a infinito obtém-se a equação de Einstein e quando $\lambda$ tende a zero obtém-se a expressão de Mackenzie (1950) para baixo cisalhamento em suspensões diluídas em cavidades. A proposta que mais se mostrou coerente com os resultados de 27 experimentos foi a de Krieger e Dougherty (1959). Nessa proposta o valor para a fração volumétrica de máximo empacotamento foi de 0,637 que corresponde ao empacotamento randômico de esferas uniformes.

Estudos numéricos de escoamento de gotas surgem com o intuito de mostrar o aperfeiçoamento de modelos que empregam uma física cada vez mais complexa para que o experimento numérico se aproxime do experimento de laboratório.

Loewenberg e Hinch (1996) estudaram o escoamento em cisalhamento simples de emulsões com fração volumétrica de até $30 \%$ com razões de viscosidade de até 5 em que o comportamento das gotas já se aproxima das partículas rígidas. Neste trabalho foi implementado o Método de Integral de Contorno com condições de contorno periódicas. A tensão de cisalhamento da emulsão foi calculada como sendo a tensão devido às características do fluido base adicionando uma tensão extra devido à pressão de gotas. Neste estudo não foram consideradas as tensões relacionadas com a presença de surfactantes nas emulsões (tensões de Marangoni). O número de capilaridade máximo foi de 0,5. Foi observado uma diminuição da viscosidade e das tensões normais que foram 
elevadas devido ao alinhamento das gotas com a direção principal do escoamento. Em comparação com a suspensão de partículas rígidas ou de gotas indeformáveis a viscosidade em função da fração volumétrica da emulsão apresentou um menor aumento.

Cunha e Loewenberg (2003) estudaram os efeitos do cisalhamento oscilatório $(\dot{\gamma} \cos (w t))$ de emulsões de alta fração volumétrica $(\phi \leq 0.68)$ em baixo número de Reynolds. Neste trabalho o destaque é a implementação numérica tridimensional do Método Integral de Contorno para a geração de emulsão de alta fração volumétrica bem como pelo procedimento numérico de interação entre gotas deformáveis $(\lambda=1)$. Os resultados foram obtidos para emulsões monodispersas. Foi observada uma região de baixa frequência em que o efeito viscoso da emulsão $\left(\eta^{\prime}\right)$ é independente da frequência de oscilação e que o efeito elástico $\left(\eta^{\prime \prime}\right)$ depende pouco dessa frequência. Nessa baixa frequência foi detectado um platô de $\eta^{\prime}$. Na emulsão concentrada $(\phi=0.60)$ o platô é cerca de quatro vezes maior que o o platô da emulsão diluída. Os autores explicam que tal fato se deve às interações hidrodinâmicas entre gotas. Os autores consideram que os resultados estão de forma qualitativa de acordo com alguns experimentos. Uma das explicações para as diferenças existentes entre o estudo numérico e o experimental é que na realidade as emulsões são polidispersas e não monodispersas como foi considerado.

Aggarwal e Sarkar (2007) por meio de simulação direta estudaram em regime permanente emulsões com propriedades viscoelásticas. Neste estudo foi observado o comportamento de uma gota (emulsão diluída) em um fluido Newtoniano. A reologia do sistema viscoelástico foi determinada como uma extensão da reologia de Batchelor (1970) para uma emulsão viscosa. Os efeitos viscoelásticos foram inseridos pelo modelo de fluido do tipo Oldroyd-B. Foi visto que a diferença entre as tensões normais $\left(\tau_{11}-\tau_{22}\right.$ e $\left.\tau_{22}-\tau_{33}\right)$ varia com o número de capilaridade. Quanto à viscosidade aparente, esta diminui com a viscoelasticidade da gota para baixos números de capilaridade e aumenta para altos números de capilaridade. Segundo os autores este comportamento é devido a competição entre os efeitos de deformação e de alinhamento da gota com o escoamento. Foi observado que o comportamento de fluido pseudoplástico da emulsão é afetado pela viscoelasticidade da gota.

Oliveira e Cunha (2011) estudaram a reologia de emulsões diluídas de altas razões de 
viscosidade em cisalhamento transiente aplicando a teoria de pequenas deformações. Em emulsões diluídas são desprezados os efeitos de interação entre gotas. O tensor de tensões da emulsão foi obtido em função da forma e da velocidade interfacial de uma gota. Estudaram também a resposta não linear da emulsão quando sujeita a um cisalhamento oscilatório. Neste estudo os autores obtiveram uma expressão para a viscosidade de uma emulsão diluída quando sujeita a um escoamento de cisalhamento simples permanente. Os resultados mostraram que mesmo em regime diluído a emulsão de altas razões de viscosidade apresentou características de um fluido elástico de Boger em regime de baixo número de capilaridade onde não existe efeitos pseudo-plásticos. O fluido de Boger é um fluido elástico caracterizado por apresentar uma viscosidade constante independente da taxa de cisalhamento. Isso possiblita separar os efeitos elásticos do esfeitos viscosos, sendo que estees efeitos podem ser determinados por fluidos Newtonianos (James (2009)). Neste tipo de fluido a diferença de tensões normais não são nulas. Para altos números de capilaridade foi observado que mesmo em pequenas deformações as emulsões diluídas apresentam um comportamento de fluido pseudoplástico. Neste regime também foi identificado que a diferença de tensões normais não são nulas, conferindo características de um fluido elástico de Boger. Como foi possível calcular as tensões devido à elasticidade do fluido separando os efeitos viscosos dos elásticos, os autores apresentam um estudo de emulsões em cisalhamento oscilatório.

O trabalho de Skartlien et al. (2012) é motivado pelo transporte de misturas de óleo, água e gás em dutos e pelos processos de separação de óleo e água na presença de polímeros sintéticos. O foco deste trabalho é estudar numericamente, usando o modelo de Lattice Boltzman tridimensional, a reologia e a morfologia de emulsões. Os dados numéricos foram comparados com os resultados experimentais de emulsões de petróleo do tipo $\mathrm{O} / \mathrm{A}$. Os resultados mostraram um aumento rápido da tensão de cisalhamento interfacial imediatamente após o começo do escoamento e um decaimento gradual em função do alinhamento das gotas com o escoamento. Tal resultado está coerente com o observado experimentalmente em polímeros. Outro interesse é investigar a distribuição de surfactante na superfície da gota quando esta é sujeita a tensões de cisalhamento. Os resultados numéricos foram comparados com observações experimentais. De forma sucinta foi verificado que as regiões com maior curvatura apresentam uma maior con- 
centração de surfactante devido ao transporte advectivo na superfície da gota. Essas regiões apresentam um maior alinhamento com o escoamento. A exemplo é o que acontece nas pontas de gotas alongadas. Tal fenômeno ocorre quando o surfactante é dito forte pois nesse caso foi observada uma queda da tensão interfacial e uma diminuição de viscosidade local. Quando o surfactante é dito fraco, observaram-se poucas regiões de elevada curvatura.

Os estudos numéricos baseados em fundamentos físicos e matemáticos tentam reproduzir os experimentos realizados em laboratório nas mais variadas condições físicas. Com o aprimoramento dos métodos numéricos é possível simular o escoamento de emulsões diluídas. Em uma primeira fase os estudos focaram as emulsões de altas razões de viscosidade para evitar os problemas de ordem numérica com relação à deformação de gotas. Com o avançar da pesquisa esse problema foi ultrapassado e a ideia é simular escoamento de emulsões de altas frações volumétricas. Aqui pode-se citar o recente trabalho de Cunha et al. (2014) no qual é estudada a reologia e os micromecanismos envolvidos no escoamento de emulsões de alta razão de viscosidade pelo Método de Integral de Contorno. Pode-se constatar um atual interesse em estudos de escoamento de emulsões com o intuito de capturar fenômenos físicos que são observáveis em complexos aparatos experimentais.

\subsubsection{Difusão de Gotas devido a Cisalhamento}

A revisão bibliográfica aqui apresentada é destinada a trabalhos sobre a migração de partículas, rígidas e deformáveis (gotas), da parede sólida para o centro do escoamento, quando sujeitas a tensões de cisalhamento em escoamento de baixo número de Reynolds. É referido em diversos trabalhos que a distribuição de concentração de partículas ao longo da altura de um capilar altera a reologia local e as características do sistema (Shauly et al. (1998)). Daqui a importância do estudo deste problema que tenta prever a região de equilíbrio das gotas em determinados sistemas (Mortzavi e Tryggvason $(2000))$.

Karin e Mason (1967) apresentam medições a respeito da taxa de migração de gotas 
em escoamento de cilindros concêntricos (escoamento de Couette) e em escoamento em dutos (escoamento de Poiseuille). No geral as medições estão de acordo com o previsto pela teoria de Chaffey (1965) que é baseada na deformação da gota e nas interações com a parede. Os autores postulam que os dados defasados da teoria podem ser atribuídos a inibição da circulação interna da gota devido às possíveis impurezas na superfície da gota. No escoamento de Couette foi verificado que a direção de migração é independente da velocidade e direção de rotação encontrando-se sempre entre as duas paredes, em uma região de equilíbrio. A taxa de migração aumentou com a distância à parede, com $\dot{\gamma}$, com o diâmetro da gota e com $\lambda$. Os resultados do escoamento de Poiseuille foram os mesmos do escoamento de Couette. Os autores referem que a diminuição da taxa de migração está associada com a ausência do escoamento interno da gota e tal não está relacionado com a adição de agentes na superfície da gota.

Chan e Leal (1979) fazem uma breve descrição sobre migração de partículas em escoamento de Poiseiulle e de Couette. Os autores fizeram um estudo com suspensões em fluido viscoelástico. Foi assumido que o fluido base e as gotas possam ser modelados como um fluido de segunda-ordem. O método de reflexões foi usado para resolver o problema de escoamento de cisalhamento simples e de Poiseuille entre placas, permitindo obter soluções analíticas nas condições em que o tamanho da gota é muito pequeno em comparação com o tamanho característico do sistema. Este método assume que as gotas não estão próxima à parede, visto que com a proximidade da parede a gota apresenta maiores deformações. Pelos resultados foi constatado que, em escoamento de Poiseuille as gotas de fluido Newtoniano dispersas em um fluido viscoelástico têm uma menor taxa de migração para a região central em comparação com esferas rígidas e com o caso de gotas dispersas em fluido Newtoniano.

Shauly et al. (1998) estudaram a migração de partículas polidispersas em uma suspensão concentrada que é descrita por potenciais de migração para várias concentrações. O modelo apresentado é uma extensão para suspensões polidispersas que tem como base por exemplo os mecanismos de migração, a taxa de cisalhamento e os gradiente de curvatura das linhas de corrente. No cálculo das expressões resultantes a quantidade de movimento e o balanço do material são resolvidos em simultâneo. Em uma suspensão monodispersa o fluxo total de partículas é a soma de três fluxos, um de cada 
mecanismo associado à migração de partículas. O primeiro mecanismo descreve que as partículas tendem a migrar para regiões de menor frequência de interação entre partículas. O segundo mecanismo se refere ao campo de viscosidade não uniforme no qual a interação entre duas partículas adjacentes não é simétrica. O terceiro mecanismo explica porque a fração volumétrica de partículas permanece uniforme em dispositivos de placas paralelas. A extensão para a suspensão polidispersa nada mais é que a consideração de diferentes tamanhos de gotas através de um somatório de concentração de cada tamanho de gota. Os resultados do modelo para o perfil de velocidade seguiram adequadamente os resultados do experimento do escoamento de Couette em cilindro concêntricos. Quanto à fração volumétrica, os resultados do modelo concordam com as medições experimentais, nas quais foi verificado um aumento de fração volumétrica em regiões de menor cisalhamento. Para sistemas polidispersos o modelo previu que as partículas se agrupam por tamanhos, com as maiores próximas a parede imóvel. As diferenças entre o experimento e o modelo em relação a distribuição total de partículas são justificadas pelo fato de que na realidade as partículas não penetram umas nas outras (região de alta concentração) ou estão em contato com a parede. No entanto, o modelo contínuo considera que pequenas variações podem ocorrer. Contudo em termos gerais o modelo previu satisfatoriamente os resultados de medidas experimentais. Do experimento de cisalhamento entre placas foi observado que as partículas de marcação (traces) se deslocaram para regiões de elevado cisalhamento. Neste caso o tamanho destas partículas é maior que o tamanho das partículas que estavam na fase contínua monodispersa. O oposto aconteceu quando as partículas de marcação eram menores que as da fase contínua. Tal fenômeno foi previsto pelo modelo desenvolvido para sistemas polidispersos. O modelo é destinado para partículas muito menores do que a distância entre a parede e o centro do escoamento. Os resultados experimentais levados em consideração utilizaram imagem por ressonância magnética nuclear e anemometria para medir o perfil de velocidades de suspensões. O autor destaca ainda que nos experimentos foram observados perfis de velocidades achatados nas regiões de maior concentração.

O trabalho de Mortzavi e Tryggvason (2000) estudam numericamente, pelo método de diferenças finitas de rastreamento frontal, o escoamento bidimensional de gotas no 
escoamento de Hagen-Poiseuille em vários regimes de números de Reynolds. O Reynolds de referência foi baseado na velocidade do centro do escoamento e no tamanho da partícula. Para Reynolds da ordem da unidade a gota com baixa razão de viscosidade se move para o centro do escoamento com uma taxa que aumenta com a deformação da gota. Mas se a razão de viscosidade for alta a gota se desloca na direção oposta ao centro do escoamento, concentrando-se em regiões semelhantes as das partículas rígidas. Em Reynolds entre 5 e 50 as pequenas gotas se concentram em regiões entre a parede e o centro do escoamento. Aumentando o número de Reynolds ou a massa específica, a gota se desloca mais para a parede. Oscilações transientes surgem a viscosidade da gota até atingir o seu estado de regime permanente. A região de oscilação é em torno da posição de equilíbrio. Os autores relatam que existe um centro de recirculação localizado perto do centro da gota de alta viscosidade, enquanto que o centro de recirculação se situa perto da parede para gotas de baixa viscosidade. A localização desta recirculação talvez esteja conectada com a direção de migração das gotas. Os autores referenciam ainda que o efeito da deformação da gota, para escoamento de Stokes se traduz somente em migração. Os resultados numéricos estão de acordo com os experimentais. O autor apresenta uma breve revisão histórica sobre este problema.

Hollingsworth e Johns (2006) apresenta uma técnica experimental para estudar a migração de gotas em escoamento de cisalhamento baseada na imagem de ressonância magnética. Segundo o autor a técnica supera a limitação de sistema óticos, pois estes estão limitados a emulsões diluídas por serem oticamente transparentes. Industrialmente as emulsões são opacas. Neste estudo foram rastreadas gotas de água em óleo de silicone no escoamento rotacional de Couette e de Poiseuille. O comportamento da gota de raio 0,54 $\mathrm{mm}$ foi analisado no escoamento de Couette. Foi visto que para distâncias de parede (gap) maiores a gota tem uma taxa de migração maior em comparação com menores distâncias de parede, indo de encontro com os experimentos de Chan e Leal (1979). O autor destaca que as teorias existentes não são adequadas para grandes gaps.

Shi et al. (2012) estudaram a reologia do sangue em escoamento de Poiseuille usando o método de fronteira imersa aplicando um modelo de mola para modelar a estrutura da membrana do esqueleto da hemácea e um método de domínio fictício para estudar o 
movimento das hemácias em um micro-canal com constrição. Neste trabalho é possível visualizar a história da forma da hemácea. O autor faz uma revisão dos trabalhos realizados dentro do contexto numérico sobre a deformação e reologia de hemácias. Foi observado que em escoamento de Poiseuille as hemácias tendem a migrar para o centro do escoamento. Essa migração é tanto mais rápida quanto menor for a razão de dilatação da hemácia. Quando a razão de dilatação é em torno de unidade as hemácias se comportam como esferas rígidas resultando em uma menor taxa de migração.

O trabalho numérico de Nourbakhsh e Mortazavi (2010) emprega o método de diferenças finitas acoplado ao método de rastreamento frontal para estudar a migração de gotas deformáveis em escoamento de Poiseuille plano para $R e>1$. Foi visto que com o aumento de $R e$ ou de $C a$ ou com a diminuição da razão de viscosidade a posição de equilíbrio é mais próxima à parede, o que vai de acordo com a teoria de Chan e Leal (1979) para a dependência da viscosidade com a migração, no limite de pequenas deformações. Foi observado que quanto mais deformáveis as gotas forem maior é a taxa de migração para o centro do escoamento. Para $R e_{g}=10$ (Reynolds avaliado com o diâmetro da gota) e $C a=0,05$ todas as gotas se deslocaram para a região entre a parede e o centro do escoamento. Analisando a deformação da gota para $R e_{g}=10 \mathrm{e}$ $C a=0,7$, esta se deforma enquanto se dirige para o centro do escoamento se orientando a 45 graus com relação ao eixo do escoamento. A gota permanece nessa posição até adquirir a sua deformação estacionária. Foi observado que gotas de maior tamanho se dirigem mais rapidamente para o centro devido à intensidade de forças de lubrificação existentes entre a parede e a superfície da gota. A velocidade axial diminui com o aumento do tamanho da gota, o mesmo acontece com a deformação. O autor explica que nesse caso o efeito da parede superior é importante devido ao aumento da pressão local entre a superfície da gota e a parede inferior provocado pelo líquido deslocado.

Pranay et al. (2012) foi motivado pela redução de arrasto devido a adição de polímeros em diversos tipos de escoamentos. Neste trabalho é apresentado um modelo que descreve a distribuição de cápsulas elásticas como sendo um balanço entre a difusão provocada pelo cisalhamento e a migração induzida pela parede devido a capacidade de deformação da cápsula. O estudo foi realizado considerado suspensão de cápsulas elásticas em fluido Newtoniano e em polímeros. O método numérico utilizado foi o de 
fronteira imersa para escoamento de Couette em regime de Stokes. Foi constatado a formação de uma camada livre de cápsulas para a suspensão em fluido Newtoniano. A espessura dessa camada é fortemente dependente da $C a$. Foi observado que se o fluido no qual as cápsulas estão suspensas tiver características viscoelásticas a formação da camada livre de células é atenuada. A contribuição inercial foi desconsiderada visto que a contribuição da parede para a formação de uma camada livre de cápsulas é maior em uma magnitude.

Em Guido e Preziosi (2012) é feita uma revisão do comportamento de gotas isoladas sujeitas em escoamento devido a um gradiente de pressão em uma secção transversal circular e rectangular. Foi observado experimentalmente que, para cada número de capilar, aumentando a razão entre o raio da gota e o diâmetro do tubo as gotas apresentam um maior alongamento na direção do escoamento, aumentando o espaço entre a superfície da gota e a parede do tubo.

Pela revisão efetuada observa-se que poucos estudos se preocupam em caracterizar reologicamente emulsões de diferentes razões de viscosidade com diferentes frações volumétricas em escoamento de cisalhamento linear e quadrático. Esta tese tem como um dos principais objetivos avaliar experimentalmente a viscosidade efetiva em função da razão de viscosidade em consolidação com a caracterização microestrutural das emulsões.

Durante a revisão bibliográfica não foi encontrado um estudo experimental de reologia de suspensão de gotas em tubo capilar e entre discos planos paralelos, para várias razões de viscosidade em função da fração volumétrica. Nesse sentido, este trabalho visa caracterizar o comportamento de emulsões em função destes parâmetros conectando a reologia com as características da microestrutura das emulsões, avaliada por microscopia óptica. A suspensão de gotas é obtida através de uma metodologia de síntese de emulsões que utiliza surfactantes cuja função é de estabilizar a emulsão evitando a coalescência de gotas. Os resultados experimentais de suspensões de gotas de baixas frações volumétricas e altas razões de viscosidade são comparados com a teoria de pequenas deformações apresentada no presente trabalho. 
A migração de gotas por cisalhamento simples é estudada por um modelo proposto que considera fenômenos de auto-difusão e de interação parede-partículas como sendo os responsáveis pela existência de um gradiente de fração volumétrica na direção perpendicular à direção principal do escoamento. O processo difusivo em análise acontece na escala do escoamento devido a uma auto-difusão hidrodinâmica que depende do número de capilaridade $(C a)$, da fração volumétrica $(\phi)$ e da razão de viscosidade entre gotafluido $(\lambda)$. Este fenômeno de migração também é observado em escoamento de sangue (Grandchamp et al. (2013)). Uma das formas de estimar a espessura da camada livre de partículas registrada em escoamento quadrático é pelo ajuste de parâmetros dos modelos teóricos de tal forma que coincidam com os resultados experimentais. Nestes modelos teóricos a viscosidade da emulsão que é função da fração volumétrica, taxa de cisalhamento e da razão de viscosidade é modelada por uma Lei de Potência. No entanto, como já mencionado, é estudada a formação dessa camada livre de partículas de forma mais consistente pela solução da equação de transporte convecção-difusão onde é possível verificar a influência da razão de viscosidade, do número de Peclet e do número de capilaridade. Os termos convectivos da Equação de Transporte levam em conta a velocidade unidirecional do escoamento e a velocidade de migração das gotas que leva em conta as tensões na superfície da gota devido à interação gota-parede. O termo de difusão considera que a variação da concentração na direção normal à parede sólida se deve à quebra da simetria do escoamento em torno da gota devido à interação entre pares de gotas em suspensões diluídas e da interação entre gota-parede. Este assunto é de interesse atual (Narsimhan et al. (2013)). Já no final desta tese tivemos conhecimento do artigo de Hariprasad e Secomb (2014) que examina o problema de migração e difusão de glóbulos vermelhos em micro-canais baseando-se em modelos relativamente simples de descrição de membrana e no mesmo princípio de balanço de um fluxo difusional de partículas descrito por Cunha e Hinch (1996) e migração de partículas por interação com paredes (Leal (1980)). Essa recente informação mostra a importância do tema e, consequentemente, dos modelos do escoamento também explorados nessa tese usando gotas de altas razões de viscosidade como um primeiro protótipo de células. 


\subsubsection{Fluidos Magnéticos}

É de se diferenciar ferrofluidos de fluidos magnetoreológicos. Nos fluidos magnetoreológicos o tamanho médio das partículas é da ordem de $\mu m$ (López-López, (2006)) enquanto que nos ferrofluidos o tamanho característico das partículas é da ordem de $n m$. Os ferrofluidos são constituídos de partículas geralmente de magnetita $\left(\mathrm{Fe}_{3} \mathrm{O}_{4}\right)$ com diâmetro médio em torno de $10 \mathrm{~nm}$ que estão suspensas em um fluido geralmente Newtoniano (óleo, água, éster ou querosene). A sedimentação das partículas devido ao campo gravitacional ou devido à aglomeração surgida da interação dos diplos magnéticos é evitada pela agitação térmica (efeito Browniano). Cada uma dessas partículas é um pequeno íman com momento dipolo permanente. Para evitar a coagulação devido à atração de Van Der Walls as partículas são cobertas por surfactantes. A espessura da camada de surfactante é em torno de $2-3 \mathrm{~nm}$ Odenbach, (2003). Quando aplicado um campo magnético externo as partículas se orientam na direção do campo aplicado possibilitando a formação de estruturas do tipo cadeias ou agregados, alterando as propriedades reológicas do fluido. As propriedades reológicas dos ferrofluidos, quando comparadas com os fluido magnetoreológicos, sofrem pequenas alterações mesmos quando sujeitos a altos campos magnéticos devido ao tamanho das partículas (Rosensweig, 1998, Odenbach, (2003)). Em Odenbach, (2002) é explicado a interação entre surfactante, partícula magnética e o fluido carreador. A viscosidade do fluido magnético depende das interações entre os vários constituintes do fluido e da concentração de surfactante (Qiang et al., (2005)). A Fig. 1.1 ilustra as partículas com surfactantes. A fração volumétrica de surfactante é em torno de $23 \%$ e de partículas é de $7 \%$.

Quanto aos fluidos magnetoreológicos, as partículas são multidomínios possibilitando a existência de intensas interações. Estas interações permitem que este tipo de fluidos mude de um comportamento típico de liquido para um comportamento típico de sólido. Essa alteração de comportamento é caracterizada por altas tensões críticas (yield stress) e elevadas mudanças na viscosidade (Bossis et al., (2002)). O comportamento reológico deste tipo de fluidos pode ser descrito pelo modelo de Bingham (Klingenberg, (2001)). No entanto, mesmo com fracos campos magnéticos os ferrofluidos sentem intensas forças 


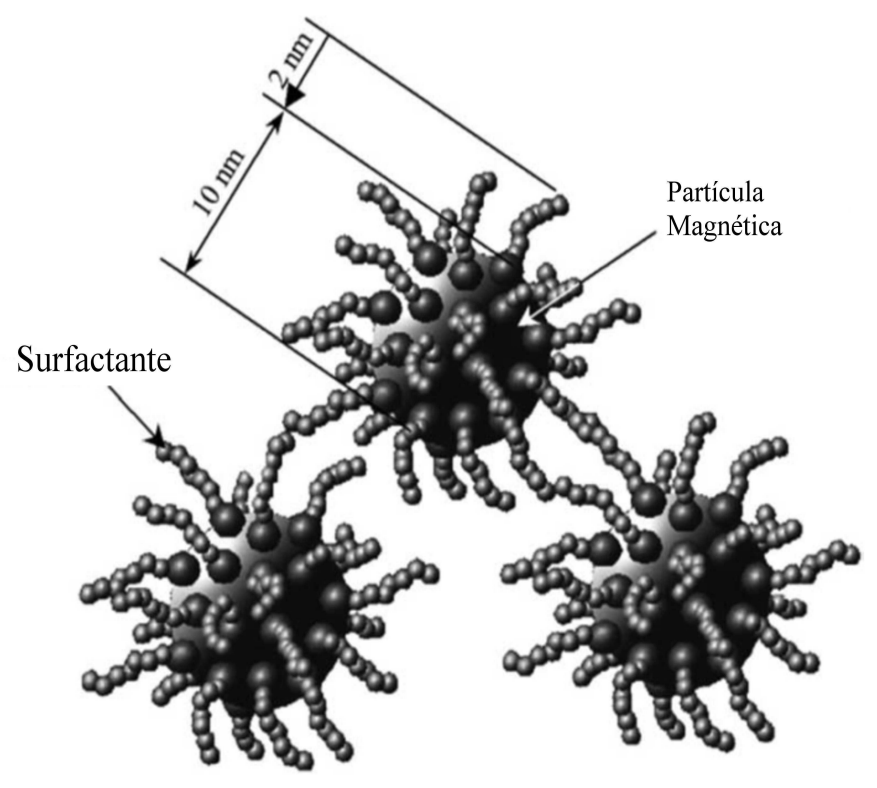

Figura 1.1: Partículas magnéticas cobertas com surfactantes. Odenbach, (2003)

magnéticas devido a sua alta susceptibilidade magnética. Esta força magnética permite controlar o escoamento de líquidos através de campos magnéticos de até $50 \mathrm{mT}$. A Fig. 1.2 mostra um exemplo da força magnética agindo em um ferrofluido.

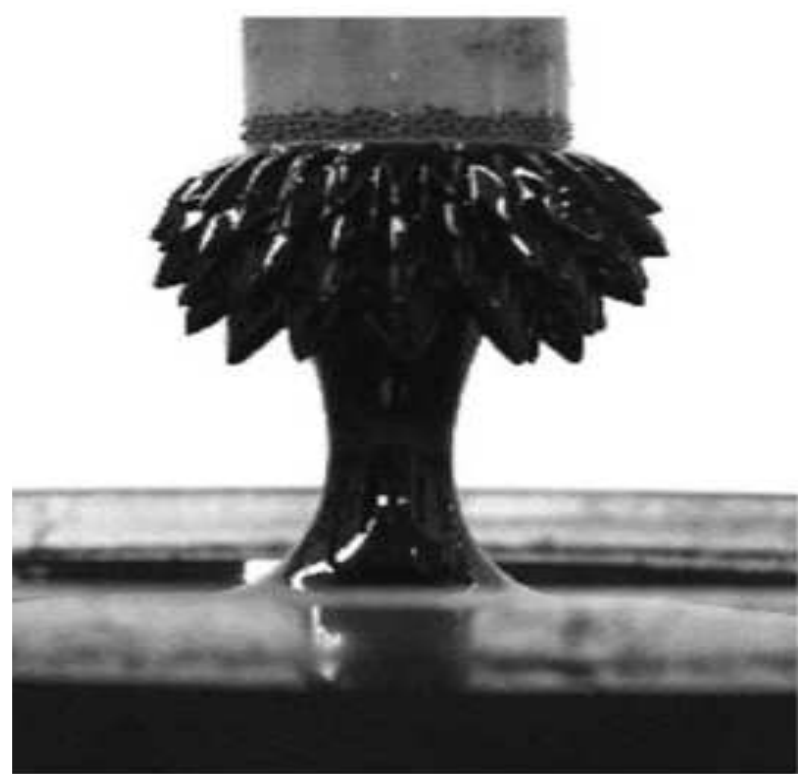

Figura 1.2: A força magnética proveniente de um electroíman aplicada a um ferrofluido é forte o suficiente para puxar o fluido contra o campo gravitacional da Terra e formar instabilidades características ("spikes"), Odenbach, (2003).

As aplicações deste tipo de fluidos são diversas e dependem da magnitude da variação das suas propriedades reológicas quando sujeitos a um campo externo. Na medicina as nanopartículas magnéticas têm sido alvo de interesse a mais de 30 anos. As nanopar- 
tículas que compõem os ferrofluidos são utilizadas na terapia de câncer (hipertermia) em que os fármacos são direcionados para a região afetada através da aplicação de um campo magnético externo (Muller et al., (2001), Jurgons et al., (2006)).

A hipertermia consiste em aquecer o tecido contaminado pelo tumor através da injeção de nanopartículas magnéticas que são excitadas por um forte gradiente de campo com frequência da ordem de $100 \mathrm{~Hz}$. A temperatura a que o tecido contaminado atinge é de $43-55{ }^{\circ} \mathrm{C}$ dependendo da concentração e da potência de calor específica do material magnético bem como dos parâmetros do campo magnético. O uso de nanopartículas para aquecer localmente os tumores foi proposto nos anos 1950 (Brunke et al., (2006), Glöckl et al., (2006)).

O tamanho das partículas dos ferrofluidos é pequeno o suficiente para evitar o bloqueio do sistema vascular em especial o escoamento em capilares. Contudo essas partículas não podem ser muito pequenas devido a sua atração com o gradiente de um campo magnético externo (Jurgons et al., (2006)). A Fig. 1.3 mostra o raio-X de um tecido com tumor onde é possível visualizar as nanopartículas no sistema vascular.

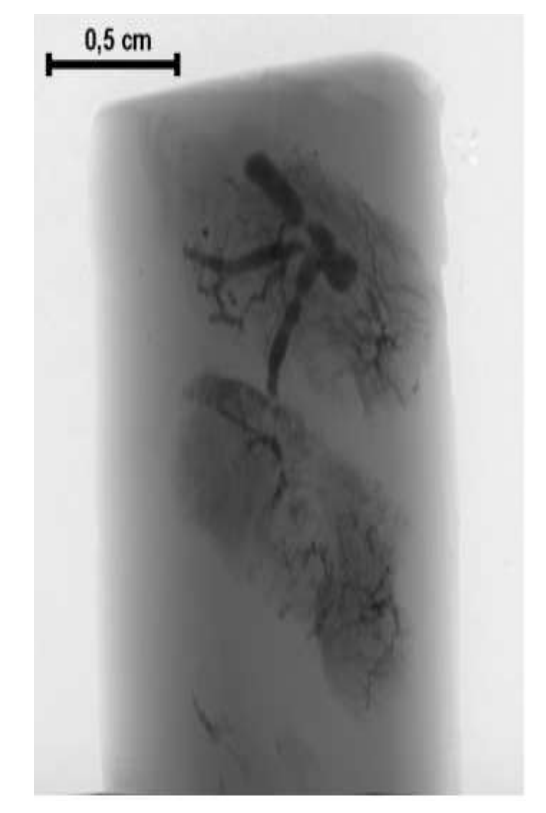

Figura 1.3: Raio-X de um tecido com tumor após ser aplicado o fármaco guiado com um campo magnético. As nanopartículas são visíveis no sistema vascular do tumor (Alexiou et al., (2006)).

Os ferrofluidos têm aplicações industriais tais como em alto-falantes de sistemas de 
som. É de se referir que os ferrofluidos caracterizados neste trabalho são sintetizados para esse propósito. Nos sistemas de Hi-Fi os ferrofluidos proporcionam o aumento da condutividade térmica aumentando a transferência de calor nos dispositivos de som. A melhoria no arrefecimento do sistema aumenta a potência máxima do sistema de som (Odenbach, (2003)). São também usados para melhorar a eficiência de máquinas eléctricas. O ferrofluido é colocado entre o estator e o rotor para aumentar a força e a quantidade de movimento em maquinas rotativas (Nethe et al., (2006)). São utilizados também em equipamentos tais como o de ressonância magnética por imagem (Pouliquen, (1989)) e em técnicas de separação magnética (Safarik e Safarikova, (1999)).

Os fluidos magnetoreológicos são aplicados em amortecedores para absorver os terremotos, absorvedores de impacto, sistemas de atuadores, embreagens, travas em equipamentos de academia (Klingenberg, (2001),Magnac et al., (2006)). Em Guldbakke e Hesselbach, (2006) foi estudado dois tipos de fluidos magnéticos para serem usados em amortecedores (fig. 1.4) e rolamentos (fig. 1.5). No caso dos amortecedores o aumento da viscosidade do fluido através da aplicação de um campo magnético permite que o amortecedor possa suportar maiores forças de amortecimento. A aplicação dos fluidos magnéticos em rolamentos permite que a distância entre as superfícies do estator e do rotor sejam mantidas independente da carga a que os rolamentos estão sujeitos. Desta forma é possível que os rolamentos aguentem maiores cargas devido a pressão magnetohidroestática que é gerada por um gradiente de campo magnético ao longo da superfície de fluido.

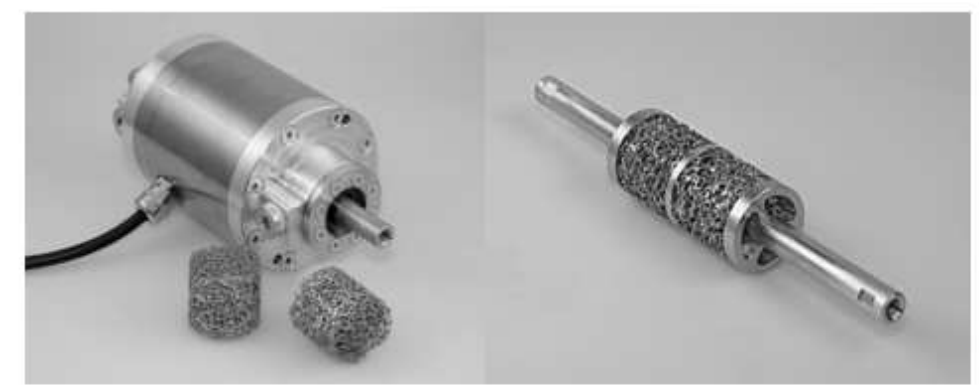

Figura 1.4: Amortecedor e malha porosa metálica.

Os trabalhos desenvolvidos na área de fluidos magnéticos têm três vertentes: teóricos, simulações numéricas e experimentais. Os modelos teóricos visam alcançar os resultados obtidos através de experimentos. A grande dificuldade é encontrar um modelo 


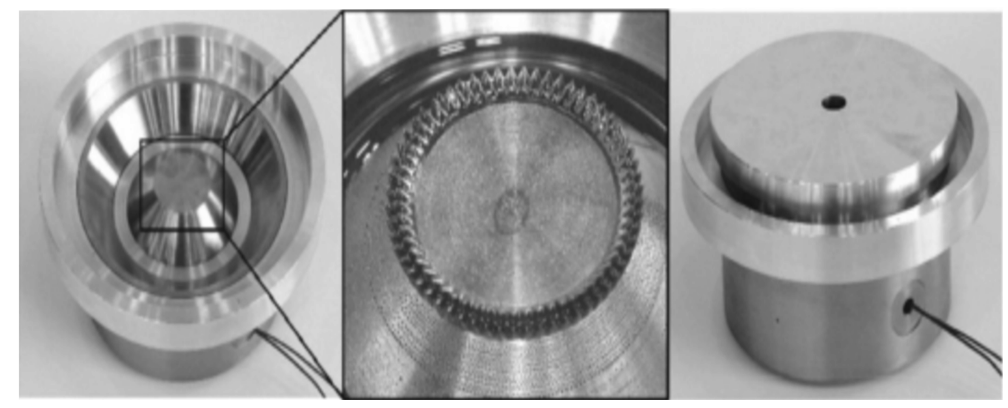

Figura 1.5: Rolamento magnetohidroestatico axial. estator (esquerda), zoom do estator com o ferrofluido (centro), rolamento montado (direita)

físico universal que expresse o comportamento reológico o mais próximo do obtido pelos experimentos de laboratório. Nesse quesito vários autores empregam diferentes técnicas numéricas para incorporar modelos físicos complexos que visão melhorar os resultados numéricos. O objetivo é obter um tensor de tensões único para qualquer tipo de fluido magnético. Os modelos teóricos e as simulações numéricas visam também explicar a dinâmica de interação das partículas do fluido magnético quando interagem com o campo magnético com ou sem a presença de escoamento (cisalhamento simples e quadrático). Pelas observações do comportamento da microestrutura do fluido é possível explicar com maior embasamento físico os motivos das alterações reológicas deste tipo de fluidos. Os experimentos visam caracterizar diferentes fluidos magnéticos com o intuito de uma aplicação industrial ou médica. Por outro lado os experimentos se preocupam em direcionar a teoria para a confirmação dos resultados obtidos em busca de explicações físicas consistentes. Devido à importância indiscutível de todas as áreas de investigação deste tema esta revisão bibliográfica visa dar exemplos de alguns trabalhos que contribuem para o entendimento e desenvolvimento de aplicações com este tipo de fluidos.

Os modelos teóricos necessitam de valores para as constantes físicas que só podem ser obtidos por experimentos de laboratório. Devido a essa necessidade vários trabalhos surgem para caracterizar diferentes fluidos magnéticos. No trabalho de Qiang et al., (2005) foi apurado que a viscosidade do fluido sujeito a um campo magnético, aumenta com a fração volumétrica das partículas, devido à formação de cadeias que se alinham na direção do campo magnético, e com a fração volumétrica do surfactante, aumentando a diferença entre o diâmetro magnético das partículas e o seu diâmetro 
hidrodinâmico (Odenbach, (2002)). Foi observado que a viscosidade aumenta com o campo magnético até alcançar um valor de saturação. Para o mesmo fluido magnético e para a mesma intensidade de campo magnético a viscosidade é maior quando o campo magnético é direcionado na direção perpendicular do escoamento em relação a um campo direcionado na direção paralela. O motivo pode ser devido à formação de cadeias ao longo da direção do campo externo que fazem resistência ao escoamento . Quanto à condutividade térmica esta é maior quando o campo é aplicado na direção paralela ao gradiente de temperatura e aumenta com a intensidade de campo magnético e com a fração volumétrica de partículas. Os autores explicam que quando o campo magnético é paralelo ao gradiente de temperatura as cadeias de partículas podem ser mais efetivas para o processo de transporte de energia ao longo da direção do gradiente de temperatura. Assim é possível controlar a transferência de calor alterando a intensidade e orientação do campo magnético externo em relação ao gradiente de temperatura. Contudo, pensa-se que existe a necessidade de maior investigação teórica e experimental para apurar estas observações. Com intenções de aplicações industriais em Motozawaa et al., (2010) é estudado os efeitos do campo magnético na transferência de calor em escoamento em dutos de seção retangular de fluidos magnéticos em regime laminar. Foi observado um aumento de $20 \%$ no coeficiente de transferência de calor na região onde foi aplicado o campo magnético. Em Gontijo (2012) é estudado o aumento da transferência de calor em uma cavidade fechada pela interação entre a convecção natural e a convecção provocada por um campo magnético externo.

Em López-López, (2006) foram estudadas as propriedades reológicas através do reômetro da Anton Paar do modelo MCR 300 idêntico ao disponível no laboratório que foi desenvolvida esta tese. O fluido de interesse é composto por partículas de ferro da ordem de mícrons dispersas em um ferrofluido de nanopartículas de magnetite. Essa combinação contribui para reduzir a sedimentação das partículas da ordem de mícrons presentes nos fluidos magnetoreológicos. Foi observado que em uma suspensão com fracção volumétrica de $10 \%$ de partículas de ferro a passagem do comportamento de sólido para líquido se verificou quando a taxa de cisalhamento foi de $10 s^{-1}$. Quando foi adicionado 21,6\% de nanopartículas de magnetite a transição de sólido para líquido foi observada quando a taxa de cisalhamento foi de $100 \mathrm{~s}^{-1}$. Isso pode ser devido à 
formação de estruturas complexas na suspensão bimodal. Os experimentos revelaram o aumento significativo da tensão crítica devido à adição de 2,7\% de nanopartículas em uma suspensão com 42,4\% de micropartículas. Os autores explicam que na ausência de nanopartículas de magnetita a formação de cadeias não é favorável reduzindo o efeito magnetoreológico devido à dificuldade de formação de cadeias de micropartículas. Este processo foi mais evidente em suspensões com maior fração volumétrica de micropartículas. Os resultados experimentais foram comparados com o modelo de cadeia "chain model" usando elementos finitos. Este modelo leva em consideração a formação de cadeias de partículas induzidas pela interação magnética entres as partículas de ferro. O aumento da tensão crítica não foi previsto pelo modelo. Os autores recomendam estudos com suspensões de menores frações volumétricas de micropartículas para se puder apurar com maior exatidão as observações destacadas.

No trabalho de Shahnazian e Odenbach, (2008) foi avaliada a tensão de cisalhamento crítica de três ferrofluidos de diferentes frações volumétricas e diâmetro médio de partícula. Através das características do fluido foi calculado um parâmetro que contabiliza a interação partícula-partícula. Foi observado que a tensão crítica de cisalhamento aumenta com o quadrado da intensidade do campo magnético. Comparando os ferrofluidos com partículas do mesmo tamanho médio $(16 \mathrm{~nm})$ o fluido com menor fracção volumétrica de grandes partículas não exibiu tensão de cisalhamento crítica mesmo na maior a intensidade de campo $(80 \mathrm{kA} / \mathrm{m})$. Por outro lado para o fluido com partículas de diâmetro médio de $10 \mathrm{~nm}$ foi obtido maiores tensões de cilhamento críticas devido à maior fração de partículas de maior tamanho. Isto mostra que existe uma relação entre a tensão crítica e a quantidade de partículas de maior tamanho responsáveis por formar cadeias/agregados. Observou-se também que a tensão de cisalhamento crítica aumenta com a diminuição da distância entre os discos do reômetro. Tal pode ser devido a interação entre as particulas bem como a quantidade de partículas de maior tamanho. Neste sentido no estudo de Liu e Jin, (2011) foi analisado a influência do volume de liquido utilizado entre os discos de um reômetro. Verificaram que a tensão de cisalhamento aumenta com o aumento do volume de liquido devido à maior quantidade de partículas magnetizadas.

No trabalho Hezaveha et al., (2012) foi sintetizado um ferrofluido com nanopartículas 
de ferro da marca Sigma-Aldrich. As nanopartículas têm diâmetro menor do que $50 \mathrm{~nm}$. Após a síntese foi apurada a formação de agregados de tamanho entre 210 - $686 \mathrm{~nm}$. Esta agregação pode ser devida às moléculas de ácido oleico que cobrem a superfície das nanopartículas. Foi detectado a presença de uma tensão de cisalhamento crítica para as maiores frações volumétricas. Acima de $20 \%$ o fluido se comportou como um fluido de Bingham. Observou-se uma queda da viscosidade com o aumento da taxa de cisalhamento, simbolizando a quebra de estruturas. Os resultados mostraram que nas taxas de cisalhamento de 0,1 e $6 s-1$ a viscosidade aumentou de forma não linear com a fração volumétrica. Nesta baixa taxa de cisalhamento o ferrofluido pode-se comportar como um sólido onde as partículas se tornam mais compactas, preenchendo os espaços que eram de fluido. Foi medida a viscosidade em função da intensidade do campo magnético para a taxa de cisalhamento de $5 \mathrm{~s}^{-1}$. Verificou-se um aumento da viscosidade com a intensidade do campo magnético. Contudo, foi observado que para uma certa intensidade de campo a viscosidade começa a diminuir. Esse efeito é mais visível em maiores frações volumétricas. Tal fenômeno pode ser atribuído à separação de fase no ferrofluido. Ou seja, pode ter ocorrido uma homogeneidade conhecida como concentração de fase de transição que ocorre nos ferrofluidos. Foi observado o aumento da viscosidade com a fração volumétrica para várias intensidades de campo magnético. Tal era de se esperar pois a interação entre partículas é intensificada com o campo magnético e as estruturas formadas são em maior número.

O artigo Rodriguez-Arco et al., (2014) estuda a reologia de fluidos magnéticos complexos. Estes fluidos são compostos por partículas diamagnéticas $(\mathrm{DM})$ com $d \approx 10 \mu \mathrm{m}$ e ferromagnéticas $(\mathrm{FM})$ com $d \approx 1 \mu \mathrm{m}$ suspensas em um ferrofluido (FF) carreador composto por partículas de magnetita com $d \approx 10 \mathrm{~nm}$. Este tipo de fluido quando sujeito a um campo magnético externo forma cadeias de estruturas organizadas. As diferentes micro-estruturas formadas devido a aplicação de um campo magnético externo alteram o comportamento macro-reológico do fluido. As suspensões em FF de partículas de diferentes tamanhos $(\mathrm{FM}+\mathrm{DM})$ são designadas por Fluidos Magnetoreológicos Inversos (FMI, batizado pelos autores). Quando a suspensão em FF é formada por partículas só do tipo FM o fluido é designado por Fluido Magnetoreológico (MR, fluido bimodal). Quando a suspensão em um FF é formada só por partículas DM os fluidos 
são designados por Ferrofluidos Inversos (FFI). Os FFI são fluidos mais monodispersos representando um modelo simples dos fluidos MR. Os autores viram diferenças nas estruturas formadas nos diversos tipos de fluidos principalmente na presença de um campo magnético externo. Na presença de campo as partículas DM formam cadeias alinhadas com o campo magnético. Nessas cadeias a partícula está alinha com a partícula anterior e com a seguinte. Com a presença das partículas FM, estas cercam a cadeia de partículas DM de forma desordenada, inibindo a formação de longas cadeias de partículas DM. Porém esse involucro de partículas FM não é perfeito deixando espaços ocupados só pelo FF (áreas de exclusão). Tal é explicado pela interação dipolodipolo entre as partículas. Os autores explicam que o momento magnético efetivo das partículas FM é alinhado com o campo e o momento magnético efetivo das partículas DM é oposto ao campo. Os autores se interessaram em medir a tensão de cisalhamento crítica e os módulos de viscoelasticidade. Observaram que a tensão crítica foi superior nos FMI e aumentou com a concentração de partículas DM. A tensão crítica foi mais elevada nos fluidos MR em comparação com os FFI devido a permeabilidade magnética das partículas FM ser maior do que nas partículas DM. A importância das partículas DM na tensão crítica foi verificada nos fluidos FMI. Quanto aos módulos viscoelásticos todos as suspensões tiveram um comportamento típico de um fluido ( $\left.G^{\prime \prime}>G^{\prime}\right)$ na ausência de campo magnético. Os FFI não apresentaram comportamento de sólido mesmo com a aplicação do campo magnético. Tal resultado evidência as baixas tensão críticas que este tipo de fluido apresenta. Na presença de campo os fluido MR se comportaram como sólido até uma faixa de amplitude de tensão. Após isso o seu comportamento foi de liquido. Para os FMI na condição sem campo a suspensão se comporta como um fluido. O módulo G" permanece quase constante para pequenas amplitudes de tensão. Com o aumento da amplitude de tensão o valor G' diminui até atingir um mínimo. Após o mínimo G' recupera com o aumento da amplitude de tensão. Na presença de campo foi observado um platô inicial para uma maior faixa de amplitudes de tensão um decréscimo para amplitudes de tensão intermediária, seguido de um pequeno platô e de um decréscimo. Para fluidos MR tal comportamento já foi explicado. A primeira queda se deve aos rearranjos de pequena escala das partículas que formam os agregados. A segunda queda é devido aos rearranjos de longa escala e a consequente ruptura das cadeias de partículas. Assim o primeiro platô pode ser entendido como sendo a força 
das partículas que formam os agregados. Devido a isso os fluidos FMI têm elevadas tensões críticas que aumenta com a fração volumétrica de partículas DM. Foi observado que o platô de G" foi maior em fluidos MR do que nos FFI. Tal resultado sugere que a fricção entre as partículas FM é maior nos FMI elevando substancialmente os valores de G". Todos os resultados mostram um aumento das propriedades magnetoreologicas em suspensões formadas por partículas FM e DM. Essas propriedades aumentam mais com a fração volumétrica de partículas DM. Os autores destacam que as partículas DM criam áreas de exclusão onde as formação de cadeia de partículas FM é impedida aumentando assim a concentração de partículas FM nas áreas permitidas. O segundo mecanismo poderá ser devido às interações entre as partículas FM e DM resultando no fortalecimento das estruturas formadas por partículas FM+DM. Os autores apresentam um modelo teórico baseado na interação entre partículas de diferentes tipos. Este modelo assume que não existe áreas de exclusão. Por isso permite explicações semi quantitativas do aumento da tensão crítica com a concentração de partículas DM e a estimativa da influencia da presença de áreas de exclusão para as partículas FM.

Os estudos teóricos sempre foram uma motivação para prever o comportamento reológico dos fluidos. Este interesse é acrescido pela busca de um modelo universal. Por outro lado este tipo de estudo permite observar com maior detalhe o comportamento da microestrutura em diferentes situações de cisalhamento e intensidade de campo magnético.

No estudo de Kamiyama e Satoh, (1989) foram analisadas as propriedades reológicas de fluidos magnéticos em escoamento de cisalhamento simples influenciado por um campo magnético aplicado na direção paralela e perpendicular em relação à direção principal do escoamento. Partindo de argumentos físicos de forças atuantes em um agregado de partículas em uma direção arbitrária de um campo magnético foi obtida uma equação governante para uma função de distribuição de orientação e um tensor de tensões. Foi observado que a viscosidade aparente dos fluidos magnéticos aumenta de forma significativa com o número de partículas que formam um agregado e com o diâmetro efetivo da partícula. A formação de agregados sustenta as observações experimentais no sentido de justificar o aumento da viscosidade do fluido magnético quando exposto a um campo externo. Foi verificado que o aumento da viscosidade é mais significativo 
quando o campo magnético está direcionado na direção perpendicular. Foi observado que a viscosidade aumenta em um intervalo de pequenas taxas de cisalhamento. Tal fato pode ser explicado devido às forças magnéticas serem superiores às forças de cisalhamento de tal forma que a estrutura não é quebrada.

Em Ilg et al., (2006) os autores verificam a validade das suposições e das simplificações dos modelos que consideram a formação de cadeias de partículas. O modelo teórico baseado em formação de cadeias assume que essas cadeias são rígidas onde as partículas estão alinhadas. Essa suposição é bastante simplificada. Este tipo de simplificação tem sido discutida. O modelo de formação de cadeias não é apropriado para baixas intensidades de campo magnético onde não existe formação de estruturas. Já o modelo dinâmico de campo médio mostra um bom comportamento para esse tipo de regime. Então é necessário um modelo que seja válido para todos os regimes de interação dipolar. O autor refere que o modelo de Shliomis é limitado por não incluir interação entre partículas e portanto esse modelo só é aplicável para ferrofluidos diluídos com baixas interações. Com o intuito de verificar o comportamento de fluido pseudo-plástico tem sido incorporada nos modelos a ideia de quebra gradual das estruturas com o aumento do cisalhamento. Por outro lado o aumento da intensidade de interação dipolar leva a um aumento da viscosidade. Esse aumento se deve à contribuição das forças entre partículas na parte simétrica da pressão viscosa bem como ao aumento da magnetização de não-equilíbrio. Segundo os autores o modelo de cadeia parece ser candidato a um modelo universal. Para isso os autores adicionaram um fator de forma. Por comparação com o fator de forma deduzido a partir de resultados de difusão e reológicos com os estimados pelo modelo dinâmico é mostrado que os resultados não estão muito de acordo para o regime de fraca interação. Contudo se o campo for orientado na direção do gradiente do escoamento, os dados reológicos sugerem que as partículas são amplamente difundidas. Os autores indicam que esses resultados são promissores para o desenvolvimento de um modelo cinético unificado que seja válido para todas as intensidades de campo magnético.

Em Liu et al., (2010) foi estudado o efeito do campo magnético em um ferrofluido em cisalhamento simples e quando sujeito a cargas de compressão. Os resultados numéricos de cisalhamento simples foram comparados com os resultados experimentais 
obtidos no reômetro da Anton-Paar MCR 301 disponível no laboratório onde se realizou os experimentos da presente tese. Para isso implementaram a teoria da Dinâmica Molecular para modelar a configuração e as propriedades de um sistema de multicorpos baseado nas leis de movimento de Newton. Foi observado em 3D a formação temporal das microestruturas quando aplicado um campo magnético externo. Verificou-se que em cisalhamento simples, as cadeias unidimensionais formadas devido ao campo magnético externo adquirem uma estrutura lamelar, ou seja, é uma estrutura formada por camadas finas e alternadas de partículas alinhadas com o escoamento. Tal fato se deve aos efeitos da força de arrasto de Stokes originadas pelo escoamento. A configuração lamelar foi observada em regimes de maior taxa de cisalhamento nas quais se verificou uma menor resistência das estruturas originando uma queda da viscosidade relativa. Para a intensidade de campo magnético de $30 \mathrm{kA} / \mathrm{m}$ observou-se que as tensões de cisalhamentos aumentaram linearmente com a taxa de cisalhamento e o fluido pode ser descrito como um fluido de Bingham. As tensões de cisalhamento foram comparadas com sucesso com os resultados experimentais. Em compressão o fluido mostrou maiores tensões críticas. Estas tensões aumentaram com a intensidade do campo magnético devido à compactação das estruturas de partículas. Neste caso o trabalho de compressão é absorvido com mais eficácia pela energia potencial repulsiva. Foi observado que a força de interação entre diferentes cadeias de partículas é mais fraca do que entre as partículas da própria cadeia. Aqui cabe referir o trabalho de Gontijo (2013) que estuda a microhidrodinâmica de suspensões magnéticas.

\subsection{OBJETIVOS}

O objetivo geral desta tese é a caracterização reológica de emulsões de altas razões de viscosidade $(\lambda>1)$ em diferentes frações volumétricas em cisalhamentos linear e quadrático e de ferrofluidos quando sujeitos a diferentes intensidades de campo magnético. Estes tipos de escoamentos estão entre os considerados padrões na caracterização reológica de fluidos (Morrison (2001)). As emulsões ensaiadas são constituídas por gotas de óleo mineral suspensas em misturas de água e glicerina. O tamanho das gotas é não coloidal $(>1 \mu m)$ o que permite que as flutuações de ordem molecular sejam desprezíveis (alto número de Peclet). Os ensaios foram efetuados em regime de baixo número 
de Reynolds, para pequenas magnitudes de capilaridade. Foram sintetizadas emulsões com diferentes razões de viscosidade $(\lambda=2,5,10,20)$ e diferentes frações volumétricas de gotas $(\phi=2 \%, 5 \%, 20 \%, 40 \%, 50 \%, 60 \%, 70 \%)$.

Devido à necessidade da adição de surfactantes como fluido estabilizador de emulsões foi estudada a variação da tensão interfacial $\left(\tau_{s}\right)$ para diferentes razões de viscosidade. A tensão interfacial foi obtida por um tensiômetro do tipo gota, cuja gota é gerada em um capilar conectado a uma seringa. A adição de surfactantes altera substancialmente a tensão interfacial entre o óleo mineral e as misturas de água e glicerina. É de se referir que a tensão interfacial é um parâmetro essencial para o cálculo do número de capilaridade.

A síntese de emulsões é um processo que gera estudos com relação à influência de surfactantes na reologia de emulsões. Daqui surge a necessidade de pesquisa sobre os processos de síntese e a escolha indicada do tipo de surfactante a ser usado para a obtenção de emulsões com características específicas. O parâmetro a ter em conta durante a síntese de emulsões é designado por Equilíbrio Hidrofílo-Lipofílo (EHL). O conhecimento deste parâmetro é importante para se conseguir emulsões de diversos tipos (A/O, O/A, A/O/A, O/A/O). Estudos referentes ao processo de síntese são relevantes uma vez que o que se procura é conhecer a influência do processo na estabilidade da emulsão. Assim é importante conhecer qual a Concentração Miscelar Crítica (CMC) que está relacionada com a estabilidade das emulsões pela tensão interfacial entre os líquidos que compõem a emulsão.

Os experimentos em cisalhamento simples e oscilatório são realizados em um reômetro de discos planos paralelos. Os experimentos em cisalhamento quadrático são gerados no interior de um tubo capilar de secção circular que pode ser usado como um viscosímetro através da medição do gradiente de pressão para uma dada vazão. A caracterização da microestrutura da emulsão foi realizada por microscopia ótica no sentido de relacionar o comportamento reológico da emulsão com as suas características da microestrutura.

As medidas de viscosidade aparente em função da taxa de cisalhamento foram ajustadas, sempre que possível, por correlações empíricas típicas usadas para descrever fluidos 
não-Newtonianos viscosos. Os dois tipos de escoamento geram diferenças devido às características do cisalhamento que influenciam a deformação, orientação, interação e distribuição de partículas na emulsão na presença de gradiente de tensões cisalhantes.

Os resultados experimentais das emulsões infinitamente diluídas de altos $\lambda$ podem ser comparados com modelos teóricos de pequenas deformações. Neste caso, o modelo incluí a presença de gotas através de um tensor que leva em consideração a distribuição, orientação, tamanho e forma das gotas. Para passar da escala discreta (i.e. escala da gota) para a escala contínua de fluido homogêneo equivalente é então necessário realizar uma média volumétrica no tensor de tensões. Com o tensor de tensões definido é possível estudar o escoamento em tubo capilar.

Como referido nas seções anteriores, as gotas suspensas em emulsões têm a tendência de se deslocarem para regiões de baixa taxa de cisalhamento surgindo uma região livre de gotas adjacente à parede sólida. Nessa situação as gotas escoam pela parte central do escoamento de tubos formando um escoamento de núcleo (core-flow). No sentido de prever a espessura livre de gotas $(\delta)$ investiga-se o escoamento no interior de tubos de forma a avaliar as predições numéricas com as medidas experimentais. Nesta análise o modelo da viscosidade aparente pode ser extraído das medições de reologia ou então de um dos modelos ad-hoc típicos para descrever os fluidos não-Newtonianos viscosos cujas constantes podem ser calibradas de forma que os resultados numéricos concordem com os resultados experimentais.

Para calcular o perfil de concentração de gotas e a espessura da camada livre de gotas adjacente a uma parede sólida no domínio semi-infinito é proposto um modelo baseado no balanço entre o fluxo difusivo e migração de gotas além de se considerar a advecção de partículas pelo escoamento. O modelo do desenvolvimento de uma região livre de gotas adjacente à parede permite ser estudado por um domínio semi-infinito no qual se considera que em uma região longe da parede não existe gradiente de fração volumétrica de gota. Este modelo procura evidenciar quais são os parâmetros físicos responsáveis por promoverem a região livre de gotas. Para a solução da equação de transporte resultante, desenvolve-se uma metodologia baseada no método de similaridade. Método este que por uma mudança de variáveis apropriada na equação que governante 
permite transformar uma Equação Diferencial Parcial (EDP) em uma Equação Diferencial Ordinária (EDO). Com este método é possível determinar as soluções do perfil de concentração de gotas reunidas no espaço de similaridade de duas variáveis sem haver necessidade de se obter soluções para cada estação temporal como ocorre no espaço nas variáveis primitivas. Com o perfil de concentração é possível predizer a camada livre de células em função dos parâmetros físicos do problema.

Neste trabalho também se apresenta a caracterização de fluidos magnéticos em cisalhamento simples e oscilatório realizado em um reômetro de discos planos e paralelos. Neste sentido procura-se extrair o comportamento deste tipo de fluidos em função da intensidade do campo magnético externo e da taxa de cisalhamento. Assim apresentamse resultados relativos à variação de viscosidade, à existência de uma tensão crítica e de uma função de relaxação e das mudanças nos módulos de viscoelasticidade em função da deformação.

\subsubsection{Objetivos Específicos}

Esta seção é destinada a específicar os objetivos e tarefas concretizadas durante a elaboração da presente tese.

1. Avaliação do comportamento reológico de líquidos em cisalhamento simples promovido por um reômetro de discos planos:

- Verificar para que distância entre discos (gap) a viscosidade é máxima (gap ótimo);

- Medir a viscosidade para diferentes taxas de cisalhamento de fluidos com comportamento Newtoniano: água, misturas de água-glicerina e óleo mineral.

- Medir a viscosidade para diferentes taxas de cisalhamento para fluidos com comportamento não-Newtoniano: suspensão de poliacrilamida. 
2. Avaliação da tensão superficial e interfacial em função da concentração de surfactante para várias misturas de água e glicerina:

- Medir a tensão superficial entre água-ar;

- Medir a tensão interfacial água-óleo;

- Medir a tensão interfacial de misturas de água e glicerina em relação ao óleo;

- Medir a tensão interfacial de água mais surfactante (Tween80) em relação ao óleo para várias concentrações de surfactante;

- Medir a tensão interfacial de água em relação ao óleo mais surfactante (Span80) para várias concentrações de surfactante;

- Extrair a concentração micelar crítica, ou seja, a saturação da tensão interfacial em função da concentração de surfactante;

- Extrair o perfil de variação da tensão interfacial com o tempo.

3. Quanto a síntese de emulsões os objetivos são:

- Preparar misturas de água-glicerina para o fluido base;

- Medir de viscosidade e massa específica das misturas da água-glicerina;

- Medir de viscosidade e massa específica do óleo mineral sendo a fase dispersa da emulsão;

- Propor e aprimorar a metodologia de síntese de emulsões.

4. A microestrutura da emulsão é caracterizada por meio de um microscópio óptico. Para realizar esta tarefa foi implementada a seguinte metodologia :

- Analisar a microestrutura das emulsões por meio de micrografias de amostras de emulsões;

- Medir o tamanho de gota;

- Avaliar a distribuição do tamanho de gota de cada amostra.

5. Estudo reológico de emulsões pela medição do gradiente de pressão em função da vazão através do escoamento da própria emulsão pelo interior de um tubo capilar de seção circular: 
- Medir o gradiente de pressão para cada vazão $(\Delta P(Q))$. O gradiente de pressão foi recolhido em uma hora contínua de experimento;

- Repetir cinco vezes o item anterior para cada taxa de cisalhamento para avaliar o erro experimental;

- Cálculo na parede da taxa de cisalhamento $\left(\dot{\gamma}_{w}\right)$, tensão de cisalhamento $\tau_{w}$ e viscosidade;

- Apresentar resultados para a viscosidade avaliada na parede do tubo capilar em função da taxa de cisalhamento e do número de capilaridade.

- Ajustar os dados experimentais com modelos empíricos;

- Relacionar a polidispersidade da emulsão com as características reológicas das emulsões;

- Avaliar a influência do aumento da razão de viscosidade e da fração volumétrica na reologia das emulsões.

6. Avaliação do comportamento reológico de emulsões em cisalhamento simples promovido por um reômetro de discos planos:

- Medir a viscosidade para diferentes taxas de cisalhamento para emulsões com diferentes razões de viscosidade e frações volumétricas;

- Repetir cinco vezes o item anterior para cada taxa de cisalhamento para avaliar o erro experimental;

- Apresentar resultados para a viscosidade em função da taxa de cisalhamento e número de capilaridade.

- Capturar os efeitos viscoelásticos de emulsões em função de parâmetros do escoamento.

7. Estudar a teoria de escoamento de líquidos em tubos capilar:

- Deduzir a equação de Weissenberg-Rabinowitsch para avaliar a viscosidade de líquidos em tubo capilar;

- Obter modelos teóricos para escoamento de líquidos não-Newtonianos em tubo capilar; 
- Obter a condição que garante escoamento unidirecional;

- Propor e desenvolver modelos para a predição da camada livre de gotas adjacente à parede do tubo capilar.

8. Comparação de Resultados:

- Comparar resultados experimentais de escoamento de emulsões em cisalhamento simples e quadrático para os diferentes $\lambda$ e $\phi$;

- Comparar os resultados experimentais entre os dois tipos de cisalhamento;

- Ajustar os resultados experimentais por calibração de constantes de modelos teóricos;

- Comparar os resultados experimentais com modelos teóricos de pequena deformação para emulsões diluídas.

9. Viscoelasticidade de Emulsões:

- Caracterizar o efeito pseudo-plástico de emulsões de alta fração volumétrica;

- Medir os módulos elásticos das emulsões em regime de viscoelasticidade linear e não-linear;

- Avaliar o efeito do aumento da fração volumétrica e da razão de viscosidade nos módulos elásticos.

10. Caracterização de fluidos magnéticos:

- Estudar a variação da viscosidade para diferentes intensidades de campo magnético;

- Estudar a variação da viscosidade em função da taxa de cisalhamento para diferentes intensidades de campo magnético;

- Obter curvas de viscosidade em função do campo magnético para diferentes taxas de cisalhamento;

- Capturar os efeitos viscoelásticos em função da amplitude de deformação para diferentes intensidades de campo magnético; 
- Capturar a tensão residual no ferrofluido para várias pré-taxas de cisalhamento;

- Estudar a influência da intensidade do campo magnético no surgimento da tensão crítica $\left(\tau_{0}\right)$ de escoamento;

- Estudar o efeito da amplitude de deformação na função de relaxação $(\Phi(t))$;

- Estudar o efeito da taxa de cisalhamento na tensão residual. 


\section{FUNDAMENTAÇÃO TEÓRICA}

Neste capítulo apresenta-se a classificação dos fluidos em relação ao seu comportamento quando sujeito a tensões de cisalhamento. Após isso, são deduzidas as equações governantes para escoamento de fluidos. Através da análise dessas equações são obtidas as equações para escoamento quadrático relacionado com o escoamento no interior de tubo capilar, e para o escoamento de cisalhamento simples relacionado com o escoamento de Couette entre discos planos.

\subsection{CONCEITOS DE REOLOGIA}

A reologia pode ser definida como a ciência que estuda o comportamento da matéria quando esta se deforma devido a ação de forças externas. Em geral quando a matéria se deforma continuamente é designada por um meio contínuo. A reologia tem como objetivo sugerir modelos e teorias que possam descrever as observações experimentais. Adicionalmente, os modelos teóricos surgem da aplicação de leis da física e de teoremas matemáticos para representar os fenômenos observados em experimentos de laboratório. Um dos interesses da reologia teórica é desenvolver equações constitutivas para o comportamento de fluidos complexos. Estas equações são desenvolvidas levando em conta as características físicas e comportamentais da microestrutura do fluido. A microestrutura é inserida na escala macroestrutural seguindo as hipóteses do meio contínuo.

Na escala microscópica a matéria é descontínua devido a distância entre as moléculas que se movimentam aleatoriamente. Se a escala do escoamento for maior que a distância entre as moléculas então a propriedade pode ser definida como contínua no interior de um volume que é menor que o volume macroscópico mas muito maior que a escala molecular. Assim, por exemplo, a massa específica em um volume é calculada como:

$$
\rho=\lim _{\Delta V \rightarrow 0} \frac{N M}{\Delta V}
$$


em que $N$ é o número de moléculas e $M$ é a massa da molécula. Como se pode ver pela fig. 2.1 quanto maior for o volume considerado para o cálculo da propriedade no meio contínuo menores serão as flutuações. Isso porque com o aumento do volume mais afastado este fica da escala molecular. É de se referir que as flutuações decrescem com $1 / \sqrt{N}$ e como tal quanto maior o número de moléculas no volume mais significativa será a média volumétrica das propriedades locais do escoamento. Todas as propriedades dos fluidos avaliadas neste trabalho estão inseridas no meio continuo. Por exemplo, o volume de emulsão utilizado nos experimentos é considerado um meio contínuo devido a escala de medição ser muito maior que a escala do tamanho médio de gota. Neste trabalho a escala de comprimento médio da gota é $14 \mu m$ (raio da gota, a) e a escala de comprimento característico do escoamento é de $250 \mu m$ (raio do tubo capilar, $R$ ) ou $400 \mu m$ (distância entre os discos planos do reômetro, $\delta$ ). A razão entre estas escalas é muito menor que a unidade. Assim pela definição do número de Knudsen $(K n=a / R)$ é possível considerar que a emulsão é um meio contínuo, devido a um volume infinitesimal da emulsão conter um número de gotas suficientemente grande de forma a constituir um fluido contínuo equivalente.
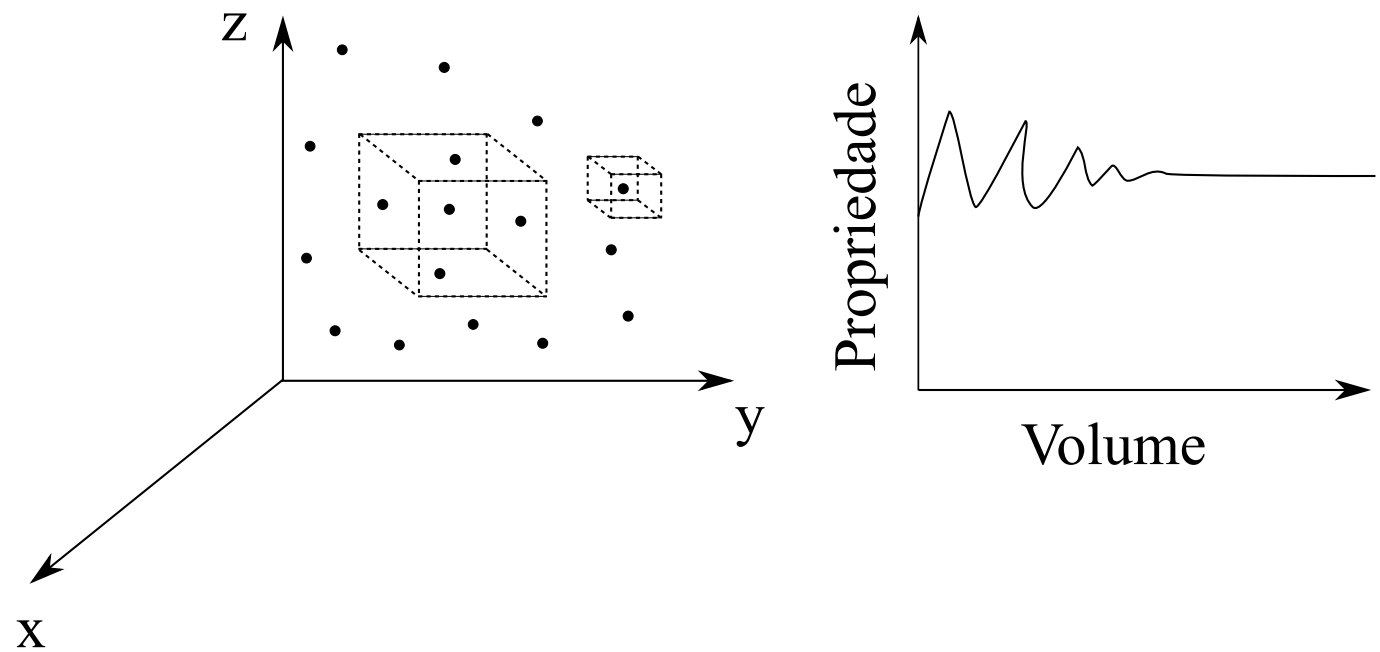

Figura 2.1: Definição de Meio Contínuo

A viscosidade é uma das propriedades do líquido de maior interesse para a reologia, uma vez que os modelos teóricos tentam representar a variação da viscosidade em diferentes regimes de escoamento. As observações de Newton levaram a uma relação linear entre tensão de cisalhamento e taxa de cisalhamento. Como tal, todos os fluidos 
que apresentem essa relação são designados por fluidos Newtonianos. A razão entre essas quantidades é designada por viscosidade $(\eta)$.

$$
\eta=\frac{\tau}{\dot{\gamma}}
$$

em que, $\dot{\gamma}=\frac{d u}{d y}$, $u$ é a velocidade na direção do escoamento e $y$ é a direção normal ao escoamento (direção do gradiente de velocidade). A tensão de cisalhamento, $\tau$, que é a força de cisalhamento aplicada em uma determinada área, tem como unidade no sistema internacional $N / m^{2}$. A taxa de cisalhamento, $\dot{\gamma}$, tem unidade de $s^{-1}$. Assim a unidade da viscosidade é Pa.s. No entanto é comum se encontrar a viscosidade medida em Poise (sistema de unidades CGS), em homenagem a Poiseuille. A relação entre as duas unidades de medida é $1 c P=1$ mPa.s. A fig. 2.2 ilustra o escoamento em cisalhamento simples como sendo a soma dos efeitos de deformação (stretching) e de rotação. Esses dois efeitos são representados por tensores: tensor taxa de deformação

$$
\boldsymbol{D}=\frac{1}{2}\left(\nabla \boldsymbol{u}+(\nabla \boldsymbol{u})^{T}\right)
$$

e tensor taxa de rotação

$$
\boldsymbol{W}=\frac{1}{2}\left(\nabla \boldsymbol{u}-(\nabla \boldsymbol{u})^{T}\right)
$$

os quais são respectivamente a parte simétrica e antissimétrica do gradiente de velocidade, $\nabla \boldsymbol{u}$.

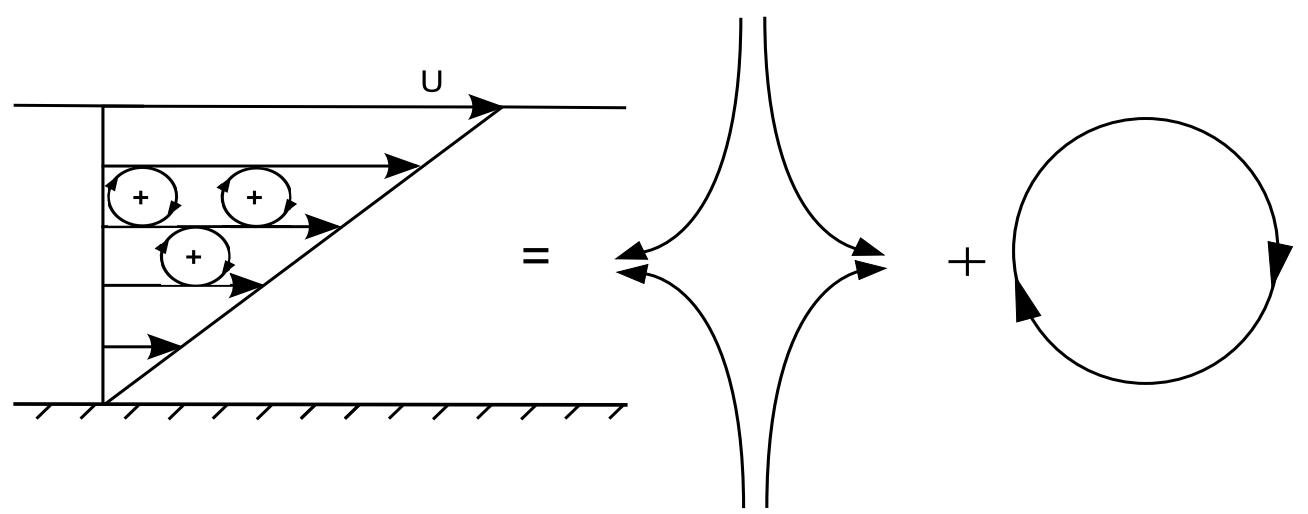

Figura 2.2: Escoamento em cisalhamento simples representado pela adição dos efeitos de deformação e de rotação

Para o caso de fluido Newtoniano, a queda da viscosidade com o aumento da tempe- 
ratura segue a Lei de Arrhenius:

$$
\eta=A \exp (B / T)
$$

em que A e B são as constantes e $T$ é a temperatura em Kelvin.

Para um mesmo par de valores pressão-temperatura, a viscosidade de um fluido nãoNewtoniano varia com a taxa de cisalhamento, não se verificando a relação linear com a tensão de cisalhamento. No entanto, alguns fluidos podem apresentar a relação linear, contudo a reta de proporcionalidade não passa na origem do gráfico $\tau(\dot{\gamma})$. Esse comportamento reflete o surgimento de uma tensão de cisalhamento crítica $\left(\tau_{0}\right)$ a partir da qual o fluido deixa de se comportar como se fosse um sólido. A viscosidade do fluido também pode ser em função do tempo e da taxa de cisalhamento $\eta=\eta(\dot{\gamma}, t)$. Neste caso a viscosidade varia com o tempo quando sujeita a uma determinada taxa de cisalhamento. Um outro grupo são os fluidos que se comportam tanto como um sólido elástico ou como um fluido viscoso. Estes fluidos são designados por fluidos viscoelásticos. Assim é definido o número adimensional Deborah $(D e)$ com o intuito de quantificar o quanto a matéria se aproxima de um comportamento de sólido ou de líquido. O número de $D e$ relaciona duas escalas de tempo: uma referente ao tempo de relaxação característico do material, $t_{m}$, e a outra referente a uma escala de tempo do escoamento (durante o qual o material está sujeito a forças que promovem a deformação), $t_{e}$.

$$
D e=\frac{t_{m}}{t_{e}}
$$

Se De tende para zero, a matéria se comporta como um líquido. Quando De tende para infinito, a matéria se comporta como um sólido. O comportamento visco-elástico é verificado quando $D e$ tem valores intermediários. Em situações em que $D e$ tende a 1, existe uma grande interação entre o escoamento e a microestrutura do fluido. Assim escoamentos com essa magnitude de De são interessantes por possibilitarem quantificar a influência da microestrutura nas propriedades do fluido.

Os fluidos que exibem comportamento visco-elástico têm como característica a presença de diferença de tensões normais $\left(N_{1}=\tau_{x x}-\tau_{y y}, N_{2}=\tau_{z z}-\tau_{y y}\right)$. É de notar que 
em baixas taxas de cisalhamento $N_{1} \propto \dot{\gamma}^{2}$. Em taxa de cisalhamento $(\dot{\gamma})$ moderadas os modelos de fluidos Newtoniano viscoso ainda são válidos. Para maiores taxas de cisalhamento $N_{1}>\tau_{12}$ e portanto maiores deformações da microestrutura do fluido os modelos ad-hoc deixam de ser confiáveis. Tipicamente a magnitude de $N_{2}$ é de cerca de $10 \%$ de $N_{1}$, mas com sinal negativo. Sabendo a magnitude de $N_{1}$ pode-se definir o material como sendo um fluido inelástico ou visco-elástico. Para se poder avaliar o estado de deformação atual de um fluido visco-elástico é necessário conhecer-se os estados de deformação passados. Os modelos para estes fluidos consideram que os estados de deformação no tempo $t^{\prime}$ (mais distantes do estado atual) têm uma importância menor para o presente estado de deformação. Os modelos teóricos levam em consideração esta hipótese por intermédio de um parâmetro designado por fading memory, como pode ser visto no modelo de Maxwell em Bird et al. (1987):

$$
\boldsymbol{\tau}=-\int_{-\infty}^{t} G(s) \dot{\gamma}\left(t^{\prime}\right) d t^{\prime}
$$

em que $G(s)$ é o módulo de relaxação e $s=t-t^{\prime}$. Quando $s$ tende a infinito diz-se que os fluidos viscoelásticos têm fading memory.

Quando a viscosidade de um fluido varia com a taxa de cisalhamento a viscosidade é designada por viscosidade aparente. Os fluidos que apresentam uma diminuição da viscosidade com o aumento da taxa de cisalhamento são designados por pseudoplásticos, cujo termo em inglês é shear thinning. Pode-se citar os polímeros, emulsões e sangue como exemplos para este tipo de fluido.

Os polímeros exibem um platô Newtoniano para as regiões de baixa e alta taxa de cisalhamento (fig. 2.3). Em baixas taxas de cisalhamento o escoamento não interage com a molécula polimérica. Nesta situação a molécula relaxa mais rápido do que as variações do escoamento conservando a sua forma original. No entanto com o aumento da taxa de cisalhamento maior será a deformação da molécula (a deformação se dá no sentido do escoamento). Nessa situação a viscosidade diminui com o aumento da taxa de cisalhamento até ao limite no qual a molécula atinge a sua máxima deformação, registrando desta forma uma viscosidade constante (platô Newtoniano para a região 
de alta taxa de cisalhamento). Assim verifica-se que:

$$
\left\{\begin{array}{l}
\eta_{0}=\lim _{\dot{\gamma} \rightarrow 0} \frac{\tau}{\dot{\gamma}} \\
\eta_{\infty}=\lim _{\dot{\gamma} \rightarrow \infty} \frac{\tau}{\dot{\gamma}}
\end{array}\right.
$$

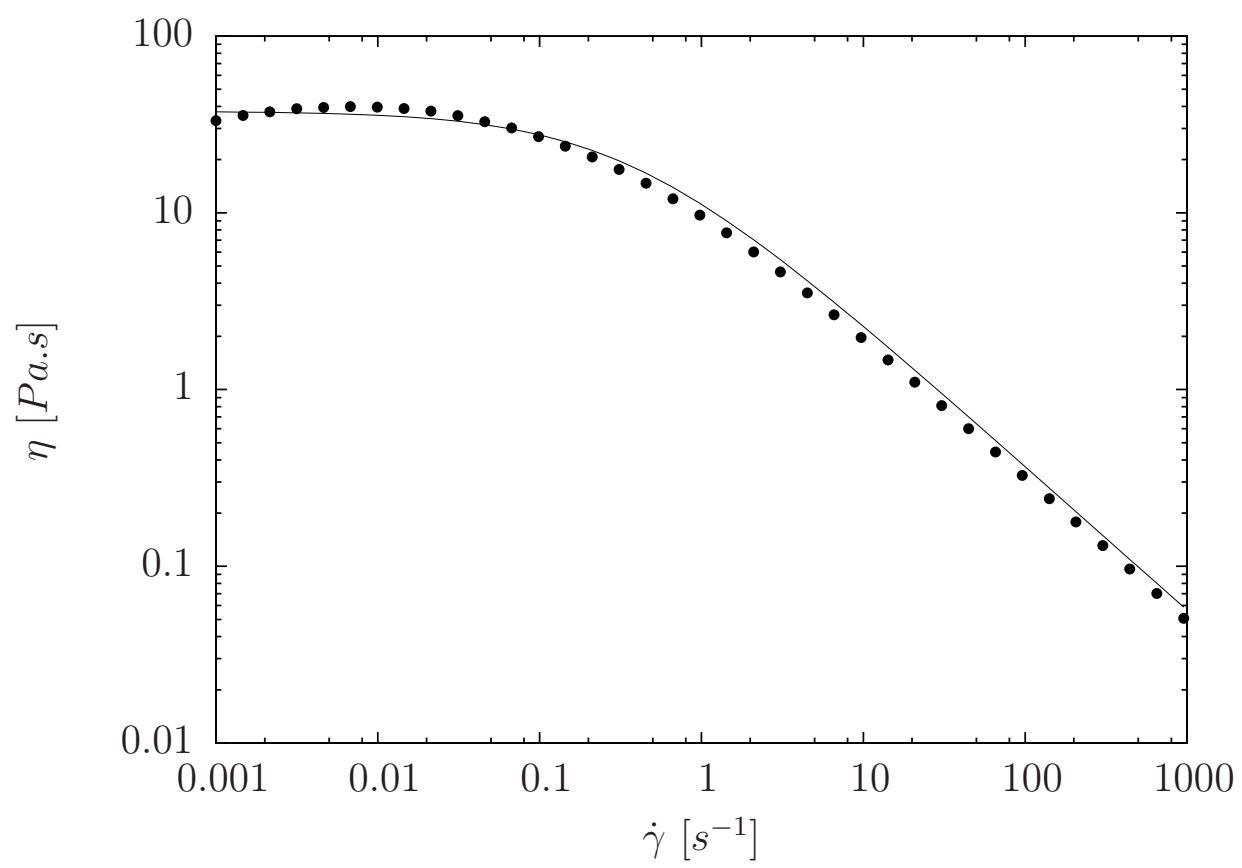

Figura 2.3: Variação da viscosidade em função da taxa de cisalhamento para uma poliacrilamida. •Resultado experimental obtido na presente tese, - Ajuste pelo modelo de Cross.

Os fluidos designados por dilatantes (shear thickening) apresentam um aumento da viscosidade aparente com o aumento da taxa de cisalhamento. Em regiões de baixas taxas de cisalhamento, o fluido que se encontra entre as partículas da microestrutura age como lubrificante, evitando portanto o contato entre partícula-partícula. No entanto quando a $\dot{\gamma}$ aumenta, o fluido é forçado a escoar, havendo assim contato entre as superfícies das partículas. Tal situação aumenta substancialmente a viscosidade. Como exemplo deste tipo de fluido pode-se citar a mistura de amido de milho com água.

Com o intuito de representar matematicamente o comportamento dos fluidos surgiram modelos baseados no empirismo. O modelo mais simples é designado por Lei de Potência (Power Law) ou modelo de Ostwald-De Waele. Este modelo se mostra inade- 
quado no ajuste de pontos experimentais em regiões em que $\dot{\gamma} \rightarrow 0$ e $\dot{\gamma} \rightarrow \infty$, ou seja, nas regiões onde se verificam os platôs Newtonianos. No entanto este modelo é muito utilizado devido a sua simplicidade.

$$
\eta=m \dot{\gamma}^{n-1}
$$

O modelo tem duas constantes: $m, n$. Para um fluido pseudo-plástico $0 \leq n<1$. Enquanto que para o fluido dilatante $n>1$. Quando $n=1$ é recuperado o modelo para fluido Newtoniano (ver eq.2.2). A constante $m$ é designada como sendo uma medida do grau de coesão do fluido. A fig. 2.4 e a fig. 2.5 mostram o comportamento do modelo para as situações de fluido Newtoniano, pseudo-plástico e dilatante.

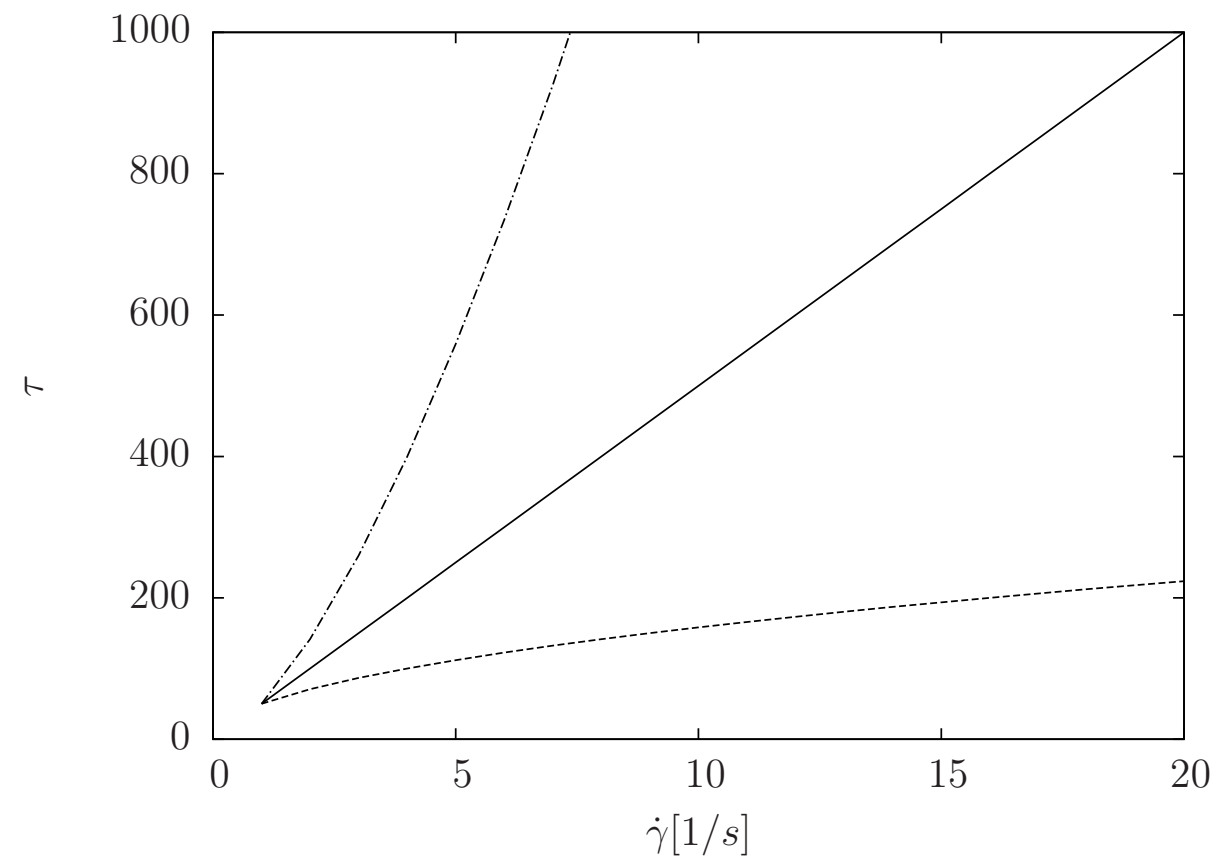

Figura 2.4: Modelo Power-Law: Parâmetros: $\mathrm{m}=50$. Legenda $-\mathrm{n}=1$ (Newtoniano) ; - - - n=0,5 (pseudoplástico) ; - - n=1,5 (dilatante). 


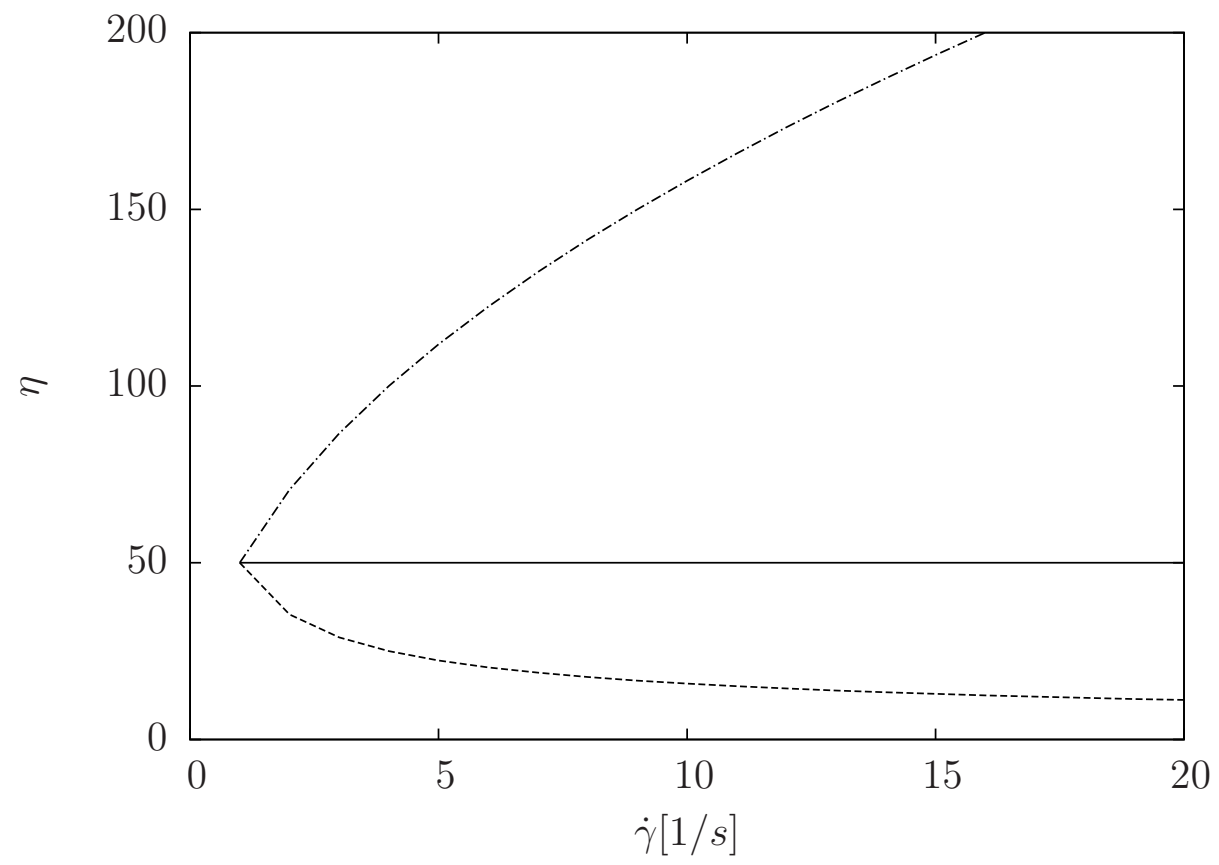

Figura 2.5: Modelo Power-Law: Parâmetros: $\mathrm{m}=50$. Legenda: $-\mathrm{n}=1$ (Newtoniano) ; - - - n=0,5 (psedoplástico) ; - - n $=1,5$ (dilatante).

O modelo de Cross (eq. 2.10) surgiu com o intuito de ultrapassar a incapacidade do modelo Power-Law de se ajustar aos resultados experimentais nas regiões de platô Newtoniano.

$$
\eta=\eta_{\infty}+\frac{\eta_{0}-\eta_{\infty}}{1+m \dot{\gamma}^{n}}
$$

em que $\eta_{\infty}$ é a é o valor da viscosidade quando $\dot{\gamma} \rightarrow \infty$ e $\eta_{0}$ é o valor da viscosidade quando $\dot{\gamma} \rightarrow 0$. Quando $\dot{\gamma} \rightarrow 0, \eta=\eta_{0}$, recuperando o primeiro platô Newtoniano, quando $\dot{\gamma} \rightarrow \infty, \eta=\eta_{\infty}$, recuperando o segundo platô Newtoniano,

Outro modelo também usado em fluidos com comportamento pseudo-plástico é o modelo de Carreau-Yassuda (eq. 2.11), que é bastante referenciado em estudos de modelos de sangue.

$$
\eta=\eta_{\infty}+\left(\eta_{0}-\eta_{\infty}\right)\left[1+(\alpha \dot{\gamma})^{a}\right]^{(n-1) / a}
$$

em que $n$ e a são constantes do modelo, e $\alpha^{-1}$ é entendido como sendo a taxa de cisalhamento a partir da qual a viscosidade começa a diminuir. A fig. 2.6 mostra o comportamento dos dois modelos. 


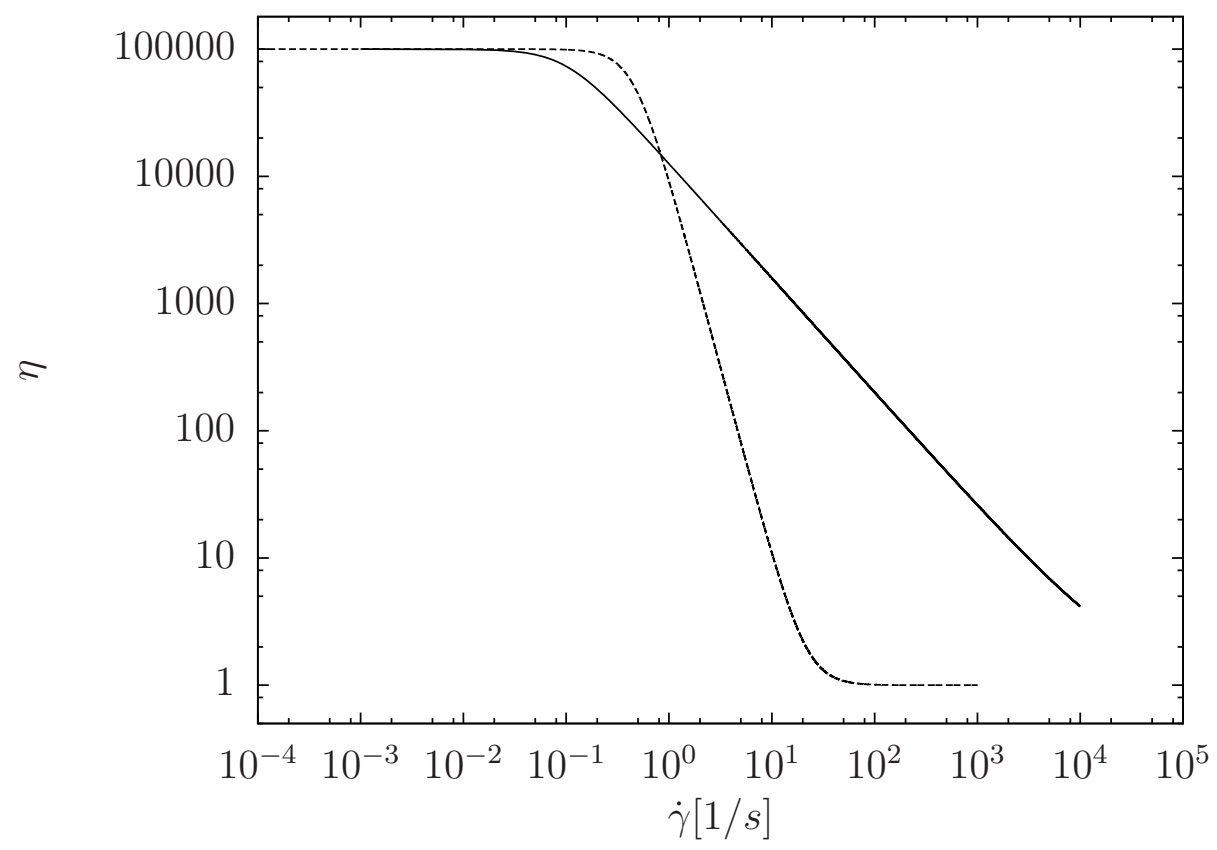

Figura 2.6: Modelos para fluidos pseudo-plásticos. Legenda: - - Cross $(\lambda=10,0$, $a=2,0, n=0,1) ;$ Carreau-Yassuda $(m=10,0, n=3)$.

O modelo matemático para os fluidos visco-elásticos designados por Bingham corresponde a:

$$
\begin{cases}\tau=\tau_{0}+\eta \dot{\gamma} & \\ \tau=0 & \tau<\tau_{0}\end{cases}
$$

em que $\tau_{0}$ é a tensão crítica a partir da qual o fluido começa a escoar. Se após ultrapassada a $\tau_{0}$ o fluido exibir um comportamento de fluido pseudo-plástico o modelo de Herschel-Bulkley é o mais adequado. Este modelo é uma extensão do modelo Lei de Potência que inclui a $\tau_{0}$.

$$
\begin{cases}\tau=\tau_{0}+m(\dot{\gamma})^{n} & \\ \tau=0 & \tau<\tau_{0} \\ \tau<\tau_{0}\end{cases}
$$

O modelo de Casson foi desenvolvido pensando em suspensões de sólidos. Este modelo é também utilizado para descrever o comportamento visco-plástico do sangue. A fig. 
2.7 apresenta o comportamento de um fluido do tipo Bingham e Casson.

$$
\begin{cases}\sqrt{\tau}=\sqrt{\tau_{0}}+\sqrt{\eta \dot{\gamma}} & \tau>\tau_{0} \\ \tau=0 & \tau<\tau_{0}\end{cases}
$$

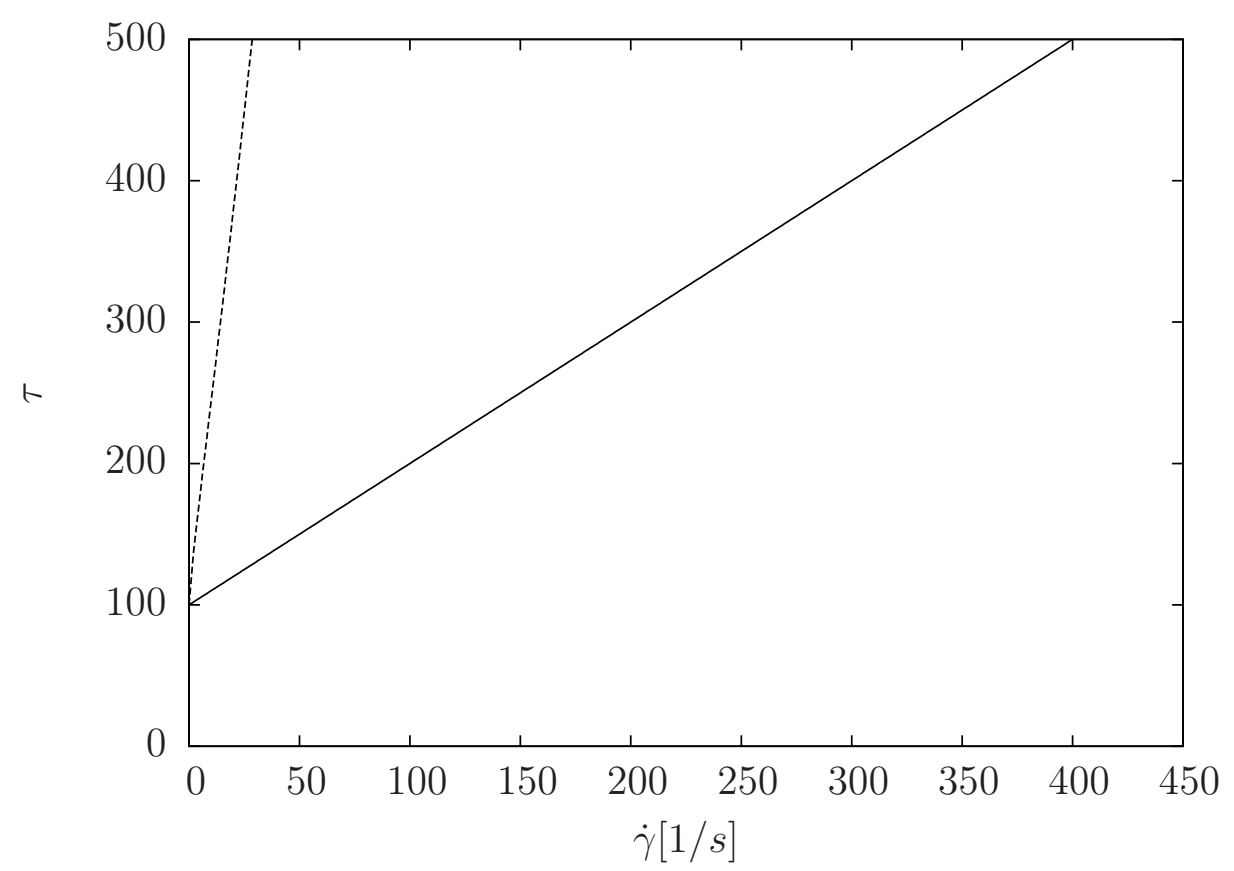

Figura 2.7: Modelos Viscoplásticos: — Casson ; - - - Bingham

Quando a viscosidade do fluido diminui com o aumento do tempo a que o fluido está sujeito a uma determinada taxa de cisalhamento é dito que o fluido apresenta comportamento tixotrópico, caso contrário é dito que é reopéxico. A diminuição da viscosidade com o tempo se deve ao fato de as estruturas da fase particulada se quebrarem com o passar do tempo quando sujeita a uma taxa de cisalhamento constante. Quando o fluido entra em repouso, as estruturas da fase particulada se reorganizam aumentando a viscosidade aparente. Como exemplos desse tipo de fluido temos: mistura de bentonita em água e suspensão de carvão em água. O gráfico para um fluido tixotrópico exibe um ciclo de histerese, em que a taxa de cisalhamento aumenta com a tensão de cisalhamento desde zero até um máximo, e diminui com a mesma taxa. 


\subsection{EQUAÇÕES GOVERNANTES PARA ESCOAMENTO DE FLUI- DOS}

As equações que regem o escoamento de fluidos são formadas pela equação da conservação de massa, também designada por equação da continuidade, pela equação da conservação da quantidade de movimento, pela equação da energia, pela equação da quantidade de movimento angular. Em casos mais simples são só consideradas as duas primerias equação, conservação da massa e da quantidade de movimento.

Considere um corpo material $\beta$ do qual uma porção $\delta \beta$ tem de volume $\delta V$, tal como mostra a fig. 2.8. A massa específica $(\rho)$ pode ser definida matematicamente como sendo:

$$
\rho=\lim _{\delta V \rightarrow 0} \frac{\delta m_{C}}{\delta V}
$$

ou seja, é a massa específica em um ponto infinitesimal pertencente ao corpo $\beta$ e como consequência a $\delta \beta$. Supondo que existe uma distribuição contínua de massa no corpo, isto é, sem pontos de concentração de massa, pode-se escrever matematicamente que a massa total do corpo é:

$$
m_{C}=\int_{V} \rho d V
$$

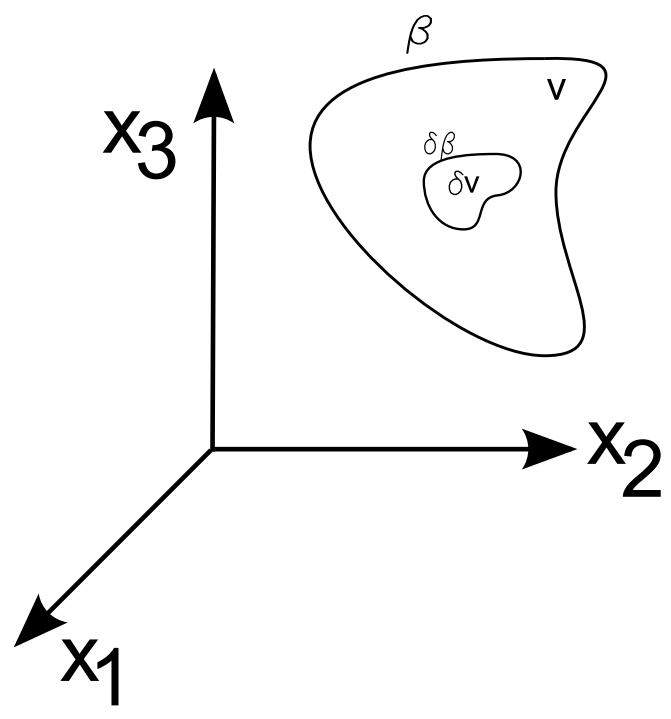

Figura 2.8: Definição da massa em um pequeno volume $\delta V$.

Pelo princípio da conservação que enuncia que os efeitos líquidos (entrada, saída, ge- 
ração da propriedade) são nulos, escreve-se a conservação da massa como sendo:

$$
\frac{D m_{C}}{D t}=0
$$

em que a derivada material é definida como:

$$
\frac{D \chi}{D t}=\frac{\partial \chi}{\partial t}+\boldsymbol{u} \cdot \nabla \chi
$$

em que $\chi$ é uma propriedade do fluido. Aplicando o Teorema de Transporte de Reynolds na eq. 2.17, escreve-se que:

$$
\frac{D}{D t} \int_{V} \rho d V=\int_{V} \frac{\partial \rho}{\partial t} d V+\int_{S} \rho \boldsymbol{u} \cdot \boldsymbol{n} d S=0
$$

em que, $\boldsymbol{u}$ é o vetor campo de velocidade, $S$ é a superfície do volume e $\boldsymbol{n}$ é o vetor normal a essa superfície e que aponta para fora da superfície. Aplicando o Teorema da Divergência pode-se escrever que:

$$
\frac{D}{D t} \int_{V} \rho d V=\int_{V}\left(\frac{\partial \rho}{\partial t}+\nabla \cdot(\rho \boldsymbol{u})\right) d V=0
$$

Como a expressão é válida para todo o volume, aplica-se o Teorema da Localização:

$$
\frac{D \rho}{D t}=\frac{\partial \rho}{\partial t}+\nabla \cdot(\rho \boldsymbol{u})=0
$$

Desenvolvendo a eq. 2.21, chega-se a Lei de Conservação de Massa:

$$
\frac{\partial \rho}{\partial t}+\rho \nabla \cdot \boldsymbol{u}+\boldsymbol{u} \cdot \nabla \rho=0 \Leftrightarrow \frac{D \rho}{D t}+\rho \nabla \cdot \boldsymbol{u}=0
$$

A quantidade de momento linear no corpo material $\beta$ é escrita como:

$$
\boldsymbol{p}=\int_{v} \rho \boldsymbol{u} d V
$$

O balanço da quantidade de momento linear em um meio contínuo é dado por:

$$
\frac{D \boldsymbol{p}}{D t}=\boldsymbol{f} \Leftrightarrow \frac{D}{D t} \int_{v} \rho \boldsymbol{u} d V=\boldsymbol{f} .
$$


Note que $\rho V$ tem unidade de massa e $\boldsymbol{u} / t$ tem unidade de aceleração. O produto dessas duas quantidades, pela segunda Lei de Newton, resulta em um somatório de forças $(\boldsymbol{f})$. Estas forças são de duas tipos: de campo e de superfície:

$$
\boldsymbol{f}=\int_{v} \rho \boldsymbol{b} d V+\int_{S} \boldsymbol{s} d S
$$

em que $\boldsymbol{b}$ é uma força por unidade de massa e $\boldsymbol{s}$ é o vetor tensão que pelo Teorema de Cauchy é dado por $\boldsymbol{n} . \boldsymbol{\tau}$, em que $\boldsymbol{\tau}$ é o tensor de tensões. Aplicando o Teorema da Divergência escreve-se que:

$$
\boldsymbol{f}=\int_{v}(\rho \boldsymbol{b}+\nabla \cdot \boldsymbol{\tau}) d V
$$

Após aplicar o Teorema da Localização na eq. 2.26 e na eq. 2.24, escreve-se que:

$$
\frac{D(\rho \boldsymbol{u})}{D t}=\rho \boldsymbol{b}+\nabla \cdot \boldsymbol{\tau}
$$

em que $\boldsymbol{b}$ é o vetor aceleração da gravidade $\boldsymbol{g}$. A eq. 2.22 e a eq. 2.27 formam as equações que regem o movimento de fluidos.

Sabendo que qualquer tensor de segunda ordem pode ser decomposto em uma parte isotrópica e uma parte deviatória, o tensor de tensões é escrito como:

$$
\boldsymbol{\tau}=-p \boldsymbol{I}+\boldsymbol{\Sigma}
$$

em que $p$ é a pressão mecânica (hidrostática) definida como $\frac{1}{3} \operatorname{tr}(\boldsymbol{\tau}), \boldsymbol{I}$ é o tensor identidade e $\boldsymbol{\Sigma}$ são os componentes deviatórios do tensor de tensões. A parte deviatória do tensor de tensões é o problema da reologia pois representa o comportamento do fluido às tensões aplicadas que depende das características dos fluidos. Para um fluido Newtoniano compressível o tensor deviatório é dado por:

$$
\boldsymbol{\Sigma}=2 \eta\left(\boldsymbol{D}-\frac{1}{3}(\nabla \cdot \boldsymbol{u}) \boldsymbol{I}\right)
$$

No caso do fluido ser incompressível, em que o fluido não apresenta variações da massa específica nem no espaço e nem no decorrer do tempo, a eq. 2.22 se torna $\nabla \cdot \boldsymbol{u}=0$. 
Assim a eq. 2.29 é simplificada em $\boldsymbol{\Sigma}=2 \eta \boldsymbol{D}$, formando as equações conhecidas como Equações de Navier-Stokes para fluido incompressível. No caso de fluido Newtoniano generalizado,

$$
\boldsymbol{\Sigma}=2 \eta(\dot{\gamma}) \boldsymbol{D}
$$

No caso do fluido ser não-Newtoniano e incompressível, o tensor de tensões é dado por:

$$
\boldsymbol{\Sigma}=2 \eta \boldsymbol{D}+\boldsymbol{\Sigma}^{N N}
$$

em que $\Sigma^{N N}$ é o tensor de tensões que representa as características físicas do fluido nãoNewtoniano que está associado com a microestrutura do fluido. Neste caso são inseridos os fluidos constituídos por partículas rígidas, gotas ou bolhas com possibilidade de serem susceptíveis a forças externas como forças associadas a campos magnéticos.

\subsection{ESCOAMENTO DE COUETTE ENTRE DISCOS PLANOS}

Nesta seção é analisado o escoamento de Couette entre discos planos relacionado ao cisalhamento simples. Este tipo de escoamento está associado com a caracaterização dos fluidos no reômetro.

O fluido quando cisalhado no reômetro é regido pelas equações da conservação da massa e da quantidade de movimento com condições de contorno de disco estacionário e disco rotativo com velocidade angular $\omega_{r}$. Devido ao fato de ser necessário somente uma pequena quantidade de fluido $(0,2-1,5 \mathrm{ml})$ para que o reômetro forneça as propriedades do fluido, o escoamento opera num regime de aproximação de lubrificação. As equações em coordenadas cilíndricas são as apropriadas para descrever o movimento imposto ao fluido (ver fig. 2.9).

Analisando o problema, constata-se que não existe motivo para que exista escoamento na direção vertical e nem na direção radial, uma vez que o movimento é imposto na direção angular. Desta forma escreve-se na forma simplificada as equações da quantidade 


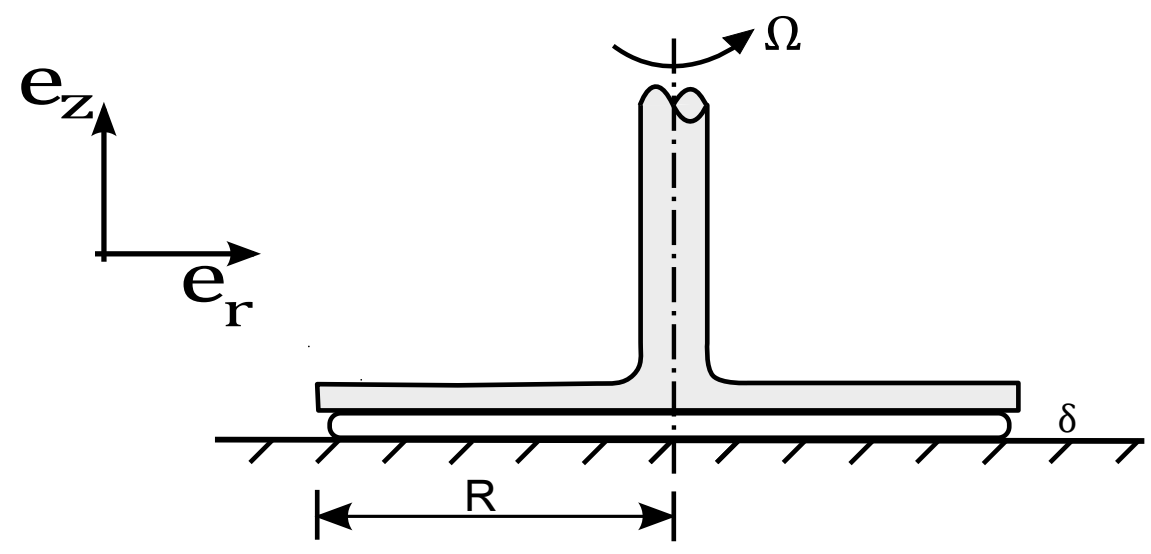

Figura 2.9: Escoamento entre disco com movimento de rotação e disco estacionário. $R$ : raio do disco móvel ; $\delta$ : região de fluido teste (gap).

de movimento que regem o escoamento nas três direções:

$$
\begin{gathered}
-\rho \frac{u_{\theta}^{2}}{r}=-\frac{\partial p}{\partial r} \\
0=-\frac{1}{r} \frac{\partial p}{\partial \theta}=\eta \frac{\partial^{2} u_{\theta}}{\partial z^{2}} \\
0=-\frac{\partial p}{\partial z} .
\end{gathered}
$$

Pela integração da eq.(2.32) e verificando-se que a velocidade na direção angular é função somente de $r$ e $z$ obtém-se uma expressão para o campo de pressão,

$$
p=\int \rho \frac{u_{\theta}^{2}}{r} d r+h(\theta, z)
$$

Das eqs. 2.33 e 2.34 observa-se que a pressão é somente função de $r$. Assim sendo não existe variação da pressão na direção $\theta$. Para obter uma expressão para o perfil de velocidades integra-se a eq. 2.33 aplicando $\partial p / \partial \theta=0$. A expressão para cada uma das duas constantes de integração é obtida aplicando as seguintes condições de contorno:

$$
\begin{aligned}
& u_{\theta}(r, z=0)=0 \\
& u_{\theta}(r, z=\delta)=\omega r .
\end{aligned}
$$


Daqui obtém-se que $u_{\theta}=\omega_{r} r z / \delta$.

O torque é uma quantidade mecânica a ser controlada no experimento de forma que esteja sempre dentro do intervalo indicado pelo fabricante do reômetro (200 $\mathrm{mNm}-$ $0,1 \mu \mathrm{Nm})$. O calculo do torque é baseado na integral da força agindo no elemento de fluido. Neste caso de disco paralelo diferente de cilindros concêntricos $\dot{\gamma}$ depende de $R, \dot{\gamma}(R)=w r / \delta$. Aqui $\delta$ representa a distância entre os discos do reômetro, designado por "gap". Assim o torque é:

$$
\mathcal{T}=\int_{0}^{R} \tau r d s=\int_{0}^{R} \eta(\omega r / \delta) 2 \pi r^{2} d r
$$

em que $R$ é o raio do disco. Resolvendo a integral da eq. 2.37, obtem-se que:

$$
\mathcal{T}=\eta \dot{\gamma}(R) \frac{\pi r^{3}}{2}
$$

Para um fluido caracterizado por uma lei de Bingham $\left(\tau=\tau_{0}+\eta \dot{\gamma}\right)$ o torque medido pode ser avaliado pela eq. 2.37:

$$
\mathcal{T}=\frac{2 \pi R^{3}}{3} \tau_{0}+\frac{\pi R^{3}}{2} \eta \dot{\gamma}(R)
$$

\subsection{ESCOAMENTO EM TUBO CAPILAR}

O escoamento em tubo de seção circular é designado por escoamento quadrático devido ao seu perfil de velocidade ser regido por uma equação de segundo grau em $r^{2}$. A geometria cilíndrica do capilar (fig. 2.10) sugere que as equações governantes sejam escritas em coordenadas cilíndricas.

O escoamento em um tubo acontece quando existe um gradiente de pressão axial que terá que vencer a resistência imposta pela viscosidade do fluido. Analisando o escoamento pode-se assumir que o mesmo é axissimétrico (apresenta simetria em relação ao eixo longitudinal), e como tal as derivadas em relação à direção $\theta$ são nulas. Adicionalmente é assumido que não existe formação de vorticidade e como tal a velocidade na direção angular $\theta$ é nula. Devido ao escoamento ser unidirecional, o campo de veloci- 

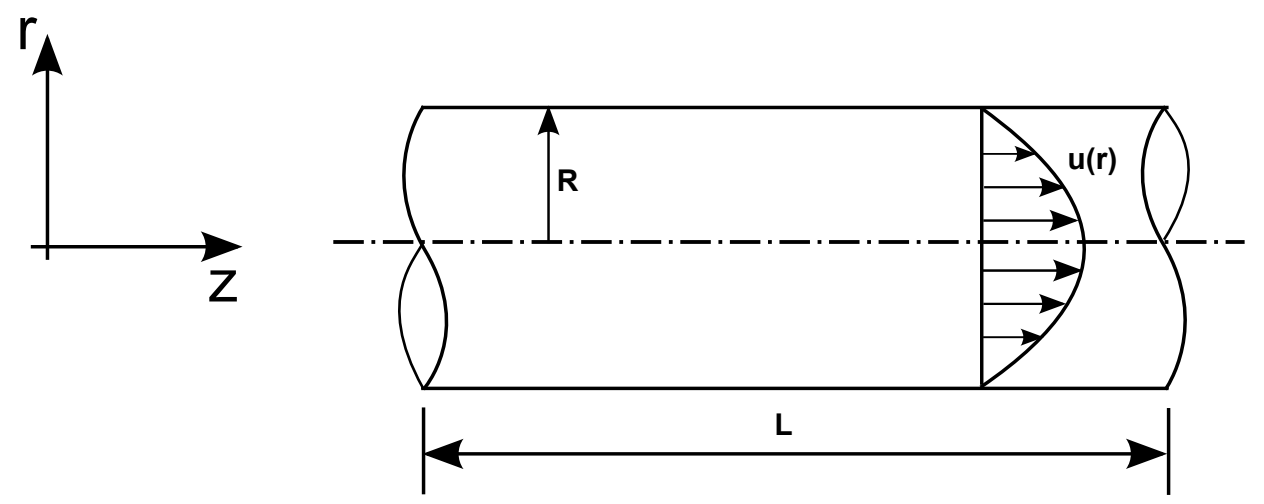

Figura 2.10: Escoamento em tubo. Legenda: $R$ : raio do tubo ; $L$ : comprimento do tubo; $u(r)$ : perfil de velocidade completamente desenvolvido

dades não apresenta alterações na direção longitudinal (direção do escoamento) e como tal $\partial u_{z} / \partial z=0$. Devido a parede ser impermeável, ou seja, não existe penetração de fluido pela parede, a velocidade na direção radial é nula. Tendo em conta as premissas enunciadas escreve-se a equação da quantidade de movimento para a direção z, que é a direção do escoamento devido a existência do gradiente de pressão:

$$
\frac{\partial p}{\partial z}=\eta\left(\frac{\partial^{2} u_{z}}{\partial r^{2}}+\frac{1}{r} \frac{\partial u_{z}}{\partial r}\right)
$$

É de notar que $\partial p / \partial z=\left(p_{L}-p_{0}\right) / L$, em que $p_{0}$ é a tomada de pressão a montante de $p_{L}$. Devido a $p_{L}<p_{0}$ o termo $\partial p / \partial z$ é negativo. Daqui define-se o parâmetro $\partial p / \partial z=-G$. Pode-se simplificar o termo da direita utilizando a definição da derivada em cadeia e a eq. 2.40 é reescrita como:

$$
-G \frac{r}{\eta}=\frac{d}{d r}\left(r \frac{d u_{z}}{d r}\right)
$$

As derivadas parciais foram substituídas por derivadas ordinárias pois cada termo da eq. 2.41 depende somente de uma direção. É habitual igualar a variação longitudinal da pressão a $-G$ uma vez que $d p=p_{L}-p_{0}$ em que $p_{L}<p_{0}$. Aqui $p_{L}$ é a pressão a jusante da tomada de pressão situada na origem onde é aferida a pressão $p_{0}$. O perfil de velocidade é obtido integrando duas vezes a eq. 2.41 levando em conta que a taxa de cisalhamento é finita no eixo longitudinal do escoamento e como tal a derivada da velocidade é nula tal como a velocidade na parede do tubo. Sobre estas condições de 
contorno o perfil de velocidade obtido é regido por uma equação parabólica:

$$
u_{z}=\frac{G}{4 \eta}\left(R^{2}-r^{2}\right)
$$

em que $R$ é o raio do tubo e $r$ é a distância radial desde o centro do tubo. É de notar que a velocidade máxima é encontrada no centro do tubo, ou seja, quando $r=0$. A velocidade média no tubo é metade da velocidade máxima e pode ser obtida avaliandose a velocidade em todo o tubo pela seguinte expressão:

$$
u_{\text {med }}=\frac{1}{\pi R^{2}} \int_{0}^{R} u_{z} 2 \pi r d r .
$$

em que $u_{z}$ é dado pela eq.(2.42).

Quando se estuda escoamento em tubos um parâmetro importante a ter em consideração é a vazão. A vazão expressa o volume de liquido que entra ou sai de uma seção transversal em cada segundo. É calculada avaliando a velocidade na direção principal do escoamento:

$$
Q=\int \boldsymbol{u} \cdot \boldsymbol{n} d S
$$

em que $\boldsymbol{u}$ é o vetor velocidade, $\boldsymbol{n}=\hat{e}_{z}$ é o vetor que aponta para o sentido do escoamento e $d S=r d r d \theta$ representa a superfície pela qual o escoamento passa. Assim a vazão é calculada por:

$$
Q=\int_{0}^{2 \pi} \int_{0}^{R} u_{z} r d r d \theta
$$

em que $u_{z}$ é dado pela eq. 2.42. Da eq. 2.45 obtém-se a expressão de Hagen-Poisseiule:

$$
Q=\frac{\pi R^{4} G}{8 \eta}
$$

\subsubsection{Condição de Unidirecionalidade}

As equações apresentadas anteriormente levaram em consideração a condição de unidirecionalidade. Aqui apresenta-se o parâmetro que indica em que condições o escoamento pode ser considerado unidirecional. Esse parâmetro surge da análise de escala 
efetuada aos termos da equação da continuidade e da quantidade de movimento na direção do escoamento $(z)$. Aplicando as seguintes escalas à equação da continuidade: $r \sim R, u_{z} \sim U$ e $z \sim L$, em que $R, U$ e $L$, são, respectivamente, o raio do capilar, a velocidade média do escoamento e o comprimento do capilar, verifica-se que:

$$
u_{r} \sim U \frac{R}{L}
$$

Como o parâmetro $R / L<<1$ então pode-se desprezar $u_{r}$. Desta forma na equação da continuidade resulta que $\partial u_{z} / \partial z=0$, indo de encontro ao que foi anteriormente assumido. Assim a equação do movimento na direção $z$ é reduzida a:

$$
\rho\left(u_{r} \frac{\partial u_{z}}{\partial r}\right)=-\frac{\partial p}{\partial z}+\eta\left(\frac{\partial^{2} u_{z}}{\partial r^{2}}+\frac{1}{r} \frac{\partial u_{z}}{\partial r}\right)
$$

Efetuando-se a análise de escala à eq. 2.48, o termo da esquerda (advectivo) escala com $\rho U^{2} / L$, enquanto que o segundo termo da direita (difusivo) escala com $\eta U / R^{2}$. Pela razão entre estes termos constata-se que o termo advectivo, associado com a inércia do escoamento, é muito inferior ao termo difusivo, resultando na expressão:

$$
\rho \frac{U R}{\eta}\left(\frac{R}{L}\right)<<1
$$

Na eq. 2.49 está implícito o número adimensional Reynolds $(R e)$ :

$$
R e_{R}\left(\frac{R}{L}\right)=R e_{L}\left(\frac{R}{L}\right)^{2}<<1
$$

em que $R e_{R}$ é o Reynolds que considera como dimensão principal o raio do capilar e $R e_{L}$ é o Reynolds que considera como dimensão principal o comprimento do capilar. Desta forma a condição de unidirecionalidade só é garantida quando a eq. 2.50 for verificada.

\subsubsection{Viscosímetro Capilar}

A equação do movimento na direção longitudinal do capilar, em coordenadas cilíndricas também pode ser escrita em função do tensor de tensões. A eq. 2.51 já considera 
escoamento unidirecional e axissimétrico:

$$
\frac{1}{r} \frac{\partial\left(r \tau_{r z}\right)}{\partial r}=\frac{\partial p}{\partial z}
$$

em que $\tau_{r z}$ é a tensão de cisalhamento que pode ser escrita da forma mais geral como:

$$
\tau_{r z}=\eta(\dot{\gamma}) \frac{d u_{z}}{d r}
$$

em que $\eta(\dot{\gamma})$ específica que a viscosidade do fluido é função da taxa de cisalhamento. Integrando a eq. 2.51 obtém-se que:

$$
\tau_{r z}=-G \frac{r}{2}
$$

Substituindo a eq. 2.52 na eq. 2.53 e integrando com as respectivas condições de contorno obtém-se a eq. 2.42 para $\eta(\dot{\gamma})=\eta$.

A viscosidade de um fluido pode ser avaliada através do escoamento do fluido em um capilar pela expressão:

$$
\eta_{w}=\frac{\tau_{w}}{\dot{\gamma}_{w}}
$$

em que $\eta_{w}, \tau_{w}, \dot{\gamma}_{w}$ são respectivamente, a viscosidade, a tensão de cisalhamento e a taxa de cisalhamento avaliadas na parede. A tensão de cisalhamento na parede pode ser obtida através do balanço de forças. O balanço de forças agindo em um volume de fluido devido ao gradiente de pressão e as forças associadas às tensões na parede que se opõem ao movimento do fluido é escrito na forma:

$$
\left(p_{0}-p_{L}\right) \pi R^{2}-\tau_{w} 2 \pi R L=0
$$

resultando em:

$$
\tau_{w}=\frac{\left(p_{0}-p_{L}\right)}{2 L} R
$$

$\operatorname{com} p_{1}>p_{2}$. Com a eq. 2.53 e a eq. 2.56 obtém-se a relação:

$$
\frac{\tau_{r z}}{\tau_{w}}=-\frac{r}{R} .
$$


Com a finalidade de se obter uma expressão para $\dot{\gamma}_{w}$, efetua-se a integração por partes da expressão 2.44, resultando em:

$$
Q=-\pi \int_{0}^{R} r^{2} \dot{\gamma} d r
$$

Da eq. 2.57 propõe-se a seguinte mudança de variáveis:

$$
\begin{aligned}
r & =-\frac{R \tau}{\tau_{w}} \\
d r & =-\frac{R}{\tau_{w}} d \tau .
\end{aligned}
$$

Após efetuar-se a integração da eq. 2.58 chega-se a relação de Weissenberg - Rabinowitsch (Bird et al. (1987))

$$
\dot{\gamma}_{w}=\frac{1}{\tau_{w}^{2}} \frac{d}{d \tau_{w}}\left[\frac{Q \tau_{w}^{2}}{\pi a^{3}}\right]
$$

Substituindo $\tau_{w}$, dada pela eq. 2.56, na eq. 2.61 obtém-se:

$$
\dot{\gamma}_{w}=\frac{Q}{\pi R^{3}}\left[3+\frac{d \ln |Q|}{d \ln |\Delta p|}\right]
$$

Pelas equações obtidas de $\tau_{w}$ e $\dot{\gamma}_{w}$ constata-se que com a medição da vazão $(Q)$ e do gradiente de pressão $(\Delta p)$ é possível avaliar a viscosidade pelo escoamento unidirecional do fluido em um tubo capilar:

$$
\eta_{w}=\tau_{w} / \dot{\gamma}_{w}
$$

Nas próximas seções aborda-se o escoamento de fluidos pela região central do tubo capilar (fig. 2.11). Este tipo de escoamento pode acontecer devido a diversos fatores. O fluido pode-se comportar como um corpo rígido quando a tensão de cisalhamento é menor que a tensão de cisalhamento crítica. Caso contrário o fluido se comporta como um liquido. Neste caso o escoamento na região central é de um corpo rígido com velocidade constante. Para esta situação é usual recorrer-se ao modelo de Bingham para a viscosidade e tensão. No entanto quando o fluido é caracterizado por uma 
suspensão de partículas ou de gotas (emulsões), estas podem migrar para a região central do escoamento. Nestes casos é formada uma região $\delta$ livre de partículas.
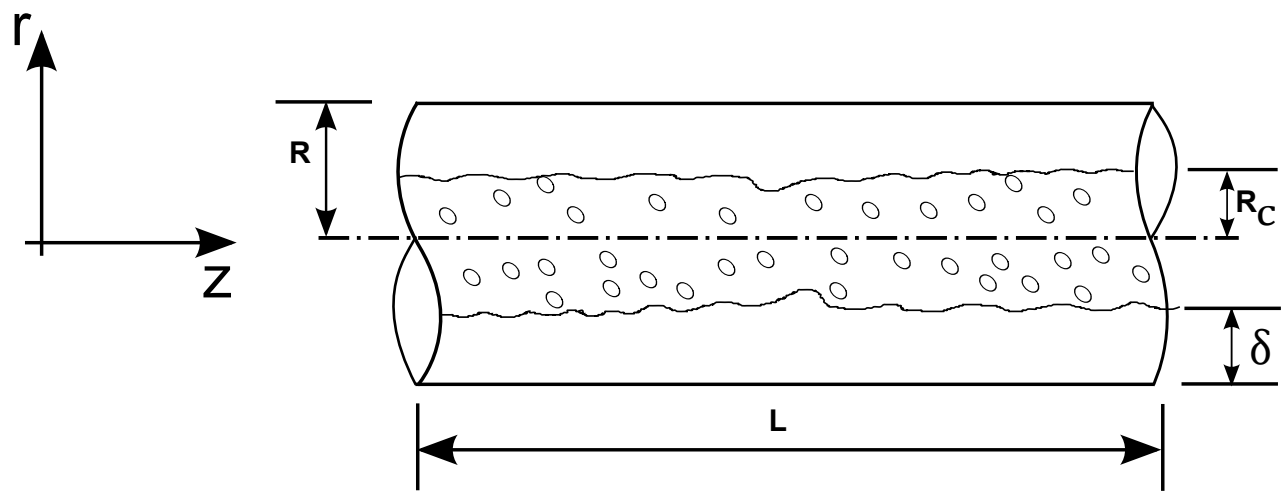

Figura 2.11: Escoamento de fluido Newtoniano adjacente a parede do capilar com concentração de partículas na região central do capilar. $L$ : comprimento do capilar; $R$ : raio do capilar $; R_{C}$ : raio da região de escoamento da suspensão ; $R_{\delta}$ : raio da região de escoamento de fluido Newtoniano

\subsubsection{ESCOAMENTO DO FLUIDO TIPO BINGHNAM EM TUBO CA- PILAR}

O fluido de Bingham é caracterizado por ter um comportamento de corpo rígido quando a tensão de cisalhamento é menor que a tensão de cisalhamento crítica $\left(\tau_{0}\right)$. Acima da tensão crítica o fluido começa a escoar. O modelo de fluido de Bingham é dado por:

$$
\begin{cases}\tau=\tau_{0}+\eta \dot{\gamma} & \tau>\tau_{0}, \\ \dot{\gamma}=0 & \tau<\tau_{0} .\end{cases}
$$

É de notar que quando o fluido se comporta como um corpo rígido, tem-se que $\eta \rightarrow \infty$. Assim vem que:

$$
\dot{\gamma}=\frac{\tau_{r z}}{\eta}=0
$$

Como $\dot{\gamma}=d u / d r$, então a velocidade é constante quando $\tau<\tau_{0}$. Portanto em $r=R_{c}$ tem-se que (fig. 2.11):

$$
\tau_{0}=-G \frac{R_{C}}{2}
$$


Da eq. 2.64 vem que:

$$
\tau=\tau_{0}+\eta_{0} \dot{\gamma} \Leftrightarrow \eta \dot{\gamma}=\tau_{0}+\eta_{0} \dot{\gamma} \Leftrightarrow \eta=\frac{\tau_{0}}{\dot{\gamma}}+\eta_{0}
$$

Para encontrar a velocidade na região $R_{C} \leq r \leq R$, região $\delta$, tem-se que:

$$
-G \frac{r}{2}=\tau_{0}+\eta_{0} \dot{\gamma}
$$

resultando em:

$$
u_{z}(r)=-G \frac{r^{2}}{4 \eta_{0}}-\frac{\tau_{0}}{\eta_{0}} r+C_{1}
$$

A condição de contorno de velocidade nula na parede do tubo $(r=R)$ permite obter $C_{1}$ :

$$
u_{z_{2}}(r)=-\frac{G}{4 \eta_{0}}\left(r^{2}-R^{2}\right)-\frac{\tau_{0}}{\eta_{0}}(r-R)
$$

Como $\eta \rightarrow \infty$ em $r=R_{C}$, tem-se que:

$$
u_{z_{1}}(r)=-\frac{G}{4 \eta_{0}}\left(R_{C}^{2}-R^{2}\right)
$$

A vazão é obtida por:

$$
Q=2 \pi \int_{0}^{R_{C}} u_{z_{1}} r d r+2 \pi \int_{R_{C}}^{R} u_{z_{2}} r d r
$$

Lembrando que $R_{C}=R-\delta$, a vazão é calculada por:

$$
Q=\frac{\pi G R^{4}}{8 \eta_{0}}\left[1-\left(1-\frac{\delta}{R}\right)^{4}+\frac{8 \tau_{0}}{3 G R}\left(1+2\left(1-\frac{\delta}{R}\right)^{3}-\frac{1}{3}\left(1-\frac{\delta}{R}\right)^{2}\right)\right]
$$

Adimensionalizando a viscosidade intrínseca, que é obtida pela Lei de Poiseuille, pela viscosidade do fluido obtém-se:

$$
\frac{\eta_{i}}{\eta_{0}}=\left[1-\left(1-\frac{\delta}{R}\right)^{4}+\frac{8 \tau_{0}}{3 G R}\left(1+2\left(1-\frac{\delta}{R}\right)^{3}-\frac{1}{3}\left(1-\frac{\delta}{R}\right)^{2}\right)\right]^{-1}
$$

Pela eq. 2.74 observa-se que a viscosidade intrínseca adimensional para um determinado $\delta$ e $R$ é função do gradiente de pressão $(G)$ e da tensão de cisalhamento crítica $\left(\tau_{0}\right)$. 
Estes parâmetros estão relacionados entre si, pois o escoamento do fluido só acontece quando o gradiente de pressão produz uma tensão de cisalhamento superior à tensão de cisalhamento crítica. Neste caso, a região $\delta$ já leva em consideração que o escoamento acontece, no entanto o escoamento central é de um sólido com velocidade constante (eq. 2.71).

Os gráficos das figs. 2.12 e 2.13 foram obtidos para um tubo de raio igual ao utilizado no experimento de escoamento de emulsões em tubo capilar $(R=250 \mu \mathrm{m})$. Com as dimensões do tubo permaneceram constantes, variou-se a região pelo qual o fluido escoa. A magnitude do gradiente de pressão é a mesma verificada nos experimentos. A tensão de cisalhamento crítica que caracteriza o fluido de Bingham foi variada no intervalo 1 - 1000 Pa.s. Para se ter uma ideia da tensão crítica de um fluido, uma suspensão de partículas de caulinita pode ser modelada com uma viscosidade de Bingham de 0,15 Pa.s e uma tensão de cisalhamento crítica de 15 Pa (King, 2002).

A fig. 2.12 mostra a variação da viscosidade intrínseca $\left(\eta_{i}\right)$, adimensionalizada com a viscosidade do fluido de Bingham $\left(\eta_{0}\right)$, com o aumento da região $\delta$. Observa-se que o aumento da energia a fornecer ao sistema $(G)$ reflete que o fluido tem maior viscosidade. Isso é mais evidente se o sistema necessitar de uma maior energia com a diminuição de $R c$ (aumento de $\delta$ ).

A fig. 2.13 mostra que se $20 \%$ da região central do tubo fôr ocupada pelo corpo rígido, para um determinado gradiente de pressão, a viscosidade intrínseca adimensionalizada pela viscosidade crítica diminui com o aumento da tensão crítica de cisalhamento. Este resultado mostra que se o fluido de menor tensão de cisalhamento crítica começar a escoar com a mesma energia que começa a escoar um fluido com maior tensão de cisalhamento crítica, o primeiro fluido tem uma viscosidade maior do que o segundo. 


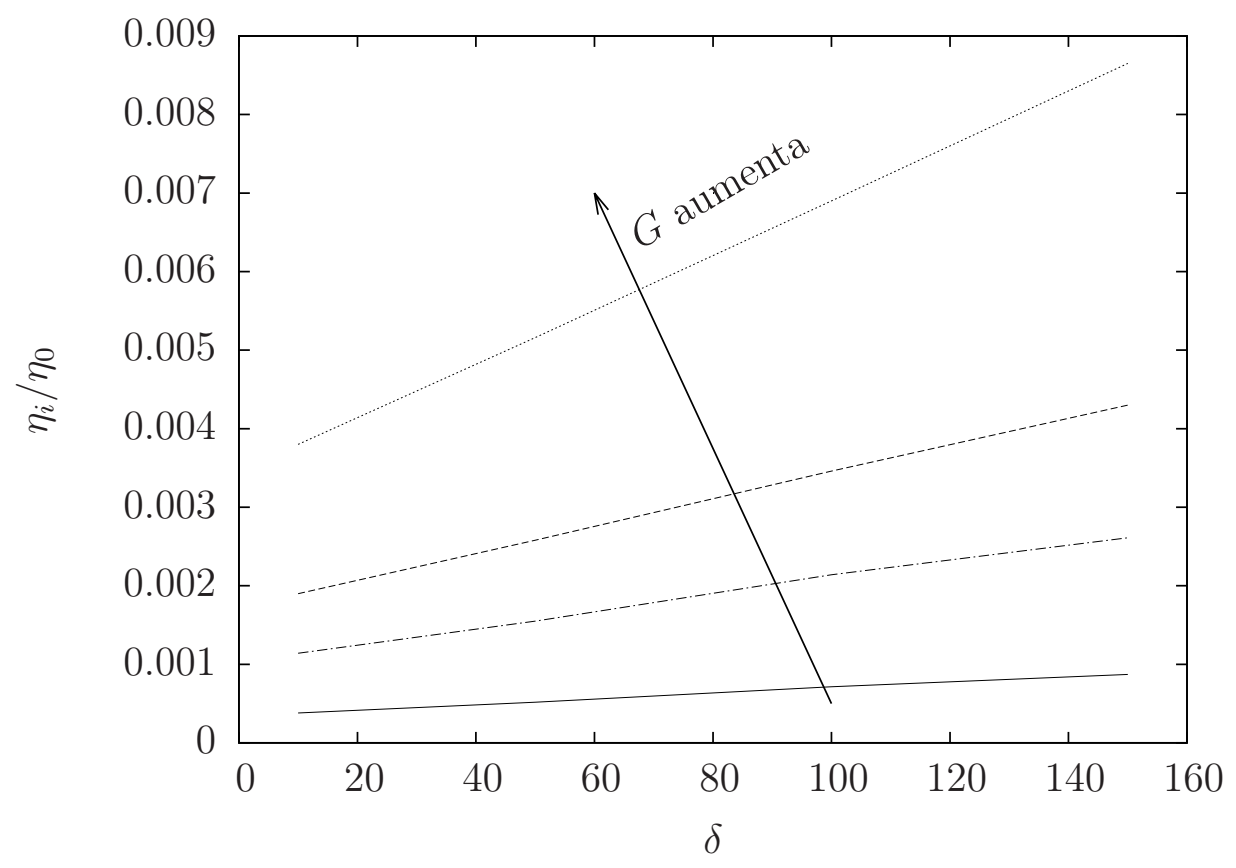

Figura 2.12: Influência do gradiente de pressão na viscosidade intrínseca adimensionalizada pela viscosidade do fluido de Bingham. Constantes: $R=250 \mu \mathrm{m}, \tau_{0}=100 \mathrm{~Pa}$. Legenda: $-G=1000 \mathrm{~Pa} / \mathrm{m},--G=3000 \mathrm{~Pa} / \mathrm{m},---G=5000 \mathrm{~Pa} / \mathrm{m}$, $\cdots G=10000 \mathrm{~Pa} / \mathrm{m}$.

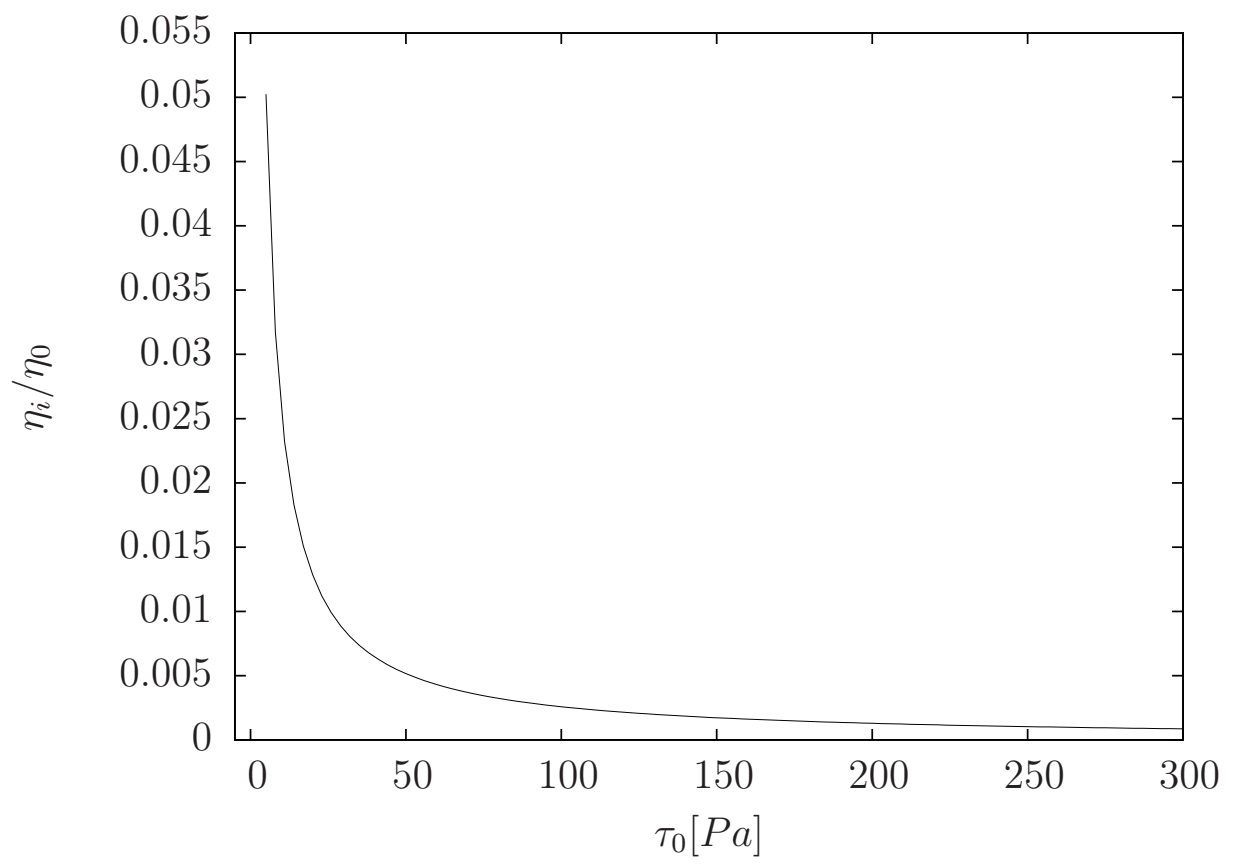

Figura 2.13: Influência da tensão de cisalhamento crítica do fluido de Bingham na viscosidade intrínseca adimensionalizada pela viscosidade do fluido de Bingham. Constantes: $R=250 \mu \mathrm{m}, \delta=50 \mu \mathrm{m}, G=5000 \mathrm{~Pa} / \mathrm{m}$. 


\subsection{ESCOAMENTO DE EMULSÃO PELA REGIÃO CENTRAL DO TUBO CAPILAR}

No escoamento de suspensões em tubo capilar em regime laminar em baixos $R e$ a fase particulada tende a migrar para regiões de menor taxa de cisalhamento. O estudo teórico aqui apresentado seguiu a mesma metodologia da dissertação de mestrado de Carvalho (2008), onde foi modelado o escoamento de sangue em microvasos. Essas regiões estão situadas no centro do tubo capilar onde existe a maior concentração de partículas fazendo com que apareça uma região livre de partículas $(\delta)$ adjacente à parede do tubo (ver fig. 2.11). Este tipo de escoamento é aqui modelado através das equações governantes do escoamento em tubo capilar. Em todos os casos estudados assume-se que um fluido Newtoniano escoa próximo à parede na região $R_{C}<r<R$. Nessa região a viscosidade do fluido é definida por $\eta_{\delta}$. Na região central a viscosidade é referida por $\eta_{C}$. Assim define-se duas regiões de escoamento:

$$
\eta(\dot{\gamma}, \phi) \frac{d u_{z}(r)}{d r}=\frac{d p}{d z} \frac{r}{2} \begin{cases}\eta(\dot{\gamma}, \phi)=\eta_{\delta} & R_{C}<r<R \\ \eta(\dot{\gamma}, \phi)=\eta_{C}(\dot{\gamma}, \phi) & 0<r<R_{C} .\end{cases}
$$

Na região central o fluido tem características não Newtonianas devido a sua viscosidade variar com $\dot{\gamma}$ e com $\phi$. Note que o modelo de $\eta(\dot{\gamma}, \phi)$ para a região central pode ser substituído pela curva de ajuste de pontos experimentais resultantes da variação da viscosidade em função de $\dot{\gamma}$ para cada $\phi$.

No primeiro modelo assumiu-se que o fluido que escoa na região central é um fluido Newtoniano imiscível com o fluido da região $\delta$. Nesse modelo o fluido central não tem concentração de partículas e é Newtoniano. No segundo modelo assumiu-se que a viscosidade do fluido central é função somente da concentração de partículas. No terceiro modelo a viscosidade é modelada por uma expressão que leva em consideração o escoamento de uma suspensão de gotas (emulsão) pela região central. 


\subsubsection{Escoamento de Fluido Viscoso pela Região Central do Tubo Capilar}

Esta situação pode retratar por exemplo o escoamento de um óleo pesado sendo a água o fluido que escoa na parede. Esse sistema diminui a resistência ao escoamento em comparação com a situação de o tubo estar completamente preenchido por óleo. Outro tipo de aplicação é encontrada na microcirculação de hemáceas. Em vasos com diâmetro menor do que $300 \mu m$ é possível observar a formação de uma camada de plasma adjacente à parede do vaso. Essa camada é sobretudo formada por plasma cuja viscosidade é próxima a da água. 

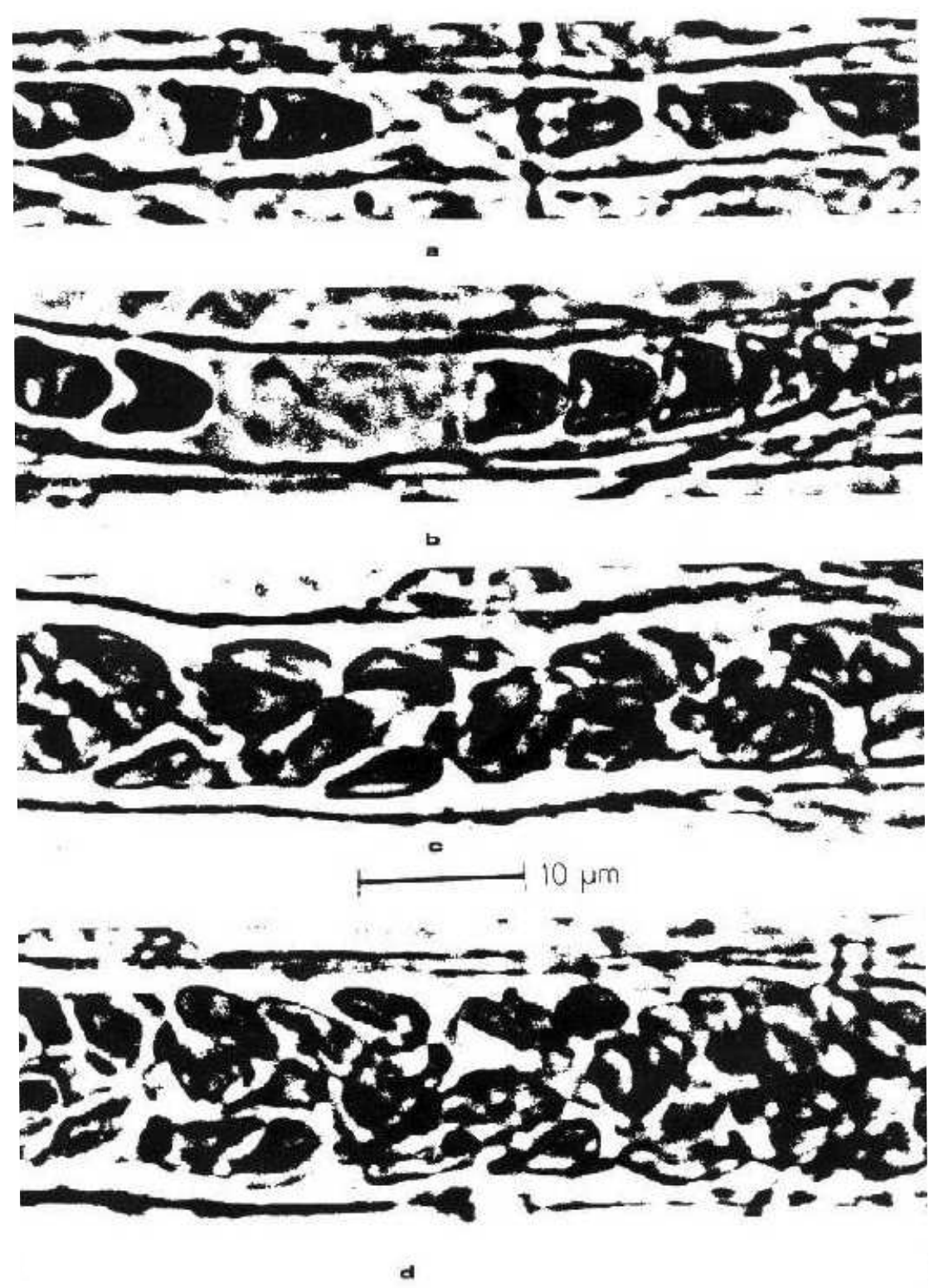

Figura 2.14: Micrografia do escoamento de glóbulos vermelhos em microvasos de diferentes diâmetros obtida na Escola de Medicina de Yale (Cunha e Lowenberg (1999)). Em a) e b) as hemácias se deslocam enfileiradas apresentando uma deformação na direção do escoamento. Aqui a dimensão do microvaso é menor que a dimensão da hemácia $(6-8 \mu \mathrm{m})$. Em c) e d) o microvaso tem dimensão $12-20 \mu \mathrm{m}$. Neste caso observa-se a formação de uma camada de plasma adjacente à parede e as células. A interação entre as células passa a ser relevante e o escoamento perde a axissimetria passando a ser tridimensional.

A expressão do perfil de velocidade para o escoamento é obtida pela integração da eq. 2.75. Para a região $\delta$ a expressão da constante de integração é obtida usando a condição de contorno de velocidade nula na parede. A constante de integração da região $R_{C}$ é calculada pela continuidade de velocidade na interface das duas regiões. Ou seja, na 
interface $u_{\delta}=u_{R_{C}}$. As expressões obtidas para a velocidade foram:

$$
\begin{cases}u_{\delta}(r)=\frac{G}{4 \eta_{\delta}}\left(R^{2}-r^{2}\right) & R_{C}<r<R \\ u_{C}(r)=\frac{G}{4 \eta_{\delta}}\left(R^{2}-R_{C}^{2}\right)+\frac{G}{4 \eta_{C}}\left(R_{C}^{2}-r^{2}\right) & 0<r<R_{C}\end{cases}
$$

A vazão é calculada pela eq. 2.44, obtendo-se:

$$
Q_{T}=\frac{\pi G}{8 \eta_{\delta}}\left(R^{4}-R_{C}^{4}\right)+\frac{\pi G}{8 \eta_{C}}\left(R_{C}^{4}\right)
$$

A viscosidade intrínseca é obtida comparando a expressão de Hagen-Poisseuille (eq. 2.46) com a eq. 2.77. A eq. 2.77 é reescrita de forma a destacar o termo da viscosidade intrínseca:

$$
Q_{T}=\frac{\pi R^{4} G}{8}\left[\frac{1}{\eta_{\delta}}\left(1-\left(\frac{R_{C}}{R}\right)^{4}\right)+\frac{1}{\eta_{C}}\left(\frac{R_{C}}{R}\right)^{4}\right]
$$

Lembrando que $R_{C}=R-\delta$ obtém-se a viscosidade intrínseca adimensionalizada pela viscosidade do fluido que escoa pela região adjacente do capilar:

$$
\frac{\eta_{i}}{\eta_{\delta}}=\left[1-\left(1-\frac{\delta}{R}\right)^{4}+\frac{\eta_{\delta}}{\eta_{C}}\left(1-\frac{\delta}{R}\right)^{4}\right]^{-1} .
$$

A fig. 2.15 mostra o resultado da eq. 2.79 no caso em que o fluido da região central tem uma viscosidade quatro vezes maior do que o fluido que escoa adjacente à parede do tubo capilar. A fig. 2.16 mostra a queda da viscosidade com o aumento de $\delta$ no caso em que $R=300 \mu \mathrm{m}$. O resultado mostra que quanto maior for a região $\delta$ menor a viscosidade intrínseca. Adicionalmente,verifica-se que, a viscosidade intrínseca é sempre menor que a viscosidade do fluido da região central. Isto mostra que o fluido de menor viscosidade, localizado na região $\delta$ age como se fosse um lubrificante, ajudando o escoamento do fluido de maior viscosidade. 


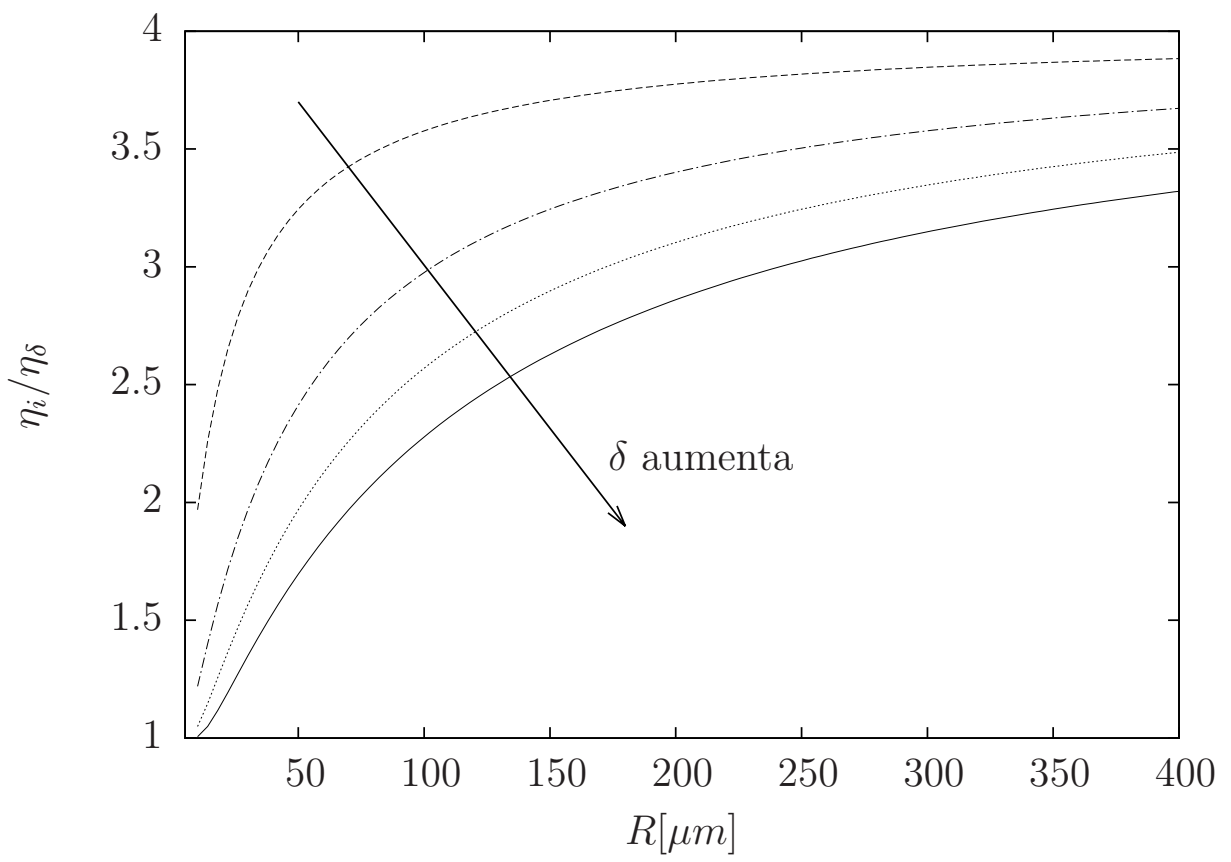

Figura 2.15: Influência da camada $\delta$ na viscosidade intrínseca no caso em que $\eta_{\delta}=$ $1 \times 10^{-3}$ Pa.s, $\eta_{C}=4 \times 10^{-3}$ Pa.s. Diminuição da viscosidade intrínseca com o aumento da região $\delta$. Fluido que escoa adjacente à parede do tubo age como se fosse um lubrificante. Legenda: - - $\delta=1,-\cdot-\delta=3, \cdots \delta=5,-\delta=7$.

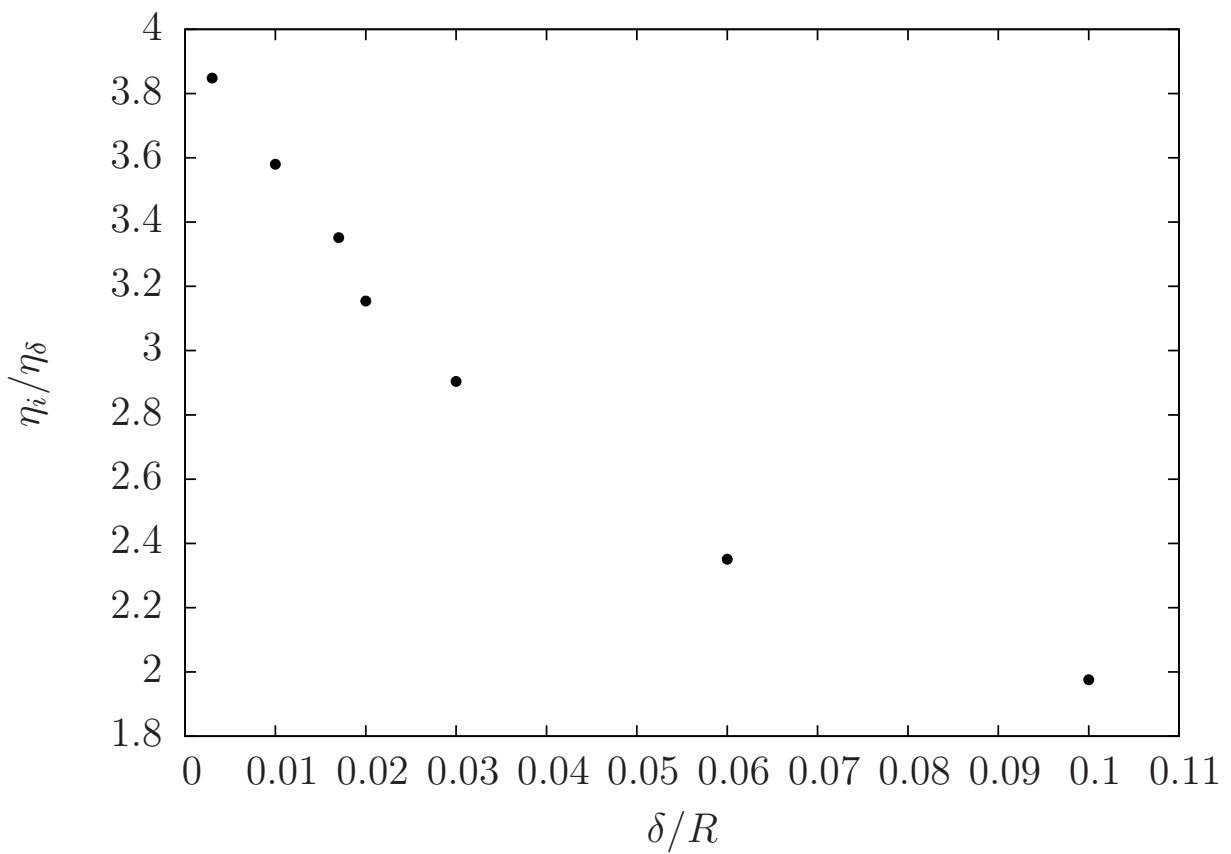

Figura 2.16: Influência da camada $\delta$ no platô da viscosidade intrínseca no caso em que $\eta_{\delta}=1 \times 10^{-3}$ Pa.s, $\eta_{C}=4 \times 10^{-3}$ Pa.s e $\delta$ é: $1,0,3,0,5,0,7,0,10,020,0$ e 30, 0 $\mu \mathrm{m}$. Neste caso o $R=300 \mu \mathrm{m}$. 


\subsubsection{Escoamento de Fluido Não Newtoniano pela Região Central do Tubo Capilar}

O fluido que escoa na região central pode ser um fluido com comportamento nãoNewtoniano do tipo uma suspensão de partículas. A viscosidade desse fluido pode ser modelada pela Lei de Potência. Como já foi referido este modelo captura somente a região da diminuição da viscosidade com o aumento da taxa de cisalhamento. Pelo modelo da Lei de Potência a viscosidade é expressa como:

$$
\eta=m \dot{\gamma}^{n-1}
$$

Propõem-se que $m$ seja:

$$
m=C f(\phi),
$$

em que $f(\phi)=(1+\phi)^{k}$. O termo $(1+\phi)^{k}$ pode ser decomposto por uma série binominal da qual resulta que $(1+\phi)^{k}=1+k \phi+O\left(\phi^{2}\right)$. Se $k=5 / 2$ obtém-se a viscosidade de Einstein para esferas rígidas (Einstein A. (1985)). A constante $C$ toma o valor da viscosidade da região central. Se no expoente da taxa de cisalhamento o parâmetro $n$ for unitário e se $\phi=0$ as expressões do perfil de velocidade, vazão e viscosidade intrínseca são iguais às obtidas no caso anterior. As expressões seguintes retratam o caso em que o fluido na região central é uma suspensão cuja viscosidade do fluido base é diferente da viscosidade do fluido que escoa na região adjacente à parede.

$$
\begin{gathered}
u_{R_{C}}(r)=\frac{G}{4 \eta_{\delta}}\left(R^{2}-R_{C}^{2}\right)+\frac{G}{4 \eta_{C}(1+k \phi)}\left(R_{C}^{2}-r^{2}\right), \\
Q_{T}=\frac{\pi R^{4} G}{8}\left[\frac{1}{\eta_{\delta}}\left(1-\left(\frac{R_{C}}{R}\right)^{4}\right)+\frac{1}{\eta_{C}(1+k \phi)}\left(\frac{R_{C}}{R}\right)^{4}\right], \\
\frac{\eta_{i}}{\eta_{\delta}}=\left[1-\left(1-\frac{\delta}{R}\right)^{4}+\frac{\eta_{\delta}}{\eta_{C}(1+k \phi)}\left(1-\frac{\delta}{R}\right)^{4}\right]^{-1} .
\end{gathered}
$$

Quando a constante $C$ toma o valor da viscosidade da região $\delta$ e $n$ o valor unitário, a situação retratada é a do caso em que partículas da suspensão migram para a região 
central do escoamento, em que o fluido base da suspensão é o fluido Newtoniano que escoa adjacente à parede do tubo. Para atender ao caso em que o fluido da região central tem como fluido base o fluido que escoa na região adjacente à parede do tubo substitui-se $\eta_{C}$ por $\eta_{\delta}$.

$$
\frac{\eta_{i}}{\eta_{\delta}}=\left[1-\left(1-\frac{\delta}{R}\right)^{4}+\frac{1}{(1+k \phi)}\left(1-\frac{\delta}{R}\right)^{4}\right]^{-1}
$$

A fig. 2.17 retrata o caso de uma suspensão de partículas rígidas que escoa pela região central do escoamento, cujo fluido base (água) é o fluido Newtoniano que escoa adjacente à parede do tubo (eq. 2.85). Pelo gráfico prevê-se um aumento da viscosidade com o aumento da fração volumétrica de partículas. A fig. 2.18 confirma o resultado da fig. 2.17 mostrando um aumento de $\eta_{i} / \eta_{\delta}$ com o aumento da fração volumétrica para a situação em que $R=300 \mu m$ e $\delta=7 \mu m$.

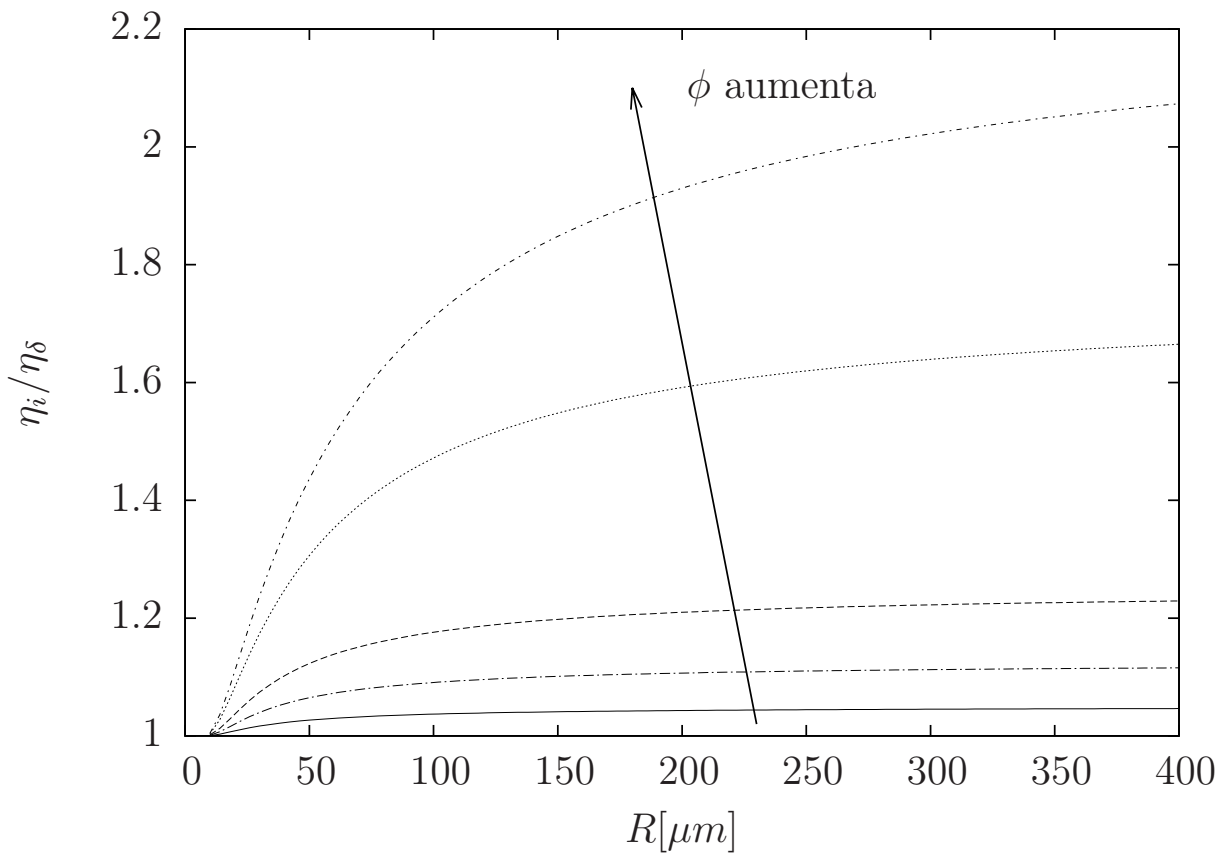

Figura 2.17: Influência de $\phi$ na viscosidade intrínseca. A fração volumétrica variou de $0,02-0,5$. A região livre de partícula foi mantida constante $(\delta=7 \mu m)$ e $k=5 / 2$. Legenda: $-\phi=0,02 ;-\cdots \phi=0,05 ;-\longrightarrow \phi=0,1 ; \cdots \phi=0,3 ;-\cdot \phi=0,5$. 


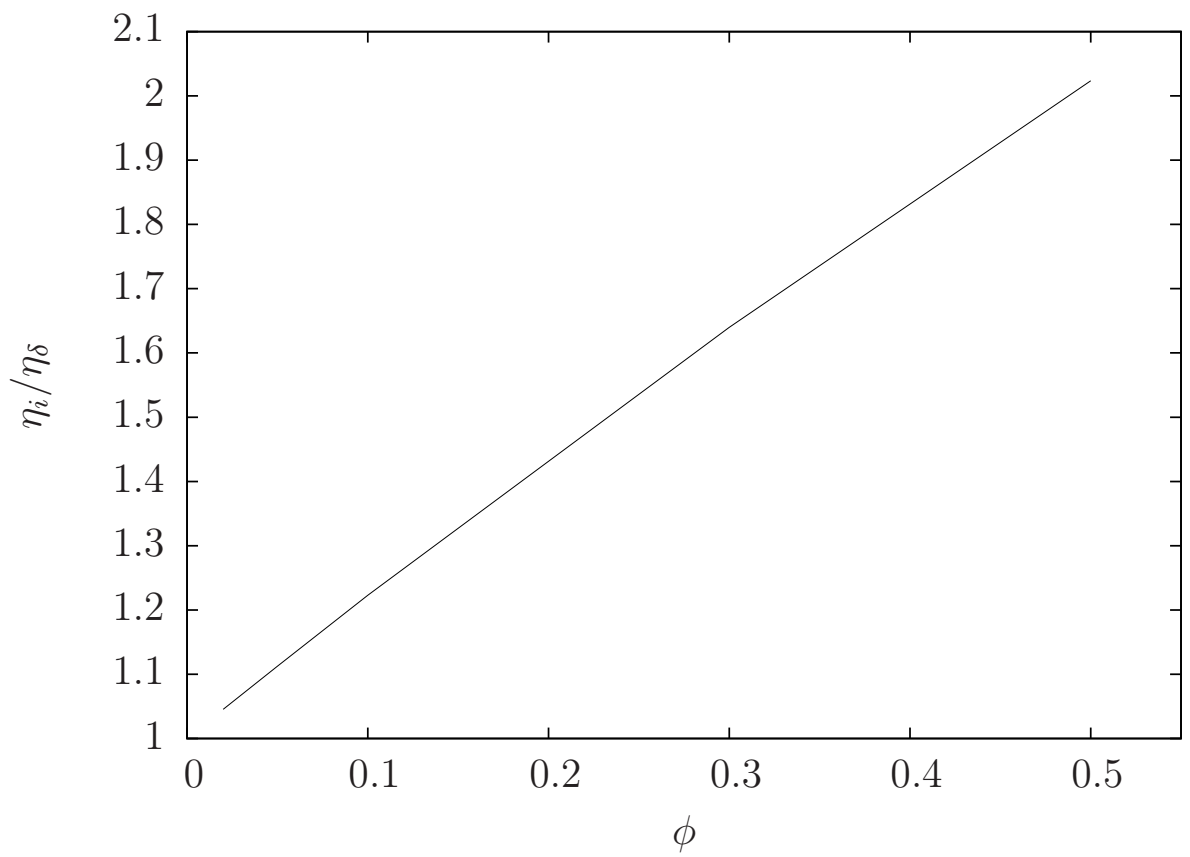

Figura 2.18: Aumento Linear da viscosidade com o aumento da concentração para o caso em que $R=300 \mu \mathrm{m}$ e $\delta=7 \mu \mathrm{m}$.

No caso mais geral em que $n \neq 1$ e $\phi>0$ as expressões obtidas, respectivamente para a: velocidade, vazão e viscosidade intrínseca são as seguintes:

$$
\begin{gathered}
u_{R_{C}}(r)=\frac{G}{4 \eta_{\delta}}\left(R^{2}-R_{C}^{2}\right)+\left(\frac{G}{2 \eta_{C}}\right)^{1 / n} \frac{R_{C}^{1 / n}-r^{1 / n+1}}{1 / n+1} \\
Q_{T}=\frac{\pi G}{8 \eta_{\delta}}\left(R^{4}-R_{C}^{4}\right)+\frac{2 \pi R_{C}^{3}}{2 / n+6}\left(\frac{G R_{C}}{2 \eta_{C}(1+k \phi)}\right), \\
\frac{\eta_{i}}{\eta_{\delta}}=\left[1-\left(1-\frac{\delta}{R}\right)^{4}+\frac{16 \eta_{\delta}}{2 / n+6} \frac{G^{1 / n-1}}{\left(2 \eta_{c}(1+k \phi)\right)^{1 / n}} \frac{(R-\delta)^{1 / n+3}}{R^{4}}\right]^{-1} .
\end{gathered}
$$

É de notar que as expressões para o primeiro caso são obtidas quando $n=1$ e $\phi=0$. Se $n=1$ e $\phi>0$ são obtidas as expressões do segundo caso.

Neste modelo explora-se a influência do gradiente de pressão $(G)$, da fração volumétrica $(\phi)$ e de $n$ na viscosidade intrínseca. Na fig. 2.19 verifica-se que a viscosidade decresce com o aumento do gradiente de pressão para o mesmo raio. Este decréscimo começa a ser perceptível a partir de $R=60 \mu \mathrm{m}$. Isto acontece porque para um tubo de menor raio o fluido teria uma maior ação da parede e assim o efeito do gradiente de pressão tem que ser muito maior para produzir escoamento. É o que acontece basicamente na rede 
de microcirculação. Pelos resultados destaca-se que o raio para o qual a viscosidade é máxima para os diferentes gradientes de pressão é o seguinte: para $G=1,0$ e raio $386 \mu m$ a viscosidade foi de 7,51 , para $G=1,5$ e raio $314 \mu m$ a viscosidade foi de 6,21 , para $G=2,0$ e raio $270 \mu m$ a viscosidade foi de 5,43 , para $G=2,5$ e raio $242 \mu m$ a viscosidade foi de 4,91.

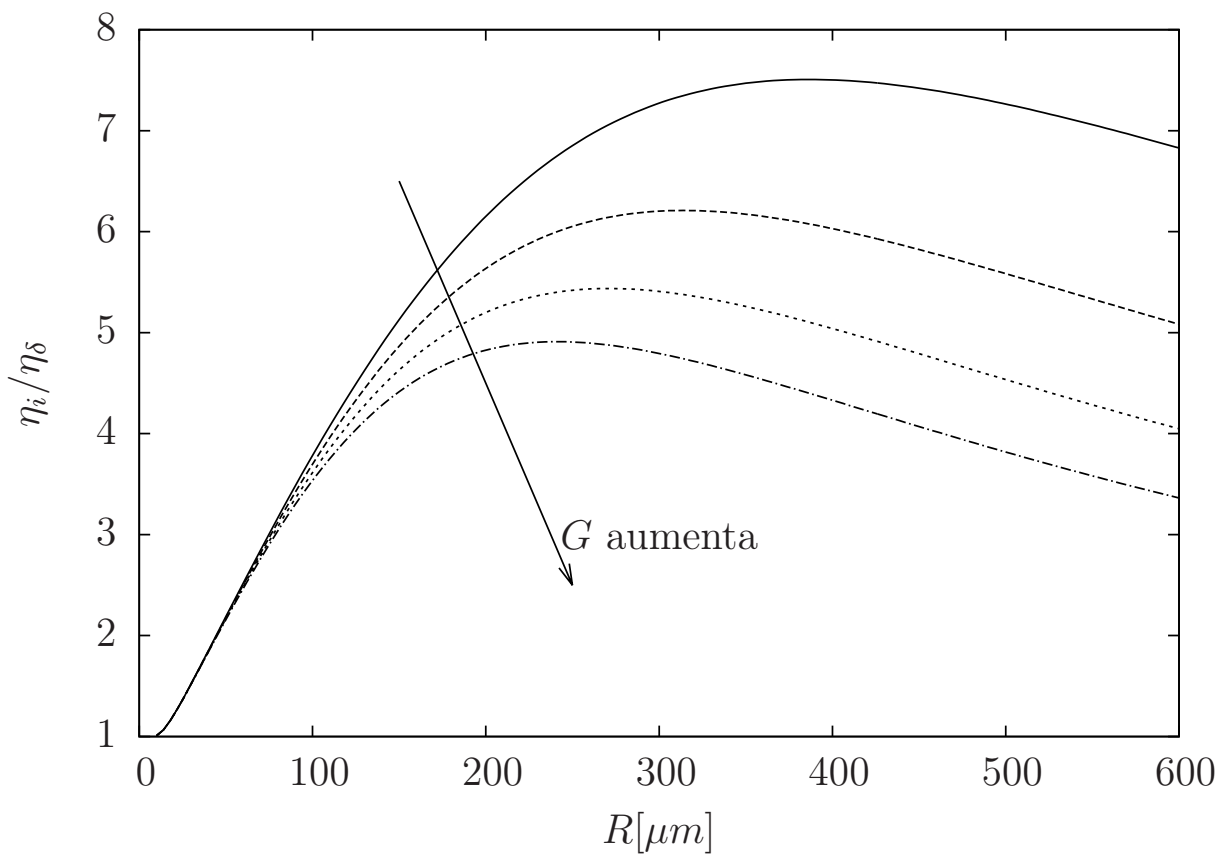

Figura 2.19: Influência do gradiente de pressão $(G)$ na viscosidade intrínseca. A viscosidade diminui com o aumento de $G$. Esse efeito é notório quando $R>60 \mu \mathrm{m}$. Legenda: $-G=1,0 ; \cdots G=1,5 ; \cdots G=2,0 ; \ldots G=2,5$. Constantes do modelo: $\phi=0,20, n=0,5$ e $\delta=7 \mu m, k=5 / 2$.

A fig. 2.20 mostra o esperado, o aumento da viscosidade com o aumento da fração volumétrica. Este aumento começa a ser visto a partir de um tubo de raio $60 \mu \mathrm{m}$. Pelos resultados destaca-se que o raio para o qual a viscosidade é máxima para as diferentes frações volumétricas é o seguinte: para $\phi=0,05$ e raio $234 \mu \mathrm{m}$ a viscosidade foi de 4,77 , para $\phi=0,1$ e raio $262 \mu \mathrm{m}$ a viscosidade foi de 5,25, para $\phi=0,3$ e raio $366 \mu m$ a viscosidade foi de 7,17 , para $\phi=0,5$ e raio $474 \mu m$ a viscosidade foi de 9,10. Os resultados do modelo mostram uma pequena diminuição da viscosidade com relação ao valor máximo da viscosidade com o aumento do raio, para as frações volumétricas menores que 0,5 . Tal pode ser devido a que após o raio crítico, onde se verifica a maior viscosidade, as partículas apresentam um maior espaço entre si e como tal são mais facilmente transportadas pelo escoamento. Isso faz com que a viscosidade possa apresentar uma queda. A fig. 2.21 mostra a influência da espessura $\delta$ quando 
o raio do tubo é de $60 \mu \mathrm{m}$. Observa-se a queda da viscosidade com o aumento de $\delta$. Quando $\delta / R>>1$ a viscosidade tende à viscosidade do fluido que escoa na região $\delta$.

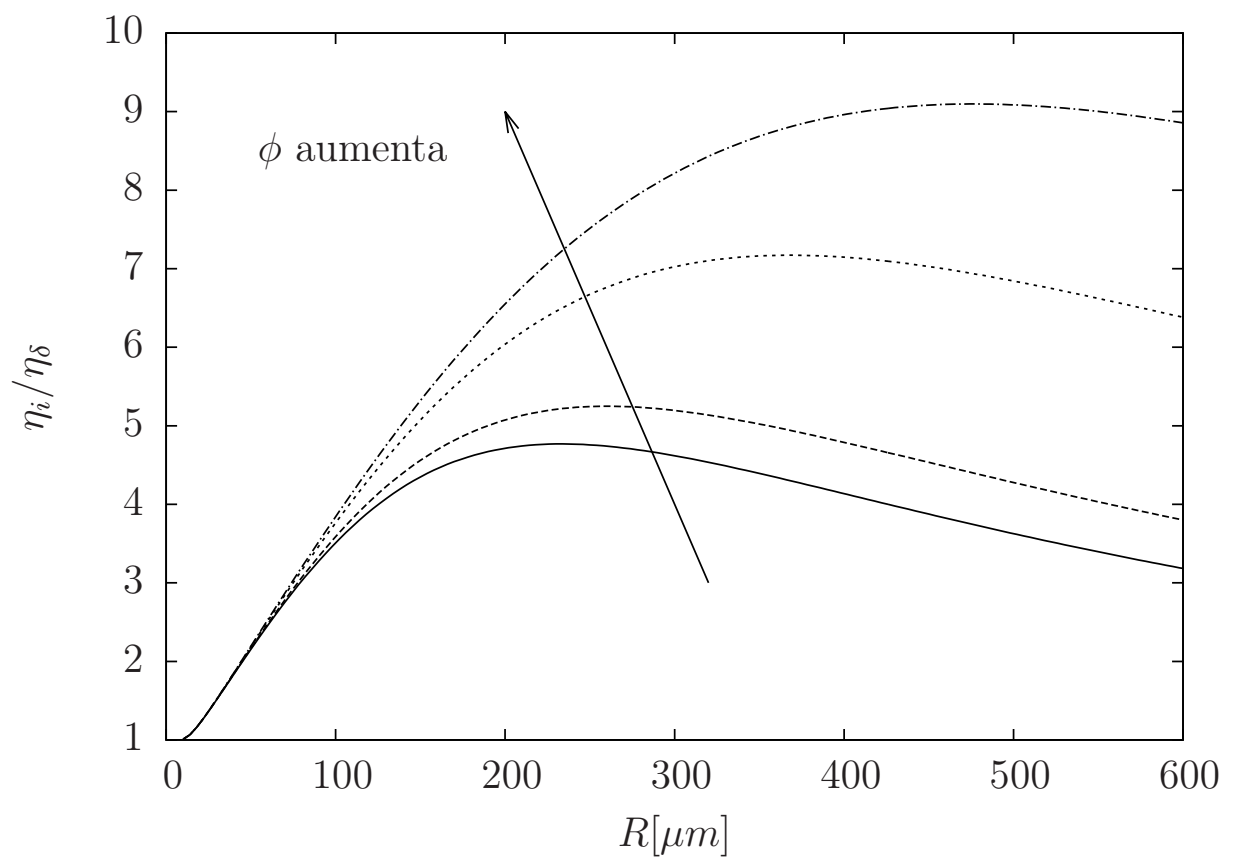

Figura 2.20: Influência de $\phi$ na viscosidade intrínseca. A viscosidade aumenta com a concentração de partículas. Esse efeito é notório quando $R>60 \mu \mathrm{m}$. Legenda: $-\phi=0,05 ; \cdots \phi=0,1 ; \cdots \phi=0,3 ;-\cdots \phi=0,5$ Constantes do modelo: $G=1,5, n=0,5$ e $\delta=7 \mu m, k=5 / 2$.

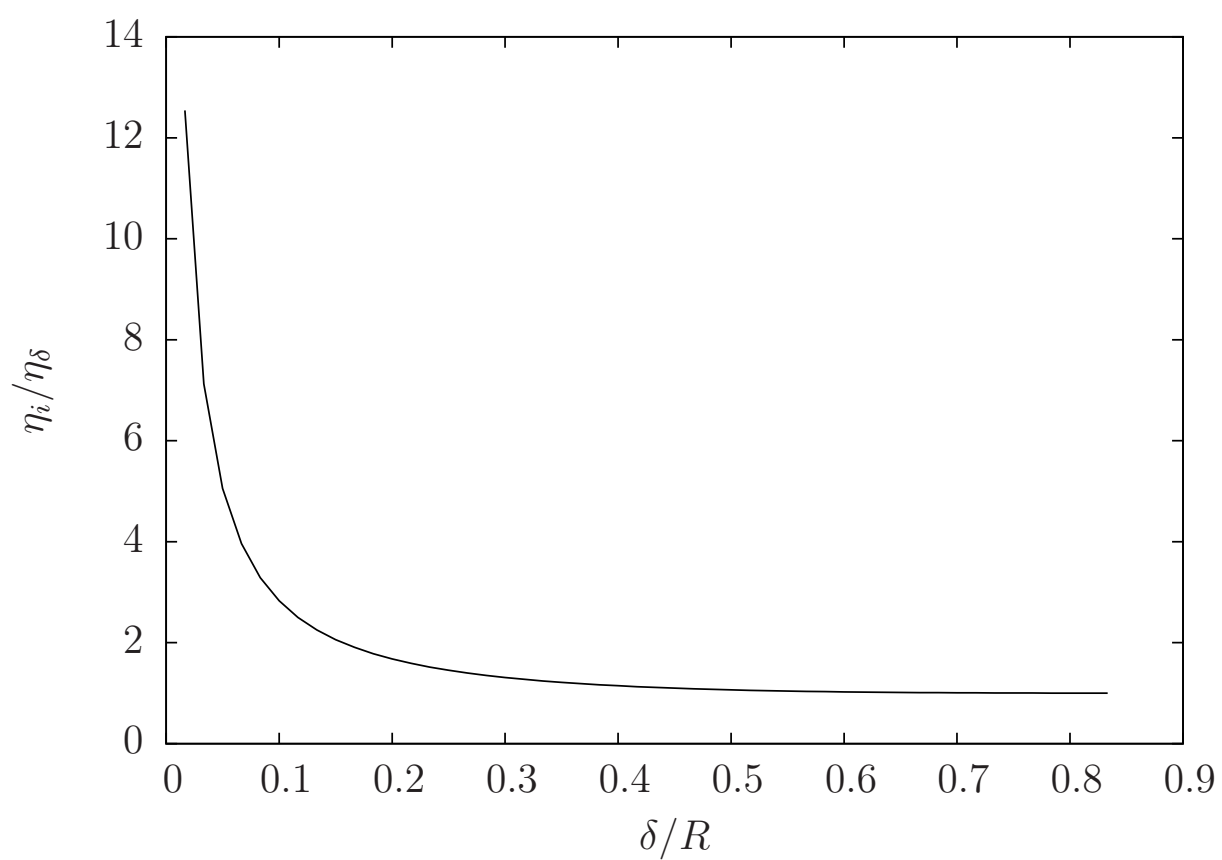

Figura 2.21: Influência da espessura $\delta$ na viscosidade para $R=60 \mu \mathrm{m}$. Constantes: $G=1,5, \phi=0,2, n=0,5$. Diminuição da viscosidade com o aumento de $\delta$ (ação de lubrificante). 
Os gráficos das fig. 2.22 e 2.23 mostram um comportamento não linear da viscosidade em função do raio do tubo quando $n<1$. A fig. 2.22 apresenta o aumento da viscosidade para diferentes valores do parâmetro $n$ (diferentes fluidos no núcleo do tubo). Observa-se que quanto mais próximo da unidade estiver o parâmetro $n$ (fluido Newtoniano) menor é a variação da viscosidade, mostrando a inibição do efeito pseudoplástico do fluido. A fig. 2.23 mostra uma saturação do efeito pseudo-plástico quando $(n \rightarrow 0)$.

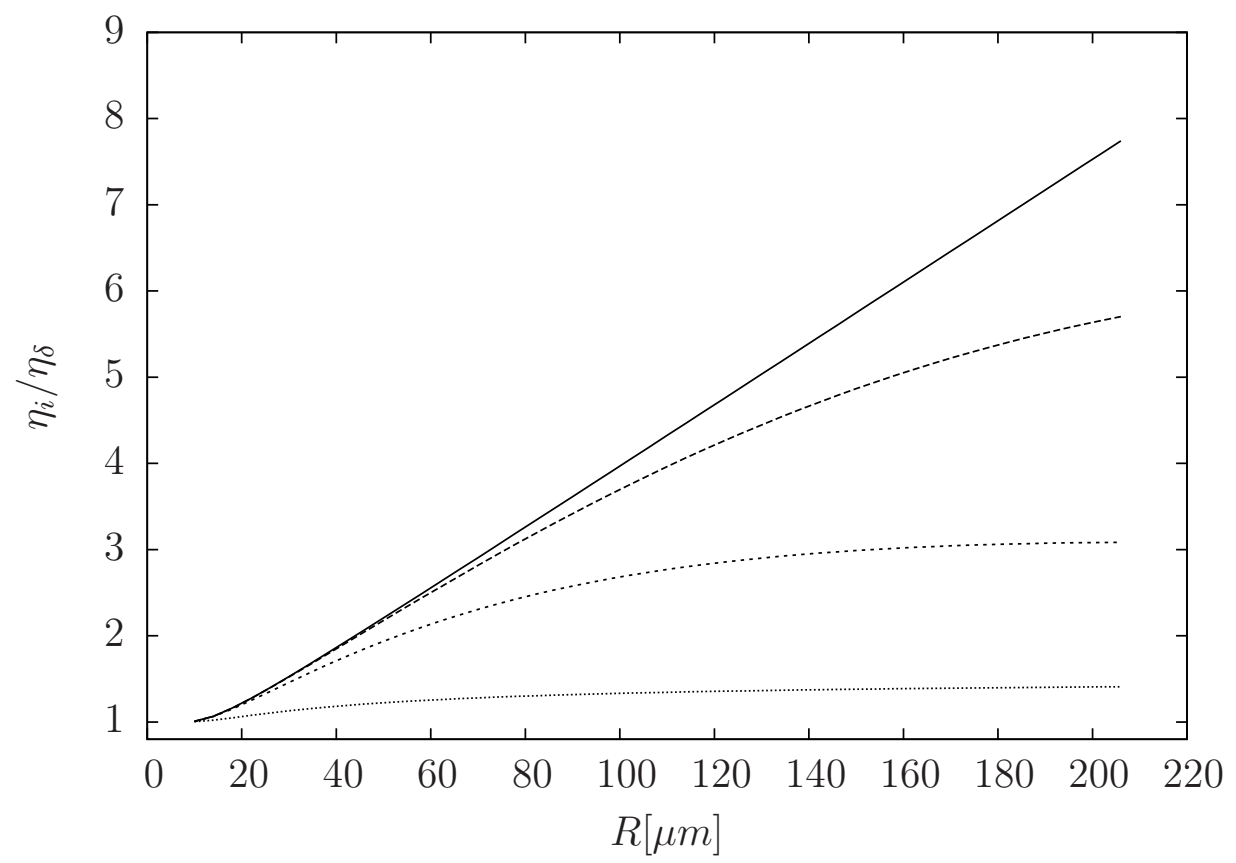

Figura 2.22: Influência de $n$ na viscosidade intrínseca. Quando $n \rightarrow 1$ mais afinante se torna o fluido. $n$ variou de $0,2-1,0$ para valor constante de $G=1,5, \phi=0,2$ e $\delta=7 \mu m$. 


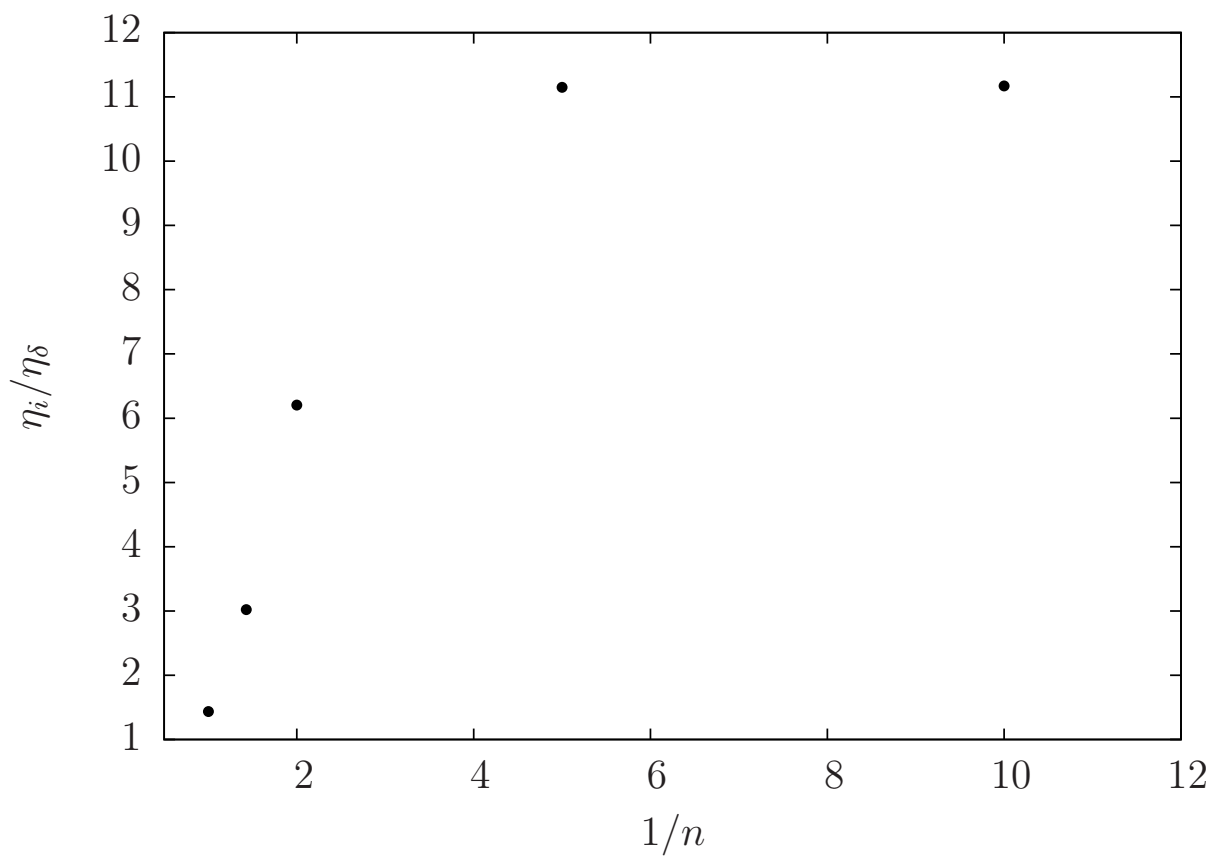

Figura 2.23: Influência do parâmetro $n$ na viscosidade intrínseca para quando $R=$ $300 \mu \mathrm{m}$. Quanto maior for $1 / n(n \rightarrow 0)$ a viscosidade tende a estabilizar em um valor indicando o valor absoluto do efeito pseudo-plástico do fluido.

\subsubsection{Escoamento de Emulsão de Alta Razão de Viscosidade e Baixa Fração Volumétrica pela Região Central do Tubo Capilar}

Para modelar o escoamento de uma emulsão diluída $(\phi<0,3)$ de altas razões de viscosidade pela região central do tubo a viscosidade do fluido na região central é dada pela viscosidade efetiva de Taylor (Taylor (1932)):

$$
\frac{\eta_{e}}{\eta}=1+\phi\left(\frac{1+5 / 2 \lambda}{1+\lambda}\right)
$$

em que $\lambda$ é a razão de viscosidade da gota pela viscosidade do fluido carreador. Considerando gotas de altas razões de viscosidade $(\lambda>>1)$ obtém-se após uma expansão da eq. 2.89 por uma série binomial a seguinte aproximação:

$$
\frac{\eta_{e}}{\eta}=1+\phi\left(\frac{5}{2}-\frac{3}{2 \lambda}\right) .
$$


Os resultados seguintes foram obtidos pela expressão:

$$
\frac{\eta_{i}}{\eta_{\delta}}=\left[1-\left(1-\frac{\delta}{R}\right)^{4}+\frac{16 \eta_{\delta}}{2 / n+6} \frac{G^{1 / n-1}}{(2 f(\phi))^{1 / n}} \frac{(R-\delta)^{1 / n+3}}{R^{4}}\right]^{-1}
$$

em que $f(\phi)$ é dado pela eq. 2.89 ou pela eq. 2.90 dependendo do caso.

A eq. 2.90 pode ser usada para frações volumétricas até 30\%, mesmo que as suspensões desta ordem de fração volumétrica possam ser consideradas quase concentradas. Os altos valores de razão de viscosidade inibem a deformação da gota fazendo com que a interação entre gotas produza um efeito menor do que a deformação das gotas originada pelas tensões de cisalhamento devido ao escoamento. Desta forma as suspensões com altas razões de viscosidade $(\lambda \geq 5)$ e $\phi<30 \%$ podem ser consideradas sistemas diluídos. Desta forma a eq. 2.89 é indicada para $\lambda<5$ e a eq. 2.90 é indicada para $\lambda \geq 5$ e $\phi<30 \%$.

A fig. 2.24 foi obtida pela eq. 2.91 em que $f(\phi)$ é dada pela eq. 2.89. Observa-se que o efeito de variação da razão de viscosidade não foi significativo para a variação da viscosidade com o raio do tubo. A máxima viscosidade $(4,50)$ se dá para o tubo de raio de $220 \mu \mathrm{m}$. Nota-se que mesmo para uma baixa fração volumétrica $(0,03)$ se consegue capturar o comportamento de escoamento de microcirculação. Para raios superior a $220 \mu \mathrm{m}$ a espessura $\delta$ começa a ser sentida pelo escoamento, fazendo com que a viscosidade diminua com o aumento do raio do tubo. A fig. 2.25 foi obtida pela eq. 2.89. Observa-se um pequeno aumento da viscosidade em função do pequeno aumento da fração volumétrica. Tal era de se esperar pois existe um maior número de partículas na suspensão. Capturou-se um máximo de viscosidade para o raio de ordem de $200 \mu m$ situando-se no regime de microcirculação. O aumento da viscosidade até um máximo devido a variação do raio do tubo é explicado pelo fato de que para raios até $200 \mu m$ o efeito lubrificante da camada $\delta$ ainda não foi sentido pelo sistema. 


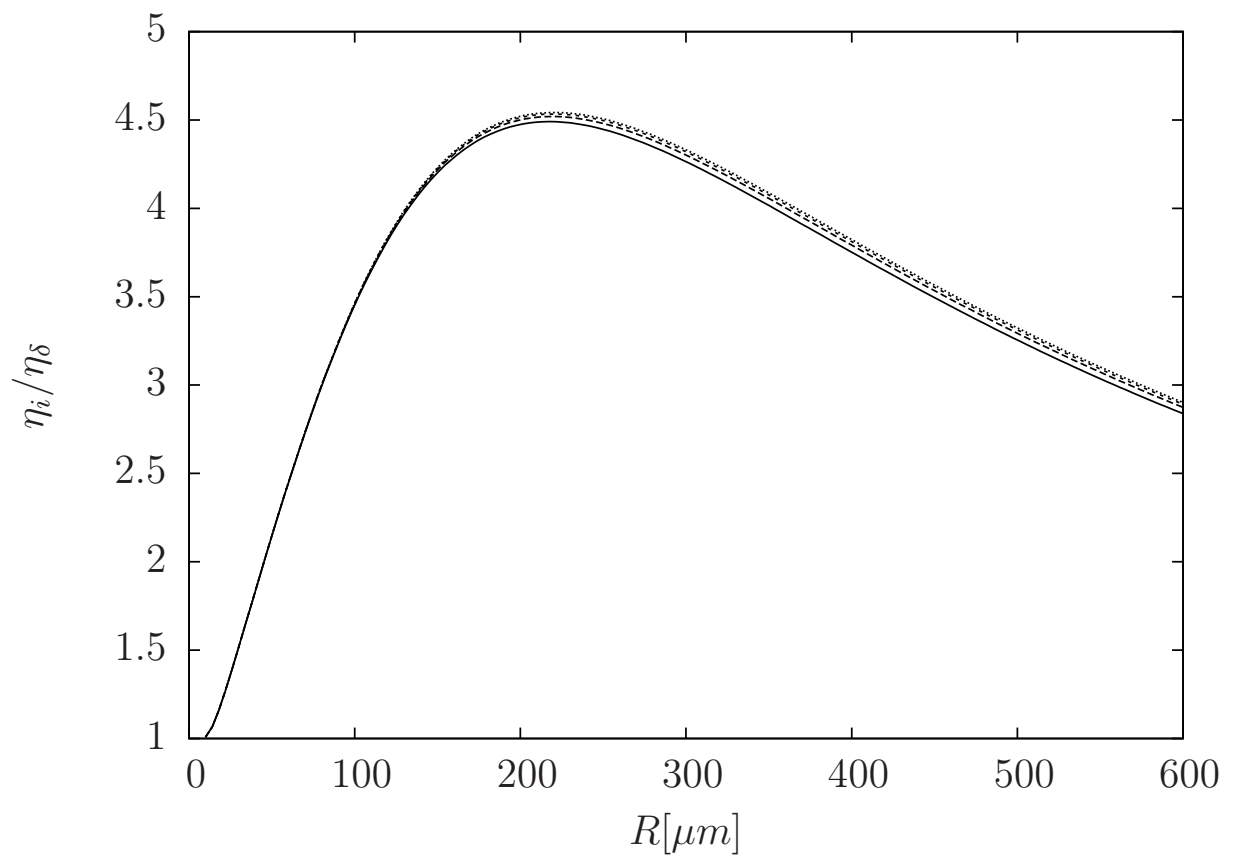

Figura 2.24: Influência da razão de viscosidade na viscosidade intrínseca. Observa-se que a viscosidade intrínseca se manteve constante para os valores as diferentes razões de viscosidade $(\lambda=1,2,3,4)$. O valor da máxima viscosidade é para o tubo de raio $220 \mu \mathrm{m}$. Constantes: $\phi=0,03, \delta=7 \mu \mathrm{m}, G=1,5, n=0,5$. Legenda: $-\lambda=1$, $--\lambda=2,--\lambda=3, \cdot \cdot \cdot \lambda=4$.

A fig. 2.26 foi obtida pela eq. 2.91 em que $f(\phi)$ é dada pela eq. 2.90 e mostra a influência da razão de viscosidade na viscosidade intrínseca. Observa-se que a máxima viscosidade acontece para raios em torno de $90 \mu \mathrm{m}$ em coerência com sistemas de microcirculação. A fig. 2.27 foi obtida pela eq. 2.90 e mostra a influência da fração volumétrica na viscosidade intrínseca. A viscosidade máxima situa-se entre o raio de $46 \mu m(\phi=0,1)$ e o de $146 \mu m(\phi=0,30)$. Este resultado mostra uma maior influência na viscosidade da fração volumétrica com relação à razão de viscosidade. Isso está de acordo com outros autores que indicam que em sistemas particulados com razão de viscosidade superior a cinco as gotas podem ser consideradas partículas rígidas. Assim, para razões de viscosidade superior a cinco a viscosidade da suspensão será mais afetada pelo aumento da fração volumétrica do que pelo aumento de $\lambda$. Com o aumento da fração volumétrica o espaço entre as gotas é diminuído dificultando portanto a passagem do fluido e também o movimento deste pelo tubo, provocando um aumento da viscosidade. Mais ainda, a não deformação das gotas dificulta a passagem do fluido uma vez que toda a tensão de cisalhamento na superfície da gota é transmitida de volta para o fluido. A fig. 2.28 mostra para que raios a viscosidade é máxima em 


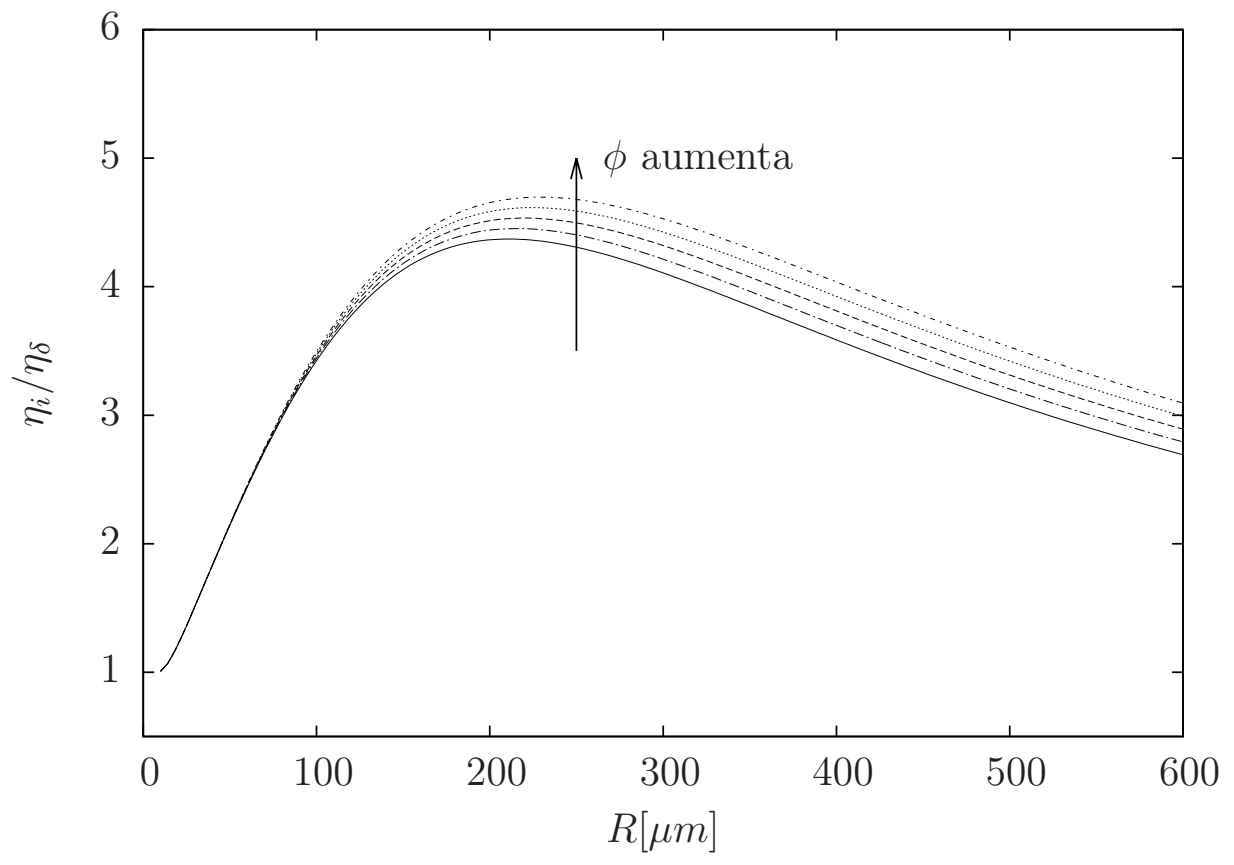

Figura 2.25: Influência da fração volumétrica na viscosidade intrínseca. A máxima viscosidade foi de 4,69 para a fração volumétrica 0,05 no raio de $230 \mu \mathrm{m}$. A mínima viscosidade foi de 4,37 para a fração volumétrica 0,01 no raio de 210 . Constantes: $\lambda=3$, $\delta=7 \mu m, G=1,5, n=0,5$. Legenda: $-\phi=0,01,-\longrightarrow \phi=0,02-\longrightarrow \phi=0,03$ $, \cdots \phi=0,04,-\cdots \phi=0,05$.

diferentes frações volumétricas. O aumento da viscosidade até a um máximo com o aumento do raio é provocado pela resistência do escoamento devido à alta fração volumétrica para um determinado raio. A diminuição da viscosidade para uma certa fração volumétrica após ser atingido o seu valor máximo se deve ao aumento do raio que com isso aumenta o espaço entre as gotas, promovendo uma maior facilidade de escoamento. 


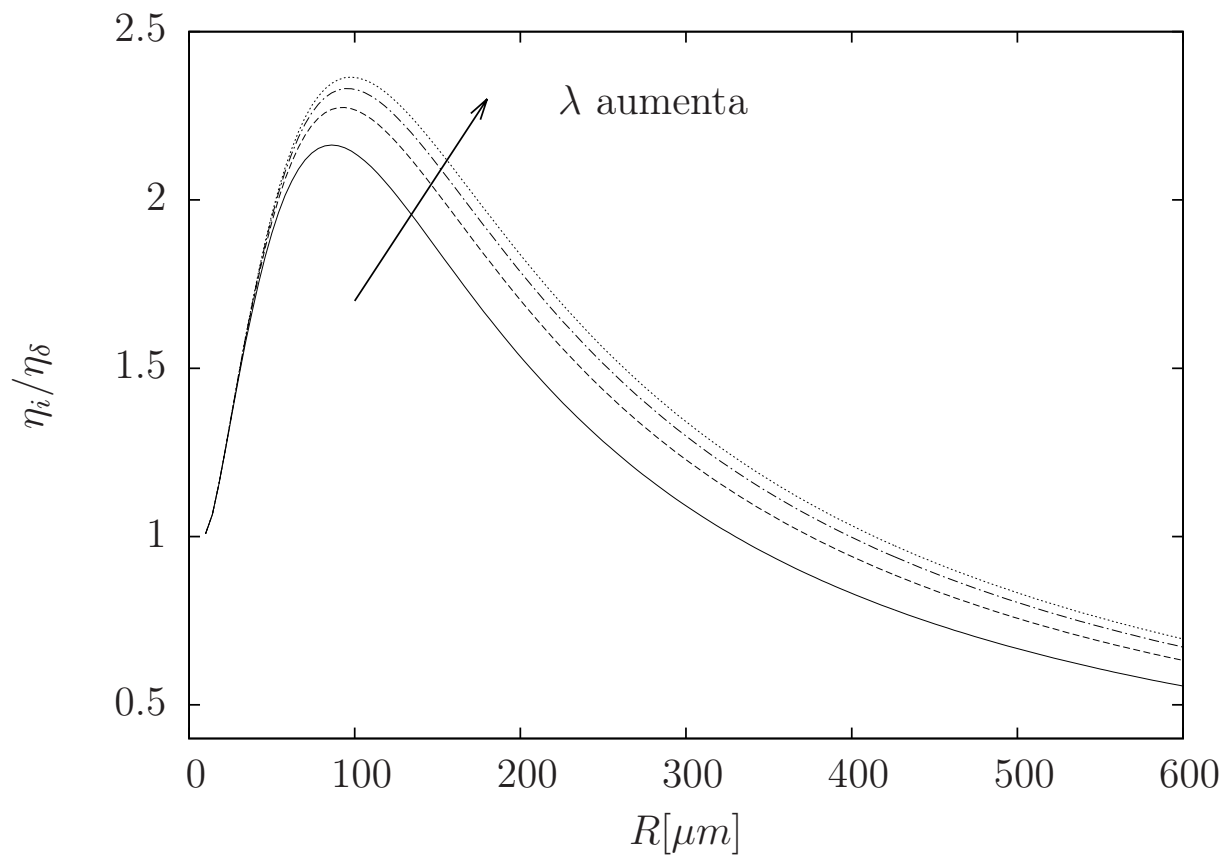

Figura 2.26: Influência da razão de viscosidade na viscosidade intrínseca. Para todos as razãoes de viscosidade a máxima viscosidade se verificou em raios em torno de $90 \mu \mathrm{m}$. Constantes: $\phi=0,2, \delta=7 \mu m, G=1,5$. Legenda: $-\lambda=5,---\lambda=10$, $-\cdot \lambda=20, \cdots \lambda=50$.

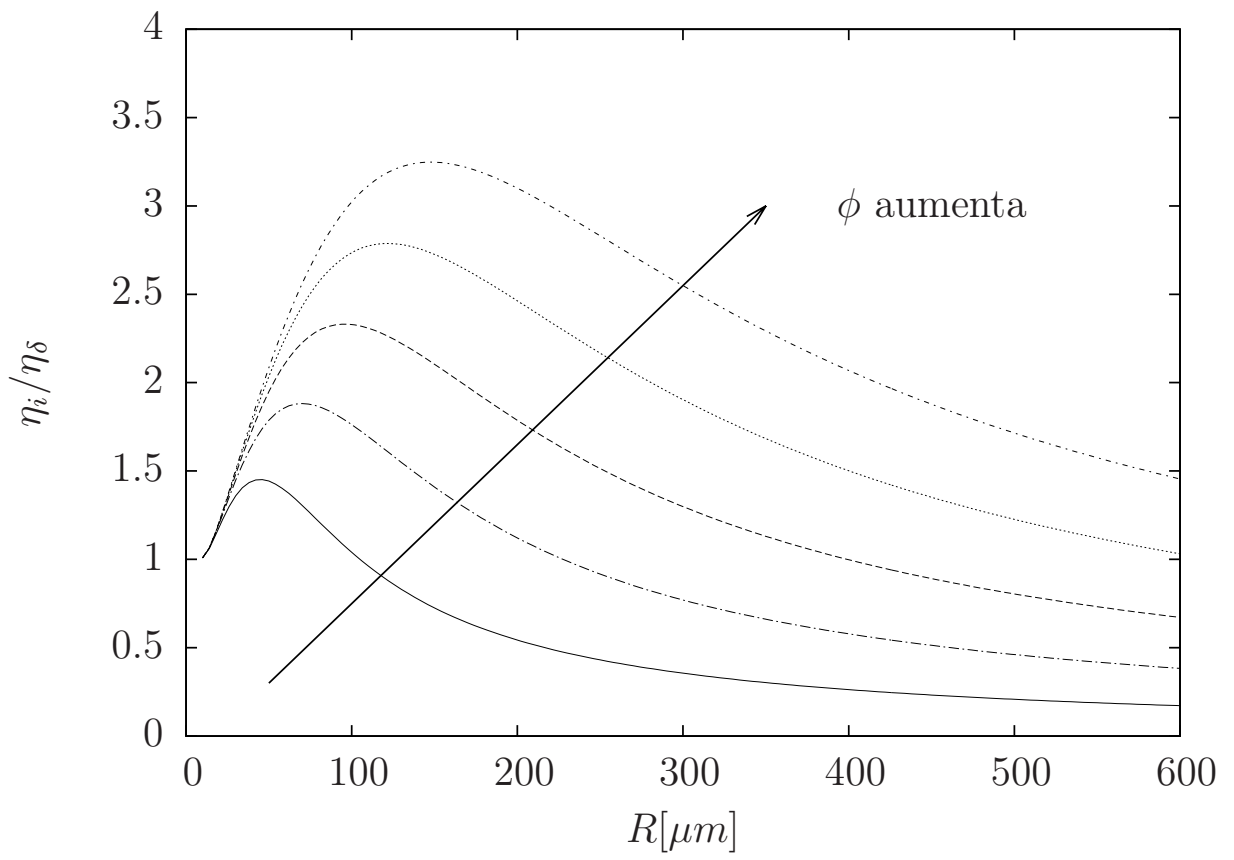

Figura 2.27: Influência da fração volumétrica na viscosidade intrínseca. Para $\phi=0,1$ a viscosidade máxima $(1,45)$ se verificou para $R=46 \mu \mathrm{m}$. Para $\phi=0,3$ a viscosidade máxima $(3,25)$ se verificou para $R=146 \mu \mathrm{m}$. Constantes: $\lambda=20, \delta=7 \mu \mathrm{m}, G=1,5$, $n=0,5$. Legenda: $-\phi=0,1,-. \phi=0,15,-\longrightarrow \phi=0,2, \cdots \phi=0,25$, $-\cdots=0,3$. 


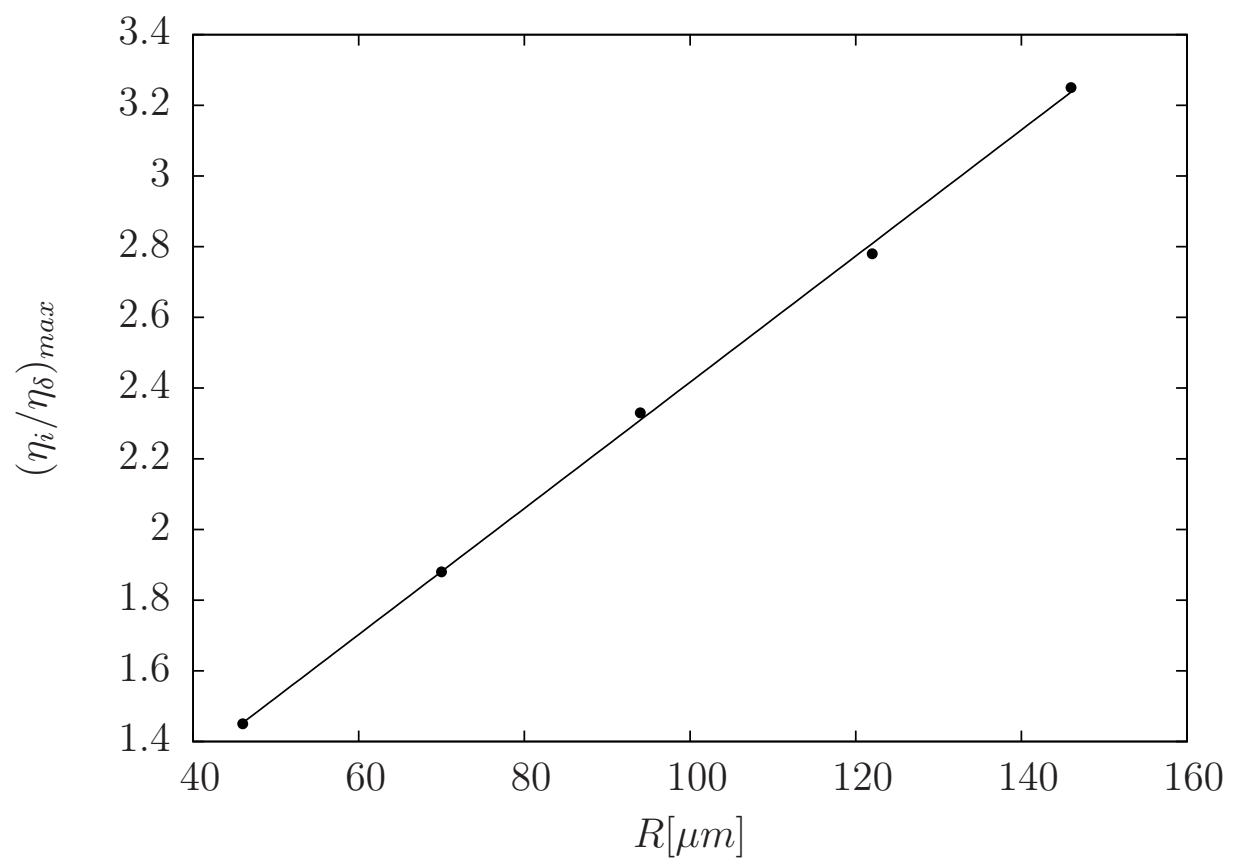

Figura 2.28: Variação do ponto de máxima viscosidade com o aumento da fração volumétrica para diferentes raios. Verifica-se um aumento linear da viscosidade com a fração volumétrica. Legenda: - Dados obtidos pela fig. $2.27,-\left(\eta_{i} / \eta_{\delta}\right)_{\max }=$ $0,632+0,0178 R$. 


\section{EMULSÕES DILUÍDAS DE ALTAS RAZÕES DE VISCOSIDADE FLUIDO-GOTA}

Considerando o escoamento de uma suspensão de gotas em regime de baixo número de Re e unidirecional, as gotas apresentam deformação na direção principal do escoamento para alto número de capilaridade, dependendo da razão de viscosidade. Em alto número de capilaridade, a escala de tempo do escoamento é muito menor que a escala de tempo de deformação da gota. Nessa situação a tensão superficial $\left(\tau_{s}\right)$, que é responsável pelo restauro da forma da gota, não consegue competir com as tensões de cisalhamento provenientes do escoamento. Para esta situação as gotas apresentam altas deformações (fig. 3.1). As gotas deformadas apresentam escoamento interno devido à vorticidade produzida pelo escoamento externo. Esse escoamento interno permite que as gotas alcancem grandes deformações (Oliveira (2007), Oliveira e Cunha (2011)). Por outro lado, em suspensões de altas razões de viscosidade, as gotas tendem a apresentar um comportamento semelhante a suspensões de esferas rígidas. Nesta situação, quando a gota se encontra no quadrante extensional (deformação) devido ao escoamento a tensão interfacial tende a restaurar a forma da gota (quadrante de compressão). Desta forma, a escala de tempo de rotação é muito menor que a escala de tempo de deformação e as gotas apresentam pequenas deformações (fig. 3.2). A modelagem dessas pequenas deformações conduz-nos a simulações numéricas de gotas de alta deformação onde são empregues métodos numéricos como o de Fronteira Imersa aliado a malhas adaptativas. É de notar que a magnitude da deformação depende do número de capilaridade, que é um parâmetro físico que representa o balanço entre a escala de tempo da deformação da gota $\left(\eta \bar{a} / \tau_{s}\right)$, associada com a viscosidade da gota e com a tensão interfacial, e a escala de tempo do escoamento, associada com o inverso da taxa de cisalhamento $(1 / \dot{\gamma})$. Nesta secção é apresentado o tensor de tensões para emulsões diluídas de altas razões de viscosidade, a equação governante para o escoamento de emulsões em tubo capilar e a respectiva solução numérica. 


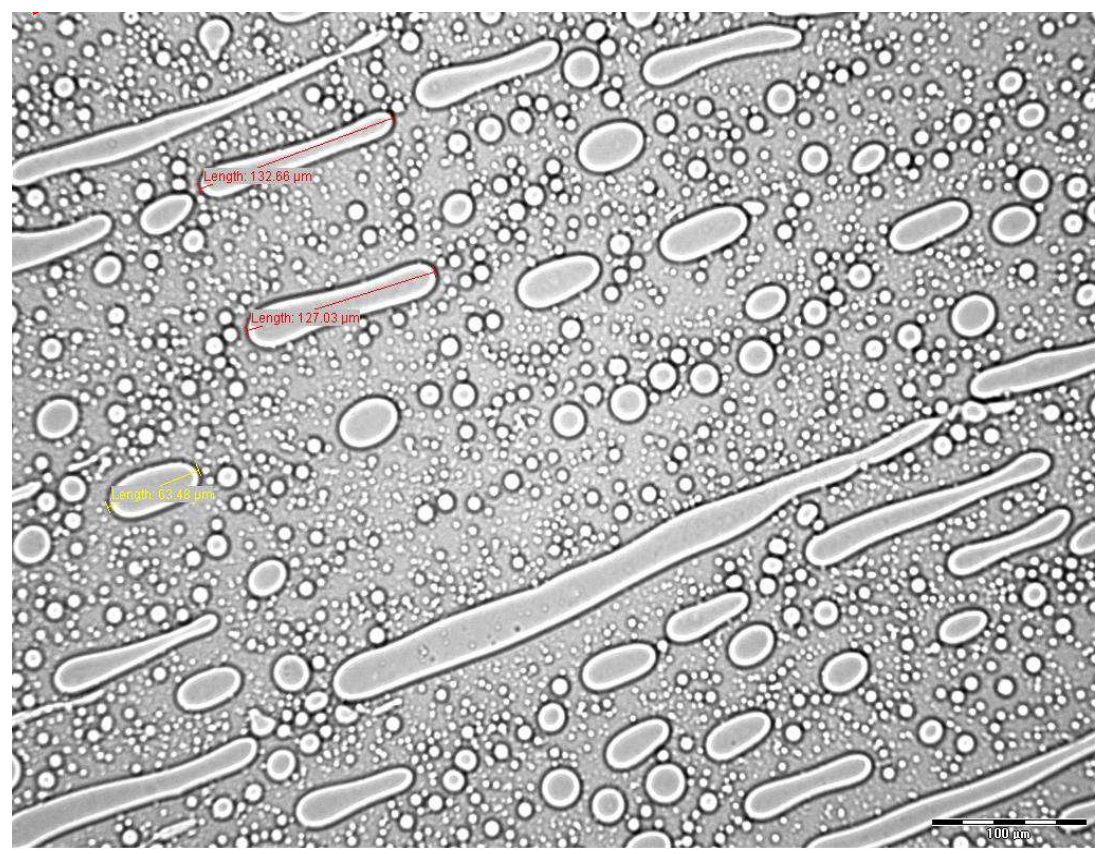

Figura 3.1: Microestutura da emulsão de $\phi=40 \%$ e $\lambda=2$. As gotas da emulsão apresentam elevada deformação na direção do cisalhamento. Imagem obtida pelo Microscópio BX51 da Olympus no Laboratório de Microhidrodinâmica e Reologia de Fluidos Complexos (Univ. de Brasília) durante o cisalhamento simples de Couette entre placas planas.

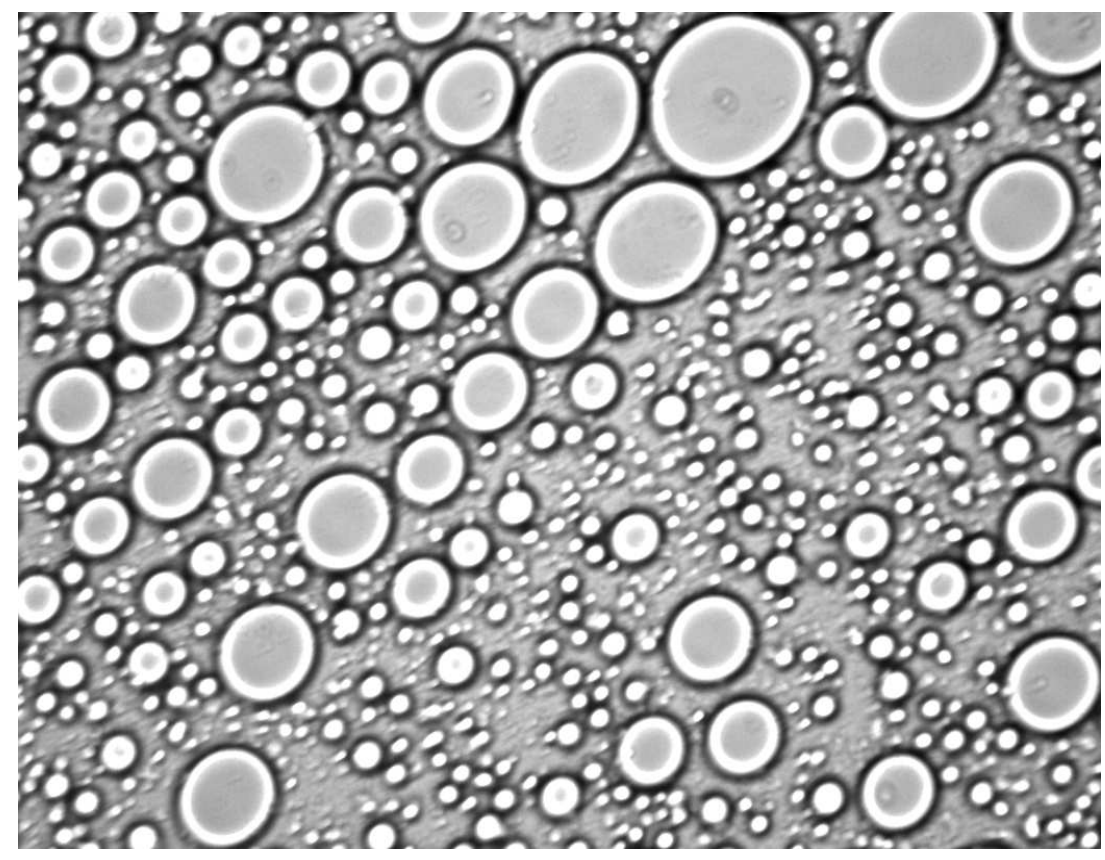

Figura 3.2: Microestutura da emulsão de $\phi=40 \%$ e $\lambda=20$. As gotas da emulsão pouco se deformam. Apresentam uma configuração de fileira na direção principal do escoamento. Imagem obtida pelo Microscópio BX51 da Olympus no Laboratório de Microhidrodinâmica e Reologia de Fluidos Complexos (Univ. de Brasília) durante o cisalhamento simples de Couette entre placas planas. 


\subsection{Tensor de Tensões}

Em emulsões infinitamente diluídas o escoamento em torno de uma gota não é influenciado pela presença das gotas vizinhas da emulsão. Esse meio discreto pode ser transformado em um meio contínuo (i.e. fluido homogêneo equivalente) por meio de uma média volumétrica aplicada a uma quantidade contínua como o tensor de tensões. Aqui a média volumétrica é aplicada ao tensor de tensões que leva em consideração a distribuição, orientação, tamanho e forma das gotas. Esse tensor é conhecido na literatura por tensor Landau-Batchelor (Batchelor (1970a)) ou por "Stresslet":

$$
\Sigma^{N N}=\Sigma^{d}=n \frac{1}{N} \sum_{\alpha}^{N} \boldsymbol{S}_{\alpha}
$$

em que $n / N=1 / V$, sendo $n$ o número de densidade, $N$ o número total de gotas e $V$ o volume. Aqui o tensor de tensões referente à presença de gotas no fluido é representado por $\boldsymbol{\Sigma}^{d}$. A quantidade $\boldsymbol{S}_{\alpha}$, que representa o Stresslet de uma gota $\alpha$, é calculada em Batchelor (1970a) como sendo:

$$
\boldsymbol{S}_{\alpha}=-2 \eta \frac{4 \pi a^{3}}{3} \boldsymbol{B}
$$

em que tensor $\boldsymbol{B}$ é um tensor de forma de superfície da gota definido em teoria de pequenas deformações por Frankel e Acrivos (1970), Barthes-Biesel e Acrivos (1973a) e Rallison (1984) :

$$
\boldsymbol{B}=-\left(\frac{5}{2}-\frac{25}{4 \lambda}\right) \boldsymbol{D}-\frac{2}{\lambda} \frac{\tau_{s}}{\eta a} \boldsymbol{A}-\frac{15}{14} \mathcal{L}(\boldsymbol{A}, \boldsymbol{D})
$$

em que:

$$
\mathcal{L}(\boldsymbol{A}, \boldsymbol{D})=\boldsymbol{A} \cdot \boldsymbol{D}+\boldsymbol{D} \cdot \boldsymbol{A}-\frac{2}{3}(\boldsymbol{A}: \boldsymbol{D}) \boldsymbol{I}
$$

Pode-se escrever a eq. 3.1 em função da fração volumétrica da emulsão monodispersa.

$$
\boldsymbol{\Sigma}^{d}=n \frac{1}{N} \sum_{\alpha}^{N}\left(-2 \eta v_{d} \boldsymbol{B}\right)
$$


em que $v_{d}$ é o volume da gota. É de notar que $\phi=n v_{d}$. Desta forma escreve-se para um meio contínuo do fluido homogêneo equivalente que:

$$
\boldsymbol{\Sigma}^{d}=-2 \eta \phi \overline{\boldsymbol{B}}
$$

O tensor referente às tensões devido à deformação da gota é dado pela seguinte equação (Oliveira e Cunha (2011)):

$$
\boldsymbol{\Sigma}^{d}=2 \eta(\lambda, \phi) \phi\left[\left(\frac{5}{2}-\frac{25}{4 \lambda}\right) \boldsymbol{D}+\frac{2}{\lambda} \frac{\tau_{s}}{\eta a} \boldsymbol{A}+\frac{15}{14} \mathcal{L}(\boldsymbol{A}, \boldsymbol{D})\right]
$$

Adimensionaliza-se a eq. 3.7 em que a escala de $\Sigma^{d}$ é $\eta \dot{\gamma}$ :

$$
\left.\frac{\boldsymbol{\Sigma}^{d}}{\phi}=\left(5-\frac{25}{2 \lambda}\right) \boldsymbol{D}+\frac{4}{\widehat{C a}} \boldsymbol{A}+\frac{15}{7}\left[\boldsymbol{A} \cdot \boldsymbol{D}+\boldsymbol{D} \cdot \boldsymbol{A}-\frac{2}{3}(\boldsymbol{A}: \boldsymbol{D}) \boldsymbol{I}\right)\right]
$$

que representa a forma adimensional do tensor de tensões na superfície da gota para uma emulsão monodispersa de altas razões de viscosidade considerando a emulsão como um fluido homogêneo equivalente.

Considerando a emulsão polidispersa o tensor de tensões na superfície da gota é obtido pelo somatório das tensões na superfície da gota de cada espécie.

$$
\boldsymbol{\Sigma}_{p}^{d}=-2 \eta \sum_{k=1}^{M} \phi_{k} \overline{\boldsymbol{B}}_{k}
$$

em que $k$ representa a espécie da gota e $M$ o número total de espécies da emulsão. Se a escala de adimensionalização do tensor de tensões for a tensão de cisalhamento $(\eta \dot{\gamma})$ e se para o tensor $\boldsymbol{B}$ for a taxa de cisalhamento do escoamento, a eq. 3.9 é reescrita como:

$$
\widetilde{\boldsymbol{\Sigma}}_{p}^{d}=-2 \sum_{M}^{k=1} \phi_{k} \overline{\widetilde{\boldsymbol{B}}}_{k}
$$

Desta forma é possível levar em conta a polidispersidade da emulsão em que $k$ está relacionado a um conjunto de gotas cujo diâmetro médio se encontra entre um determinado intervalo. O histograma de distribuição de tamanho de gota fornece estes dados. Esta informação é obtida pela caracterização microestutural da emulsão por 
microscopia ótica como destacado na seção 7 de resultados experimentais.

O tensor distorção adimensional $\boldsymbol{A}$ é um tensor simétrico associado com a deformação e relaxação da gota que está relacionado com os efeitos de restauração da forma da gota pela tensão interfacial e $\boldsymbol{I}$ é o tensor identidade. A equação da evolução da forma da gota é dada por (Oliveira (2007)):

$$
\frac{d \boldsymbol{A}}{d t}=\boldsymbol{W} \cdot \boldsymbol{A}-\boldsymbol{A} \cdot \boldsymbol{W}+\frac{5}{2 \lambda} \boldsymbol{D}-\frac{\tau_{s}}{\lambda \eta a}-c \boldsymbol{A}
$$

em que $\tau_{s}$ é a tensão interfacial entre a gota e o fluido base, $c=20 / 19$ e $a$ é o raio da gota. Os tensores $\boldsymbol{D}$ e $\boldsymbol{W}$ são definidos como:

$$
\begin{gathered}
\boldsymbol{D}=\frac{1}{2}\left(\boldsymbol{\nabla} \boldsymbol{u}+(\boldsymbol{\nabla} \boldsymbol{u})^{T}\right) \\
\boldsymbol{W}=\frac{1}{2}\left(\boldsymbol{\nabla} \boldsymbol{u}-(\boldsymbol{\nabla} \boldsymbol{u})^{T}\right) .
\end{gathered}
$$

Para adimensionalizar a eq. 3.11 são consideradas as seguintes escalas adimensionais: $\widetilde{t}=t / \sigma_{r}, \widetilde{\boldsymbol{D}}=\boldsymbol{D} / \dot{\gamma}_{c}, \widetilde{\boldsymbol{W}}=\boldsymbol{W} / \dot{\gamma}_{c}$, em que $\dot{\gamma}_{c}$ a escala característica do escoamento associado ao gradiente de velocidade, $\boldsymbol{\nabla} \boldsymbol{u}$ (suprimindo o "til"da quantidade adimensionalizada para tornar a nomenclatura mais simples), e $\sigma_{r}=a \eta / \tau_{s}$ é definido como sendo o tempo característico de relaxação da gota. Assim a eq. 3.11, na forma adimensionalizada é dada por:

$$
\frac{d \boldsymbol{A}}{d t}=\widehat{C a}\left[\boldsymbol{W} \cdot \boldsymbol{A}-\boldsymbol{A} \cdot \boldsymbol{W}+\frac{5}{2 \lambda} \boldsymbol{D}\right]-c \boldsymbol{A}
$$

O parâmetro adimensional $\widehat{C a}$ é o número de capilaridade modificado, como definido em Oliveira e Cunha (2011). O número de capilaridade ( $C a$ ) denota a razão entre o tempo associado com a relaxação da gota $\left(\sigma_{r}\right)$, relacionado portanto com a tensão interfacial, e o tempo característico do escoamento $(1 / \dot{\gamma})$. Este parâmetro físico adimensional leva em consideração a viscosidade do fluido base e da gota por meio de $\lambda$ :

$$
\widehat{C a}=\lambda \frac{\eta \dot{\gamma} a}{\tau_{s}}=\lambda \frac{\eta U_{c}}{\tau_{s}} \frac{a}{R}
$$


em que $U_{c}$ é a velocidade característica do escoamento, $R$ o raio do tubo e $a$ o raio médio da gota.

Nesta análise assume-se o regime permanente da deformação da gota, logo $(d \boldsymbol{A} / d t)$ é nulo. Nestas condições as componentes do tensor $\boldsymbol{A}$ são encontradas por meio da solução do sistema de equações tendo em atenção as características de tensor simétrico (D) e anti-simétrico $(\boldsymbol{W})$.

\subsubsection{Escoamento de Emulsão Diluída de Altas Razões de Viscosidade em Tubo Capilar}

Considerando o escoamento no interior de um tubo capilar de secção circular, tem-se que (ver Apêndice B, Oliveira (2007)):

$$
\begin{aligned}
A_{r z} & =\frac{5}{4 \lambda} \sqrt{\epsilon} \dot{\gamma}\left(\epsilon \dot{\gamma}^{2}+1\right)^{-1} \\
A_{z z} & =\frac{5}{4 \lambda} \epsilon \dot{\gamma}^{2}\left(\epsilon \dot{\gamma}^{2}+1\right)^{-1} \\
A_{r r} & =-\frac{5}{4 \lambda} \epsilon \dot{\gamma}^{2}\left(\epsilon \dot{\gamma}^{2}+1\right)^{-1}
\end{aligned}
$$

em que $\epsilon=(\widehat{C a} / c)^{2}$ e $\dot{\gamma}=d u_{z} / d r$. Conhecendo-se as componentes do tensor $\boldsymbol{A}$ podese efetuar as operações tensoriais da eq. 3.8. A componente de interesse do tensor é a componente $\Sigma_{r z}^{d}$ que atua no plano r-z na direção z. Assim escreve-se para uma emulsão monodispersa que:

$$
\Sigma_{r z}^{d}=\phi\left(\frac{5}{2}-\frac{25}{4 \lambda}\right) \dot{\gamma}+\frac{5 \phi}{\lambda c} \dot{\gamma}\left(\epsilon \dot{\gamma}^{2}+1\right)^{-1}
$$

Tendo definido o tensor de tensões devido à deformação da gota, este é substituído na equação do movimento que rege o escoamento de líquidos em dutos. A equação 2.41 é, então, modificada pela adição da contribuição do tensor de tensões devido a presença de gotas no fluido. Portanto

$$
\frac{\partial p}{\partial z}=\eta \frac{1}{r} \frac{\partial}{\partial r}\left(r \frac{\partial u_{z}}{\partial r}\right)+\frac{1}{r} \frac{\partial}{\partial r}\left(r \Sigma_{r z}^{d}\right) .
$$


A eq. 3.18 foi adimensionalizada com os seguintes parâmetros: $\widetilde{r}=r / R, \widetilde{u}=u / U_{c}$, $\widetilde{\Sigma}_{r z}^{d}=\Sigma_{r z}^{d}\left(\eta U_{c} / R\right), \widetilde{G}=G /\left(1 /(8 R) \rho U_{c}^{2}\right)$. Efetuando-se as operações de integração, encontra-se que (suprimindo a notação "til"referente a adimensionalização):

$$
\frac{\partial u}{\partial r}+\Sigma_{r z}^{d}=-\frac{G R e}{16} r
$$

Procedendo-se com a substituição do termo de $\sum_{r z}^{d}$ dada pela eq.3.17 chega-se a:

$$
\dot{\gamma} \eta_{T}+\epsilon\left(\dot{\gamma}^{3} \eta_{B}+\dot{\gamma}^{2} \frac{R e G}{16} r\right)=-\frac{R e G}{16} r
$$

Aqui,

$$
\eta_{T}=1+\phi\left(\frac{5}{2}-\frac{3}{2 \lambda}\right)
$$

$\mathrm{e}$

$$
\eta_{B}=1+\phi\left(\frac{5}{2}-\frac{25}{4 \lambda}\right)
$$

A eq. 3.21 é a viscosidade de Taylor adimensionalizada pela viscosidade da fase contínua para emulsões diluídas de altas razões de viscosidade. A eq. 3.22 é a viscosidade efetiva da emulsão em altas taxas de cisalhamento em que neste limite Newtoniano os tempos de relaxação da gota são muito menores que a escala de tempo típica do escoamento.

Para uma emulsão polidispersa diluída com alta razão de viscosidade a eq. 3.20 é escrita da seguinte forma:

$$
\dot{\gamma} \eta_{T}^{p}+\epsilon\left(\dot{\gamma}^{3} \eta_{B}^{p}+\dot{\gamma}^{2} \frac{\operatorname{Re} G}{16} r\right)=-\frac{R e G}{16} r
$$

em que:

$$
\eta_{T}^{p}=1+\sum_{k=1}^{M}\left(\phi_{k}\left(\frac{5}{2}-\frac{3}{2 \lambda}\right)\right)
$$

e

$$
\eta_{B}^{p}=1+\sum_{k=1}^{M}\left(\phi_{k}\left(\frac{5}{2}-\frac{25}{4 \lambda}\right)\right)
$$

A $\eta_{T}^{p}$ e a $\eta_{B}^{p}$ são as expressões da eq. 3.21 e da eq. 3.22 considerando as características da microestrutura de uma emulsão polidispersa. A concentração da espécie $\left(\phi_{k}\right)$ é 
calculada como:

$$
\phi_{k}=n_{k} v_{k}=\frac{N_{k}}{V} v_{k}=\frac{N_{k}}{V_{O}} \phi v_{k}=\frac{N_{k}}{\sum_{k=1}^{M} a_{k}^{3}} \phi a_{k}^{3}
$$

em que $a_{k}$ é o raio da partícula pertencente à espécie $k, n_{k}$ é o número de densidade de gotas da espécie $k, N_{k}$ é o número total de gotas da espécie $k, V_{O}$ é o volume da fase

oleosa, $\sum_{k=1}^{M} a_{k}$ é a soma dos raios das partículas de todas as espécies e $\phi$ é a fração volumétrica da emulsão. Essas informações são extraídas do histograma de tamanho de gotas obtido pela análise microestrutural da emulsão.

\subsection{Solução Numérica do Escoamento de Emulsões Diluídas de Alta Razão de Viscosidade}

Aqui é apresentada a solução da equação diferencial ordinária não-linear (eq. 3.20) que representa a equação da quantidade de movimento para o escoamento em tubo capilar de uma emulsão infinitamente diluída de altos $\lambda$. A análise da solução numérica da eq. 3.20 é realizada em termos de parâmetros físicos adimensionais. Elaborou-se um programa computacional, tal como mostrado em Oliveira (2007), pelo qual a eq. 3.20 é avaliada numericamente em cada ponto espacial permitindo obter a taxa de cisalhamento $(\dot{\gamma})$ no domínio discreto. Resolvendo a derivada $d u / d r=\dot{\gamma}$ obtém-se a velocidade no domínio discreto. Conhecendo-se a velocidade, a vazão é calculada pela integral da velocidade no domínio discreto. Como a eq. 3.20 é dada na forma adimensional, todas as quantidades físicas obtidas por meio dessa equação são quantidades adimensionais.

Conhecendo-se o perfil de velocidades calcula-se a vazão. A vazão calculada também é uma grandeza adimensional sendo a mesma dada pela equação de Hagen-Poiseuille para escoamentos em tubos capilares de secção circular:

$$
Q_{P}=\frac{\pi R^{4} \Delta P}{8 \eta L}
$$

em que $Q_{P}$ é a vazão de Poiseuille, $R$ é o raio do tubo capilar, $\Delta P$ é a diferença de 
pressão avaliada em duas regiões diferentes, $\eta$ é a viscosidade do fluido e $L$ é a dimensão longitudinal do tubo capilar. A vazão de Poiseuille pode ser adimensionalizada pela vazão calculada pela velocidade média do escoamento:

$$
Q=\pi R^{2} U
$$

em que $U$ é a velocidade média do escoamento. Desta maneira,

$$
\widetilde{Q}=\frac{Q_{P}}{Q}
$$

A pressão é adimensionalizada pelas escalas envolvidas na equação da quantidade de movimento para fluido invíscido.

$$
\frac{\widetilde{\Delta P}}{L / R}=\frac{\Delta P}{(1 / 8) \rho U^{2} L / R}
$$

De uma forma abreviada,

$$
G=\frac{\rho U^{2}}{8 R} \widetilde{G}
$$

em que $G=\Delta P(L / R)$. Substituindo a eq. 3.29 e a eq. 3.31 na eq. 3.27, obtém-se a vazão adimensionalizada:

$$
\widetilde{Q}=\frac{R e \widetilde{G}}{64}
$$

em que Re é o número de Reynolds. No escoamento em tubo capilar a viscosidade efetiva (ou intrínseca), $\eta_{e}$, é dada pela expressão de Hagen-Poiseuille:

$$
\eta_{e}=\frac{\pi R^{4} G}{8 Q_{P}}
$$

Para adimensionalizar a viscosidade efetiva divide-se a eq. 3.33 pela viscosidade do fluido base e substitui-se $G$ dada pela eq. 3.31 e $Q_{P}$ dada pela eq. 3.29, obtendo-se que:

$$
\widetilde{\eta}_{e}=\frac{R e \widetilde{G}}{64 \widetilde{Q}} .
$$

A discretização espacial do código numérico foi obtida pela divisão do domínio de dimensão unitária em 50 pontos igualmente espaçados (malha uniforme). A taxa de cisalhamento em cada ponto foi obtida pelo método clássico Newton-Raphson (Press 
et al. (1992)). A convergência da taxa de cisalhamento em cada ponto foi de $10^{-3}$. Conhecendo-se a taxa de cisalhamento, foi aplicado um Método de Diferenças Finitas para encontrar o valor da velocidade em cada ponto da malha numérica. Na parede foi aplicada a condição de contorno tipo Dirichelet $(u(r=1)=0)$ e no centro do tubo a condição de simetria do tipo Neumann $(\dot{\gamma}(r=0)=0)$. A vazão foi calculada pelo Método do Trapézio Composto para resolver numericamente a integração da velocidade no domínio discreto. O ciclo de cálculo iterativo termina quando a diferença entre a vazão obtida e a vazão adimensional é menor que a tolerância $(\Delta r)^{2} / 10$, em que $(\Delta r)$ é a distância entre os pontos do domínio discreto. No caso de não ser obtida essa condição de parada, é incrementado um valor ao $R e$ de entrada de $\Delta R e=10^{-5} R e$. Com o novo valor de $R e$ são calculados $\dot{\gamma}(r), u(r)$ e uma nova vazão. Essa nova vazão é usada no cálculo da evolução de $R e$ para que um novo ciclo de cálculo seja iniciado até que seja verificada o critério de parada da vazão. A expressão para a evolução do novo Re é dada segundo o método Newton-Raphson:

$$
R e_{n}=R e_{a}-\frac{\Delta R e Q(R e)}{Q(R e+\Delta R e)-Q(R e)} .
$$

Na eq. 3.35, $R e_{n}$ e $R e_{a}$ são respectivamente, o novo e o antigo Reynolds. As funções $Q(R e)$ e $Q(R e+\Delta R e)$ referem-se respectivamente à vazão calculada com o $R e$ antigo e com o Re antigo mais o incremento de Re. Após a convergência da vazão é calculada a viscosidade efetiva adimensionalizada dada pela eq. 3.34. O algoritmo do programa numérico é apresentado em seguida:

1. Entrada: $G, \epsilon, R e, \Delta R e, \phi, \lambda$;

2. Método de Newton-Raphson: $\widetilde{\dot{\gamma}}(r)$;

3. Método de Diferenças Finitas: $\widetilde{u}(r)$;

4. Método do Trapézio: $\widetilde{Q}$;

5. Se $\widetilde{Q}(R e)-1,0<(\Delta R)^{2} / 10$ Então $\rightarrow$ Termina Calculo ;

6. Incremento de Reynolds: $R e=R e+\Delta R e$;

7. Calculo da Nova Vazão: Repetir os passos 2,3,4;

8. Calculo do Novo Reynolds: Eq. 3.35 ;

9. Voltar ao passo 2. 


\subsubsection{Discussão dos Resultados do Modelo para Escoamento de Emulsão Diluída com Altas Razões de Viscosidade}

O modelo apresentado para o escoamento de emulsões infinitamente diluídas com altas razões de viscosidade, $\lambda$, permite estimar o comportamento da viscosidade aparente em função da fração volumétrica $(\phi)$, do gradiente de pressão $(G)$ e o número de capilaridade $(C a)$. Aqui os resultados são apresentados com o intuito de se avaliar a resposta do modelo para diferentes magnitudes dos diversos parâmetros físicos identificados.

A fig. 3.3 mostra a influência da $\phi$ e de $\lambda$ na viscosidade efetiva $\widetilde{\eta}_{e}$. A viscosidade efetiva cresce com o aumento da concentração de gotas. Vê-se que as retas tendem a colidir em uma única reta com a diminuição da deformação da gota. Ou seja, as gotas com altas razões de viscosidade tendem-se a comportar como esferas rígidas. O fator que multiplica $\phi$ na expressão teórica da viscosidade de Einstein tem o valor de 5/2. Do ajuste da reta para $\lambda=50$ resultou em um fator de 2,42 .

A fig. 3.4 mostra a influência da razão de viscosidade na viscosidade efetiva para diferentes valores do parâmetro $\epsilon=(\widehat{C a} / c)^{2}$. Observa-se um aumento da viscosidade efetiva com o aumento da razão de viscosidade para uma mesma fração volumétrica. Comportamento este, fisicamente consistente uma vez que com a diminuição da deformação da gota cria uma maior resistência ao escoamento. Por outro lado nota-se que com o aumento do parâmetro $\epsilon$ a viscosidade tende para um valor constante mas diferente para cada $\lambda$. O parâmetro $\epsilon$ é proporcional a $C a^{2}$. Quando maior for o número de capilaridade maior é taxa de cisalhamento e como tal a gota se deforma alinhando-se com o escoamento. Esse alinhamento é tanto maior quanto menor for $\lambda$. Por esse motivo é que o menor valor da viscosidade efetiva se verifica para $\lambda=5$. A fig. 3.5 mostra a saturação da viscosidade efetiva $\left(\tilde{\eta}_{e, \infty}\right)$ com o aumento da razão de viscosidade. Nota-se uma variação da viscosidade efetiva de $25 \%$ no intervalo $5 \leq \lambda \leq 50$. 


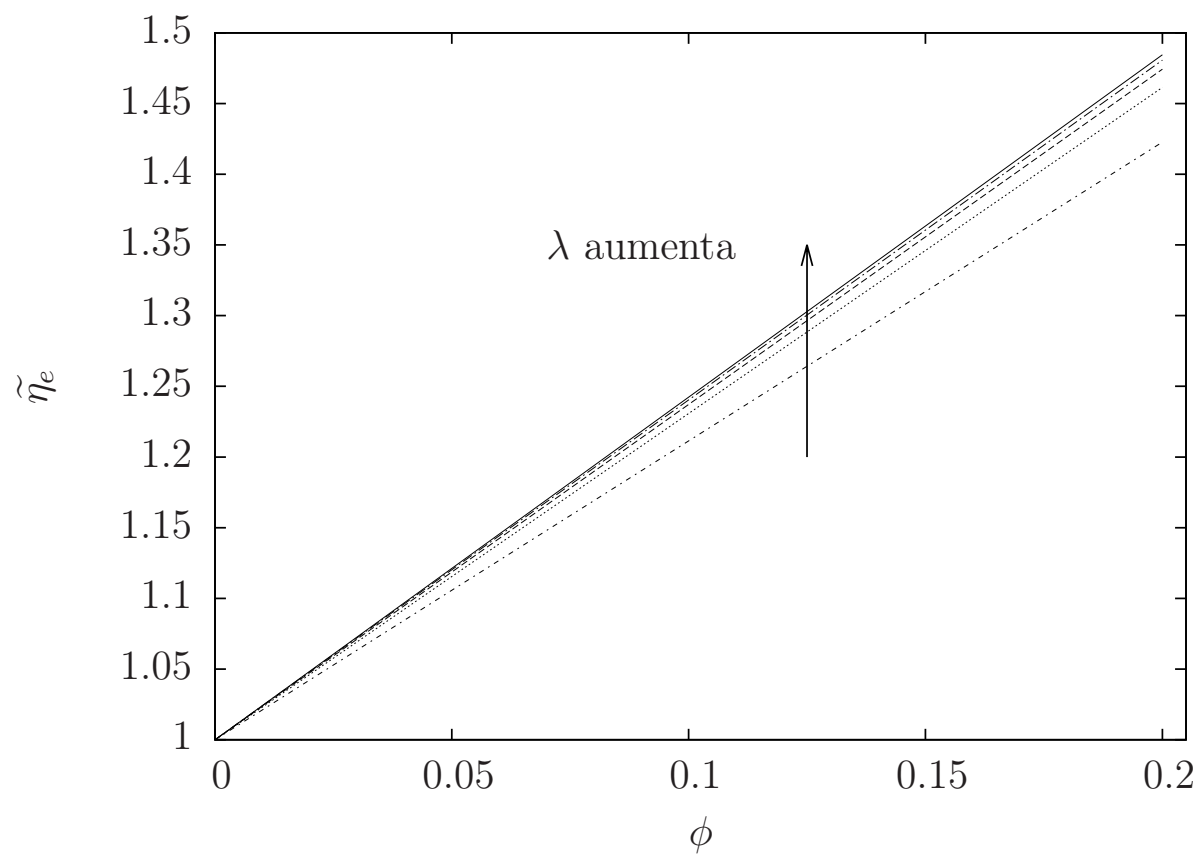

Figura 3.3: Influência da razão de viscosidade na viscosidade efetiva para diferentes frações volumétricas. Pelos resultados nota-se que o aumento da razão de viscosidade pouco afeta a viscosidade efetiva. Legenda: $-\cdot \lambda=10, \cdots \lambda=20,--\lambda=30$, $\longrightarrow \times \lambda=40-\lambda=50$.

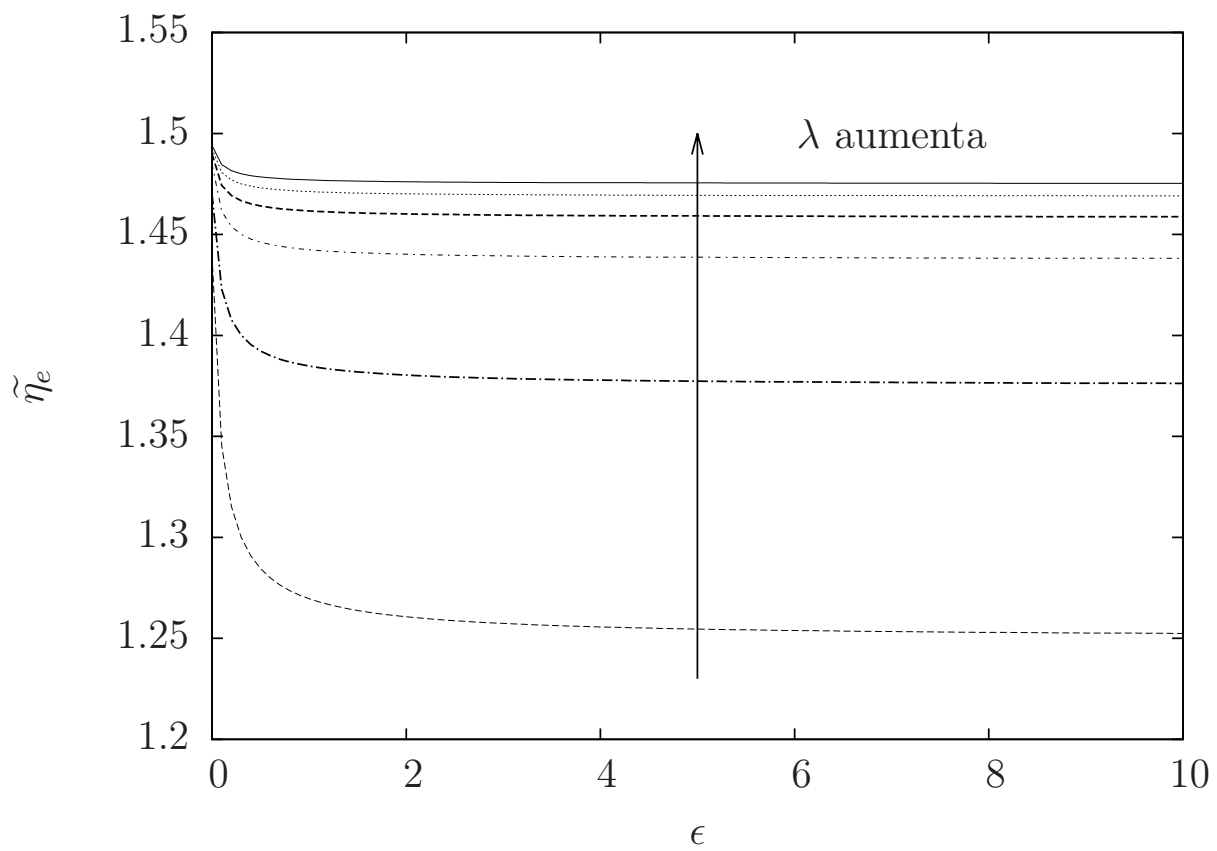

Figura 3.4: Influência da razão de viscosidade na viscosidade efetiva para diferentes valores do parâmetro $\epsilon$. Com o aumento de $\epsilon$ maior é a intensidade do escoamento. Isso faz com que a viscosidade efetiva atinga um platô para valores de $\epsilon \geq 2$. Legenda: $--\lambda=5,-\lambda=10,-\cdots \lambda=20,-\longrightarrow \lambda=30, \cdots \lambda=40,-\lambda=50$. 


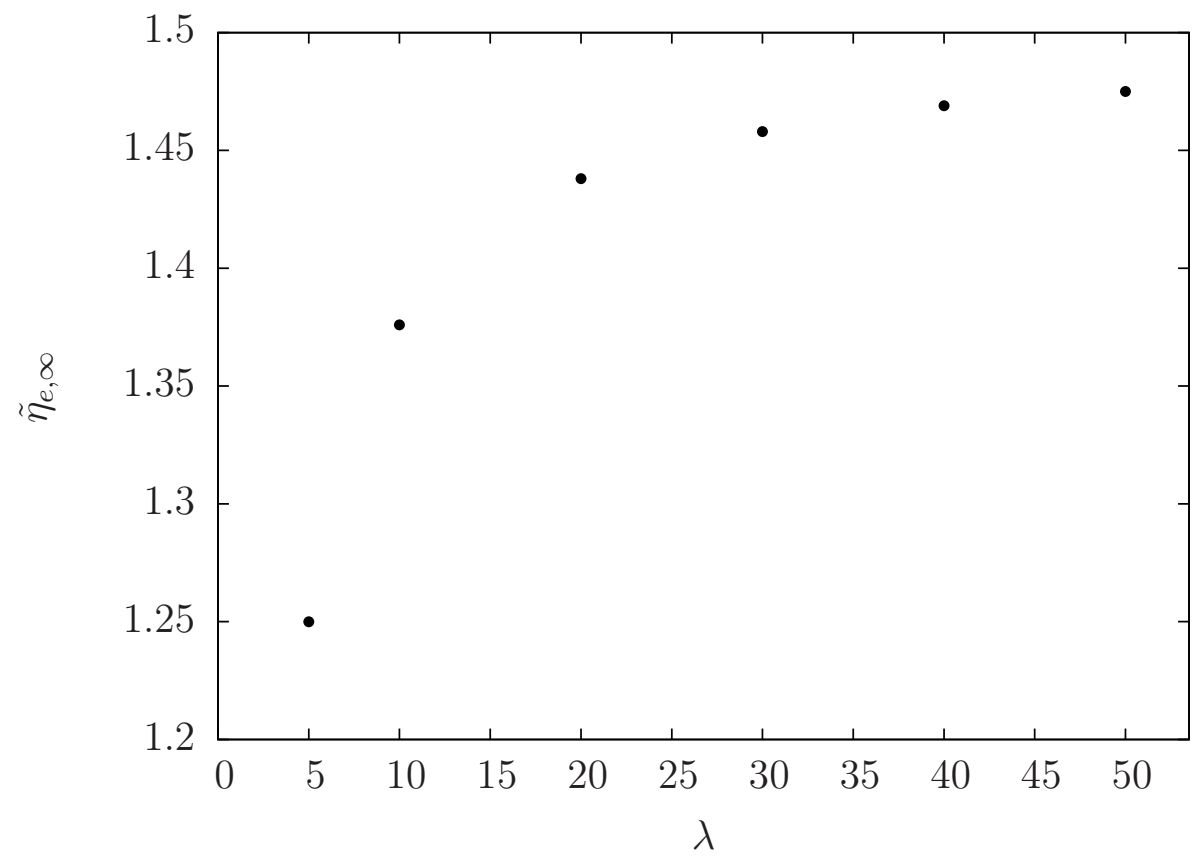

Figura 3.5: Saturação da viscosidade efetiva com o aumento da razão de viscosidade.

\subsubsection{Viscosidade de Emulsão Diluída de Altas Razões de Viscosidade em Cisalhamento Permanente}

É possível estimar a viscosidade de uma emulsão infinitamente diluída de altos $\lambda$ em cisalhamento através da teoria de pequenas deformações (Frankel e Acrivos (1970)). Determinou-se a média volumétrica do tensor de tensões de partícula dada pela eq. 3.2 com o intuito de passar da escala discreta para o meio contínuo do fluido homogêneo equivalente resultando em:

$$
<\boldsymbol{S}>=-2 \eta \phi \boldsymbol{B}
$$

em que $\boldsymbol{B}$ é dado pela eq. 3.3. A componente de interesse para avaliar a viscosidade em cisalhamento simples é:

$$
B_{12}=-\left(\frac{5}{2}-\frac{25}{4 \lambda}\right) \frac{\dot{\gamma}}{2}-\frac{2}{\lambda} \frac{\tau_{s}}{\eta a} A_{12}
$$

em que (ver Apêndice C):

$$
A_{12}=\frac{J K}{K^{2}+\dot{\gamma}^{2}}\left[1-e^{-K t} \cos (\dot{\gamma} t)+\frac{\dot{\gamma}}{K} e^{-K t} \operatorname{sen}(\dot{\gamma} t)\right],
$$


e

$$
\begin{gathered}
J=\frac{5 \dot{\gamma}}{4 \lambda}, \\
K=\frac{\tau_{s}}{\eta a \lambda} .
\end{gathered}
$$

Note que a viscosidade é definida como sendo a razão entre a tensão de cisalhamento e a taxa de cisalhamento. Da eq. 3.37 escreve-se que:

$$
\frac{\eta_{e}}{\eta}=-2 \phi \frac{B_{12}}{\dot{\gamma}}
$$

Substituindo a eq. 3.38 na eq. 3.42, fica:

$$
\frac{\eta_{e}}{\eta}=\phi\left[\left(\frac{5}{2}-\frac{25}{4 \lambda}\right)+\frac{4}{\lambda C a} A_{12}\right] .
$$

Note que para $t \rightarrow \infty$ (regime permanente) os termos transientes da eq. 3.39 decaem e consequentemente a componente $A_{12}$ se reduz a:

$$
A_{12}=\frac{5}{4 \lambda} \frac{V}{V^{2}+1}
$$

em que:

$$
V=\frac{c}{\lambda \widehat{C a}}
$$

em que $c=20 / 19$. Nestas condições a forma da gota não varia mais para uma determinada taxa de cisalhamento. A eq. 3.44 é melhor representada em termos de parâmetros adimensionais, tal que $\widehat{C a}=\lambda C a$.

\subsection{MODELO PARA MIGRAÇÃO DE PARTÍCULAS DE UMA SUS- PENSÃO EM CISALHAMENTO}

De resultados experimentais e numéricos presentes na literatura sabe-se que partículas ou gotas de uma suspensão em escoamento em regime de baixo Reynolds, entre superfícies rígidas impermeáveis (parede), migram de regiões de alta taxa de cisalhamento para regiões de baixa taxa de cisalhamento. Essa migração é o resultado líquido da interação partícula-partícula em que as partículas se deslocam na direção centro-parede e da interação partícula-parede em que as partículas se deslocam na direção parede- 
centro. Vale apena ressaltar que o processo aqui analisado não está relacionado com a escala molecular, mas sim com a escala hidrodinâmica do escoamento e que depende da mesma.

Esta seção apresenta a solução do problema de migração de partículas deformáveis (gotas) de emulsão de baixa fração volumétrica e alta razão de viscosidade. É considerado regime de baixo número de Reynolds em que gotas se encontram próximas à parede e em movimento devido à velocidade do escoamento. Nesta magnitude de altas razões de viscosidade as gotas apresentam pequenas deformações devido ao seu baixo módulo de elasticidade. Estas pequenas deformações são devidas à inexistência do movimento no interior da gota, fazendo com que a escala de tempo de rotação $(1 / \dot{\gamma})$ seja muito menor que a escala de tempo de deformação $(\lambda / \dot{\gamma})$. Assim a gota tem um movimento rotacional predominante em relação à deformação. Tal fato pode ser explicado pelo seguinte, quando a gota se encontra no quadrante extensional de cisalhamento rapidamente se posiciona no quadrante de compressão apresentando assim pequenas deformações. A pequena deformação é suficiente para produzir tanto um fluxo difusivo transversal induzido pelo escoamento na direção da parede devido a interação gota-gota bem como um deslocamento transversal médio na direção do centro do escoamento devido a interação gota-parede. Com este estudo pretende-se encontrar uma solução de similaridade que prediga a variação de fração volumétrica de gotas no espaço e no tempo que poderá ser confirmada pelo método de diferenças finitas.

A região de interesse é delimitada por uma parede e uma região no infinito na qual não existe variação da concentração de gotas $(\partial \phi / \partial y=0)$. O problema é tratado como sendo um problema semi-infinito, com foco em regiões próximas da parede na qual existe a possibilidade da formação de uma região livre de gotas. Este modelo busca destacar quais são os parâmetros físicos responsáveis por promoverem o surgimento de uma região livre de gotas. Considera-se que em cada posição espacial, do domínio em estudo, existe uma determinada concentração de gotas. A concentração é nula na região de espessura $\delta$ adjacente à parede. Esta condição de contorno de $\phi=0$ surge de forma natural na resolução do problema transiente devido ao balanço entre os mecanismos de transporte advectivos e difusivos. 
A equação governante do problema é dada pela Equação de Transporte que representa o balanço entre os efeitos de advecção e de difusão que ocorre na escala do próprio escoamento $(1 / \dot{\gamma})$, ou seja, são mecanismos que não ocorrem na escala molecular. O efeito de advecção deve-se ao dipolo hidrodinâmico de tensão produzido pela parede sobre a partícula. A difusão hidrodinâmica é provocada pela deformação das gotas que interagem em pares. A velocidade de advecção é a velocidade de migração da gota na direção normal ao escoamento $\left(u_{y}\right)$ e o termo difusivo é representado por um coeficiente de difusão $(\mathcal{D})$ que depende da fração volumétrica. Tratando a emulsão como um meio contínuo equivalente pode-se escrever para uma variação temporal da fração volumétrica de gotas $\phi(y, t)$ a seguinte equação transporte:

$$
\frac{\partial \phi}{\partial t}=-u_{x} \frac{\partial \phi}{\partial x}-u_{y} \frac{\partial \phi}{\partial y}+\frac{\partial}{\partial y}\left(\mathcal{D} \frac{\partial \phi}{\partial y}\right)
$$

em que $x$ é a coordenada na direção do cisalhamento, $y$ é coordenada transversal, $t$ o tempo, $u_{x}=\dot{\gamma} y$ é a velocidade de cisalhamento, $u_{y}$ a velocidade de migração transversal e $\mathcal{D}$ o coeficiente de difusão hidrodinâmico transversal.

\subsubsection{Modelo de Migração Induzido por Cisalhamento}

No trabalho de Leal (1980) foi obtida a velocidade de migração de uma partícula deformável sujeita a um escoamento de cisalhamento simples, ocorrendo entre duas paredes sólidas. O autor destaca que a taxa de migração da gota depende da magnitude da deformação da mesma, da distância entre a gota e a parede, da razão de viscosidades e do número de capilaridade. A expressão da velocidade é função do dipolo hidrodinâmico induzido pelo contorno sólido sobre a superfície da partícula em regime de baixo número de Reynolds expresso por uma tensão de partícula designada por stresslet (Kim e Karrila (1989)).

$$
\boldsymbol{S}=-2 \eta \frac{4}{3} \pi a^{3} \boldsymbol{\Sigma}
$$

Essa tensão de partícula incorpora a deformação da gota que modifica o campo de velocidades do escoamento. O trabalho de Smart e Leighton (1991) apresenta a velocidade de migração de uma gota normal à superfície rígida e à superfície livre. A expressão é 
dada por:

$$
u_{y}=-\frac{9}{64 \pi \eta y^{2}}\left\langle S_{y y}\right\rangle
$$

em que $\left\langle S_{y y}\right\rangle$ é a média volumétrica da componente normal da tensão na superfície da gota por unidade de volume, considerando a deformação de cada gota isolada na emulsão diluída.

O trabalho de Schowalter et al. (1968) apresenta o tensor de tensões $\boldsymbol{\Sigma}$ calculado por uma teoria de segunda ordem, $O\left(\dot{\gamma}^{2}\right)$ para uma emulsão infinitamente diluída sujeita a um cisalhamento simples, válida para qualquer razão de viscosidade $(\lambda)$. A obtenção deste tensor de tensões seguiu a ideia de que o tensor de tensões total é o somatório da contribuição de cada gota para o tensor de tensões. A expressão resultante é:

$$
\Sigma_{y y}=-\frac{3}{140} \frac{\eta^{2} a \dot{\gamma}^{2}}{\tau_{s}} H(\lambda)
$$

em que:

$$
H(\lambda)=\frac{(19 \lambda+16)\left(9 \lambda^{2}+17 \lambda+9\right)}{(\lambda+1)^{3}}
$$

Para o limite de altas razões de viscosidade $(\lambda>>1)$ a eq. 3.50 reduz-se a:

$$
H(\lambda)=\frac{171 \lambda+467}{\lambda+3}
$$

\subsubsection{Modelo de Difusão Hidrodinâmico Induzido por Deformação}

O modelo para o coeficiente de difusão da eq. 3.46 segue a ideia de Cunha e Hinch (1996) (partículas rígidas) e de Lowenberg, Hinch (1997) (gotas) em cisalhamento simples. A difusão de partículas em baixas concentrações ocorre devido à interação entre pares. Em regiões de maior concentração essas interações se dão com maior frequência surgindo um fluxo difusional de regiões de maior para menor concentração. Existe também uma auto-difusão que é resultante da quebra de simetria das trajetórias devido a rugosidade (deformação) das partículas (gotas). O coeficiente de difusão proposto por Cunha e Hinch (1996) incorpora esses dois efeitos. No presente problema, o processo difusivo gera um fluxo líquido que tende a aumentar a concentração das partículas na direção da parede, enquanto a interação da parede sobre a partícula induz o movimento 
que tende a expulsar a partícula da parede. Supõem-se que é do balanço entre esses dois mecanismos que surge uma região livre de partículas adjacente à parede.

Para o coeficiente de difusão hidrodinâmica $(\mathcal{D})$ é proposto um modelo em que a interação entre pares de gotas dominam a hidrodinâmica (regime diluído). Como a emulsão é considerada infinitamente diluída e de altos $\lambda$, em regime de pequenas deformações o coeficiente $\mathcal{D}$ pode ser definido como encontrado no trabalho de Cunha e Hinch (1996) aplicado à partículas rígidas de baixa rugosidade:

$$
\mathcal{D}=D_{0} \phi V(\lambda)
$$

em que $D_{0}$ é um coeficiente de difusão típico do escoamento dado por:

$$
D_{0}=a^{2} \dot{\gamma}
$$

A função $V(\lambda)$ é baseada no trabalho de Cunha e Hinch (1996) e está associada com a quebra de simetria da trajetória devido à alterações na superfície de uma partícula.

$$
V(\lambda)=\lambda^{c_{1}}\left(c_{2}+c_{3} \ln \lambda\right)^{c_{4}}
$$

em que $c_{1}=-0,2915, c_{2}=1,347, c_{3}=2 / 3$ e $c_{4}=-0,7012$

\subsubsection{Adimensionalização e Definição do Problema}

As escalas do problema em análise são o raio da gota $a$, a tensão interfacial entre a gota e o fluido base $\tau_{s}$, a viscosidade do fluido base $\mu$ e a fração volumétrica no infinito $\phi_{\infty}$. O infinito se situa em uma região tal que $\partial \phi / \partial y$ é nula. As grandezas adimensionais são definidas com base nas escalas apresentadas.

$$
\widetilde{u}=\frac{u}{\tau_{s} / \mu}, \widetilde{y}=\frac{y}{a}, \widetilde{\phi}=\frac{\phi}{\phi_{\infty}}, \widetilde{t}=\frac{t}{a \eta / \tau_{s}} .
$$


Com as escalas propostas adimensionaliza-se a Equação de Transporte:

$$
\frac{\partial \widetilde{\phi}}{\partial \widetilde{t}}=-\widetilde{u}_{x} \frac{\partial \widetilde{\phi}}{\partial \widetilde{x}}-\widetilde{u}_{y} \frac{\partial \widetilde{\phi}}{\partial \widetilde{y}}+\frac{V(\lambda) \phi_{\infty}}{P e} \frac{\partial}{\partial \widetilde{y}}\left(\widetilde{\phi} \frac{\partial \widetilde{\phi}}{\partial \widetilde{y}}\right)
$$

O número de Peclet $(P e)$ é definido como:

$$
P e=\frac{\tau_{s} a / \eta}{D_{0}}
$$

que representa fisicamente a razão entre uma escala de tempo difusivo $\left(a^{2} / D_{0}\right)$ e uma escala de tempo convectiva ou de deformação da gota $\left(a \eta / \tau_{s}\right)$. A velocidade na direção do escoamento de cisalhamento simples em termos adimensionais é dada por:

$$
\widetilde{u}_{x}=C a \widetilde{y}
$$

A velocidade na direção normal ao escoamento adimensionalizada é escrita como sendo:

$$
\widetilde{u_{y}}=-\frac{3}{8 y^{2}} \widetilde{\Sigma}_{y y}
$$

em que,

$$
\widetilde{\Sigma}_{y y}=-\frac{3}{140} C a^{2} H(\lambda)
$$

resultando em:

$$
\widetilde{u_{y}}=\frac{9}{1120} \frac{C a^{2}}{y^{2}} H(\lambda)
$$

em que o número de capilaridade $(C a)$ é definido como:

$$
C a=\frac{\dot{\gamma} \mu a}{\tau_{s}}
$$

Substituindo $\widetilde{u}_{x}$ e $\widetilde{u_{y}}$ a eq. 3.56 toma a seguinte forma adimensional:

$$
\frac{\partial \widetilde{\phi}}{\partial \widetilde{t}}=-C a \widetilde{y} \frac{\partial \widetilde{\phi}}{\partial \widetilde{x}}-\frac{9}{1120} \frac{C a^{2}}{\widetilde{y}^{2}} H(\lambda) \frac{\partial \widetilde{\phi}}{\partial \widetilde{y}}+\frac{V(\lambda) \phi_{\infty}}{P e} \frac{\partial}{\partial \widetilde{y}}\left(\widetilde{\phi} \frac{\partial \widetilde{\phi}}{\partial \widetilde{y}}\right)
$$


As condições de contorno e inicial que definem o problema no domínio físico são:

$$
\left\{\begin{array}{lll}
\phi(t, y)=0 & \text { em } & 0 \leq y \leq \delta(t) \\
\phi(t, \infty)=\phi_{\infty} & \text { em } & y=\infty
\end{array}\right.
$$

em que $\delta(t)$ é a espessura da camada livre de partículas adjacente a parede que é parte da solução do problema.

\subsection{SOLUÇÃO ASSINTÓTICA EM REGIME PERMANENTE PARA REGIÕES DE PAREDE}

Nesta seção apresenta-se uma solução assintótica em regiões de parede $(\widetilde{y} \sim \widetilde{\delta})$ para condição de regime permanente. O desenvolvimento deste tipo de solução para predizer a camada livre de gotas na região adjacente à parede foi motivada pelo trabalho de Carvalho et al., (2007). Neste limite o transporte advectivo induzido pela tensão da parede sobre a partícula que escala com $1 / \widetilde{y}^{2}$ domina a convecção devido ao cisalhamento externo que escala com $\widetilde{y}$, já que $\widetilde{y}$ assume valores pequenos. Portanto, nestas condições a eq. 3.63 para condição de regime permanente é simplificada para:

$$
0=-\frac{9}{1120} \frac{C a^{2}}{\widetilde{y^{2}}} H(\lambda) \frac{d \widetilde{\phi}}{d \widetilde{y}}+\frac{V(\lambda) \phi_{\infty}}{P e} \frac{d}{d \widetilde{y}}\left(\widetilde{\phi} \frac{d \widetilde{\phi}}{d \widetilde{y}}\right)
$$

Com este modelo no limite assintótico pretende-se mostrar que com a solução analítica obtida já é possível predizer gradientes de concentração adjacentes na região de parede, ou seja, identificar uma camada limite de concentração além de avaliar uma primeira expressão explícita que mostra a dependência da espessura $\delta$ em função dos parâmetros físicos identificados no problema em questão.

Por integração direta da eq. 3.65 nos limites do escoamento onde se aplica as condições de contorno de $\tilde{\delta}$ a $\widetilde{y}$ e de 0 a $\widetilde{\phi}$ obtém-se:

$$
\widetilde{\phi}(\widetilde{y})=\frac{9}{1120} \frac{C a^{2} \operatorname{Pe} H(\lambda)}{\phi_{\infty} V(\lambda)}\left(-\frac{1}{\widetilde{y}}+\frac{1}{\widetilde{\delta}}\right)
$$


É de se referir que a solução da eq. 3.65 pode ser obtida por método numérico. Para o caso de diferenças finitas forward, a equação a ser resolvida é:

$$
\frac{d \phi}{d y} \approx \frac{-3 \phi_{i}+4 \phi_{i+1}-\phi_{i+2}}{2 \Delta y}+\mathcal{O}\left((\Delta y)^{2}\right)
$$

em que $\Delta y$ representa a espessura da malha uniforme. $\mathrm{O}$ domínio espacial foi descritizado em 200 pontos com $\Delta y=0,5$. Pela fig. 3.6 vê-se que o esquema numérico representa com exatidão satisfatória a solução analítica do problema.

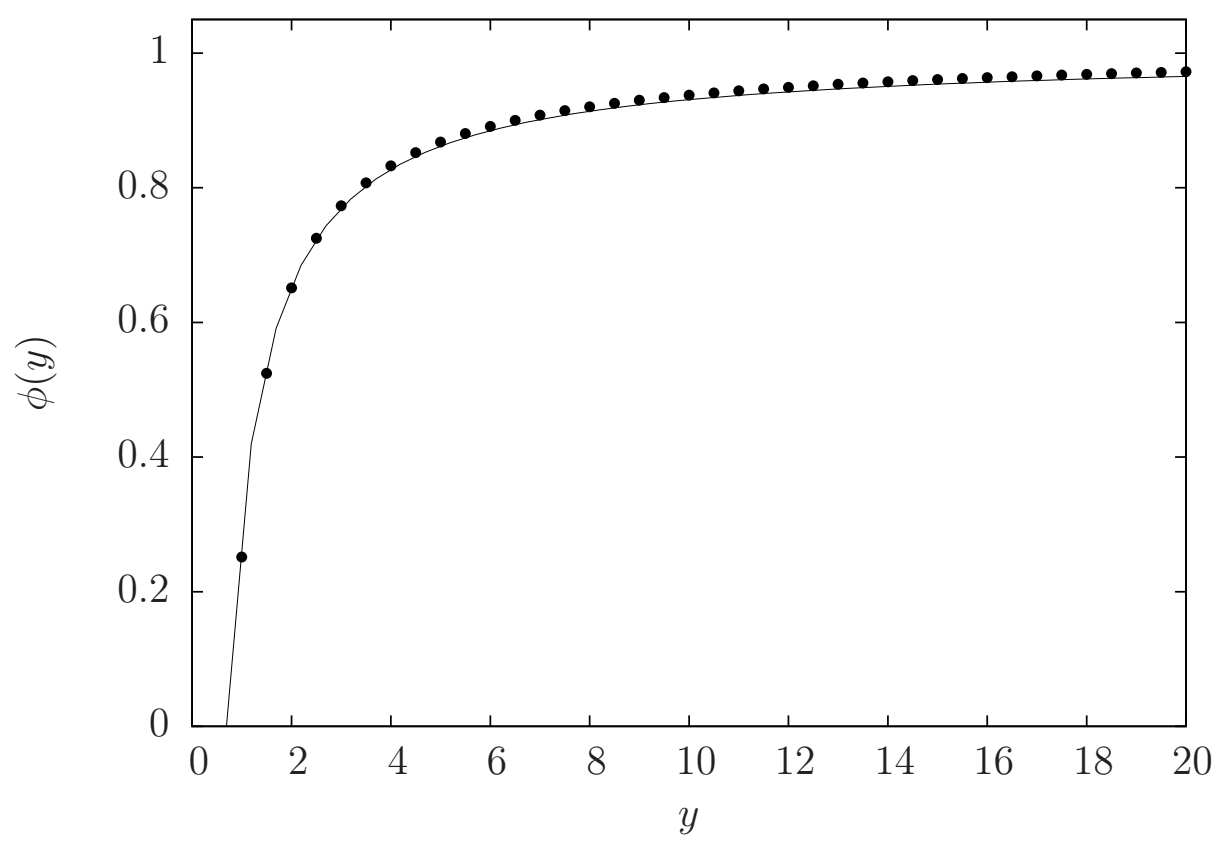

Figura 3.6: Aproximação da primeira derivada pelo esquema de diferenças finitas forward de $O\left((\Delta y)^{2}\right)$ é representativo da solução analítica da eq. 3.67. Para este caso os parâmetros físicos foram: $P e=5,0, C a=0,5, \lambda=10,0$

A espessura da camada livre de gotas $(\widetilde{\delta})$ pode ser estimada por esse modelo quando utiliza-se a condição de contorno no infinito. Nessa região $\widetilde{y} \gg \widetilde{\delta}$ e $\widetilde{\phi}=1.0$. É de notar que $\widetilde{\phi}=\phi / \phi_{\infty}$. Isto resulta que:

$$
\widetilde{\delta}=\frac{9}{1120} \frac{C a^{2} P e H(\lambda)}{\phi_{\infty} V(\lambda)}
$$

A espessura da camada de concentração $\left(\delta_{c}\right)$ é obtida pela diferença entre a altura $y$ na qual $\phi(y)=0,99 \phi_{\infty}$ e a espessura da camada livre de gotas, $\delta$. Esta altura é referida como $y^{*}$. Assim $\widetilde{\delta}_{c}=\widetilde{y}^{*}-\widetilde{\delta}$. Substituindo $\widetilde{\phi}(\widetilde{y})=0,99$ e $\widetilde{y}=\widetilde{y}^{*}$ na eq.3.66 obtém-se 
que:

$$
\widetilde{y}^{*}=\frac{\widetilde{\delta}}{0,01} .
$$

Desta forma a espessura da camada de concentração pode ser calculada pela seguinte expressão analítica:

$$
\widetilde{\delta}_{c}=99 \widetilde{\delta}
$$

De seguida apresenta-se a influência dos parâmetros no perfil da fração volumétrica de gotas na direção normal ao escoamento. O gráfico da fig. 3.7 mostra o perfil de fração volumétrica para vários números de capilaridade. Observa-se que o aumento do número de capilaridade modifica o perfil da fração volumétrica de gotas, originando perfis com uma maior curvatura. Isto significa que com o aumento de capilaridade aumenta o intervalo de variação da fração volumétrica fazendo com que o perfil seja mais suave. Em termos físicos isso representa uma maior intensidade da taxa de cisalhamento na escala da gota (ver eq. 3.62), representando uma maior deformação.

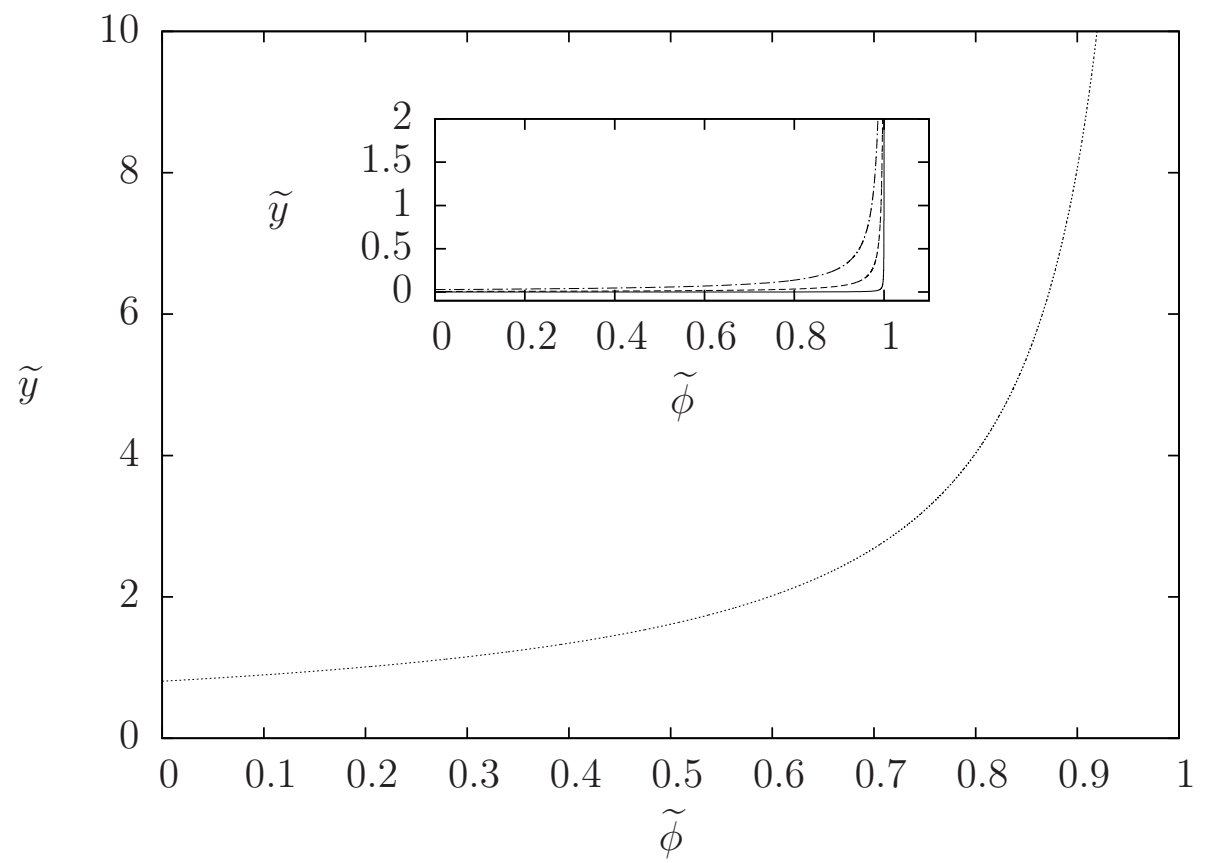

Figura 3.7: Influência do número de capilaridade no perfil de $\widetilde{\phi}$. Constantes: $P e=$ $5,0, \lambda=10,0, \phi_{\infty}=10,0$. Legenda: $-C a=0,01,-\longrightarrow C a=0,05,-\cdot C a=$ $0.1, \cdots C a=0,5$

O gráfico da fig. 3.8 mostra como varia a espessura da camada livre de gotas $(\widetilde{\delta})$ em função da razão de viscosidade $(\lambda)$. Observa-se um aumento de $\widetilde{\delta}$ com o aumento de $\lambda$ 
refletindo que quanto menor a capacidade de deformação da gota maior é a espessura da camada livre de gotas.

Os resultados mostraram que a solução assintótica em regime permanente apresentada nessa seção fornece um resultado preliminar que já foi capaz de identificar toda a física envolvida no problema mesmo que ainda de ponto de vista mais qualitativo. Isso de certa forma mostra a funcionalidade do modelo que numa próxima étapa será resolvido numericamente.

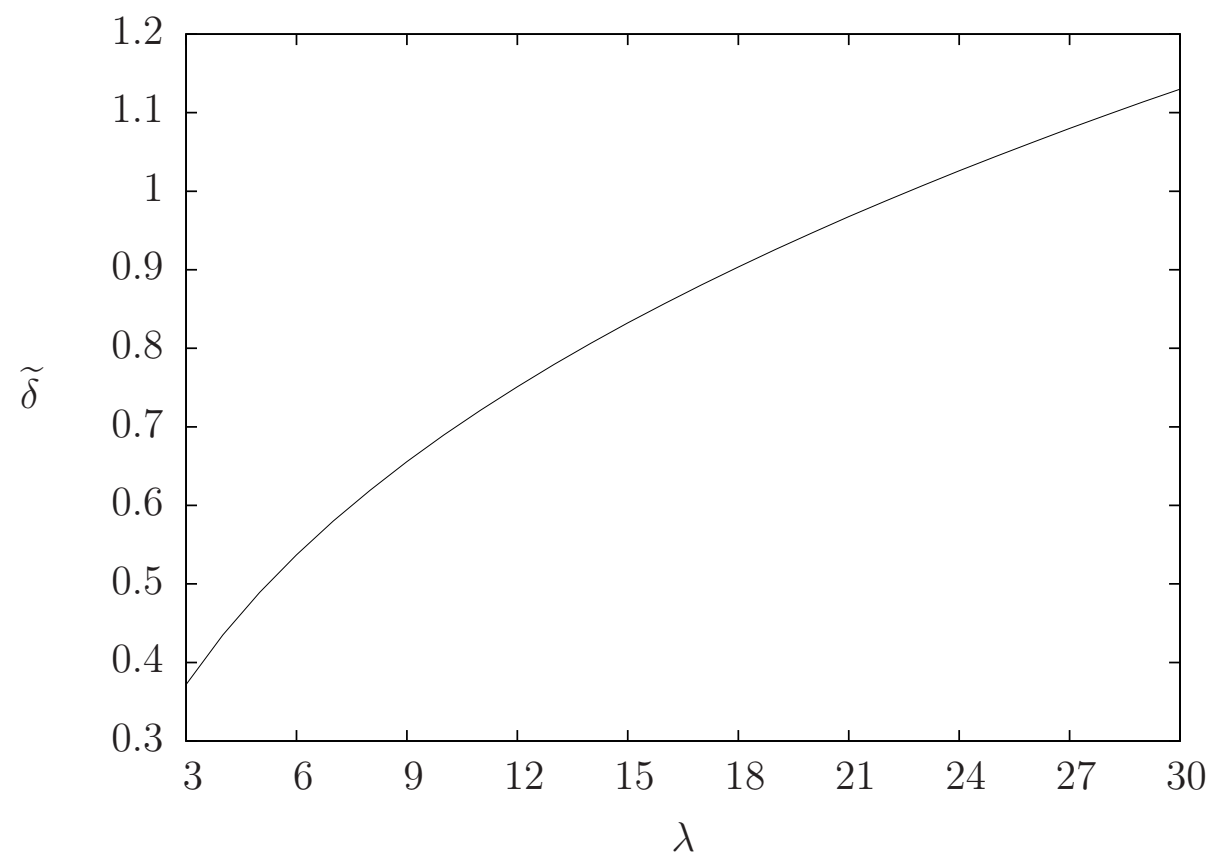

Figura 3.8: Influência da razão de viscosidade $(\lambda)$ na formação da camada livre de gotas $(\widetilde{\delta})$. O modelo prevê o aumento de $\widetilde{\delta}$ com o aumento de $\lambda$.

\subsection{SOLUÇÃO POR MÉTODO DE SIMILARIDADE}

Nesta seção propõem-se uma solução do problema pelo Método de Similaridade. Para este caso não se apresentam resultados. Este método permite resolver uma equação diferencial parcial no domínio $(y, x)$ através de uma equação diferencial ordinária (EDO) no domínio das variáveis de similaridade. Este método tem a vantagem de representar as soluções da EDP pela solução de uma EDO através das relações entre variáveis de similaridade e variáveis do domínio físico. No caso apresentado a solução no domínio físico é $\phi(y, x)$. No domínio de similaridade a solução é $F$. A EDO resultante não 
deve depender de derivadas temporais para que exista solução de similaridade. Para resolver o caso de regime permanente da eq. $3.63(\partial \widetilde{\phi} / \partial \widetilde{t}=0)$ propõem-se a seguinte mudança de variáveis:

$$
\begin{gathered}
\eta=\frac{y}{g(x)} \\
\phi=g(x)^{p} F(\eta)
\end{gathered}
$$

Com as variáveis de similaridade definidas calcula-se as derivadas presentes na eq. 3.63.

$$
\begin{gathered}
\frac{\partial \phi}{\partial x}=\frac{d}{d x}\left(g^{p} F\right)=F \frac{d\left(g^{p}\right)}{d x}+g^{p} \frac{d F}{d x}= \\
=F p g^{p-1} \frac{d g}{d x}+g^{p}\left(\frac{d F}{d \eta} \frac{d \eta}{d x}\right)= \\
=\frac{d g}{d x}\left(g^{p-1}\left(F p-F^{\prime} \eta\right)\right) . \\
\frac{\partial \phi}{\partial y}=\frac{d}{d y}\left(g^{p} F\right)=g^{p} \frac{d F}{d y}=g^{p} \frac{d F}{d \eta} \frac{d \eta}{d y}=g^{p-1} F^{\prime} \\
\frac{\partial}{\partial y}\left(\phi \frac{\partial \phi}{\partial y}\right)=\left(g^{p-1} F^{\prime}\right)^{2}+g^{p} F \frac{d}{d y}\left(\frac{d \phi}{d y}\right)= \\
=g^{2 p-2} F^{\prime} F^{\prime}+g^{p} F \frac{d}{d y}\left(g^{p-1} F^{\prime}\right)= \\
=g^{2 p-2}\left(F^{\prime} F^{\prime}+F F^{\prime \prime}\right) .
\end{gathered}
$$

Após inserir as derivadas anteriores na eq. 3.63, obtém-se:

$$
\frac{d g}{d x}\left(F p-F^{\prime} \eta\right)=-\frac{9}{1120} \frac{C a}{\eta^{3} g^{3}} H(\lambda) F^{\prime}+\frac{V(\lambda)}{P e C a \eta} \phi_{\infty} g^{p-2}\left(F^{\prime} F^{\prime}+F F^{\prime \prime}\right) .
$$

em que $F^{\prime \prime}=d F^{\prime} / d \eta$ e $F^{\prime}=d F / d \eta$. Pela análise dos coeficientes da eq. 3.76 verifica-se que a existência de solução similar é possível se e somente se $(p-2)=-3$ resultando em $d g / d x=g^{-3}$, levando a $g=(4 x)^{1 / 4}$. Este resultado garante que os coeficientes da equação governante no espaço similar $(\eta, F)$ não dependam da direção do escoamento $(x)$. Assim, a equação governante do escoamento estudado no espaço $(\eta, F(\eta))$ é reduzida a:

$$
F^{\prime \prime} F+F^{\prime} F^{\prime}+\left(\frac{P e C a}{V(\lambda) \phi_{\infty}} \eta^{2}-\frac{9}{1120} \frac{H(\lambda) P e C a^{2}}{V(\lambda) \phi_{\infty} \eta^{2}}\right) F^{\prime}+\frac{P e C a}{V(\lambda) \phi_{\infty}} \eta F=0
$$


De uma forma mais compacta, a eq. 3.77 pode ser escrita como:

$$
F^{\prime \prime} F+F^{\prime} F^{\prime}+\left(C_{1} \eta^{2}+\frac{C_{1} C_{2}}{\eta^{2}}\right) F^{\prime}+C_{1} \eta F=0
$$

em que:

$$
C_{1}=\frac{P e C a}{V(\lambda) \phi_{\infty}}
$$

e

$$
C_{2}=-\frac{9}{1120} H(\lambda) C a
$$

No espaço de solução similar as condições de contorno passam a ser :

$$
\left\{\begin{array}{l}
\eta \leq \eta_{\delta}=\delta / g(x), \quad F(\eta)=0 \\
\eta \rightarrow \infty, \quad F(\eta)=g(x) \phi_{\infty}(x)=z(x)
\end{array}\right.
$$

A solução da eq. 3.78 pode ser obtida pelo método de Runge-Kutta de Quarta Ordem. Define-se que:

$$
\left\{\begin{array}{l}
F^{\prime}=K_{1}=\frac{d F}{d \eta} \Rightarrow d F=K_{1} d \eta, \\
F^{\prime \prime}=K_{2}=\frac{d K_{1}}{d \eta} \Rightarrow d K_{1}=K_{2} d \eta
\end{array}\right.
$$

Desta forma rescreve-se a eq. 3.78 na seguinte forma:

$$
K_{2}=-\frac{K_{1} K_{1}}{F}-\left(C_{1} \eta^{2}+\frac{C_{1} C_{2}}{\eta^{2}}\right) \frac{K_{1}}{F}-C_{1} \eta \Leftrightarrow K_{2}=\mathcal{G}\left(F, K_{1}, \eta\right) .
$$

É de se referir que para iniciar o método numérico é necessário um chute para $F(\eta=\infty)$ e para $F^{\prime}(\eta=\infty)$. O valor de $F^{\prime \prime}(\eta=\infty)$ pode ser obtido pela eq. 3.83. Como trabalho futuro sugere-se resolver o problema completo por método de similaridade (no caso da eq. 3.83 ) e por método numérico (no caso da eq. 3.56). 


\section{APARATO EXPERIMENTAL E INSTRUMENTAÇÃO}

A viscosidade dos fluidos foi medida no reômetro e na bancada experimental para o estudo de escoamento de fluidos em tubos capilares. A massa específica foi medida em um densímetro. Recorreu-se a termômetros de mercúrio para medições de temperatura na fase de síntese de emulsões e termômetros digitais para avaliar a temperatura do laboratório. A microestrutura das emulsões foi avaliada por microscopia óptica.

\subsection{Reômetro}

O reômetro da Anton Paar do modelo Physica MCR 301 (fig. 4.1), está instalado sobre uma mesa robusta e isolada de vibrações. Permite estudar tanto fluidos newtonianos como não-newtonianos com ou sem influência de campo magnético, em cisalhamento simples e oscilatório. Uma das grandes vantagens deste reômetro é a necessidade de pequenas quantidades de amostra (máxima de $2 \mathrm{ml}$ ). Esta característica promove a economia de fluidos de elevado custo como também fluidos biológicos permitindo ensaiar amostras muitas vezes menores do que $1 \mathrm{ml}$.

A temperatura da amostra é controlada pelo sistema (Peltier). Esse sistema permite o controlo de temperatura $\left(-40-200^{\circ} \mathrm{C}\right)$ do disco sobre o qual a amostra do fluido é colocada (ver fig. 4.2). Este sistema é constituído por materiais, que recebem/doam elétrons, que percorridos com uma corrente elétrica mantêm uma diferença de temperatura. Quando são realizados experimentos nos quais se pretende variar o campo magnético em função de uma corrente eléctrica (fig. 4.3(a)) é necessário trocar o disco onde se coloca a amostra de liquido. Devido a essa troca o sistema de refrigeração da amostra é efetuado pelo banho térmico da Lauda (4.3(b)).

O reômetro é alimentado por ar-comprimido gerado pelo compressor da Shulz (modelo MSV6), do tipo médico-odontológico. O ar-comprimido antes de chegar ao reômetro é limpo e desumidificado através de filtros e desumidificadores (fig. 4.4). O sistema de ar 
comprimido possibilita um torque de operação no intervalo de $0,1 \mu N m$ a200 $\mathrm{mNm}$. A resolução do torque do reômetro é de $0,2 \mu \mathrm{Nm}$. O torque é uma quantidade mecânica a ser controlada de forma que esteja sempre dentro do intervalo indicado pelo fabricante do reômetro. Dependendo da viscosidade do fluido de ensaio a taxa de cisalhamento pode chegar a valores em torno de $5000 \mathrm{~s}^{-1}$, superando os viscosímetros padrões. É de se destacar que o sistema de ar-comprimido permite o deslocamento automático do braço do reômetro com uma rapidez e precisão considerável. O espaçamento entre a ferramenta de trabalho e o prato onde se localiza a amostra pode ser menor do que $0,5 \mathrm{~mm}$.

Sabendo que o torque está relacionado diretamente com a viscosidade do fluido e com a taxa de cisalhamento (eq. 2.37), conclui-se que para fluidos com alta viscosidade a taxa de cisalhamento tem que ser baixa para que o torque não seja tão elevado a ponto de superar os limites de potência do sistema motor do reômetro. Assim o espaçamento (distância entre a placa e a ferramenta de trabalho) tem que ser grande para manter uma $\dot{\gamma}$ possível de ensaiar nas condições estabelecidas. Conhecendo-se a dimensão do espaçamento entre dois discos e o diâmetro do disco rotativo pode-se calcular o volume de líquido da amostra. Aconselha-se que o volume de líquido colocado sobre o disco do reômetro seja um pouco acima do estimado, para que o disco rotativo seja completamente preenchido pelo fluido. A incerteza da medição da viscosidade foi obtida pelo valor máximo entre o desvio padrão das 5 repetições de medição da viscosidade para cada taxa de cisalhamento e a incerteza avaliada através da equação do cálculo do torque (eq.2.38). Para mais detalhes ver o Anexo D.

A questão do controle do espaçamento dos discos é importante uma vez que existe um valor ótimo para este parâmetro de forma que a medição da viscosidade permaneça inalterada para uma determinada taxa de cisalhamento. Nos ensaios com a emulsão a dimensão das gotas tem que ser muito menor que o espaçamento dos discos para que se garanta um meio contínuo e evite uma condição de deslizamento entre a gota e os contornos sólidos do escoamento. Afinal, a condição de contorno de deslizamento é uma hipótese para um fluido contínuo ou um sistema complexo fluido que possa ser aproximado por um meio homogêneo equivalente. 
O número de $R e$ do escoamento entre os discos do reômetro pode ser calculado considerando como escala de comprimento o raio do disco rotativo $(R)$, e como escala de velocidade do escoamento o fator $\dot{\gamma} \delta$ :

$$
R e=\frac{\rho \dot{\gamma} \delta R}{\eta}
$$

em que $\delta$ é à distância entre os discos.

Para que o escoamento seja unidirecional é necessário garantir que o número de $R e$ modificado seja muito menor que a unidade $\left(R e_{R}<<1\right)$. Analisando a razão entre as forças viscosas e as forças de inércia, obtém-se que:

$$
R e_{R}=\operatorname{Re}\left(\frac{\delta}{R}\right)^{2}<<1
$$

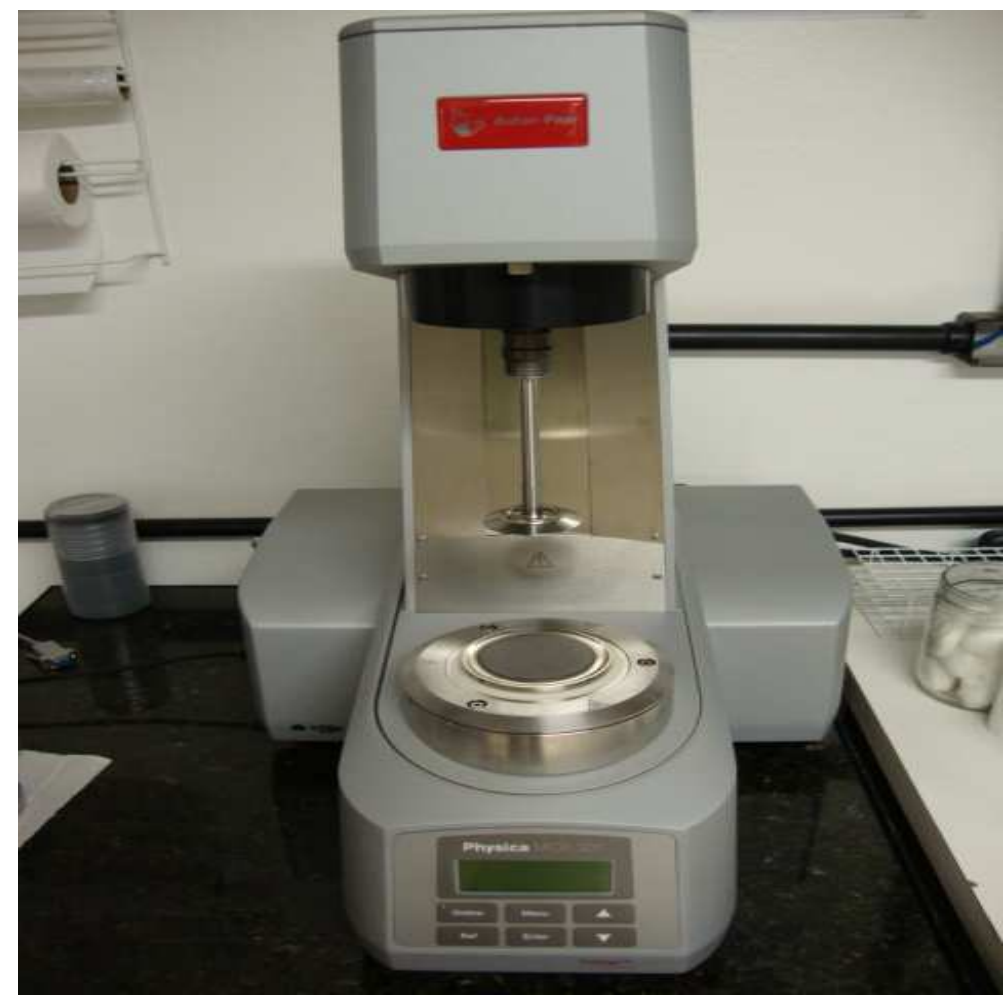

Figura 4.1: Reômetro MCR 301 da Anton Paar: Esta figura destaca a ferramenta de trabalho rotativa e o disco imóvel cuja temperatura é controlada pelo sistema Peltier e sobre o qual se posiciona a amostra do fluido. 


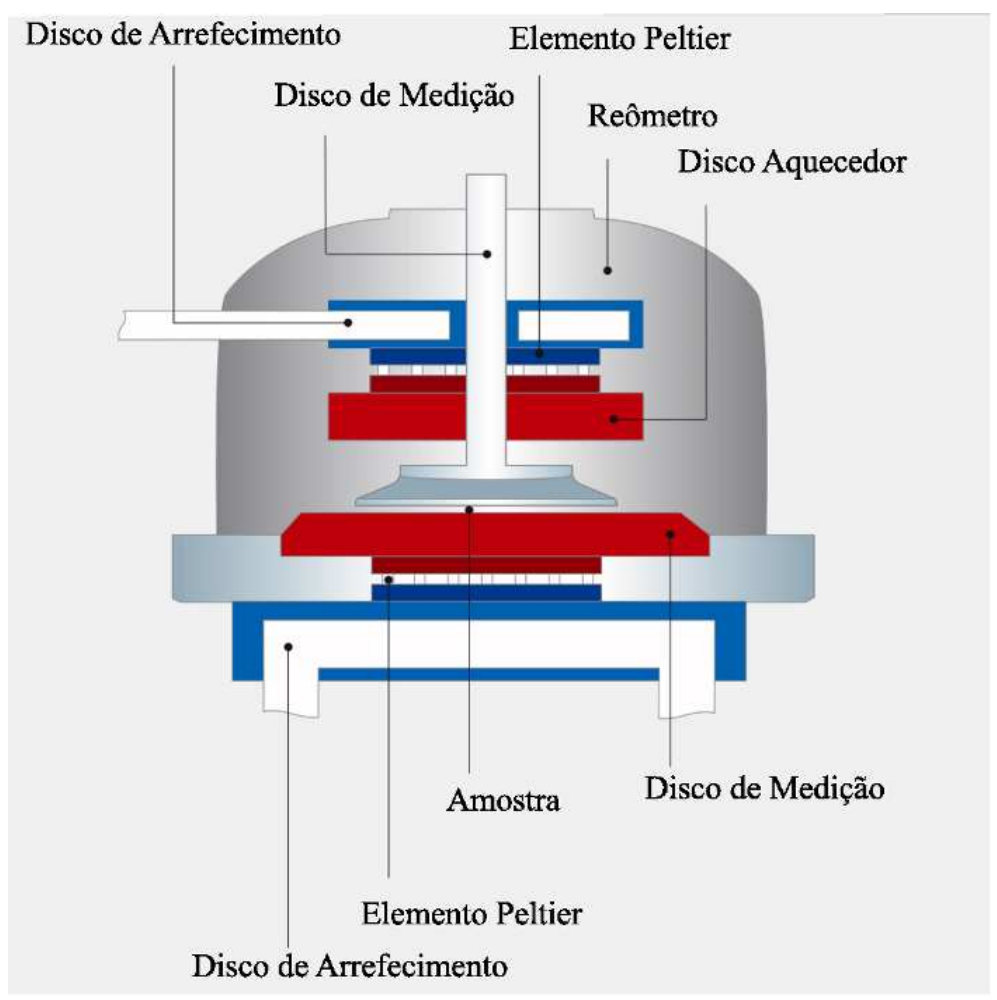

Figura 4.2: Sistema Peltier do Reômetro MCR301 da Anton-Paar.

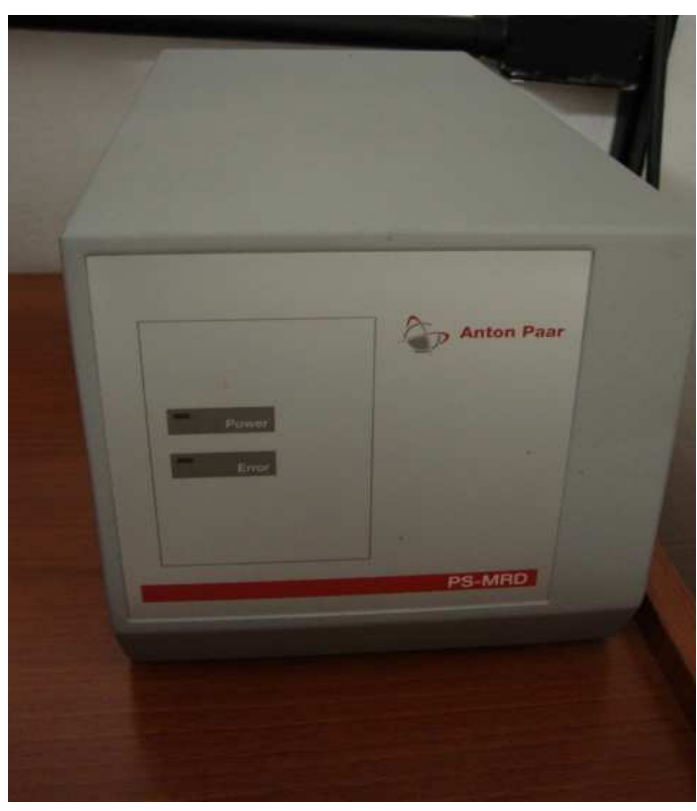

(a) Fonte para geração de campo magnético na seção de teste da amostra

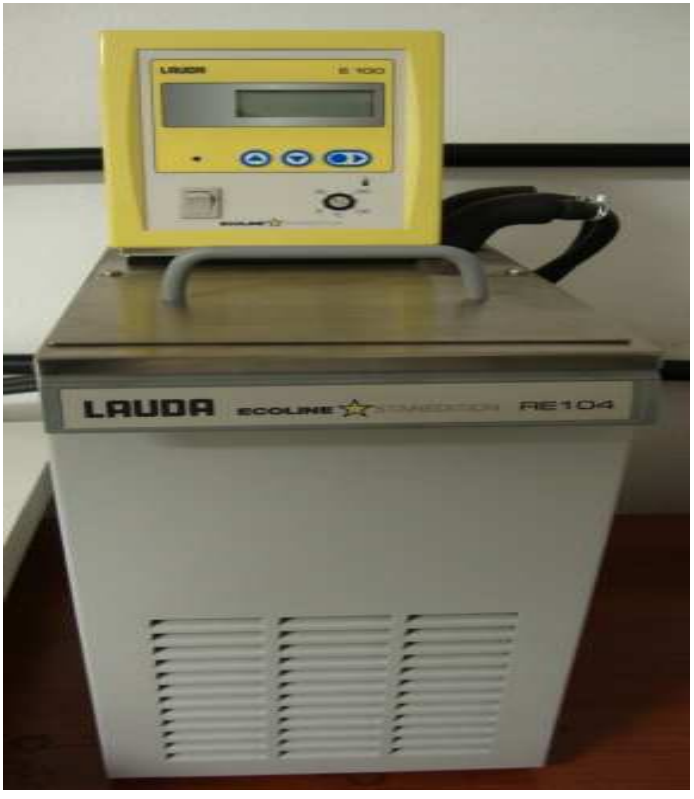

(b) Banho Térmico

Figura 4.3: Fonte para geração de campo magnético na seção de teste da amostra; Banho Térmico 


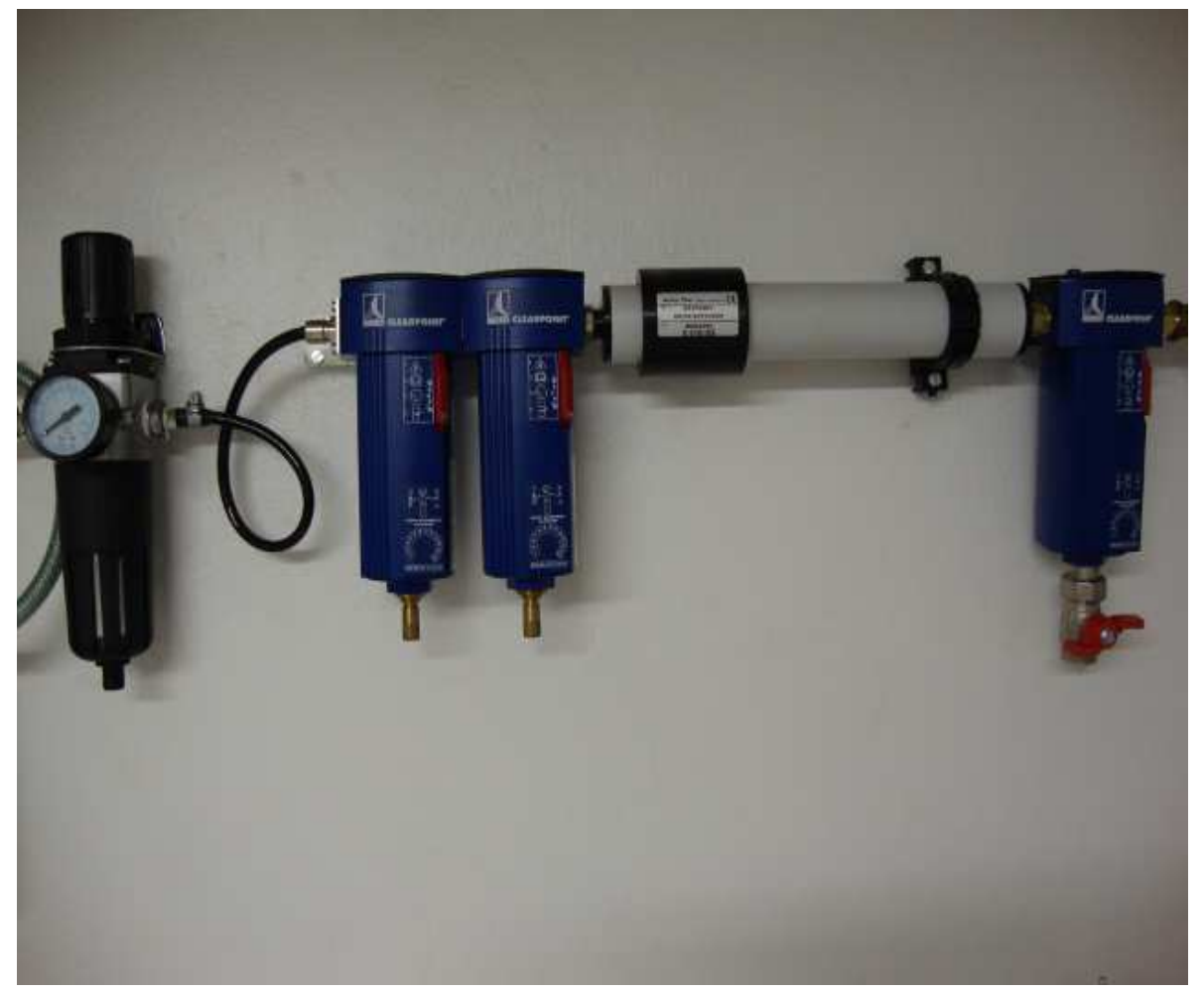

Figura 4.4: Sistemas de filtros de óleo (os dois filtros da esquerda), desumidificador (braço branco horizontal central) e filtro de partículas(filtro da extrema direita) 


\subsection{Bancada para Estudo de Escoamento Quadrático}

Nesta seção é descrita a bancada destinada ao escoamento no interior de tubos capilares de seção circular. A bancada é constituída por capilares, seringas, manômetro, transdutor de pressão e bomba de seringa.

A bomba de seringa da Cole \& Parmer do modelo KDS 210 (fig. 4.5), tem mostrador digital, é automática em relação ao recuo e avanço do dispositivo de encaixe do êmbolo da seringa e permite ser programada de forma que seja efetuado um avanço e um recuo com diferentes velocidades. Internamente possui dados relativos a várias marcas de seringa, permitindo assim selecionar a marca de seringa de trabalho bem como a sua capacidade em $\mathrm{cm}^{3}$. Com essas informações o sistema fornece o diâmetro interno da seringa selecionada. Assim imposta uma vazão, facilmente a bomba adquire a velocidade adequada aos parâmetros introduzidos. A vazão máxima permitida é de $36 \mathrm{ml} / \mathrm{min}$ e a mínima é de $1,426 \mu \mathrm{l} / \mathrm{h}$. A precisão da bomba vai até a terceira casa decimal.

O manômetro da marca Zurich é um manômetro digital cujo sensor tem uma incerteza máxima de $0,1 \%$ do fundo de escala $(280 \mathrm{mmHg})$. O sensor foi calibrado para medir pressão relativa. Assim sendo, o manômetro tem a capacidade de internamente se auto-ajustar à pressão atmosférica local. O manômetro tem precisão de duas casas decimais. Em uma primeira fase o manômetro está conectado a seringa (fig. 4.6) com o intuito de calibrar o transdutor de pressão.

No interior do transdutor (fig. 4.7(a)) está alojada uma membrana (fig. 4.7(b)). As membranas disponíveis têm diferentes espessuras. As mais espessas têm a capacidade de suportar maiores pressões. Pela deformação da membrana, um sinal elétrico é gerado e enviado para uma placa de aquisição de dados que está conectada a um computador. Na tabela 4.1 estão os resultados da calibração das membranas. A membrana 22 foi calibrada com etileno glicol, enquanto as restante foram calibradas com óleo mineral. O diâmetro interno do capilar utilizado em todas as calibrações foi de $500 \mu \mathrm{m}$. A temperatura de calibração foi de $25^{\circ} \mathrm{C}$ para todas as calibrações. Constatou-se que as medições para a viscosidade dos líquidos usados na calibração foram bastante próximas 
quando comparadas com as medições no reômetro (óleo mineral: capilar 144, 33 + / $0,57 c P$, reômetro $142+/-1,32 c P$; etileno glicol: capilar $11,0+/-0,59 c P$, reômetro $17,20 \pm 1,44 c P)$.

Tabela 4.1: Constantes de Calibração das Membranas

\begin{tabular}{|c|c|}
\hline Membrana & Constante de Calibração \\
\hline 22 & $172 \pm 25,50$ \\
30 & $541 \pm 18,78$ \\
34 & $1230 \pm 29,76$ \\
36 & $1630 \pm 49,00$ \\
\hline
\end{tabular}

Os capilares (fig. 4.6) utilizados são da marca Hilgenberg e são fabricados em vidro com comprimento de $15 \mathrm{~cm}$ e diâmetro externo de $3 \mathrm{~mm}$. O diâmetro interno dos capilares varia entre $5 \mu \mathrm{m}$ e $1 \mathrm{~mm}$. A incerteza da medição da viscosidade foi obtida pelo cálculo da incerteza da eq. 2.63. Para mais detalhes ver o Anexo D. Quanto à incerteza da diferença de pressão, optou-se pelo máximo entre o desvio padrão da pressão recolhida durante uma hora de experimento constante, para cada vazão imposta, e a resolução do manômetro digital. 


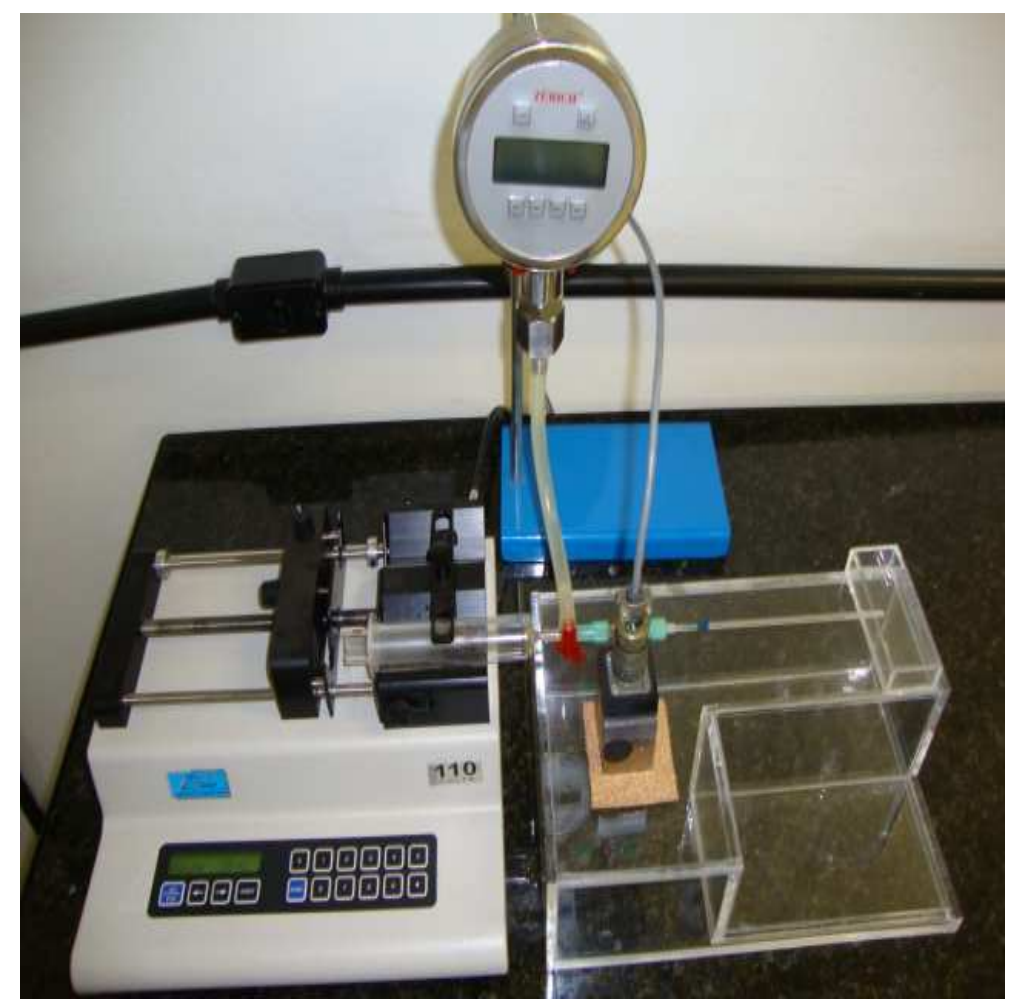

Figura 4.5: Bancada para estudo de escoamento em tubo capilar constituída por: manômetro digital, seringa de vidro, transdutor de pressão,tubo capilar de vidro e bomba de seringa.

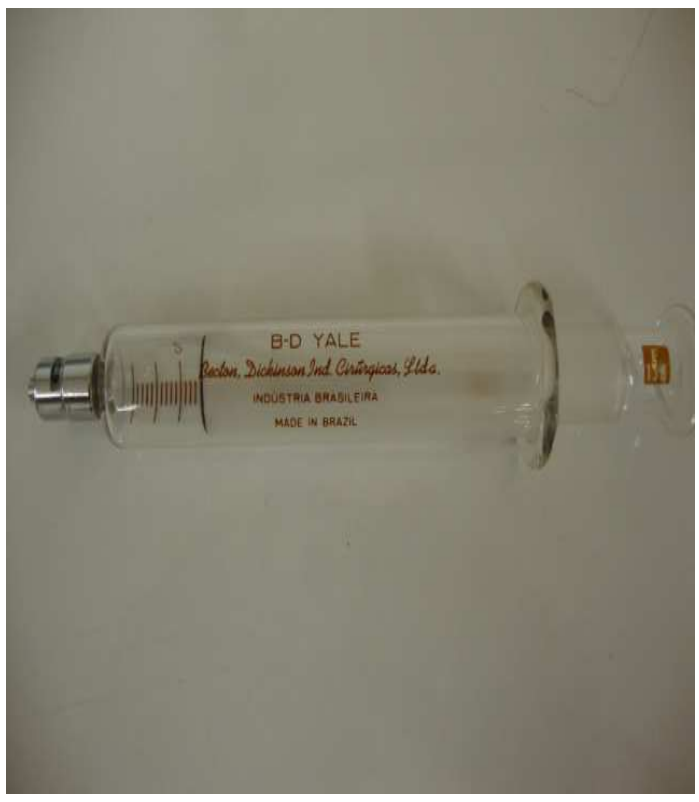

(a) Seringa

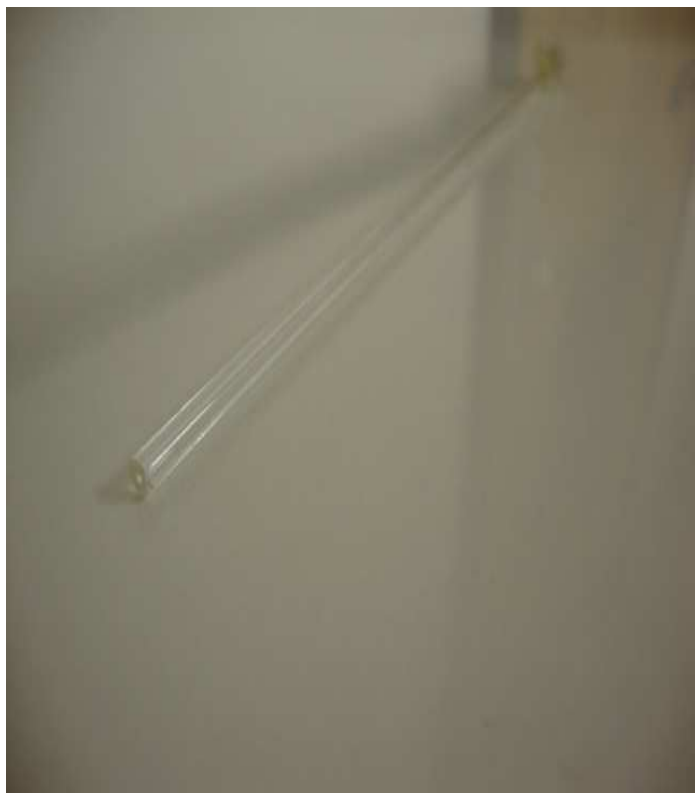

(b) Tubo Capilar

Figura 4.6: Seringa B-D YALE 10 ml ;Tubo Capilar com diâmetro interno de $1000 \mu \mathrm{m}$ 


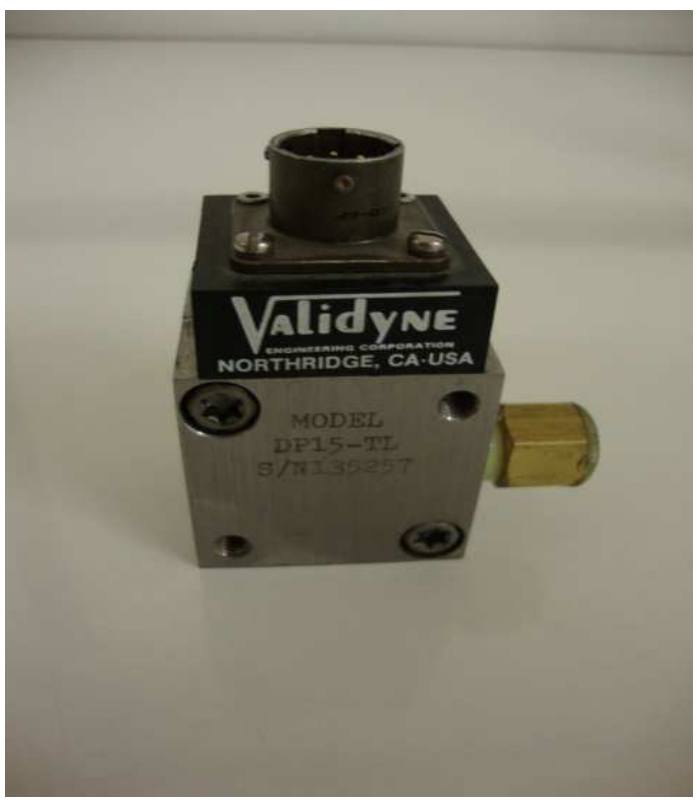

(a) Transdutor

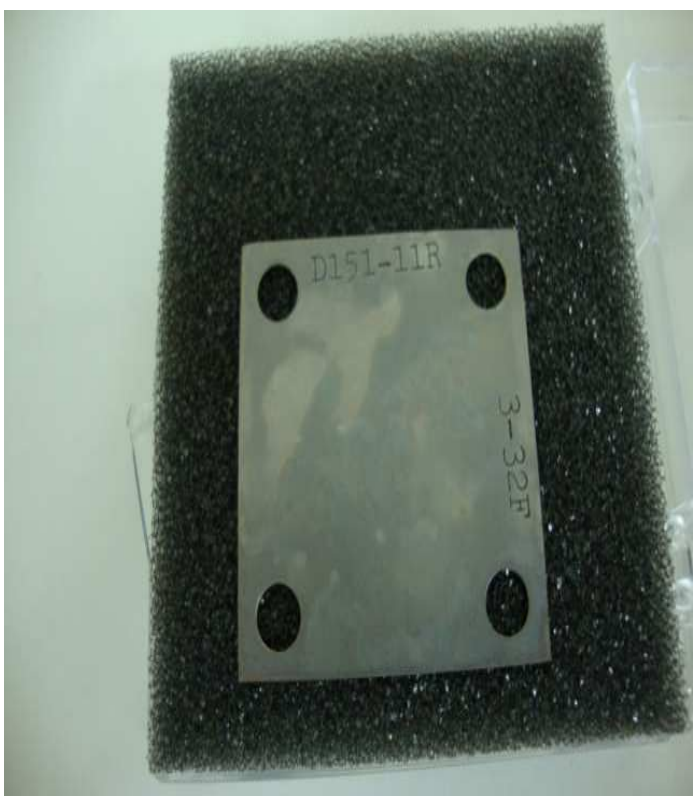

(b) Membrana

Figura 4.7: Transdutor e Membrana(22) (VALIDYNE)

\subsection{Microscópio}

A emulsão pode ser classificada como monodispersa ou polidispersa. Nas emulsões monodispersas as gotas têm todas o mesmo tamanho. Já nas polidispersas as gotas têm diferentes tamanhos. Um método para determinar a polidispersividade é avaliar o diâmetro da gota por obervação microscópica de várias amostras da mesma emulsão. Em Walstra (2005) é citado o uso de microscópio de escaneamento a laser. Neste trabalho a caracterização da microestrutura foi feita por microscopia ótica com o microscópio do modelo BX51 da Olympus (fig. 4.8).

O microscópio possui diversos filtros que por combinação permitem imagens de elevado contraste e vários níveis de iluminação. O mesmo está equipado com uma câmera designada por UC30 de 3,2 megapixels que permite a interface com o computador via FireWire, promovendo a visualização da amostra por imagens coloridas ou monocromáticas, em tempo real. A velocidade da câmera é de 7,0fps na resolução $2080 \mathrm{x}$ 1544 e de $35 f p s$ na resolução 688 x 514. As imagens são recolhidas por um software fornecido com o próprio microscópio. Através desse software é possível detectar super- 


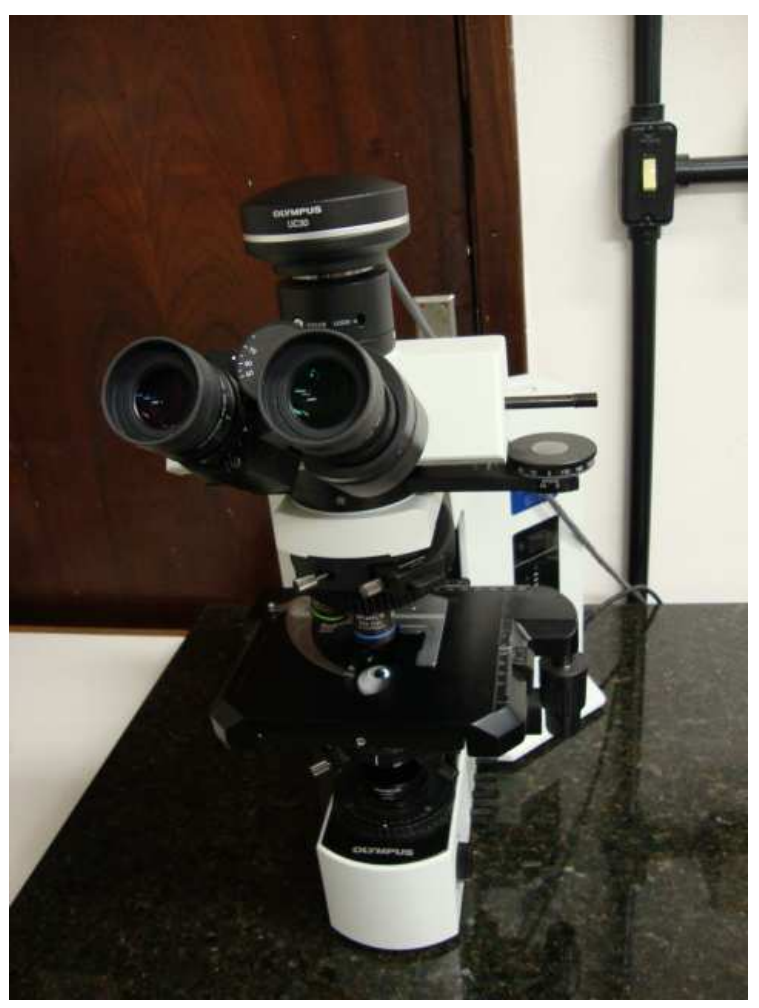

Figura 4.8: Microscópio Olympus BX51 com câmera UC30 e ampliação ocular é 10X As lentes disponíveis têm apliação de 2X,5X,10X,20X e 50X.

fícies de diferentes contrastes, recolher informação das características geométricas das superfícies, do tipo: dimensão, área, e número de partículas. Essas informações são reunidas em folha de cálculo do tipo Excel. Este microscópio está equipado com as lentes de 2X,5X,10X,20X e 50X sendo que a ampliação ocular é de 10X. Assim, se por exemplo for selecionada a lente 2X, a ampliação é de 20 vezes (fig. 4.9). O microscópio está instalado sobre uma mesa desprovida de vibrações, plana e robusta. A incerteza referente à medição do diâmetro da gota foi avaliada pelo desvio padrão calculado para cada intervalo de gota considerado. 


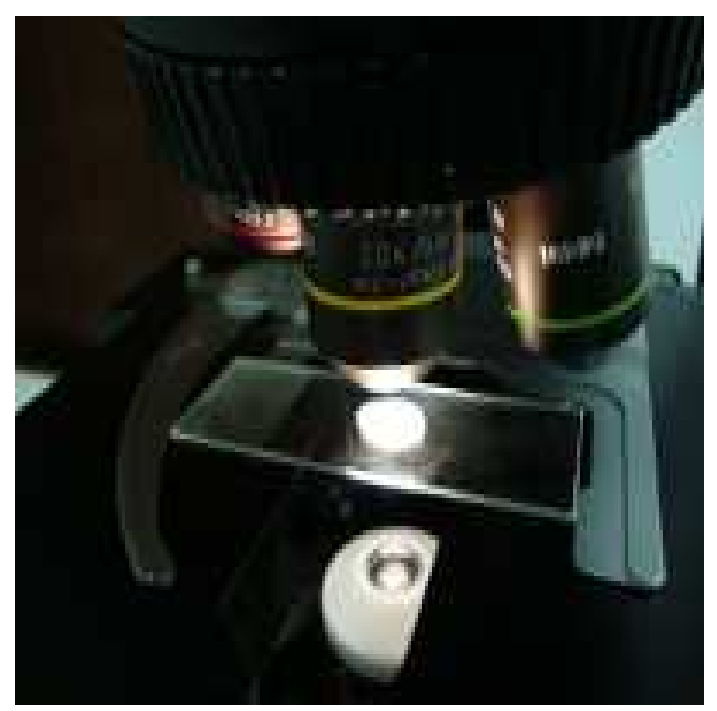

Figura 4.9: Emulsão analisada por microscópio óptico.

\subsection{Tensiômetro}

Considere uma gota formada por um líquido A que está imersa em um líquido B, menos denso que o líquido A (Fig. 4.10). A gota se mantém presa no capilar devido a tensão interfacial. Com o aumento gradual do volume da gota, a gota se desprenderá do capilar quando atingir o seu volume crítico. Nesse caso a tensão interfacial não é mais capaz de balancear o par peso-empuxo de Arquimedes. Nesse instante, o ângulo entre a superfície da gota e a horizontal do capilar é de $90^{\circ}$. A tensão interfacial é medida através do volume da gota:

$$
\tau_{s}=\frac{\Delta \rho V g}{2 \pi R} F
$$

em que $V$ é o volume da gota, $g$ é a aceleração da gravidade, $\Delta \rho$ é a diferença da massa específica da interface formada pelo líquido da gota e pela fase adjacente à gota, $F$ é um fator de correção e $R$ é o raio do capilar. O fator de correção é fornecido pelo fabricante em forma de tabela e por ajuste polinomial aos pontos tabelados.

O tensiômetro da Lauda TVT2 (fig. 4.11) é um tensiômetro de gota. Este tensiômetro mede a tensão superficial (liquído-ar) e a tensão interfacial (líquido-líquido). As partes que constituem o tensiômetro são, unidade de controle eletrônico, unidade mecânica, cuba de temperatura, seringa de $2,5 \mathrm{ml}$, capilar $(d=2,77 \mathrm{~mm})$ e banho térmico da Lauda. A água do banho térmico passa pelo interior da cuba na qual está inserida a 


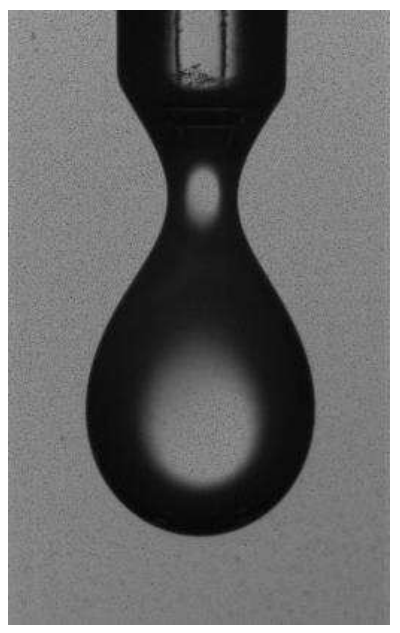

Figura 4.10: Gota de um líquido A imersa em um líquido B, formada na ponta de um capilar. Note que a gota se encontra no volume crítico, no qual a tensão interfacial não é mais capaz de balancear a força gravitacional. Imagem retirada de Lautrup , (2011)

seringa. Dessa forma é possível medir a tensão interfacial em função da temperatura. A unidade eletrônica auxilia a unidade mecânica, permitindo interromper e reiniciar o movimento do braço do tensiômetro que pressiona o êmbolo da seringa. O software que acompanha o tensiômetro permite o ajuste de parâmetros (massa específica dos líquidos, velocidade de formação de gota, raio interno do capilar) do experimento e coleta os dados.

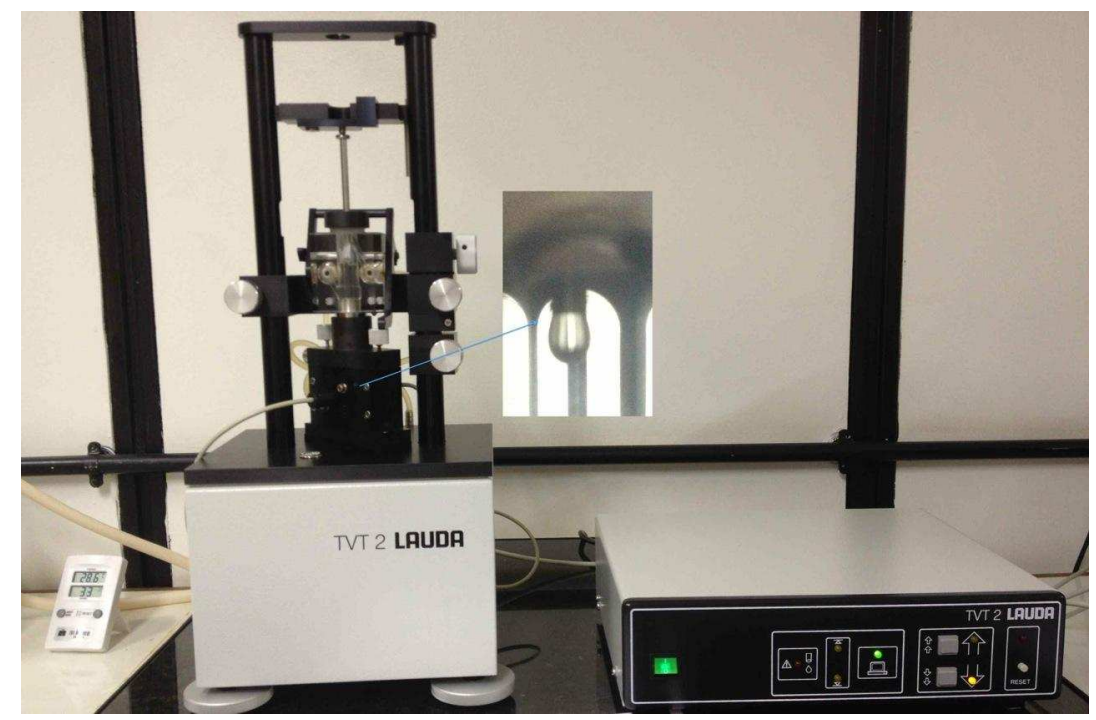

Figura 4.11: Tensiômetro TVT2 - Lauda. Formação da gota na extremidade do capilar.

Para as medidas da tensão interfacial, o líquido com maior molhabilidade deve ser colocado na seringa. O capilar fica imerso em um recipiente de vidro, que é preenchido 


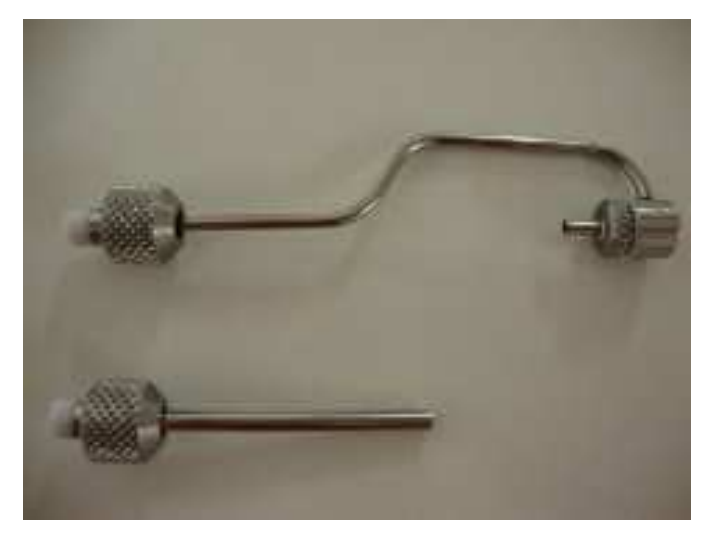

Figura 4.12: Capilar reto e reverso.

com um outro líquido. Se o líquido na seringa for aquele de maior massa específica, utiliza-se o capilar reto. Se esse líquido for aquele de menor massa específica, deve-se utilizar um capilar reverso (fig. 4.12), no qual a gota se forma abaixo da barreira de luz, e sobe até o topo devido à diferença da massa específica. A gota formada é detectada quando passa pela barreira de luz. Assim é calculado o volume crítico da gota e o tempo de formação.

Este tipo de tensiômetro tem como vantagem acrescida o fato de ser necessária somente pequenas quantidades de líquido para avaliar a tensão interfacial. O fabricante recomenda realizar a medição da tensão superficial da água a $24^{\circ} \mathrm{C}$ para verificar se o equipamento está a funcionar conforme o esperado. O valor obtido foi de 71, $11 \mathrm{mN} / \mathrm{m}$ que está dentro do esperado $(71-72 \mathrm{mN} / \mathrm{m})$, indicando que o equipamento está em perfeito funcionamento e que a água pode ser considerada sem impurezas. A fig. 4.13 mostra os resultados da calibração realizada. Observa-se que os valores de tensão superficial na interface ar-água destilada está em absoluta concordância com a recomendação do fabricante do referido equipamento.

O tensiômetro dispõe de três modos de funcionamento, o padrão (STD), o dinâmico (DYN) e o quasi-estático (QST). No modo padrão, o único parâmetro ajustável é a velocidade de formação da gota, que se mantém constante durante todo o experimento. Desta maneira, todas as gotas possuem o mesmo tempo de formação. Esse é o método mais adequado para obter valores de tensão interfacial sem dependência com o tempo. O modo dinâmico funciona controlando a velocidade de formação da gota. As primei- 


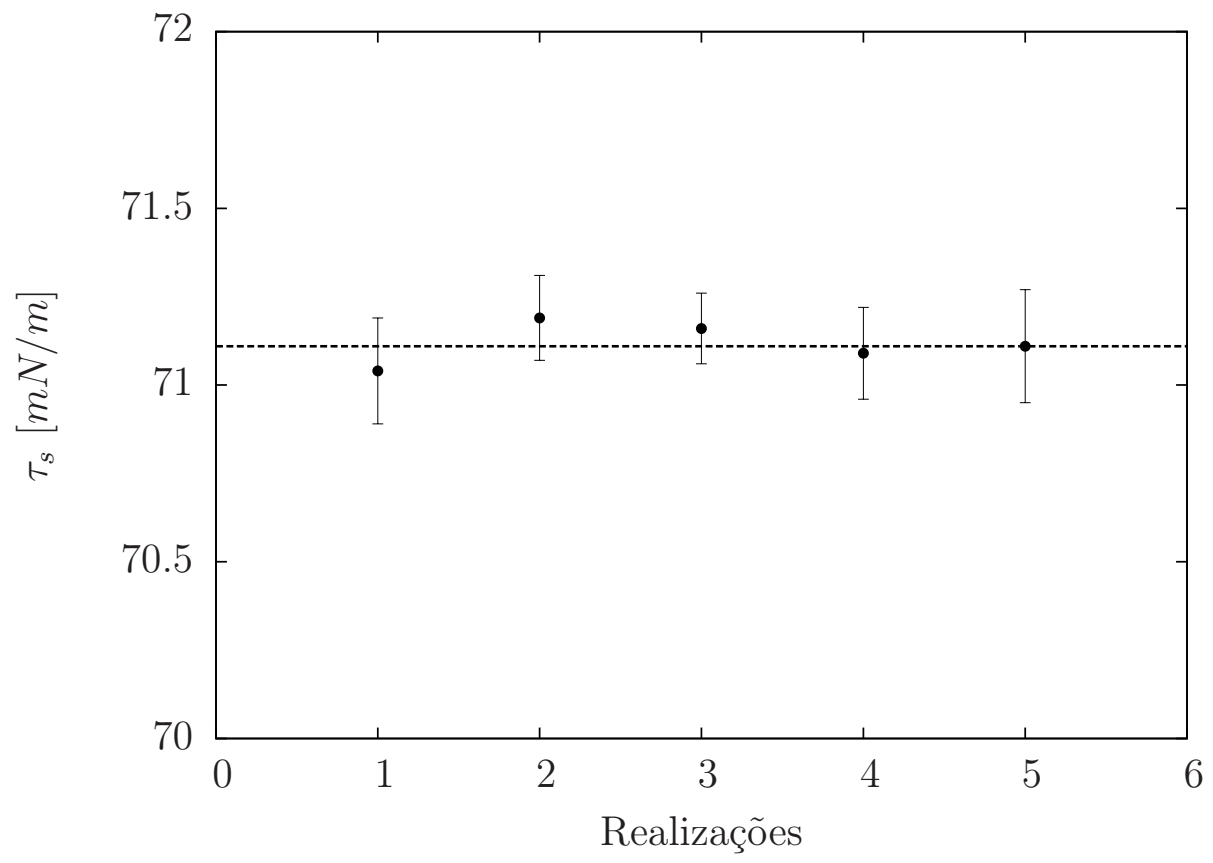

Figura 4.13: Tensão Interfacial $\left(\tau_{s}\right)$ da água destilada-ar. As medições foram feitas a $T=24^{\circ} \mathrm{C}$. Em cada realização foi avaliada a tensão interfacial de 5 gotas de água. A tensão interfacial média foi de $71,11[\mathrm{mN} / \mathrm{m}]$

ras medidas são feitas com a velocidade máxima de formação. De forma gradual o tensiômetro vai reduzindo a velocidade de formação da gota, aumentando o tempo de formação da gota. Durante o processo de formação da gota, a velocidade de formação é constante. A medida que o tempo de formação aumenta, a tensão interfacial tende a diminuir, ou seja, o volume crítico também diminui. Este modo é adequado para verificar se existe dependência da tensão superficial com o tempo de formação da gota. No modo quasi-estático funciona controla-se o volume da gota formada. No início o tensiômetro forma uma gota rapidamente até que ela se desprenda. O volume dessa gota é definido como o volume crítico. Em seguida, uma nova gota é formada rapidamente, mas o tensiômetro para antes que se atinja o volume crítico. Como a tensão interfacial diminuí com o tempo, a gota irá se desprender quando a tensão atingir um valor crítico. Para cada ciclo, o tensiômetro produz gotas cada vez menores, fazendo com que se obtenha tempos de formação cada vez maiores. O método consegue obter tempos de formação de superfície da gota de até 1 hora. Este modo é o mais adequado para estudar soluções com surfactante, nas quais a tensão interfacial apresenta dependência com o tempo. O tensiômetro leva cerca de $20 \mathrm{~s}$ para formar a gota. Por esse motivo, medidas de tensão interfacial para tempos menores que $20 s$ não são possíveis. 
Tempos menores que $60 s$ apresentam elevado erro, pois o tempo de formação real da superfície da gota não corresponde ao tempo cronometrado. O erro se torna desprezível para tempos maiores que $60 \mathrm{~s}$. A incerteza da tensão interfacial foi calculada através do desvio padrão referente a 5 medições realizadas em cada experimento.

\subsection{Densímetro}

A massa específica dos fluidos foi medida no densímetro da marca Anton Paar (modelo DMA38, fig. 4.14). Este densímetro é indicado para fluidos com massa específica de até $3,0 \mathrm{~g} / \mathrm{cm}^{3}$. O volume de amostra de fluido necessária é de $1 \mathrm{ml}$. A resolução da massa específica é de $0,001 \mathrm{~g} / \mathrm{cm}^{3}$ e da temperatura é de $0,1^{\circ} \mathrm{C}$ podendo operar com fluidos até $40^{\circ} \mathrm{C}$. O método de medição é o do tubo oscilante em U. O tubo preenchido de fluido é sujeito a uma força eletromagnética que faz oscilar o tubo. A partir da frequência e do período de oscilação característicos $(f)$, a massa específica pode ser determinada por:

$$
\rho=A+B f^{2}
$$

As constantes $A$ e $B$ são obtidas pela calibração do instrumento com substâncias de massa específica conhecida, tipicamente água e ar, (Furtado et al., (2009)). A incerteza da massa específica foi calculada através do desvio padrão referente a 5 medições da massa específica.

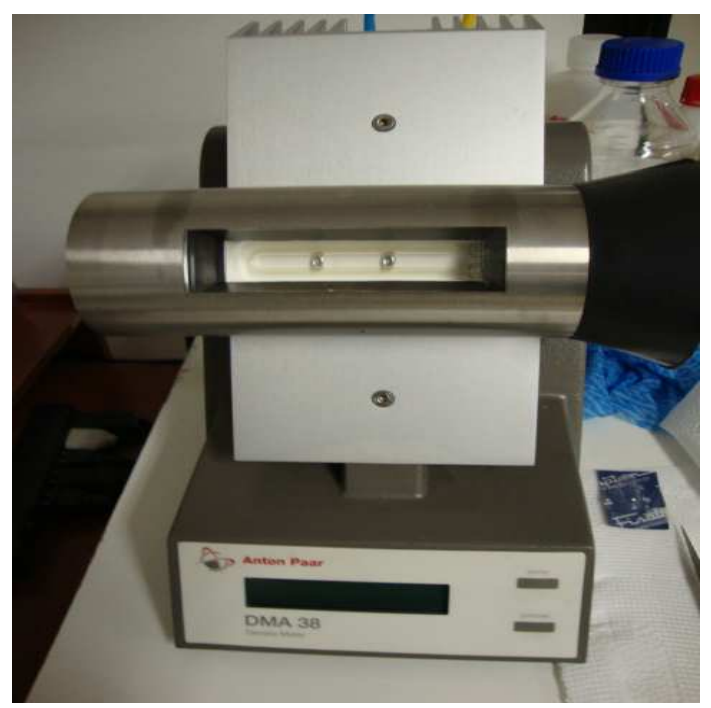

Figura 4.14: Densímetro Anton Paar modelo DMA38 


\subsection{Agitador Mecânico e Magnético}

Na preparação de emulsões a faze aquosa e oleosa foram aquecidas na chapa aquecedora FISATOM (fig. 4.15). Esta chapa permitiu a mistura dos surfactantes com a fase aquosa por agitação promovida por uma cápsula cujo movimento é proporcionado por uma hélice situada na parte inferior do aquecedor. O botão direito permite intensificar o movimento da hélice e o botão direito permite ajuste da temperatura.

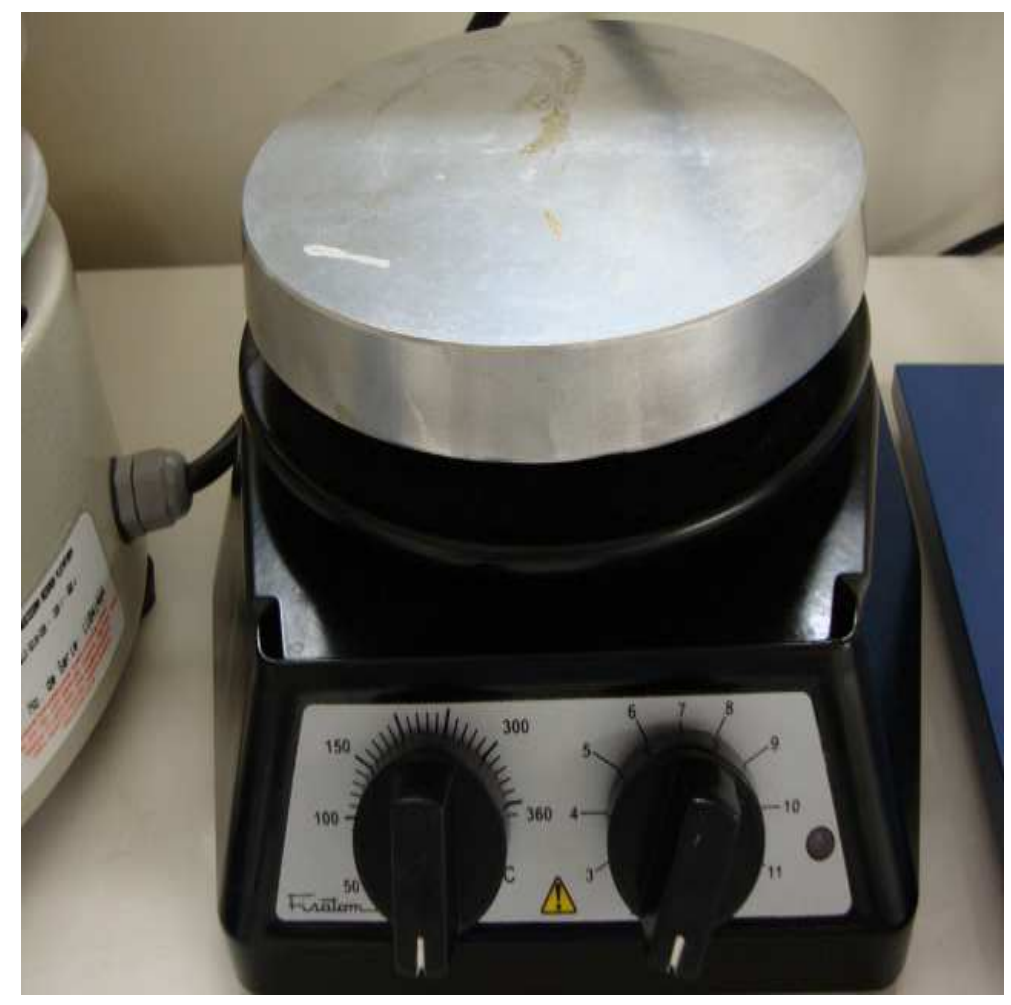

Figura 4.15: Chapa Aquecedora FISATOM

Para sintetizar as emulsões é necessário um misturador ou um homogeneizador. Foi usado o misturador da marca IKA (modelo RW20) com mostrador digital (fig. 4.16). Esse misturador tem a capacidade de misturar 20 litros de líquido com viscosidade máxima de 10000 cP. A velocidade máxima do motor é de $2000 \mathrm{rpm}$. A haste de mistura utilizada é do tipo âncora (modelo R1330). É indicada para fluidos com viscosidade média a alta em baixas velocidades. Esta haste promove altas taxas de cisalhamento nas bordas e evita a entrada de ar na mistura. 


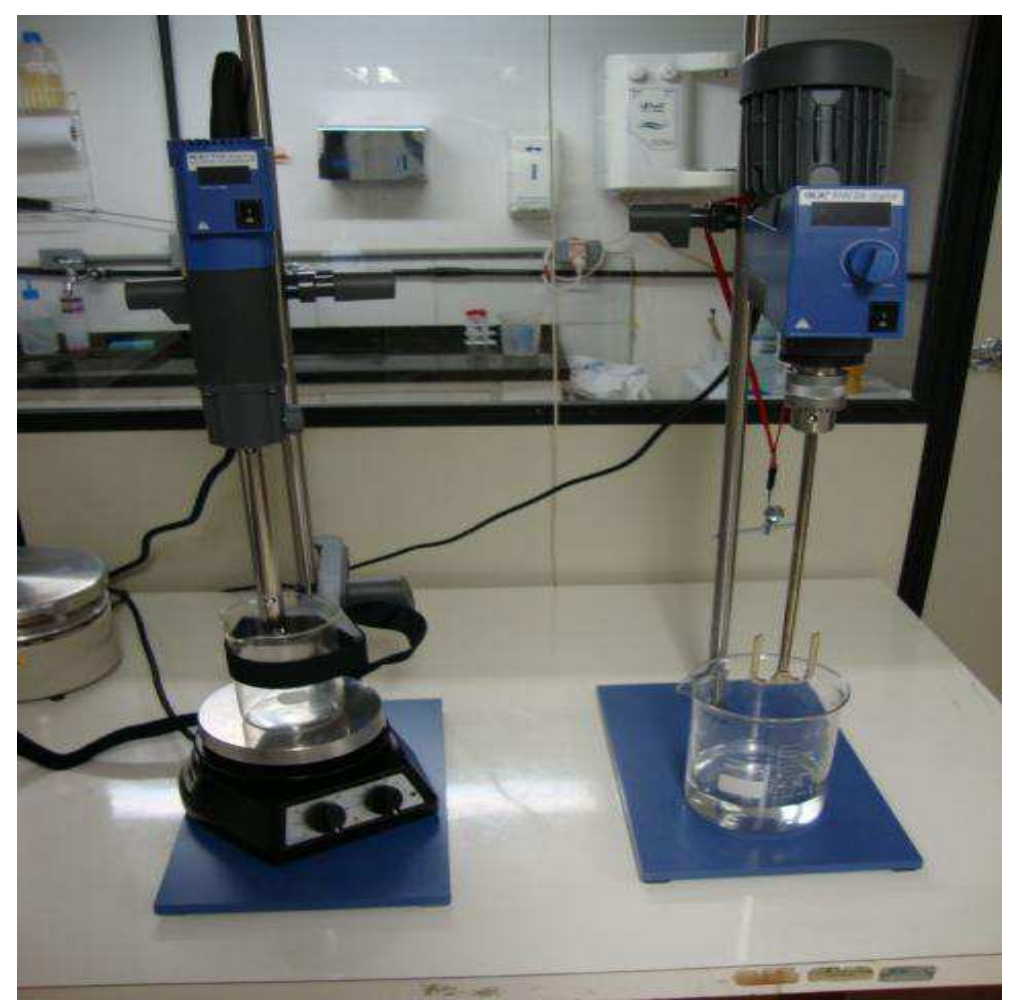

Figura 4.16: Homogeneizador e Misturador. 


\section{MEDIÇÕES DE TENSÃO INTERFACIAL}

Nesta seção estuda-se a tensão interfacial entre o óleo mineral e misturas de água com glicerina com e sem a presença de surfactantes. A tensão interfacial é um parâmetro físico que fornece a tensão da interface entre dois líquidos e o seu conhecimento é essencial, por exemplo, para o cálculo do número de capilaridade:

$$
C a=\frac{\eta \dot{\gamma} R}{\tau_{s}}
$$

A tensão interfacial é um importante parâmetro para a reologia das emulsões pela sua relação com as tensões de cisalhamento que provocam o escoamento interno na gota e a sua deformação em altas taxas de cisalhamento. Considerando uma gota isolada, o escoamento interfacial contribui para minimizar as perturbações devido ao escoamento externo à gota e a dissipação de energia em comparação com partículas rígidas. A dinâmica da tensão interfacial é controlada pelo balanço entre a convecção e a difusão de surfactante na superfície da gota (Otsubo e Prud'homme (1994)). O modelo de Butler, (1932) que prevê a tensão interfacial entre duas fases imiscíveis, com vários componentes se reduz à equação de Szyszkowski (1908) indicada para uma solução aquosa diluída com apenas um soluto:

$$
\tau_{s}=\tau_{s_{o}}+A \ln (1+B \phi)
$$

em que $\tau_{s_{o}}$ é a tensão interfacial para a água pura, $\phi$ é a concentração de soluto e A e B são constantes experimentais.

Os gradientes de tensão interfacial e os efeitos de adsorção/dessorção contribuem para a redução da tensão interfacial com o tempo, até ser atingida uma tensão de equilíbrio. Os gradientes de tensão interfacial surgem devido à redistribuição do surfactante na interface dos líquidos, que está associada com as tensões de Marangoni. Cada surfactante tem o seu tempo característico de redistribuição. Quando esse tempo é muito 
menor que a escala típica do experimento, o surfactante é dito incompressível, e o tempo de relaxação é considerado desprezível. O transporte de surfactante na interface dos líquidos é governado pela equação:

$$
\frac{\partial \phi}{\partial t}+\nabla_{s} \cdot\left(\phi \boldsymbol{u}^{s}\right)+\phi\left(\nabla_{s} \cdot \boldsymbol{n}\right)(\boldsymbol{u} \cdot \boldsymbol{n})=D_{s} \nabla_{s}^{2} \phi-\alpha\left(\phi-\phi_{o}\right)
$$

O termo $\partial \phi / \partial t$ representa a variação da concentração de surfactante na superfície da gota ao longo do tempo, $\nabla_{s} \cdot\left(\phi \boldsymbol{u}^{s}\right)$ representa o transporte convectivo do surfactante na superfície da gota devido ao cisalhamento do escoamento, $\phi\left(\nabla_{s} \cdot \boldsymbol{n}\right)(\boldsymbol{u} \cdot \boldsymbol{n})$ representa a distribuição do surfactante na superfície da gota devido à variação de forma que é função da curvatura média da gota $\left(\left(\nabla_{s} \cdot \boldsymbol{n}\right) / 2\right)$. Estes termos são balanceados com o termo associado com o mecanismo de difusão de surfactante $\left(D_{s} \nabla_{s}^{2} \phi\right)$ na superfície da gota e com o termo de fonte $\alpha\left(\phi-\phi_{o}\right)$ que representa a adsorção/dessorção de surfactante.

\subsection{Forma Generalizada da Equação de Young-Laplace para o Salto de Tensões Interfacial na Presença de Surfactantes}

Considere um elemento infinitesimal da interface de separação entre dois fluidos (Fig. 5.1). O elemento é retangular, de dimensões $d l_{1}$ e $d l_{2}$, orientado pela normal $\hat{\mathbf{n}}$ e tem raios de curvatura $R_{1}$ e $R_{2}$. Sendo $\tau_{s}$ a tensão interfacial do sistema, os elementos de força nas laterais são dados por:

$$
d f_{1}=\tau_{s} d l_{1} \quad e \quad d f_{2}=\tau_{s} d l_{2} .
$$

A componente normal à superfície (direção $\hat{\mathbf{n}}$ ) se relaciona com $d f_{1}$ por:

$$
d f_{1}^{n}=\tan \left(\frac{d \theta_{2}}{2}\right) d f_{1}
$$




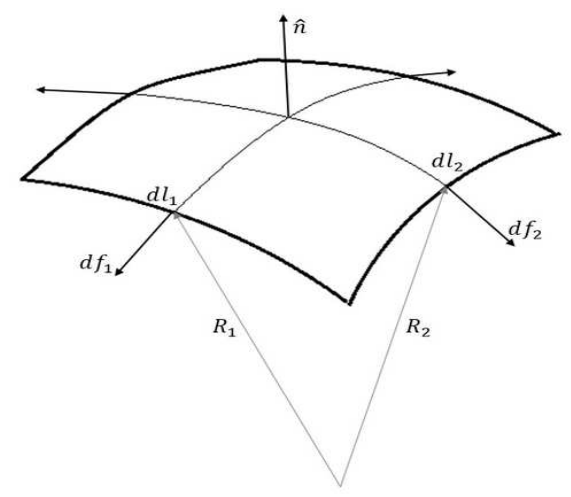

(a)

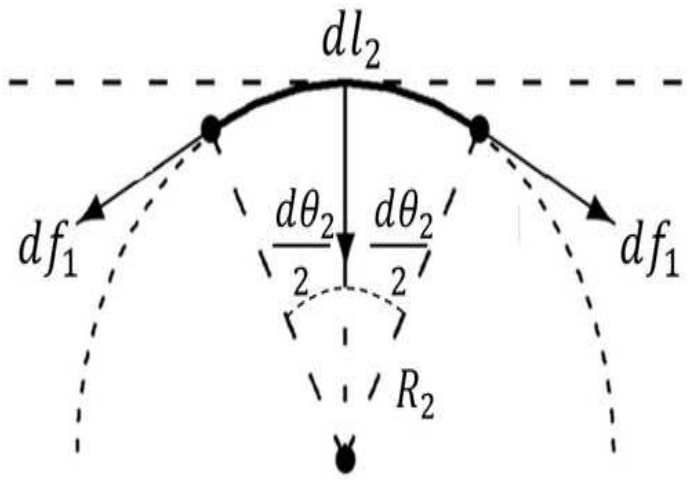

(b)

Figura 5.1: (a) Interface entre dois fluidos imiscíveis; (b) Detalhe de uma aresta da interface

Para um ângulo $d \theta_{2}$ pequeno, $\tan \left(d \theta_{2} / 2\right) \approx d \theta_{2} / 2$.

$$
d f_{1}^{n}=\frac{d \theta_{2}}{2} d f_{1}
$$

O ângulo $d \theta_{2}$ se relaciona com o lado $d l_{2}$ por $d \theta_{1}=d l_{2} / R_{2}$, portanto,

$$
d f_{1}^{n}=\frac{d l_{2}}{2 R_{2}} d f_{1}
$$

Combinando com eq. 5.4:

$$
d f_{1}^{n}=\frac{\tau_{s}}{2 R_{2}} d l_{1} d l_{2}
$$

De maneira similar:

$$
d f_{2}^{n}=\frac{\tau_{s}}{2 R_{1}} d l_{1} d l_{2} .
$$

Somando a componente normal das 4 arestas, obtém-se:

$$
d F^{n}=2 d f_{1}^{n}+2 d f_{2}^{n}=\tau_{s}\left(\frac{1}{R_{1}}+\frac{1}{R_{2}}\right) d l_{1} d l_{2} .
$$

A densidade de força superficial $f^{\tau_{s}}$ é definida como a soma das forças nas 4 arestas, normalizada pela área $d A=d l_{1} d l_{2}$ :

$$
f^{\tau_{s}}=\tau_{s}\left(\frac{1}{R_{1}}+\frac{1}{R_{2}}\right)
$$

A expressão obtida é conhecida como Equação de Young-Laplace. Definindo a curva- 
tura média da interface como sendo $\bar{\kappa}=1 / 2\left(1 / R_{1}+1 / R_{2}\right)$, podemos reescrever $(5.11)$ como:

$$
f^{\tau_{s}}=2 \tau_{s} \bar{\kappa}
$$

No caso particular de uma superfície esférica, os raios de curvatura são iguais $\left(R_{1}=\right.$ $R_{2}=R$ ), portanto, a curvatura média é igual a $1 / R$. Nesse caso a eq. 5.12 se reduz a:

$$
f^{\tau_{s}}=\frac{2 \tau_{s}}{R}
$$

\subsection{Salto de Tensões numa Interface com Tensão Interfacial Isotrópica}

Considere a interface $\mathcal{I}$ de separação entre dois fluidos caracterizada por uma tensão interfacial $\tau_{s}$ isotrópica. Sendo $\Delta \mathbf{f}$ a densidade de força na interface, $\hat{\mathbf{n}}$ o vetor normal unitário à interface, $\hat{\mathbf{t}}$ o vetor tangente unitário à fronteira da interface, o balanço de forças na interface (livre de inércia) é:

$$
\int_{\mathcal{I}} \Delta \mathbf{f} d S+\int_{\partial \mathcal{I}} \tau_{s}(\hat{\mathbf{t}} \times \hat{\mathbf{n}}) d l=\mathbf{0}
$$

Como $(\hat{\mathbf{t}} \times \hat{\mathbf{n}})=-(\hat{\mathbf{n}} \times \hat{\mathbf{t}})$, podemos reescrever a eq. 5.14 como:

$$
\int_{\mathcal{I}} \Delta \mathbf{f} d S=\int_{\partial \mathcal{I}} \tau_{s}(\hat{\mathbf{n}} \times \hat{\mathbf{t}}) d l
$$

Seja $\mathbf{F}$ um vetor qualquer e $\hat{\mathbf{n}}$ diferenciável, temos:

$$
\int_{\partial \mathcal{I}}(\mathbf{F} \times \hat{\mathbf{t}}) d l=\int_{\mathcal{I}}(\hat{\mathbf{n}}(\nabla \cdot \mathbf{F})-(\nabla \mathbf{F}) \cdot \hat{\mathbf{n}}) d S
$$

Aplicando o Teorema de Stokes em (5.15), fazendo $\mathbf{F}=\tau_{s} \hat{\mathbf{n}}$, obtemos:

$$
\begin{aligned}
\int_{\mathcal{I}} \Delta \mathbf{f} d S & =\int_{\mathcal{I}}\left(\hat{\mathbf{n}}\left(\nabla \cdot\left(\tau_{s} \hat{\mathbf{n}}\right)\right)-\left(\nabla\left(\tau_{s} \hat{\mathbf{n}}\right)\right) \cdot \hat{\mathbf{n}}\right) d S \\
\int_{\mathcal{I}} \Delta \mathbf{f} d S & =\int_{\mathcal{I}}\left(\hat{\mathbf{n}} \tau_{s}(\nabla \cdot \hat{\mathbf{n}})+\hat{\mathbf{n}}\left(\hat{\mathbf{n}} \cdot\left(\nabla \tau_{s}\right)\right)-\left(\tau_{s} \nabla \hat{\mathbf{n}}+\hat{\mathbf{n}} \nabla \tau_{s}\right) \cdot \hat{\mathbf{n}}\right) d S
\end{aligned}
$$


Note que o termo $\nabla \hat{\mathbf{n}} \cdot \hat{\mathbf{n}}=0$. Assim:

$$
\begin{aligned}
\int_{\mathcal{I}} \Delta \mathbf{f} d S & =\int_{\mathcal{I}}\left(\hat{\mathbf{n}} \tau_{s}(\nabla \cdot \hat{\mathbf{n}})+\hat{\mathbf{n}}\left(\hat{\mathbf{n}} \cdot\left(\nabla \tau_{s}\right)\right)-\hat{\mathbf{n}}\left(\nabla \tau_{s} \cdot \hat{\mathbf{n}}\right)\right) d S \\
\int_{\mathcal{I}} \Delta \mathbf{f} d S & =\int_{\mathcal{I}}\left(\hat{\mathbf{n}} \tau_{s}(\nabla \cdot \hat{\mathbf{n}})+\hat{\mathbf{n}}\left(\hat{\mathbf{n}} \cdot\left(\nabla \tau_{s}\right)\right)-I \nabla \tau_{s}\right) d S \\
\int_{\mathcal{I}} \Delta \mathbf{f} d S & =\int_{\mathcal{I}}\left(\tau_{s}\left(\nabla^{s} \cdot \hat{\mathbf{n}}\right) \hat{\mathbf{n}}-(I-\hat{\mathbf{n}} \hat{\mathbf{n}}) \nabla \tau_{s}\right) d S .
\end{aligned}
$$

Fazendo a interface $\mathcal{I}$ tender a um ponto, podemos igualar os integrandos. Assim, obtém-se que:

$$
\Delta \mathbf{f}=\tau_{s}\left(\nabla^{s} \cdot \hat{\mathbf{n}}\right) \hat{\mathbf{n}}-(I-\hat{\mathbf{n}} \hat{\mathbf{n}}) \nabla \tau_{s}
$$

que é a equação constitutiva de $\Delta \mathbf{f}$ para uma interface com tensão interfacial.

\subsection{Medidas da Tensão Interfacial}

As medições de tensão interfacial foram obtidas para o sistema óleo-água a temperatura constante de $25^{\circ} \mathrm{C}$. O óleo utilizado foi o óleo mineral da Sigma-Aldrich e a água foi destilada. Foi adicionado glicerina da Sigma-Aldrich à água destilada. Este procedimento foi usado para variar a razão de viscosidade entre o fluido disperso e o fluido carreador das emulsões. Nas medições de tensão interfacial entre o óleo mineral e o fluido base, constituído por misturas de água e glicerina (tab .5.1), foi utilizado o modo Padrão do tensiômetro . Nos experimentos com surfactantes avaliou-se, separadamente, a influência do Span80 (adicionado ao óleo mineral) e do Tween80 (adicionado à água) na tensão interfacial entre óleo-água. Este experimento foi realizado no modo Quasi-Estático.

A avaliação da tensão interfacial é função do tempo de desprendimento da gota da ponta do capilar. Esse tempo é obtido quando a gota passa pela barreira de luz. Verificou-se que a gota não é detectada pelo tensiômetro quando o índice de refração entre os líquidos são idênticos (encarte da fig. 5.2). Assim foi necessário extrapolar a tensão interfacial para concentrações superiores a 0,7 (tab. 5.2). Para tal foram usados os dados da tensão interfacial de $\phi=0,5,0,6$ e 0,7. A fig. 5.2 mostra os dados obtidos 
Tabela 5.1: Tensão interfacial entre óleo mineral e o fluido base variando a fração volumétrica de glicerina.

\begin{tabular}{|c|c|}
\hline$\phi$ & $\tau_{s}(m N / m)$ \\
\hline 0 & $50,06 \pm 0,74$ \\
0,05 & $46,21 \pm 0,11$ \\
0,1 & $43,89 \pm 0,26$ \\
0,15 & $41,63 \pm 0,10$ \\
0,2 & $37,10 \pm 0,15$ \\
0,3 & $35,12 \pm 0,06$ \\
0,4 & $33,67 \pm 0,03$ \\
0,5 & $31,84 \pm 0,22$ \\
0,6 & $30,66 \pm 0,02$ \\
0,7 & $29,26 \pm 0,09$ \\
\hline
\end{tabular}

ajustados pela eq. 5.2 em que $\tau_{s}$ é a tensão interfacial obtida e $\tau_{s_{o}}$ é a tensão interfacial entre o óleo e a água sem adição de glicerina. Observa-se que a tensão interfacial decaí com o aumento da fração volumétrica da glicerina.

Tabela 5.2: Valores extrapolados de tensão interfacial para $\phi>0,7$.

\begin{tabular}{|c|c|}
\hline$\phi$ & $\tau_{s}(m N / m)$ \\
\hline 0,8 & 28,0 \\
0,9 & 26,7 \\
1,0 & 25,4 \\
\hline
\end{tabular}

A fig. 5.3 mostra a variação da tensão interfacial, adimensionalizada pela tensão interfacial entre óleo-água, com a razão de viscosidade. Para o ajuste dos dados experimentais foi necessário modificar a equação de Szyszkowski:

$$
\frac{\tau_{s}}{\tau_{s o}}=1+A \ln \left(1+B \ln \left(\frac{\lambda}{\lambda_{o}}\right)\right)
$$

em que $\lambda_{o}$ é a razão de viscosidade entre o óleo e a água destilada pura. É de notar que a expressão resultante duplamente logarítmica é necessária tendo em vista a dependência implícita de $\phi$ na equação em termos de $\lambda(\phi)$. 


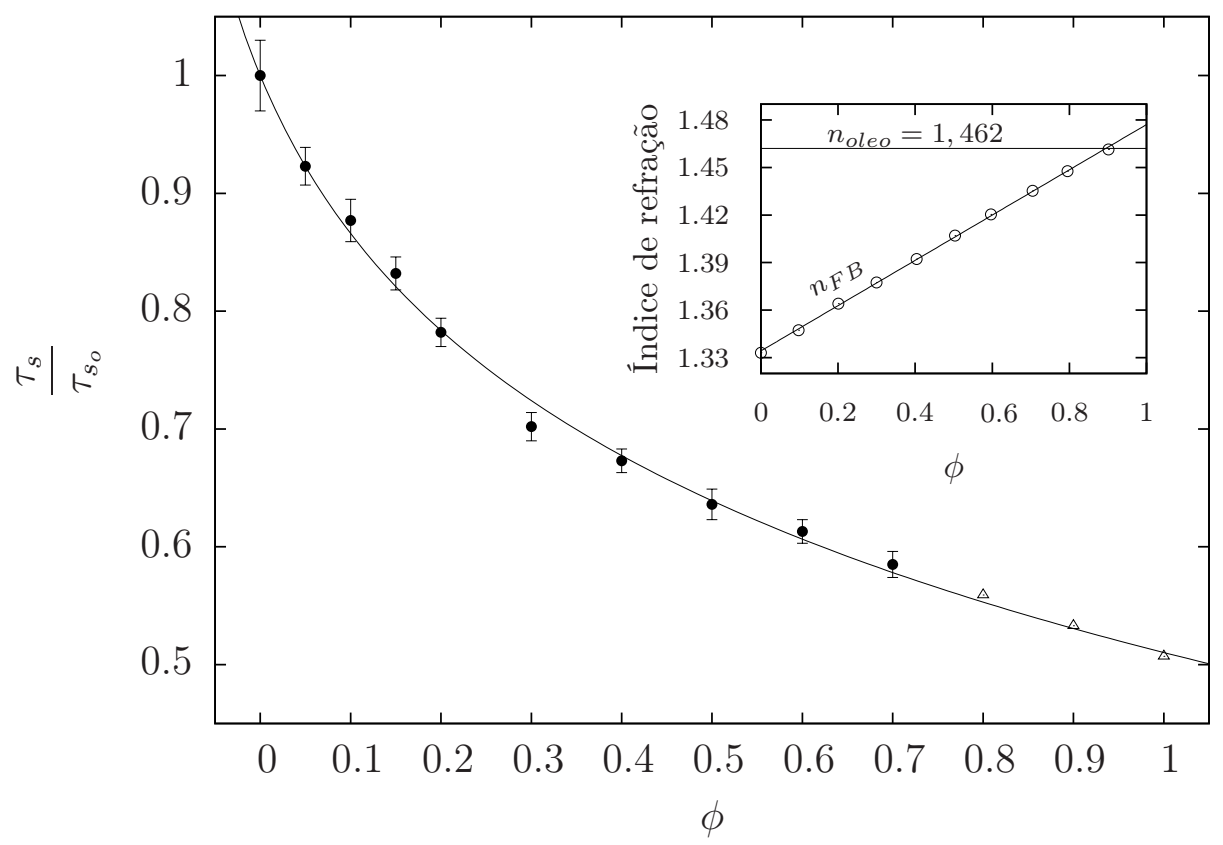

Figura 5.2: Tensão interfacial normalizada em função da fração volumétrica de glicerina. As constantes obtidas foram: $A=-0,22, B=8,55$. $\bullet$ Dados experimentais, $\triangle$ Valores extrapolados,- Equação de Szyszkowski (eq. 5.2). Encarte: Índice de refração da mistura de água destilada e glicerina em função da fração volumétrica de glicerina. - Dados experimentais, Glycerine Producers Association (1963) .

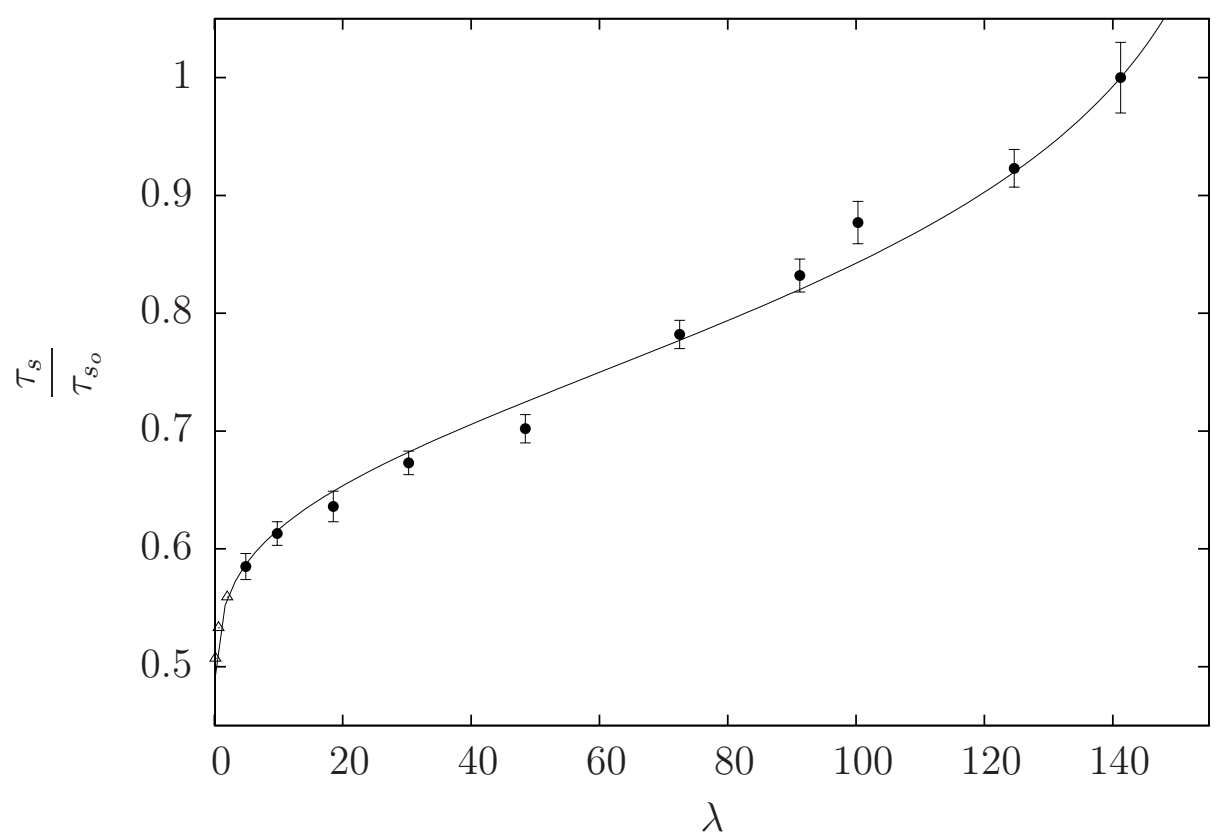

Figura 5.3: Tensão interfacial normalizada em função da razão de viscosidade entre o óleo mineral e o fluido base. As constantes obtidas foram: $A=-0,130, B=-6,837$. - Dados experimentais, $\triangle$ Valores extrapolados,- Equação de Szyszkowski modificada 5.20 . 


\subsection{Equação de Adsorção de Gibbs}

A Equação de Adsorção de Gibbs é uma importante equação fundamental em processos de adsorção (Rosen (2004)). Seja $\Gamma_{i}$ a concentração superficial de excesso do componente i, Gibbs mostra que:

$$
d \tau_{s}=-\sum \Gamma_{i} d \mu_{i}
$$

O potencial químico $\mu_{i}$, é dado por:

$$
d \mu_{i}=R T d \ln \left(\alpha_{i}\right)
$$

Substituindo a eq. 5.22 na eq. 5.21, obtém-se:

$$
d \tau_{s}=-R T \sum \Gamma_{i} d\left(\ln \left(\alpha_{i}\right)\right)
$$

Para soluções diluídas de um soluto, a atividade do solvente é 1 e a atividade do soluto é igual a concentração $\phi$. Assim, a Equação de Adsorção de Gibbs se reduz a sua forma mais comum:

$$
\Gamma=-\frac{1}{R T}\left(\frac{d \tau_{s}}{d(\ln (\phi))}\right)
$$

que mostra a linearidade entre a tensão interfacial e o logaritmo da concentração. Para soluções diluídas, a concentração superficial de excesso $\Gamma$ é dada pelo número de mols do soluto dividido pela área da interface.

$$
\Gamma=n^{s} / A
$$

Assim, a área por molécula na interface é dada por:

$$
A_{m}=\frac{1}{\Gamma N_{A}}
$$

em que $N_{A}$ é o número de Avogrado. 


\subsection{Dependência da tensão interfacial com o tempo}

Hua e Rosen (1988) apresentaram uma correlação empírica para a relação temporal da tensão superficial de soluções aquosas de surfactante:

$$
\frac{\tau_{s_{o}}-\tau}{\tau-\tau_{s_{e}}}=\left(\frac{t}{t^{*}}\right)^{n}
$$

em que $t^{*}$ e $n$ são os parâmetros de ajuste da equação. Essa correlação empírica é análoga às correlações tipo Cross usadas na descrição de fluidos newtonianos generalizados analisados no contexto da Mecânica dos Fluidos (Cross (1967)):

$$
\tau_{s}-\tau_{s_{e}}=\frac{\tau_{s o}-\tau_{s_{e}}}{1+\left(\frac{t}{t^{*}}\right)^{n}}
$$

O tempo para atingir o equilíbrio é estimado como sendo o tempo para o qual a diferença entre a tensão interfacial no instante $t\left(\tau_{s}\right)$ e a tensão interfacial de equilíbrio $\left(\tau_{s_{e}}\right)$ é um décimo da diferença entre a tensão interfacial inicial $\left(\tau_{s_{o}}\right)$ e a tensão interfacial no instante $t$.

$$
\tau_{s}-\tau_{s_{e}}=\frac{1}{10}\left(\tau_{s_{o}}-\tau_{s}\right)
$$

Substituindo a eq. 5.28 na eq. 5.26, obtém-se:

$$
{\frac{t^{n}}{t^{*}}}^{n}=10
$$

Aplicando o logaritmo decimal nos dois membros, obtém-se:

$$
n\left(\log _{10} t-\log _{10} t^{*}\right)=1 \text {. }
$$

Sendo $t_{e}$ o tempo de início da região de equilíbrio:

$$
\log _{10} t_{e}=\log _{10} t^{*}+\frac{1}{n}
$$

Obtendo-se das medições que a tensão interfacial entre o óleo mineral e a água destilada sem surfactante, $\tau_{s_{o}}$, é de $50,5 \mathrm{mN} / \mathrm{m}$, estima-se a tensão interfacial de equilíbrio $\tau_{s_{e}}$, 
para cada concentração. Os parâmetros $t^{*}$ e $n$ foram utilizados para ajustar a curva. O tempo de equilíbrio, $t_{e}$, foi estimado como o tempo em que $\tau_{s}-\tau_{s_{e}}$ é igual a $1 / 10$ de $\tau_{s_{o}}-\tau_{s}$, e é obtido pela eq. 5.31. As constantes obtidas estão indicadas na tab. 5.3.

Tabela 5.3: Constantes referentes à correlação empírica de Cross.

\begin{tabular}{|c|c|c|c|c|}
\hline \multicolumn{5}{|c|}{ Tween 80 } \\
\hline$\phi$ & $\tau_{s_{e}}(m N / m)$ & $\mathrm{n}$ & $t^{*}(s)$ & $t_{e}(s)$ \\
\hline $5 \times 10^{-7}$ & 38 & 1,17 & 1032 & 7385 \\
$1 \times 10^{-6}$ & 28 & 1,64 & 1212 & 4934 \\
$1,5 \times 10^{-6}$ & 23 & 1,31 & 1069 & 6199 \\
$2,5 \times 10^{-6}$ & 19 & 0,88 & 522 & 7145 \\
$5 \times 10^{-6}$ & 12 & 0,77 & 287 & 5709 \\
$1 \times 10^{-5}$ & 12 & 0,83 & 115 & 1862 \\
$1 \times 10^{-3}$ & 10 & 0,44 & 0,12 & 22 \\
$5 \times 10^{-3}$ & 7,5 & 0,25 & 0,013 & 156 \\
$5 \times 10^{-2}$ & 4 & 0,34 & 0,28 & 245 \\
\hline \multicolumn{5}{|c|}{$\mathrm{Span} \mathbf{8 0}$} \\
\hline $5 \times 10^{-6}$ & 42 & 0,99 & 910 & 9314 \\
$1 \times 10^{-5}$ & 36 & 0,67 & 261 & 8113 \\
$2 \times 10^{-5}$ & 30 & 1,02 & 345 & 3298 \\
$5 \times 10^{-5}$ & 23 & 1,02 & 115 & 1099 \\
$1 \times 10^{-4}$ & 16 & 0,87 & 85 & 1199 \\
$2 \times 10^{-4}$ & 11 & 0,97 & 39 & 419 \\
$5 \times 10^{-4}$ & 3,5 & 0,7 & 18 & 483 \\
$1 \times 10^{-3}$ & 3 & 0,73 & 5,6 & 131 \\
$5 \times 10^{-3}$ & 2,5 & 0,67 & 0,45 & 14 \\
$1 \times 10^{-2}$ & 2,5 & 0,44 & 0,25 & 47 \\
\hline
\end{tabular}

A variação da tensão interfacial com o tempo é mostrada na fig. 5.4, para o caso do Tween80 adicionado à água e na fig. 5.5 para o Span80 adicionado ao óleo mineral. O tempo de equilíbrio diminui com o aumento da concentração. Para as maiores concentrações a região de equilíbrio é atingida em torno de 14 s a $250 \mathrm{~s}$. Enquanto que para as menores concentrações, o tempo de equilíbrio varia de $420 \mathrm{~s}$ a $9300 \mathrm{~s}$, ultrapassando o limite de medição do tensiômetro, de $3600 \mathrm{~s}$. 


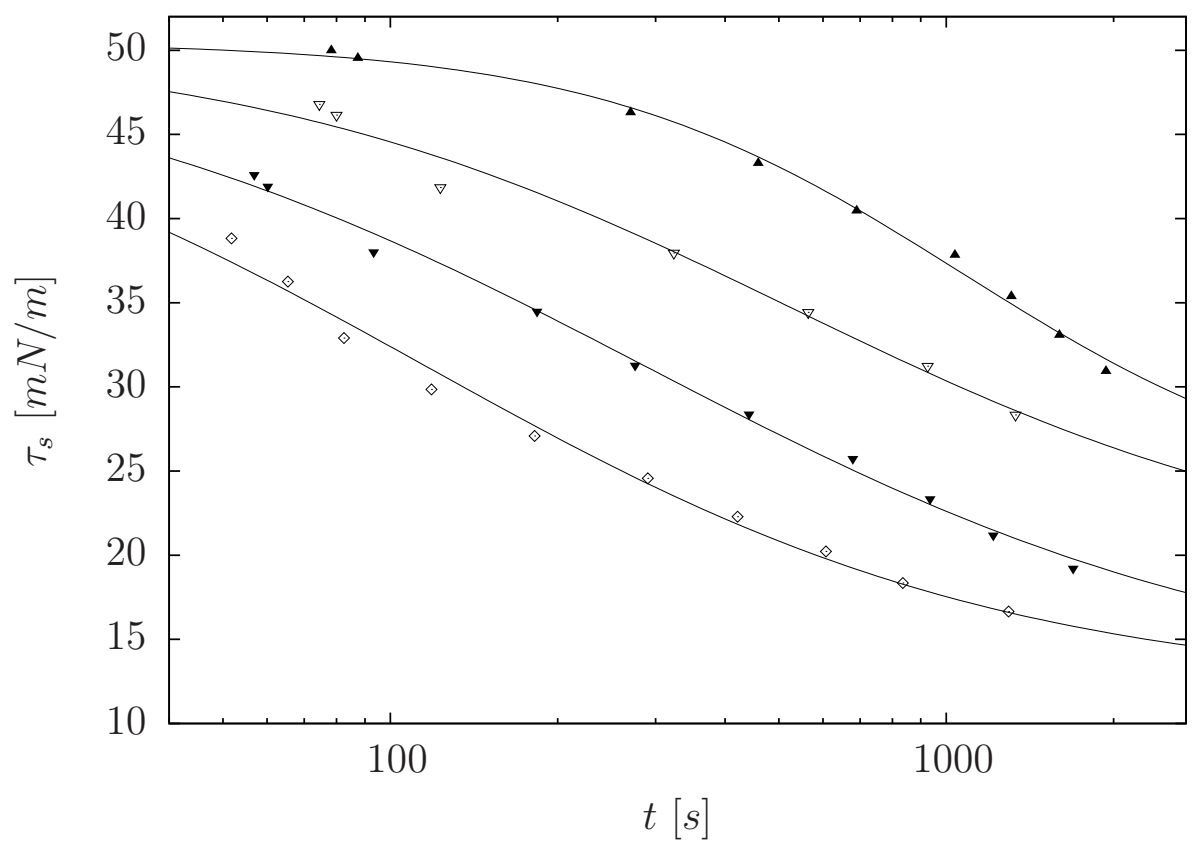

Figura 5.4: Tensão interfacial em função do tempo de formação da gota na presença de surfactante Tween 80. As medidas foram feitas em temperatura controlada de $25^{\circ} \mathrm{C}$. - Correlação de Cross. $\boldsymbol{\Delta} \phi=1,5 \times 10^{-6}, \nabla \quad \phi=2,5 \times 10^{-6}, \boldsymbol{\nabla} \phi=5 \times 10^{-6}, \diamond \phi=$ $1 \times 10^{-5}$.

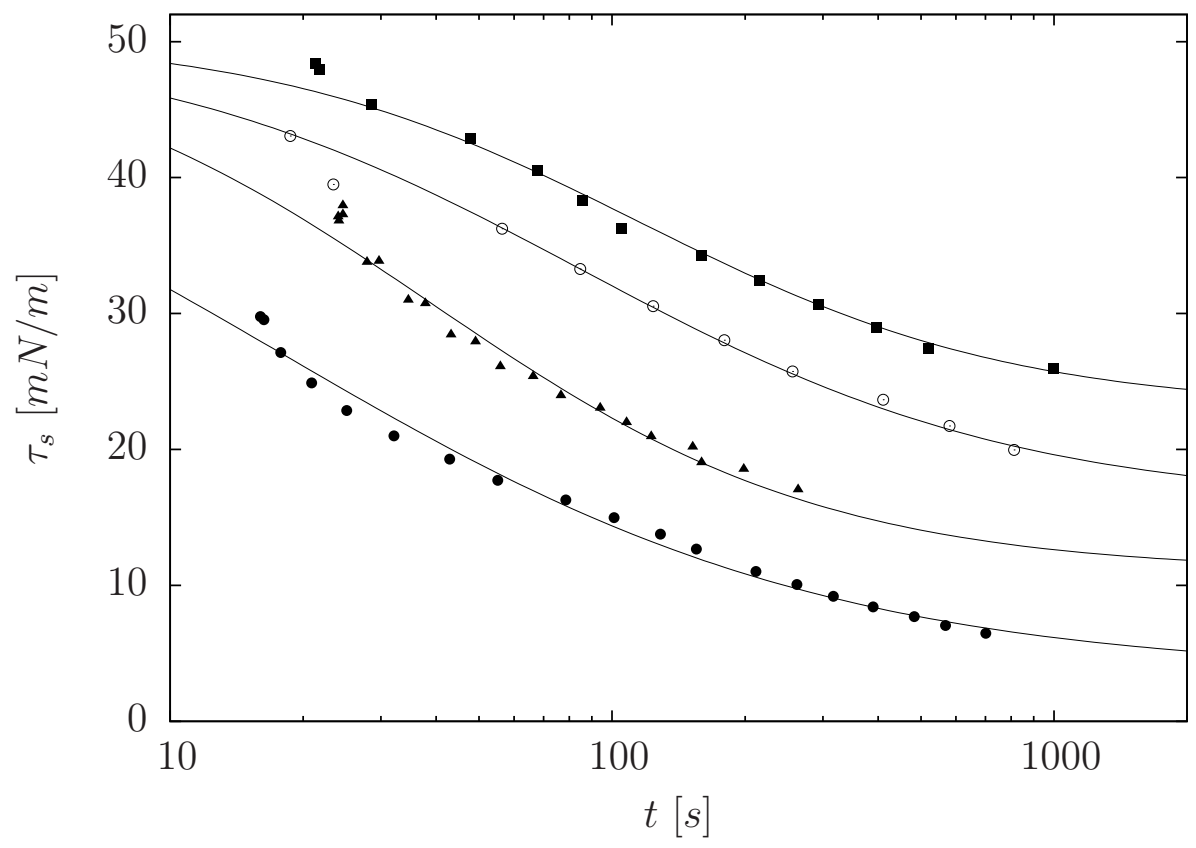

Figura 5.5: Tensão interfacial em função do tempo de formação da gota na presença de surfactante Span 80. As medidas foram feitas em temperatura controlada de $25^{\circ} \mathrm{C}$. Correlação de Cross. - $\phi=5 \times 10^{-5}, \circ \phi=1 \times 10^{-4}, \boldsymbol{\Delta} \phi=2 \times 10^{-4}, \bullet \phi=5 \times 10^{-4}$.

A variação da tensão interfacial de equilíbrio foi analisada em função da concentração 
de surfactante, com o intuito de se obter a fração volumétrica crítica de surfactante $\left(\phi_{c}\right)$. As figs. 5.6 e 5.7 mostram essa variação, respectivamente para o Tween 80 e o Span 80. Nota-se uma região de decaimento rápido seguida pela formação de um platô. Para o Tween 80 , o platô se inicia na concentração de $\phi=5 \times 10^{-6}$, com o valor de $12 \mathrm{mN} / \mathrm{m}$. Para concentrações bem mais altas, a tensão interfacial volta a decair até o valor de $4 \mathrm{mN} / \mathrm{m}$. Para o Span 80, o platô se inicia na concentração de $\phi=5 \times 10^{-4}$, a partir da qual a tensão interfacial se mantém constante em $3 \mathrm{mN} / \mathrm{m}$, desviando apenas $0,5 \mathrm{mN} / \mathrm{m}$ deste valor.

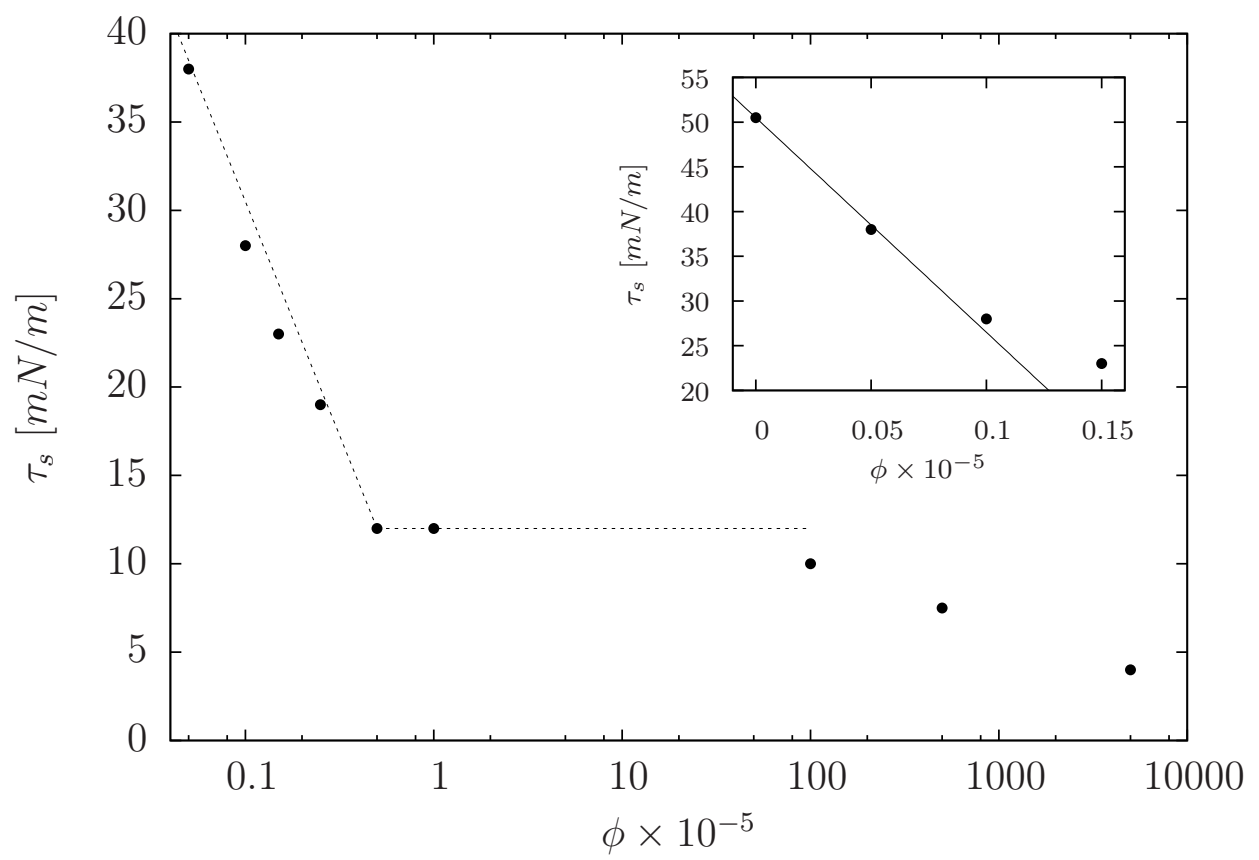

Figura 5.6: Tensão interfacial de equilíbrio em função da concentração de Tween 80. Note que a tensão interfacial para água pura não aparece. - - Ajuste (5.32) . O encarte da figura mostra detalhe da tensão interfacial para concentrações muito baixas. Ajuste (Eq. 5.33). As medidas foram feitas em temperatura controlada de $25^{\circ} \mathrm{C}$. Tween 80. $\phi_{c}=5,0 \times 10^{-6}$.

Para a região de decaimento rápido, a tensão interfacial decai com o logaritmo da concentração, conforme prevê a Equação de Adsorção de Gibbs. Os dados foram ajustados por:

$$
\tau_{s}=a \ln (\phi)+b,
$$

com $a=-11,5$ e $b=-128$, para o Tween 80 e $a=-8,4$ e $b=-60$, para o Span 80 . Para concentrações muito baixas ( $\phi$ menor que $1 \times 10^{-6}$ para o Tween 80 e $\phi$ menor que $1 \times 10^{-5}$ para o Span 80 ), esse ajuste não é mais válido. Para essas concentrações, 


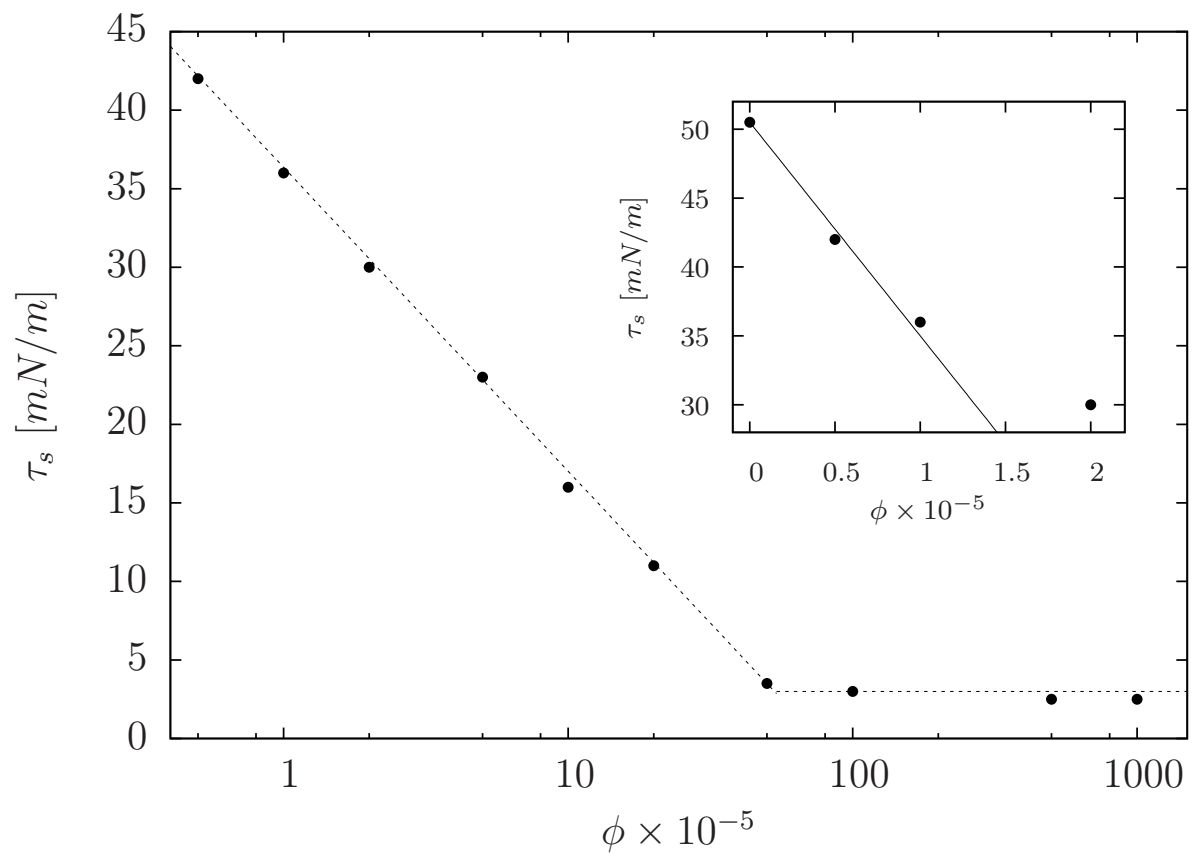

Figura 5.7: Tensão interfacial de equilíbrio em função da concentração de Span 80. Note que a tensão interfacial para água pura não aparece. - - Ajuste (5.32). O encarte da figura mostra detalhe da tensão interfacial para concentrações muito baixas, com o eixo horizontal em escala linear. - Ajuste (Eq. 5.33). As medidas foram feitas em temperatura controlada de $25^{\circ} \mathrm{C}$. Span $80 . \phi_{c}=5,3 \times 10^{-4}$.

a tensão interfacial é melhor ajustada por uma série de McLaurin de primeira ordem:

$$
\tau_{s}=a \phi+b
$$

com $a=-2,4 \times 10^{7}$ e $b=50,5$ para o Tween 80 e $a=-1,55 \times 10^{6}$ e $b=50,5$ para o Span 80.

A concentração micelar crítica $\phi_{c}$ pode ser obtida pela interseção entre as retas do declínio da tensão interfacial e o platô. Dessa forma substitui-se o valor de tensão interfacial do platô na eq. 5.32 e resolve-se para $\phi$ (ver tab. 5.4). É recomendável trabalhar com frações volumétricas de surfactante acima da concentração micelar crítica devido à formação de micelas, garantindo o preenchimento da interface dos líquidos com moléculas de surfactante. Para cada surfactante foram calculados a $\phi_{c}$ e as grandezas correspondente a essa concentração: a tensão interfacial, $\tau_{s, c m c}$, a pressão superficial, $p_{s, c m c}$, e a área molecular, $A_{c m c}$, a partir das equações 5.24 e 5.25 (ver tab. 5.4). Observa-se que a $\phi_{c}$ do Span 80 é aproximadamente de 100 vezes maior que o valor para o Tween 80, 
logo, este é mais eficiente. Mas a pressão superficial na $\phi_{c}$ para o Span 80 é maior, o que torna este surfactante mais efetivo. Portanto, o Tween 80 necessita de uma menor concentração de surfactante para reduzir a tensão interfacial de uma emulsão, mas o Span 80 permite atingir um menor valor de tensão interfacial.

Tabela 5.4: Constante referentes a cada surfactante.

\begin{tabular}{|c|c|c|}
\hline & Tween 80 & Span 80 \\
\hline$\phi_{c}(\mathrm{v} / \mathrm{v})$ & $5 \times 10^{-6}$ & $5,3 \times 10^{-4}$ \\
$\tau_{s, c m c}(m N / m)$ & 12 & 3 \\
$p_{s, c m c}(m N / m)$ & 38,5 & 47,5 \\
$\mathrm{~A}_{c m c}\left(\AA^{2}\right)$ & 36 & 49 \\
\hline
\end{tabular}

A fig. 5.8 apresenta a relação entre o tempo de equilíbrio e a concentração de Tween 80 e Span 80. Observa-se que o tempo de equilíbrio diminui com o aumento da concentração, até se reduzir a ordem de poucos minutos em altas concentrações. Os dados são aproximadamente ajustados, a exceção para concentrações muito baixas, por uma correlação empírica de Sisko, (1958):

$$
t_{e}=t_{\infty}+C \phi^{n-1}
$$

em que $t_{\infty}$ é o tempo de equilíbrio quando $\phi \rightarrow \infty$ e $C$ e $n$ são constantes de ajuste. Para o Span 80, $t_{\infty}=30 s, C=0,0081 s$ e $n=-0,2$. Para o Tween $80, t_{\infty}=100 s$, $C=0,0006 s$ e $n=-0,3$.

Devido à instabilidade das soluções em baixas concentrações, verificou-se um espalhamento de pontos nessa região, principalmente para o Tween 80. Por esse motivo, o tensiômetro usado nas medições não permite estudar a região de platô da tensão interfacial para baixos tempos (região de indução, Huan e Rosen (1988)) pois a gota leva cerca de $20 s$ para se formar, impedindo as medições para tempos muito baixos. O tempo de equilíbrio em $\phi_{c}$ para o Tween80 foi de $5000 s$ e para o Span 80 foi $500 s$. Observou-se que o tensiômetro mostrou medições confiáveis para a faixa de $60-3600 \mathrm{~s}$. 


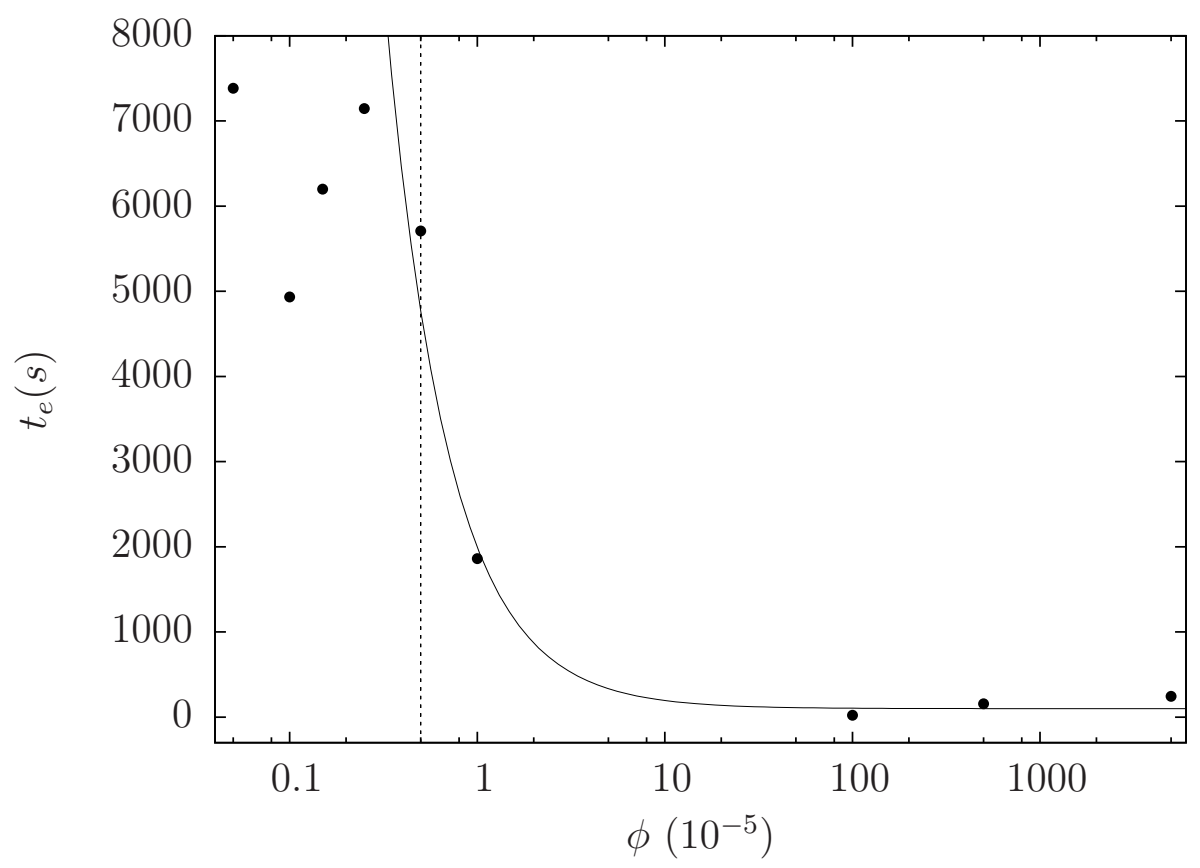

(a) Tween 80

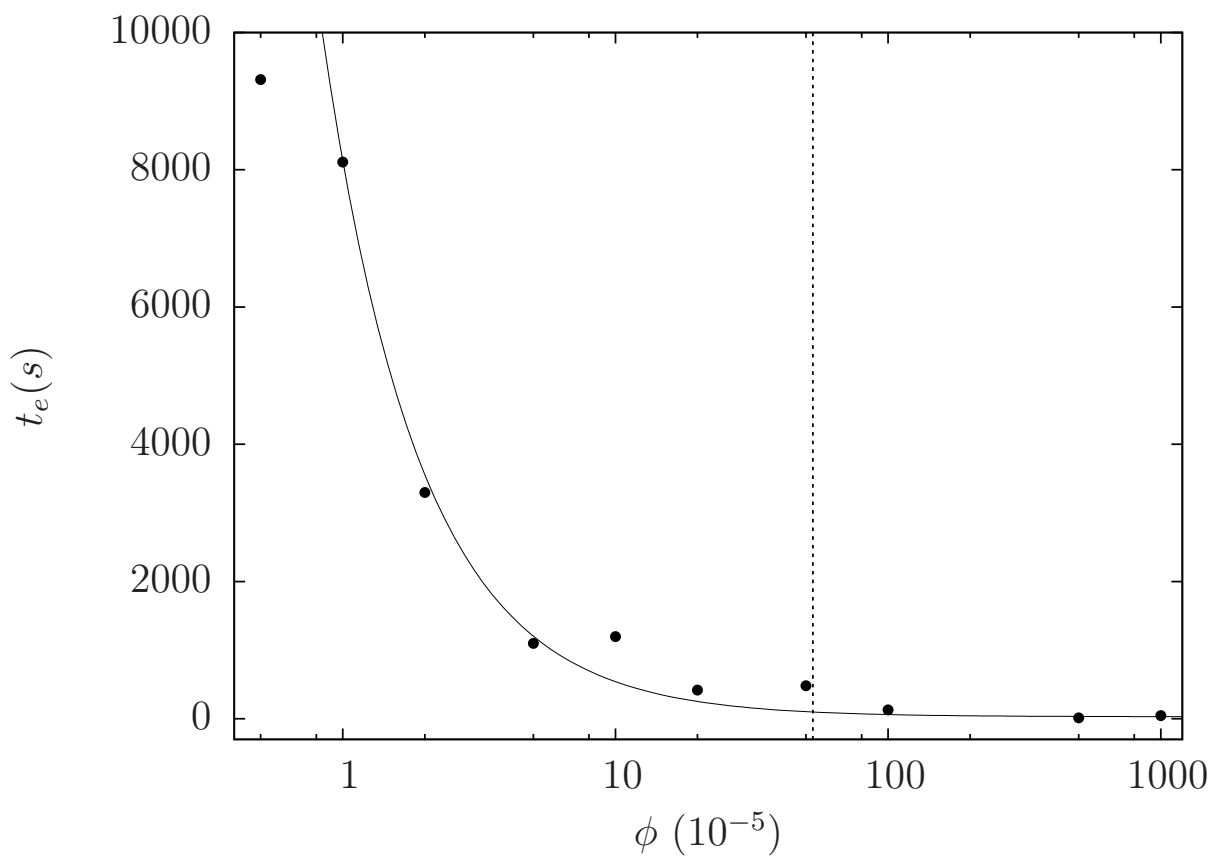

(b) $\operatorname{Span} 80$

Figura 5.8: Tempo de equilíbrio em função da concentração. • Dados experimentais. - Ajuste (eq. 5.34). - - $\phi_{c}$. 


\section{SÍNTESE DE EMULSÕES}

As emulsões sintetizadas na presente tese são compostas por líquidos imiscíveis que compõem a fase oleosa e a fase aquosa. Por convenção uma emulsão O/A (óleo/água) é formada por uma fase dispersa de gotas de óleo em uma fase contínua de água. Existem emulsões do tipo $\mathrm{A} / \mathrm{O}, \mathrm{A} / \mathrm{O} / \mathrm{A}$ e $\mathrm{O} / \mathrm{A} / \mathrm{O}$. O tipo de emulsão determina em qual dos líquidos a emulsão pode ser diluída. Dependendo da fração volumétrica $(\phi)$ a emulsão pode apresentar um comportamento de fluido newtoniano viscoso ou de um sólido elástico (Derkach, S. R (2009)). Uma emulsão com $\phi=0,3$ já pode exibir comportamento de fluido pseudoplástico (Mason (1999)).

A reologia da emulsão é influenciada pelas características reológicas da fase contínua, pelas características físicas e mecânicas das partículas, por $\lambda$, pelo tamanho e distribuição das partículas e pela natureza das interações entre as gotas (Barnes (1994)). Por outro lado o envelhecimento temporal da emulsão, caracterizado pela coalescência de gotas e a existência de fluido da fase contínua no interior das gotas, é um fator que também influencia a reologia da emulsão. Neste caso observa-se um aumento da viscosidade em baixas taxas de cisalhamento (Derkach, S. R (2009)).

A reologia da emulsão também depende do tipo de surfactantes, da espessura da camada de surfactantes na superfície da gota e da elasticidade desta camada superficial, de fatores de difusão de moléculas de surfactantes entre a gota e fluido base e da distribuição dessas moléculas na superfície das gotas (Derkach, S. R (2009)). Os surfactantes adicionados às fases diminuem a tensão superficial e têm a função de evitar a coalescência entre gotas prevenindo a separação entre as fases (Pal (2001), Mason (1999),Walstra (2005)). Em outras palavras, os surfactantes garantem a estabilidade físico-química das emulsões. Os surfactantes são alojados na interface O/A (superfície da gota) e devem de ser solúveis em pelo menos em um dos líquidos (Leal-Calderon et al. (2007)). 
Os surfactantes quando presentes em baixa concentração em um sistema, adsorvem para a interface de separação entre fases, onde sua energia é menor. Como consequência, altera drasticamente a energia livre da interface. Em outras palavras, reduz a tensão interfacial do sistema Rosen (2004). Em uma emulsão de óleo e um fluido aquoso, o surfactante reduz a tensão interfacial entre as fases e evita a coalescência das gotas dispersas. Quimicamente, a molécula do surfactante possui duas partes, uma parte hidrofílica e uma parte lipofílica. A parte hidrofílica confere solubilidade em água para o surfactante, mas a parte lipofílica é a responsável pelo efeito de redução de tensão interfacial. Quando uma molécula de surfactante está dissolvida em um fluido aquoso, sua parte lipofílica provoca um aumento na energia do sistema, devido a baixa interação com o solvente. A resposta do sistema é minimizar o contato entre o solvente e a parte lipofílica. Quando em baixas concentrações, o surfactante adsorve para a interface, com sua parte lipofílica voltada para a fase de óleo. O resultado é a formação de uma camada de moléculas de surfactante na interface. Como as forças de coesão entre o óleo e a parte lipofílica é maior do que com as moléculas de água, a tensão interfacial do sistema diminui.

A medida que a concentração de surfactante aumenta, o número de moléculas na interface vai crescer até atingir um limite, no qual a interface não aceita mais moléculas. A partir dessa concentração, chamada de Concentração Micelar Crítica ( $\phi_{c}$ ), o sistema busca outras formas de reduzir a superfície de contato entre o fluido aquoso e a parte lipofílica. A principal é a micelização. As moléculas de surfactante se aglomeram com as partes lipofílicas voltadas para dentro. A tensão interfacial diminui rapidamente com o aumento da concentração de surfactante na interface. Quando a concentração na solução atingi o $\phi_{c}$, a tensão interfacial passa a se manter quase constante, pois a concentração na interface se mantém quase uniforme. O cmc pode ser facilmente calculado a partir de um gráfico de tensão interfacial pelo logaritmo da concentração, pela interseção entre as retas da declínio da tensão interfacial e do platô final.

Quanto às características moleculares, os surfactantes são compostos por moléculas lipofílicas (cauda da molécula; insolúvel em água) e hidrofílicas (cabeça da molécula; solúvel em água). Quando essas moléculas formam agregados, passam a ser designadas por micelas (fig. 6.1). Independente da configuração desses agregados a parte hidro- 
fóbica é direcionada para o óleo e a parte hidrofílica é direcionada para a água (Davis (1994)). Existem vários tipos de surfactantes: iônicos, não-iônicos, aniônicos e zwitteriônica hidrofílico (Davis (1994)). A elevadas temperaturas os surfactantes não-iônicos, destinados a emulsão $\mathrm{O} / \mathrm{A}$, se tornam surfactantes destinados a $\mathrm{A} / \mathrm{O}$.

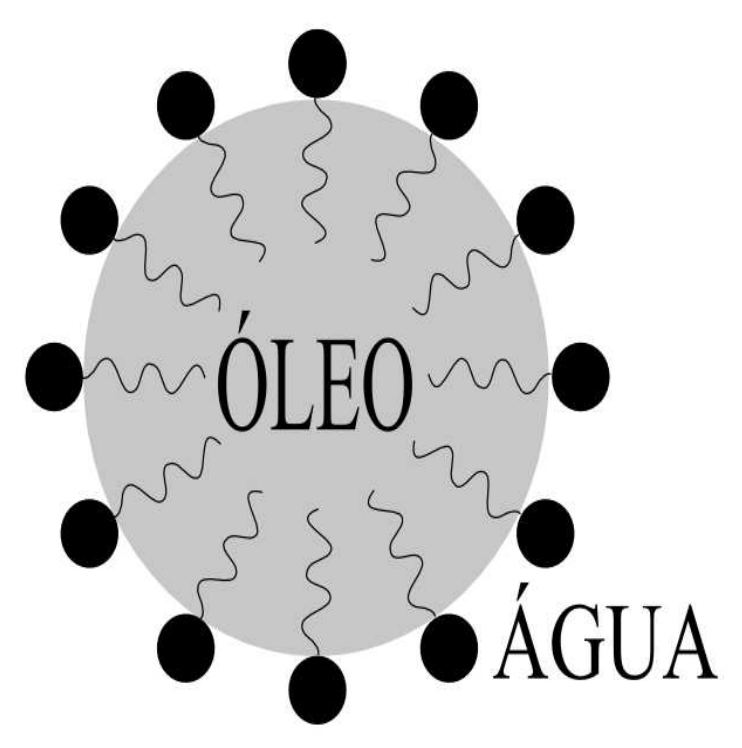

Figura 6.1: Representação da orientação das moléculas de surfactantes em uma gota de óleo rodeada por água.

O balanço entre as moléculas que compõem os surfactantes é designado por EHL (Equilíbrio Hidrófilo-Lipófilo). Uma emulsão O/A é obtida com moléculas preferencialmente hidrofílicas (Arditty et al. (2003)). Os surfactantes não-iônicos com EHL entre 2 - 6 (mais solúvel no óleo) são destinados para emulsões A/O. O EHL das emulsões O/A deve de estar entre 10 - 18 (Walstra (2005)). Um excesso de emulsificante provoca um aumento de viscosidade da fase contínua refletindo-se na viscosidade de toda a emulsão.

Existem diversas técnicas para sintetizar uma emulsão. A homogenização a alta pressão é utilizada na indústria alimentícia. A emulsificação espontânea ocorre sem a necessidade de energia externa. Tal acontece quando fluidos de baixa tensão superficial entram em contato. Na emulsificação por membrana a fase dispersa é pressionada perpendicularmente contra uma matriz porosa. A inversão de fases é usada com frequência na indústria cosmética para emulsões de elevada fração volumétrica com características monodispersas. O processo ocorre quando a fase contínua vira fase dispersa, devido a 
alteração da temperatura, salinidade, proporções de água e óleo e pressão. Um método bastante usado é o Método de Inversão por Temperatura (PIT) quando se usa surfactantes não-iônicos (Leal-Calderon et al. (2007)). Abaixo da temperatura PIT surgem as emulsões $\mathrm{O} / \mathrm{A}$. Acima da temperatura PIT, são formadas emulsões A/O (Walstra (2005)). Existem ainda os métodos de nucleação e crescimento, por ultrassom e agitação. Alguns métodos necessitam de energia externa que pode ser do tipo elétrica, química ou mecânica. Neste método o líquido é intensamente agitado. As ferramentas que produzem a deformação e rompimento do líquido para a formação de gotas dependem da viscosidade dos líquidos. O tempo de mistura influência o tamanho final da gota, alterando as características reológicas da emulsão ( Prinderre et al. (1998) e Walstra (2005)). Quanto menores forem as gotas menos deformação adquirem e como tal têm um menor efeito na reologia da emulsão (Tandros (1994)). A fig. 6.2 mostra a sintese de uma emulsão pelo método de agitação mecânica usando a ferramenta em formato de âncora.

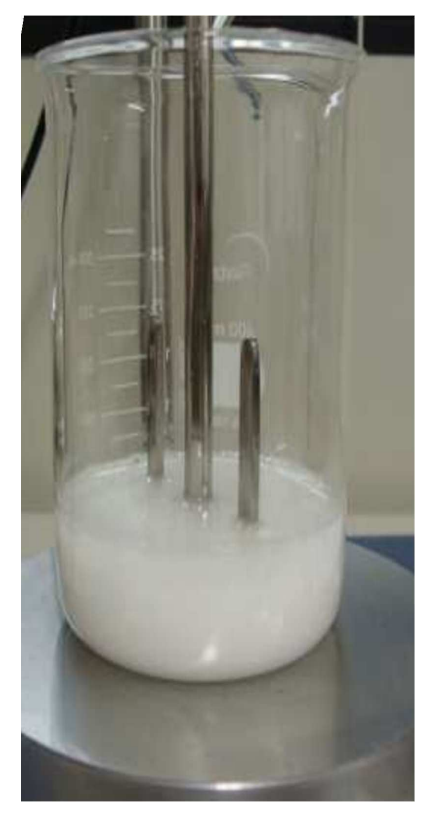

Figura 6.2: Emulsão gerada por agitação mecânica.

O grau de estabilidade da emulsão é maior quanto menor for o tamanho da gota. Gotas de tamanho maior têm menor área superficial promovendo a instabilidade termodinâmica do sistema. Essa instabilidade do sistema é devido ao excedente de energia superficial livre existente nas emulsões (Derkach, S. R (2009)). Assim, a função do surfactante é a estabilização termodinâmica do sistema evitando a coalescência progressiva das gotas até ao limite de separação total das duas fases. Partindo da própria definição 
da taxa de cisalhamento $\dot{\gamma}=d u / d y$, uma simples análise de escalas com $y \sim a$ e $u \sim \dot{\gamma} a$, mostra que a deformação de uma gota é proporcional ao número de capilaridade, $(\mathrm{Ca})$, para condição de pequena deformação. Mas, $C a \sim a$, tal que quanto menor o raio da gota menor será sua deformação.

A instabilidade de uma emulsão pode ocorrer de diferentes formas: agregação, coalescência, sedimentação e efeito de rigidez de Ostwald. A agregação ocorre quando as gotas permanecem juntas, formando agregados originando espaços vazios na microestrutura. Em geral a agregação está associada com forças de Van der Waals. A coalescência surge quando gotas se unem e formam gotas de tamanho maior, originando uma nítida separação entre as fases oleosas e aquosas. A sedimentação é observada quando a fase particulada se concentra no fundo do recipiente. No caso das emulsões pode acontecer que as gotas se concentrem no topo do recipente formando uma região designada de creaming (formação de uma camada cremosa na superfície da emulsão). A sedimentação pode ser quebrada através do processo de agitação manual. O tempo de sedimentação da gota é $a / U_{s}$ em que $U_{s}$ é a velocidade de sedimentação da gota de raio $a$ avaliada pela Lei de Stokes (eq. 6.1), em que $\eta_{0}$ é a viscosidade da fase contínua. Assim para que a sedimentação de gotas seja desprezível durante a deformação das mesmas é necessário que o tempo característico de cisalhamento seja muito menor que $a / U_{s}$. Nesse caso durante os experimentos se observará a gota deformando e, ou girando sem sedimentar. Em termos práticos o importante para evitar a sedimentação é ter a massa específica do fluido base aproximadamente igual à massa específica da gota tal que $\left(\rho-\rho_{0}\right) / \rho_{0}<<1$, em que $\rho$ e $\rho_{0}$ é a massa específica da fase dispersa e da fase continua, respetivamente.

$$
U_{s}=\frac{2}{9} a^{2}\left(\rho-\rho_{0}\right) \frac{g}{\eta_{0}}
$$

Em emulsões do tipo $\mathrm{O} / \mathrm{A}$ a velocidade de sedimentação é negativa o que leva à formação de um creme da região de topo, pelo fato de existir floculação das gotas com massa específica menor do que a do meio. Quando a emulsão é o tipo A/O a sedimentação leva à formação de uma camada de creme (agregado de gotas) na base do recipiente. É de se referir que a velocidade de Stokes foi formulada para emulsões diluídas, nas quais o movimento de uma gota isolada não é influenciado pelas suas vizinhas. Em 
Greenwald (1955) e em Derkach, S. R (2009) é discutida a velocidade de sedimentação em sistemas com múltiplas gotas. Quanto ao efeito de Ostwald, este acontece quando a matéria que forma as gotas menores se difunde até alcançar uma gota de maior tamanho (destilação). Este efeito está associado com o potencial químico da superfície das gotas (Walstra (2005)).

A quebra de gota pode acontecer ao longo do escoamento e está associada com a deformação da gota. A deformação da gota está associada com o número de capilaridade. Como abordado anteriormente, este parâmetro adimensional mede a importância relativa de forças viscosas e forças de tensão interfacial que agem sobre uma gota. Enquanto a tensão viscosa produzida pelo escoamento age no sentido de deformar a gota, a força de tensão interfacial tem um efeito de restaurar a forma da gota. Pode-se dizer também que o número de capilaridade pode ser definido com a razão entre o tempo característico para restaurar a gota, $\eta a / \tau_{s}$ e o tempo característico do escoamento $1 / \dot{\gamma}$. Para baixos $C a$, ou seja, a tensão interfacial da gota é muito superior as tensões provocadas pelo escoamento, a gota pouco se deforma, existindo escoamento no interior da gota. A circulação de líquido no interior da gota reduz o escoamento em torno da gota (Tandros (1994)). Do ponto de vista experimental, a deformação de uma gota em escoamento cisalhante é quantificada pela quantidade adimensional: $D=(L-B) /(L+B)$. O parâmetro $D$ também pode ser visto como uma medida de anisotropia da gota já que $L$ e $B$ estão nas direções principais perpendiculares entre si. No modelo de Taylor de emulsões diluídas, a anisotropia da gota é calculada como:

$$
D=\frac{16+19 \lambda}{16(\lambda+1)} C a
$$

Da eq. 6.2 é imediato se concluir que maiores taxas de cisalhamento, ou em termos adimensionais $C a$, levam a maiores deformações de gotas. A quebra de gotas (ruptura) acontece quando o número de capilaridade crítico $C a_{c}$ é atingido,ou seja, $C a \geq C a_{c}$.

Quanto menor for a razão de viscosidade $(\lambda)$, maior será o número de capilaridade crítico. Para suspensões com $\lambda>4$ as gotas não rompem em cisalhamento simples (apenas em escoamento de extensão pura) devido ao tempo característico de deformação da gota, $t_{d}$, ser muito maior do que o tempo de rotação, $t_{r}$, em que, $t_{d}=\lambda t_{r}$. Assim 
a gota gira muito mais rápido do que deforma e não rompe (Kiss et al. (2011)). No entanto a ruptura de gotas acontece com maior facilidade em emulsões concentradas devido à existência de maiores tensões entre as gotas (Derkach, S. R (2009)).

A vantagem de estudos com emulsões monodispersas está na facilidade em estudar a reologia, contrapondo à complexidade das emulsões polidispersas devido à existência de gotas de diferentes tamanhos (Mason (1999)). Leal-Calderon et al. (2007) refere que o aumento da quantidade de surfactante, que aumenta a viscosidade da fase contínua, pode originar emulsões de baixa polidispersividade para uma determinada intensidade de cisalhamento. Por outro lado se a quantidade de surfactante for insuficiente resulta na floculação das gotas devido a instabilidade do sistema (Barnes (1994)). Assim, é interessante entender como é que a polidispersividade afeta as propriedades macroscópicas. Para tal, pensa-se que o estudo de emulsões de mesma viscosidade mas com diferentes microestruturas seria a forma mais indicada para apurar esse efeito.

Segundo Tandros (1994) a microestrutura de emulsões de altas concentrações quando sujeita a altas taxas de cisalhamento fica completamente destruída refletindo um aumento de viscosidade. A distância média de separação entre as gotas $\left(h_{m}\right)$ está relacionada com o diâmetro da gota $\left(d_{m}\right)$ e com a fração volumétrica pela expressão:

$$
h_{m}=d_{m}\left[\left(\phi_{\max } / \phi\right)^{1 / 3}-1\right]
$$

em que $\phi_{\max }$ é a fração de máximo empacotamento, igual a 0,74 para esferas monodispersas empacotadas hexagonalmente. Nas emulsões esse fator pode ser maior do que 0,74 , tendo em vista que as gotas ao entrarem em contato podem-se deformar. Pela equação anterior vê-se que o valor crítico de $h_{m}$ é alcançado para pequenas gotas em uma menor fração volumétrica em comparação com gotas de maior tamanho. Com o aumento da fração volumétrica de gotas a viscosidade da emulsão aumenta em regime de baixa taxa de cisalhamento (Derkach, S. R (2009), Prinderre et al. (1998)). 


\subsection{Metodologia de Síntese de Emulsões do Presente Trabalho}

Para evitar a coalescência de gotas foi usado o emulsificante Tween80 (hidrofílico) e o surfactante Span80 (lipofílico), como agentes estabilizadores. A coalescência é evitada devido à formação de filmes interfaciais de complexos intermoleculares na interface O/A, melhorando a estabilidade das emulsões (Wan Rusmawati et al., (2005)). A quantidade de fluido estabilizador usado nas emulsões foi no total de $5 \mathrm{ml}$. A pipetagem foi o método seguido para medir o volume de líquido em todas as misturas. Foram usadas pipetas de $5 \mathrm{ml}$ e de $1 \mathrm{ml}$ por permitir um maior controle da quantidade dos diferentes líquidos requerida pela síntese de emulsões. É necessário que o EHL da mistura de surfactantes esteja próximo do EHL da fase oleosa. A mistura de surfactantes pode aumentar a estabilidade da emulsão em comparação com o uso de um único surfactante (Wan Rusmawati et al., (2005)). O óleo mineral tem um EHL entre 10 - 11. O Tween80 tem um EHL de 15, 0 e o Span80 tem um EHL de 4,3. Em todas as emulsões a quantidade usada de Tween80 foi de 3,5 $\mathrm{ml}$ e de Span80 foi de 1,5 $\mathrm{ml}$ conforme explicação do cálculo a seguir. O cálculo do EHL da mistura dos surfactantes é dado pela seguinte expressão:

$$
E H L=E H L_{\text {sur }_{1}} \times \% \text { sur }_{1}+E H L_{s u r_{2}} \times \% s u r_{2}
$$

em que, $E H L_{\text {sur }_{1}}$ é o $E H L$ do surfactante 1, EHL $L_{\text {sur }_{2}}$ é o $E H L$ do surfactante 2 $\%$ sur $_{1}$ é a porcentagem do surfactante 1 e \%sur 2 é a porcentagem do surfactante 2. Neste estudo $E H L_{\text {sur }_{1}}=E H L_{T W 80}=15,0, E H L_{\text {sur }_{2}}=E H L_{S P 80}=4,3, \%$ sur $_{1}=$ $\%_{s u r}{ }_{T 60}=0,7$ e $\%$ sur $_{1}=\% \operatorname{sur}_{S P 80}=0,3$, resultando em um EHL de 11,79. Desta forma o volume de Tween80 usado foi de $V_{T W 80}=0,7 \times 5=3,5 \mathrm{ml}$ e o volume de $\operatorname{Span} 80$ foi de $V_{S P 80}=0,3 \times 5=1,5 \mathrm{ml}$, conforme citado acima. Este tipo de cálculo é usual em áreas como a farmacêutica e a de cosméticos onde existe a necessidade de utilizar diversos óleos para, por exemplo, sintetizar cremes. Nesse contexto é necessário estudar os surfactantes disponíveis que se adequem tanto ao EHL da fase oleosa quando às necessidades dermatológicas. Pode-se encontrar este

tipo de abordagem em literatura das referidas áreas onde são destacados exemplos claros do procedimento de cálculo citado acima (Prista et al. (1991), Prinderre et al. 
(1998), (http://www.firp.ula.ve/site/es/)).

Após a fase aquosa estar pronta adicionou-se a mistura dos líquidos estabilizadores. A fase oleosa e a mistura da fase aquosa com os agentes estabilizadores foi aquecida até os $60^{\circ} \mathrm{C}$ na chapa aquecedora FISATOM (ver seção 4.6). Após atingida essa temperatura, a fase oleosa foi colocada em um recipiente de maior capacidade $(200 \mathrm{ml})$. Este pré-aquecimento permite que a viscosidade das duas fases estejam mais próximas que quando estavam a temperatura ambiente. É de notar que a fase aquosa contém os líquidos estabilizadores, que são óleos. Por outro lado o aumento da temperatura promove uma diminuição da tensão superficial, produzindo fortes gradientes de tensão superficial. O movimento produzido pelos gradientes de tensão superficial ajuda a promover uma distribuição mais homogênea dos líquidos estabilizadores na superfície da gota. Tal garante que a superfície da gota esteja envolvida com uma espessura de líquido estabilizador que promove um efeito repulsivo entre a fase aquosa e oleosa da emulsão.

Como já foi mencionado o tempo de mistura $\left(t_{m}\right)$, associado com o inverso da frequência da rotação do misturador (ver seção 4.6), influencia o tamanho final da gota. Neste trabalho não existe o interesse em estudar gotas de tamanho coloidal $(a<1 \mu \mathrm{m})$. Por outro lado precisa-se evitar gotas de tamanhos grandes $(a<50 \mu \mathrm{m})$ para evitar a instabilidade da emulsão por floculação de gotas. Desta forma o ideal é desenvolver uma metodologia com base em diferentes escalas de tempos. O tempo de mistura tem que ser muito maior que o período de rotação da haste do misturador e muito menor do que o tempo que a gota demora a flocular (calculado pela eq. 6.1). Por estas escalas de tempo é possível controlar a faixa de tamanho gota obtida no final do processo de síntese da emulsão. É conhecido que o tamanho da gota diminui com o aumento da energia de mistura, ou seja, com o aumento da rotação do misturador (Pérez et al., 2002)

De forma a controlar a mistura da fase aquosa na fase oleosa o misturador é ajustado para a sua menor velocidade $270 \mathrm{rpm}$. Este procedimento permite que pequenos volumes de fase aquosa em contato com todo o volume da fase oleosa sejam adequadamente misturados. O processo de adição da fase aquosa é feito na mesma velocidade até o 
fim da sua adição na fase oleosa. Quanto mais volume de fase aquosa é adicionado, maior terá que ser a rotação do misturador. Essa exigência é justificável pois maior volume de liquido se encontra no interior do recipiente de mistura e como tal uma maior velocidade permite uma maior taxa de cisalhamento. Esse aumento de velocidade empurra o fluido para a parede do recipiente promovendo também a formação de gotas. A velocidade máxima do misturador foi de $800 \mathrm{rpm}$. O tempo de adição da fase aquosa na fase oleosa foi de 2 minutos. Após a adição completa da fase aquosa espera-se o tempo necessário para que a mistura atinja a temperatura de $40^{\circ} \mathrm{C}$. Este tempo permite que as duas fases adquiram uma temperatura homogênea e que as gotas formadas estejam já envolvidas com o surfactante. Para aumentar a tensão superficial mergulha-se o recipiente de mistura em água gelada e o processo de mistura continua até que a mistura atinja a temperatura de laboratório $\left(25^{\circ} \mathrm{C}\right)$. No final do processo é verificado o tamanho de gota obtido. O procedimento de síntese de emulsão adotado neste trabalho está descrito em Sagitani, 1981 e é chamado de Método de Emulsificação Inverso. É de se referir que após a síntese a emulsão é armazenada a temperatura constante de $3^{\circ} \mathrm{C}$ por 24 horas antes do primeiro experimento. É também de se referir que não foi efetuado um estudo sobre a repetibilidade da distribuição do tamanho de gotas. O foco foi a geração de emulsões estáveis por um tempo maior do que o tempo total do experimento com gotas de tamanho não coloidal. É de se referir que a instabilidade por floculação é mais propícia nas emulsões com maior tamanho de gota. 


\section{RESULTADOS DA CARACTERIZAÇÃO DO FLUIDO BASE E DAS EMULSÕES}

Esta seção caracteriza as propriedades físicas (viscosidade e massa específica) do fluido base e das emulsões. O fluido base da emulsão é constituído por uma mistura de água destilada e glicerina que permite a variação da razão de viscosidade da emulsão. Todas as medidas foram realizadas a temperatura constante de $25^{\circ} \mathrm{C}$.

\subsection{CARACTERIZAÇÃO DO FLUIDO BASE DAS EMULSÕES}

A variação de razão de viscosidade da emulsão foi possível devido à variação da viscosidade do fluido carreador constituído por misturas de glicerina $\left(\mathrm{C}_{3} \mathrm{H}_{5}(\mathrm{OH})_{3}\right)$ e água destilada $\left(\mathrm{H}_{2} \mathrm{O}\right)$. O fabricante do tensiômetro indica que a tensão superficial da água destilada livre de impurezas é em torno de $72 \mathrm{mN} / \mathrm{m}$. A fig. 4.11 mostra que a tensão superficial da água destilada, utilizada nas diluições, obtida à temperatura de $25^{\circ} \mathrm{C}$ foi de $\tau_{s}=71,11 \mathrm{mN} / \mathrm{m}$. Este resultado mostra que a água destilada é adequada para a realização da síntese de emulsões. A fig. 7.1 mostra o aumento da viscosidade da mistura glicerina e água destilada em função da fração volumétrica de glicerina. A tab. 7.1 apresenta as propriedades das misturas que constituem o fluido base das emulsões ensaiadas.

Tabela 7.1: Propriedades das misturas Água-Glicerina.

\begin{tabular}{|c|c|c|c|}
\hline$\lambda$ & $\phi$ & $\rho\left[\mathrm{kg} / \mathrm{m}^{3}\right]$ & $\eta[$ Pa.s $]$ \\
\hline 20 & 0,5 & 1139 & $0,00739 \pm 0,000721$ \\
10 & 0,6 & 1166 & $0,1399 \pm 0,000963$ \\
5 & 0,7 & 1192 & $0,28071 \pm 0,000568$ \\
2 & 0,8 & 1260 & $0,68343 \pm 0,000512$ \\
\hline
\end{tabular}




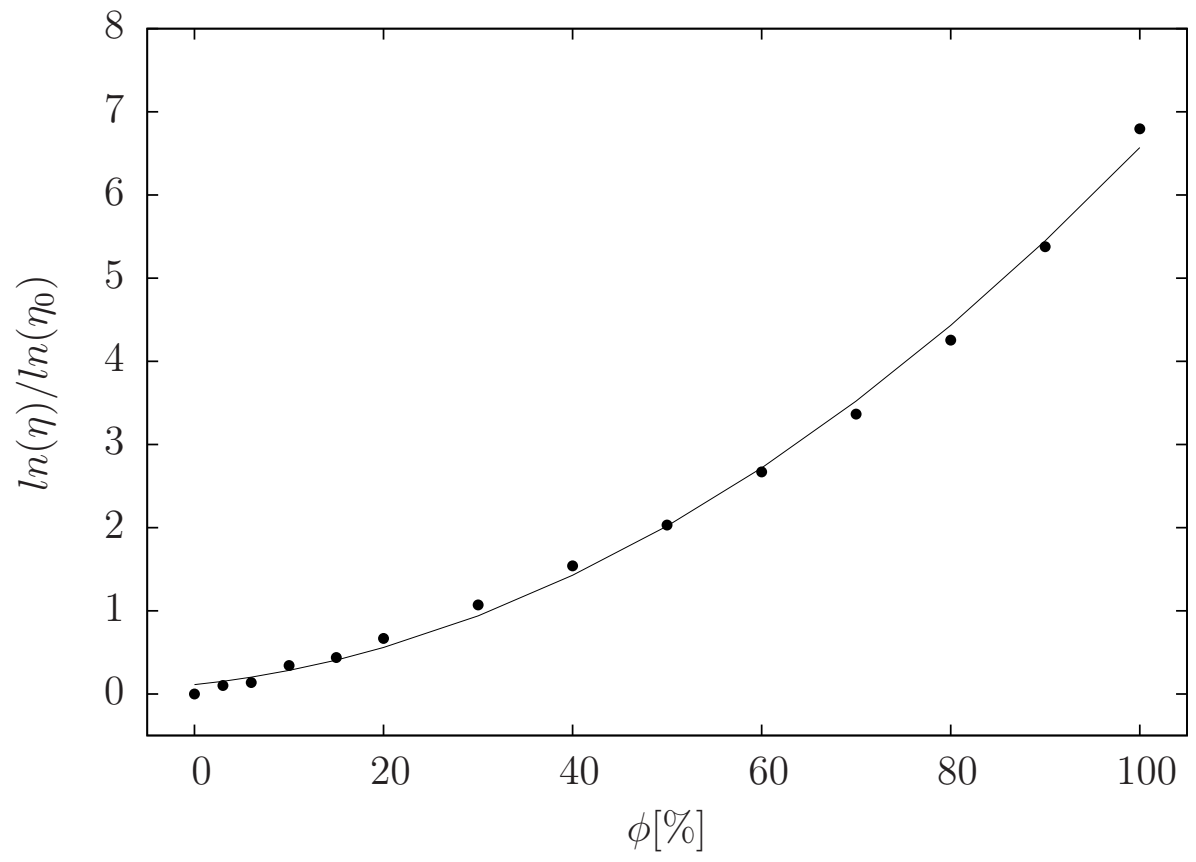

Figura 7.1: Variação da viscosidade da mistura Água-Glicerina. Os dados foram ajustados com um polinômio de segundo grau $\left(a_{1}+a_{2} \phi+a_{3} \phi^{2}\right)$ com os coeficientes: $a_{1}=0,11, a_{2}=0,012, a_{3}=0,00083$. A viscosidade $\eta_{0}$ é referente à viscosidade da água destilada.

\subsection{CARACTERIZAÇÃO DAS EMULSÕES: MASSA ESPECÍFICA E MICROESTRUTURA}

As seções 7.2, 7.3 e 7.4 apresentam os resultados de emulsões com frações volumétricas $2 \%, 5 \%, 20 \%$ e $40 \%$ para as razões de viscosidade $2,5,10$ e 20 . As emulsões de menor fração volumétrica foram obtidas por diluição da emulsão de $\phi=40 \%$.

A tab. 7.2 lista a massa específica das emulsões avaliadas no densímetro (ver seção 4.5). As medições foram realizadas a temperatura de $25^{\circ} \mathrm{C}$. O erro das medições foi avaliado através do desvio padrão de um conjunto de medições. Pelos resultados observa-se que a massa específica aumenta com a diminuição da razão de viscosidade devido ao aumento da quantidade de glicerina e com a diminuição da fração volumétrica devido à presença de menor número de gotas de óleo mineral cuja massa específica $\left(868 \mathrm{~kg} / \mathrm{m}^{3}\right)$ é menor que a massa específica do fluido base.

Após a medição dos diâmetros das gotas da microestrutura da emulsão, com o sistema de microscopia ótica descrito na seção 4.3, realizou-se um tratamento estatístico que 
Tabela 7.2: Massa Específica $\left[\mathrm{kg} / \mathrm{m}^{3}\right]$

\begin{tabular}{|c|c|c|c|c|}
\hline$\phi[\%]$ & $\lambda=2$ & $\lambda=5$ & $\lambda=10$ & $\lambda=20$ \\
\hline 2 & $1204,5 \pm 7,106$ & $1186,8 \pm 0,837$ & $1159,0 \pm 0,000$ & $1135,0 \pm 0,71$ \\
5 & $1190,2 \pm 3,490$ & $1185,4 \pm 0,548$ & $1150,0 \pm 1,000$ & $1129,6 \pm 0,89$ \\
20 & $1131,0 \pm 2,683$ & $1129,0 \pm 1,000$ & $1096,4 \pm 6,600$ & $1089,8 \pm 2,28$ \\
40 & $1080,0 \pm 0,894$ & $1061,4 \pm 2,610$ & $1049,6 \pm 2,190$ & $1019,8 \pm 2,59$ \\
\hline
\end{tabular}

permite verificar a distribuição dos diâmetros das gotas e investigar sobre uma função densidade de probabilidade para a distribuição do tamanho de gota. Para analisar a microestrutura de cada emulsão em cada fração volumétrica para cada razão de viscosidade foram recolhidas cinco amostras das quais foram capturadas cinco regiões de análise. Do conjunto resultam 25 regiões com gotas de tamanhos diferentes. No total foram analisadas 400 fotos. Em cada foto foram analisadas, em média, 90 gotas. Nas amostras referentes às emulsões de maior concentração o número de gotas capturado foi, em média, de 160 gotas. O tratamento estatístico foi obtido através de um programa computacional escrito na linguagem FORTRAN adequado para ler de forma direta os arquivos de saída do sistema de microscopia que contêm os diâmetros das gotas das amostras analisadas. A distribuição de tamanho de gotas segue uma função densidade de probabilidade do tipo log-normal (Barnes (1994)):

$$
p(x)=\frac{C_{1}}{x \sqrt{2 \pi \sigma_{\ln (x)}^{2}}} \exp \left[-\frac{\left(\ln \left(x / C_{2}\right)-\overline{\ln (x)}\right)^{2}}{2 \sigma_{\ln x}^{2}}\right]
$$

com

$$
\begin{gathered}
\sigma_{\ln x}^{2}=\ln \left(1+\frac{\sigma_{x}^{2}}{\bar{x}^{2}}\right), \\
\overline{\ln (x)}=\ln (\bar{x})-0,5 \ln \left(\sigma_{\ln x}^{2}\right),
\end{gathered}
$$

em que:

$$
\sigma_{x}=\frac{1}{N} \sum_{i=1}^{N}\left(x_{i}-\bar{x}\right)^{2}
$$

Aqui $N$ é o número total de gotas, $x=d / \bar{d}$ em que $\bar{d}$ é diâmetro médio das gotas. É de notar que se na eq. 7.1 $C_{1}$ e $C_{2}$ forem unitários recupera-se a expressão da log-normal padrão. A quantidade de amostras recolhidas para avaliar a microestrutura da emulsão 
obedeceu à saturação da média volumétrica dos diâmetros.

A fig. 7.2 e a fig. 7.3 apresentam a foto, histograma e a distribuição log-normal de uma microestrutura típica de uma emulsão. No anexo A encontram-se os demais histogramas de tamanho de gota acompanhado com uma foto típica da microestrutura para cada emulsão.

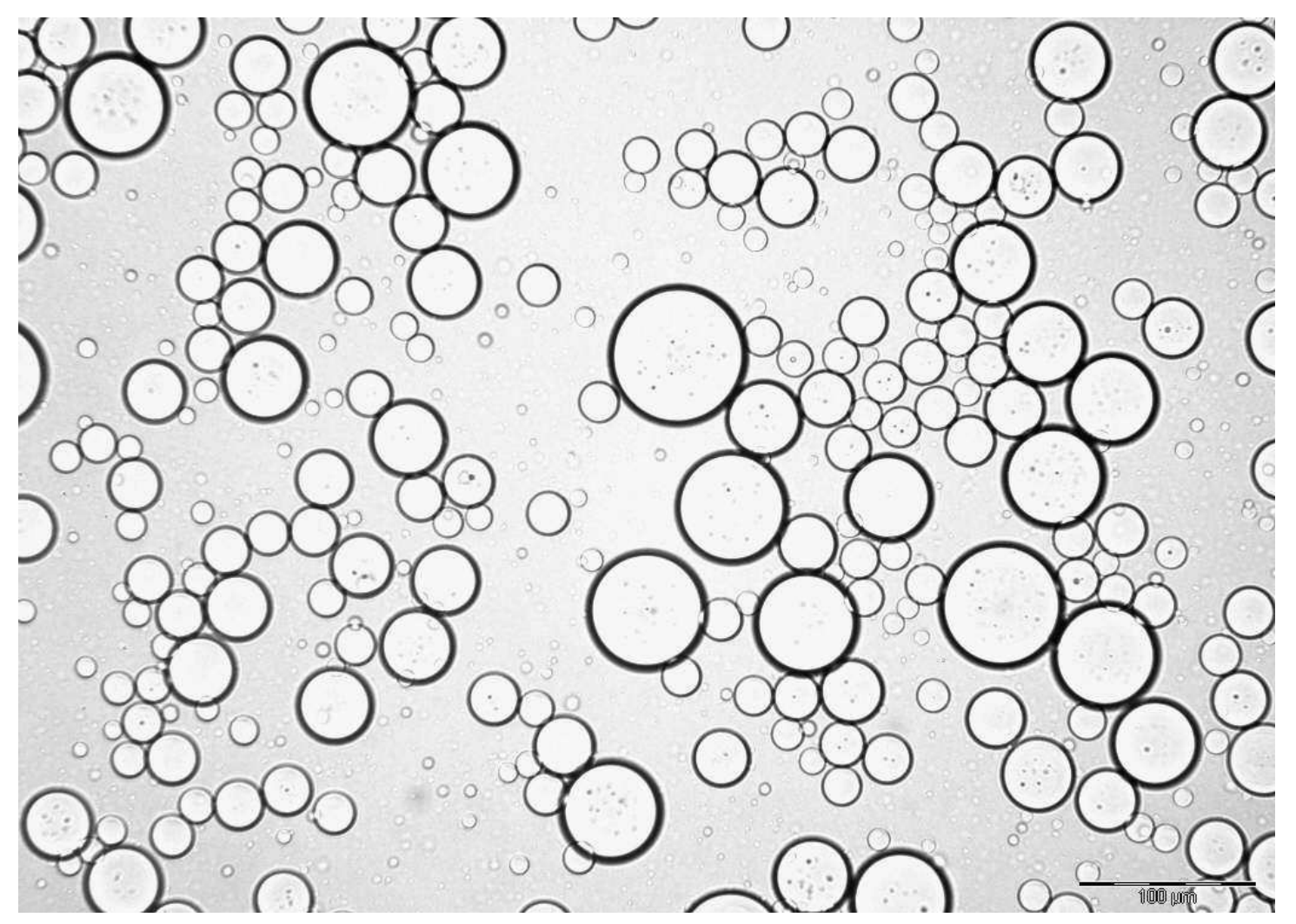

Figura 7.2: Imagem da Microestrutura da Emulsão $\lambda=2$ e $\phi=2 \%$. 


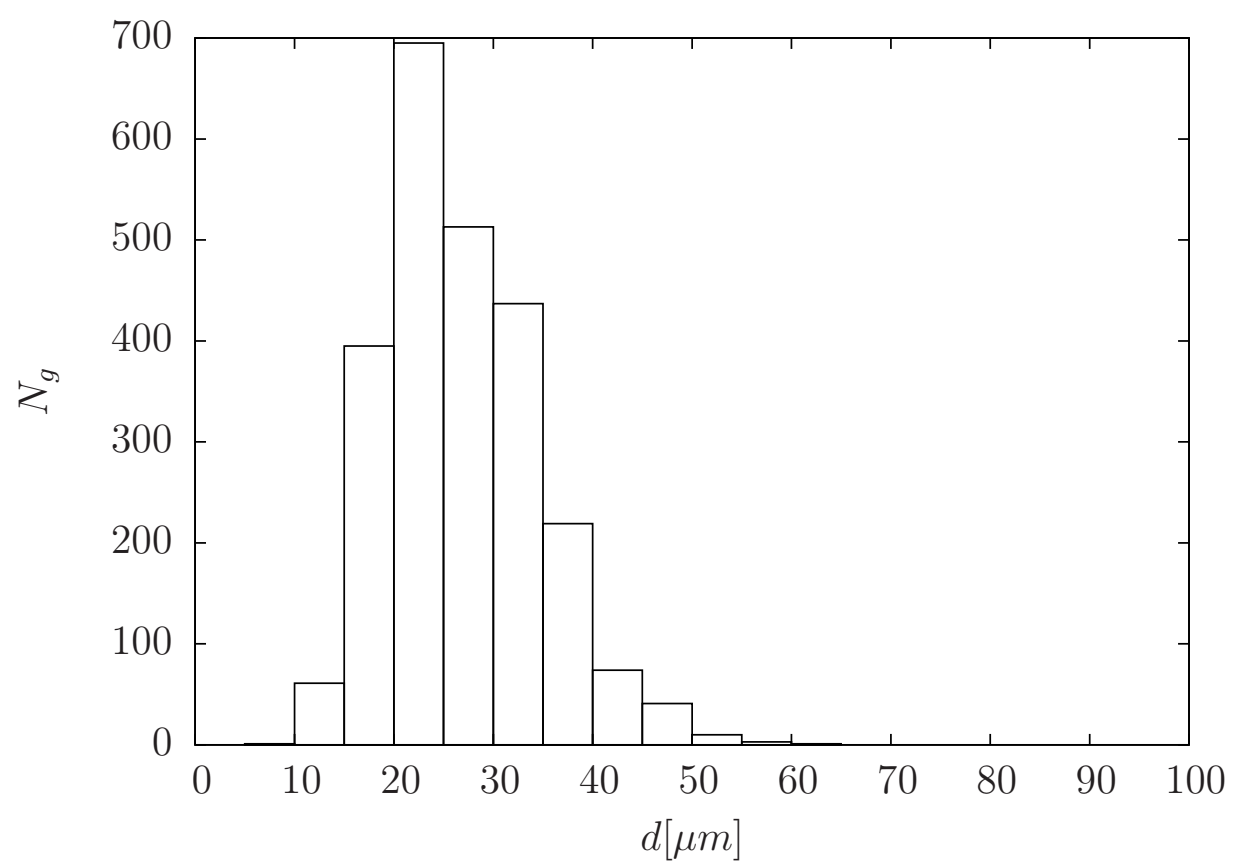

(a) Distribuição de Tamanho de gota para a emulsão. Características da microestrutura: $N_{g}=2450, \bar{a}=13,37 \mu m, p=0,286$

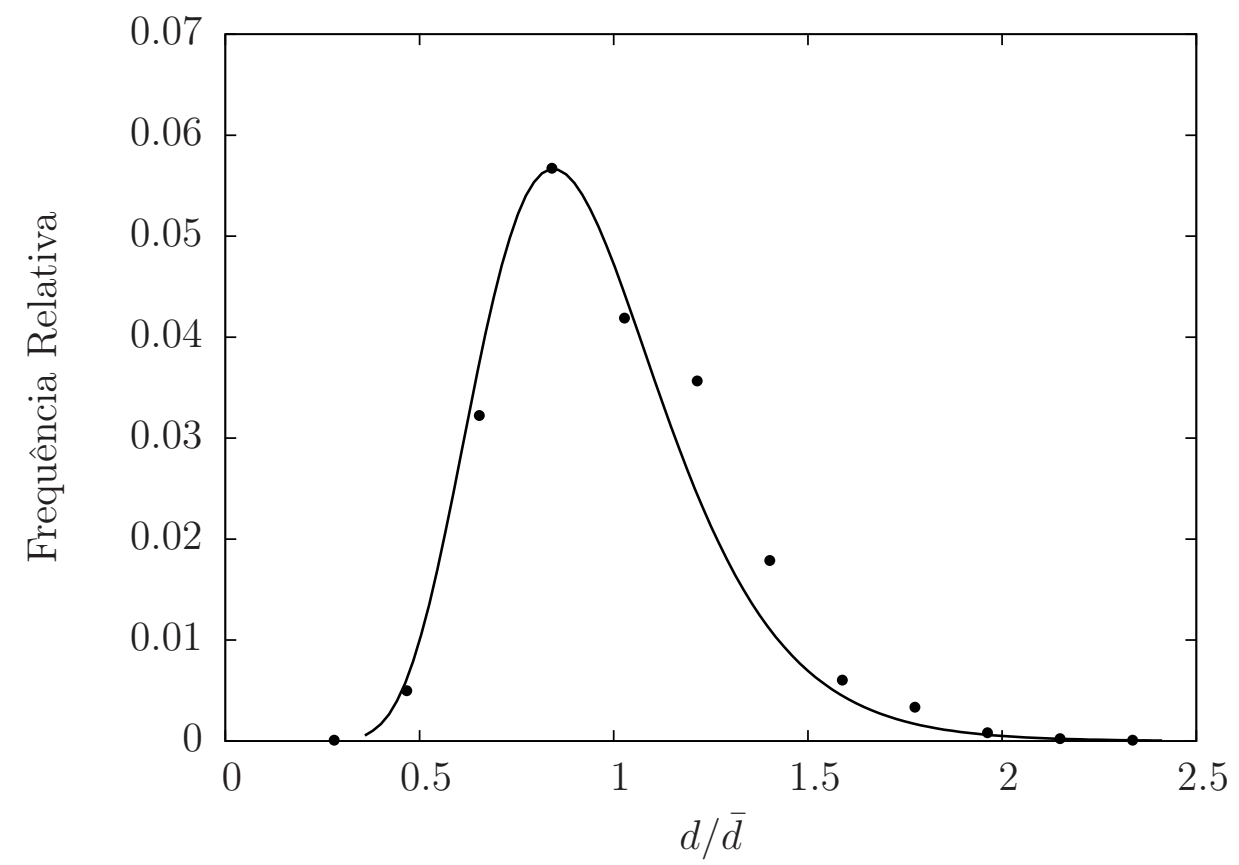

(b) Frequência Relativa $\left(N_{\text {gint }} /\left(\operatorname{Dim}_{\text {int }} \times N_{\text {gtot }}\right)\right.$. Constantes da Log-Normal: $C_{1}=0,035, C_{2}=0,95$.

Figura 7.3: Distribuição de Tamanho de Gota e Frequência Relativa típica de uma emulsão $(\lambda=2$ e $\phi=2 \%)$. 
A polidispersidade da emulsão foi calculada pela razão entre o desvio padrão, em relação ao diâmetro médio da gota (Mason (1999), Whitby et al., (2007), Patty e Frisken (2006)). A tab. 7.3 resume as características das microestrutura das emulsões. Os resultados mostram que a polidispersidade ficou entre 0,27 e 0,44. Analisando o raio médio das gotas das emulsões verifica-se que as emulsões com gotas de maior raio médio são as de $\lambda=10$ e 20. A emulsão com gota de menor raio médio é a emulsão de $\lambda=5$. É de se referir que durante a síntese de emulsões em misturadores mecânicos, onde é difícil controlar o número, tamanho e distribuição de tamanho de gotas (Pal, (2011)), a quebra de gotas é maior em emulsões de menor razão de viscosidade, para uma mesma velocidade de mistura. Depois de um tempo suficientemente longo de mistura a emulsão polidispersa se aproxima de uma emulsão monodispersa devido às maiores gotas se terem subdividido em menores gotas. Em maiores razões de viscosidade as gotas giram muito mais rápido do que se deformam e por isso a taxa de ruptura é menor. O resultado é as emulsões de maiores razões de viscosidade apresentarem gotas de maior tamanho e uma maior polidispersidade. Em geral, conforme sugere a literatura (Pal (2000a), Salager et al., (1995)), quanto mais polidispersa for a emulsão menor é a viscosidade, contudo, quanto menor o tamanho médio de gota, maior é a viscosidade (Masalov (2011),Pal (2000a),Otsubo e Prud'homme (1994)) . É de se referir que gotas de maior tamanho são mais propensas à deformação devido à menor pressão de Laplace ( Saiki et al., (2008)). A pressão de Laplace relaciona a diferença de pressão entre a região externa e interna da gota com a curvatura da superfície da gota. Para uma análise mais detalhada da microestrutura da emulsão subdividiu-se o histograma de distribuição de diâmetro de gotas em quatro categorias:

1. diâmetro que teve o maior número de gotas,

2. diâmetros inferiores à $1^{\mathrm{a}}$ categoria,

3. diâmetros superiores mas de dimensão próxima à $1^{\mathrm{a}}$ categoria,

4. diâmetros superiores à $3^{\mathrm{a}}$ categoria.

As tabs. 7.4, 7.5, 7.6 e 7.7 contêm os dados das categorias dos diâmetros de gotas em porcentagem relativa ao número total de gotas da amostra de cada emulsão para, respectivamente, $\lambda=2, \lambda=5, \lambda=10, \lambda=20$. A análise é feita comparando emulsões com a mesma fração volumétrica. 
Analisando as emulsões de fração volumétrica $\phi=2 \%$ observa-se que as emulsões de $\lambda=2$ e 5 apresentam $100 \%$ das gotas no intervalo de $15<d<55 \mu \mathrm{m}$. Enquanto que as emulsões de $\lambda=10$ e 20 apresentam $40 \%$ das gotas dentro do intervalo $15<$ $d<55 \mu \mathrm{m}$. É de notar que $15 \%$ das gotas de $\lambda=10$ têm diâmetro superior a $55 \mu \mathrm{m}$, enquanto que a emulsão de $\lambda=20$ tem somente $5 \%$.

Para $\phi=5 \%$ a emulsão de $\lambda=5$ apresenta gotas de diâmetro menor em comparação com a emulsão de $\lambda=2$. Para o intervalo $12<d<40$ a emulsão que representa maior porcentagem é de $\lambda=2$ e $5(\approx 100 \%)$. As emulsões de $\lambda=10$ e 20 têm $\approx 70 \%$ de gotas no intervalo $12<d<40$. É de notar que a emulsão de $\lambda=10$ tem a maior polidispersidade $(0,44)$.

Para a emulsão $\phi=20 \%$ a microestrutura revela configurações idênticas para as emulsões de $\lambda=2$ e de $\lambda=5$. A única diferença está na porcentagem da categoria 3 que é maior para a emulsão de $\lambda=2$. Para gotas de $5<d<40$ as emulsões de $\lambda=2$ e 5 apresentam a maior porcentagem $(\approx 100 \%)$ enquanto que as emulsões de $\lambda=10$ e 20 têm $\approx 70 \%$ de gotas no intervalo $5<d<40$. É de destacar que o diâmetro máximo da gota das emulsões de $\lambda=10$ e 20 é de cerca de $100 \mu m$. Tal pode estar relacionado com a maior polidispersidade destas duas emulsões face às restantes, para a fração volumétrica de $20 \%$. Para $\phi=40 \%$ a emulsão de $\lambda=2$ apresenta porcentagens maiores em todas as categorias face à $\lambda=5$ excepto para a categoria 1 . A polidispersidade da emulsão $\lambda=2$ é maior entre estas duas emulsões. Isso reflete que a emulsão de $\lambda=2$ tem uma maior variação no tamanho de gotas. Tal pode proporcionar um maior efeito pseudo-plástico. Para gotas no intervalo $5<d<40$ a emulsão de $\lambda=5$ apresenta a maior porcentagem $(\approx 100 \%)$ de seguida vem a emulsão de $\lambda=2(\approx 85 \%)$ e as emulsões $\lambda=10$ e $\lambda=20(\approx 70 \%)$. Apesar de as emulsões de maior razão de viscosidade apresentarem gotas de maior tamanho espera-se que o efeito pseudo-plástico seja menor devido à menor deformação das gotas. É de se referir que o diâmetro máximo da gota da emulsão de $\lambda=10$ é de cerca de $90 \mu m$ e da emulsão de $\lambda=20$ é de cerca de $120 \mu \mathrm{m}$, conferindo a maior polidispersidade destas emulsões para a fração volumétrica de $40 \%$. 
Tabela 7.3: Polidispersidade das Emulsões $\sigma / \bar{d}$.

\begin{tabular}{|c|c|c|c|}
\hline \multicolumn{4}{|c|}{$\lambda=2$} \\
\hline$\phi$ & $N_{g}$ & $\bar{a}[\mu m]$ & $\sigma / \bar{d}$ \\
\hline 2 & 2450 & 13,37 & 0,29 \\
\hline 5 & 1650 & 12,49 & 0,32 \\
\hline 20 & 2555 & 12,14 & 0,29 \\
\hline 40 & 3570 & 14,22 & 0,34 \\
\hline \hline \multicolumn{4}{|c|}{$\lambda=5$} \\
\hline$\phi$ & $N_{g}$ & $\bar{a}[\mu m]$ & $\sigma / \bar{d}$ \\
\hline 2 & 1150 & 10,00 & 0,30 \\
\hline 5 & 1385 & 9,61 & 0,39 \\
\hline 20 & 2320 & 11,78 & 0,27 \\
\hline 40 & 3115 & 11,81 & 0,28 \\
\hline \hline \multicolumn{4}{|c|}{$\lambda=10$} \\
\hline$\phi$ & $N_{g}$ & $\bar{a}[\mu m]$ & $\sigma / \bar{d}$ \\
\hline 2 & 2670 & 21,00 & 0,30 \\
\hline 5 & 1870 & 16,00 & 0,44 \\
\hline 20 & 2440 & 17,40 & 0,39 \\
\hline 40 & 2720 & 17,00 & 0,38 \\
\hline \hline \multicolumn{4}{|c|}{$\lambda=20$} \\
\hline$\phi$ & $N_{g}$ & $\bar{a}[\mu m]$ & $\sigma / \bar{d}$ \\
\hline 2 & 4950 & 16,39 & 0,27 \\
\hline 5 & 7500 & 17,88 & 0,27 \\
\hline 20 & 4970 & 21,53 & 0,32 \\
\hline 40 & 5000 & 21,00 & 0,33 \\
\hline \multicolumn{4}{|c}{}
\end{tabular}


Tabela 7.4: Categorização dos diâmetros de gotas das emulsão com $\lambda=2$.

\begin{tabular}{|c|c|}
\hline \multicolumn{2}{|l|}{$\phi=2 \%$} \\
\hline Categoria $d[\mu m]$ & $\%$ \\
\hline $1: d=22$ & 29,57 \\
\hline $2: 12 \leq d<17$ & 18,37 \\
\hline $3: 22<d \leq 37$ & 38,00 \\
\hline 4: $37<d \leq 52$ & 14,06 \\
\hline \multicolumn{2}{|l|}{$\phi=5 \%$} \\
\hline Categoria $d[\mu m]$ & $\%$ \\
\hline $1: 12 \leq d \leq 22$ & 51,52 \\
\hline $2: d=12$ & 6,55 \\
\hline $3: 22<d \leq 32$ & 30,30 \\
\hline 4: $32<d \leq 47$ & 12,65 \\
\hline \multicolumn{2}{|l|}{$\phi=20 \%$} \\
\hline Categoria $d[\mu m]$ & $\%$ \\
\hline $1: 12<d \leq 22$ & 55,38 \\
\hline $2: d=12$ & 6,29 \\
\hline $3: 22<d \leq 37$ & 35,02 \\
\hline $4: 37<d \leq 50$ & 3,35 \\
\hline \multicolumn{2}{|l|}{$\overline{\phi \phi}=40 \%$} \\
\hline Categoria $d[\mu m]$ & $\%$ \\
\hline $1: d=22$ & 28,01 \\
\hline $2: 10 \leq d<22$ & 16,24 \\
\hline $3: 22<d \leq 37$ & 41,46 \\
\hline 4: $37<d \leq 67$ & 14,29 \\
\hline
\end{tabular}


Tabela 7.5: Categorização dos diâmetros de gotas das emulsão com $\lambda=5$.

\begin{tabular}{|l|c|}
\hline \multicolumn{2}{|c|}{$\phi=2 \%$} \\
\hline Categoria $d[\mu m]$ & $\%$ \\
\hline 1: $d=17$ & 36,52 \\
\hline 2: $7 \leq d<17$ & 17,39 \\
\hline 3: $17<d \leq 27$ & 39,13 \\
\hline 4: $27<d \leq 42$ & 6,96 \\
\hline \hline \multicolumn{2}{|c|}{$\phi=5 \%$} \\
\hline Categoria $d[\mu m]$ & $\%$ \\
\hline 1: $7<d \leq 17$ & 51,26 \\
\hline 2: $d=7$ & 7,22 \\
\hline 3: $17<d \leq 27$ & 29,60 \\
\hline 4: $27<d \leq 47$ & 11,92 \\
\hline \hline \multicolumn{2}{|c|}{$\phi=20 \%$} \\
\hline Categoria $d[\mu m]$ & $\%$ \\
\hline 1: $12<d \leq 22$ & 59,48 \\
\hline 2: $d=12$ & 5,17 \\
\hline 3: $22<d \leq 32$ & 28,45 \\
\hline 4: $32<d \leq 50$ & 6,90 \\
\hline \hline \multicolumn{2}{|c|}{$\phi=40 \%$} \\
\hline Categoria $d[\mu m]$ & $\%$ \\
\hline 1: $12 \leq d<22$ & 63,24 \\
\hline 2: $7 \leq d<12$ & 3,85 \\
\hline 3: $22 \leq d \leq 37$ & 32,10 \\
\hline 4: $37<d \leq 52$ & 0,81 \\
\hline \multicolumn{2}{|c|}{} \\
\hline
\end{tabular}


Tabela 7.6: Categorização dos diâmetros de gotas das emulsão com $\lambda=10$.

\begin{tabular}{|l|c|}
\hline \multicolumn{2}{|c|}{$\phi=2 \%$} \\
\hline Categoria $d[\mu m]$ & $\%$ \\
\hline 1: $30<d \leq 45$ & 46,44 \\
\hline 2: $15 \leq d \leq 30$ & 14,98 \\
\hline 3: $45<d \leq 55$ & 23,60 \\
\hline $4: 55<d \leq 95$ & 14,98 \\
\hline \hline \multicolumn{2}{|c|}{$\phi=5 \%$} \\
\hline Categoria $d[\mu m]$ & $\%$ \\
\hline 1: $15 \leq d \leq 40$ & 65,78 \\
\hline 2: $5 \leq d<15$ & 7,49 \\
\hline 3: $40<d \leq 55$ & 18,45 \\
\hline 4: $55<d \leq 100$ & 8,29 \\
\hline \hline \multicolumn{2}{|c|}{$\phi=20 \%$} \\
\hline Categoria $d[\mu m]$ & $\%$ \\
\hline 1: $20<d \leq 40$ & 58,61 \\
\hline 2: $5 \leq d \leq 20$ & 11,89 \\
\hline 3: $40<d \leq 55$ & 21,72 \\
\hline 4: $55<d \leq 100$ & 7,79 \\
\hline \hline \multicolumn{2}{|c|}{$\phi=40 \%$} \\
\hline Categoria $d[\mu m]$ & $\%$ \\
\hline 1: $20 \leq d<40$ & 61,58 \\
\hline 2: $5 \leq d<20$ & 11,14 \\
\hline 3: $40 \leq d<55$ & 20,29 \\
\hline 4: $55<d \leq 90$ & 6,99 \\
\hline
\end{tabular}


Tabela 7.7: Categorização dos diâmetros de gotas das emulsão com $\lambda=20$.

\begin{tabular}{|l|c|}
\hline \multicolumn{2}{|c|}{$\phi=2 \%$} \\
\hline Categoria $d[\mu m]$ & $\%$ \\
\hline 1: $25 \leq d<40$ & 52,53 \\
\hline 2: $10 \leq d<25$ & 22,22 \\
\hline 3: $40 \leq d<50$ & 20,20 \\
\hline 4: $50<d \leq 70$ & 5,05 \\
\hline \hline \multicolumn{2}{|c|}{$\phi=5 \%$} \\
\hline Categoria $d[\mu m]$ & $\%$ \\
\hline 1: $30 \leq d<40$ & 46,67 \\
\hline 2: $10 \leq d<30$ & 23,60 \\
\hline 3: $40 \leq d<55$ & 24,00 \\
\hline 4: $55<d \leq 100$ & 5,73 \\
\hline \hline \multicolumn{2}{|c|}{$\phi=20 \%$} \\
\hline Categoria $d[\mu m]$ & $\%$ \\
\hline 1: $30 \leq d<50$ & 61,27 \\
\hline 2: $15 \leq d<30$ & 11,27 \\
\hline 3: $50 \leq d<70$ & 23,14 \\
\hline 4: $70<d \leq 110$ & 4,33 \\
\hline \hline \multicolumn{2}{|c|}{$\phi=40 \%$} \\
\hline Categoria $d[\mu m]$ & $\%$ \\
\hline 1: $30 \leq d<45$ & 49,80 \\
\hline 2: $10 \leq d<30$ & 14,40 \\
\hline 3: $45 \leq d<65$ & 26,00 \\
\hline 4: $65<d \leq 120$ & 9,80 \\
\hline \multicolumn{2}{|c|}{}
\end{tabular}




\subsection{CISALHAMENTO LINEAR EM REGIME PERMANENTE}

Nesta seção são apresentadas as medidas de viscosidade para várias emulsões em vários regimes de taxa de cisalhamento, respeitando a hipótese de escoamento unidirecional. Os experimentos foram realizados a uma temperatura de laboratório constante de $25^{\circ} \mathrm{C}$. Para extrair a viscosidade da emulsão em uma determinada taxa de cisalhamento repetiu-se o experimento por cinco vezes. Para cada repetição a viscosidade é considerada válida quando não existe variação da mesma em função do tempo para uma determinada taxa de cisalhamento (regime permanente).

O tempo necessário para que as emulsões de fração volumétrica de $40 \%$ de diferentes razões de viscosidade atinjam o regime permanente com relação à viscosidade é apresentado pelas figs. 7.4, 7.5, 7.6 e 7.7, quando sujeitas a uma taxa de cisalhamento de $5 s^{-1}$. Os resultados mostram que o tempo para que a viscosidade atinja o seu regime permanente diminui com o aumento da razão de viscosidade. Este comportamento pode estar associado com o tempo necessário para que as gotas atinjam o seu regime permanente com relação à deformação provocada pelo cisalhamento do escoamento. As gotas de maiores razões de viscosidade apresentam menores deformações, pois estas giram mais rápido do que deformam. Por outro lado, a microestrutura das emulsões de menores razões de viscosidade apresentam diferentes configurações até que as gotas atinjam a sua forma permanente para uma determinada taxa de cisalhamento, e por isso apresentam uma maior região transiente de viscosidade. 


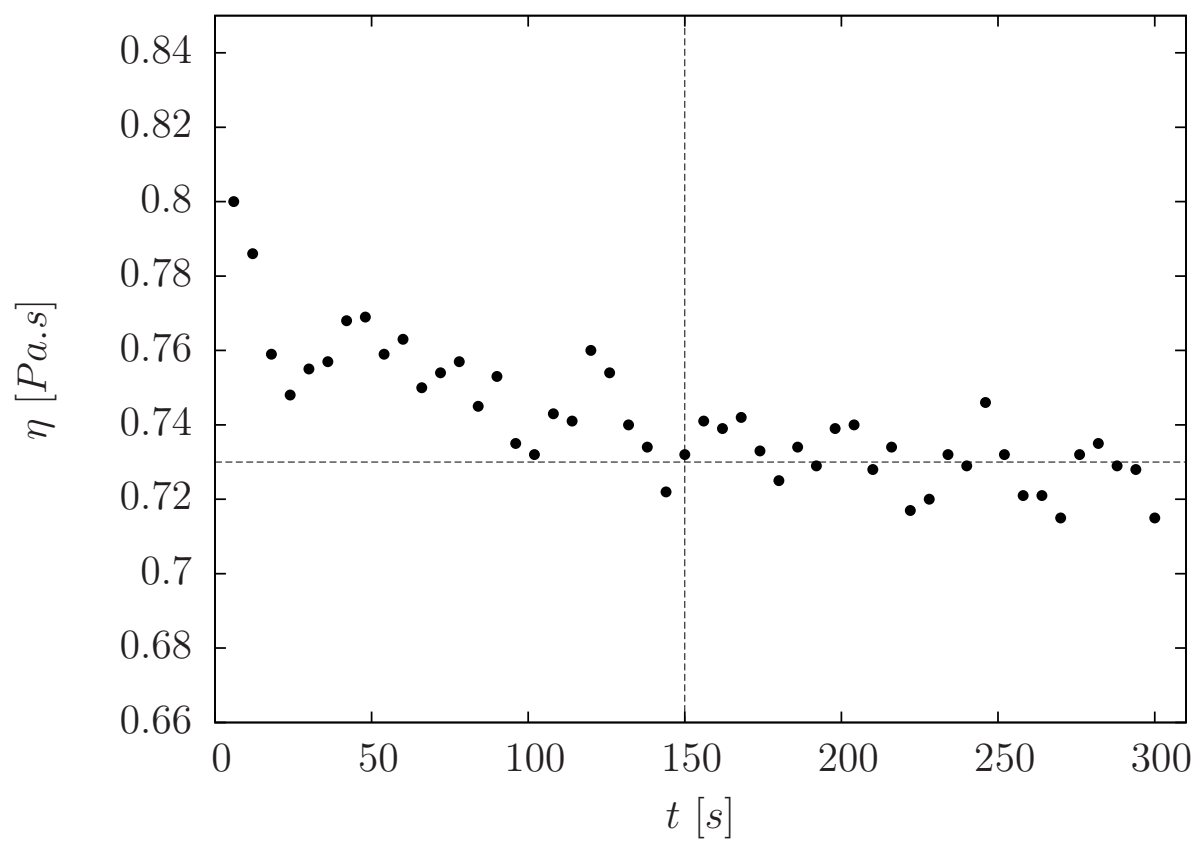

Figura 7.4: Regime Permanente atingido em $t=150 \mathrm{~s}$ para uma emulsão de $\phi=40 \%$ e $\lambda=2$ sujeita a $\dot{\gamma}=5 s^{-1}$. O valor da viscosidade obtido foi $\eta=0,73 \pm 0,0084$ Pa.s.

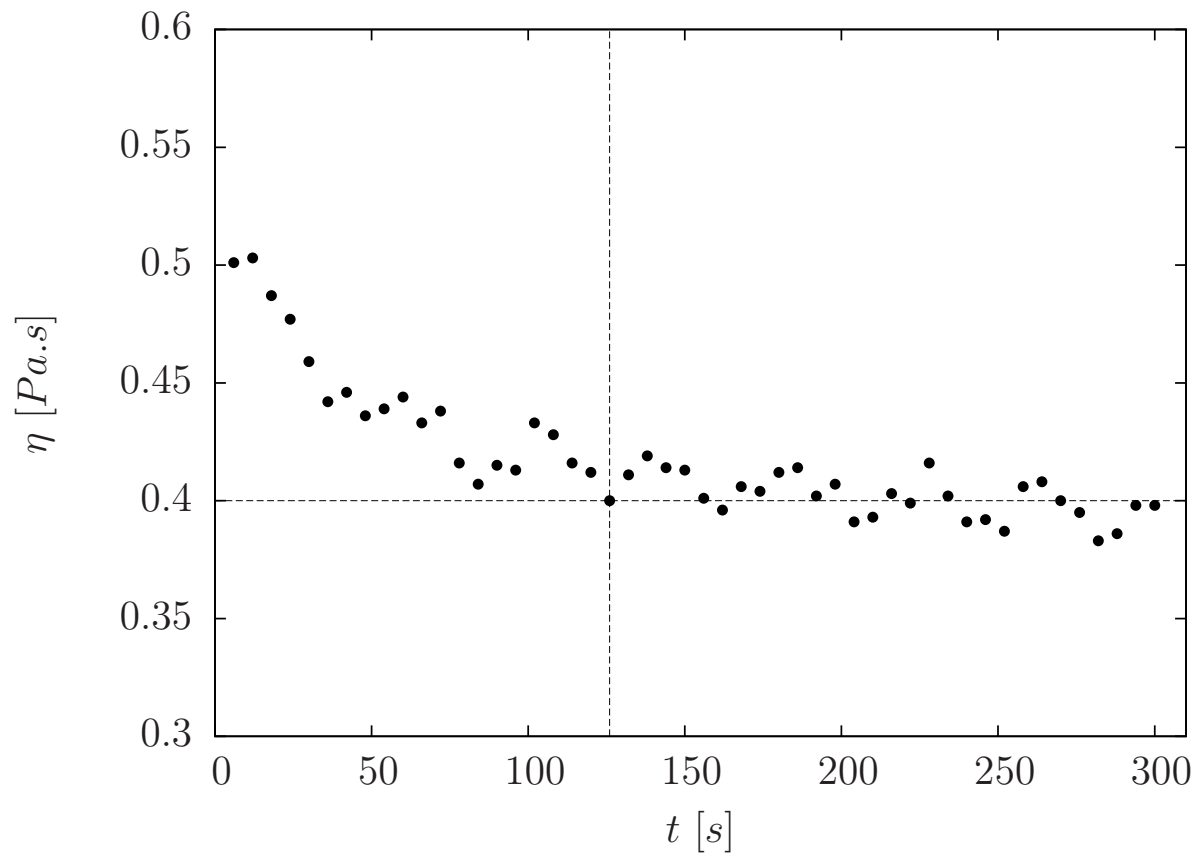

Figura 7.5: Regime Permanente atingido em $t=126 \mathrm{~s}$ para uma emulsão de $\phi=40 \%$ e $\lambda=5$ sujeita a $\dot{\gamma}=5 s^{-1}$. O valor da viscosidade obtido foi $\eta=0,40 \pm 0,0094$ Pa.s . 


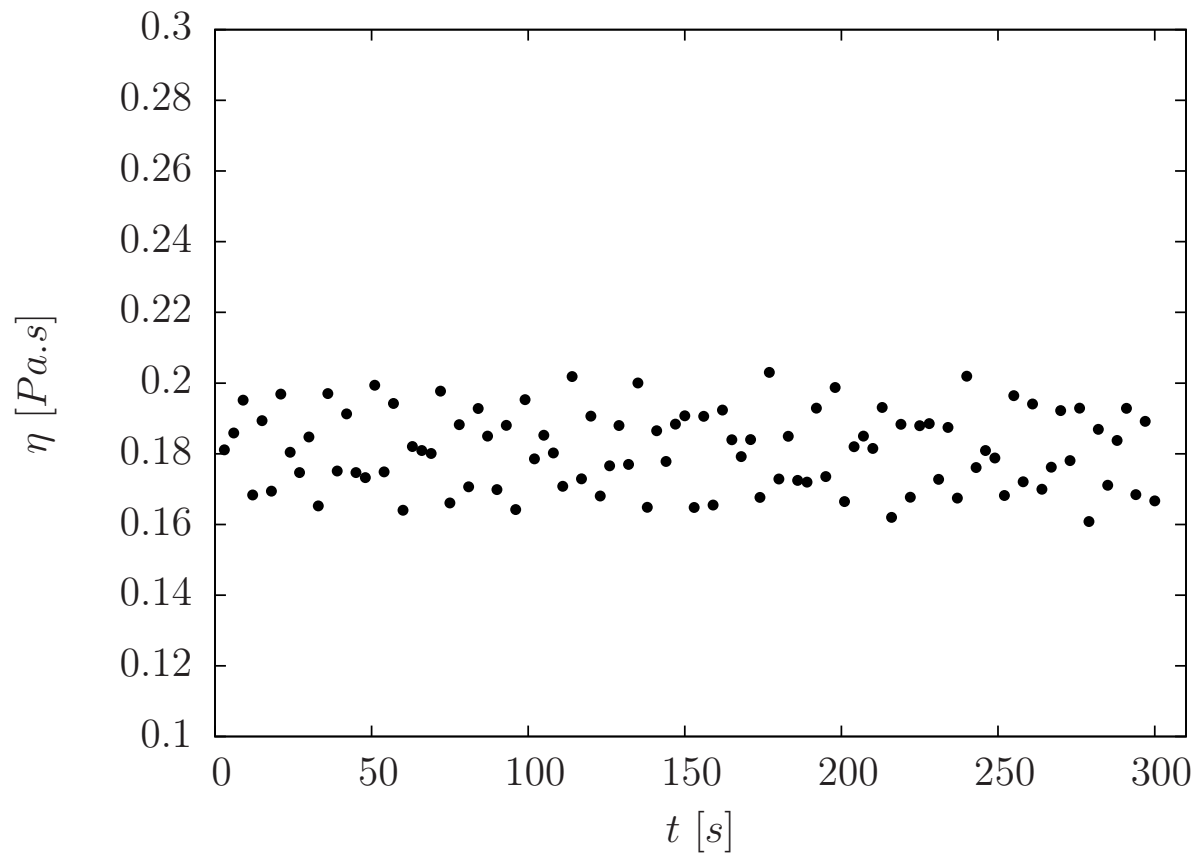

Figura 7.6: Viscosidade de uma emulsão de $\phi=40 \%$ e $\lambda=10$ sujeita a $\dot{\gamma}=5 \mathrm{~s}^{-1}$. Durante o tempo experimental a emulsão não apresentou regime transiente da viscosidade. O valor da viscosidade obtido foi de $\eta=0,181 \pm 0,011$ Pa.s .

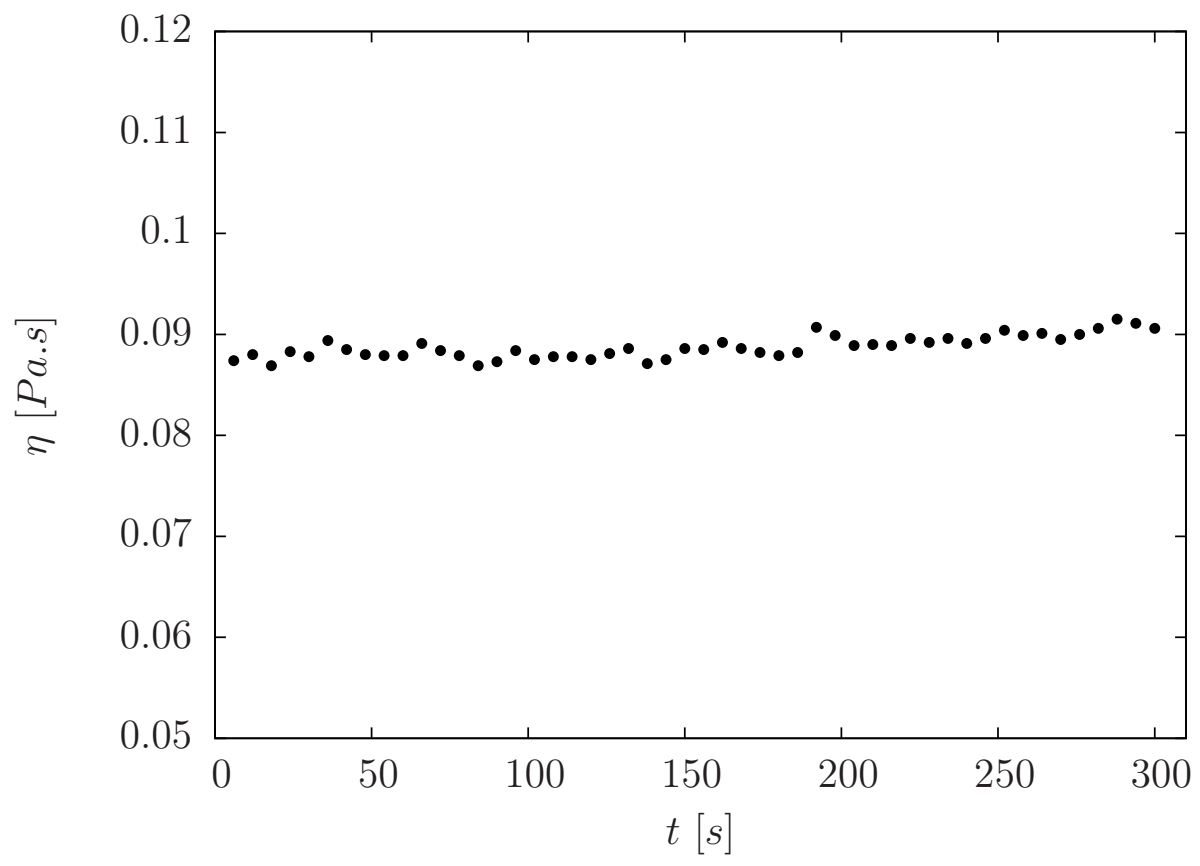

Figura 7.7: Viscosidade de uma emulsão de $\phi=40 \%$ e $\lambda=20$ sujeita a $\dot{\gamma}=5 \mathrm{~s}^{-1}$. Durante o tempo experimental a emulsão não apresentou regime transiente da viscosidade. O valor da viscosidade obtido foi de $\eta=0,089 \pm 0,0011$ Pa.s . 
Os resultados relativos à reologia das emulsões apresentam a variação da viscosidade adimensionalizada pela viscosidade do fluido base em função do número de capilaridade A tensão interfacial utilizada para o cálculo do número de capilaridade foi a obtida pelos experimentos da seção 5 (ver tab. 5.1). Optou-se por calcular o número de capilaridade com a viscosidade obtida pelo experimento. Para calcular o número de capilaridade com a viscosidade do fluido base $\left(\eta_{b}\right)$ ou com a viscosidade do fluido disperso $\left(\eta_{g}\right)$ é necessário efetuar uma reescala, respectivamente:

$$
\begin{aligned}
C a^{*} & =\frac{C a}{\left(\eta / \eta_{b}\right)}, \\
C a^{*} & =C a \frac{\eta_{g}}{\left(\eta / \eta_{b}\right) \eta_{b}}=C a \frac{\lambda}{\left(\eta / \eta_{b}\right)},
\end{aligned}
$$

em que $\lambda$ é a razão de viscosidade e $\left(\eta / \eta_{b}\right)$ é a viscosidade da emulsão adimensionalizada pela viscosidade do fluido base destacada nos gráficos apresentados nesta seção.

\subsubsection{Ensaios de uma emulsão com razão de viscosidade 2}

Aqui são apresentados os resultados para as emulsões de $\lambda=2$ para $\phi=2 \%, 5 \%$, $20 \%$ e $40 \%$.

A fig 7.8 apresenta a variação da viscosidade com a taxa de cisalhamento para a emulsão $\lambda=2 \operatorname{com} \phi=2 \%$. Observa-se que a viscosidade relativa $\left(\eta / \eta_{b}\right)$ se mantém praticamente constante com o número de capilaridade nessa baixa fração volumétrica caracterizando um comportamento Newtoniano da emulsão. Isto se justifica porque mesmo que as gotas sejam deformadas pelo cisalhamento do escoamento nesta baixa razão de viscosidade a fração volumétrica é ainda muito baixa para que essas deformações influenciem a viscosidade aparente da emulsão, produzindo um efeito pseudoplástico. Nota-se no entanto em baixa taxa de cisalhamento uma pequena variação da viscosidade com a taxa de cisalhamento. Isso é o reflexo das deformações das gotas devido ao aumento da intensidade da taxa de cisalhamento do escoamento. A viscosidade média obtida foi de $0,063 \pm 3 \times 10^{-3}[$ Pa.s]. A viscosidade relativa efetiva foi de $0,90 \pm 0,07$. 
A fig. 7.9 mostra que o comportamento da emulsão de $\lambda=2$ com $\phi=5 \%$ é idêntico da emulsão de $\lambda=2 \operatorname{com} \phi=2 \%$. A viscosidade relativa efetiva foi próxima da unidade indicando que as baixas frações volumétricas não influenciam a viscosidade da emulsão. No entanto, nesta baixa razão de viscosidade já se deteta um pequeno efeito pseudo-plástico nos menores números de capilaridade. Para maiores intensidade de escoamento a emulsão se comporta como um fluido Newtoniano, tal como $\phi=2 \%$.

A fig. 7.10 mostra o comportamento da emulsão de $\lambda=2$ com $\phi=20 \%$. Observa-se uma queda inicial da viscosidade adimensional com o aumento de $C a$ refletindo um comportamento de fluido pseudo-plástico. Nesta maior fração volumétrica e em baixas razões de viscosidade o efeito pseudo-plástico e as diferenças de tensões normais são mais pronunciadas devido a deformação das gotas vizinhas induzirem uma deformação extra numa gota de referência. Esta deformação extra é adicionada à deformação mais relevante associada com as tensões de cisalhamento do escoamento. Nesta fração volumétrica o platô ocorre em altas taxas de cisalhamento, onde o tempo de deformação da gota é muito maior que o tempo de característico do escoamento. Ou seja, a gota deixa de responder na escala do escoamento. É uma condição análoga às gotas sem tensão interfacial, portanto não apresenta efeito pseudo-plástico, mas pode apresentar diferenças de tensões normais devido ao alinhamento da gota com o escoamento (i.e. o que equivale ao comportamento de fluido de Boger). A viscosidade no platô para as maiores taxas de cisalhamento é de $0,079 \pm 4 \times 10^{-3}[$ Pa.s] .

A fig. 7.11 mostra o comportamento da emulsão de $\lambda=2$ e $\phi=40 \%$. É possível ver que a emulsão apresenta um comportamento de fluido não-Newtoniano. Este comportamento é devido à deformação da gota pelo escoamento com a contribuição da deformação induzida pelas gotas vizinhas sobre uma gota de referência, responsável por produzir uma faixa de dependência da viscosidade aparente da emulsão com o aumento do número de capilaridade (efeito pseudo-plástico) maior do que em menores frações volumétricas de gotas. Comparando a reologia desta emulsão com os casos anteriores, verificou-se um aumento da viscosidade efetiva devido à maior fração volumétrica e um maior efeito pseudo-plástico. A viscosidade tende para 0,252 $\pm 0,016$ [Pa.s]. A viscosidade relativa efetiva tende para um platô de $3,7 \pm 0,4$. 
Para esta razão de viscosidade o comportamento pseudo-plástico começou a ser detectado para a $\phi=20 \%$ se tornando evidente para $\phi=40 \%$. Essa evidência é justificável pela maior interação entre gotas. Quanto a microestrutura a emulsão de $\phi=40 \%$ é aquela que apresenta uma maior porcentagem de gotas de maior tamanho enquanto que a emulsão $\phi=20 \%$ é a que apresenta maior porcentagem de gotas de tamanho menor. As gotas de maior tamanho apresentam maiores deformações, associado ao efeito não-linear da emulsão, com relação a gotas de menor tamanho. A fig 7.12 mostra, como era esperado, um aumento da viscosidade adimensional com a fração volumétrica. A viscosidade da emulsão foi considerada a dos maiores números de capilaridade obtidos durante o experimento. Pelo encarte da fig. 7.12 observa-se que a viscosidade adimensional pode ser ajustada pela expressão da viscosidade de Taylor para frações volumétricas em torno de $5 \%$.

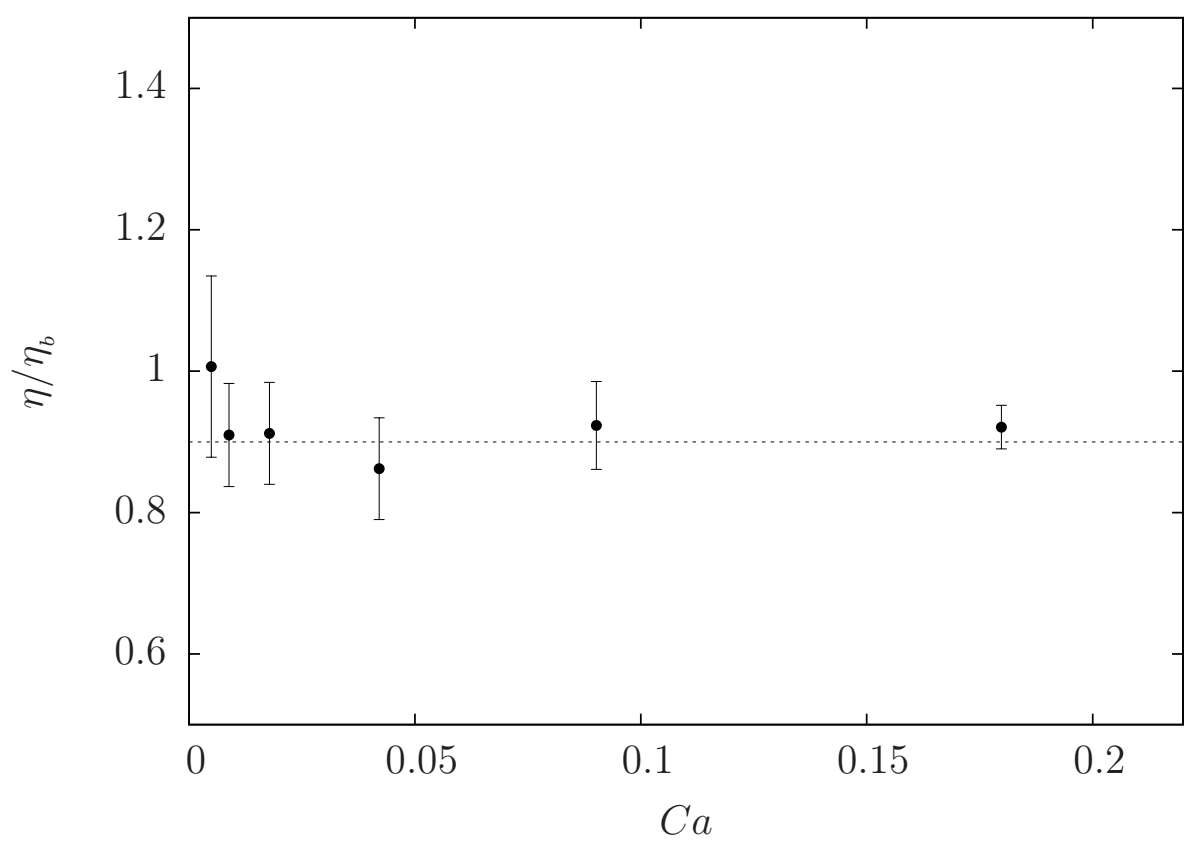

Figura 7.8: Variação da viscosidade em função da $C a$ para $\lambda=2$ e $\phi=2 \%$.O número de capilaridade foi calculado por $C a=\left(\eta \dot{\gamma} \delta_{R}\right) / \tau_{s}$ em que $\delta_{R}=0,4 \mathrm{~mm}$ é a distância entre os discos do reômetro e $\tau_{s}=0,028 \mathrm{~N} / \mathrm{m}$ é a tensão interfacial. $--\eta / \eta_{b}=0,9 \pm 0,072$. 


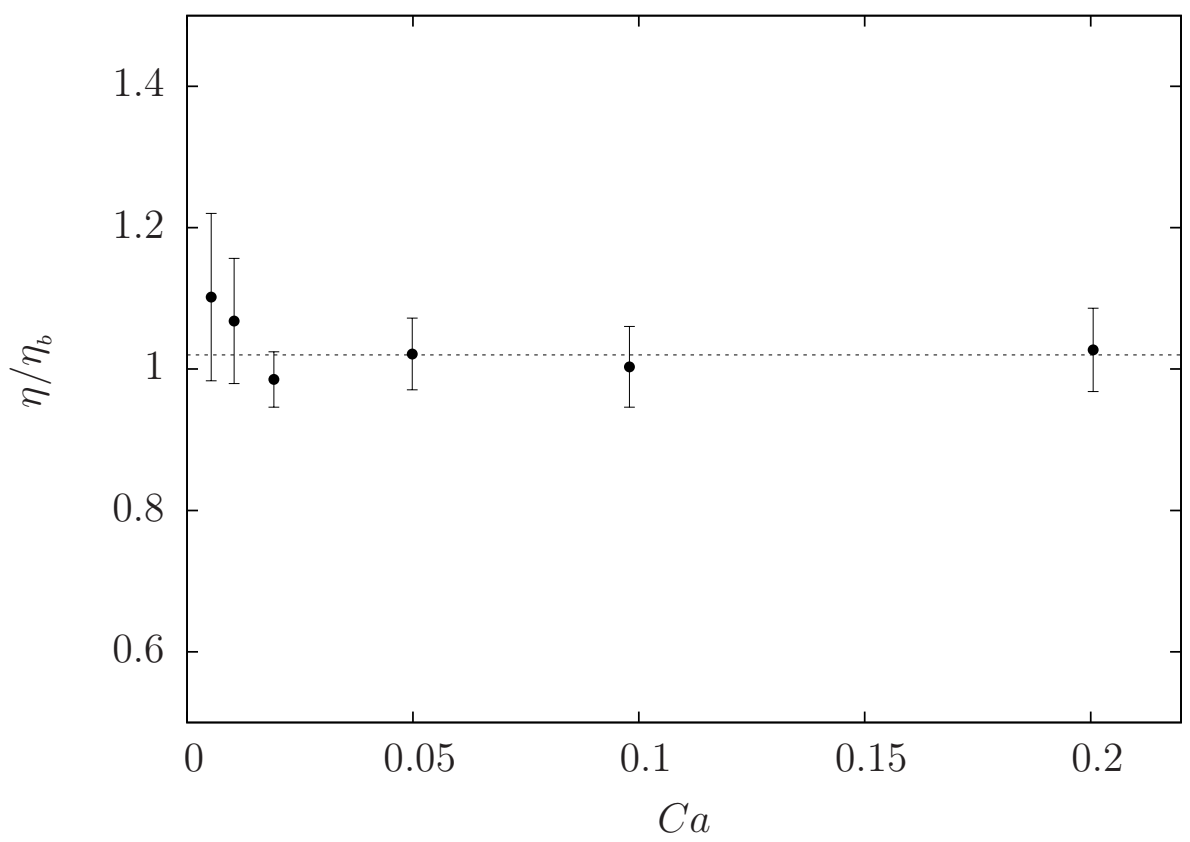

Figura 7.9: Variação da viscosidade em função da $C a$ para $\lambda=2$ e $\phi=5 \%$. O número de capilaridade foi calculado por $C a=\left(\eta \dot{\gamma} \delta_{R}\right) / \tau_{s}$ em que $\delta_{R}=0,4 \mathrm{~mm}$ é a distância entre os discos do reômetro e $\tau_{s}=0,028 \mathrm{~N} / \mathrm{m}$ é a tensão interfacial. $--\eta / \eta_{b}=1,02 \pm 0,17$.

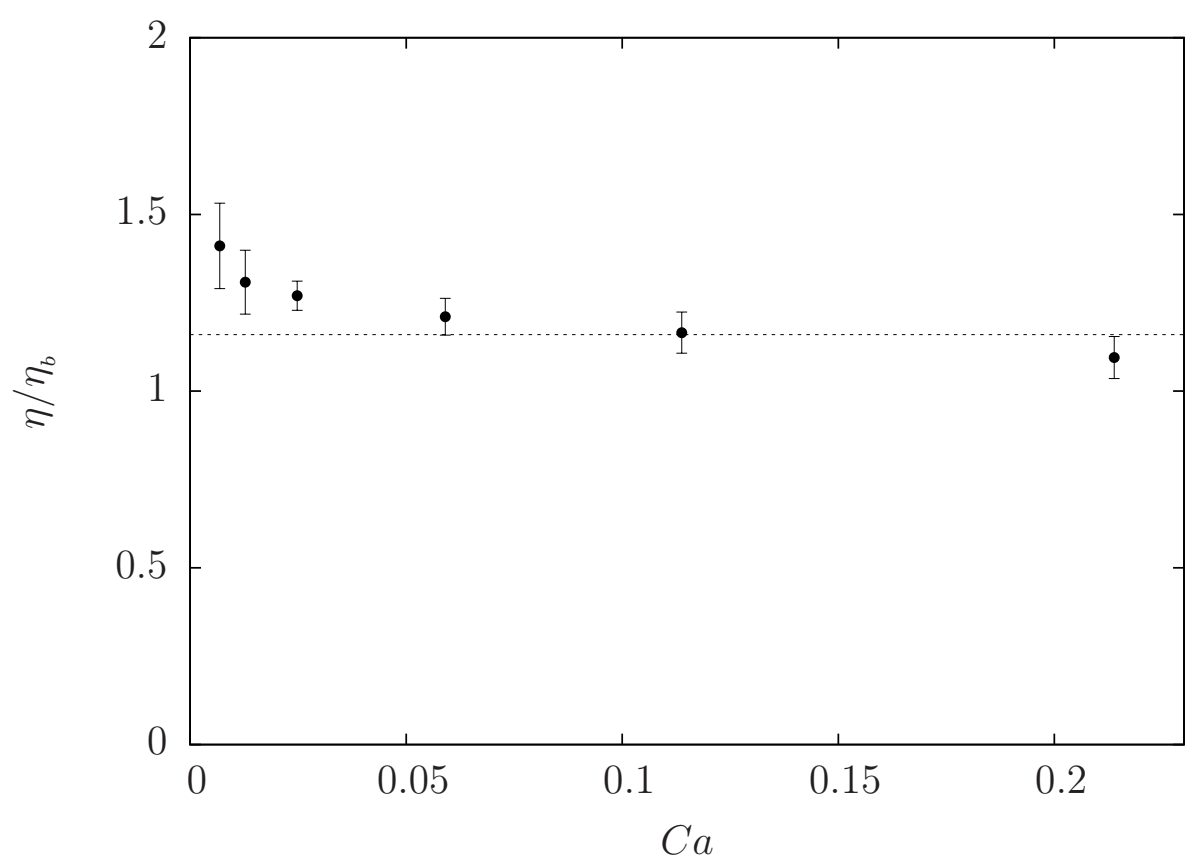

Figura 7.10: Variação da viscosidade em função da $C a$ para $\lambda=2$ e $\phi=20 \%$. O número de capilaridade foi calculado por $C a=\left(\eta \dot{\gamma} \delta_{R}\right) / \tau_{s}$ em que $\delta_{R}=0,4 \mathrm{~mm}$ é a distância entre os discos do reômetro e $\tau_{s}=0,028 \mathrm{~N} / \mathrm{m}$ é a tensão interfacial. $--\eta / \eta_{b}=1,16 \pm 0,059$. 


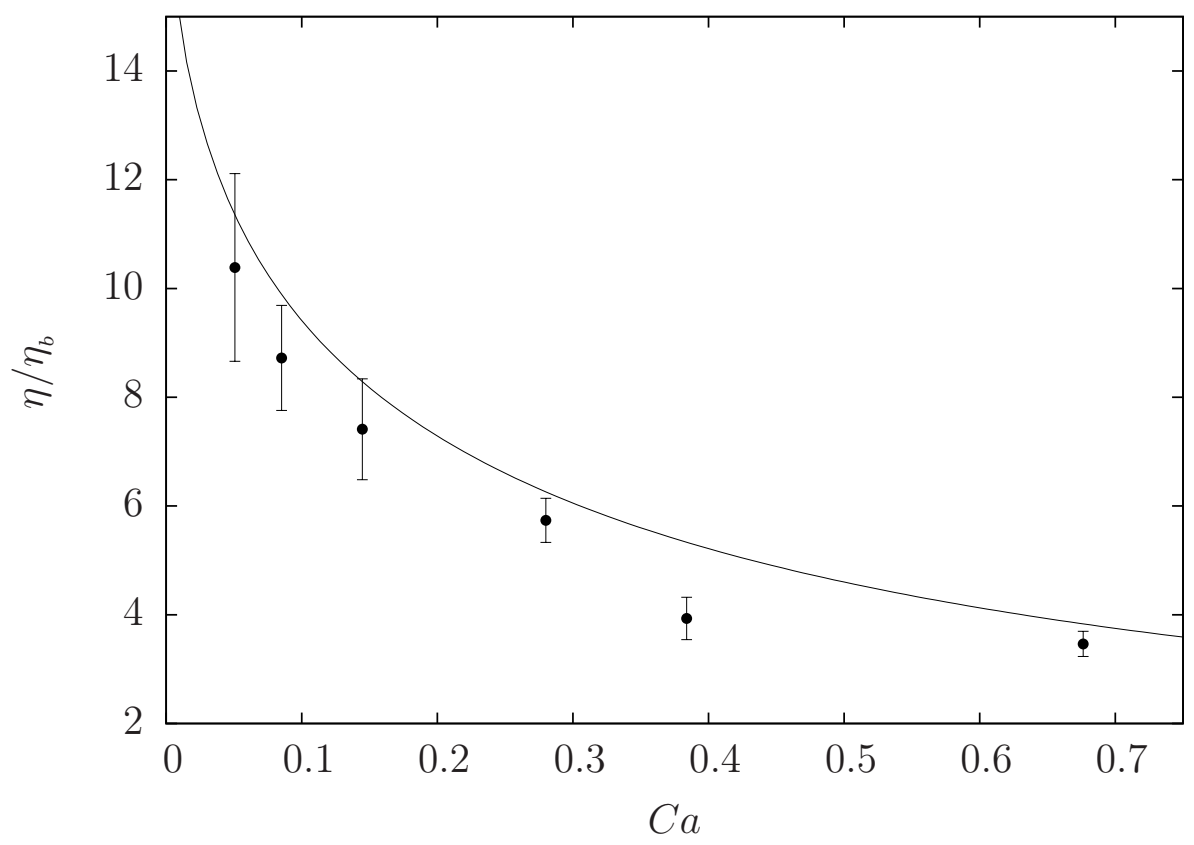

Figura 7.11: Variação da viscosidade em função da $C a$ para $\lambda=2$ e $\phi=40 \%$. O número de capilaridade foi calculado por $C a=\left(\eta \dot{\gamma} \delta_{R}\right) / \tau_{s}$ em que $\delta_{R}=0,4 \mathrm{~mm}$ é a distância entre os discos do reômetro e $\tau_{s}=0,028 \mathrm{~N} / \mathrm{m}$ é a tensão interfacial. -Modelo Carreau-Yasuda (eq. 2.11) $\eta_{\infty} / \eta_{b}=1,0, \eta_{0} / \eta_{b}=19,0, \alpha=0,21, n=-2,11$, $a=0,49$.

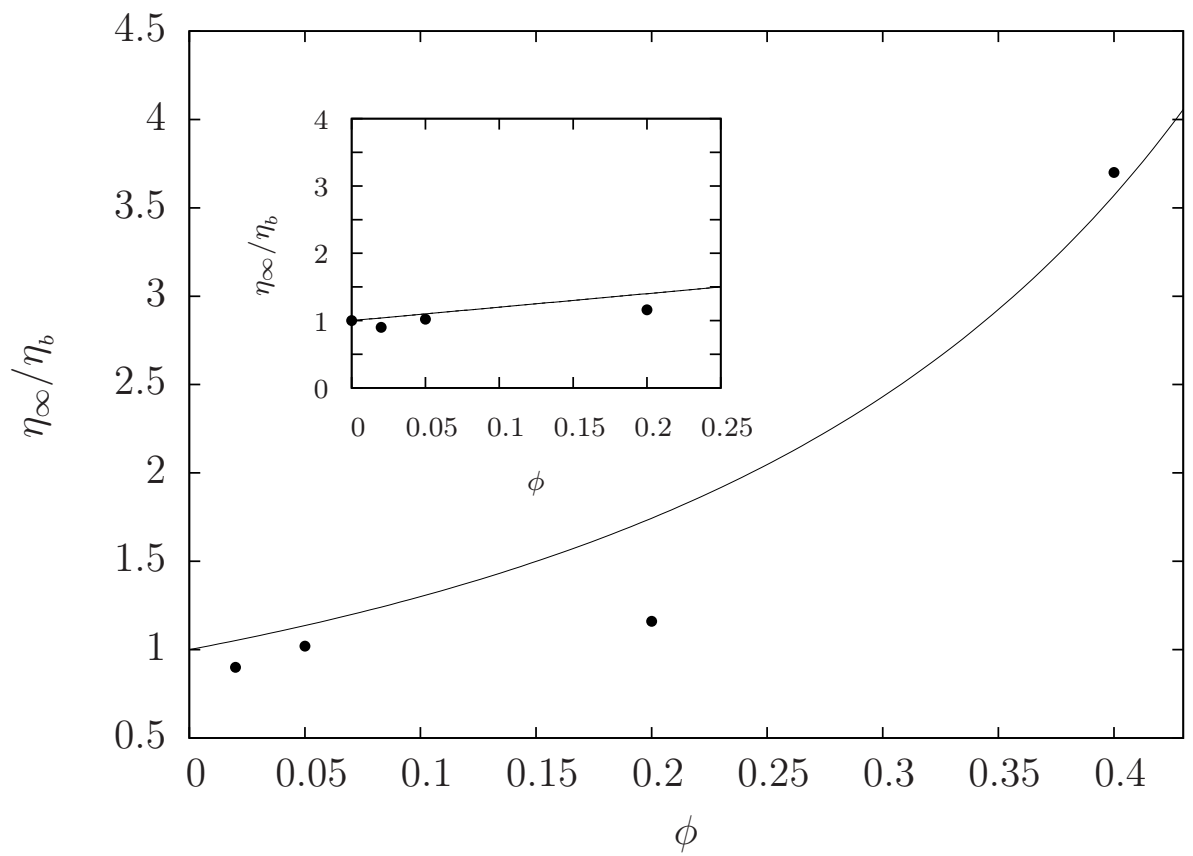

Figura 7.12: Aumento da viscosidade com a fração volumétrica $-\eta_{\infty} / \eta_{b}=(1-\phi)^{-n}$ em que $n=2,49$. Dado experimentais para $C a \approx 0,2$ e $\lambda=2$.Encarte: - Ajuste pela expressão da viscosidade de Taylor. 


\subsubsection{Ensaios da Emulsão com razão de viscosidade 5}

Aqui apresentam-se os resultados experimentais para $\lambda=5$ e para $\phi=2,5,20$ e $40 \%$ (ver figs. 7.13-7.16). Comparando os resultados de $\lambda=5$ com $\lambda=2$ observa-se um aumento da viscosidade aparente $\left(\eta / \eta_{b}\right)$ para todas as frações volumétricas. Este aumento não é devido ao fluido base. O aumento se deve ao fato de a maior razão de viscosidade inibir a deformação das gotas. Como para $\lambda=2$ o efeito pseudo-plástico começa a ser detectado com $\phi=20 \%$. Esse efeito está associado com a deformação das gotas pelo escoamento e devido a influência do escoamento gerado pelas gotas vizinhas nessa concentração.

Pode-se observar por comparação dos resultados de $\lambda=5 \operatorname{com} \lambda=2$, para $\phi=40 \%$, que em $\lambda=5$ o efeito pseudo-plástico foi maior. Tal pode ser devido às diferenças de microestrutura. A emulsão $\lambda=5$ e $\phi=40 \%$ apresenta uma polidispersidade de 0,28 , em que $66 \%$ das gotas são de menor tamanho. Enquanto a polidispersidade da emulsão $\lambda=2$ e $\phi=40 \%$ é de 0,34 , em que $44 \%$ das gotas são de menor tamanho. É de se referir que as gotas de maior razão de viscosidade apresentam menores deformações. A fig. 7.17 mostra, como era esperado, um aumento da viscosidade adimensional com a fração volumétrica. 


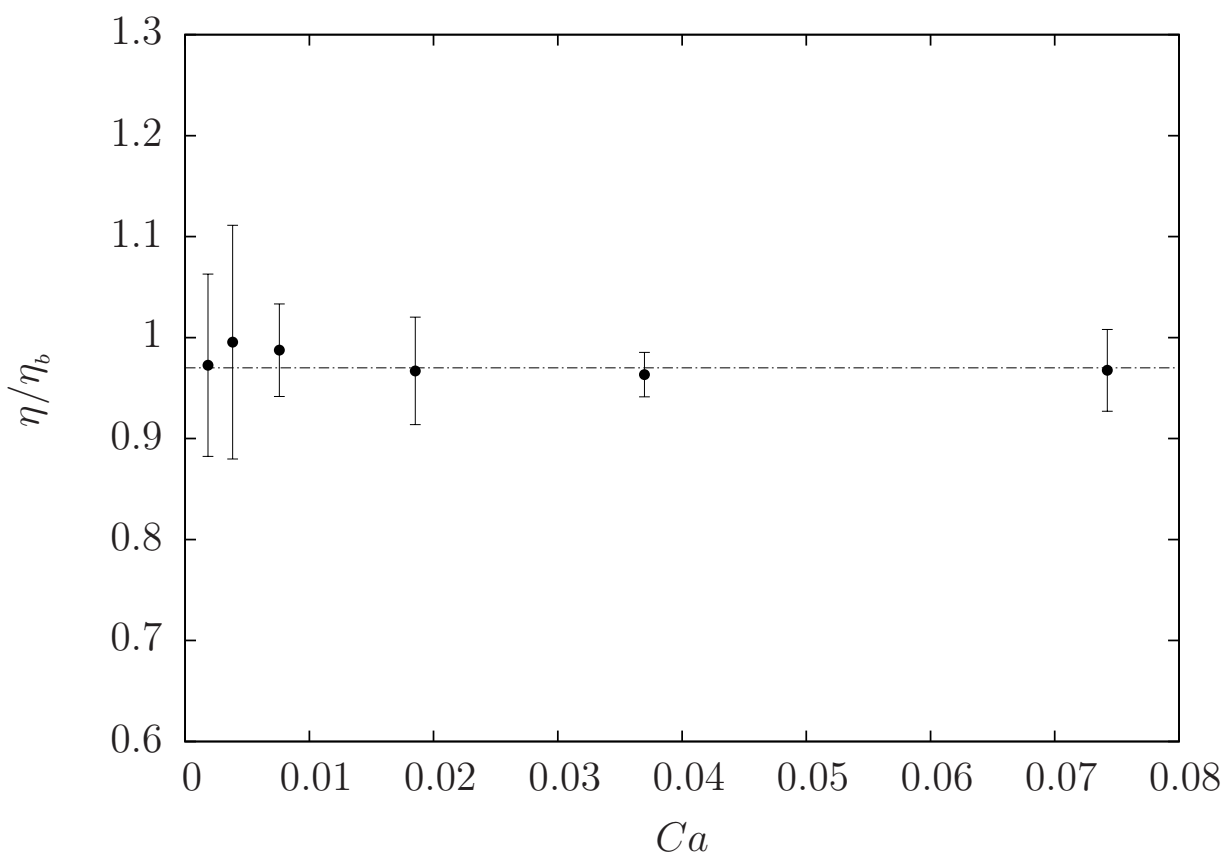

Figura 7.13: Variação da viscosidade em função da $C a$ para $\lambda=5$ e $\phi=2 \%$. O número de capilaridade foi calculado por $C a=\left(\eta \dot{\gamma} \delta_{R}\right) / \tau_{s}$ em que $\delta_{R}=0,4 \mathrm{~mm}$ é a distância entre os discos do reômetro e $\tau_{s}=0,02926 \mathrm{~N} / \mathrm{m}$ é a tensão interfacial. $---\eta / \eta_{b}=0,97 \pm 0,011$.

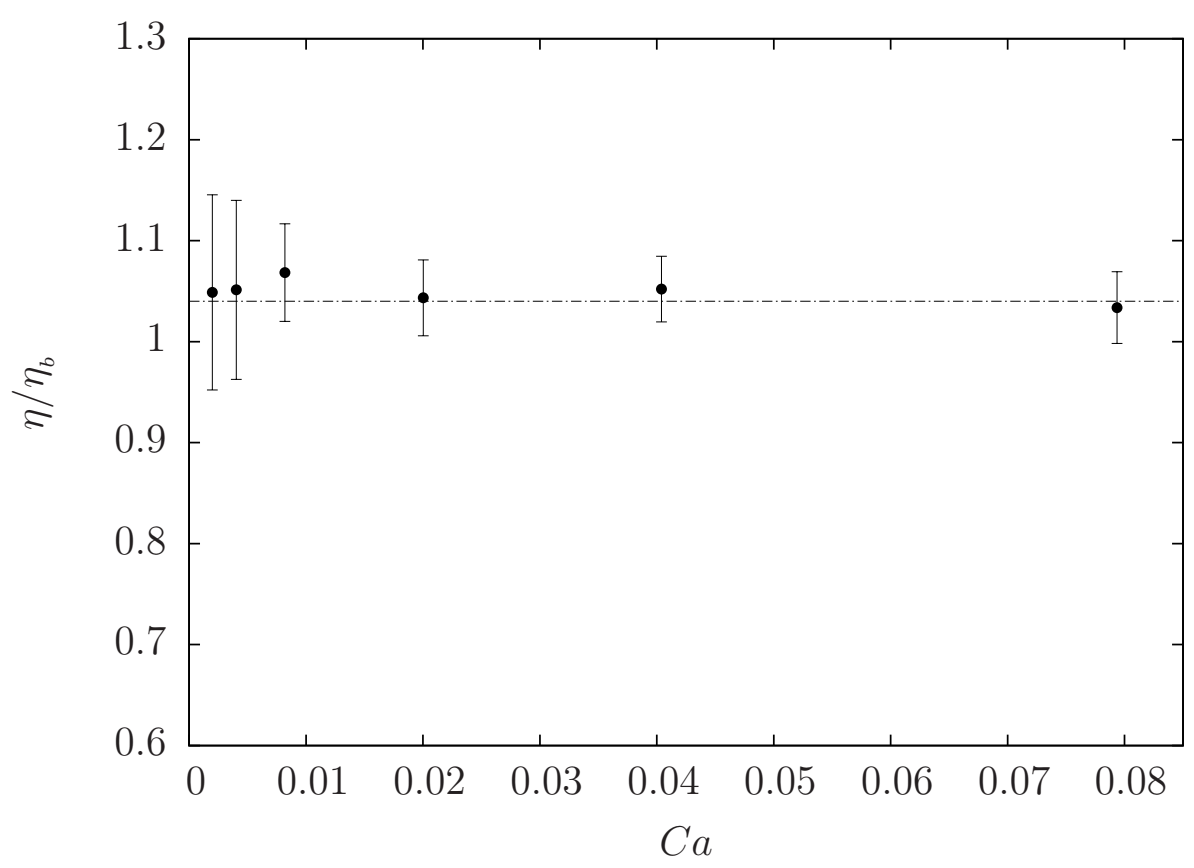

Figura 7.14: Variação da viscosidade em função da $C a$ para $\lambda=5$ e $\phi=5 \%$. O número de capilaridade foi calculado por $C a=\left(\eta \dot{\gamma} \delta_{R}\right) / \tau_{s}$ em que $\delta_{R}=0,4 \mathrm{~mm}$ é a distância entre os discos do reômetro e $\tau_{s}=0,02926 \mathrm{~N} / \mathrm{m}$ é a tensão interfacial. $--\eta / \eta_{b}=1,04 \pm 0,037$. 


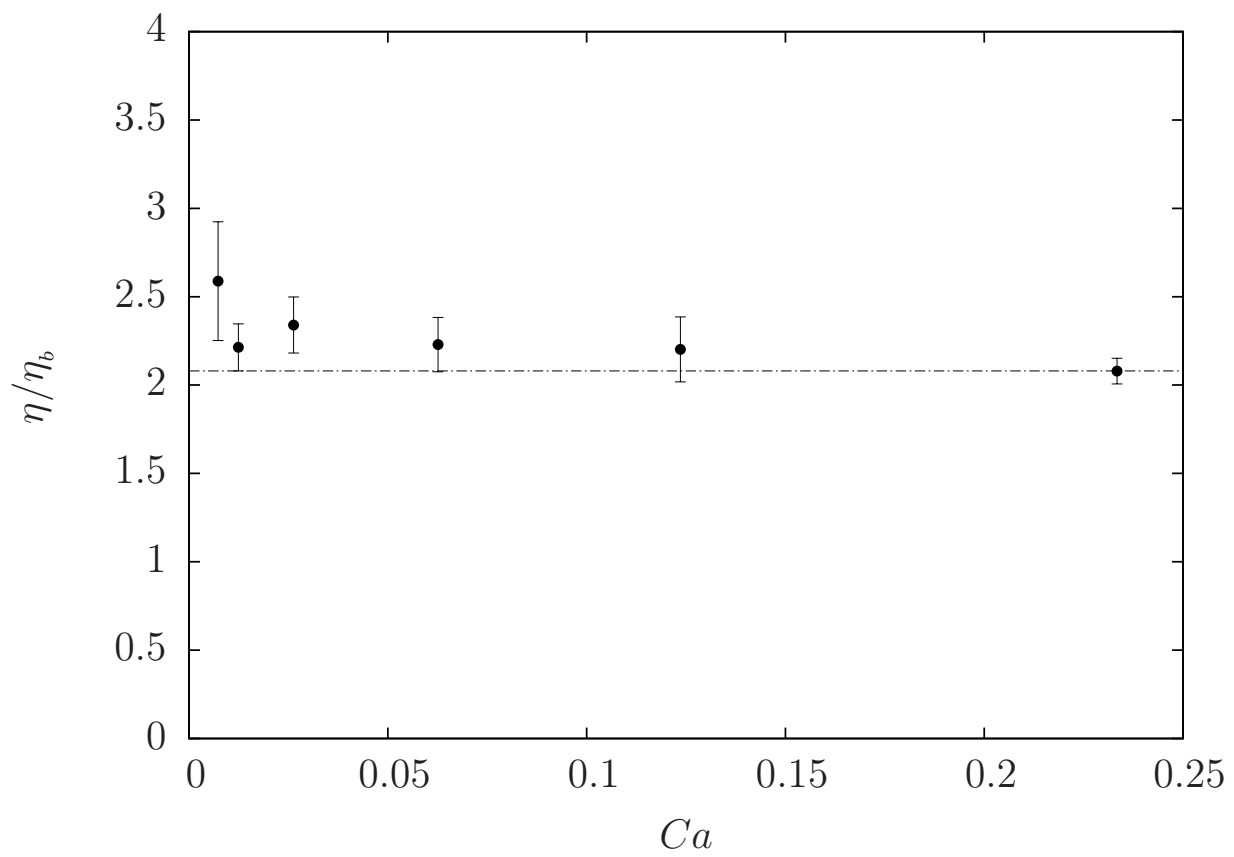

Figura 7.15: Variação da viscosidade em função da $C a$ para $\lambda=5$ e $\phi=20 \%$. O número de capilaridade foi calculado por $C a=(\eta \dot{\gamma} \delta) / \tau_{s}$ em que $\delta_{R}=0,4 \mathrm{~mm}$ é a distância entre os discos do reômetro e $\tau_{s}=0,02926 \mathrm{~N} / \mathrm{m}$ é a tensão interfacial . $---\eta / \eta_{b}=2,17 \pm 0,16$.

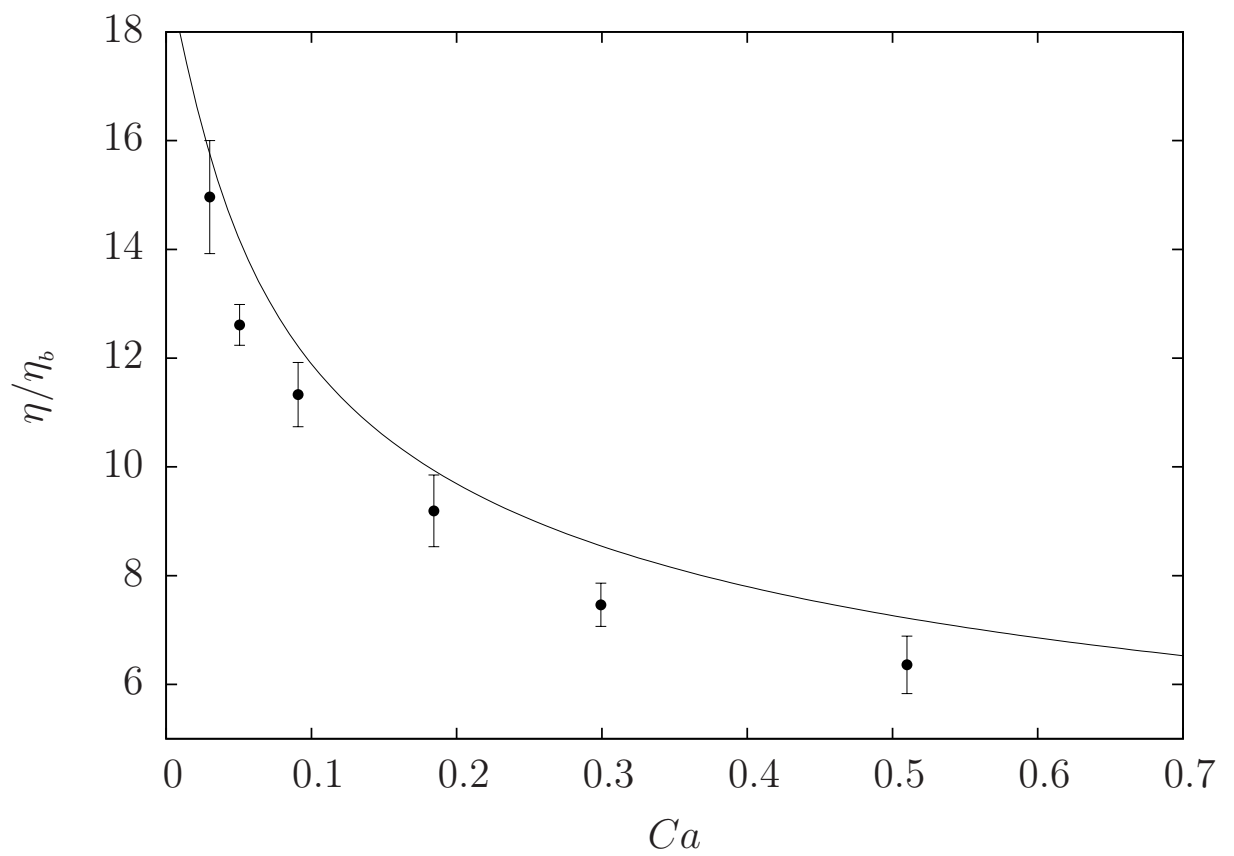

Figura 7.16: Variação da viscosidade em função da $C a$ para $\lambda=5$ e $\phi=40 \%$. O número de capilaridade foi calculado por $C a=\left(\eta \dot{\gamma} \delta_{R}\right) / \tau_{s}$ em que $\delta_{R}=0,4 \mathrm{~mm}$ é a distância entre os discos do reômetro e $\tau_{s}=0,02926 \mathrm{~N} / \mathrm{m}$ é a tensão interfacial. -Modelo Carreau-Yasuda (eq. 2.11) $\eta_{\infty} / \eta_{b}=0,5, \eta_{0} / \eta_{b}=19,0, \alpha=51,2, n=0,65$, $a=1,31$. 


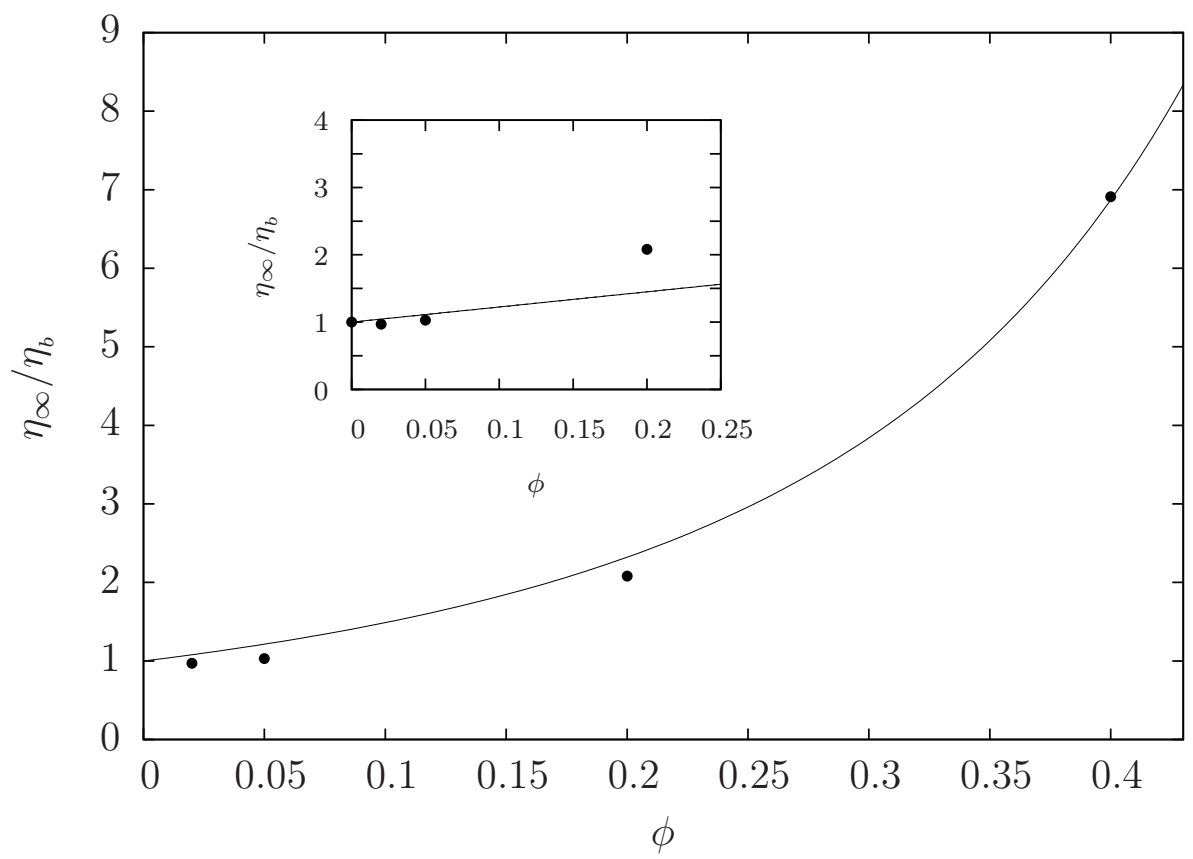

Figura 7.17: Aumento da viscosidade com a fração volumétrica $-\eta_{\infty} / \eta_{b}=(1-\phi)^{-n}$ em que $n=3,77$. Dados recolhidos para $C a \approx 0,02$ e $\lambda=5$. Encarte: - Ajuste pela expressão da viscosidade de Taylor.

\subsubsection{Ensaios da Emulsão com razão de viscosidade 10}

Aqui são apresentados os resultados para as emulsões de $\lambda=10$ e para $\phi=2,5,20$ e $40 \%$.

Pela análise dos resultados experimentais das figs. 7.18-7.21 observa-se que o comportamento pseudo-plástico é detectado somente em $\phi=40 \%$. Comparando para baixas frações volumétricas os resultados desta emulsão com os de $\lambda=2$ e 5 verifica-se que o aumento da razão de viscosidade parece inibir o aparecimento do comportamento pseudo-plástico.

O efeito pseudo-plástico da emulsão $\phi=40 \%$ e $\lambda=10$ é maior em comparação com a emulsão de $\lambda=2$ e 5. Pela microestrutura observa-se que a polidispersidade e a porcentagem de gotas de menor tamanho é maior do que na emulsão de $\lambda=2$ e 5 . É de se referir que o tamanho médio das gotas consideradas pequenas nesta emulsão de $\lambda=10$ é o dobro das emulsões de $\lambda=2$ e 5 . A fig 7.22 mostra, como era esperado, um aumento da viscosidade com a fração volumétrica. 


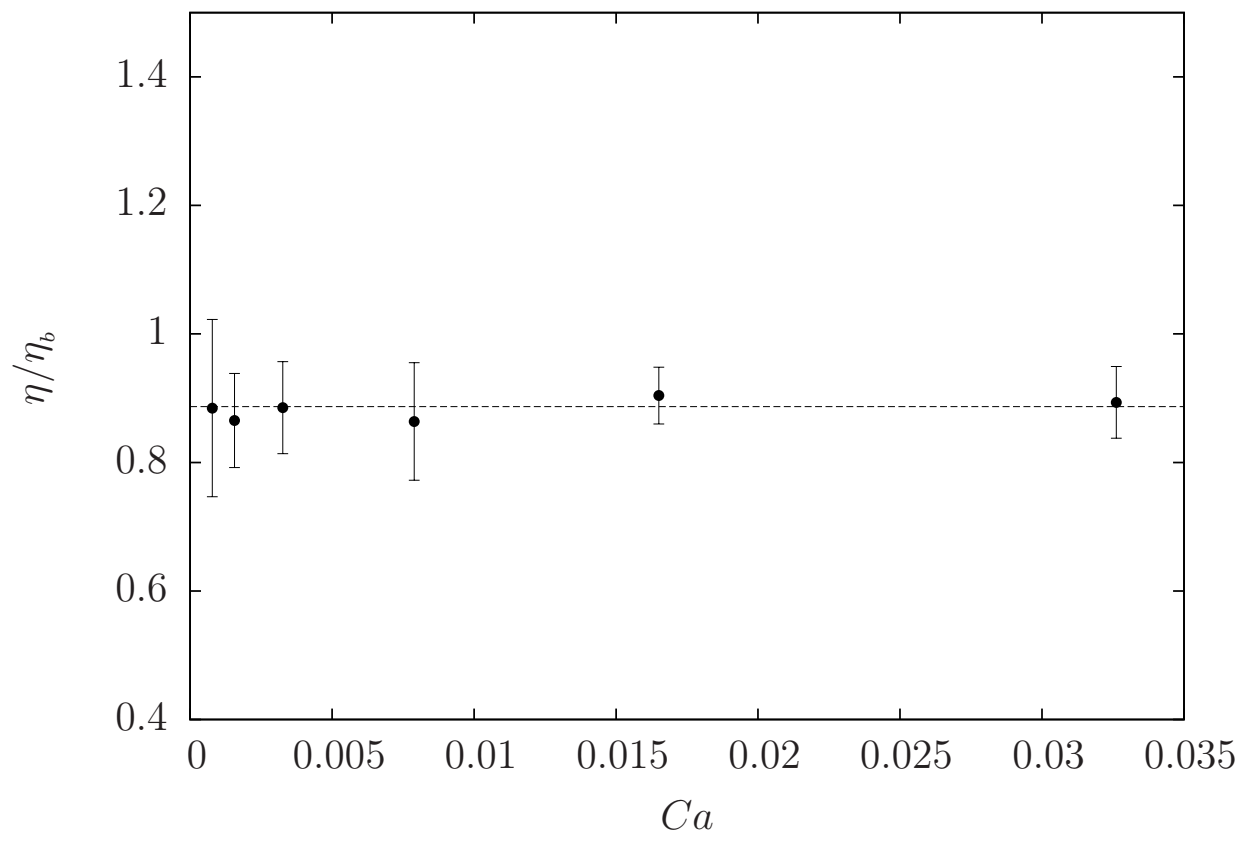

Figura 7.18: Variação da viscosidade em função da $C a$ para $\lambda=10$ e $\phi=2 \% . O$ número de capilaridade foi calculado por $C a=\left(\eta \dot{\gamma} \delta_{R}\right) / \tau_{s}$ em que $\delta_{R}=0,4 \mathrm{~mm}$ é a distância entre os discos do reômetro e $\tau_{s}=0,03066 \mathrm{~N} / \mathrm{m}$ é a tensão interfacial. $--\eta / \eta_{b}=0,887 \pm 0,021$.

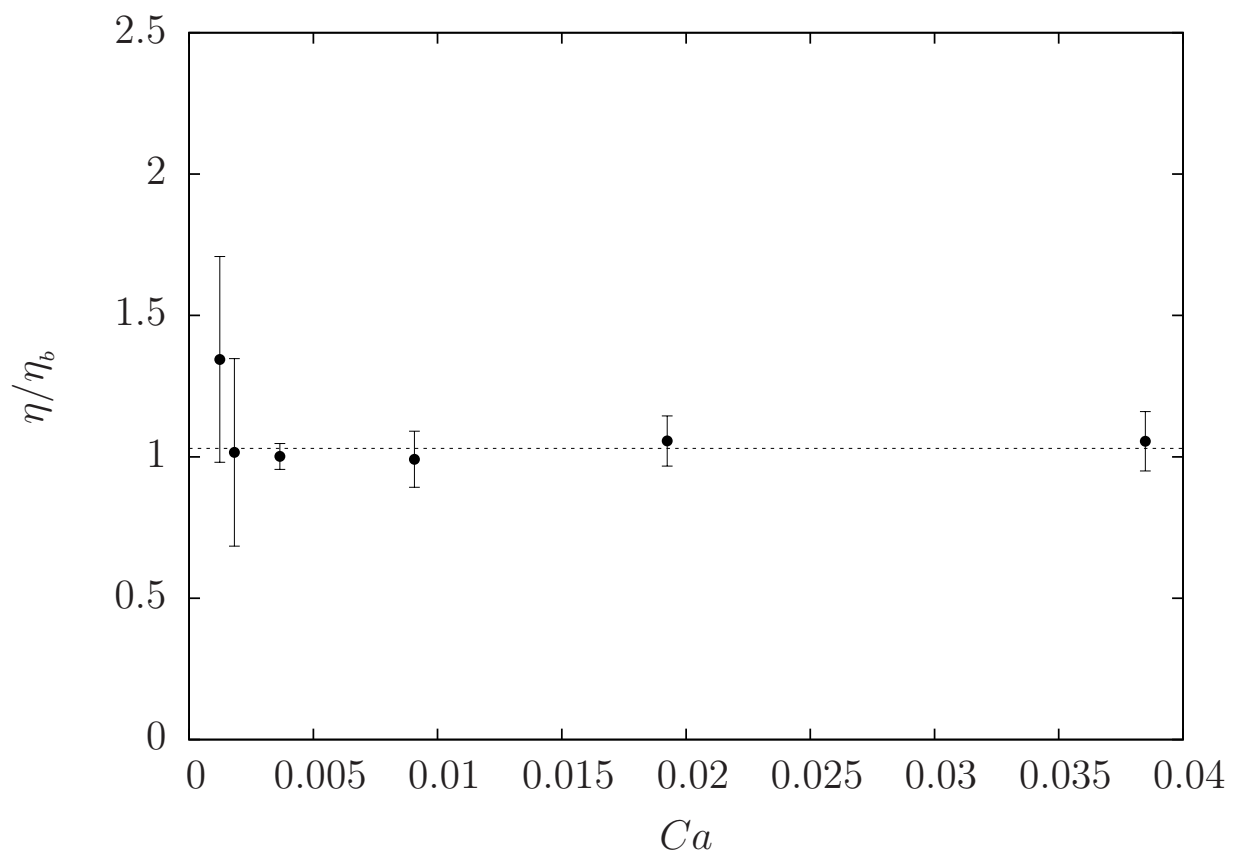

Figura 7.19: Variação da viscosidade em função da $C a$ para $\lambda=10$ e $\phi=5 \% . O$ número de capilaridade foi calculado por $C a=\left(\eta \dot{\gamma} \delta_{R}\right) / \tau_{s}$ em que $\delta_{R}=0,4 \mathrm{~mm}$ é a distância entre os discos do reômetro e $\tau_{s}=0,03066 \mathrm{~N} / \mathrm{m}$ é a tensão interfacial. $--\eta / \eta_{b}=1,03 \pm 0,034$. 


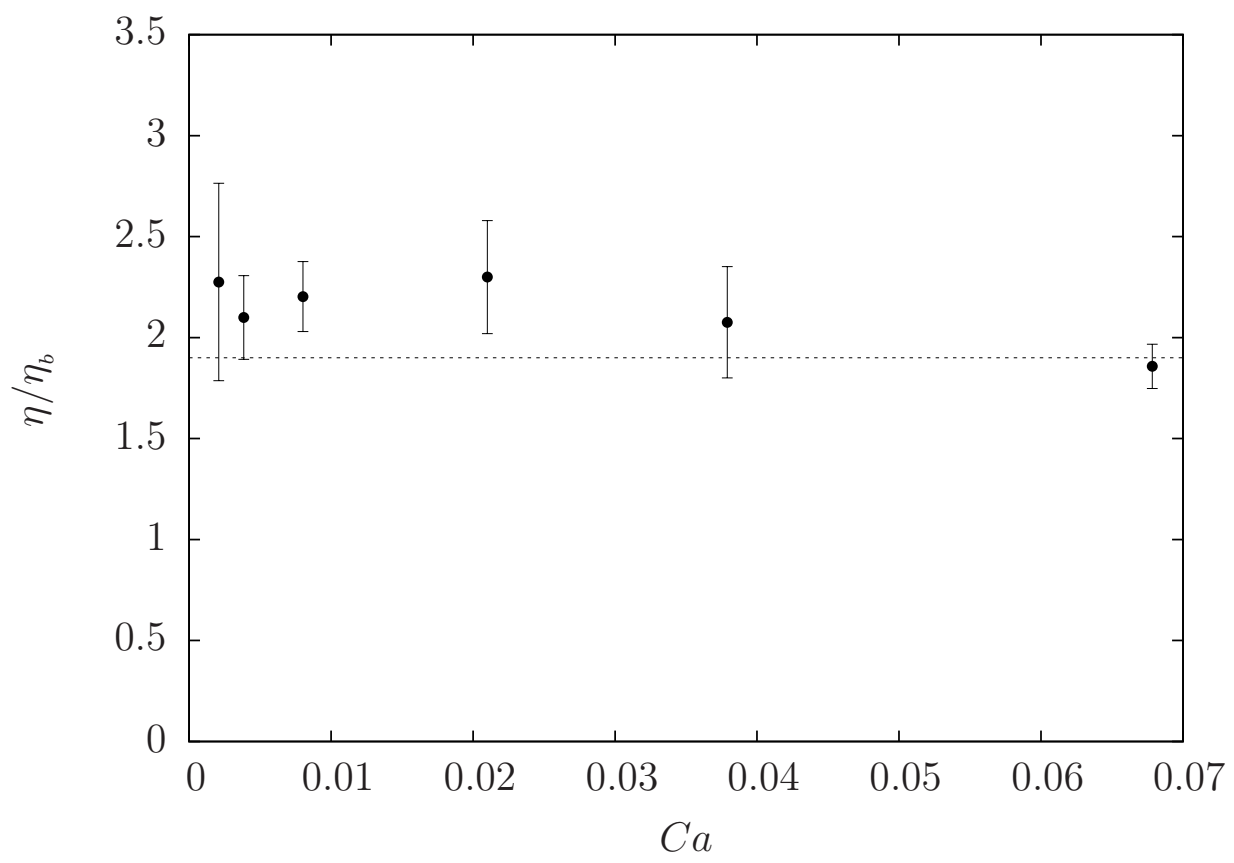

Figura 7.20: Variação da viscosidade em função da $C a$ para $\lambda=10$ e $\phi=20 \% . O$ número de capilaridade foi calculado por $C a=\left(\eta \dot{\gamma} \delta_{R}\right) / \tau_{s}$ em que $\delta_{R}=0,4 \mathrm{~mm}$ é a distância entre os discos do reômetro e $\tau_{s}=0,03066 \mathrm{~N} / \mathrm{m}$ é a tensão interfacial. $---1,90 \pm 0,191$.

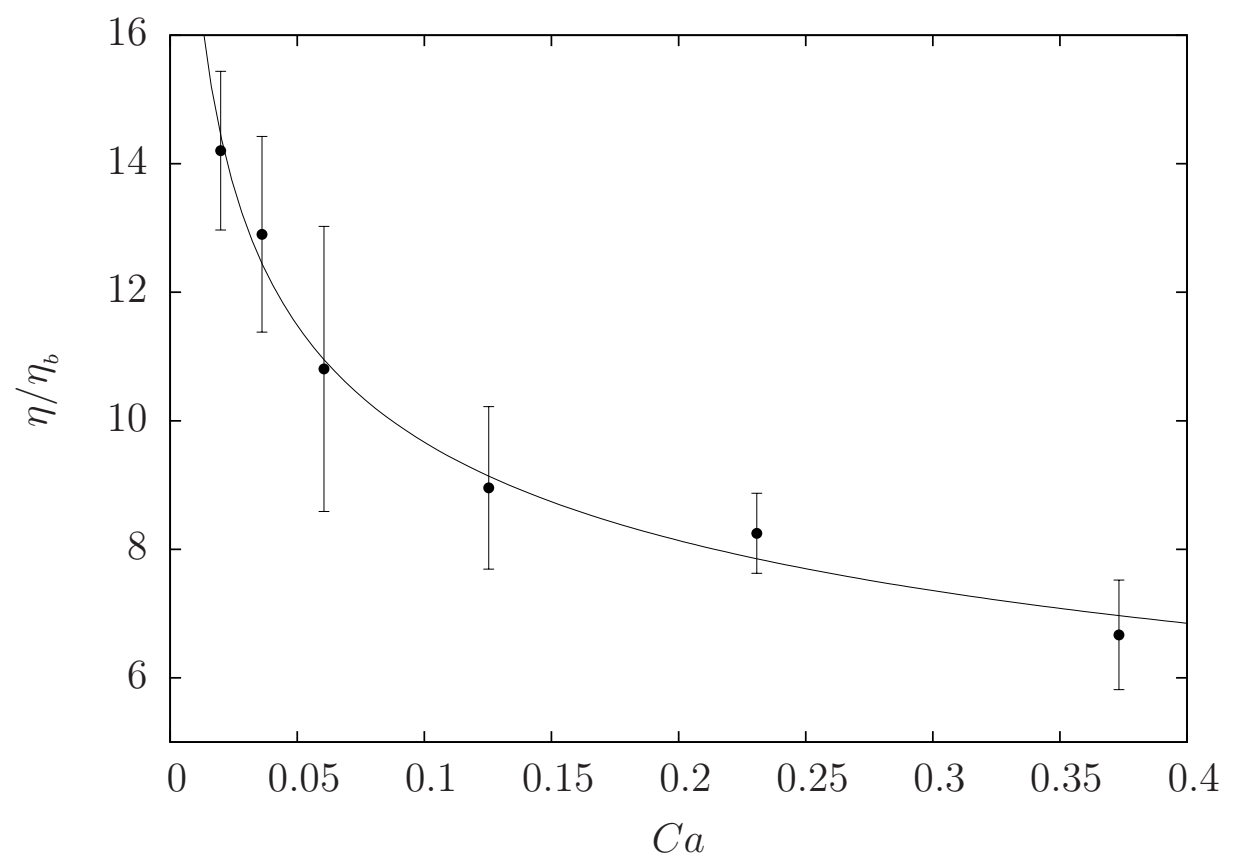

Figura 7.21: Variação da viscosidade em função da $C a$ para $\lambda=10$ e $\phi=40 \% . O$ número de capilaridade foi calculado por $C a=\left(\eta \dot{\gamma} \delta_{R}\right) / \tau_{s}$ em que $\delta_{R}=0,4 \mathrm{~mm}$ é a distância entre os discos do reômetro e $\tau_{s}=0,03066 \mathrm{~N} / \mathrm{m}$ é a tensão interfacial. Observa-se uma tendência para formar um platô em $\eta_{\infty} / \eta_{b}=7,58 \pm 1,286$. $-\eta / \eta_{b}=$ $5,65 C a^{0,76-1}$. 


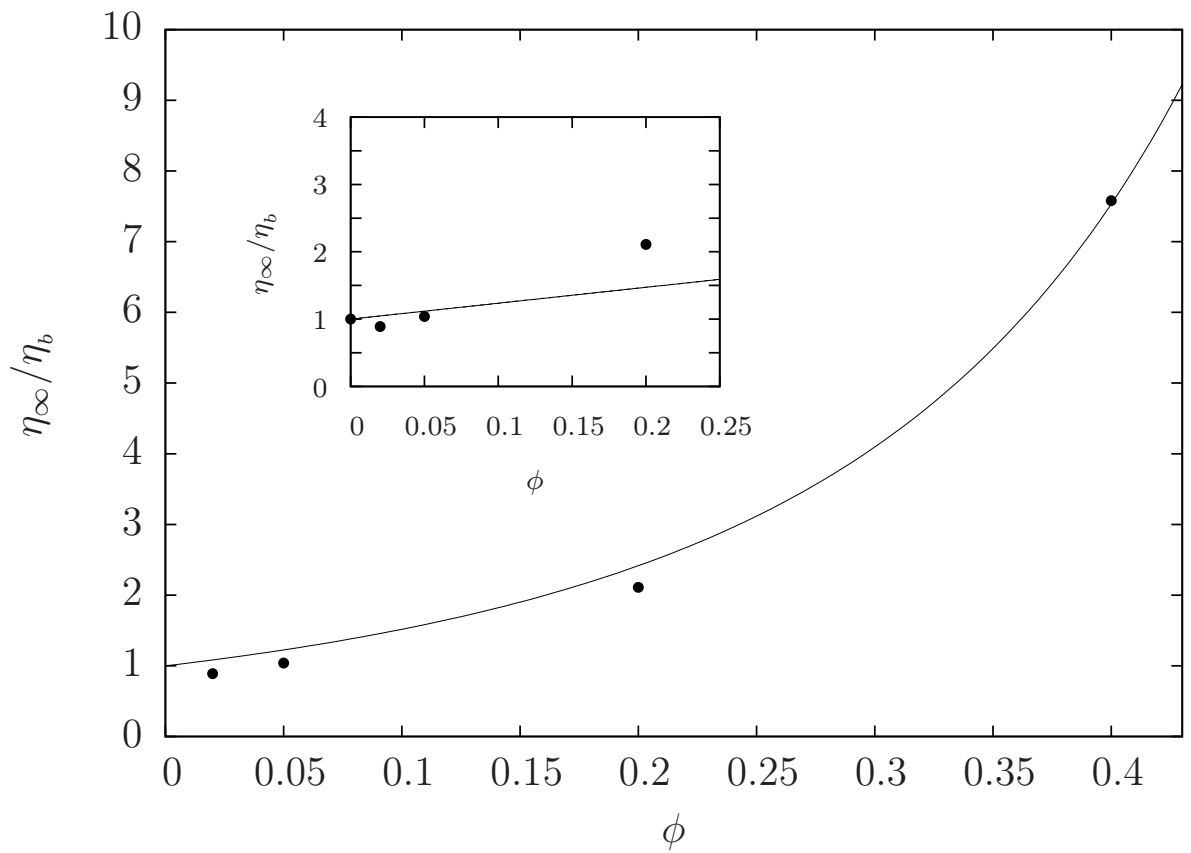

Figura 7.22: Aumento da viscosidade com a fração volumétrica $-\eta_{\infty} / \eta_{b}=(1-\phi)^{-n} \mathrm{em}$ que $n=3,95$. Dados experimentais para $C a \approx 0,04$ e $\lambda=10$. Dados Experimentais para $C a=0,02$ para $\lambda=10$. Encarte: - Ajuste pela expressão da viscosidade de Taylor.

\subsubsection{Ensaios da Emulsão com razão de viscosidade de $\lambda=20$}

Aqui são apresentados os resultados para as emulsões de $\lambda=20$ para $\phi=2 \%$, $5 \%, 20 \%$ e $40 \%$. Comparando as emulsões de $\lambda=2,5$ e 10, parece que o efeito nãoNewtoniano para a fração volumétrica de $20 \%$ começa a desaparecer com o aumento da razão de viscosidade. O efeito pseudo-plástico para esta emulsão começa a ser evidente na fração volumétrica $40 \%$, tal como aconteceu para as emulsões de razão de viscosidade menor.

O efeito pseudo-plástico, para $\phi=40 \%$, foi maior nesta emulsão do que na emulsão de $\lambda=2$. A polidispersidade destas emulsões é idêntica, mas a emulsão de $\lambda=20$ tem gotas de maior tamanho.

Para a fração volumétrica de $40 \%$, a porcentagem de gotas de menor tamanho é idêntica entre as emulsões de $\lambda=5$ e 20. No entanto, o efeito pseudo-plástico é maior para a emulsão de $\lambda=20$. É de se referir que a microestrutura da emulsão de $\lambda=20$ tem um 
número maior de gotas de tamanho maior do que a emulsão de $\phi=40 \%$ e $\lambda=5$.

Comparando as emulsões de $\lambda=10$ e 20, para a fração volumétrica de $40 \%$, a emulsão de razão de viscosidade 10 apresenta um maior efeito pseudo-plástico. Isto pode estar relacionado com o fato de o experimento em $\lambda=20$ ter sido realizado em menores números de capilaridade, e por a emulsão de $\lambda=10$ apresentar a maior polidispersidade entre todas as emulsões de fração volumétrica de $40 \%$.

As observações indicam que o efeito pseudo-plástico pode ser maior em emulsões com gotas de maior tamanho e de maior polidispersidade. Nesta fração volumétrica, tal como nas anteriores, observou-se um aumento da viscosidade com a fração volumétrica (fig. 7.27).

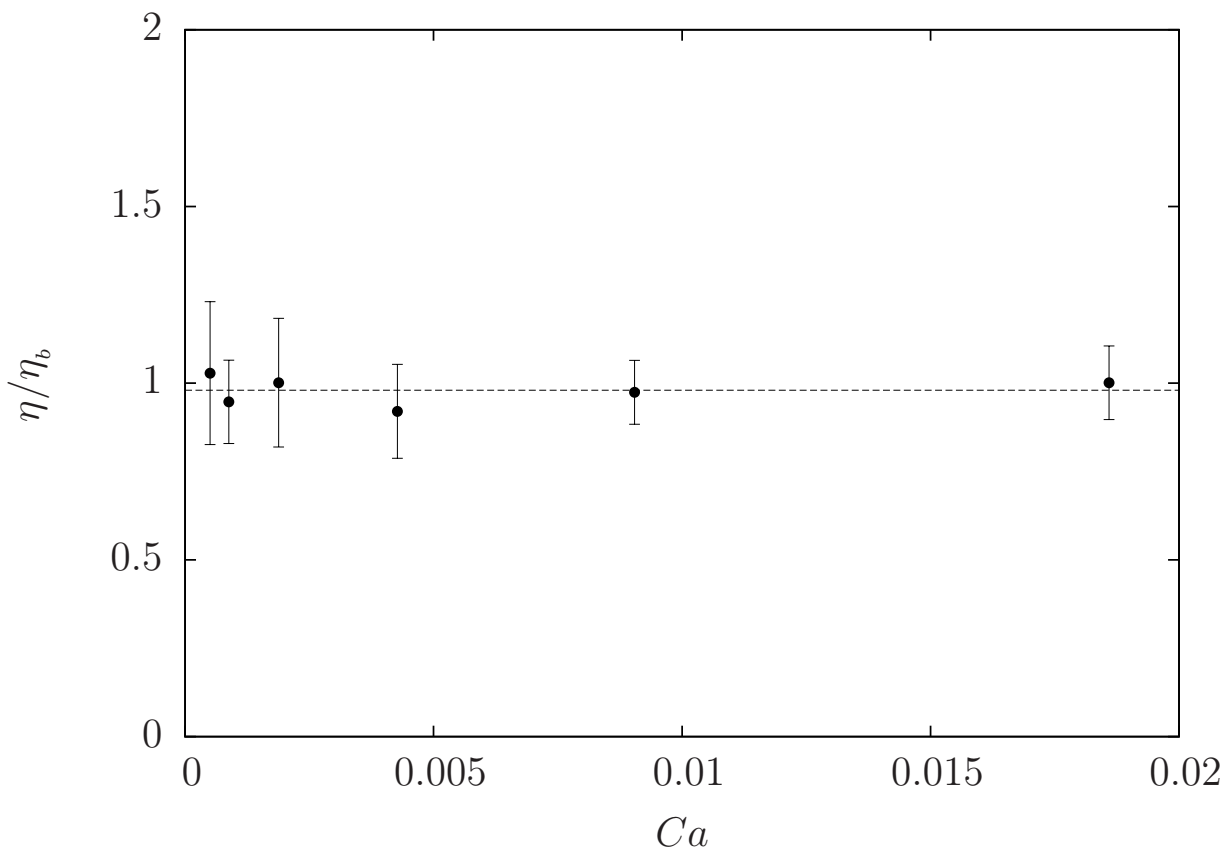

Figura 7.23: Variação da viscosidade em função da $C a$ para $\lambda=20$ e $\phi=2 \%$.O número de capilaridade foi calculado por $C a=(\eta \dot{\gamma} \delta) / \tau_{s}$ em que $\delta=0,4 \mathrm{~mm}$ é a distância entre os discos do reômetro e $\tau_{s}=0,03184 \mathrm{~N} / \mathrm{m}$ é a tensão interfacial. $--\eta / \eta_{b}=0,98 \pm 0,040$. 


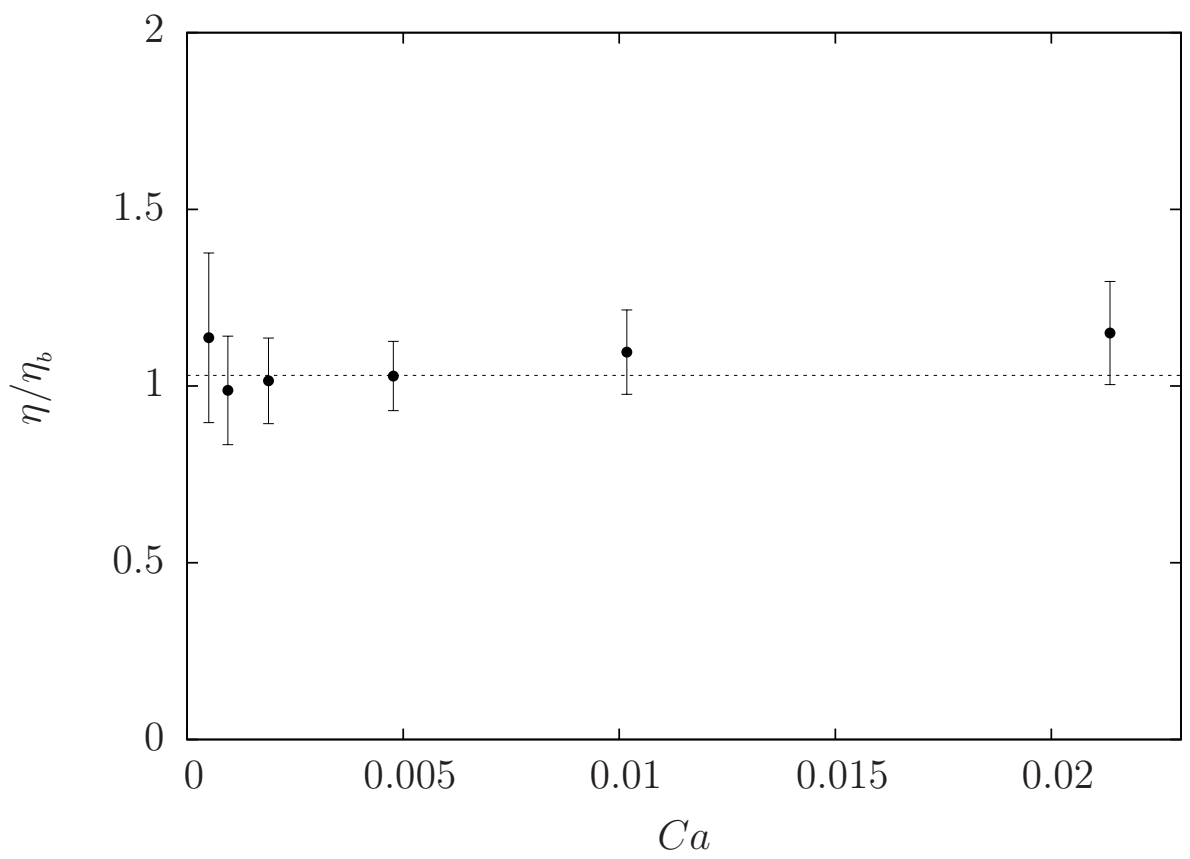

Figura 7.24: Variação da viscosidade em função da $C a$ para $\lambda=20$ e $\phi=5 \% . O$ número de capilaridade foi calculado por $C a=(\eta \dot{\gamma} \delta) / \tau_{s}$ em que $\delta=0,4 \mathrm{~mm}$ é a distância entre os discos do reômetro e $\tau_{s}=0,03184 \mathrm{~N} / \mathrm{m}$ é a tensão interfacial. $--\eta / \eta_{b}=1,03 \pm 0,034$.

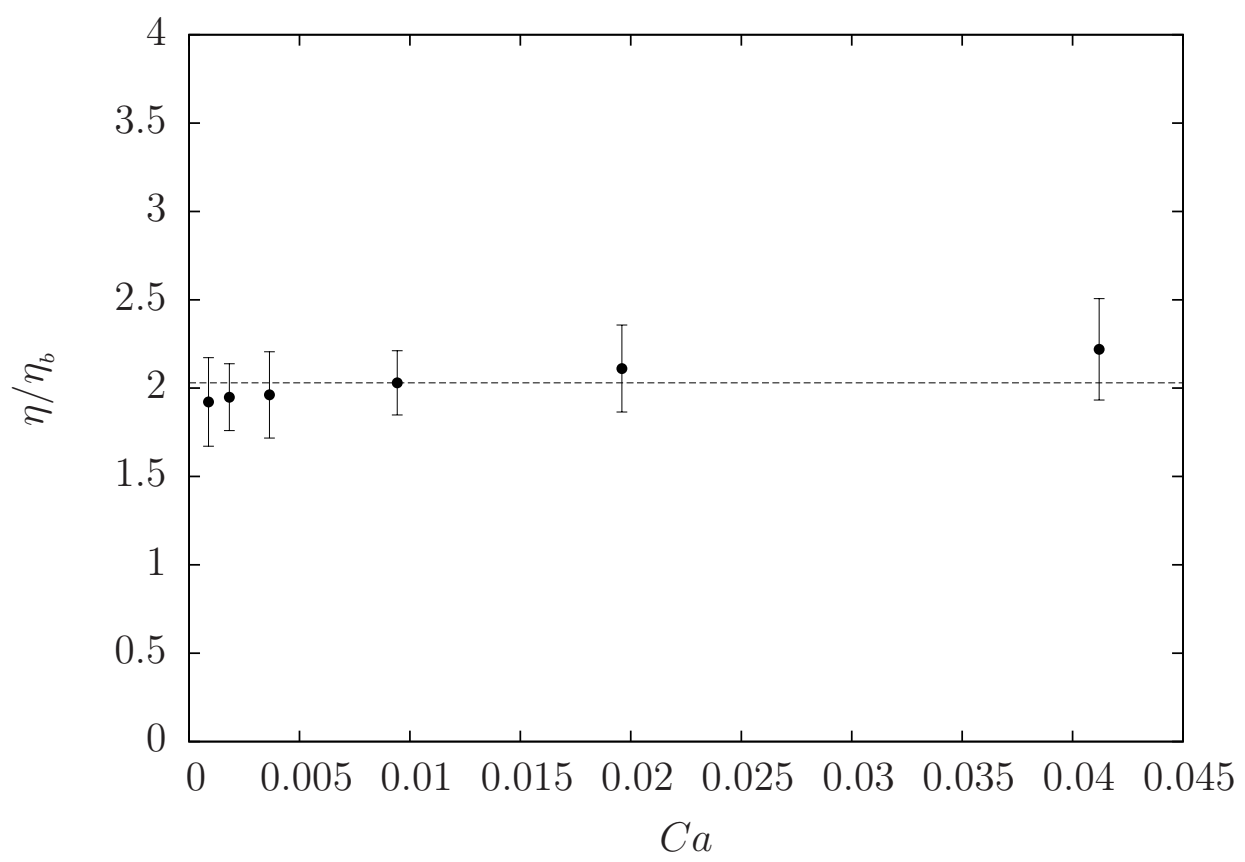

Figura 7.25: Variação da viscosidade em função da $C a$ para $\lambda=20$ e $\phi=20 \% . \mathrm{O}$ número de capilaridade foi calculado por $C a=(\eta \dot{\gamma} \delta) / \tau_{s}$ em que $\delta=0,4 \mathrm{~mm}$ é a distância entre os discos do reômetro e $\tau_{s}=0,03184 \mathrm{~N} / \mathrm{m}$ é a tensão interfacial. $--\eta / \eta_{b}=2,03 \pm 0,134$. 


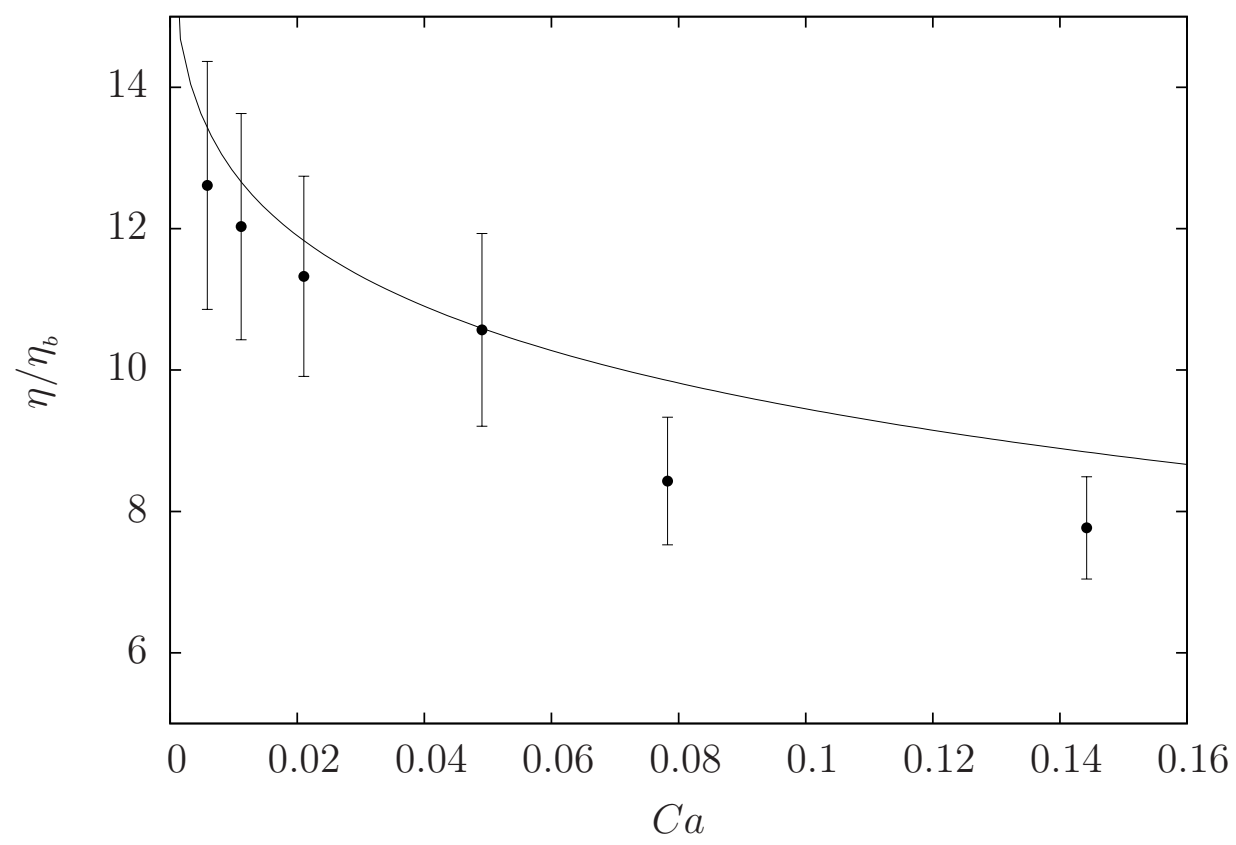

Figura 7.26: Variação da viscosidade em função da $C a$ para $\lambda=20$ e $\phi=40 \% . O$ número de capilaridade foi calculado por $C a=(\eta \dot{\gamma} \delta) / \tau_{s}$ em que $\delta=0,4 \mathrm{~mm}$ é a distância entre os discos do reômetro e $\tau_{s}=0,03184 \mathrm{~N} / \mathrm{m}$ é a tensão interfacial. -Modelo Carreau-Yasuda (eq. 2.11) $\eta_{\infty} / \eta_{b}=1,0, \eta_{0} / \eta_{b}=19,0, \alpha=4 \times 10^{-5}$, $n=-7,6, a=0,28$.

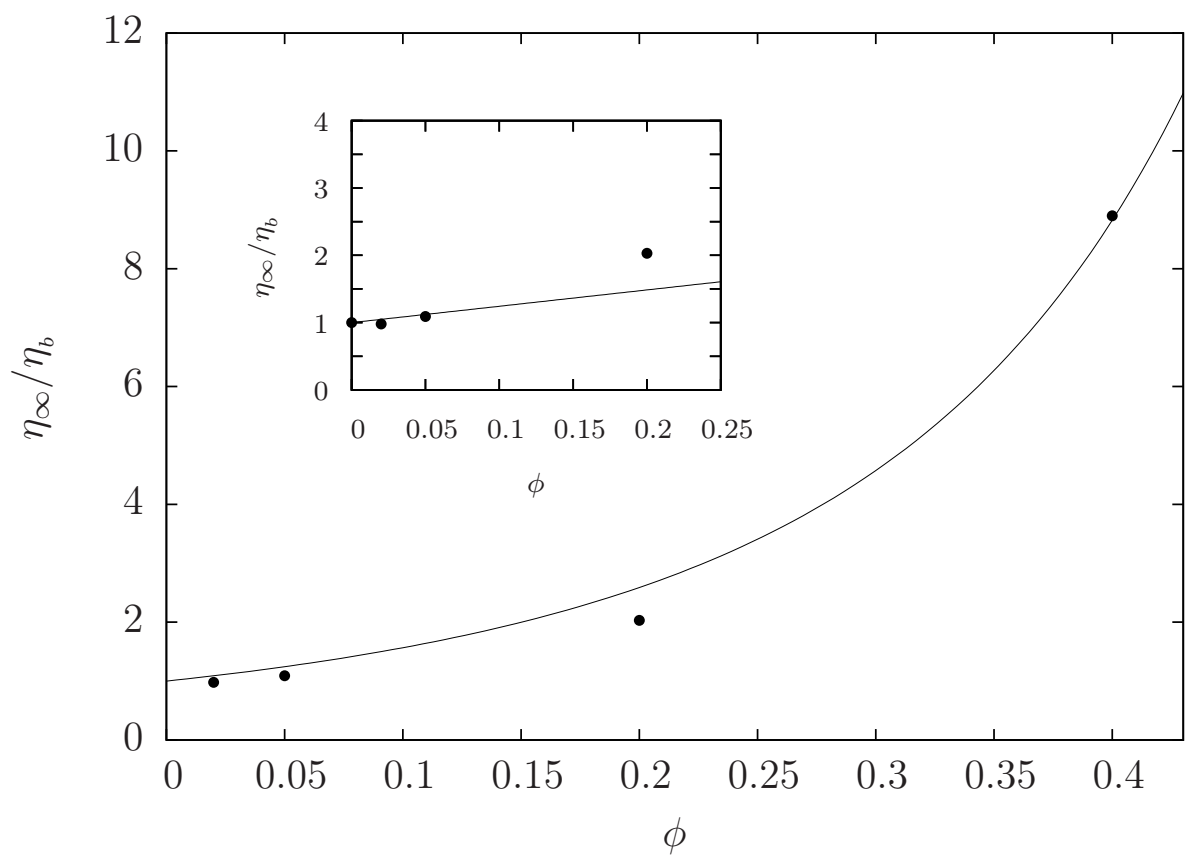

Figura 7.27: Aumento da viscosidade com a fração volumétrica $-\eta_{\infty} / \eta_{b}=(1-\phi)^{-n}$ em que $n=4,26$. Dados experimentais para $C a \approx 0,01$ e $\lambda=20$. Encarte: - Ajuste pela expressão da viscosidade de Taylor.

Para efeitos de comparação a tab. 7.8 mostra a variação da viscosidade aparente em 
altos número de capilaridade $\left(\eta_{\infty}\right)$ adimensionalizada pela viscosidade do fluido base. Observa-se um aumento da viscosidade $\eta_{\infty} / \eta_{b}$ com o aumento da fração volumétrica devido à existência de um maior número de gotas. A viscosidade aparente também aumentou com a razão de viscosidade $(\lambda)$ evidenciando que a inibição da deformação das gotas influencia a viscosidade aparente adimensionalizada da emulsão (fig. 7.28). Relacionando as características da microestrutura verifica-se que a emulsão que teve o maior efeito pseduo-plástico $(\phi=40 \%, \lambda=10)$ foi a emulsão com maior polidispersidade, uma vez que 1/4 das gotas que constituem a microestrutura são de tamanho considerado grande $(d=40-90 \mu m)$.

Tabela 7.8: Variação da viscosidade $\eta_{\infty} / \eta_{b}$ em função da fração volumétrica e da razão de viscosidade

\begin{tabular}{|c|c|c|c|c|}
\hline$\lambda$ & $\phi=2 \%$ & $\phi=5 \%$ & $\phi=20 \%$ & $\phi=40 \%$ \\
\hline 20 & 0,98 & 1,09 & 2,03 & 8,9 \\
10 & 0,89 & 1,04 & 2,11 & 7,58 \\
5 & 0,97 & 1,03 & 2,08 & 6,91 \\
2 & 0,90 & 1,02 & 1,16 & 3,70 \\
\hline
\end{tabular}

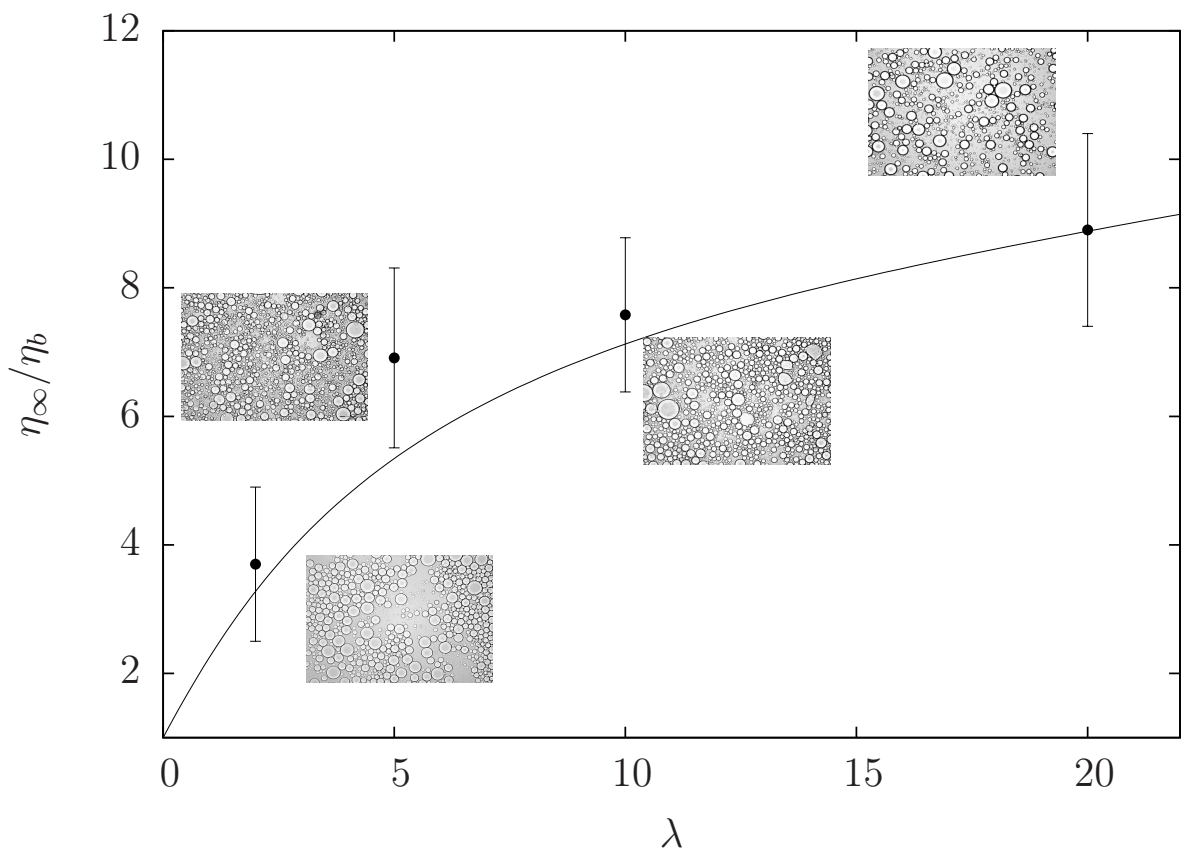

Figura 7.28: Aumento da viscosidade adimensinalizada em altos números de capilaridade para a emulsão de fração volumétrica $40 \% \operatorname{com} C a \approx 6 \times 10^{-2}$. 


\subsection{ESCOAMENTO NO INTERIOR DO TUBO CAPILAR DE SEÇÃO CIRCULAR}

Nesta seção são apresentados os resultados da caracterização reológica de emulsões pelo escoamento destas em um tubo capilar de seção circular. A bancada experimental é descrita na seção 4.2 que possibilita avaliar a viscosidade de emulsões em baixo número de Re. Os experimentos foram realizados com uma temperatura de laboratório constante de $25^{\circ} \mathrm{C}$. Os valores de pressão foram recolhidos, após a estabilização da pressão, durante uma hora de escoamento contínuo, para cada vazão imposta ao sistema. Durante o experimento, observou-se a possibilidade da existência de floculação no interior da seringa. Tal fenômeno quando presente foi observado em torno de 50 minutos do ínicio do experimento. Nesses casos, interrompeu-se o experimento e a emulsão no interior da seringa foi agitada até quebrar a instabilidade observada. Após isso foi repetido o experimento até completar uma hora de experimento.

Com as medições da pressão em função da vazão imposta calculou-se a tensão de cisalhamento na parede $\left(\tau_{w}\right)$ e a taxa de cisalhamento de parede $\left(\dot{\gamma}_{w}\right)$ como descrito na seção 2.4.2. Da razão entre essas duas quantidades físicas resulta a viscosidade na parede $\eta_{w}$. Os resultados experimentais são apresentados em função da viscosidade adimensionalizada pela viscosidade do fluido base da emulsão e do número de capilaridade que depende da tensão interfacial entre o fluido base e o fluido disperso.

A partir da região linear do gráfico $Q$ vs $\Delta P$, calcula-se a viscosidade efetiva baseada na Lei de Hagen-Poiseuille:

$$
\frac{\Delta P}{Q}=\frac{8 \eta L}{\pi R^{4}}=K
$$

em que $\Delta P=p_{0}-p_{L}$ sendo $p_{0}$ a pressão no início do tubo capilar e $p_{L}$ a pressão no final do tubo capilar. Pela equação anterior observa-se que $K=\tan \theta$ em que $\theta$ é o ângulo entre a recta que passa na origem, que representa a região linear do gráfico, e o eixo das abcissas do gráfico $\Delta P$ e $Q$. A viscosidade efetiva é calculada como:

$$
\eta=\frac{\pi R^{4}}{8 L} K
$$


sendo $L=15 \mathrm{~cm}$ o comprimento do capilar e $R=250 \mu \mathrm{m}$ o raio do capilar.

\subsubsection{Ensaios de uma emulsão com razão de viscosidade 2}

Aqui são apresentados os resultados experimentais das emulsões de $\lambda=2$ para $\phi=$ $2 \%, 5 \%, 20 \%$ e $40 \%$.

As figs. 7.29, 7.31, 7.33 e 7.35 mostram a variação da diferença de pressão com a vazão. A viscosidade efetiva é calculada pelo declive da recta que liga a origem do gráfico com os pontos alinhados nas menores vazões. Os pontos que não apresentam alinhamento com esta recta representam os efeitos não lineares da interação do fluido com o cisalhamento. Observa-se um alinhamento dos últimos pontos, excepto na fig. 7.35. Esse alinhamento representa uma saturação da viscosidade, indicando que a microestrutura da emulsão se alinhou com a direção principal do escoamento. Todas as emulsões apresentaram um decaimento da viscosidade adimensional com o aumento do número de capilaride (efeito pseudo-plástico).

Observa-se pela fig. 7.30 que a emulsão rapidamente atinge o seu regime de platô. Isso se deve ao fato que para esta razão de viscosidade as gotas se alinham rapidamente com o escoamento. Neste caso o tempo de deformação é menor do que o tempo de escoamento.

Com relação à microestrutura a emulsão de $\phi=40 \%$ apresenta uma maior polidispersidade e gotas de maior tamanho do que a emulsão de $\phi=2 \%$. Isso também representa condições para um maior efeito pseudo-plástico. Pela fig. 7.37 observa-se que a viscosidade aumenta com a fração volumétrica, tal como esperado. 


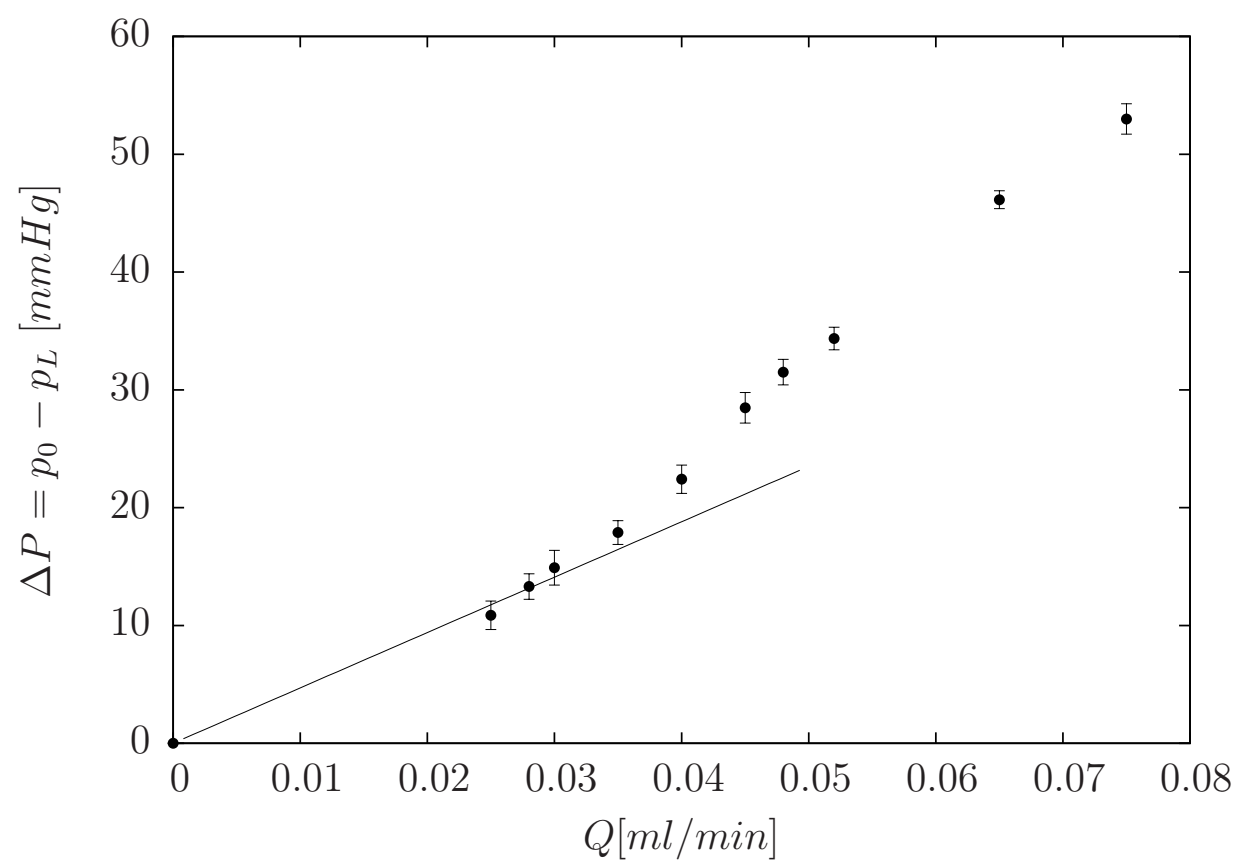

Figura 7.29: Variação da pressão em função da vazão para $\lambda=2$ e $\phi=2 \%$. Pontos Experimentais ; - Região Linear. A viscosidade efetiva é de 34,85 cP que adimensionalizada pela viscosidade do fluido base é 0,51 .

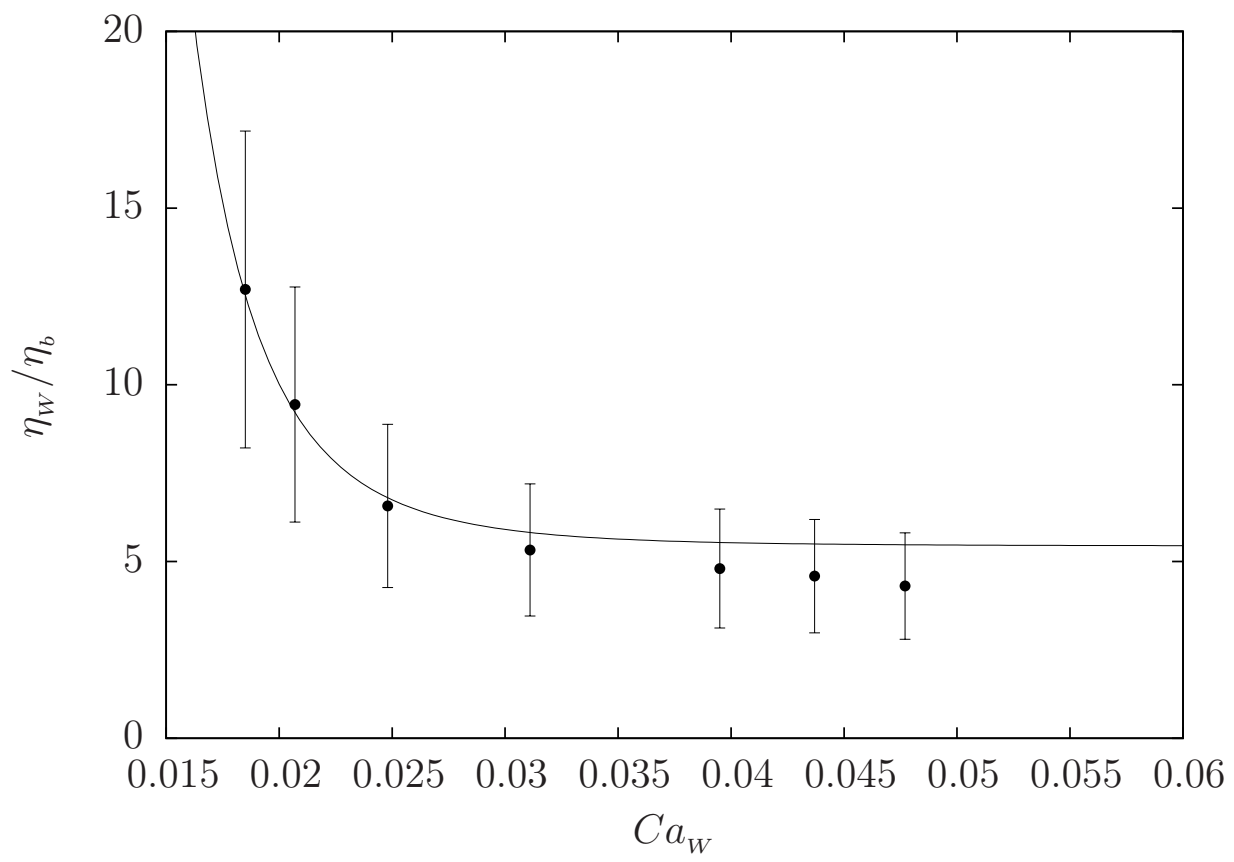

Figura 7.30: Variação da viscosidade aparente é $\eta_{w} / \eta_{b}$ com o número de capilaridade avaliado na parede $\left(C a_{w}=\left(\dot{\gamma}_{w} \eta_{w} R\right) / \tau_{s}\right)$ para $\lambda=2 \mathrm{e} \phi=2 \%$ em que $\tau_{s}=0,028 \mathrm{~N} / \mathrm{m}$. A viscosidade $\eta_{w, \infty} / \eta_{b}=5,44 \pm 2,628$. - Ajuste com modelo de Sisko: $\eta_{w} / \eta_{b}=$ $\eta_{w, \infty} / \eta_{b}+K C a_{w}^{n-1}$, com $K=1.26 \times 10^{-9}$ e $n=-4,62$. 


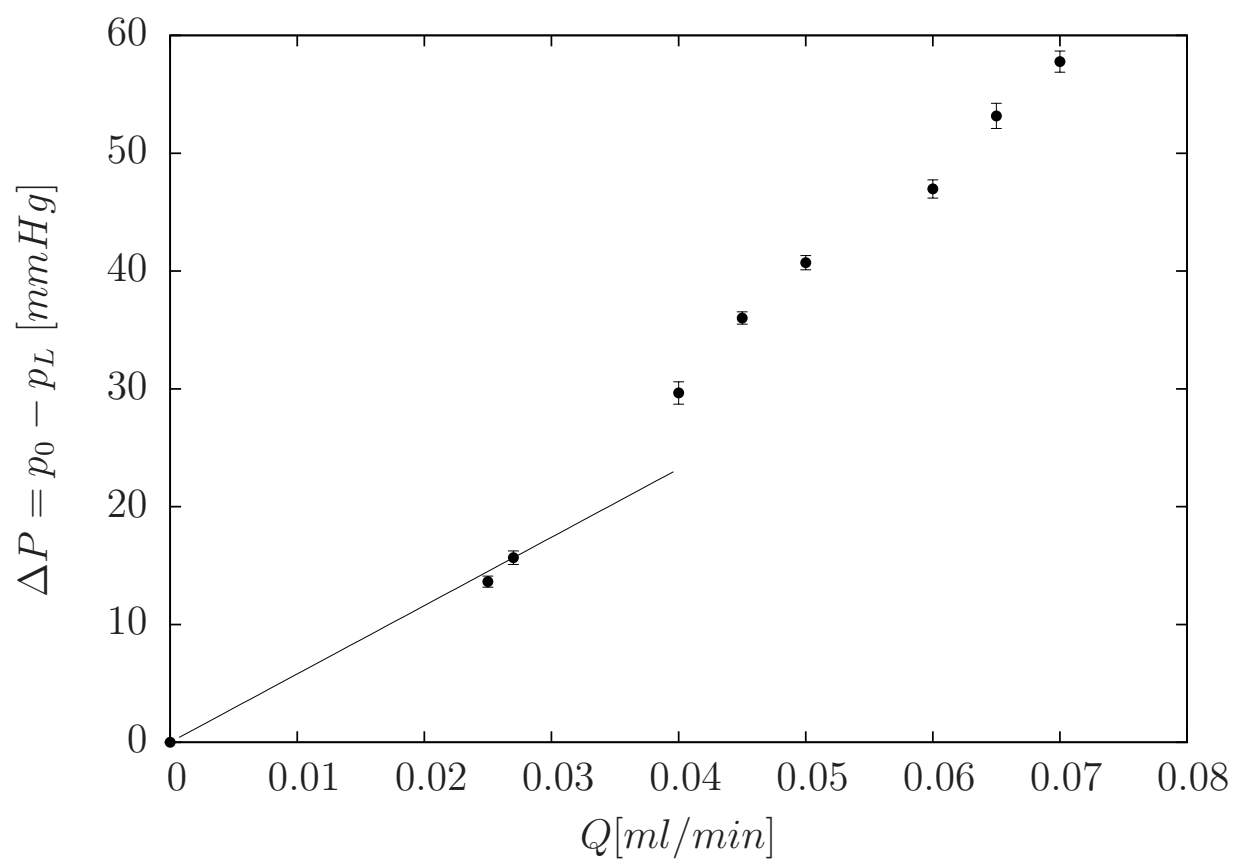

Figura 7.31: Variação da pressão em função da vazão para $\lambda=2$ e $\phi=5 \%$. • Pontos Experimentais ; - Região Linear da emulsão. A viscosidade efetiva é de $45 c P$ que adimensionalizada pela viscosidade do fluido base é 0,66 .

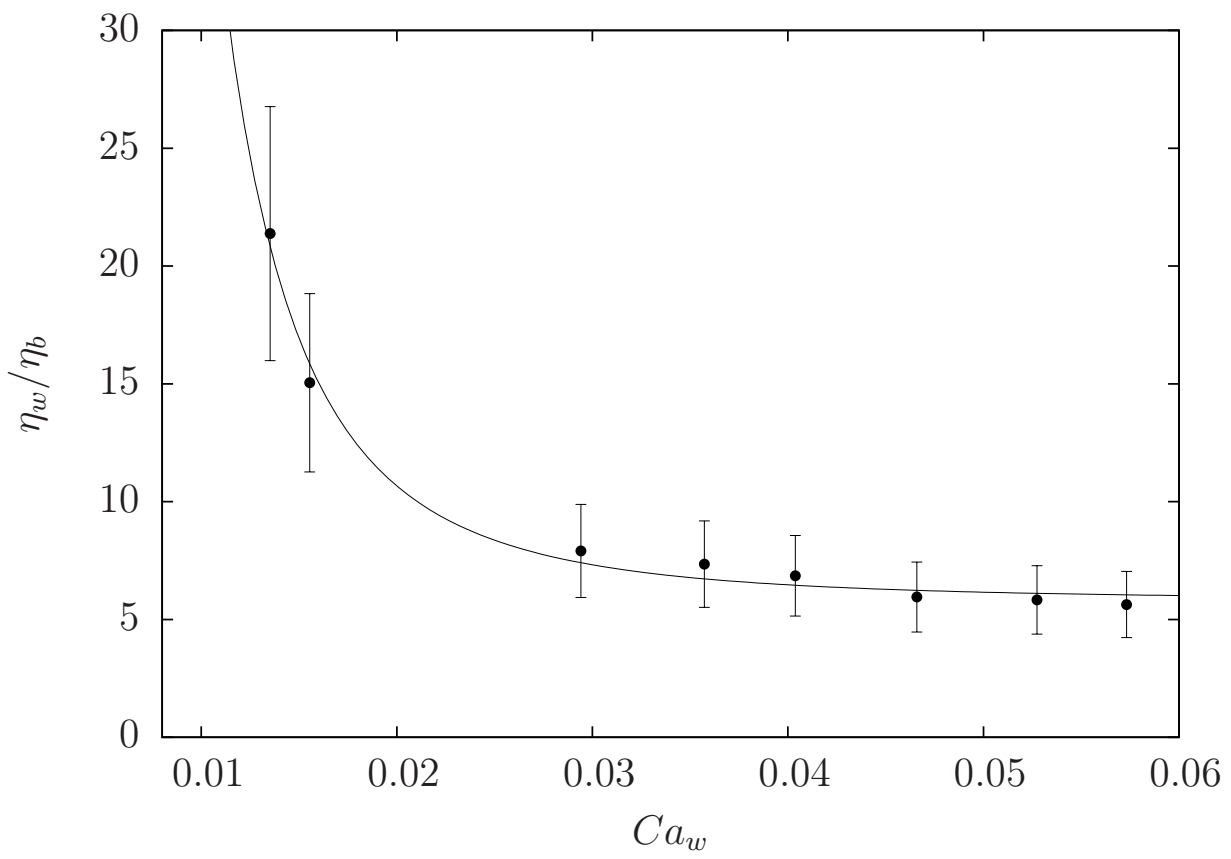

Figura 7.32: Variação da viscosidade aparente é $\eta_{w} / \eta_{b}$ com o número de capilaridade avaliado na parede $\left(C a_{w}=\left(\dot{\gamma}_{w} \eta_{w} R\right) / \tau_{s}\right)$ para $\lambda=2$ e $\phi=5 \%$ em que $\tau_{s}=0,028 \mathrm{~N} / \mathrm{m}$. A viscosidade $\eta_{w, \infty} / \eta_{b}=5,81 \pm 1,493$. - Ajuste com modelo de Sisko: $\eta_{w} / \eta_{b}=$ $\eta_{w, \infty} / \eta_{b}+K C a_{w}^{n-1}$, com $K=6,2 \times 10^{-5}$ e $n=-1,88$. 


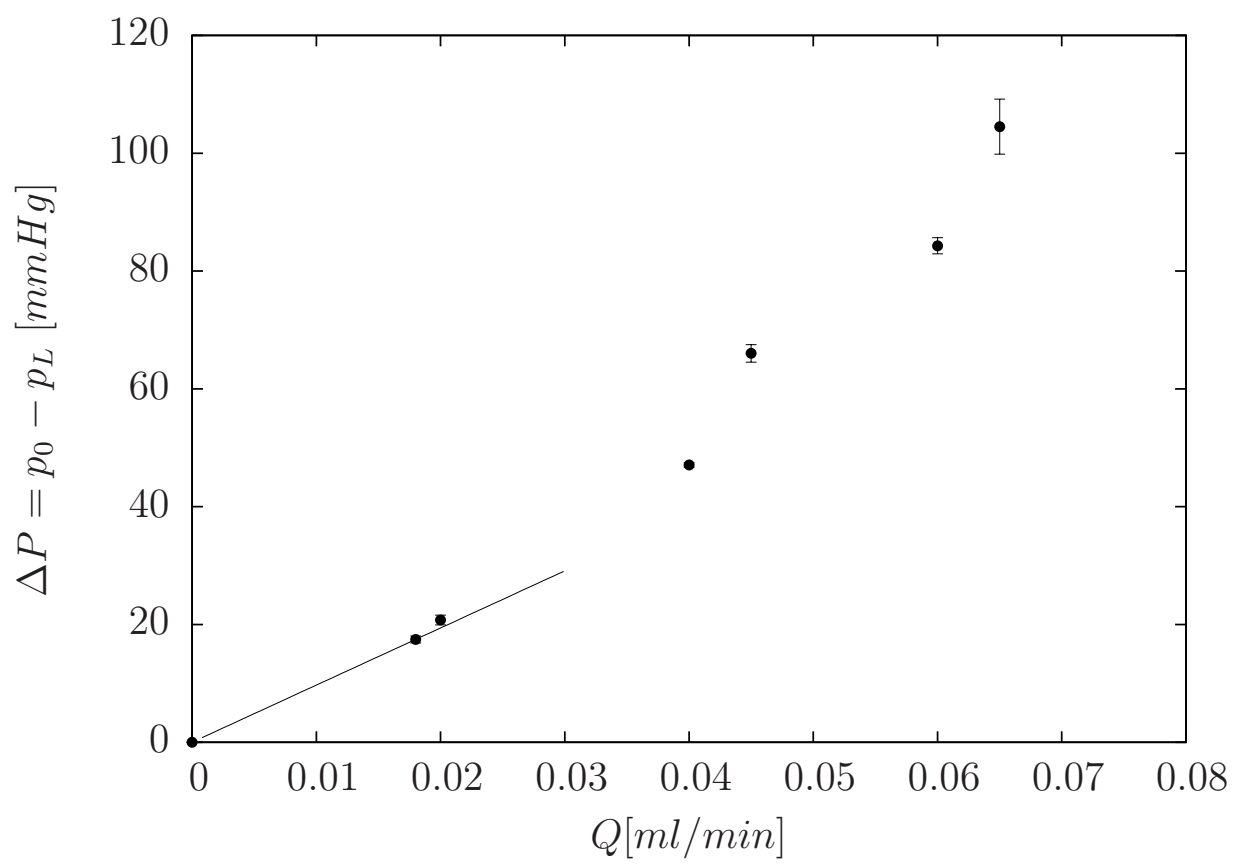

Figura 7.33: Variação da pressão em função da vazão para $\lambda=2$ e $\phi=20 \%$. • Pontos Experimentais ; - Região Linear da emulsão. A viscosidade efetiva é de $81,32 c P$ que adimensionalizada pela viscosidade do fluido base é 1,19 .

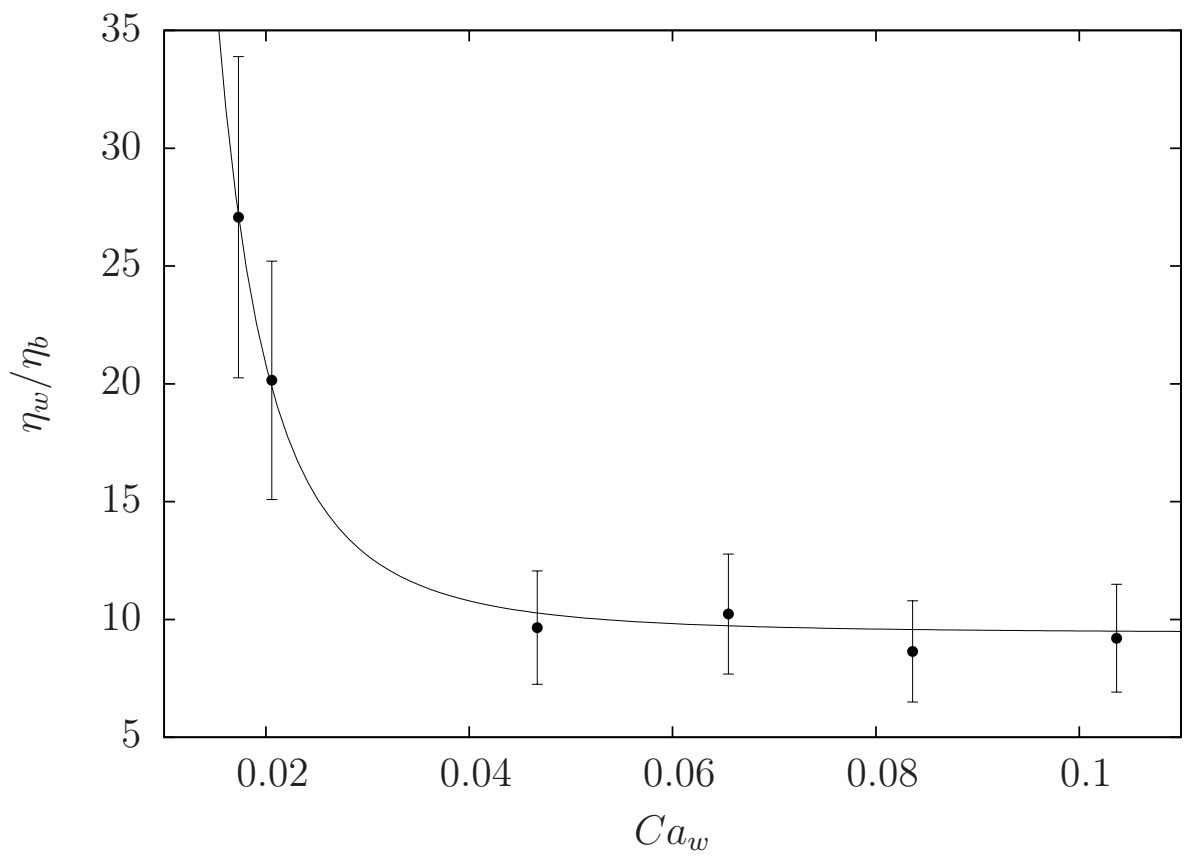

Figura 7.34: Variação da viscosidade aparente é $\eta_{w} / \eta_{b}$ com o número de capilaridade avaliado na parede $\left(C a_{w}=\left(\dot{\gamma}_{w} \eta_{w} R\right) / \tau_{s}\right)$ para $\lambda=2$ e $\phi=20 \%$ em que $\tau_{s}=0,028 \mathrm{~N} / \mathrm{m}$. A viscosidade $\eta_{w, \infty} / \eta_{b}=9,43 \pm 2,557$. - Ajuste com modelo de Sisko: $\eta_{w} / \eta_{b}=\eta_{w, \infty} / \eta_{b}+K C a_{w}^{n-1}$, com $K=1,9 \times 10^{-4}$ e $n=-2,07$. 


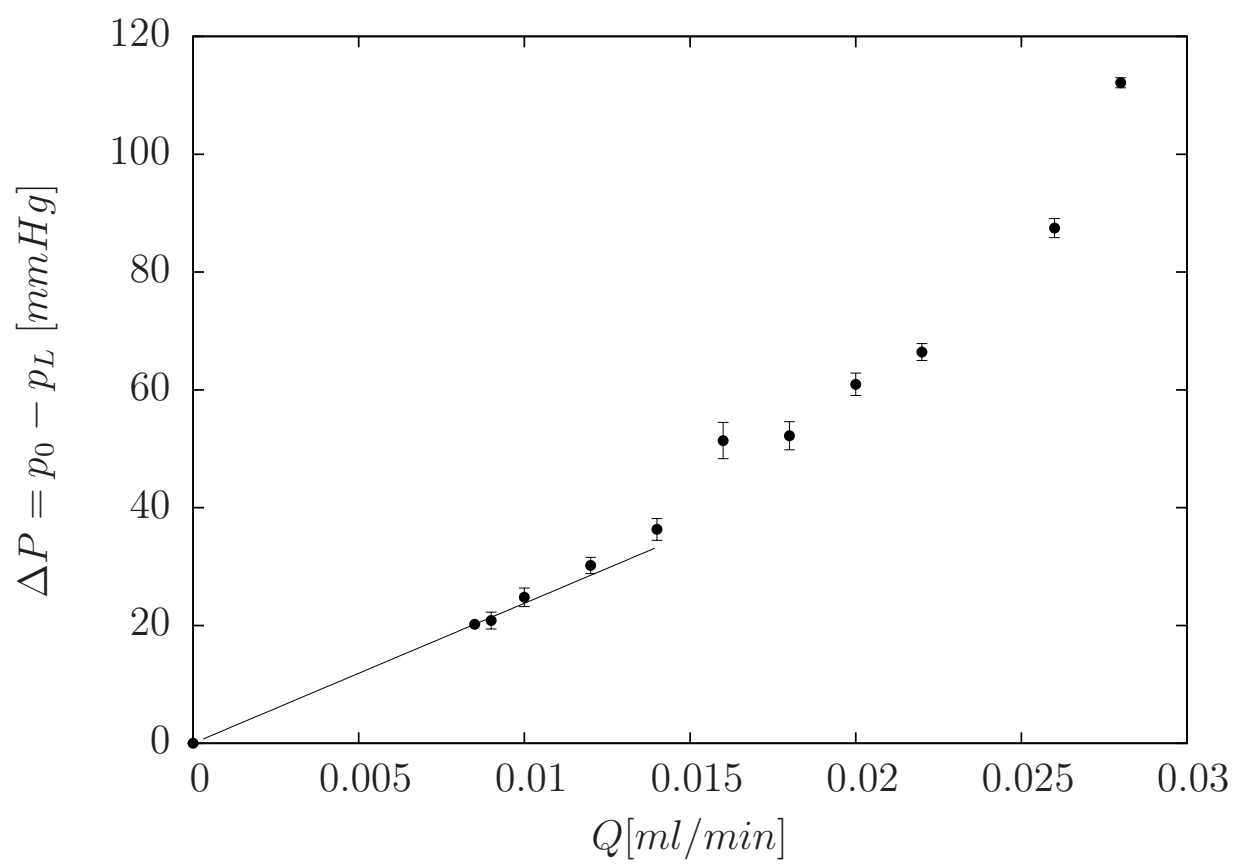

Figura 7.35: Variação da pressão em função da vazão para $\lambda=2$ e $\phi=40 \%$. • Pontos Experimentais ; - Região Linear da emulsão. A viscosidade efetiva é de $204 c P$ que adimensionalizada pela viscosidade do fluido base é 2,98 .

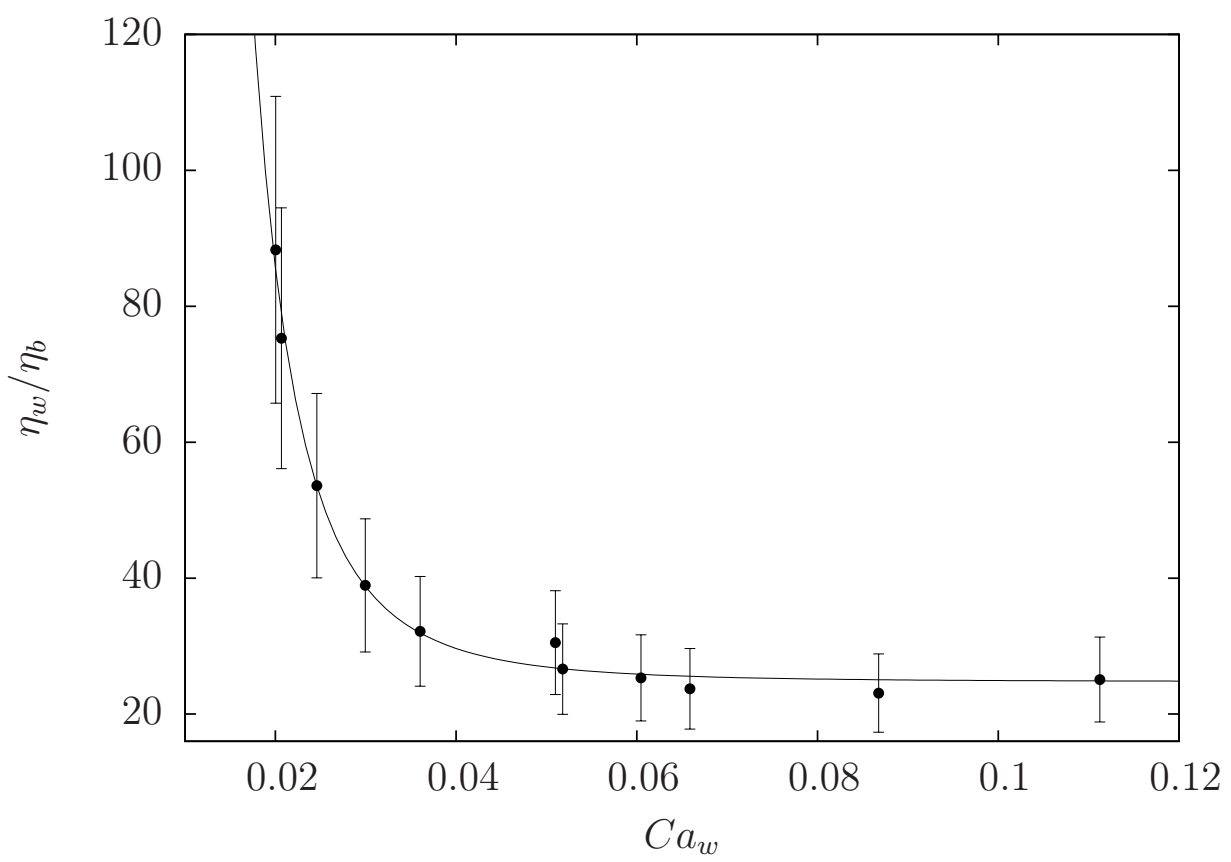

Figura 7.36: Variação da viscosidade aparente é $\eta_{w} / \eta_{b}$ com o número de capilaridade avaliado na parede $\left(C a_{w}=\left(\dot{\gamma}_{w} \eta_{w} R\right) / \tau_{s}\right)$ para $\lambda=2$ e $\phi=40 \%$ em que $\tau_{s}=0,028 \mathrm{~N} / \mathrm{m}$. A viscosidade $\eta_{w, \infty} / \eta_{b}=24,76 \pm 11,329$. - Ajuste com modelo de Sisko: $\eta_{w} / \eta_{b}=\eta_{w, \infty} / \eta_{b}+K C a_{w}^{n-1}, \operatorname{com} K=4 \times 10^{-5}$ e $n=-2,63$. 


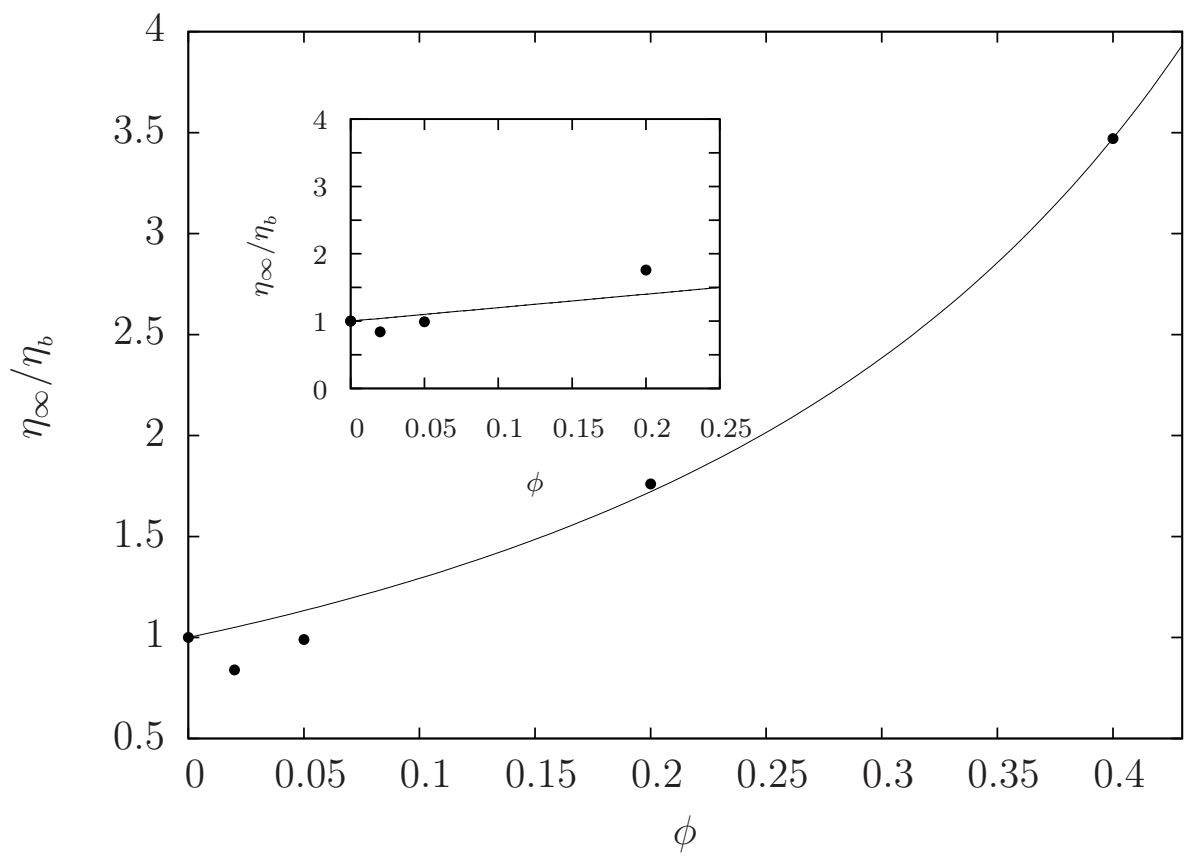

Figura 7.37: Aumento da viscosidade intrínseca com a fração volumétrica $-\eta_{\infty} / \eta_{b}=$ $(1-\phi)^{-n}$ em que $n=-2,44$. Dado experimentais para $C a_{w} \approx 5,8 \times 10^{-2}$ e $\lambda=2$. Encarte: - Ajuste pela expressão da viscosidade de Taylor.

\subsubsection{Ensaios da Emulsão com razão de viscosidade 5}

Aqui são apresentados os resultados experimentais das emulsões de $\lambda=5$ para $\phi=$ $40 \%, 20 \%, 5 \%$ e $2 \%$.

Os resultados desta emulsão são idênticos aos da emulsão de $\lambda=2$ nas quais se observou uma queda da viscosidade com o aumento do número de capilaridade. Pelos gráficos da variação da diferença de pressão com a vazão nota-se um menor desalinhamento dos pontos experimentais refletindo uma menor deformação da microestrutura da emulsão. Esse fato pode estar relacionado com o aumento da razão de viscosidade. Após a rápida diminuição da viscosidade, esta estabiliza devido ao alinhamento da microestrutura na direção do escoamento.

Pela fig. $7.44(\phi=40 \%, \lambda=5)$ observa-se que os pontos se encontram alinhados refletindo que as medições foram obtidas no regime de comportamento linear da emulsão. No entanto, a fig. 7.45 apresenta o comportamento pseudo-plástico da emulsão. Este comportamento é devido à presença de um maior número de gotas na emulsão. Pela 
fig. 7.46 observa-se que a viscosidade aumenta com a fração volumétrica, tal como esperado.

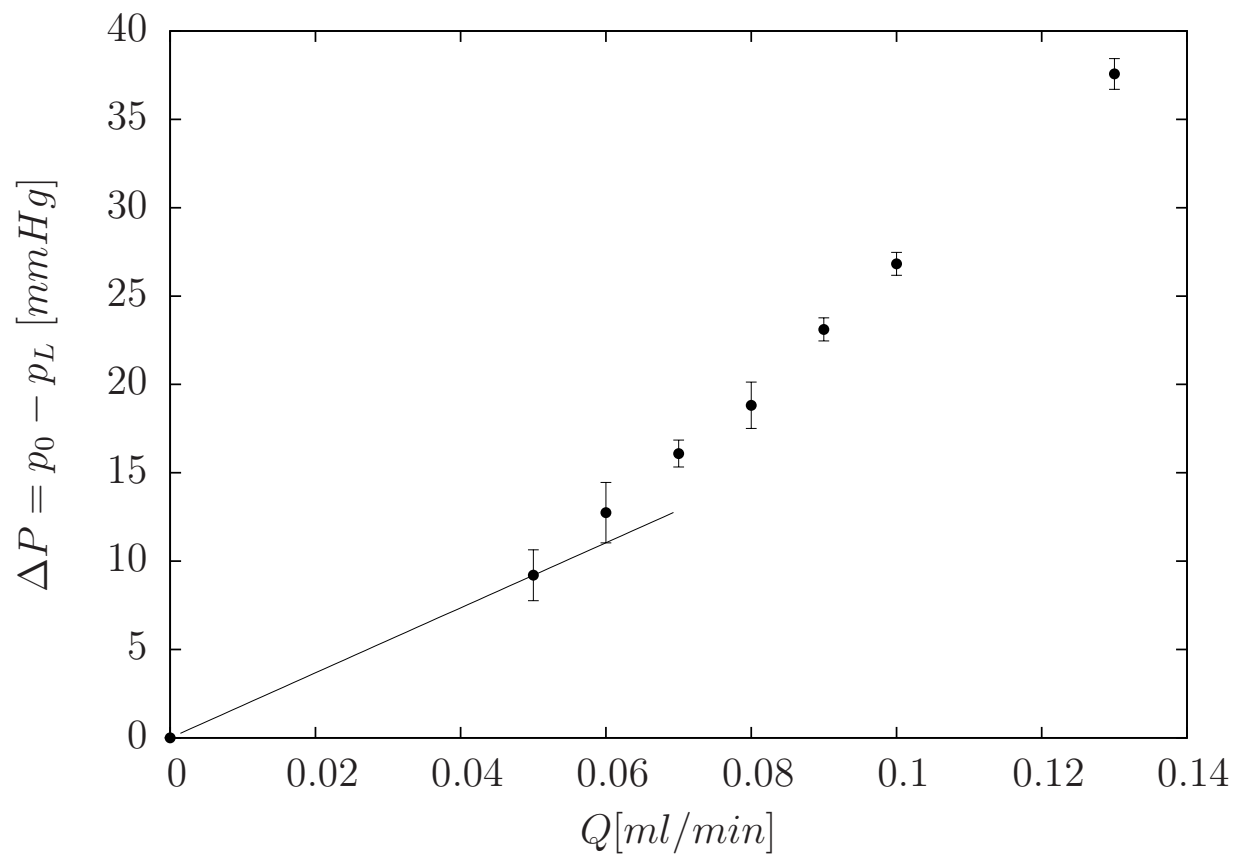

Figura 7.38: Variação da pressão em função da vazão para $\lambda=5$ e $\phi=2 \%$. • Pontos Experimentais ; - Região Linear da emulsão. A viscosidade efetiva é de 15, 2 cP que adimensionalizada pela viscosidade do fluido base é 0,54 .

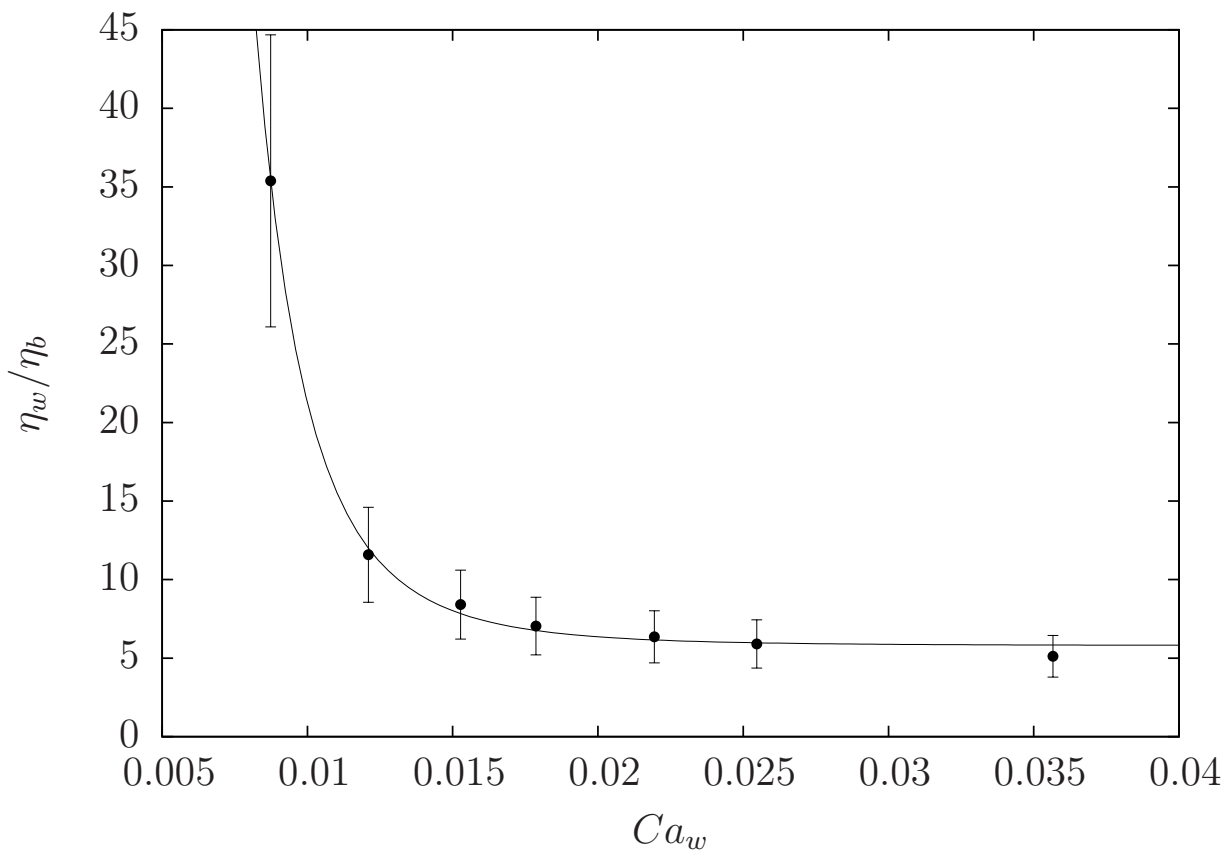

Figura 7.39: Variação da viscosidade aparente é $\eta_{w} / \eta_{b}$ com o número de capilaridade avaliado na parede $\left(C a_{w}=\left(\dot{\gamma}_{w} \eta_{w} R\right) / \tau_{s}\right)$ para $\lambda=5$ e $\phi=2 \%$ em que $\tau_{s}=0,02926 \mathrm{~N} / \mathrm{m}$. A viscosidade $\eta_{w, \infty} / \eta_{b}=5,80 \pm 2,92$. - Ajuste com modelo de Sisko: $\eta_{w} / \eta_{b}=\eta_{w, \infty} / \eta_{b}+K C a_{w}^{n-1}, \operatorname{com} K=4 \times 10^{-9}$ e $n=-3,80$. 


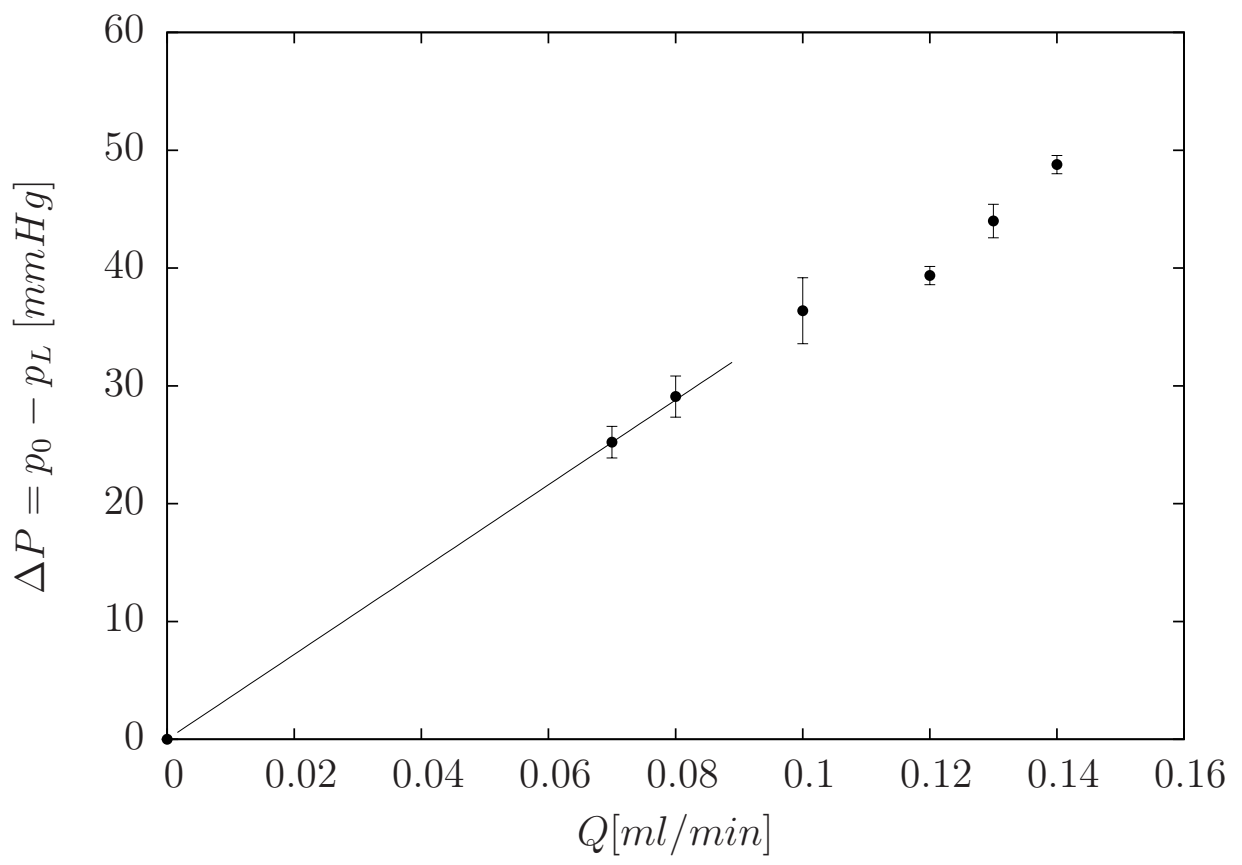

Figura 7.40: Variação da pressão em função da vazão para $\lambda=5$ e $\phi=5 \%$. • Pontos Experimentais ; - Região Linear da emulsão. A viscosidade efetiva é de $29 c P$ que adimensionalizada pela viscosidade do fluido base é 1,02 .

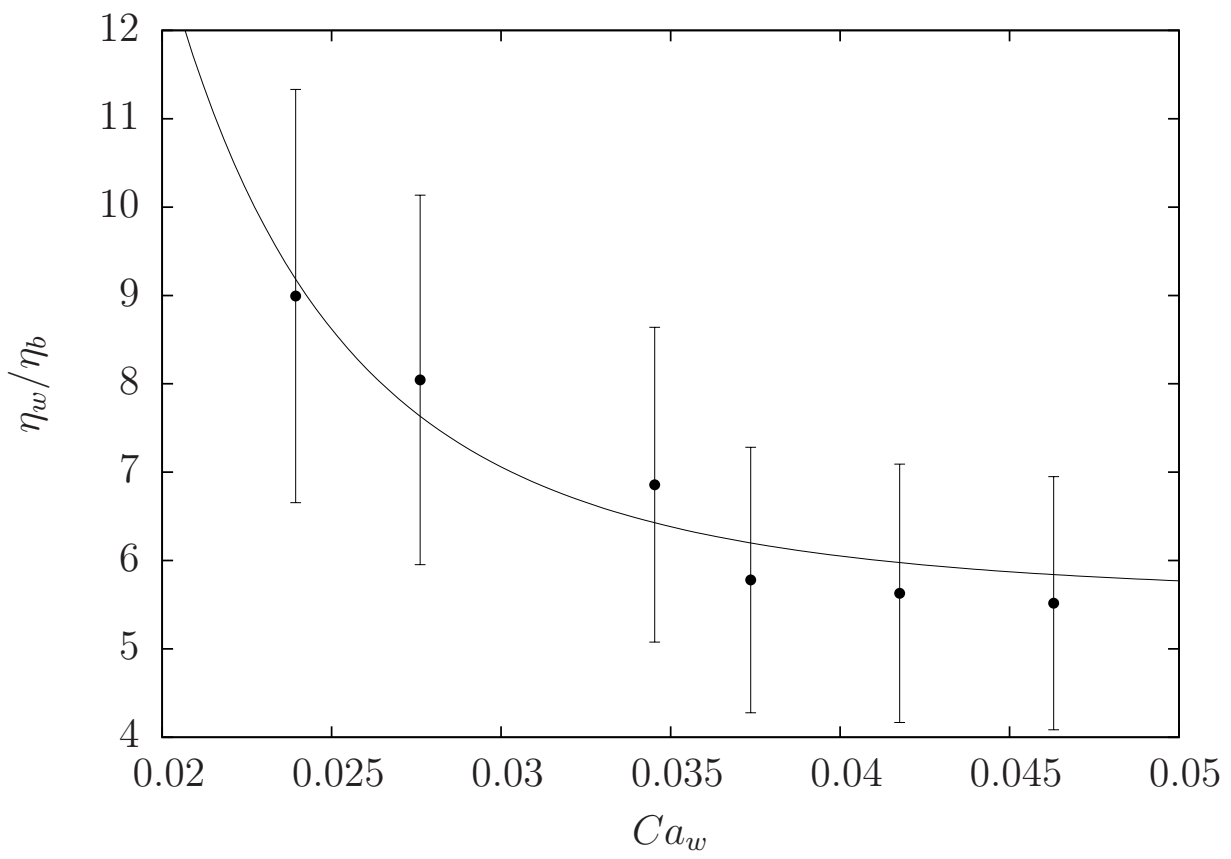

Figura 7.41: Variação da viscosidade aparente é $\eta_{w} / \eta_{b}$ com o número de capilaridade avaliado na parede $\left(C a_{w}=\left(\dot{\gamma}_{w} \eta_{w} R\right) / \tau_{s}\right)$ para $\lambda=5$ e $\phi=5 \%$ em que $\tau_{s}=0,02926 \mathrm{~N} / \mathrm{m}$. A viscosidade $\eta_{w, \infty} / \eta_{b}=5,57 \pm 2,50$. - Ajuste com modelo de Sisko: $\eta_{w} / \eta_{b}=\eta_{w, \infty} / \eta_{b}+K C a_{w}^{n-1}$, com $K 1.55 \times 10^{-6}$ e $n=-2,93$. 


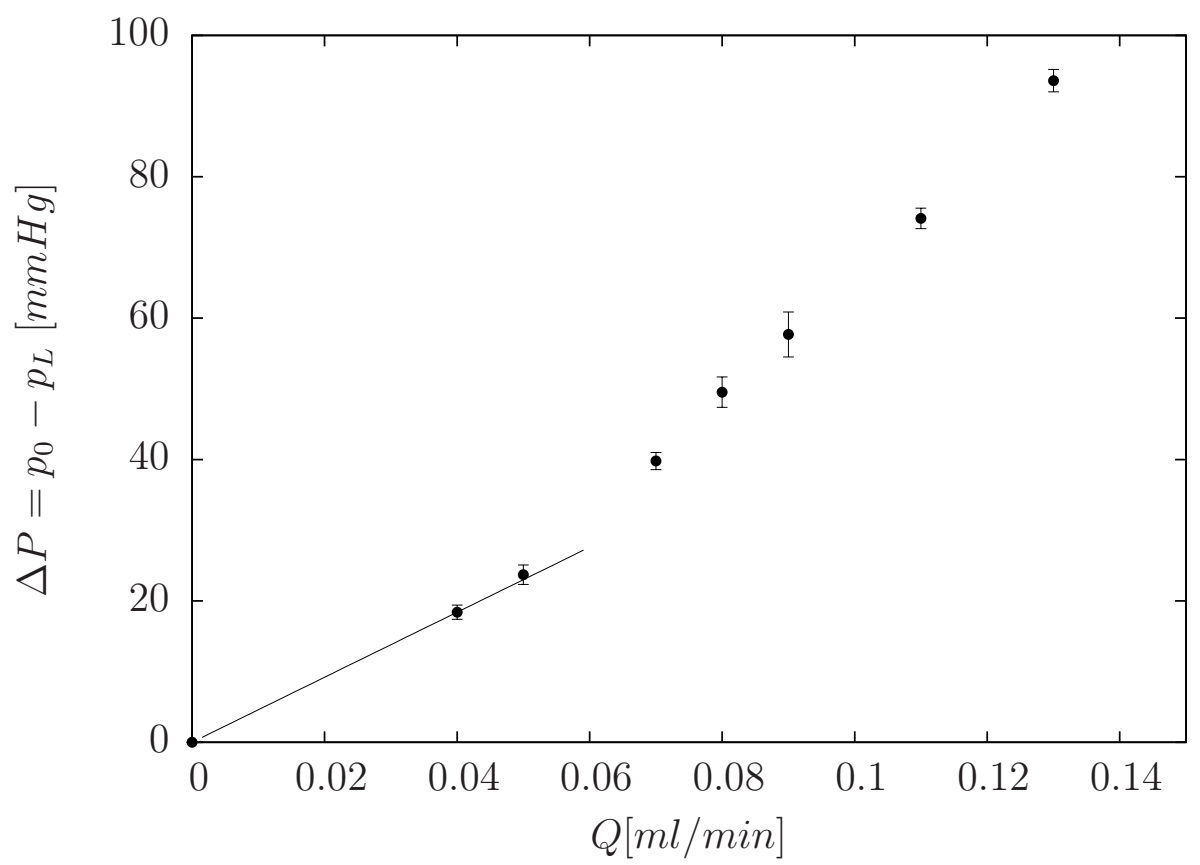

Figura 7.42: Variação da pressão em função da vazão para $\lambda=5$ e $\phi=20 \%$. • Pontos Experimentais ; - Região Linear da emulsão. A viscosidade efetiva é de $38,5 c P$ que adimensionalizada pela viscosidade do fluido base é 1,37 .

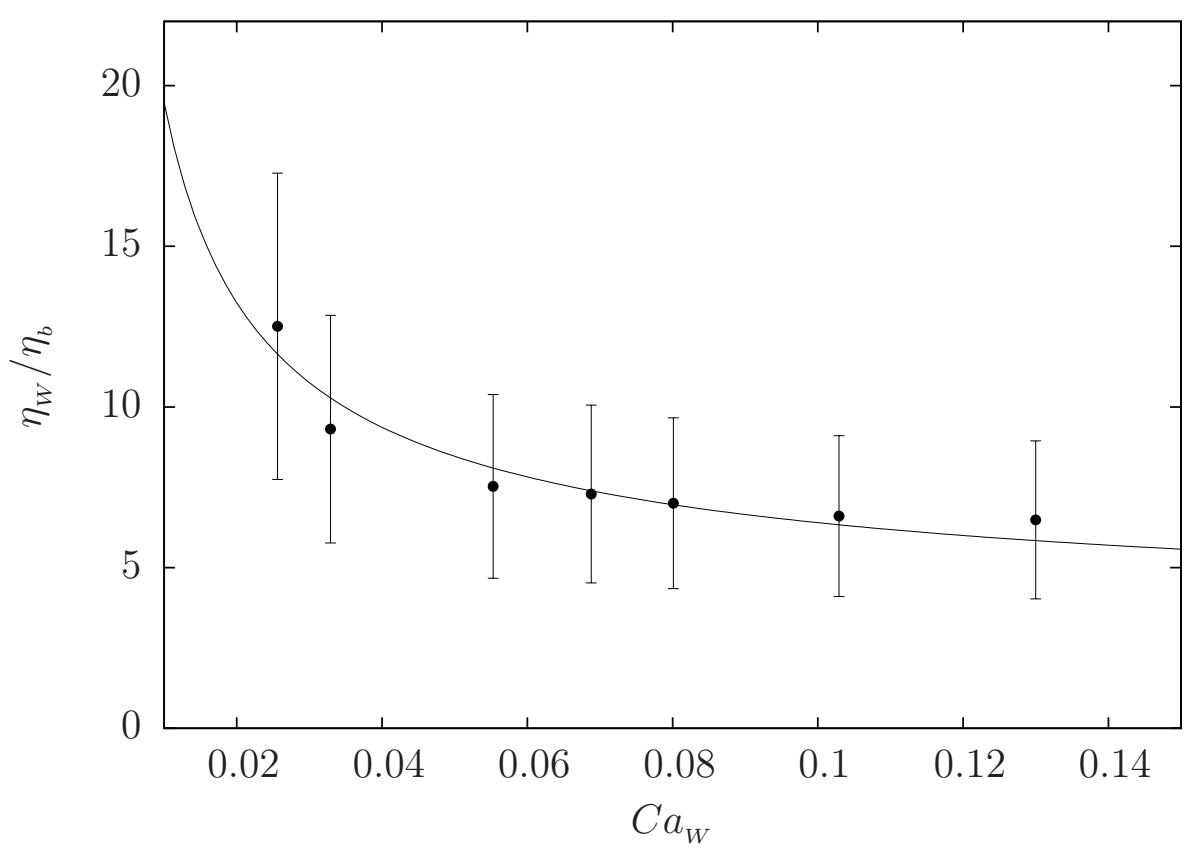

Figura 7.43: Variação da viscosidade aparente é $\eta_{w} / \eta_{b}$ com o número de capilaridade avaliado na parede $\left(C a_{w}=\left(\dot{\gamma}_{w} \eta_{w} R\right) / \tau_{s}\right)$ para $\lambda=5$ e $\phi=20 \%$ em que $\operatorname{tau}_{s}=$ $0,02926 \mathrm{~N} / \mathrm{m}$. A viscosidade $\eta_{w, \infty} / \eta_{b}=3,00 \pm 0,70$. Ajuste com modelo de Sisko: $\eta_{w} / \eta_{b}=\eta_{w, \infty} / \eta_{b}+K C a_{w}^{n-1}, \operatorname{com} K=0,7$ e $n=0,31$. 


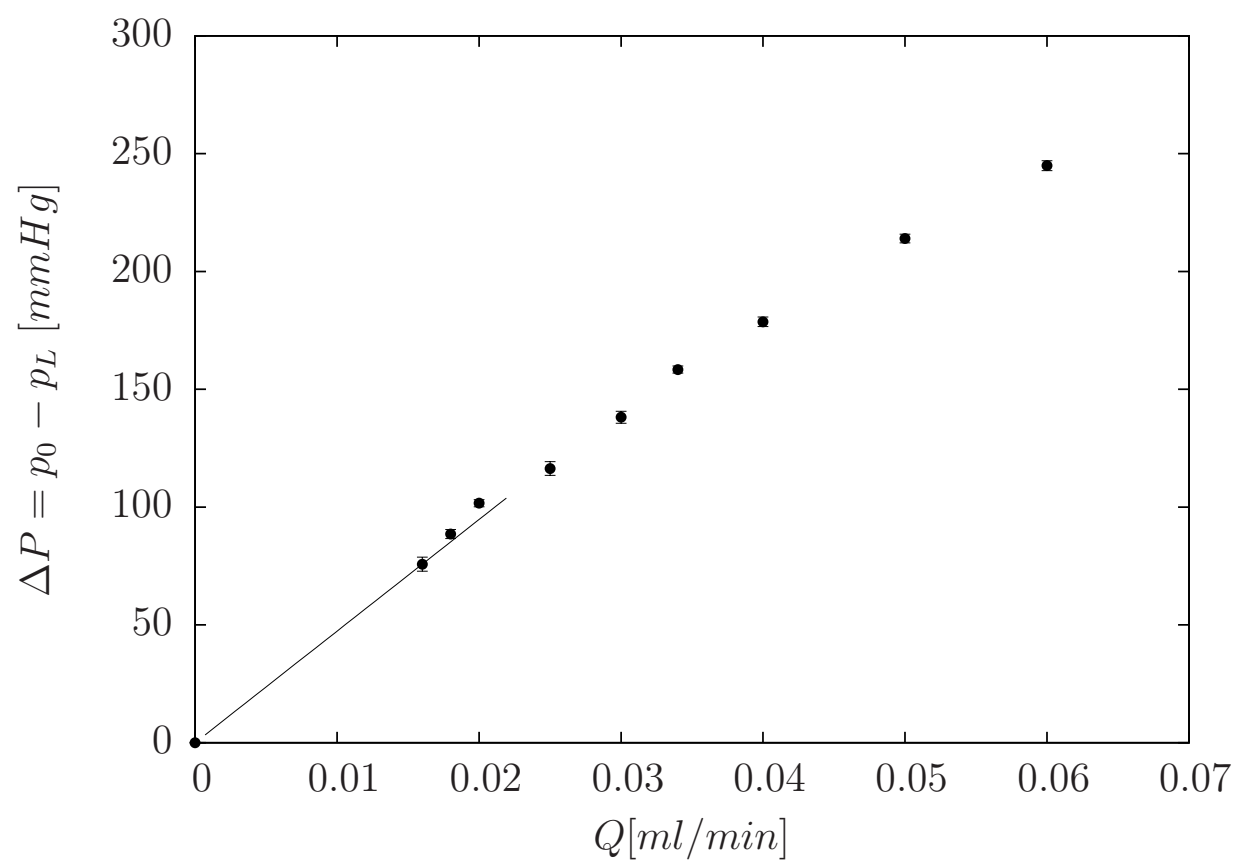

Figura 7.44: Variação da pressão em função da vazão para $\lambda=5$ e $\phi=40 \%$. • Pontos Experimentais ; - Região Linear da emulsão. A viscosidade efetiva é de $367 c P$ que adimensionalizada pela viscosidade do fluido base é 13, 08 .

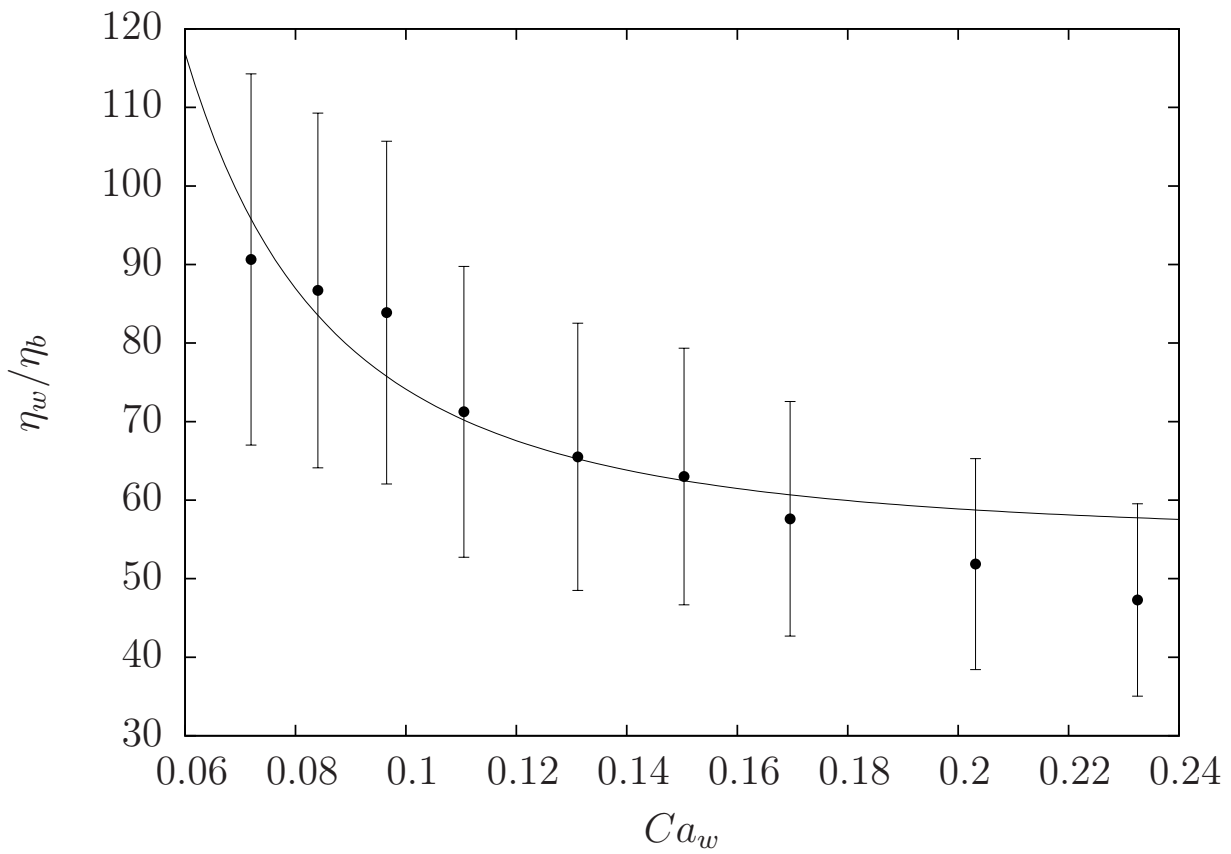

Figura 7.45: Variação da viscosidade aparente é $\eta_{w} / \eta_{b}$ com o número de capilaridade avaliado na parede $\left(C a_{w}=\left(\dot{\gamma}_{w} \eta_{w} R\right) / \tau_{s}\right)$ para $\lambda=5$ e $\phi=40 \%$ em que $\tau_{s}=0,02926 \mathrm{~N} / \mathrm{m}$. A viscosidade $\eta_{w, \infty} / \eta_{b}=55,00 \pm 4,70$. - Ajuste com modelo de Sisko: $\eta_{w} / \eta_{b}=\eta_{w, \infty} / \eta_{b}+K C a_{w}^{n-1}, \operatorname{com} K=0,09$ e $n=-1,30$. 


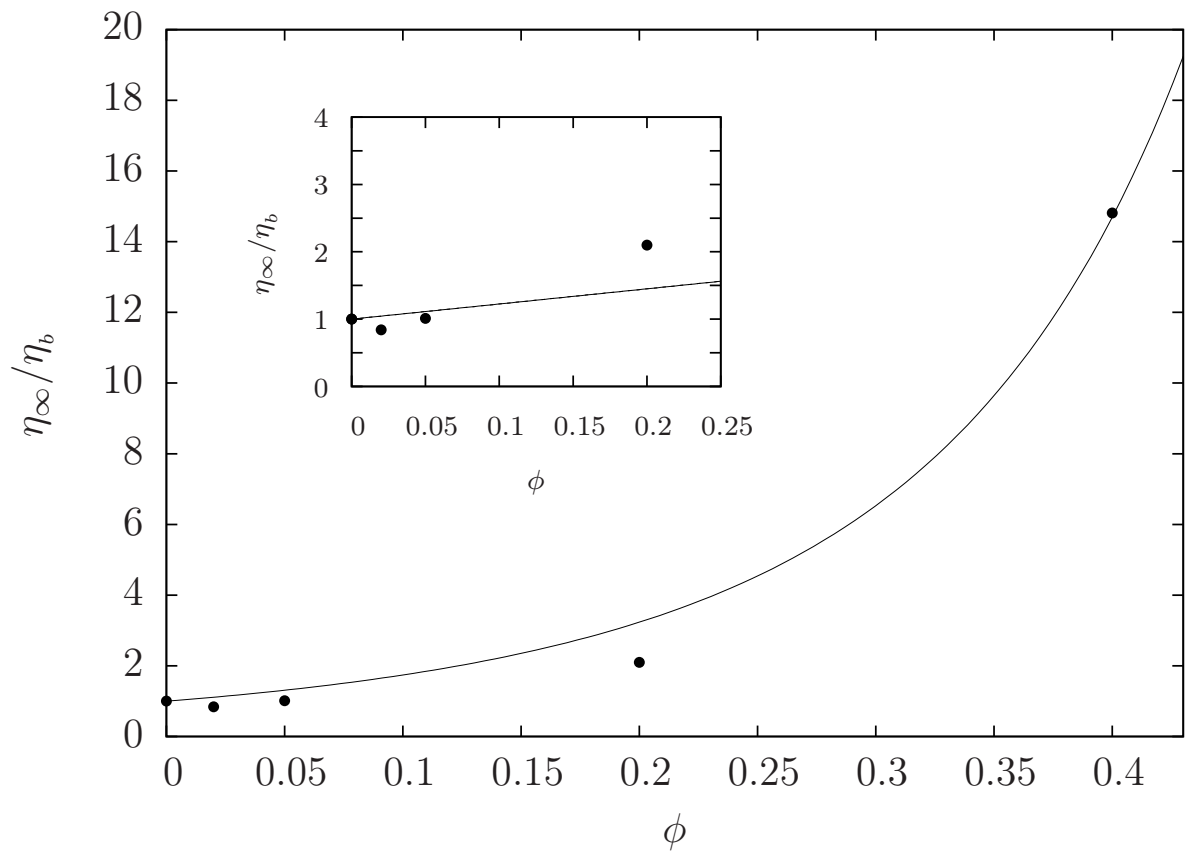

Figura 7.46: Aumento da viscosidade intrínseca com a fração volumétrica $-\eta_{\infty} / \eta_{b}=$ $(1-\phi)^{-n}$ em que $n=-5,26$. Dado experimentais para $C a_{w} \approx 6 \times 10^{-2}$ e $\lambda=5$. Encarte: - Ajuste pela expressão da viscosidade de Taylor.

\subsubsection{Ensaios da Emulsão com razão de viscosidade 10}

Aqui são apresentados os resultados experimentais das emulsões de $\lambda=10$ para $\phi=$ $2 \%, 5 \%, 20 \%$ e $40 \%$.

Em todas as frações volumétricas observa-se uma diminuição da viscosidade para os menores números de capilaridade e de seguida a saturação da viscosidade representando o alinhamento da microestrutura com a direção principal do escoamento. Observa-se que a faixa do número de capilaridade no experimento das emulsões de $\phi=5 \%$ e $10 \%$ foi menor do que nas outras razões de viscosidade. Isso reflete o menor efeito pseudoplástico das emulsões. Na emulsão de $\phi=40 \%$ o comportamento pseudo-plástico é mais evidente devido ao maior número de gotas existente na emulsão. Pela fig. 7.55 observa-se que a viscosidade aumenta com a fração volumétrica, tal como esperado. 


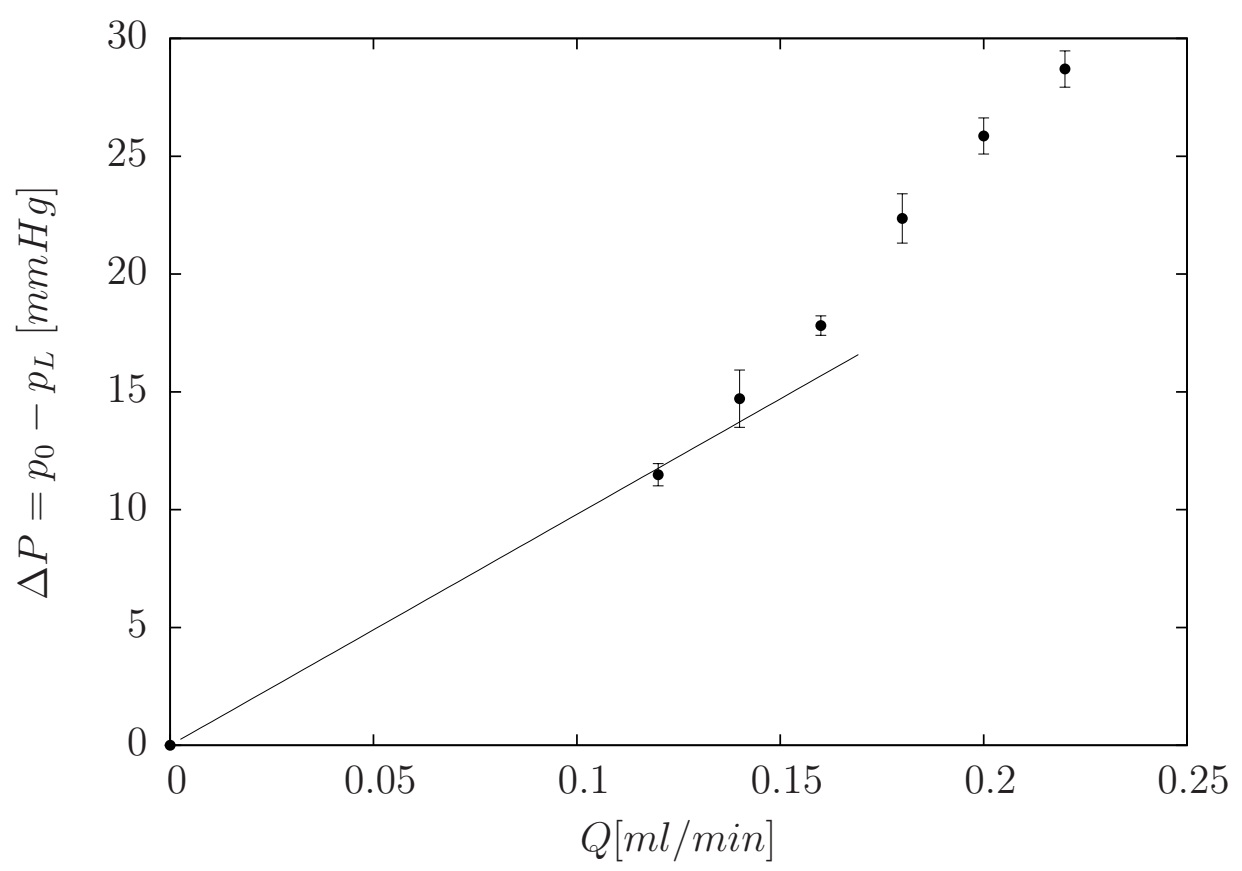

Figura 7.47: Variação da pressão em função da vazão para $\lambda=10$ e $\phi=2 \%$. • Pontos Experimentais ; - Região Linear da emulsão. A viscosidade efetiva é de 7, $6 c P$ que adimensionalizada pela viscosidade do fluido base é 0,47 .

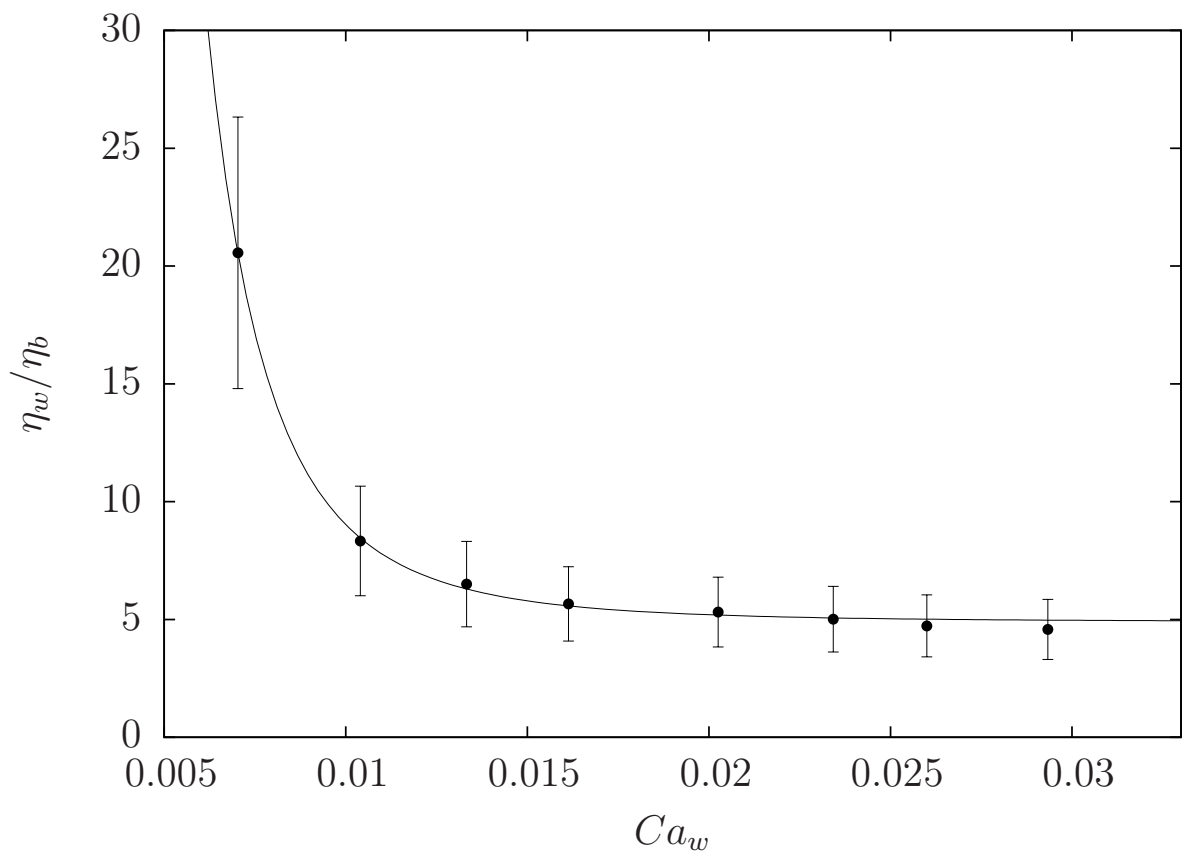

Figura 7.48: Variação da viscosidade aparente é $\eta_{w} / \eta_{b}$ com o número de capilaridade avaliado na parede $\left(C a_{w}=\left(\dot{\gamma}_{w} \eta_{w} R\right) / \tau_{s}\right)$ para $\lambda=10$ e $\phi=2 \%$ em que $\tau_{s}=0,03066 \mathrm{~N} / \mathrm{m}$. A viscosidade $\eta_{w, \infty} / \eta_{b}=4,90 \pm 0,33$. - Ajuste com modelo de Sisko: $\eta_{w} / \eta_{b}=\eta_{w, \infty} / \eta_{b}+K C a_{w}^{n-1}, \operatorname{com} K=1,12 \times 10^{-7}$ e $n=-2,78$. 


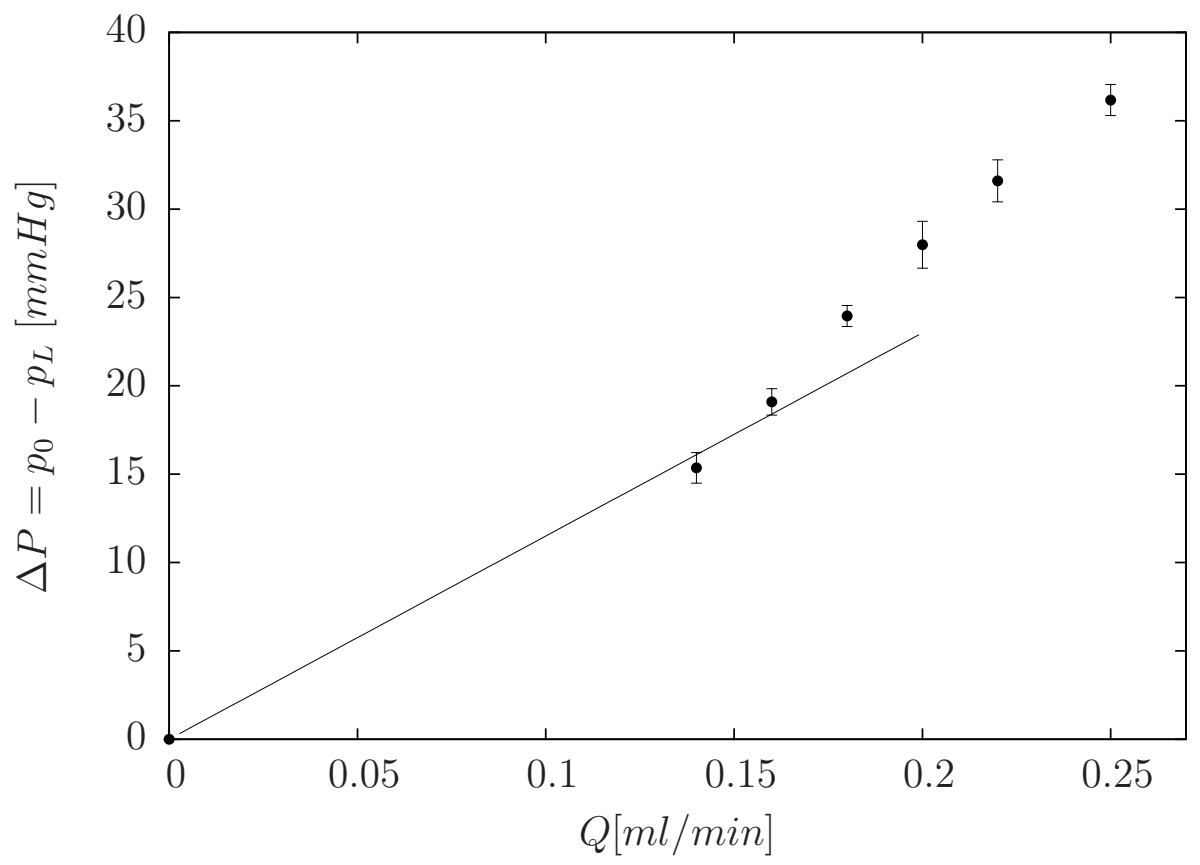

Figura 7.49: Variação da pressão em função da vazão para $\lambda=10$ e $\phi=5 \%$. • Pontos Experimentais ; - Região Linear da emulsão. A viscosidade efetiva é de $8 c P$ que adimensionalizada pela viscosidade do fluido base é 0,58 .

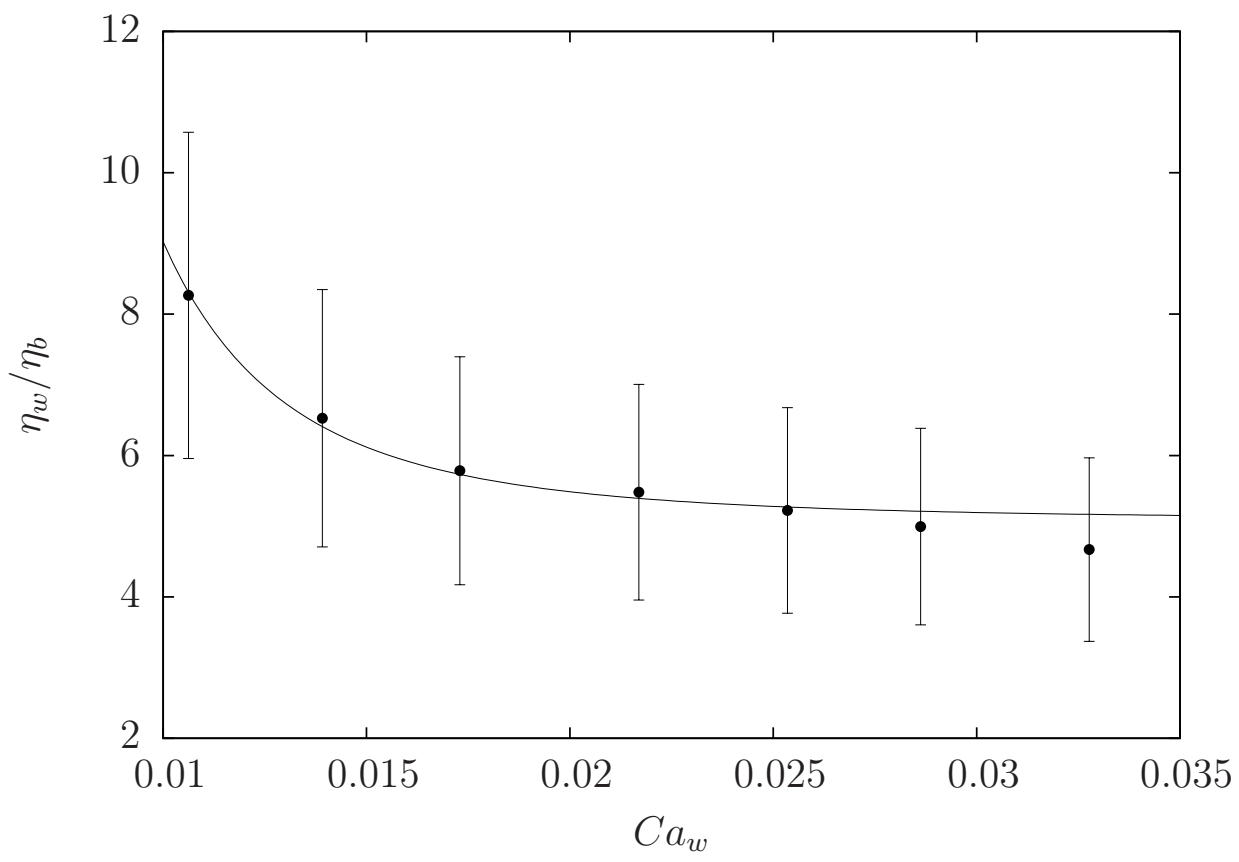

Figura 7.50: Variação da viscosidade aparente é $\eta_{w} / \eta_{b}$ com o número de capilaridade avaliado na parede $\left(C a_{w}=\left(\dot{\gamma}_{w} \eta_{w} R\right) / \tau_{s}\right)$ para $\lambda=10$ e $\phi=5 \%$ em que $\tau_{s}=0,03066 \mathrm{~N} / \mathrm{m}$. A viscosidade $\eta_{w, \infty} / \eta_{b}=5,09 \pm 0,34$. - Ajuste com modelo de Sisko: $\eta_{w} / \eta_{b}=\eta_{w, \infty} / \eta_{b}+K C a_{w}^{n-1}, \operatorname{com} K=9,54 \times 10^{-7}$ e $n=-2,31$. 


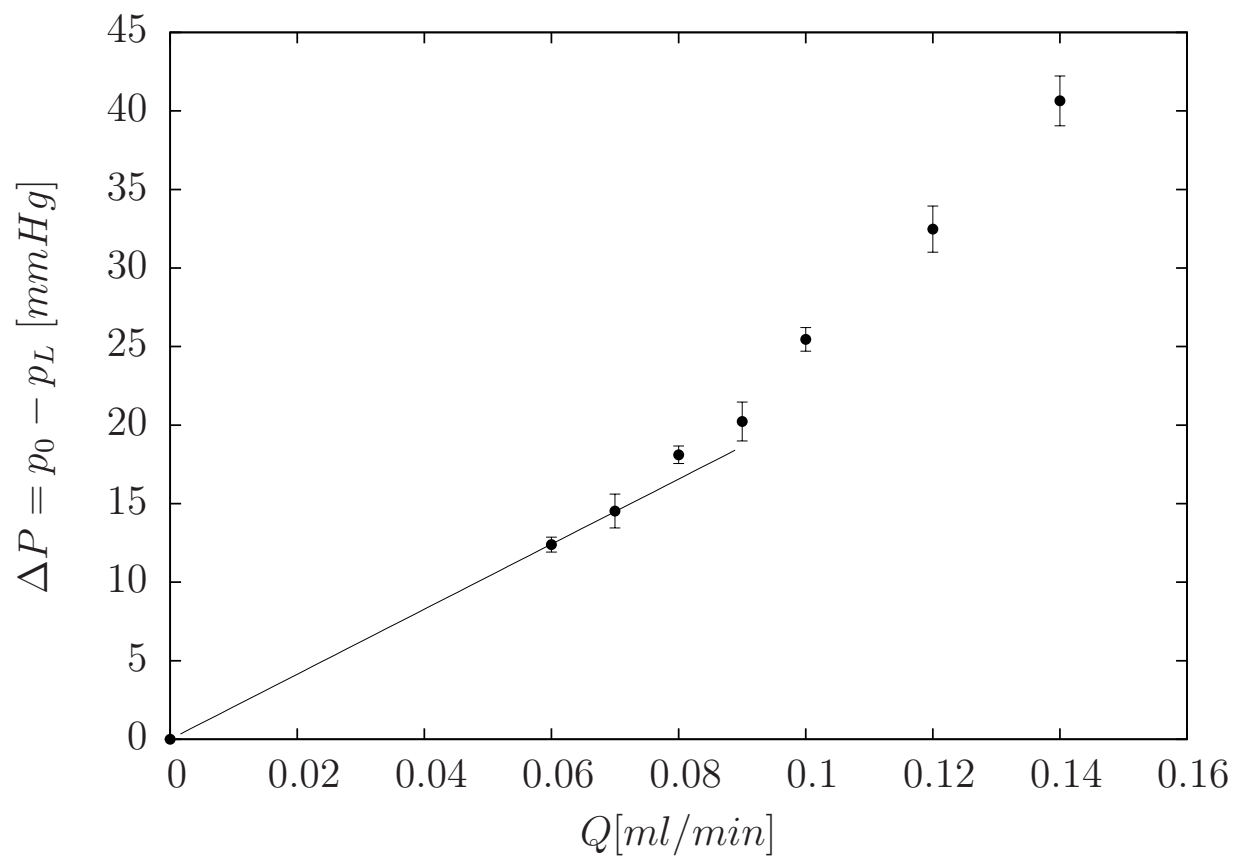

Figura 7.51: Variação da pressão em função da vazão para $\lambda=10$ e $\phi=20 \%$. Pontos Experimentais ; - Região Linear da emulsão. A viscosidade efetiva é de $16 c P$ que adimensionalizada pela viscosidade do fluido base é 1,17 .

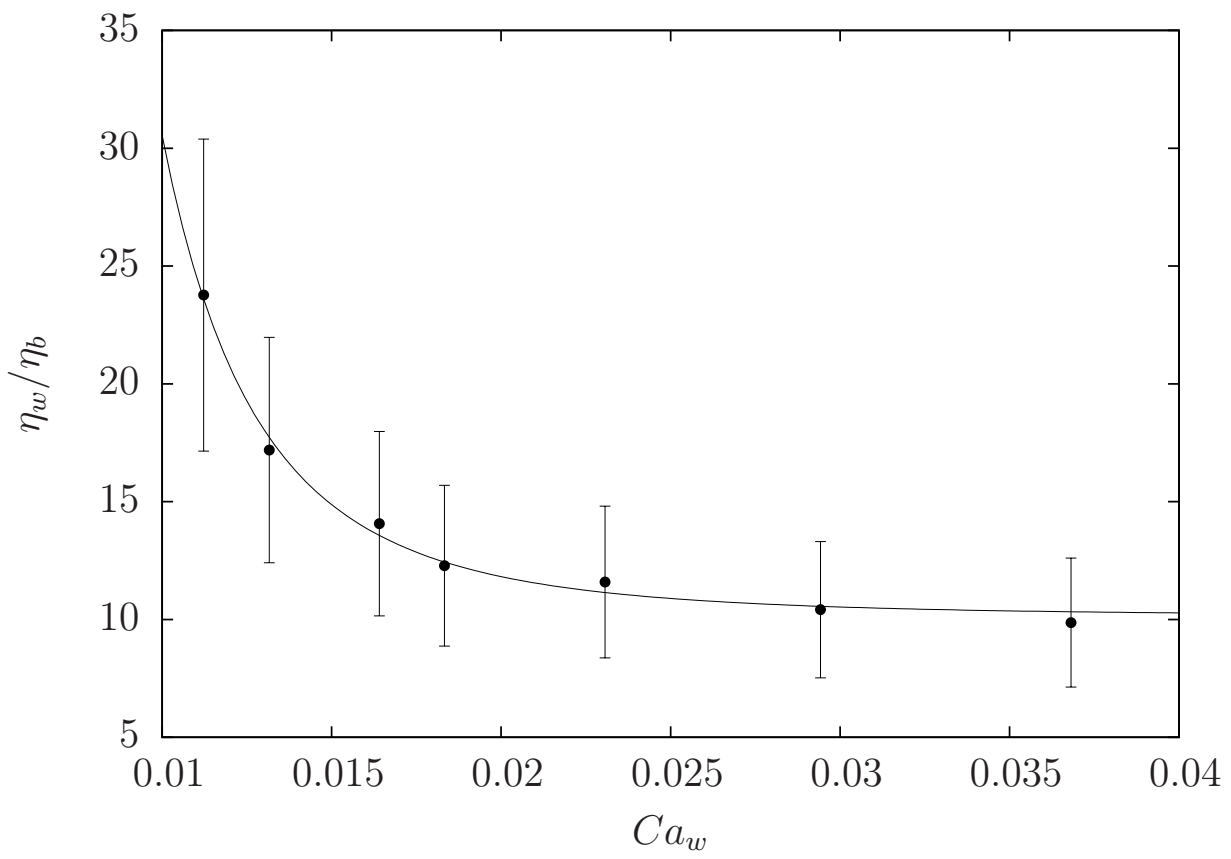

Figura 7.52: Variação da viscosidade aparente é $\eta_{w} / \eta_{b}$ com o número de capilaridade avaliado na parede $\left(C a_{w}=\left(\dot{\gamma}_{w} \eta_{w} R\right) / \tau_{s}\right)$ para $\lambda=10$ e $\phi=20 \%$ em que $\tau s=$ $0,03066 \mathrm{~N} / \mathrm{m}$. A viscosidade $\eta_{w, \infty} / \eta_{b}=10,14 \pm 0,38$. Ajuste com modelo de Sisko: $\eta_{w} / \eta_{b}=\eta_{w, \infty} / \eta_{b}+K C a_{w}^{n-1}, \operatorname{com} K=1,26 \times 10^{-6}$ e $n=-2,60$. 


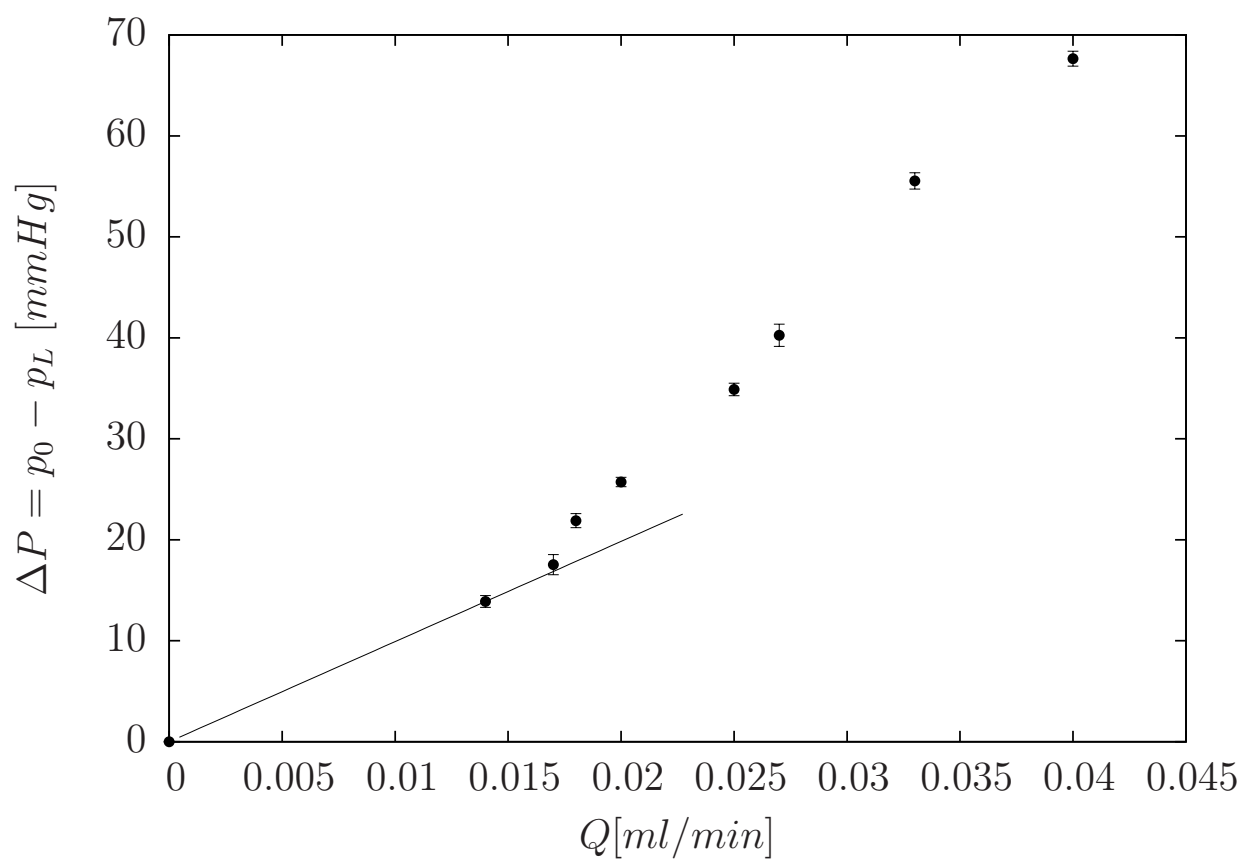

Figura 7.53: Variação da pressão em função da vazão para $\lambda=10$ e $\phi=40 \%$. • Pontos Experimentais ; - Região Linear da emulsão. A viscosidade efetiva é de 81,62 $c P$

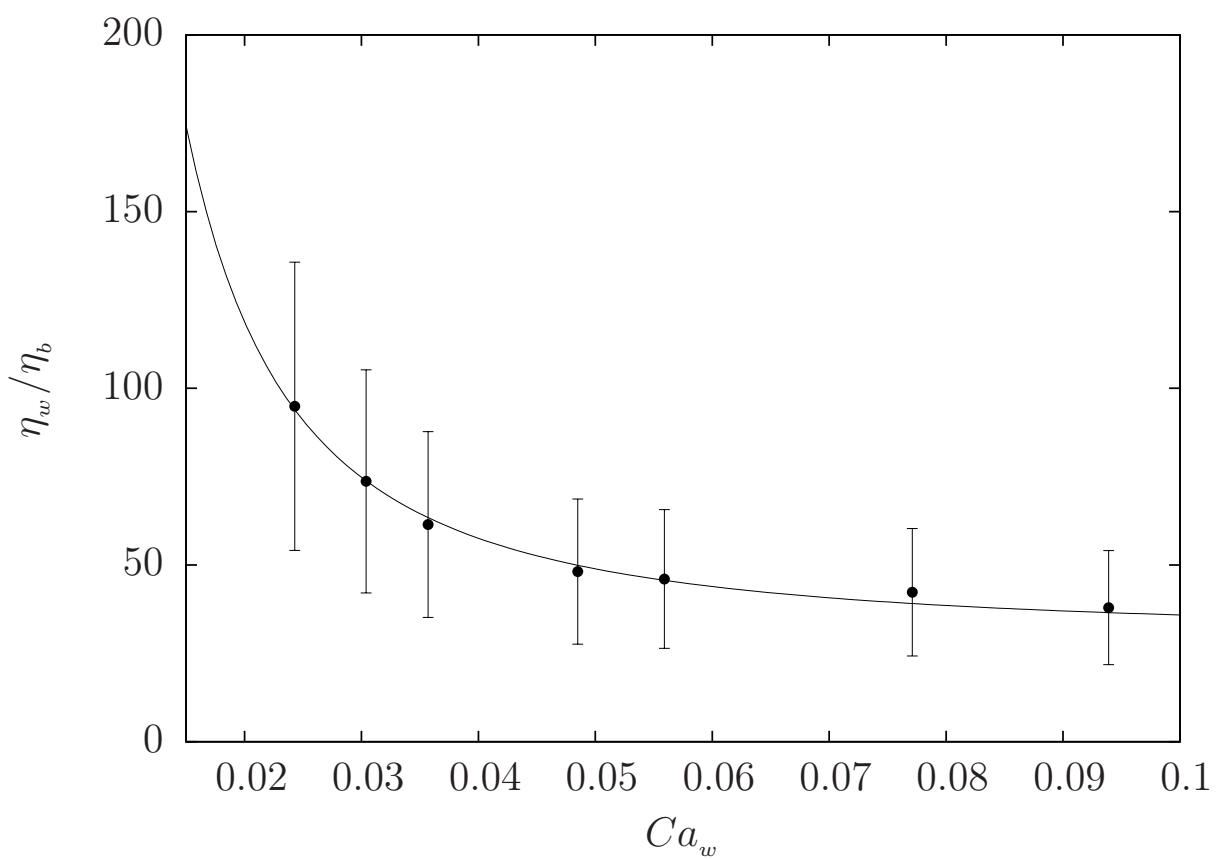

Figura 7.54: Variação da viscosidade aparente é $\eta_{w} / \eta_{b}$ com o número de capilaridade avaliado na parede $\left(C a_{w}=\left(\dot{\gamma}_{w} \eta_{w} R\right) / \tau_{s}\right)$ para $\lambda=10$ e $\phi=40 \%$ em que $\tau_{s}=$ $0,03066 \mathrm{~N} / \mathrm{m}$. A viscosidade $\eta_{w, \infty} / \eta_{b}=30,0 \pm 6,86$. - Ajuste com modelo de Sisko: $\eta_{w} / \eta_{b}=\eta_{w, \infty} / \eta_{b}+K C a_{w}^{n-1}, \operatorname{com} K=0,12$ e $n=-0,68$. 


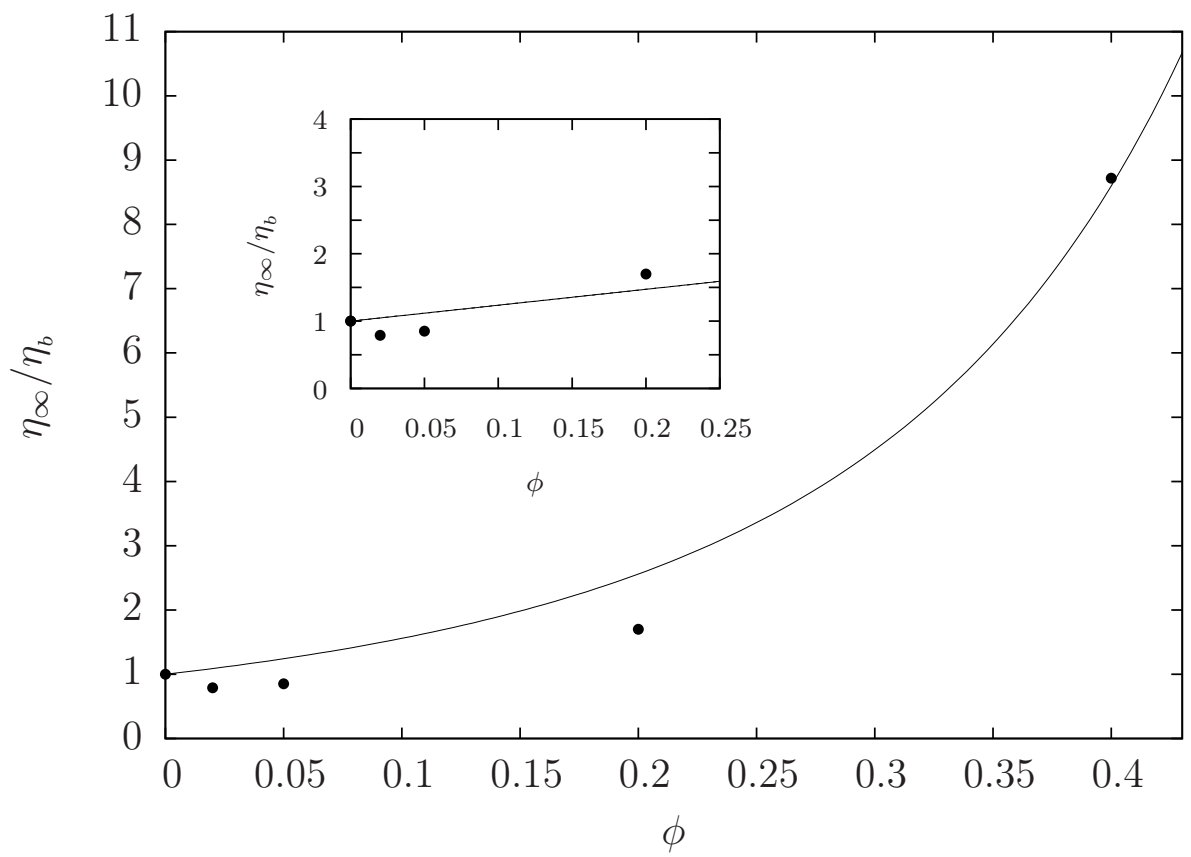

Figura 7.55: Aumento da viscosidade intrínseca com a fração volumétrica $-\eta_{\infty} / \eta_{b}=$ $(1-\phi)^{-n}$ em que $n=-4,20$. Dado experimentais para $C a_{w} \approx 3,4 \times 10^{-2}$ e $\lambda=10$. Encarte: - Ajuste pela expressão da viscosidade de Taylor.

\subsubsection{Emulsão de $\lambda=20$}

Aqui são apresentados os resultados experimentais das emulsões de $\lambda=20$ para $\phi=$ $40 \%, 20 \%, 5 \%$ e $2 \%$.

Os resultados revelam uma rápida queda da viscosidade em uma pequena variação do número de capilaridade. Tal indica que, a microestrutura se alinha rapidamente com a direção principal do escoamento. A emulsão $\phi=40 \%$ é a que apresenta um maior efeito pseudo-plástico devido à maior presença de gotas. Comparando as frações volumétricas de 5\% com 20\%, parece que a menor fração volumétrica é a que apresenta maior efeito-pseudo-plástico. No entanto, se a comparação for feita no mesmo intervalo do número de capilaridade observa-se que o efeito pseudo-plástico é maior em $\phi=20 \%$. Quanto à microestrutura, a emulsão de $\phi=20 \%$ apresenta maior polidispersidade $\mathrm{e}$ gotas de maior raio médio em comparação com a emulsão de fração volumétrica de 5\%. Pela fig. 7.64 observa-se que a viscosidade aumenta com a fração volumétrica, tal como esperado. 


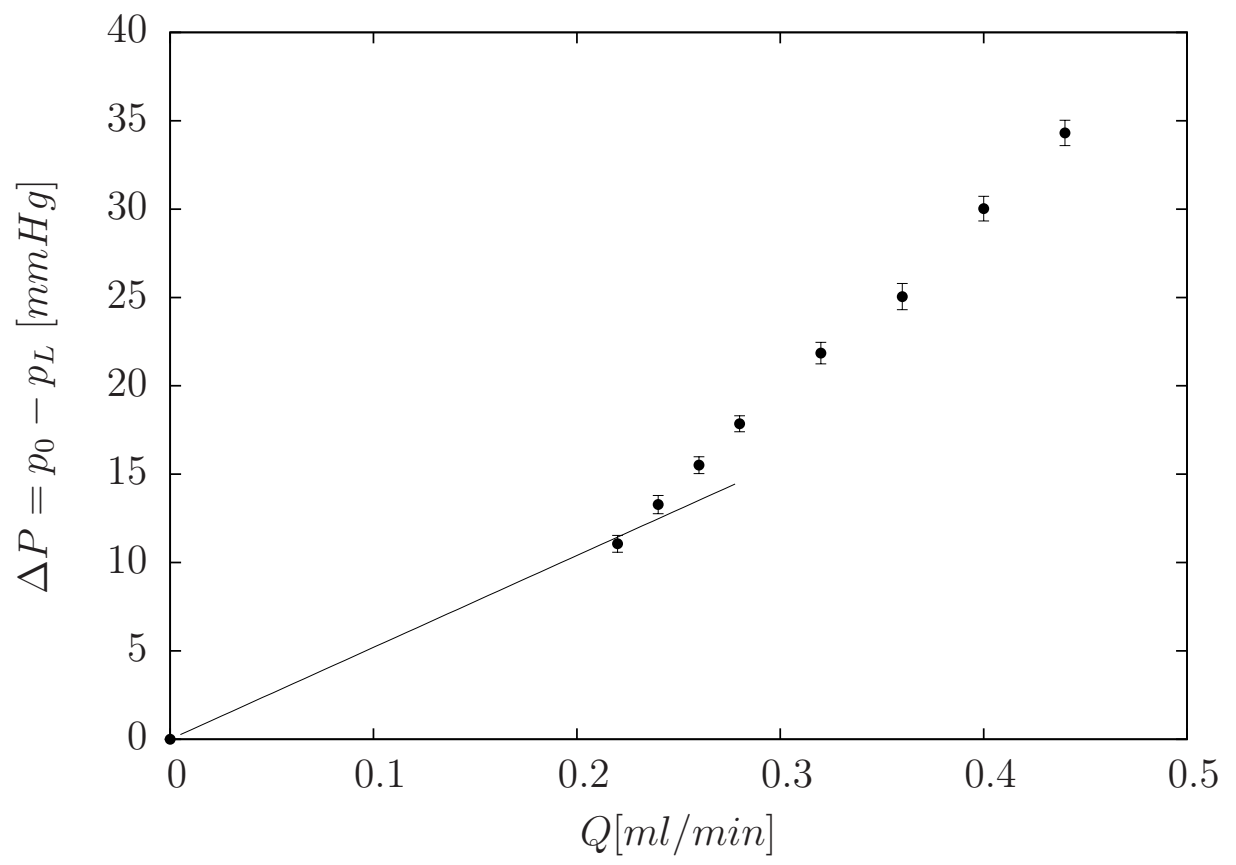

Figura 7.56: Variação da pressão em função da vazão para $\lambda=20$ e $\phi=2 \%$. • Pontos Experimentais ; - Região Linear da emulsão. A viscosidade efetiva é de $3,5 c P$ que adimensionalizada pela viscosidade do fluido base é 0,47 .

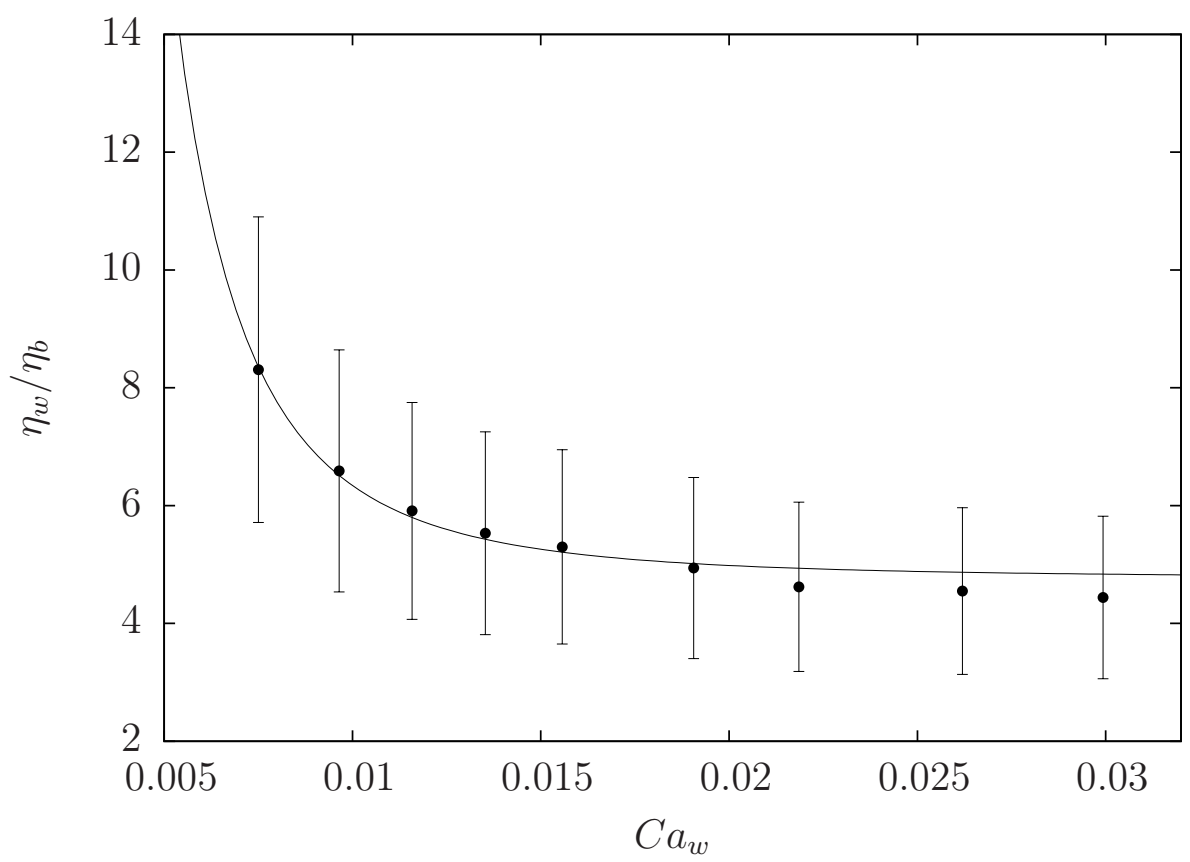

Figura 7.57: Variação da viscosidade aparente é $\eta_{w} / \eta_{b}$ com o número de capilaridade avaliado na parede $\left(C a_{w}=\left(\dot{\gamma}_{w} \eta_{w} R\right) / \tau_{s}\right)$ para $\lambda=20$ e $\phi=2 \%$ em que $\tau_{s}=0,03184 \mathrm{~N} / \mathrm{m}$. A viscosidade $\eta_{w, \infty} / \eta_{b}=4,77 \pm 0,33$. - Ajuste com modelo de Sisko: $\eta_{w} / \eta_{b}=\eta_{w, \infty} / \eta_{b}+K C a_{w}^{n-1}, \operatorname{com} K=2,77 \times 10^{-6}$ e $n=-1,88$. 


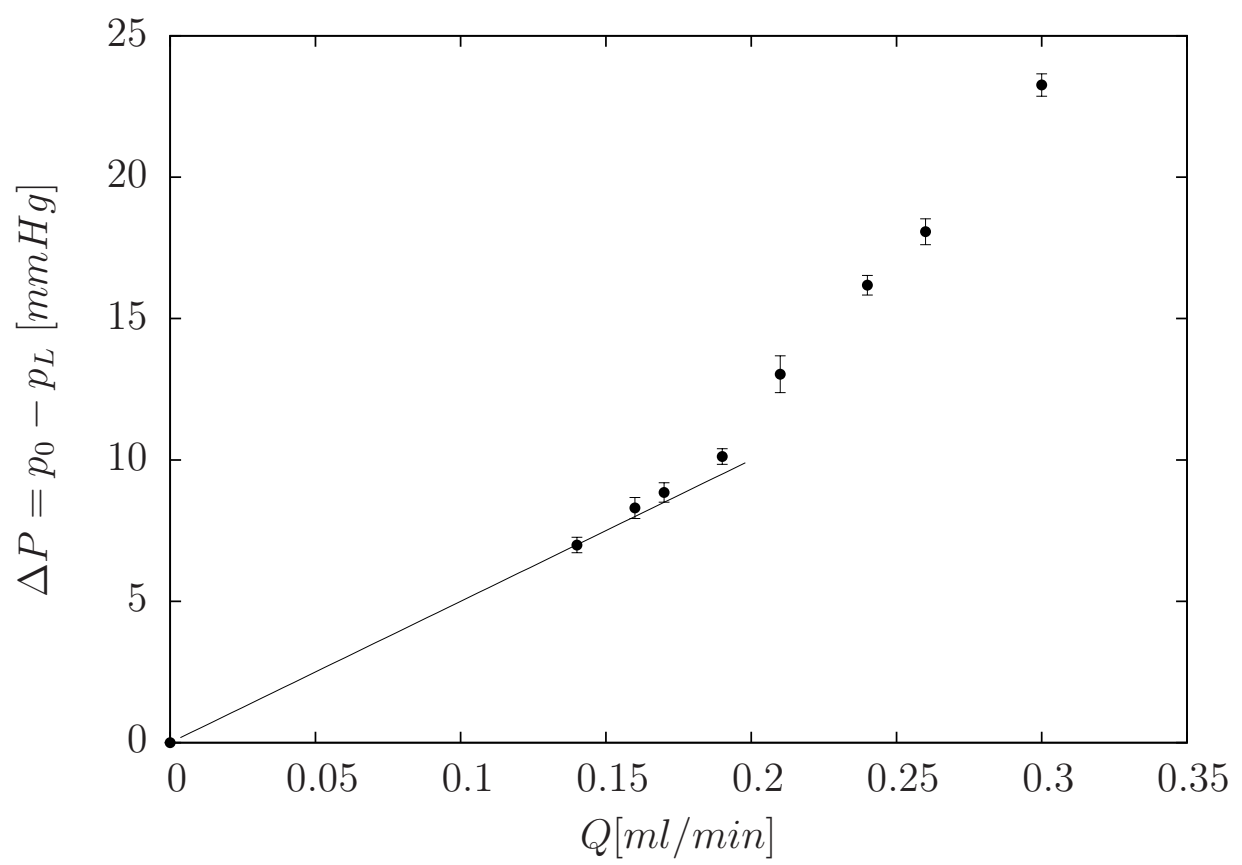

Figura 7.58: Variação da pressão em função da vazão para $\lambda=20$ e $\phi=5 \%$. • Pontos Experimentais ; - Região Linear da emulsão. A viscosidade efetiva é de $4,1 c P$ que adimensionalizada pela viscosidade do fluido base é 0,55 .

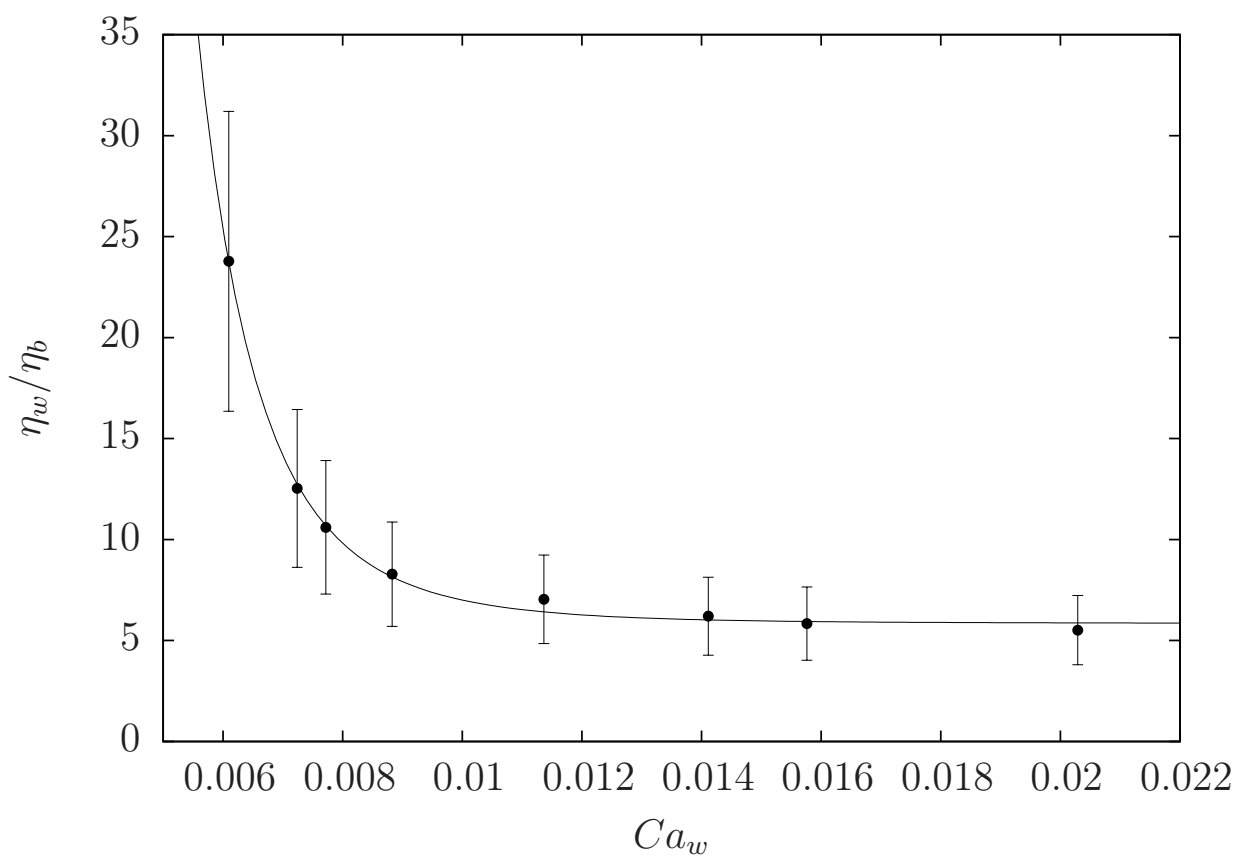

Figura 7.59: Variação da viscosidade aparente é $\eta_{w} / \eta_{b}$ com o número de capilaridade avaliado na parede $\left(C a_{w}=\left(\dot{\gamma}_{w} \eta_{w} R\right) / \tau_{s}\right)$ para $\lambda=20$ e $\phi=5 \%$ em que $\tau_{s}=0,03184 \mathrm{~N} / \mathrm{m}$. A viscosidade $\left.\eta_{w, \infty} / \eta_{b}\right)_{\infty}=5,85 \pm 0,65$. Ajuste com modelo de Sisko: $\eta_{w} / \eta_{b}=\left(\eta_{w} / \eta_{b}\right)_{\infty}+K C a_{w}^{n-1}$, com $K=9,61 \times 10^{-12}$ e $n=-4,54$. 


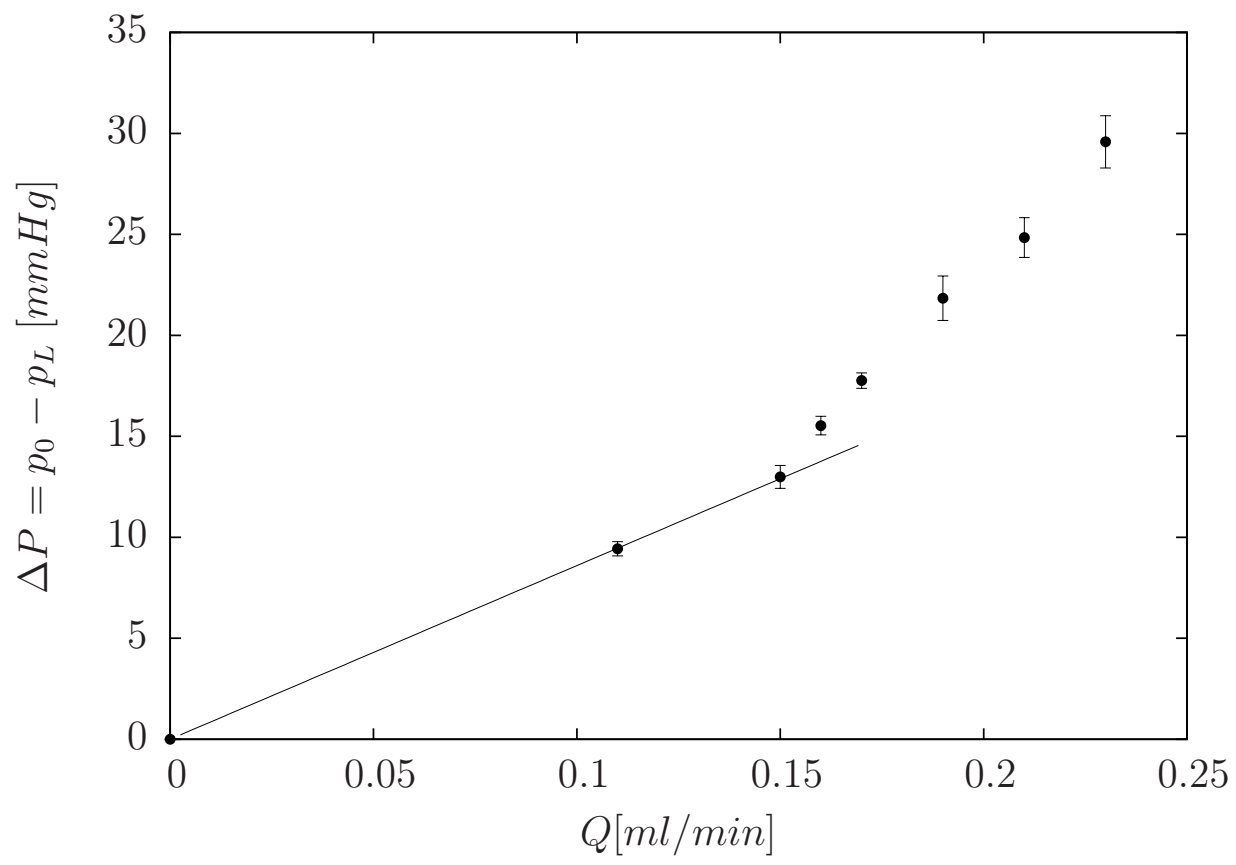

Figura 7.60: Variação da pressão em função da vazão para $\lambda=20$ e $\phi=20 \%$. Pontos Experimentais ; - Região Linear da emulsão. A viscosidade efetiva é de $7 c P$ que adimensionalizada pela viscosidade do fluido base é 0,94 .

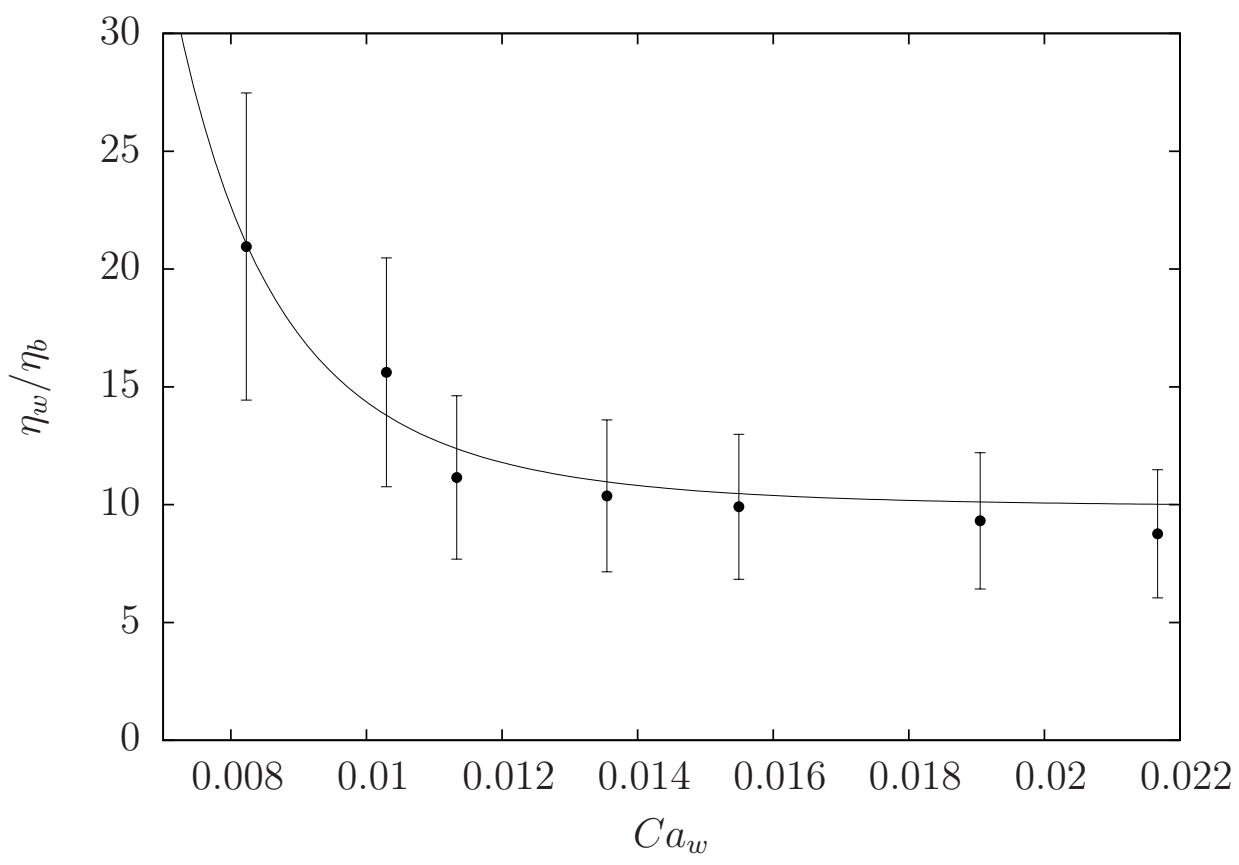

Figura 7.61: Variação da viscosidade aparente é $\eta_{w} / \eta_{b}$ com o número de capilaridade avaliado na parede $\left(C a_{w}=\left(\dot{\gamma}_{w} \eta_{w} R\right) / \tau_{s}\right)$ para $\lambda=20$ e $\phi=20 \%$ em que $\tau_{s}=$ $0,03184 \mathrm{~N} / \mathrm{m}$. A viscosidade $\eta_{w, \infty} / \eta_{b}=9,90 \pm 1,09$. Ajuste com modelo de Sisko: $\eta_{w} / \eta_{b}=\eta_{w, \infty} / \eta_{b}+K C a_{w}^{n-1}, \operatorname{com} K=1,69 \times 10^{-9}$ e $n=-3,71$. 


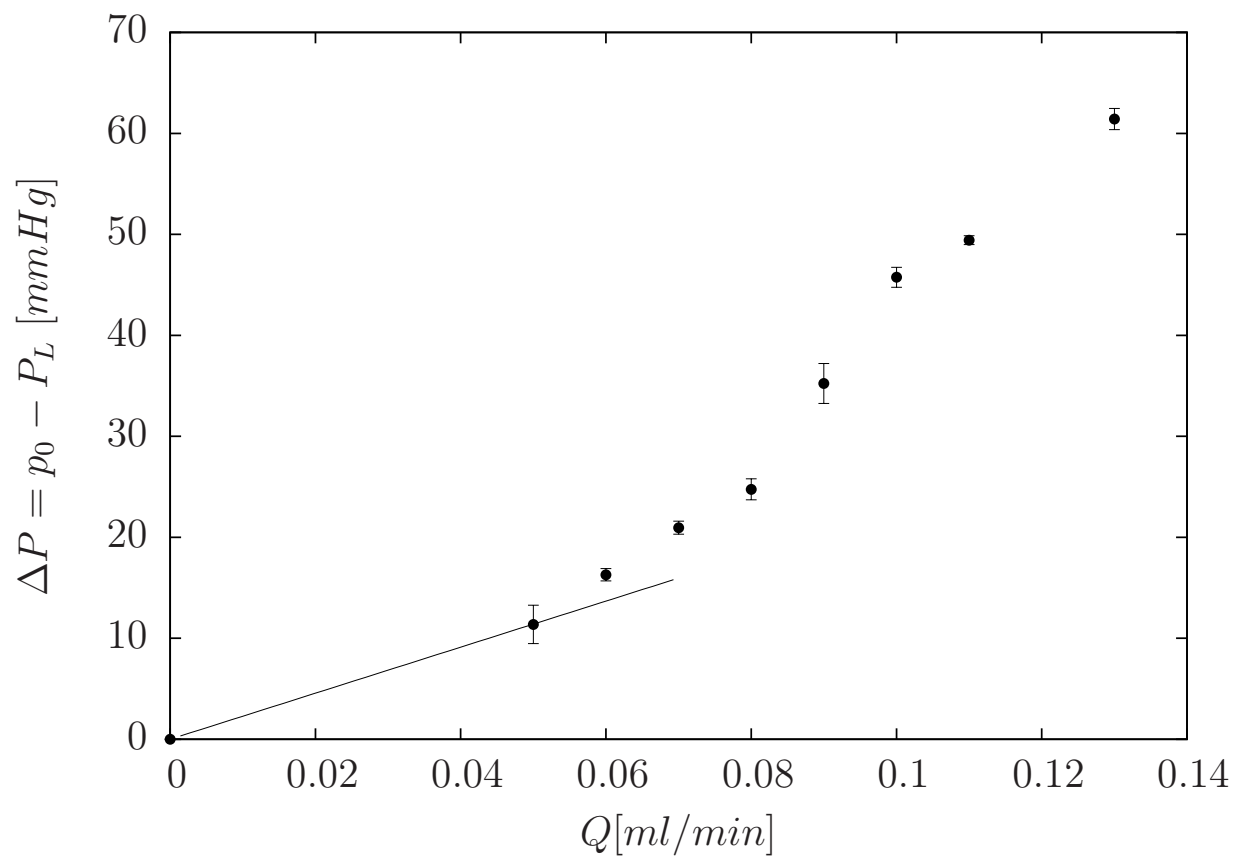

Figura 7.62: Variação da pressão em função da vazão para $\lambda=20$ e $\phi=40 \%$. Pontos Experimentais ; - Região Linear da emulsão. A viscosidade efetiva é de $19 c P$ que adimensionalizada pela viscosidade do fluido base é 2,54 .

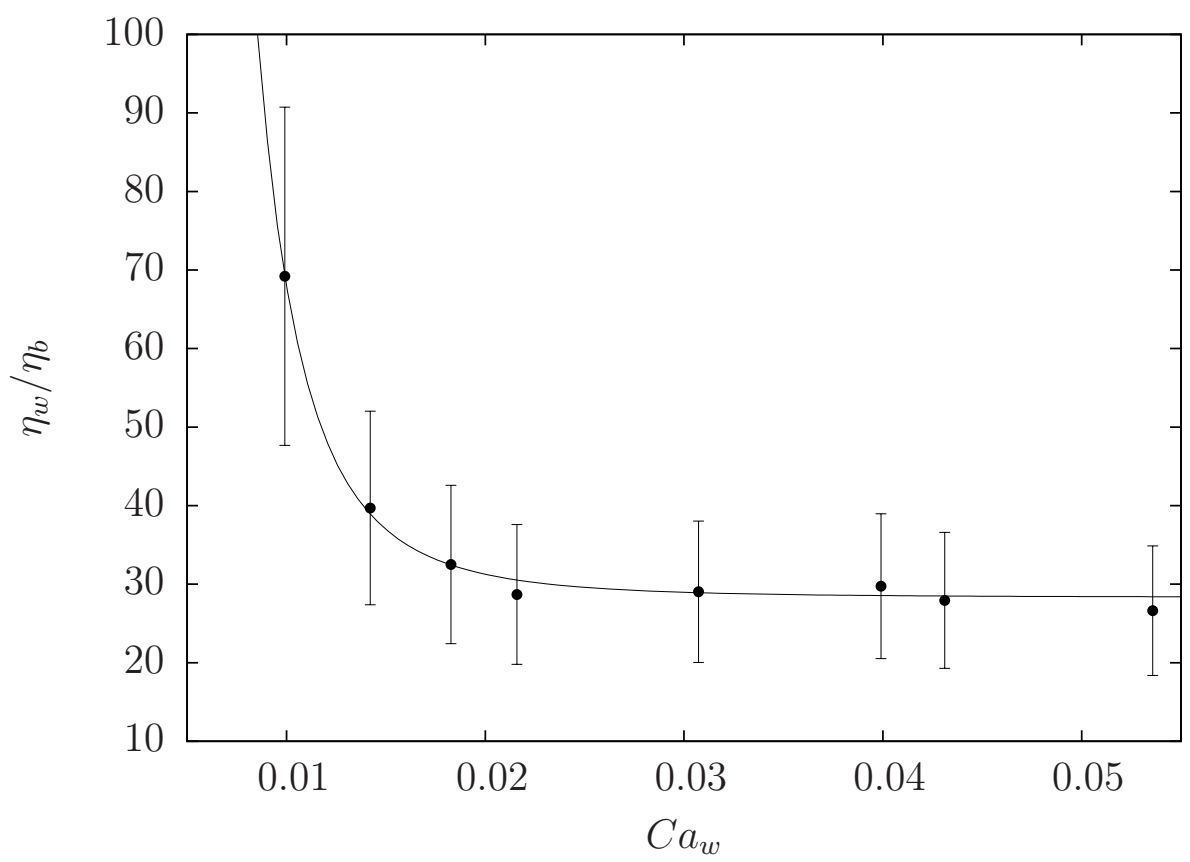

Figura 7.63: Variação da viscosidade aparente é $\eta_{w} / \eta_{b}$ com o número de capilaridade avaliado na parede $\left(C a_{w}=\left(\dot{\gamma}_{w} \eta_{w} R\right) / \tau_{s}\right)$ para $\lambda=20$ e $\phi=40 \%$ em que $\tau_{s}=$ $0,03184 \mathrm{~N} / \mathrm{m} \mathrm{m}$. A viscosidade $\eta_{w, \infty} / \eta_{b}=28,33 \pm 1,36$. - Ajuste com modelo de Sisko: $\eta_{w} / \eta_{b}=\eta_{w, \infty} / \eta_{b}+K C a_{w}^{n-1}, \operatorname{com} K=1,20 \times 10^{-6}$ e $n=-2,76$. 


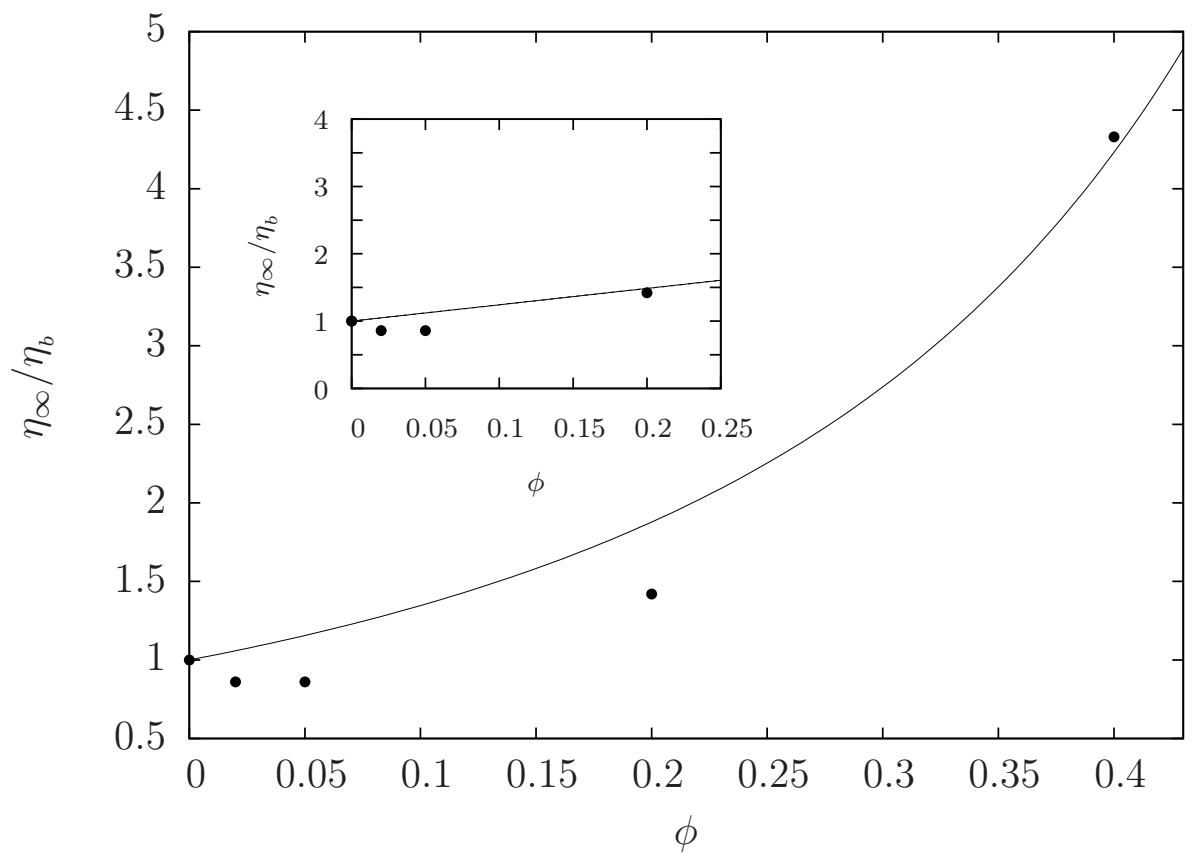

Figura 7.64: Aumento da viscosidade intrínseca com a fração volumétrica $-\eta_{\infty} / \eta_{b}=$ $(1-\phi)^{-n}$ em que $n=-2,82$. Dado experimentais para $C a_{w} \approx 3 \times 10^{-2}$ e $\lambda=20$. Encarte: - Ajuste pela expressão da viscosidade de Taylor.

Em resumo, os resultados experimentais de cisalhamento quadrático de emulsões de diferentes razões de viscosidade e frações volumétricas apresentaram uma queda de viscosidade com o da diferença de pressão. Os resultados mostraram uma rápida queda da viscosidade com o aumento do número de capilaridade, refletindo a presença do efeito pseudo-plástico. Observou-se que com o aumento da razão de viscosidade o alinhamento dos pontos do grafico de $\Delta P$ vs $Q$ é maior. Esse fato pode ser devido a uma menor deformação das gotas. Verificou-se que a viscosidade efetiva aumentou com a fração volumétrica mas diminuiu com a razão de viscosidade. Foi observado que a viscosidade $\eta_{w} / \eta_{b}$ aumentou com a fração volumétrica devido a um maior efeito hidrodinâmico gota-gota adicionado ao efeito ainda maior entre gota e escoamento. Relacionou-se o efeito pseudo-plástico com o tamanho médio das gotas e foi notado uma tendência da diminuição do efeito pseudo-plástico com a maior porcentagem de gotas de menor tamanho presente na microestrutura.

A tab. 7.9 expressa a variação da viscosidade aparente em altos números de capilaridade $\left(\eta_{\infty}\right)$ adimensionalizada pela viscosidade do fluido base $\left(\eta_{b}\right)$ para cada razão de viscosidade e fração volumétrica. Observa-se que para cada razão de viscosidade a 
viscosidade $\eta_{\infty} / \eta_{b}$ aumenta com a fração volumétrica, isso devido à maior quantidade de gotas adicionado com a interação entre gotas e com um efeito de maior intensidade entre gota e escoamento. Para a maior fração volumétrica existe a tendência de a viscosidade aumentar com o aumento da razão de viscosidade. No entanto para $\lambda=20$ e $\phi=40 \%$ a viscosidade $\eta_{\infty} / \eta_{b}$ foi menor que o esperado. Para $\phi<40 \%$ a viscosidade $\eta_{\infty} / \eta_{b}$ não apresentou alterações significativas com o aumento da razão de viscosidade. Para $\phi=2 \%$ e $5 \%$, ou seja, para baixas frações volumétricas, a intensidade de interação entre gotas é baixa. Mais ainda, com o aumento da razão de viscosidade menores são as deformações provocadas pelo escoamento. Para $\phi=20 \%$ não foi detectada alterações significativas na viscosidade $\eta_{\infty} / \eta_{b}$ tal como ocorreu no escoamento de cisalhamento simples. A tab. 7.10 mostra que a viscosidade do fluido base, que aumenta com a diminuição da razão de viscosidade, afeta de forma direta a viscosidade da emulsão.

Tabela 7.9: Variação da viscosidade aparente em altos números de capilaridade adimensionalizada pela viscosidade do fluido base em função da fração volumétrica e da razão de viscosidade

\begin{tabular}{|c|c|c|c|c|}
\hline$\lambda$ & $\phi=2 \%$ & $\phi=5 \%$ & $\phi=20 \%$ & $\phi=40 \%$ \\
\hline 20 & 4,77 & 5,85 & 9,90 & 28,33 \\
10 & 4,90 & 5,09 & 10,14 & 66,80 \\
5 & 5,80 & 5,57 & 10,00 & 55,00 \\
2 & 5,44 & 5,81 & 9,43 & 24,76 \\
\hline
\end{tabular}

Tabela 7.10: Variação da viscosidade aparente em altos números de capilaridade em função da fração volumétrica e da razão de viscosidade

\begin{tabular}{|c|c|c|c|c|}
\hline$\lambda$ & $\phi=2 \%$ & $\phi=5 \%$ & $\phi=20 \%$ & $\phi=40 \%$ \\
\hline 20 & 35,25 & 43,23 & 73,16 & 209 \\
10 & 68,55 & 71,21 & 141,86 & 934 \\
5 & 162,8 & 156,35 & 280,71 & 1543 \\
2 & 371,78 & 397 & 644 & 1692 \\
\hline
\end{tabular}




\subsection{Comparação entre a Viscosidade da Parede e a Viscosidade Intrínseca}

Em geral a viscosidade em tubo capilar é apurada através da Lei de Poiseuille, resultando em uma viscosidade denominada por intrínseca ou efetiva $\left(\eta_{p}\right)$. No entanto a Lei de Poiseuille não leva em consideração a existência de efeitos não-Newtonianos. Por outro lado, a viscosidade pode ser calculada pela razão entre a eq. 2.56 e a eq. 2.62 resultando em uma viscosidade avaliada na parede do capilar $\left(\eta_{w}\right)$. A tab. 7.11 mostra a diferença entre essas duas viscosidades, juntamente com a viscosidade calculada pela expressão de Taylor $\left(\eta_{T}\right)$. Os resultados mostram o erro obtido quando se assume que a viscosidade de Poiseuille é a viscosidade da emulsão quando esta escoa em tubo capilar. Observa-se também que a viscosidade de Taylor é idêntica à viscosidade de Poiseuille. Para a fração de $40 \%$ existe diferença entre estas duas viscosidades uma vez que a viscosidade de Taylor é obtida para emulsões de baixa fração volumétrica e em baixo número de capilaridade. Como é esperado observa-se um aumento da viscosidade de Taylor e de Poiseuille adimensional com o aumento da fração volumétrica. Era de se esperar que a viscosidade $\eta_{w}$ aumenta-se com a razão de viscosidade em virtude do aumento da razão de viscosidade. O aumento da razão de viscosidade faz com que a deformação das gotas seja menor. Nas emulsões sintetizadas o aumento da razão de viscosidade significa uma diminuição da viscosidade do fluido base. A viscosidade do fluido base é um dos parâmetros que influência a reologia de emulsões. No entanto, nos maiores números de capilaridade foi verificada uma tendêncida de a viscosidade $\eta_{\infty} / \eta_{b}$ aumentar com a razão de viscosidade (ver tab. 7.9). 
Tabela 7.11: Comparação entre a viscosidade da parede, intrínseca e de Taylor adimensionalizada pela viscosiade do fluido base, para diferentes emulsões de $\mathrm{O} / \mathrm{A}$ em cisalhamento quadrático.

\begin{tabular}{|c|c|c|c|c|}
\hline \multicolumn{5}{|c|}{$\phi=2 \%$} \\
\hline$\lambda$ & $C a_{w}$ & $\eta_{w} / \eta_{b}$ & $\eta_{p} / \eta_{b}$ & $\eta_{T}$ \\
\hline 2 & 0,018 & 9,2 & 0,61 & 1,04 \\
\hline 5 & 0,018 & 7,0 & 0,68 & 1,045 \\
\hline 10 & 0,018 & 5,7 & 0,65 & 1,047 \\
\hline 20 & 0,016 & 5,3 & 0,71 & 1,048 \\
\hline \multicolumn{5}{|c|}{$\phi=5 \%$} \\
\hline$\lambda$ & $C a_{w}$ & $\eta_{w} / \eta_{b}$ & $\eta_{p} / \eta_{b}$ & $\eta_{T}$ \\
\hline 2 & 0,016 & 15,0 & 0,69 & 1,100 \\
\hline 5 & 0,017 & 9,0 & 1,04 & 1,112 \\
\hline 10 & 0,017 & 5,8 & 0,70 & 1,118 \\
\hline 20 & 0,016 & 5,8 & 0,77 & 1,121 \\
\hline \multicolumn{5}{|c|}{$\phi=20 \%$} \\
\hline$\lambda$ & $C a_{w}$ & $\eta_{w} / \eta_{b}$ & $\eta_{p} / \eta_{b}$ & $\eta_{T}$ \\
\hline 2 & 0,017 & 27,1 & 1,16 & 1,40 \\
\hline 5 & 0,017 & 18,3 & 1,34 & 1,45 \\
\hline 10 & 0,018 & 12,3 & 1,31 & 1,47 \\
\hline 20 & 0,019 & 9,3 & 1,27 & 1,49 \\
\hline \multicolumn{5}{|c|}{$\phi=40 \%$} \\
\hline$\lambda$ & $C a_{w}$ & $\eta_{w} / \eta_{b}$ & $\eta_{p} / \eta_{b}$ & $\eta_{T}$ \\
\hline 2 & 0,052 & 26,6 & 3,47 & 1,80 \\
\hline 5 & 0,072 & 90,6 & 13,80 & 1,90 \\
\hline 10 & 0,050 & 64,8 & 9,84 & 1,94 \\
\hline 20 & 0,053 & 25,7 & 5,23 & 1,97 \\
\hline \multicolumn{5}{|c|}{}
\end{tabular}

\subsection{Conclusões: Microestrutura e Cisalhamento}

Da análise da microestrutura verificou-se que as emulsões sintetizadas foram caracterizadas como polidispersas e com tamanho de gota não coloidal. Da análise dos resultados observou-se por comparação, entre os resultados dos experimentos em tubo capilar, que as emulsões que apresentaram um menor efeito pseudo-plástico tem uma microestrutura com um número maior de gotas de menor tamanho. Da análise microestrutural verificou-se que a polidispersidade variou entre $0,44(\lambda=10, \phi=5 \%)$ e $0,27(\lambda=5, \phi=20 \% ; \lambda=20, \phi=2, \phi=5 \%)$. No geral, as emulsões com gotas de maior diâmetro foram as de $\lambda=10$ e $\lambda=20$. A emulsão $\phi=2 \%$ e $\lambda=20$ apresentou uma maior porcentagem de gotas dentro do intervalo de $15<d<55 \mu \mathrm{m}$ $(95 \%)$. Para $\phi=5 \%$ as emulsões com maior porcentagem de tamanho de gotas no 
intervalo $12<d<40 \mu \mathrm{m}$ foram $\lambda=2$ e 5 . Para $\phi=20 \%$ as emulsões com maior porcentagem de tamanho de gotas no intervalo $5<d<40 \mu \mathrm{m}$ foram $\lambda=2$ e 5 . Para $\phi=40 \%$ a emulsão de $\lambda=5$ apresenta a maior porcentagem de gotas no intervalo $5<d<40 \mu m(\approx 100 \%)$.

Em todos os experimentos detectou-se um aumento da viscosidade da emulsão com o aumento da viscosidade do fluido base independentemente da razão de viscosidade e da fração volumétrica. Observou-se que, para as emulsões de maior fração volumétrica a tendência de a viscosidade efetiva adimensionalizada pela viscosidade do fluido aumentar com o aumento da razão de viscosidade (ver fig. 7.28 e tab. 7.9). Nas emulsões de menor razão de viscosidade o escoamento desenvolvido no interior da gota devido às tensões tangenciais oriundas do cisalhamento do escoamento externo resultam em uma redução da distorção do escoamento externo. Esse comportamento resulta em uma menor dissipação de energia, diminuindo a viscosidade da emulsão com a diminuição da razão de viscosidade (Otsubo e Prud'homme (1994)). Isso está de acordo com a teoria que relaciona o aumento da viscosidade com a menor deformação da superfície das gotas.

Dos resultados obtidos do cisalhamento linear conclui-se que o efeito não-Newtoniano aparece em emulsões com fração volumétrica superior a 20\%. Isto significa que para altas razões de viscosidade mesmo em fração volumétrica aparentemente alta a emulsão pode ser considerada diluída tendo em vista que o movimento das gotas vizinhas não influencia a deformação da gota teste. Para a mesma razão de viscosidade, a viscosidade aparente das emulsões que apresentaram efeito Newtoniano diminui com o aumento da diluição. Tal era esperado uma vez que a diluição faz com que menos gotas estejam presentes na emulsão.

Pelos experimentos de escoamento quadrático observou-se uma queda acentuada da viscosidade em baixos números de capilaridade seguido de uma saturação da viscosidade. Nas maiores razões de viscosidade, a saturação da viscosidade pode ser uma indicação do alinhamento da microestrutura na direção do escoamento. A saturação da viscosidade é identificada nos gráficos $\Delta P \operatorname{com} Q$ pelo alinhamento dos pontos experimentais em altas vazões. A variação da viscosidade é detectada pelo desvio dos 
pontos da recta que passa na origem e pelos pontos experimentais em baixas vazões.

As comparações entre o escoamento linear e o quadrático são feitas contrapondo a viscosidade para os mesmos números de capilaridade (ver tabs. 7.12 e 7.14). Observou-se que para os mesmos número de capilaridade a viscosidade avaliada pelo escoamento no interior do tubo capilar $\left(\eta_{w}\right)$ foi maior em relação ao escoamento de cisalhamento simples. É de notar que no escoamento quadrático existe um gradiente de taxa de cisalhamento crescente do centro para a parede do tubo. Esse gradiente gera diferentes deformações das gotas que por sua vez promovem alterações na configuração da microestrutura na direção normal à parede. Devido às altas taxas de cisalhamento na região de parede as gotas das emulsões de baixas razões de viscosidade tendem a apresentarem maiores deformações.

A tab. 7.12 permite comparar a viscosidade em função da razão de viscosidade e da fração volumétrica para números de capilaridade idênticos respeitante ao experimento de cisalhamento linear. Pelos resultados observa-se que a viscosidade aumenta com o aumento da fração volumétrica (maior número de gotas) e com a diminuição da razão de viscosidade (aumento da porcentagem de glicerina no fluido base). A tab. 7.13 apresenta uma indicação que a viscosidade adimensional aumenta com o aumento da razão de viscosidade, devido à menor deformação das gotas.

A tab. 7.14 permite comparar a viscosidade em função da razão de viscosidade e da fração volumétrica para números de capilaridade idênticos respeitante ao experimento de cisalhamento quadrático. Dos resultados obtidos verifica-se que para a mesma fração volumétrica a viscosidade aumenta com a diminuição da razão de viscosidade devido ao fluido base ser mais viscoso (maior porcentagem de glicerina no fluido base). Observase que para $\phi=40 \%$ a viscosidade de $\lambda=2$ foi inferior a $\lambda=5$. Isso é devido a que a viscosidade para $\lambda=2$ foi avaliada na região do platô Newtoniano de cisalhamento máximo enquanto que para $\lambda=5$ a viscosidade corresponde à região de menor cisalhamento. Na tab. 7.15 obtém-se as mesmas conclusões mas em relação a quantidades adimensionais. No entanto, não se verificou um aumento da viscosidade relativa com o aumento da razão de viscosidade. Contudo na tab. 7.9 esse aumento foi verificado para $\phi=40 \%$. A diferença entre os dois resultados é que na tab. 7.9 os valores da 
viscosidade foram retirados nas maiores intensidades de escoamento.

Tabela 7.12: Comparação da viscosidade para diferentes $\lambda$ e $\phi$ para número de capilaridade idênticos em cisalhamento simples.

\begin{tabular}{|l|l|l|l|l|l|l|l|l|}
\hline$\lambda$ & \multicolumn{2}{|c|}{$\phi=2 \%$} & \multicolumn{2}{c|}{$\phi=5 \%$} & \multicolumn{2}{c|}{$\phi=20 \%$} & \multicolumn{2}{c|}{$\phi=40 \%$} \\
\hline & $C a$ & $\eta[$ Pa.s $]$ & $C a$ & $\eta[$ Pa.s $]$ & $C a$ & $\eta[$ Pa.s $]$ & $C a$ & $\eta[$ Pa.s $]$ \\
\hline 2 & 0,018 & 0,062 & 0,011 & 0,073 & 0,059 & 0,082 & 0,14 & 0,51 \\
\hline 5 & 0,019 & 0,027 & 0,008 & 0,030 & 0,041 & 0,063 & 0,18 & 0,25 \\
\hline 10 & 0,017 & 0,013 & 0,009 & 0,014 & 0,038 & 0,029 & 0,15 & 0,12 \\
\hline 20 & 0,019 & 0,0074 & 0,01 & 0,0081 & 0,044 & 0,016 & 0,14 & 0,057 \\
\hline
\end{tabular}

Tabela 7.13: Comparação da viscosidade adimensional pela viscosidade de cada fluido base para diferentes $\lambda$ e $\phi$ para número de capilaridade idênticos em cisalhamento simples.

\begin{tabular}{|l|l|l|l|l|l|l|l|l|}
\hline$\lambda$ & \multicolumn{2}{|c|}{$\phi=2 \%$} & \multicolumn{2}{c|}{$\phi=5 \%$} & \multicolumn{2}{c|}{$\phi=20 \%$} & \multicolumn{2}{c|}{$\phi=40 \%$} \\
\hline & $C a$ & $\eta / \eta_{b}$ & $C a$ & $\eta / \eta_{b}$ & $C a$ & $\eta / \eta_{b}$ & $C a$ & $\eta / \eta_{b}$ \\
\hline 2 & 0,018 & 0,091 & 0,011 & 1,07 & 0,059 & 1,2 & 0,14 & 7,4 \\
\hline 5 & 0,019 & 0,97 & 0,008 & 1,07 & 0,041 & 2,2 & 0,18 & 9,2 \\
\hline 10 & 0,017 & 0,90 & 0,009 & 1,00 & 0,038 & 2,1 & 0,15 & 8,2 \\
\hline 20 & 0,019 & 1,00 & 0,01 & 1,10 & 0,044 & 2,2 & 0,14 & 7,7 \\
\hline
\end{tabular}

Tabela 7.14: Comparação da viscosidade para diferentes $\lambda$ e $\phi$ para número de capilaridade idênticos em cisalhamento quadrático.

\begin{tabular}{|c|c|c|c|c|c|c|c|c|}
\hline$\lambda$ & \multicolumn{2}{|c|}{$\phi=2 \%$} & \multicolumn{2}{c|}{$\phi=5 \%$} & \multicolumn{2}{c|}{$\phi=20 \%$} & \multicolumn{2}{c|}{$\phi=40 \%$} \\
\hline & $C a_{w}$ & $\eta_{w}[$ Pa.s $]$ & $C a_{w}$ & $\eta_{w}[$ Pa.s $]$ & $C a_{w}$ & $\eta_{w}[$ Pa.s $]$ & $C a_{w}$ & $\eta_{w}[$ Pa.s $]$ \\
\hline 2 & 0,018 & 0,63 & 0,016 & 1,025 & 0,017 & 1,85 & 0,052 & 1,82 \\
\hline 5 & 0,018 & 0,17 & 0,017 & 0,19 & 0,017 & 0,51 & 0,072 & 2,54 \\
\hline 10 & 0,016 & 0,08 & 0,017 & 0,08 & 0,018 & 0,17 & 0,050 & 0,91 \\
\hline 20 & 0,016 & 0,04 & 0,016 & 0,042 & 0,019 & 0,068 & 0,053 & 0,19 \\
\hline
\end{tabular}

Tabela 7.15: Comparação da viscosidade adimensional pela viscosidade de cada fluido base para diferentes $\lambda$ e $\phi$ para número de capilaridade idênticos em cisalhamento quadrático.

\begin{tabular}{|c|c|c|c|c|c|c|c|c|}
\hline$\lambda$ & \multicolumn{2}{|c|}{$\phi=2 \%$} & \multicolumn{2}{c|}{$\phi=5 \%$} & \multicolumn{2}{c|}{$\phi=20 \%$} & \multicolumn{2}{c|}{$\phi=40 \%$} \\
\hline & $C a_{w}$ & $\eta_{w} / \eta_{b}$ & $C a_{w}$ & $\eta_{w} / \eta_{b}$ & $C a_{w}$ & $\eta_{w} / \eta_{b}$ & $C a_{w}$ & $\eta_{w} / \eta_{b}$ \\
\hline 2 & 0,018 & 9,2 & 0,016 & 15,0 & 0,017 & 27,1 & 0,052 & 26,6 \\
\hline 5 & 0,018 & 7,0 & 0,017 & 9,0 & 0,017 & 18,3 & 0,072 & 90,6 \\
\hline 10 & 0,016 & 5,7 & 0,017 & 5,8 & 0,018 & 12,3 & 0,050 & 64,8 \\
\hline 20 & 0,016 & 5,3 & 0,016 & 5,8 & 0,019 & 9,3 & 0,053 & 25,7 \\
\hline
\end{tabular}

Também se comparou a viscosidade aparente obtida nos dois tipos de cisalhamento para a mesma taxa de cisalhamento. Observa-se pelos resultados da tab. 7.16 que a viscosidade avaliada na região de parede $\left(\eta_{w}\right)$ é maior que a viscosidade detectada pelo 
reômetro $(\eta)$. Então pode-se concluir que para uma suspensão de gotas a viscosidade é diferente para diferentes tipos de cisalhamento.

Tabela 7.16: Comparação da viscosidade aparente obtida em cisalhamento simples e pelo escoamento em tubo capilar para a mesma taxa de cisalhamento.

\begin{tabular}{|c|c|c|c|c|c|}
\hline$\phi \%$ & $\lambda$ & $\dot{\gamma}_{w}\left[s^{-1}\right]$ & $\eta_{w}[$ Pa.s $]$ & $\dot{\gamma}\left[s^{-1}\right]$ & $\eta[$ Pa.s $]$ \\
\hline \multirow{4}{*}{2} & 2 & 9,30 & 0,41 & 10 & 0,062 \\
& 5 & 10,57 & 0,19 & 10 & 0,03 \\
& 10 & 48,20 & 0,061 & 50 & 0,012 \\
& 20 & 50,60 & 0,04 & 50 & 0,0068 \\
\hline \multirow{5}{*}{5} & 2 & 9,70 & 0,47 & 10 & 0,073 \\
& 5 & 21,00 & 0,19 & 20 & 0,030 \\
& 10 & 50,24 & 0,07 & 50 & 0,014 \\
& 20 & 4,42 & 0,17 & 5 & 0,0084 \\
\hline \multirow{5}{*}{20} & 2 & 10,50 & 0,7 & 10 & 0,090 \\
& 5 & 22,30 & 0,29 & 20 & 0,065 \\
& 10 & 10,20 & 0,20 & 10 & 0,031 \\
& 20 & 51,5 & 0,064 & 50 & 0,015 \\
\hline \multirow{4}{*}{40} & 2 & 7,30 & 1,71 & 10 & 0,60 \\
& 5 & 20,50 & 1,33 & 20 & 0,18 \\
& 10 & 9,23 & 0,81 & 10 & 0,18 \\
& 20 & 18,24 & 0,21 & 20 & 0,084 \\
\hline
\end{tabular}




\section{COMPARAÇÕES DOS RESULTADOS EXPERIMENTAIS COM TEORIAS E OUTROS AUTORES}

\subsection{Estimativa da Espessura da Camada $\delta$}

Como referido em capítulos anteriores, o escoamento em tubo capilar de uma emulsão pode proporcionar o aparecimento de uma região livre de gotas adjacente à parede do tubo. Aqui propõem-se o uso do modelo apresentado pela eq. 2.79 para a predição da espessura da camada $\delta$. É de se referir que a viscosidade do fluido que escoa na região central do capilar $\left(\eta_{c}\right)$ é expressa pela viscosidade de Taylor, indicada para suspensões de baixas frações volumétricas em escoamento de regime de baixo número de capilaridade. Enquanto que $\eta_{\delta}$ é a viscosidade do fluido que escoa adjacente à parede, que representa a viscosidade do fluido base da emulsão, $\eta_{b}$. Desta forma obtém-se que:

$$
\tilde{\delta}_{q}=\frac{\delta}{R}=1-\left[\frac{1-\eta_{i} / \eta_{b}}{\frac{1-f_{T}(\phi)}{f_{T}(\phi)} \eta_{i} / \eta_{b}}\right]^{1 / 4},
$$

em que $f_{T}(\phi)=1+\phi(1+5 / 2 \lambda) /(1+\lambda)$. A viscosidade intrínseca é obtida pela equação de Poiseiulle de escoamento em tubo:

$$
\eta_{i}=\frac{\pi R^{4} G}{8 Q}
$$

A espessura da camada livre de gotas para o escoamento em cisalhamento linear pode ser estimada pelo modelo baseado no balanço entre os efeitos de advecção e de difusão presentes na equação de transporte da propriedade $\phi$ em regime permanente para emulsões de baixa fração volumétrica e altas razões de viscosidade em baixos números 
de capilaridade (ver seção 3.3):

$$
\tilde{\delta}=\frac{9}{1120} \frac{C a^{2} P e}{\phi_{\infty}} \frac{H(\lambda)}{V(\lambda)}
$$

É de se referir que os parâmetros físicos deste modelo $(C a, P e)$ são calculados em função do raio médio da gota da emulsão, $\bar{a}$. Assim, para se utilizar os dados de $C a$ e de $P e$ experimentais é necessário multiplicar-se a eq. 8.3 por $(\bar{a} / R)^{2}$ e por $R / \bar{a}$, em que $R$ é a distância entre os discos do reômetro, $400 \mu m$. Observa-se que a expressão é função de $\phi_{\infty}$ que é uma quantidade desconhecida do modelo. Com o intuito de se ultrapassar essa dependência multiplica-se e divide-se a eq. 8.3 por $\phi$, que é a fração volumétrica da emulsão. É de lembrar que este modelo considera que em regiões muito distantes da parede $\tilde{\phi}=\phi / \phi_{\infty}=1$. Aplicando estas modificações a eq. 8.3 fica:

$$
\tilde{\delta}_{s}=\frac{9}{1120} \frac{C a^{2} P e}{\phi} \frac{\bar{a}}{R} \frac{H(\lambda)}{V(\lambda)} .
$$

Analisando os dados da tab. 8.1 observa-se que a viscosidade medida pelo viscosímetro capilar é maior que a viscosidade avaliada pelo reômetro. Observando os dados da tab. 8.2 é evidente que a taxa de cisalhamento nas regiões de parede do capilar é significativamente menor do que a imposta no reômetro. Esse fato pode ser a justificação para as maiores viscosidades obtidas no viscosímetro capilar. Observa-se pelos dados da tab. 8.1 que a viscosidade medida no reômetro é próxima da viscosidade do fluido base da emulsão exceto para as frações volumétricas 20 e 40 \%. Em frações desta ordem um novo mecanismo se faz presente devido a deformação de uma gota ser induzida pelo movimento das demais. As interações entre gotas passam a ser relevantes. Isso ficou mais evidente em emulsões de menor razão de viscosidade. Quanto à predição da espessura da camada livre de gotas observa-se que quanto menor é a fração volumétrica e maior é a razão de viscosidade a teoria do meio contínuo aplicada ao escoamento em tubo capilar é próxima à teoria de cisalhamento simples. Isso porque a estimativa da espessura da camada livre de gotas em cisalhamento simples foi obtida para uma gota de alta razão de viscosidade. 
Tabela 8.1: Predição da Espessura da Camada $\delta$ em cisalhamento quadrático (eq. 8.1) e simples (eq. 8.4)

\begin{tabular}{|c|c|c|c|c|c|c|c|c|c|}
\hline$\phi \%$ & $\lambda$ & $C a$ & $C a_{w}$ & $\eta[P a . s]$ & $\eta_{w}[$ Pa.s $]$ & $\eta_{i}[$ Pa.s $]$ & $\eta_{i} / \eta_{b}$ & $\tilde{\delta}_{q}$ & $\tilde{\delta}_{s}$ \\
\hline \multirow{3}{*}{2} & 2 & 0,0178 & 0,0177 & 0,0623 & 0,628 & 0,0418 & 0,612 & 0,116 & - \\
& 5 & 0,0185 & 0,0178 & 0,0271 & 0,198 & 0,0192 & 0,685 & 0,18 & - \\
& 10 & 0,0165 & 0,0165 & 0,0126 & 0,0792 & 0,0091 & 0,651 & 0,152 & - \\
& 20 & 0,0186 & 0,0191 & 0,0074 & 0,0365 & 0,0056 & 0,756 & 0,26 & 0,28 \\
\hline \multirow{5}{*}{5} & 2 & 0,0498 & 0,0465 & 0,0697 & 0,407 & 0,0640 & 0,937 & 0,5 & - \\
& 5 & 0,0403 & 0,0417 & 0,0295 & 0,158 & 0,0277 & 0,986 & 0,664 & - \\
& 10 & 0,0385 & 0,0328 & 0,0176 & 0,0653 & 0,018 & 0,846 & 0,364 & - \\
& 20 & 0,0101 & 0,0114 & 0,0085 & 0,0521 & 0,005 & 0,687 & 0,2 & - \\
\hline \multirow{3}{*}{20} & 2 & 0,0248 & 0,0206 & 0,0680 & 1,37 & 0,0848 & 1,24 & - & - \\
& 5 & 0,0179 & 0,0175 & 0,0657 & 0,514 & 0,0376 & 1,34 & - & - \\
& 10 & 0,0383 & 0,0368 & 0,0294 & 0,140 & 0,0237 & 1,60 & - & - \\
& 20 & 0,0196 & 0,0190 & 0,0156 & 0,0688 & 0,0094 & 1,27 & - & - \\
\hline \multirow{3}{*}{40} & 2 & 0,0507 & 0,0510 & 0,71 & 2,08 & 0,263 & 3,47 & - & - \\
& 5 & 0,0869 & 0,0841 & 0,318 & 2,43 & 0,365 & 14.8 & - & - \\
& 10 & 0,0235 & 0,0233 & 0,18 & 1,32 & 0,122 & 7,52 & - & - \\
& 20 & 0,0210 & 0,0216 & 0,0837 & 0,212 & 0,0253 & 3,42 & - & - \\
\hline
\end{tabular}

$C a$ : Capilaridade do Escoamento Linear; $C a_{w}$ : Capilaridade do Escoamento Quadrático; $\eta$ : Viscosidade Experimental obtida por cisalhamento linear; $\eta_{w}$ : Viscosidade Experimental obtida na região de parede do tubo capilar ; $\eta_{i}$ : Viscosidade Intrínseca avaliada pela Equação de Hagen-Poiseiulle; $\tilde{\delta}_{q}$ : Espessura da camada livre de gotas adimensionalizada pelo raio do tubo capilar de $250 \mu \mathrm{m} ; \tilde{\delta}_{s}$ : Espessura da camada livre de gotas adimensionalizada pela distância entre os discos do reômetro (gap).

Tabela 8.2: Taxa de Cisalhamento correspondente ao número de capilaridade da tab. 8.1 .

\begin{tabular}{|c|c|c|c|}
\hline$\phi \%$ & $\lambda$ & $\dot{\gamma}_{w}$ & $\dot{\gamma}$ \\
\hline \multirow{5}{*}{2} & 2 & 3,16 & 20 \\
& 5 & 10,57 & 50 \\
& 10 & 24,28 & 100 \\
& 20 & 6,48 & 200 \\
\hline \multirow{5}{*}{5} & 2 & 12,82 & 50 \\
& 5 & 30,92 & 100 \\
& 10 & 50,24 & 200 \\
& 20 & 27,81 & 200 \\
\hline \multirow{5}{*}{20} & 2 & 1,67 & 20 \\
& 5 & 3,98 & 50 \\
& 10 & 32,72 & 200 \\
& 20 & 35,25 & 200 \\
\hline \multirow{4}{*}{40} & 2 & 2,73 & 50 \\
& 5 & 4,04 & 20 \\
& 10 & 2,17 & 200 \\
& 20 & 12,97 & 200 \\
\hline
\end{tabular}




\subsection{Comparação dos dados experimentais obtidos em cisalhamento simples com modelos teóricos}

A expressão da viscosidade de Taylor é indicada para estimar a viscosidade de emulsões diluídas:

$$
\frac{\eta}{\eta_{b}}=1+\phi\left(\frac{1+5 / 2 \lambda}{1+\lambda}\right)
$$

que em altas razões de viscosidade tem a seguinte forma:

$$
\frac{\eta}{\eta_{b}}=1+\phi\left(\frac{5}{2}+\frac{3}{2 \lambda}\right)
$$

em que $\eta$ é a viscosidade da emulsão e $\eta_{b}$ é a viscosidade do fluido base. A tab. 8.3 lista a viscosidade da emulsão adimensionalizada pela viscosidade do fluido base obtida no experimento de cisalhamento simples (reômetro) e compara com a expressão da viscosidade de Taylor (eq. 8.5). Verifica-se que a viscosidade pouco variou para uma determinada fração volumétrica. Isto é coerente porque o regime é de baixo número de capilaridade e o efeito da razão de viscosidade indica que as gotas são praticamente esféricas. Esses resultados reforçam a ideia que mesmo para $\lambda=5$ as gotas podem já ser consideradas rígidas sem apresentarem deformação para baixos números de capilaridade. A previsão da viscosidade de Taylor está coerente com os resultados experimentais. Contudo, para a fração volumétrica de $20 \%$ a viscosidade de Taylor é duas vezes inferior em relação à viscosidade obtida experimentalmente. Para a fração volumétrica de $40 \%$ essa diferença foi ainda maior. Isso mostra que a expressão da viscosidade de Taylor não é apropriada para emulsões de altas frações volumétricas, mesmo em altas razões de viscosidade. 
Tabela 8.3: Comparação entre a viscosidade adimensional obtida em cisalhamento linear (reômetro) com a predição pela expressão de Taylor.

\begin{tabular}{|c|c|c|c|c|c|}
\hline$\phi \%$ & $\lambda$ & $C a \times 10^{-2}$ & $\eta / \eta_{b}$ & $\eta_{\text {Tay }}$ & $\left|\left(\eta_{\text {Tay }}-\eta / \eta_{b}\right) / \eta_{\text {Tay }}\right|$ \\
\hline \multirow{5}{*}{2} & 2 & 1,78 & 0,912 & 1,004 & 0,123 \\
& 5 & 1,86 & 0,967 & 1,0045 & 0,075 \\
& 10 & 1,65 & 0,904 & 1,0047 & 0,14 \\
& 20 & 1,86 & 1,001 & 1,0048 & 0,045 \\
\hline \multirow{5}{*}{5} & 2 & 1,92 & 0,985 & 1,01 & 0,025 \\
& 5 & 2,00 & 1,043 & 1,011 & 0,031 \\
& 10 & 1,92 & 1,056 & 1,012 & 0,044 \\
& 20 & 2,13 & 1,150 & 1,012 & 0,14 \\
\hline \multirow{5}{*}{20} & 2 & 1,28 & 1,308 & 1,04 & 0,26 \\
& 5 & 1,80 & 2,340 & 1,042 & 1,24 \\
& 10 & 2,10 & 2,299 & 1,047 & 1,19 \\
& 20 & 1,96 & 2,110 & 1,018 & 1,01 \\
\hline
\end{tabular}

A viscosidade efetiva adimensional em função da fração volumétrica pode ser também ajustada pela equação de Krieger-Dougherty:

$$
\eta_{r}=\eta / \eta_{b}=\left[1-\left(\phi / \phi_{p}\right)\right]^{-[\eta] \phi_{p}}
$$

O valor do parâmetro $[\eta]$ foi de 2,5 . O valor do parâmetro $\phi_{p}$ é encontrado através do gráfico $\eta^{-1 / 2}(\phi)$ quando se extrapola a recta para $\eta^{-1 / 2}=0$. O valor encontrado foi de $\phi_{p}=0,61$. No entanto, o valor de $\phi_{p}$ que mais se adequou aos resultados experimentais foi o de 0,5. A tab. 8.4 mostra os valores experimentais e os obtidos pela eq. 8.7.

Tabela 8.4: Comparação entre a viscosidade adimensional obtida em cisalhamento linear (reômetro) com a predição pela expressão Krieger-Dougherty para a emulsão de $\lambda=20$ e $\dot{\gamma}=200 \mathrm{~s}^{-1}$.

\begin{tabular}{|c|c|c|}
\hline$\phi$ & $\eta / \eta_{b}$ & $\eta_{r}$ \\
\hline 0,02 & 1 & 1,05 \\
\hline 0,05 & 1,15 & 1,14 \\
\hline 0,2 & 2,2 & 1,90 \\
\hline 0,4 & 7,8 & 7,50 \\
\hline
\end{tabular}

Os dados da tab. 8.3 estão representados pelas figs. 8.1, 8.2 e 8.3. Observa-se que para as frações volumétricas 2 e $5 \%$ a teoria de Taylor é aceitável. Contudo, para a fração volumétrica de $20 \%$ a teoria de pequenas deformações de Taylor $(\mathrm{Ca} \rightarrow 0)$ resulta em predições distantes dos resultados experimentais. Isto porque a teoria de Taylor é adequada para baixas frações volumétricas, em baixos números de capilaridade. 


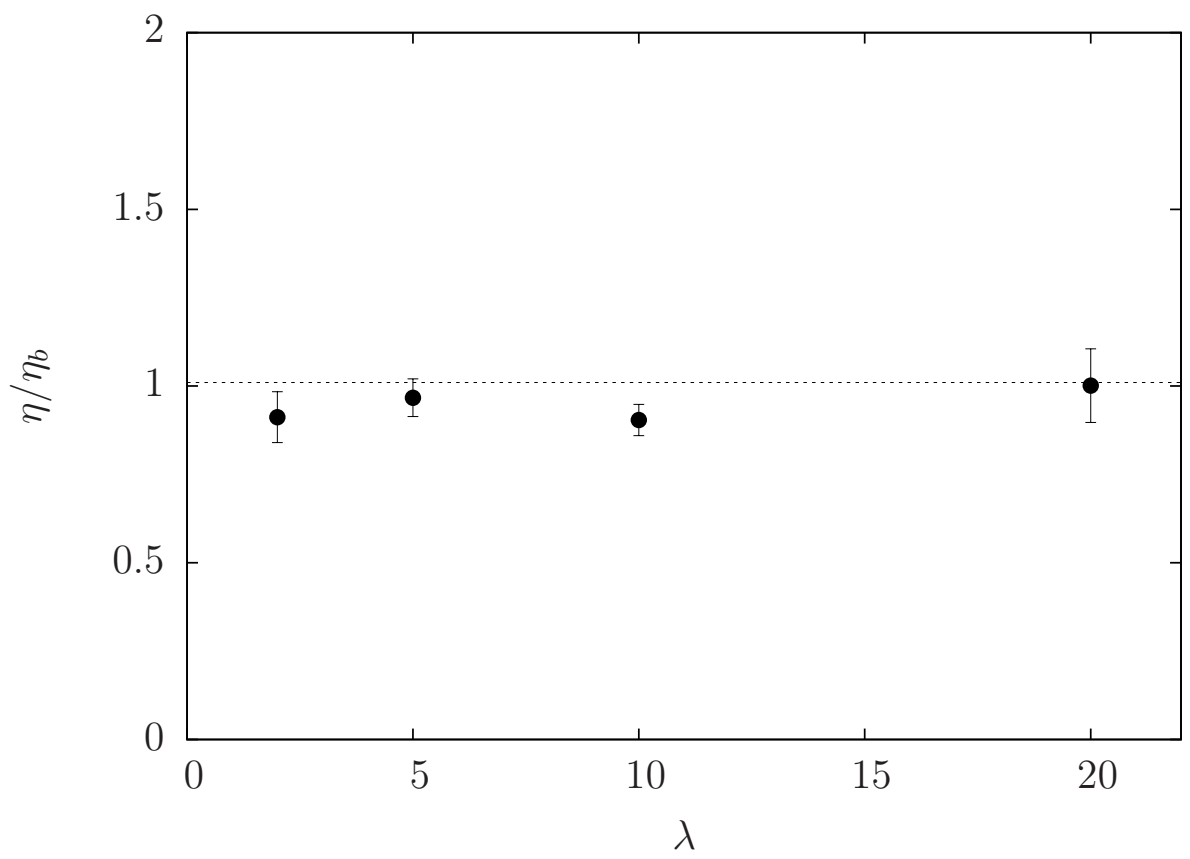

Figura 8.1: Comparação entre a viscosidade experimental $(\bullet)$ adimensionalizada pela viscosidade do fluido base e a viscosidade teórica de Taylor $(---$, eq. 8.6) para $\phi=2 \%$ em função da razão de viscosidade.

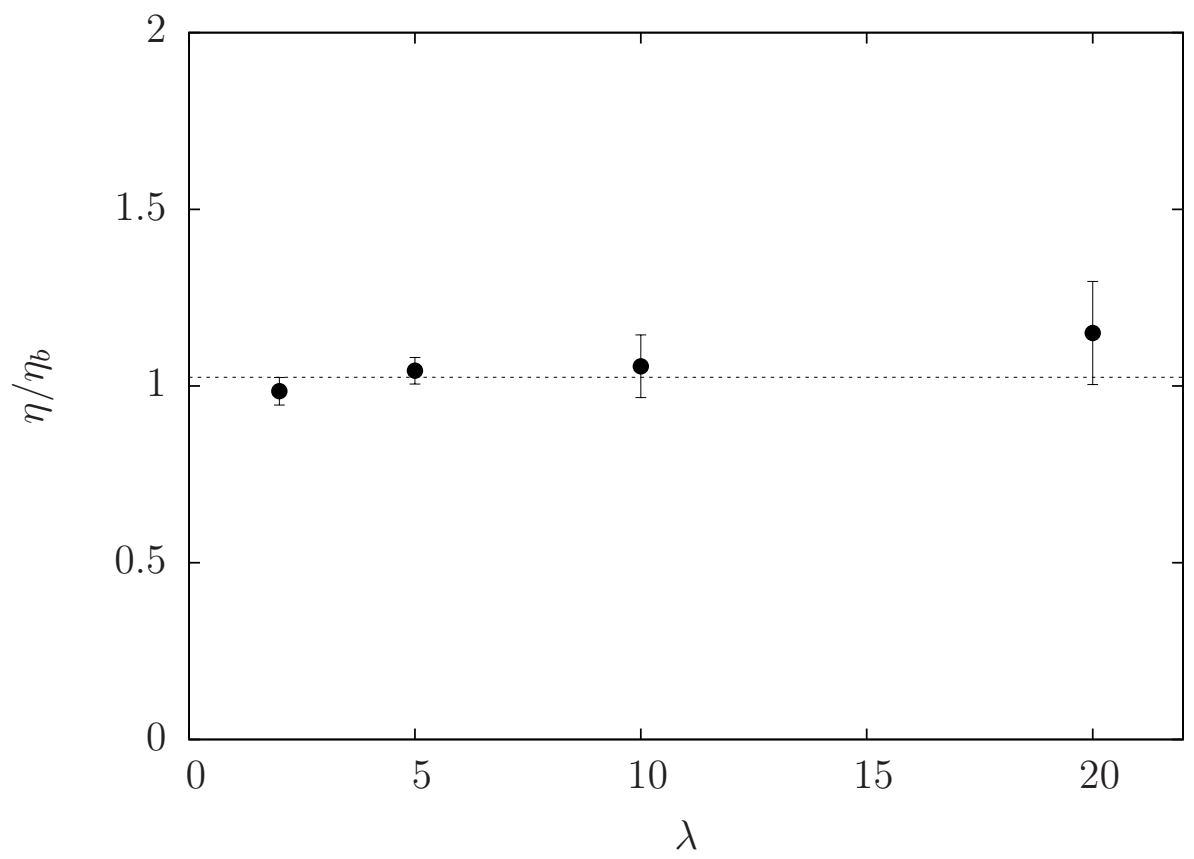

Figura 8.2: Comparação entre a viscosidade experimental $(\bullet)$ adimensionalizada pela viscosidade do fluido base e a viscosidade teórica de Taylor (---, eq. 8.6) para para $\phi=5 \%$ em função da razão de viscosidade. 


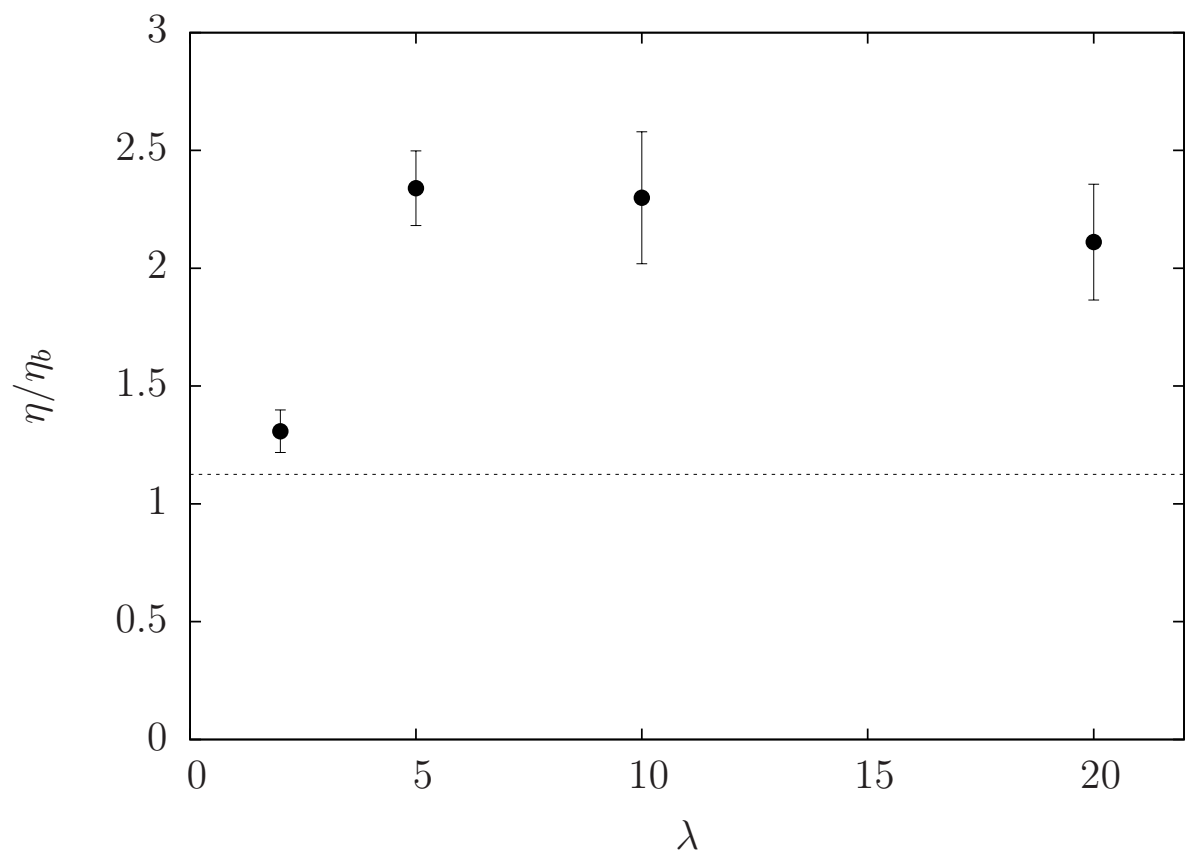

Figura 8.3: Viscosidade experimental adimensionalizada pela viscosidade do fluido base para $\phi=20 \%$ em função da razão de viscosidade. (-- ) Viscosidade teórica de Taylor (eq. 8.6). (•) Viscosidade Experimental da presente tese.

A fig. 8.4 mostra a variação da viscosidade adimensionalizada pela viscosidade do fluido base em função da fração volumétrica. Como era esperado a viscosidade aumenta com a fração volumétrica. A região linear foi ajustada pela eq. 8.5 em que a constante de ajuste foi 5/2. Para fazer essas comparações foi necessário extrair a viscosidade em números de capilaridade idênticos (para cada razão de viscosidade) visto que em nenhum experimento se obtém exatamente o mesmo número de capilaridade que é função da viscosidade, taxa de cisalhamento e da tensão interfacial. É de se referir que a expressão de Taylor é apropriada para emulsões monodispersas e estatisticamente homogêneas em baixas concentrações e para número de capilaridade tendendo a zero. Fatores como a presença de surfactantes e a heterogeneidade de concentração espacial de gotas não são levados em consideração pela teoria. Estes parâmetros contribuem para a existência de diferenças entre a teoria e os dados experimentais. 


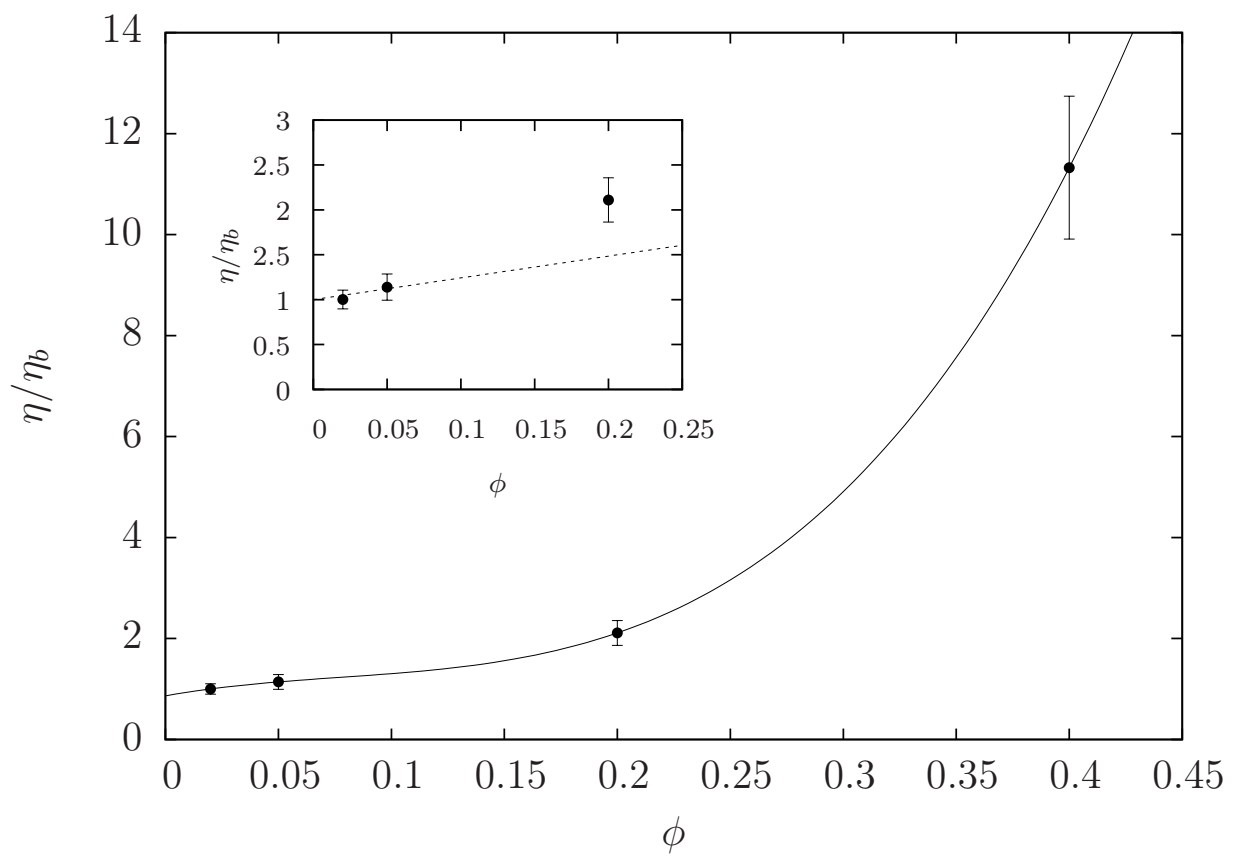

Figura 8.4: Variação da viscosidade adimensional com a fracção volumétrica para $\lambda=$ 20 e $C a \approx 0,020$. A constante obtida para o ajuste dos dois primeiros pontos foi de $K=5 / 2$.

A expressão da eq. 3.43 representa a viscosidade de uma emulsão diluída de alta razão de viscosidade em cisalhamento simples em regime permanente (Oliveira e Cunha (2011)):

$$
\frac{\eta}{\eta_{b}}=1+\phi\left(\frac{5}{2}-\frac{25}{4 \lambda}\right)+\phi\left(\frac{5}{\lambda} \frac{c}{c^{2}+(\lambda C a)^{2}}\right)
$$

Esta expressão foi obtida a partir do tensor de tensões de uma partícula isolada após ter-se efetuado o procedimento comum de média volumétrica que permite passar de uma escala discreta para uma escala contínua. O primeiro termo da equação representa a viscosidade do fluido base, o segundo termo é referente à situação em que as gotas apresentam diferenças de tensões normais mas conservam a sua forma e o terceiro termo é a contribuição do efeito pseudo-plástico da emulsão. A fig. 8.5 apresenta a comparação entre os resultados experimentais desta tese para a emulsão de fração volumétrica de $2 \%$ com razão de viscosidade 20 e a estimativa da eq. 8.8. Observa-se que a teoria está de acordo com os resultados experimentais. Na fig. 8.5 também está representada a variação do termo de contribuição pseudo-plástico com o número de capilaridade. Verifica-se que este termo é de magnitude menor que o somatório dos restantes termos. Ou seja, o efeito pseudo-plástico é inibido pela magnitude da viscosidade do fluido base e do termo que representa a viscosidade na situação onde 
as gotas não apresentam variação de forma. Assim a emulsão pode ser considerada como um fluido Newtoniano para esta fração volumétrica e razão de viscosidade. Isso é coerente visto que a emulsão é diluída e de alta razão de viscosidade, inibindo a deformação da gota em baixos número de capilaridade. A fig. 8.6 mostra a variação da viscosidade adimensional com a razão de viscosidade para um número de capilaridade fixo $\left(C a=\eta_{b} \dot{\gamma} \bar{a} / \tau_{s} \approx 2 \times 10^{-4}\right)$ comparando com a previsão teórica da eq. 8.5 e da eq. 8.8. Observa-se que as duas teorias são aceitáveis quando comparadas com os resultados experimentais. É de lembrar que estas teorias foram obtidas para emulsões diluídas para $C a \rightarrow 0$.

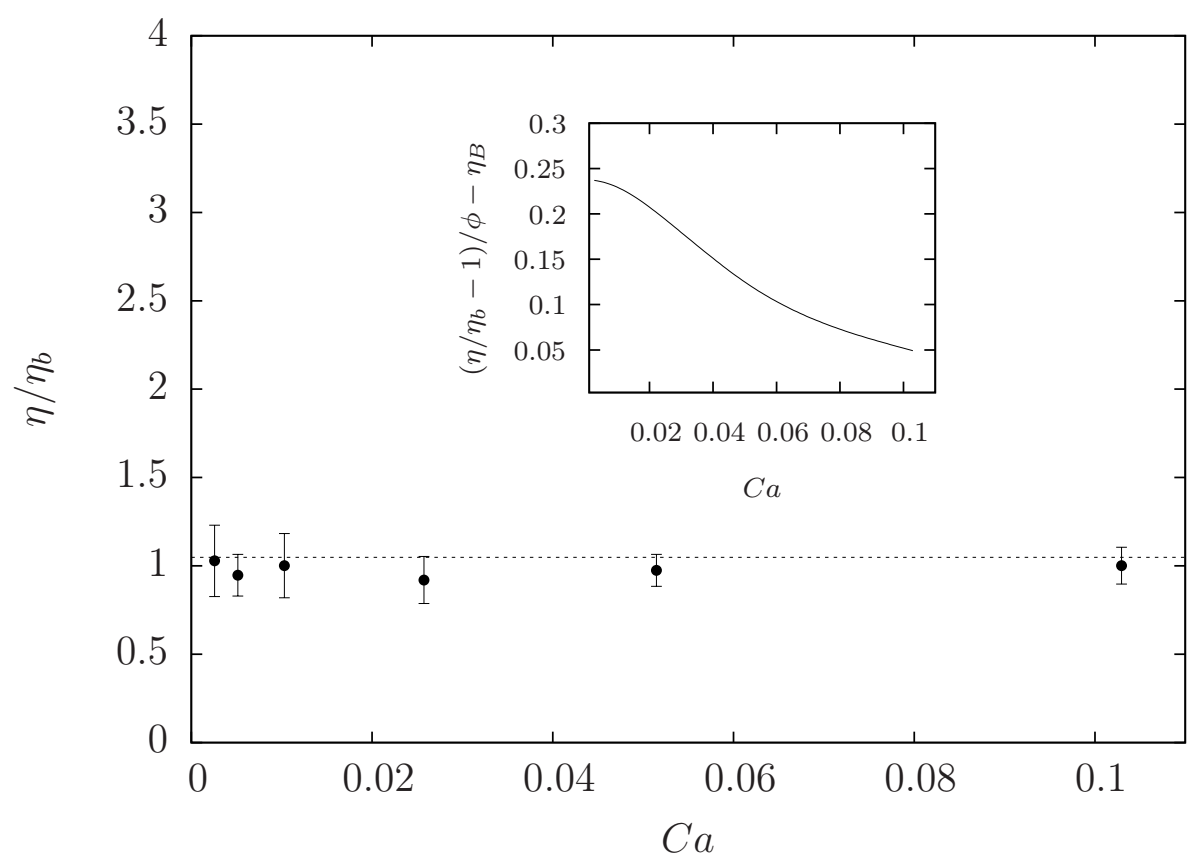

Figura 8.5: Variação da viscosidade aparente em função do número de capilaridade $\left(C a=\eta_{b} \dot{\gamma} \bar{a} / \tau_{s}\right)$ para a fração volumétrica $2 \%$ e razão de viscosidade 20 . • Experimentos da presente tese, --- Eq. 8.8. 


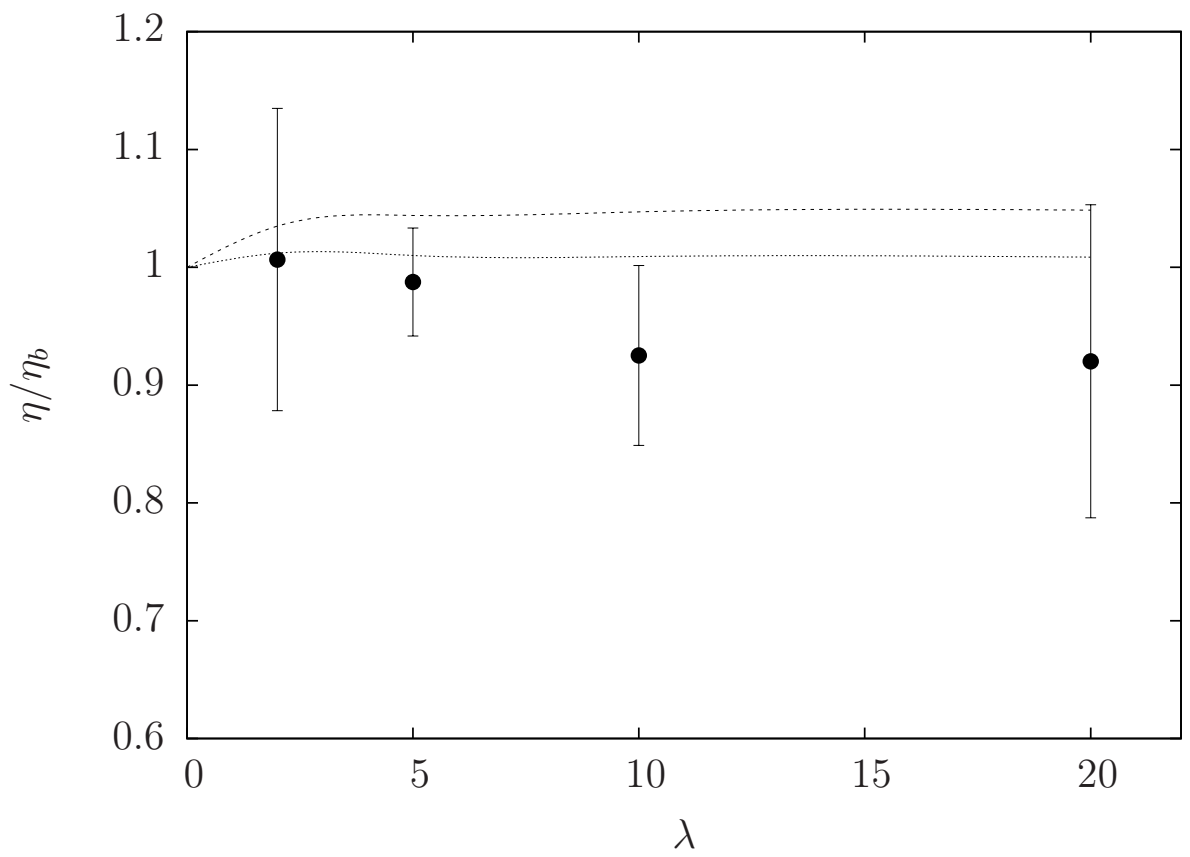

Figura 8.6: Variação da viscosidade adimensional em função da razão de viscosidade para a emulsão de $\phi=2 \%$ e $C a=\eta_{b} \dot{\gamma} \bar{a} / \tau_{s} \approx 2 \times 10^{-4}$. $\bullet$ Experimentos da presente tese. --- Eq. 8.8. $\cdots$ Eq. 8.5.

A fig. 8.7 mostra a variação da viscosidade relativa em função da razão de viscosidade, no máximo número de capilaridade experimental. Pelo gráfico observa-se que a viscosidade relativa aumenta com a razão de viscosidade devido às menores deformações das gotas. Com o aumento da razão de viscosidade o comportamento das gotas tendem para a situação de partículas rígidas onde passam a girar mais rápido do que se deformam. Também se destaca que a viscosidade relativa aumenta com a fração volumétrica de gotas devido ao fato da existência de um maior número de gotas aumentando os efeitos das interações hidrodinâmicas gota-gota.

No trabalho de Loewenberg e Hinch (1996) foi examinada a reologia de emulsões por meio de simulação numérica (Método de Integral de Contorno) de 12 gotas utilizando a condições de contorno periódicas. É de se referir que uma das limitações do modelo numérico é que este não considerou o efeito de surfactante na superfície das gotas que tem influência na reologia de emulsões e nem os possíveis efeitos de parede existentes no reômetro. O modelo numérico de Loewenberg e Hinch (1996) prevê a formação de um possível platô newtoniano para baixos números de capilaridade e um efeito pseudoplástico com o aumento do número de capilaridade. A tab. 8.5 compara os valores 


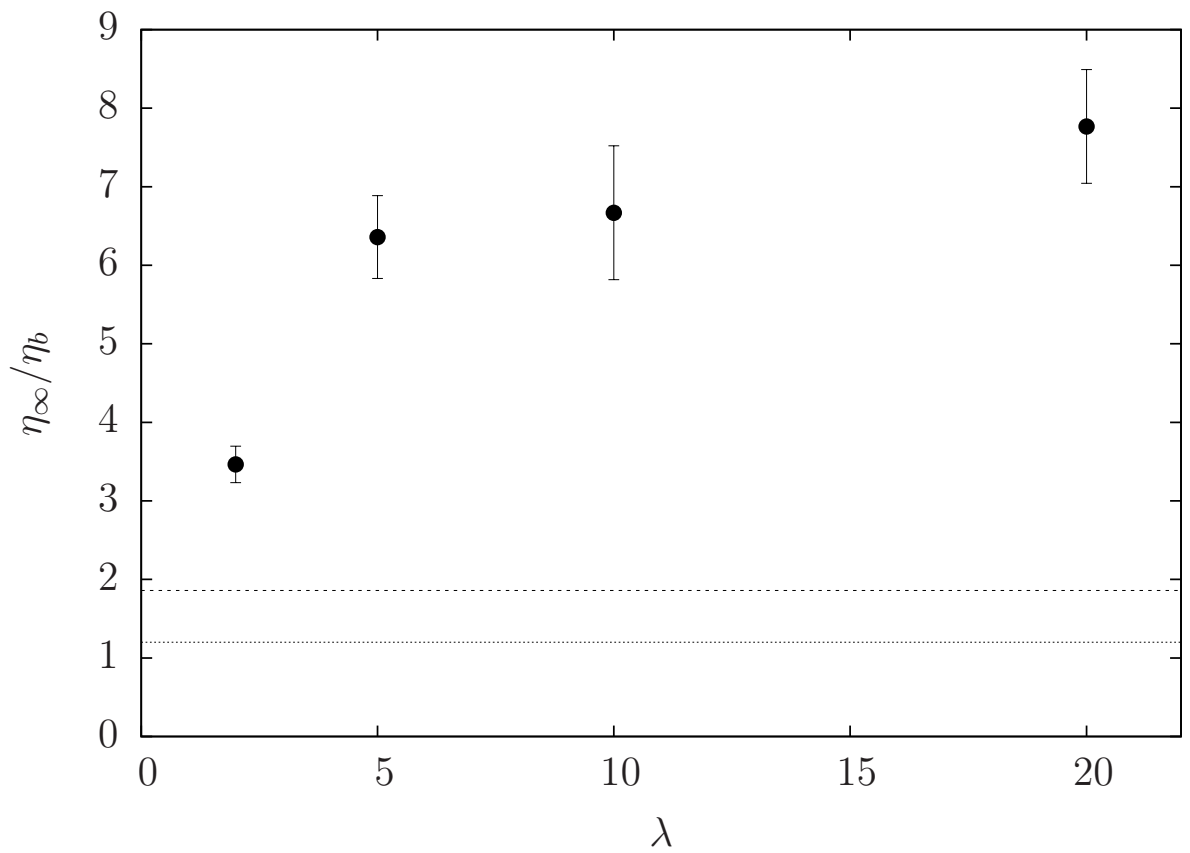

Figura 8.7: Variação da viscosidade no máximo número de capilaridade experimental adimensionalizada pela viscosidade do fluido base em função da razão de viscosidade para a emulsão de $\phi=40 \%$. • Experimento da presente tese. - - Eq. 8.8. ‥ Eq. 8.5 .

numéricos com os dados experimentais da presente tese. Observa-se que as frações volumétricas entre o estudo numérico e os experimentos desta tese são diferentes mas a razão de viscosidade é próxima. Observa-se pelos valores da tab. 8.5 que para o mesmo número de capilaridade a tensão na gota numérica $\left(\Sigma_{12}\right)$ pouco variou com o aumento da fração volumétrica (de 10\% para 30\%). Nos experimentos verifica-se que o aumento da fração volumétrica de 5\% para 40\% aumenta a tensão associada com a gota. Este acontecimento é devido às interações hidrodinâmicas gota-gota em maiores frações volumétricas que contribuem com o maior efeito da tensão gerada pelo cisalhamento do escoamento na superfície da gota. Comparando os dados experimentais desta tese com os numéricos de Loewenberg e Hinch (1996) era esperado um aumento mais evidente da tensão avaliada pelo método numérico com a fração volumétrica como aconteceu com os resultados experimentais. 
Tabela 8.5: Comparação entre resultados numéricos de Loewenberg e Hinch (1996) com os resultados experimentais da presente tese para $C a=0,20$.

\begin{tabular}{|c|c|}
\hline$\left(\eta / \eta_{b}\right) C a / \phi$ & $\Sigma_{12}$ \\
\hline$\phi=5 \% ; \lambda=2$ & $\phi=10 \% ; \lambda=1$ \\
\hline 0,11 & 0,35 \\
\hline$\phi=40 \% ; \lambda=2$ & $\phi=30 \% ; \lambda=1$ \\
\hline 1,20 & 0,38 \\
\hline
\end{tabular}

\subsection{Comparação dos dados experimentais obtidos pelo escoamento em tubo capilar com modelos teóricos}

A da viscosidade de Taylor é universal já que não envolve interação hidrodinâmica gota-gota, descrevendo uma emulsão com comportamento Newtoniano com viscosidade efetiva dada pela expressão:

$$
\eta_{T}=\frac{\eta}{\eta_{b}}=1+\phi\left(\frac{1+5 / 2 \lambda}{1+\lambda}\right)
$$

Desta forma a viscosidade de Taylor é invariante com o tipo de escoamento. Assim sendo, pode-se usar os valores da viscosidade dada pela teoria de Taylor para comparar com os resultados experimentais desta tese obtidos no escoamento em capilares.

Na seção 3.2 foi apresentada uma teoria para escoamento de emulsões diluídas de altas razões de viscosidade em capilar de secção circular em regime permanente. Na expressão da quantidade de movimento linear o termo do tensor de tensões é a soma do tensor de tensões hidrodinâmico com o tensor de tensões devido à presença de gotas (Batchelor (1970a)). Este último tensor é constituído por um tensor de forma obtido pela teoria de pequenas deformações (Frankel e Acrivos (1970)) e leva em consideração a distribuição, orientação, tamanho e forma das gotas. Assumiu-se que neste caso as gotas presentes no escoamento não alteram a sua forma, ou seja, considerou-se um regime de deformação permanente. É de se referir que no escoamento quadrático a taxa de cisalhamento varia na direção normal ao escoamento. Essa variação da taxa de cisalhamento origina diferentes deformações nas gotas. Porém em emulsões diluídas a deformação de uma gota não é influenciada pela deformação das gotas vizinhas e em altas razões de viscosidade as gotas apresentam pequenas deformações. Em Oliveira 
(2007) foi obtida uma expressão algébrica baseada no modelo da secção 3.2 para prever a viscosidade de emulsões de baixas frações volumétricas e altas razões de viscosidade:

$$
\eta_{a p}=\frac{\eta_{B} C a_{\lambda}^{4}}{C a_{\lambda}^{4}-g_{1} C a_{\lambda}^{2}+g_{2} \ln \left(16 \eta_{B} C a_{\lambda}^{2}+\eta_{T} c^{2}\right)+g_{3}}
$$

em que:

$$
\begin{aligned}
& g_{1}=\frac{\left(\eta_{T}-\eta_{B}\right) c^{2}}{8 \eta_{B}}, \\
& g_{2}=\frac{\eta_{T} c^{2}}{16 \eta_{B}} g_{1}, \\
& g_{3}=-\ln \left(\eta_{T} c^{2}\right) g_{2},
\end{aligned}
$$

e:

$$
\begin{aligned}
& \eta_{T}=1+\phi\left(\frac{5}{2}-\frac{3}{2 \lambda}\right) \\
& \eta_{B}=1+\phi\left(\frac{5}{2}-\frac{25}{4 \lambda}\right)
\end{aligned}
$$

O número de capilaridade foi calculado como sendo:

$$
C a_{\lambda}=\lambda \frac{\eta_{b} U_{c}}{\tau_{s}} \frac{\bar{a}}{R}
$$

em que:

$$
U_{c}=\frac{G R^{2}}{8 \eta_{b}}
$$

Pela tab. 8.6 constata-se que a viscosidade efetiva predita pela teoria de Taylor coincide com a viscosidade aparente obtida pela teoria de altas razões de viscosidade para emulsões diluídas. A coincidência destas teorias se deve aos baixos números de capilaridade, onde a teoria de Taylor é válida. A viscosidade calculada pela equação de Poiseuille se mostrou próxima da viscosidade aparente calculada pela eq. 8.10 e da viscosidade calculada pela expressão de Taylor, para baixos regimes de número de capilaridade. Os maiores valores da viscosidade de parede podem ser devido às propriedades de parede, a polidispersidade e às diferenças de fração volumétrica na direção perpendicular à direção principal do escoamento que está relacionada com a migração de gotas de 
maior tamanho para a região de menor taxa de cisalhamento, fazendo com que gotas de menor tamanho se posicionem perto da região de parede.

Tabela 8.6: Comparação entre a viscosidade adimensional obtida em cisalhamento quadrático (capilar) com a predição pela expressão de Taylor.

\begin{tabular}{|c|c|c|c|c|c|c|c|}
\hline$\phi \%$ & $\lambda$ & $C a_{w} \times 10^{-2}$ & $C a_{\lambda} \times 10^{-5}$ & $\eta_{w} / \eta_{b}$ & $\eta_{P} / \eta_{b}$ & $\eta_{T}$ & $\eta_{a p}$ \\
\hline 2 & 10 & 2,03 & 5,74 & 5,31 & 0,73 & 1,047 & 1,047 \\
& 20 & 1,90 & 5,81 & 4,94 & 0,76 & 1,049 & 1,048 \\
\hline 5 & 10 & 2,17 & 4,44 & 5,48 & 0,78 & 1,118 & 1,122 \\
& 20 & 2,03 & 4,83 & 5,51 & 0,86 & 1,121 & 1,119 \\
\hline
\end{tabular}

$C a_{w}$ : Capilaridade do Escoamento Quadrático; $C a_{\lambda}$ : Capilaridade calculado pela eq. 8.13; $\eta_{w} / \eta_{b}$ : Viscosidade de Parede adimensionalizada pela viscosidade do fluido base; $\eta_{T}$ : Viscosidade calculada pela teoria de Taylor (eq. 8.9); $\eta_{P} / \eta_{b}$ : Viscosidade Intrínseca calculada pela equação de Poiseuille adimensionalizada pela viscosidade do fluido base $\left(\eta_{b}\right)$; $\eta_{a p}$ : Viscosidade calculada pela eq. 8.10

A fig. 8.8 compara a viscosidade de Taylor com a eq. 8.10. Observa-se que para baixos números de capilaridade as estimativas teóricas são coincidentes e próximas dos resultados experimentais. Pela fig. 8.9 observa-se uma subida da viscosidade associada com a razão de viscosidade. Esse acontecimento está coerente com a teoria.

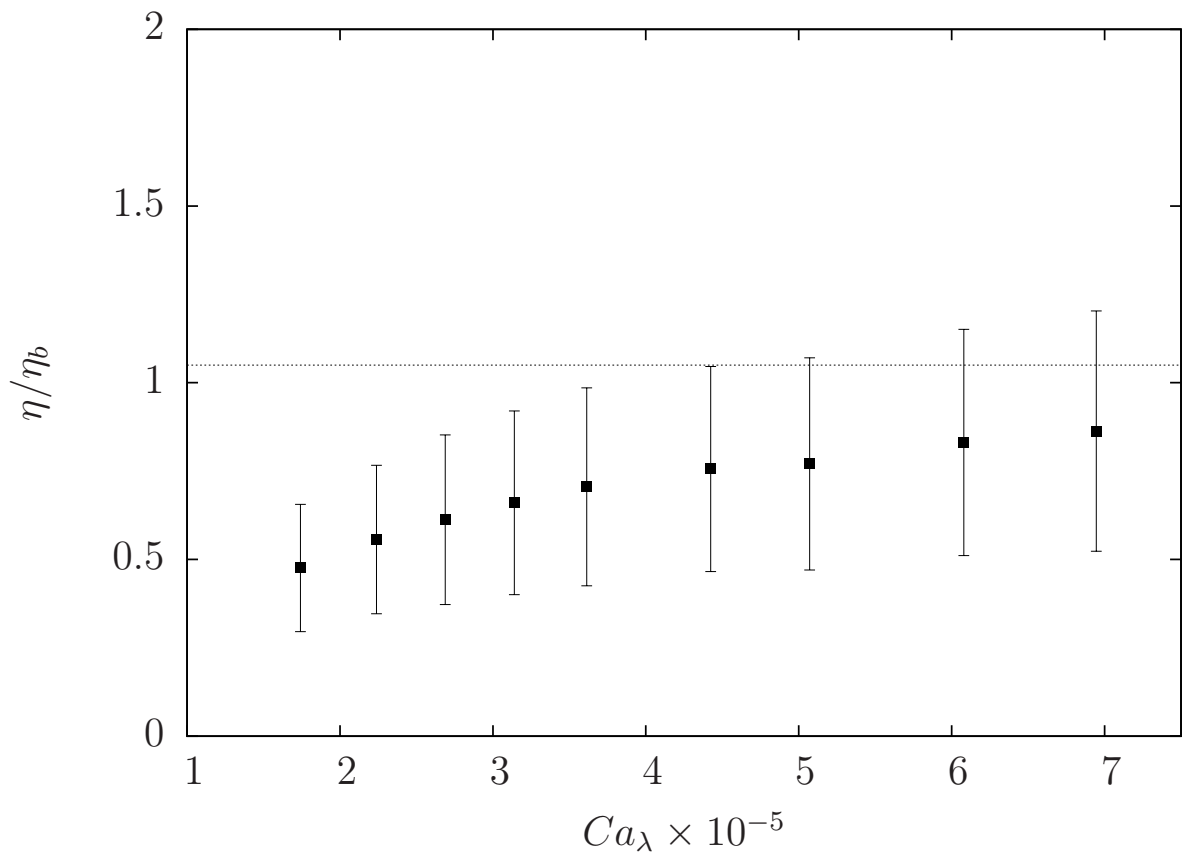

Figura 8.8: Variação da viscosidade aparente com o número de capilaridade $C a_{\lambda}$ para a emulsão de fração volumétrica $2 \%$ e razão de viscosidade 20 . $\eta_{P} / \eta_{b} ; \cdots$ Resultado Teórico da eq. 8.9 e da eq. 8.10 são coincidentes para baixos números de capilaridade. 


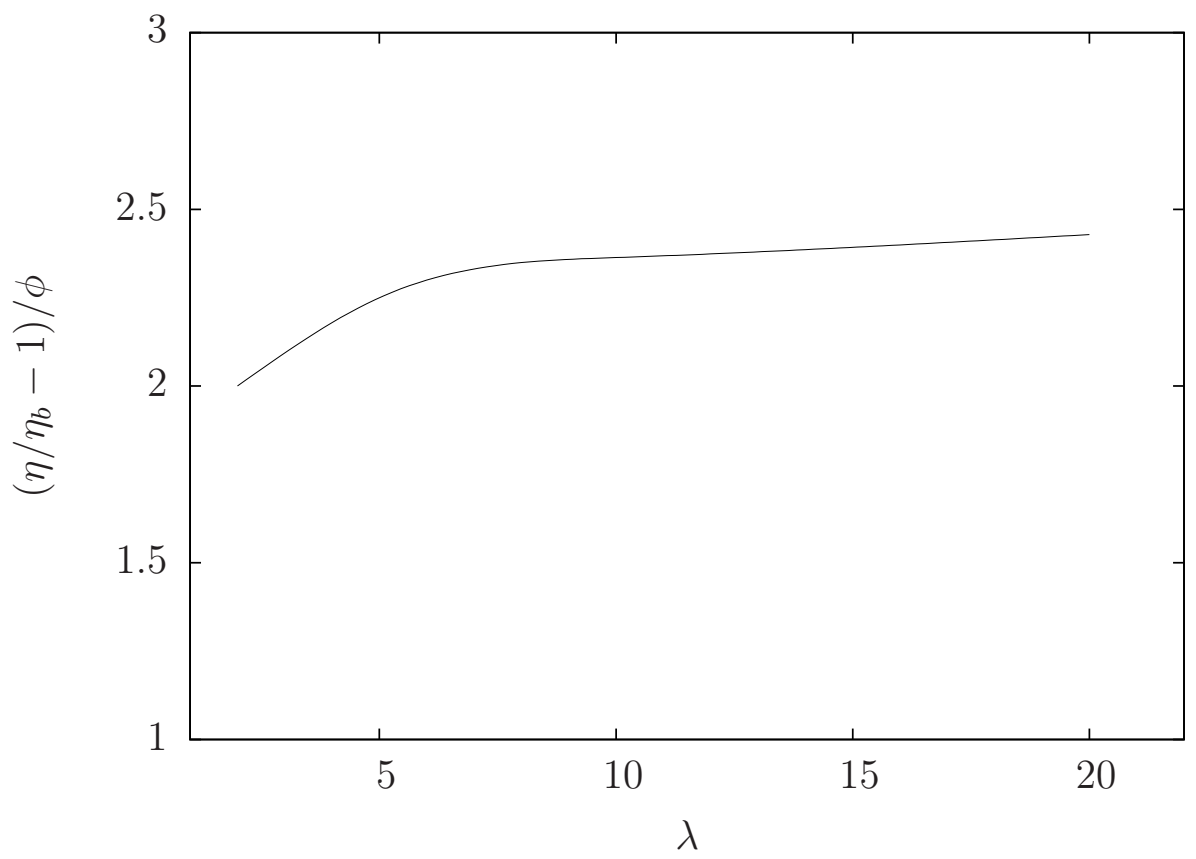

Figura 8.9: Variação da viscosidade aparente com a razão de viscosidade para $C a_{w} \approx$ 0,02 para a emulsão de fração volumétrica $2 \%$ Resultado Teórico da eq. 8.9 e da eq. 8.10 são coincidentes.

\subsection{Comparação dos dados experimentais com outros trabalhos}

Esta seção tem como objetivo comparar os resultados experimentais obtidos com outros autores sempre que possível para condições de escoamento semelhantes e emulsões do mesmo tipo. Desde já é de se referir que diferentes trabalhos experimentais obtêm diferentes resultados. Isso pode ser devido aos diferentes líquidos envolvidos, à polidispersidade de gotas bem como à heterogeneidade da emulsão, aos efeitos hidrodinâmicos de interação gota-gota e à distribuição espacial de surfactante na superfície da gota regida pela eq. 5.3. Dependendo da intensidade do escoamento pode haver ruptura de gota, modificando as propriedades microestruturais da emulsão e como tal a reologia deste fluido complexo. Na procura por trabalhos de cisalhamento de emulsões em reômetros e de escoamentos de emulsões em capilar verificou-se que na literatura existe uma grande preocupação teórica de apresentar modelos ou simulações cujos resultados possam ser comparados com os resultados obtidos experimentalmente. Por outro lado os trabalhos experimentais presentes na literatura se preocupam em estudar o comportamento de emulsões com vista à aplicações específicas. Por esses motivos sentiu-se dificuldades em encontrar trabalhos na literatura que possam ser comparáveis com os resultados 
apresentados nesta tese. As principais conclusões destes trabalhos reafirmam o que se conhece em relação às características reológicas de emulsões: comportamento de fluido pseudo-plástico, influência do tamanho de gota na reologia e aumento da viscosidade com o aumento da fração volumétrica de surfactante e da fração volumétrica da fase dispersa. Também se sentiu a falta de trabalhos de escoamento de emulsões de gotas em capilar. Observou-se que este tipo de trabalhos são direcionados para a indústria de petróleo onde as emulsões são a base de óleos desse tipo. O principal interesse é avaliar o fator de atrito em função das altas frações volumétricas envolvidas. Este fator de atrito nada mais é que a tensão de parede adimensionalizada $\left(2 \tau_{w} /\left(\rho U^{2} L\right)\right)$. Os trabalhos mais teóricos da vertente numérica têm como objetivo traçar o perfil de velocidades do escoamento, visualização da deformação da gota e identificar a formação da camada livre de gotas nas proximidades da parede.

\subsubsection{Experimentos realizados em Reômetros}

O trabalho de Jayasuriya et al. (1986) mediu as propriedades reológicas de emulsões $\mathrm{O} / \mathrm{A}$ em um reômetro de cilindros concêntricos. O fluido base é constituído por água deionizada $(49,5 w t \%)$ misturada com glicerol $(49,5 w t \%)$ onde é adicionado o surfactante Tween80 (1 wt\%). A viscosidade do fluido base é $9 c P$. O fluido disperso é constituído por óleo mineral (90wt\%) e surfactante Span80 (10 wt\%). A viscosidade da fase oleosa é $46 \mathrm{cP}$. As medições foram realizadas a temperatura de $25^{\circ} \mathrm{C}$. Com estes dados pode-se obter que a razão de viscosidade é aproximadamente 5. Os autores efetuaram medições com frações volumétricas entre 15\% e 75\%. A distribuição de tamanho das gotas foi medido por um analisador de tamanho de partícula da Malvern do modelo ST 1800. O raio da gota variou de 5, 4 a $33 \mu \mathrm{m}$. Para comparar os resultados obtidos nesta tese com os resultados de Jayasuriya et al. (1986) selecionou-se a emulsão de fracção volumétrica $15 \%$ e 40\%, cujo raio médio das gotas é respectivamente de 1, 4 e 2,7 $\mu \mathrm{m}$. Desde já é de notar que o raio médio das gotas da emulsão da presente tese é superior, pois a intenção foi de gerar emulsões de gotas não coloidais para evitar os efeitos das flutuações térmicas moleculares designadas como efeitos Brownianos. Na presente tese para a emulsão com razão de viscosidade de 5: $\phi=40 \%, \bar{a}=11,81 \mu \mathrm{m}$ 
e $\phi=20 \%-\bar{a}=11,78 \mu \mathrm{m}$. A comparação é efetuada para a viscosidade $\eta / \eta_{b} \mathrm{em}$ que $\eta$ é a viscosidade aparente medida no reômetro. Para a fração volumétrica de $20 \%$ (fig. 8.10) observa-se uma certa concordância entre os resultados da presente tese e de Jayasuriya et al. (1986) mesmo com as possíveis diferenças de polidispersidade, da viscosidade dos fluidos envolvidos, da distribuição de surfactante na superfície da gota e da distribuição espacial de gotas. Para a fração volumétrica de $40 \%$ a emulsão da presente tese apresenta um aumento significativo da viscosidade enquanto que a emulsão de Jayasuriya et al. (1986) para fração volumétrica de $40 \%$ mostrou um menor efeito pseudo-plástico. O resultado apresentado por Jayasuriya et al. (1986) não está coerente com as observações da maioria dos trabalhos onde é referido que emulsões com altas frações volumétricas exibem uma maior variação da viscosidade com o aumento da taxa de cisalhamento.

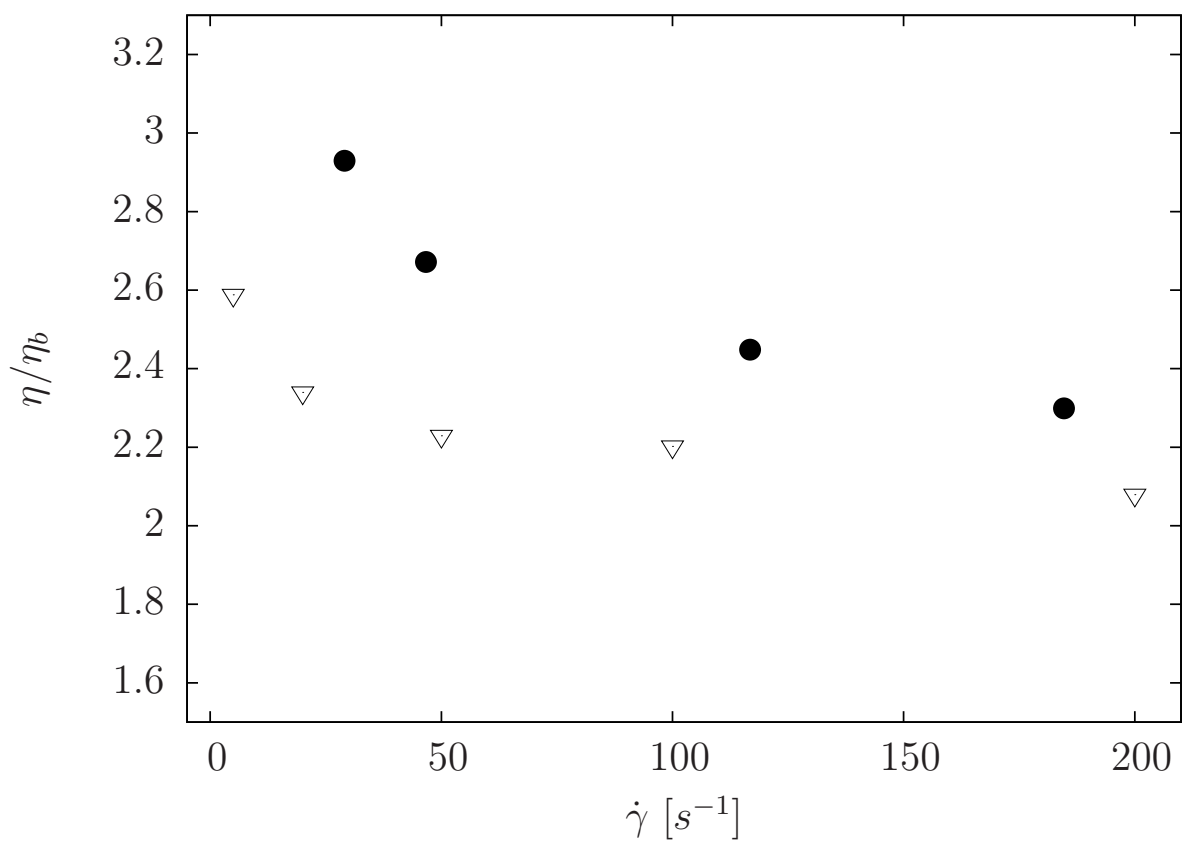

Figura 8.10: Variação da viscosidade aparente em função da taxa de cisalhamento para a emulsão $\mathrm{O} / \mathrm{A}$ de $\lambda=5$. • Jayasuriya et al. (1986) $\phi=15 \% ; \nabla$ Presente Trabalho $\phi=20 \%$.

No trabalho de Pal (1992) foi estudado a influência do aumento da fração volumétrica de surfactante em emulsão $\mathrm{O} / \mathrm{A}(0,2,12,8,25,7 \% w t)$. A fase oleosa é petróleo de viscosidade 6,4 cP. O surfactante utilizado foi o Triton X-100 solúvel na água de viscosidade $240 c P$. Os autores verificaram que o aumento da fração de surfactante 
evidência as propriedades de fluido pseudo-plástico das emulsões. É de se observar que a viscosidade do surfactante é cerca de 40 vezes maior que a viscosidade da fase oleosa. A razão de viscosidade destas emulsões é de 6,4. Os experimentos foram realizados a temperatura de $24^{\circ} \mathrm{C}$ em um reômetro de cilindros concêntricos. Selecionou-se as emulsões de fração volumétrica 0,16 e 0,31 para serem comparadas com as emulsões desta tese de fração volumétrica 0,20 e 0,40 para a razão de viscosidade 5. Pela fig. 8.11 observa-se que a viscosidade aparente adimensional, da emulsão da presente tese está é semelhante á emulsão de Pal (1992). Não se pode dizer nada sobre o tamanho de gota e da sua polidispersidade devido a falta desses dados no trabalho de Pal (1992). O que se pode dizer é que a emulsão de fração volumétrica de $20 \%$ se comporta como um fluido newtoniano. Pela fig. 8.12 vê-se que a emulsão da presente tese e de Pal (1992) são idênticas exibindo uma ligeira perda de viscosidade com o aumento da tensão de cisalhamento.

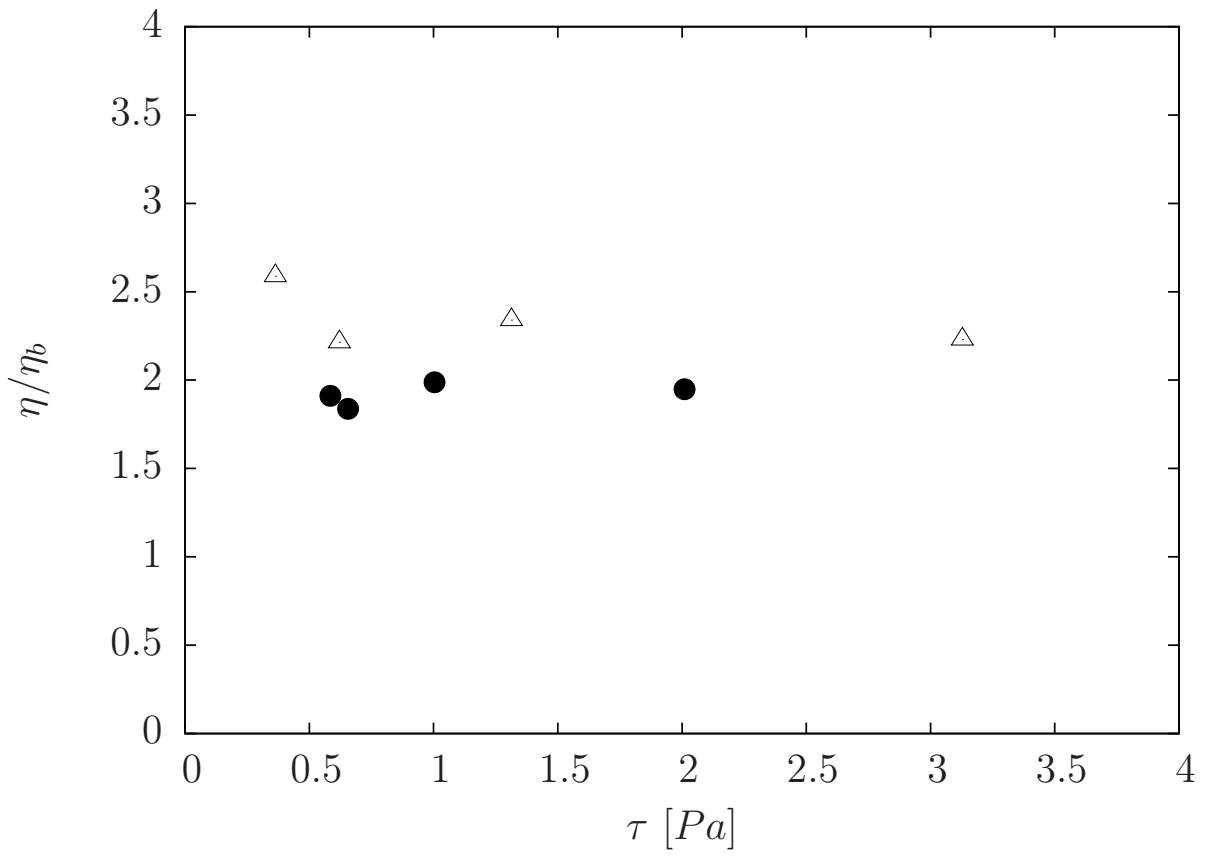

Figura 8.11: Variação da viscosidade aparente com a tensão de cisalhamento para a emulsão $\mathrm{O} / \mathrm{A}$ de $\lambda \approx 5$. $\bullet$ Pal (1992) $\phi=16 \%$ e $0,2 \%$ wt de surfactante ; $\triangle$ Presente Trabalho $\phi=20 \%$. 


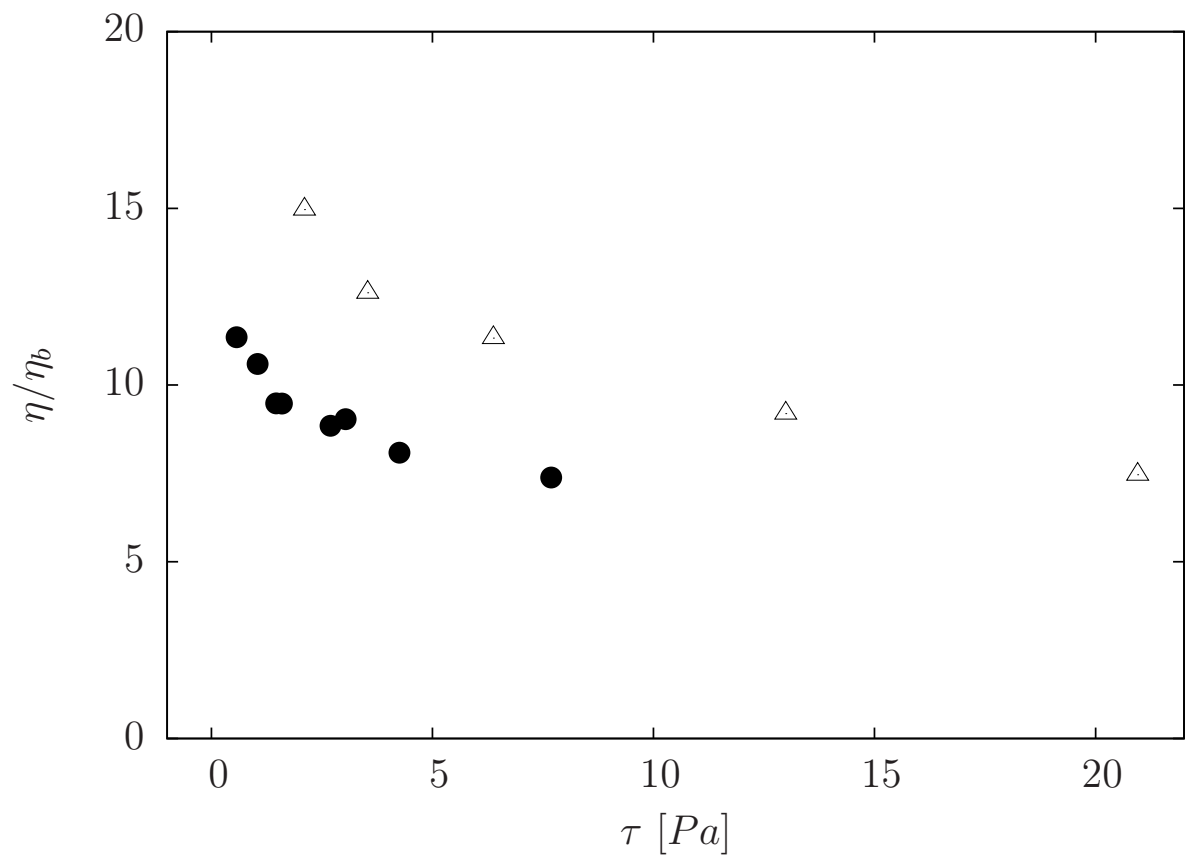

Figura 8.12: Variação da viscosidade aparente com a tensão de cisalhamento para a emulsão $\mathrm{O} / \mathrm{A}$ de $\lambda \approx 5$. • Pal (1992) $\phi=31 \%$ e 12,8 \%wt de surfactante ; $\triangle$ Presente Trabalho $\phi=40 \%$. 


\section{VISCOELASTICIDADE}

Diversos fluidos (soluções poliméricas, emulsões de alta fração volumétrica) têm características viscoelásticas que lhes conferem comportamento do tipo sólido e do tipo liquido. Estes materiais têm então uma componente elástica e uma componente viscosa. Os materiais com componente elástica têm um tempo de relaxação que é caracterizado pela recuperação da tensão após a interrupção instantânea da taxa de cisalhamento. Uma equação para fluidos em regime de viscosidade linear (pequenas taxas de deformação) pode ser escrita na forma (Oldroyd (1964)):

$$
\left(1+\alpha_{1} \frac{\partial}{\partial t}+\alpha_{2} \frac{\partial^{2}}{\partial t^{2}}+\alpha_{n} \frac{\partial^{n}}{\partial t^{n}}\right) \tau_{x y}=\left(\beta_{0}+\beta_{1} \frac{\partial}{\partial t}+\beta_{2} \frac{\partial^{2}}{\partial t^{2}}+\beta_{m} \frac{\partial^{m}}{\partial t^{m}}\right) \gamma
$$

em que, $\alpha_{n}$ e $\beta m$ são parâmetros materiais e $\tau_{x y}$ e $\gamma$ são respectivamente a tensão de cisalhamento e a deformação relativas ao cisalhamento simples.

O primeiro modelo para este tipo de fluidos foi proposto por Maxwell (Bird et al. (1987)). Este modelo pode ser representado pela associação em série de uma mola com um amortecedor. Sendo $\alpha_{1}$ e $\beta_{1}$ os únicos parâmetros da eq. 9.1 diferentes de zero e igualando $\beta_{1}$ à viscosidade $\eta$ obtém-se o modelo de Maxwell pode ser escrita em termos da seguinte integral de convolução:

$$
\boldsymbol{\tau}+\alpha_{1} \frac{\partial \tau}{\partial t}=\eta \dot{\gamma}
$$

em que, $\dot{\gamma}=\partial \gamma / \partial t=2 \boldsymbol{D}$ e $\alpha_{1}=\eta / G$ que é referido como o tempo de relaxação e $G$ como o módulo elástico. A equação constitutiva para o fluido de Maxwell pode ser escrita como:

$$
\boldsymbol{\tau}(t)=\int_{-\infty}^{t} \Phi_{M}\left(t-t^{\prime}\right) \boldsymbol{D}\left(t^{\prime}\right) d t^{\prime}
$$

em que, $\Phi_{M}\left(t-t^{\prime}\right)$ é designado por Módulo de Relaxação. No caso particular de um 
fluido de Maxwell:

$$
\Phi_{M}\left(t-t^{\prime}\right)=\frac{2 \eta}{\alpha_{1}} e^{-\left(t-t^{\prime}\right) / \alpha_{1}}
$$

A eq. 9.3 descreve a tensão no presente tempo $(t)$ como sendo função do estado de deformação atual e dos estados de deformação antecessores. Quanto mais distante um determinado estado de deformação estiver do atual menor será a sua contribuição para a tensão no presente tempo. Essa contribuição decai exponencialmente (eq.9.4). Este conceito é designado por "fading memory".

O modelo de Jeffrey é um modelo mais geral do que o modelo de Maxwell e inclui a derivada temporal $\partial \boldsymbol{D} / \partial t$ surgindo duas constantes temporais:

$$
\boldsymbol{\tau}+\alpha_{1} \frac{\partial \boldsymbol{\tau}}{\partial t}=2 \eta\left(\boldsymbol{D}+\alpha_{2} \frac{\partial \boldsymbol{D}}{\partial t}\right)
$$

A constante $\beta_{2}$ é designada como tempo de retardação (Bird et al. (1987)). A forma integral do modelo de Jeffrey é obtida usando a condição inicial que $\boldsymbol{\tau}, \boldsymbol{D}, \partial \boldsymbol{D} / \partial t$ sejam finitos para $t=-\infty$ :

$$
\boldsymbol{\tau}(t)=\int_{-\infty}^{t} \Phi_{J}\left(t-t^{\prime}\right) \boldsymbol{D}\left(t^{\prime}\right) d t^{\prime}
$$

em que, $\Phi_{J}\left(t-t^{\prime}\right)$ é designado por Módulo de Relaxação do modelo de Jeffrey:

$$
\Phi_{J}\left(t-t^{\prime}\right)=\frac{2 \eta_{0}}{\alpha_{1}}\left(1-\frac{\alpha_{2}}{\alpha_{1}}\right) e^{-\left(t-t^{\prime}\right) / \alpha_{1}}+4 \eta_{0} \frac{\alpha_{1}}{\alpha_{2}} \delta_{D}\left(t-t^{\prime}\right)
$$

em que $\delta_{D}$ é a distribuição delta de Dirac. Modelos mais complexos podem ser obtidos a partir da eq. 9.1 tomando outros parâmetros materiais diferente de zero.

Quando se compara os dois modelos apresentados vê-se que são formados por uma integral no intervalo de todos os tempos passados de um módulo de relaxação multiplicado por um tensor taxa de deformação. Assim pode-se representar estes modelos, e os mais complexos, por um modelo geral de viscoelasticidade linear:

$$
\boldsymbol{\tau}(t)=\int_{-\infty}^{t} \Phi\left(t-t^{\prime}\right) \boldsymbol{D}\left(t^{\prime}\right) d t^{\prime}
$$


em que $\Phi\left(t-t^{\prime}\right)$ é o módulo de relaxação de tensões.

\subsection{Escoamentos para capturar Propriedades Viscoelásticas}

Dentro do contexto experimental é possível capturar as propriedades viscoelásticas através de experimentos no regime de viscoelasticidade linear e não-linear. Nesse sentido descreve-se os diferentes tipos de experimentos relacionando-os com as propriedades reológicas dos fluidos que se podem medir.

\subsubsection{Cisalhamento Oscilatório em Pequena Amplitude (SAOS)}

Este tipo de cisalhamento é realizado na região de viscoelasticidade linear e é proposto para medir a resposta transiente da amostra de fluido. No reômetro a amostra é colocada entre os dois discos. O disco superior se desloca com pequenas oscilações sinusoidais com frequência $\omega$ promovendo a deformação do fluido por cisalhamento:

$$
\gamma(t)=\gamma_{0} \operatorname{sen}(\omega t)
$$

em que $\gamma_{0}$ é a amplitude de deformação. Derivando $\gamma(t)$ no tempo encontra-se a taxa de deformação (ou taxa de cisalhamento):

$$
\dot{\gamma}(t)=\dot{\gamma}_{0} \cos (\omega t)
$$

com $\dot{\gamma}_{0}=\omega \gamma_{0}$. Para um fluido Newtoniano a tensão de cisalhamento está em fase com a taxa de de deformação e não existe tensões normais. No entanto, para fluido não-Newtoniano a tensão de cisalhamento não está em fase com $\gamma(t)$ e $\dot{\gamma}(t)$ :

$$
\tau_{x y}=A(\omega) \gamma_{0} \operatorname{sen}(\omega t+\alpha), 0 \leq \alpha \leq \pi / 2
$$

Pode-se escrever a eq. 9.11 em função de $\dot{\gamma}_{0}$ :

$$
\tau_{x y}=B(\omega) \dot{\gamma}_{0} \cos (\omega t-\beta), 0 \leq \beta \leq \pi / 2
$$


em que $\alpha$ é a diferença de fase entre a onda de deformação e a resposta da tensão e $\beta=\pi / 2-\alpha$. Recorrendo a expressões trigonométricas escreve-se para a eq. 9.11:

$$
\tau_{x y}=A(\omega) \gamma_{0} \cos (\alpha) \operatorname{sen}(\omega t)+A(\omega) \gamma_{0} \operatorname{sen}(\alpha) \cos (\omega t)
$$

e para a eq. 9.12

$$
\tau_{x y}=B(\omega) \dot{\gamma}_{0} \cos (\beta) \operatorname{sen}(\omega t)+B(\omega) \dot{\gamma}_{0} \operatorname{sen}(\beta) \cos (\omega t)
$$

É habitual re-escrever as eqs. 9.11 e 9.12 de forma a explicitar as componentes da tensão de cisalhamento que estão em fase e fora de fase com $\gamma(t)$ e $\dot{\gamma}(t)$ :

$$
\tau_{x y}=G^{\prime}(\omega) \gamma_{0} \operatorname{sen}(\omega t)+G^{\prime \prime}(\omega) \gamma_{0} \cos (\omega t)
$$

e para a eq. 9.12

$$
\tau_{x y}=\eta^{\prime}(\omega) \dot{\gamma}_{0} \cos (\omega t)+\eta^{\prime \prime}(\omega) \dot{\gamma}_{0} \operatorname{sen}(\beta) \cos (\omega t)
$$

em que: $G^{\prime}(\omega)=A(\omega) \cos (\alpha)$ (componente em fase com $\gamma$, parte elástica), $G^{\prime \prime}(\omega)=$ $A(\omega) \operatorname{sen}(\alpha)$ (componente fora de fase com $\gamma$, parte viscosa); $\eta^{\prime}(\omega)=(\omega) \cos (\beta)(\operatorname{com}-$ ponente em fase com $\dot{\gamma}$ : parte viscosa), $\eta^{\prime \prime}(\omega)=B(\omega) \operatorname{sen}(\beta)$ (componente fora de fase com $\dot{\gamma}$, parte elástica). Assim define-se que:

$$
A(\omega)=\sqrt{G^{2}+G^{\prime \prime 2}}=\left|G^{*}\right|, \tan (\alpha)=G^{\prime \prime} / G^{\prime}
$$

e

$$
B(\omega)=\sqrt{\eta^{\prime 2}+\eta^{\prime 2}}=\left|\eta^{*}\right|, \tan (\beta)=\eta^{\prime \prime} / \eta^{\prime}
$$

em que $\left|G^{*}\right|$ é a magnitude do módulo complexo e $\left|\eta^{*}\right|$ é a magnitude da viscosidade complexa. O módulo complexo está relacionado com a viscosidade complexa:

$$
G^{*}=G^{\prime}(\omega)+i G^{\prime \prime}(\omega)=i \omega \eta^{*}(\omega)=\omega \eta^{\prime \prime}(\omega)+i \omega \eta^{\prime} \omega
$$

Devido a $G^{\prime}, G^{\prime \prime}, \eta^{\prime}$ e $\eta^{\prime \prime}$ determinarem a tensão de cisalhamento que é linear com a 
deformação (ou com a taxa de deformação), estas funções materiais são designadas por propriedades viscoelásticas lineares. No sentido de entender o que as propriedades viscoelásticas lineares representam, $G^{\prime}$ é equivalente ao módulo de elasticidade $(G)$ para um sólido puramente elástico $\left(G^{\prime \prime}=0\right)$. Para um fluido Newtoniano $\eta^{\prime}$ é igual à viscosidade dinâmica $(\eta)$ e $\eta^{\prime \prime}=0$. Por este motivo $G^{\prime}$ é designado de módulo de armazenamento que está associado ao carácter elástico do fluido ou com a energia armazenada que ocorre durante a deformação, $G^{\prime \prime}$ é designado por módulo de perda que está associado ao carácter viscoso do fluido ou à dissipação de energia durante o escoamento e $\eta^{\prime}$ é designada por viscosidade dinâmica.

O habitual é realizar-se experimentos em cisalhamento oscilatório para averiguar a faixa de viscoelasticidade linear do fluido. Dos experimentos de viscoelasticidade linear podese determinar a viscosidade do fluido e o tempo de relaxação. Para tal é definido uma frequência de oscilação, $f,(\omega=2 \pi f$; típico $\omega=1-10 \mathrm{rad} / \mathrm{s})$ na qual é avaliado $G^{\prime}$ e $G^{\prime \prime}$ em função da amplitude $\left(\gamma_{0}=0,01-100 \%\right)$. A região linear é detectada no intervalo em que $G^{\prime}$ e $G^{\prime \prime}$ não dependem de $\gamma_{0}$. Este experimento é designado por "Amplitude Sweep Test". Para detectar quando o material passa de um comportamento sólido para um comportamento de liquido seleciona-se um $\gamma_{0}$ dentro do regime linear e varia-se a frequência $(\omega=100-0,1 \mathrm{rad} / \mathrm{s})$. A este experimento se dá o nome de "Frequency Sweep Test"(Teste de Varramento de Frequência). O ponto em que a curva de $G^{\prime}$ intersecta a curva de $G^{\prime \prime}$ é designado de "Yield Point"(Ponto Crítico). Este ponto representa a condição em que o fluido passa de um comportamento sólido para um comportamento líquido.

\subsubsection{Resultados Experimentais}

As emulsões de baixas frações volumétricas não apresentam efeitos viscoelásticos. Aqui analisa-se o comportamento viscoelástico de emulsões com fração volumétrica maior do que $40 \%$ para diferentes razões de viscosidade. Novamente, os experimentos foram realizados no reômetro da Anton-Paar do modelo MCR-301 à temperatura de $25^{\circ} \mathrm{C}$.

A caracterização inicial de um fluido não Newtoniano consiste em verificar a curva 
característica da viscosidade em função da taxa de cisalhamento. Para tal, 0,8 $\mathrm{ml}$ de emulsão foi colocada entre os discos do reômetro. A fig. 9.1 representa a variação da viscosidade em função do aumento da taxa de cisalhamento para várias frações volumétricas de gotas. Estes testes foram repetidos diversas vezes até se conseguir obter curvas de viscosidade idênticas. Pode-se observar que a viscosidade efetiva aumenta com a fração volumétrica, e que as emulsões apresentam uma viscosidade superior à viscosidade do fluido base. Porém neste caso a viscosidade da emulsão de fração volumétrica $50 \%$ foi idêntica à fração volumétrica $60 \%$. De um ponto de vista físico, devido a alta razão de viscosidade a deformação das gotas não é significativa. Com o aumento da quantidade de gotas (aumento da fração volumétrica para 70\%) as gotas vizinhas já têm influência em uma gota teste aumentando o efeito pseudo-plástico (diminuição da viscosidade com o aumento da taxa de cisalhamento). Quanto à emulsão de fração volumétrica $70 \%$ destaca-se a região do aumento de viscosidade nas menores taxas de cisalhamento. Nesta faixa de taxa de cisalhamento a escala de tempo do escoamento é maior que a escala de tempo de deformação da gota. Esse efeito é adicionado à possível formação de conjunto de gotas que se comportam como se fosse um corpo rígido, aumento a viscosidade do fluido. Com o aumento da taxa de cisalhamento a escala de tempo do escoamento começa a ser menor do que a escala de tempo da deformação da gota, promovendo à deformação das gotas e a queda de viscosidade. A viscosidade decaí até ser atingido o seu regime permanente, onde as gotas permanecem com deformação constante.

O método de extrair os módulos de viscoelasticidade designado na literatura por LAOS (Large Amplitude Oscillatory Shear) permite monitorizar a estabilidade da estrutura de emulsões concentradas (Masalov (2011)). Este tipo de experimento consiste em observar a resposta da emulsão com relação aos módulos $G^{\prime}$ e $G^{\prime \prime}$ quando se aumenta de forma progressiva a deformação $\gamma$ para uma determinada frequência. Os experimentos apresentados nesta seção foram realizados com $f=0,8 H z$ A fig. 9.2 mostra os resultados sobre o comportamento viscoelástico da emulsão $\phi=50 \%$ e $\lambda=10$. O que se observa é que a emulsão se comporta mais como um líquido $\left(G^{\prime \prime}>G^{\prime}\right)$ em toda a faixa de deformação $(\gamma)$. Os módulos $G^{\prime}$ e $G^{\prime \prime}$ mantêm-se constante em praticamente toda a faixa de deformação. Para uma deformação maior do que 0,01 a emulsão apresenta 


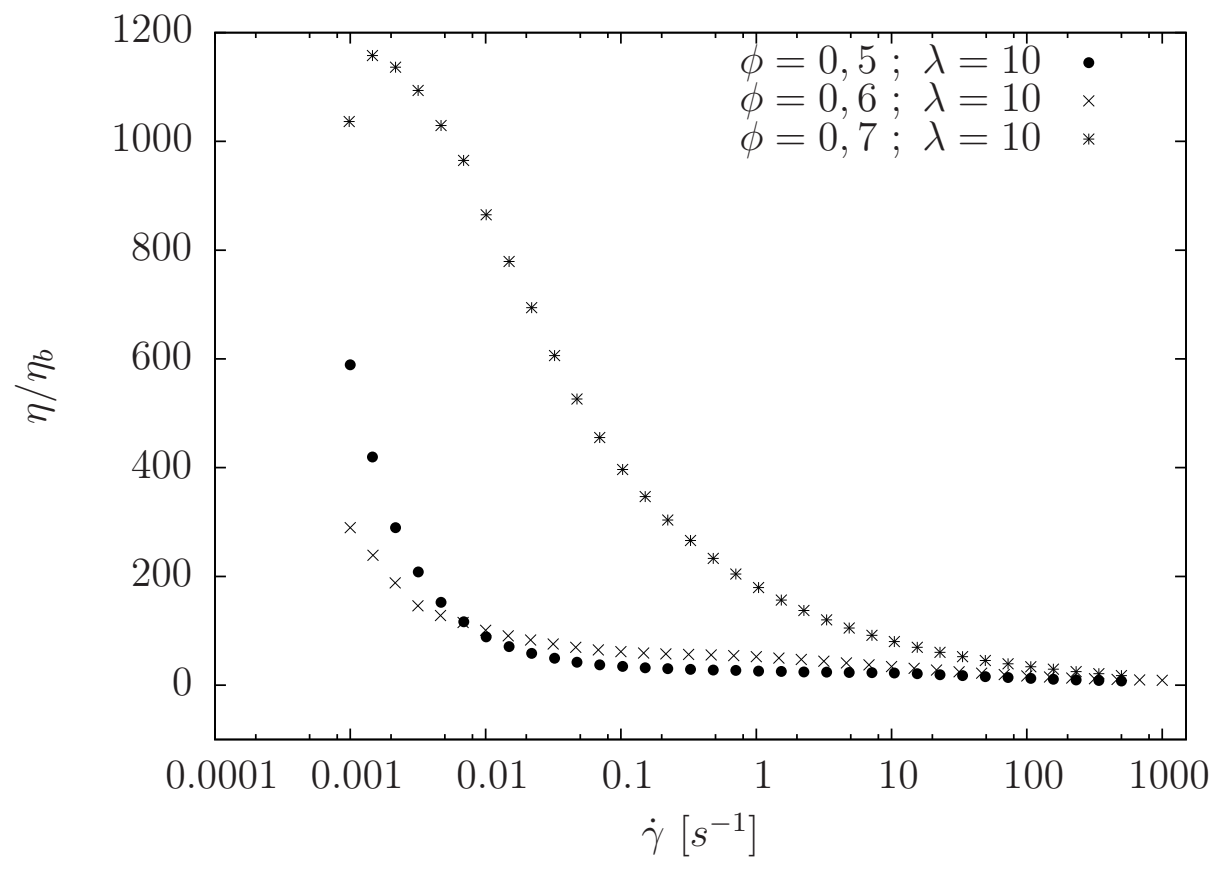

Figura 9.1: Variação da viscosidade com o aumento da taxa de cisalhamento para emulsões com razão de viscosidade 10 de diferentes frações volumétricas.

uma região de viscoelasticidade não-linear. Para maiores deformações observa-se um decaimento de $G^{\prime}$ refletindo uma perda de elasticidade, acompanhando o decaimento suave de $G^{\prime \prime}$. A queda dos valores dos módulos está associada com a deformação e orientação das gotas e com a interação hidrodinâmica gota-gota.

A fig. 9.3 apresenta a variação dos módulos de viscoelasticidade em função da deformação para $\phi=60 \%$ e $\lambda=10$. Observa-se que o comportamento qualitativo é idêntico à emulsão de fração volumétrica 50\%. No entanto, a emulsão $60 \%$ apresenta uma maior queda no módulo relacionado com a parte elástica da emulsão para as maiores deformações indicando que a microestrutura sofreu significativas modificações produzida pela deformação das gotas e anisotropia e interação gota-gota. Sugere-se experimentos com diferentes emulsões mas com a mesma fração volumétrica e razão de viscosidade para melhor apurar este comportamento. 


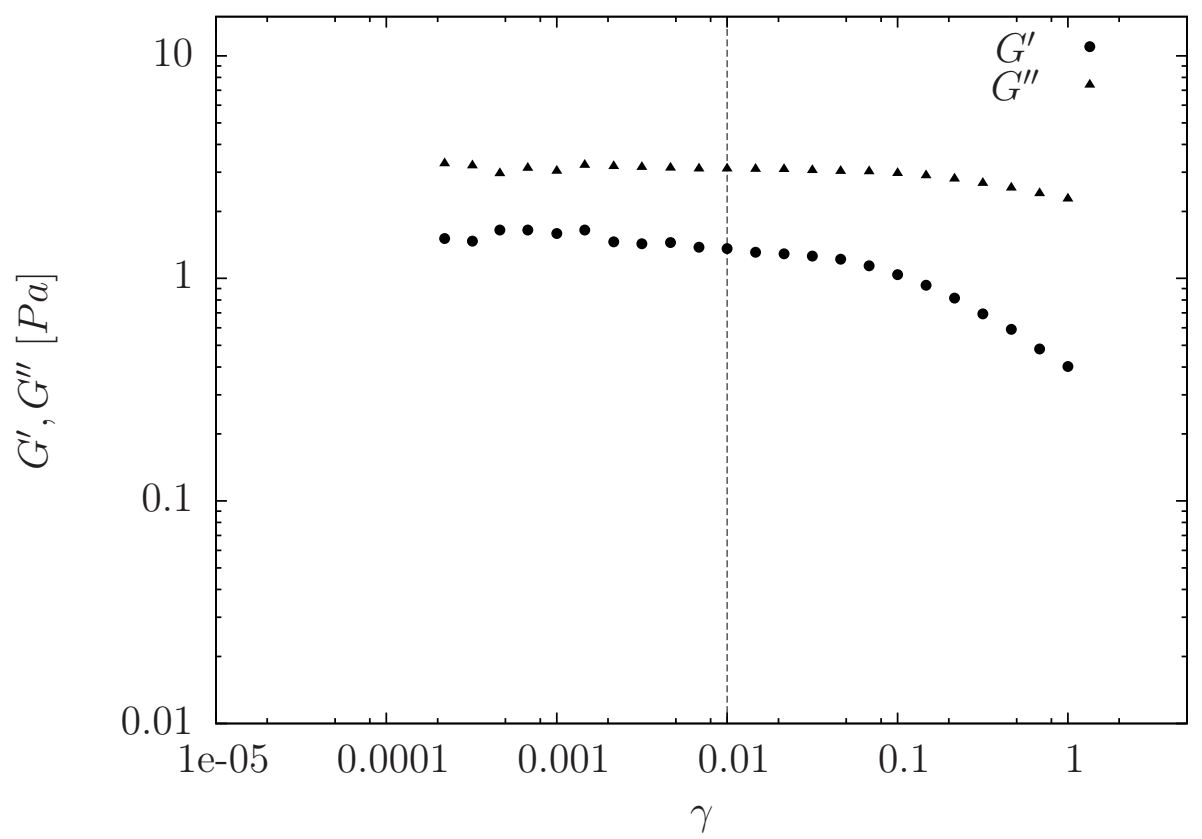

Figura 9.2: Variação dos módulos viscoelásticos $\left(G^{\prime}, G^{\prime \prime}\right)$ em função da deformação $(\gamma)$ da emulsão de $\phi=50 \%$ e $\lambda=10 \mathrm{com} \omega=5 \mathrm{rad} / \mathrm{s} . \quad \gamma<0,01$ : Regime de Viscoelasticidade Linear. $\gamma \geq 0,01$ : Regime de Viscoelasticidade Não-Linear.

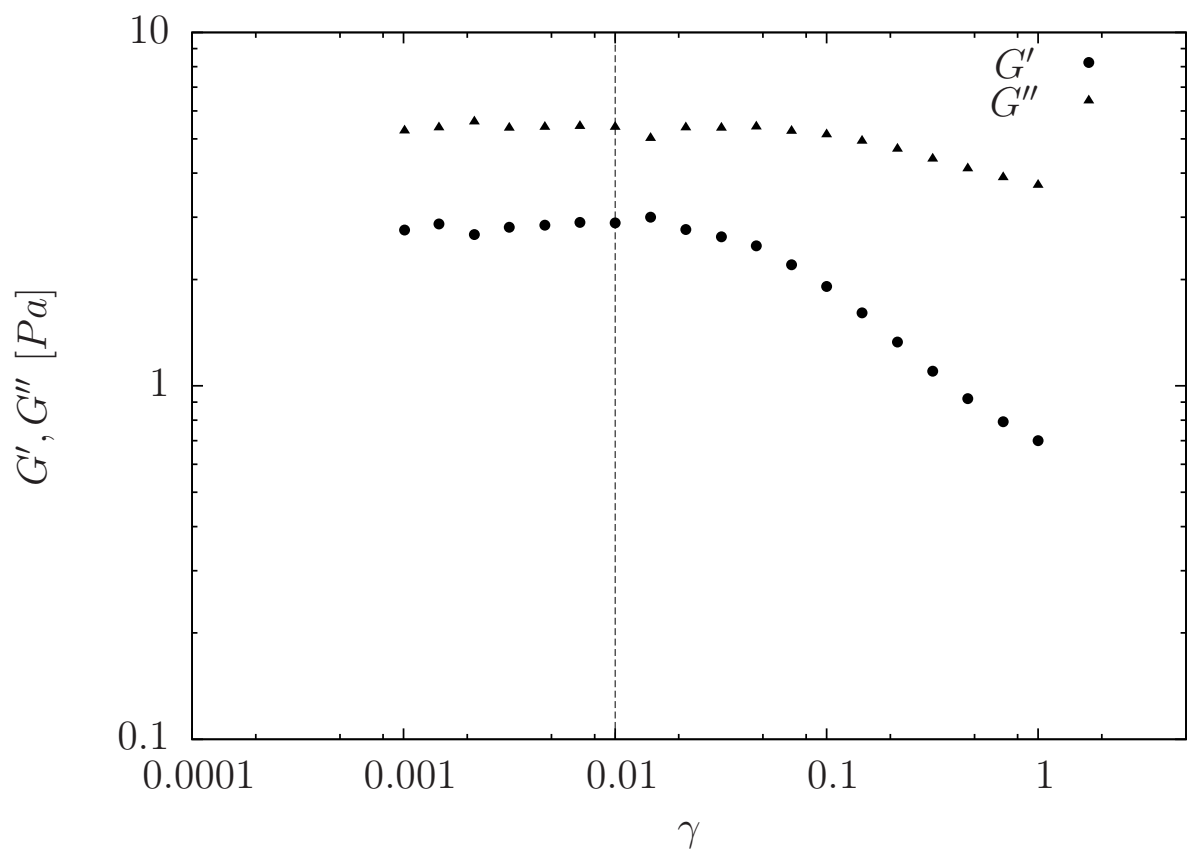

Figura 9.3: Variação dos módulos viscoelásticos $\left(G^{\prime}, G^{\prime \prime}\right)$ em função da deformação $(\gamma)$ da emulsão de $\phi=60 \%$ e $\lambda=10 \mathrm{com} \omega=5 \mathrm{rad} / \mathrm{s} . \quad \gamma<0,01$ : Regime de Viscoelasticidade Linear. $\gamma \geq 0,01$ : Regime de Viscoelasticidade Não-Linear.

A fig. 9.4 apresenta resultados de $G^{\prime}$ e $G^{\prime \prime}$ em função da deformação $\gamma$ para $\phi=70 \%$ e $\lambda=10$. Observa-se que para deformações moderadas os módulos de elasticidade coincidem representando um comportamento na transição de sólido para líquido de- 
vido ao aumento da fração volumétrica. Após esse estágio, o aumento da deformação provoca um decréscimo dos módulos viscoelásticos. Esse decréscimo representa a diminuição (efeito pseudo-plástico) de viscosidade devido à deformação das gotas e como consequência o decréscimo da propriedade elástica da emulsão.

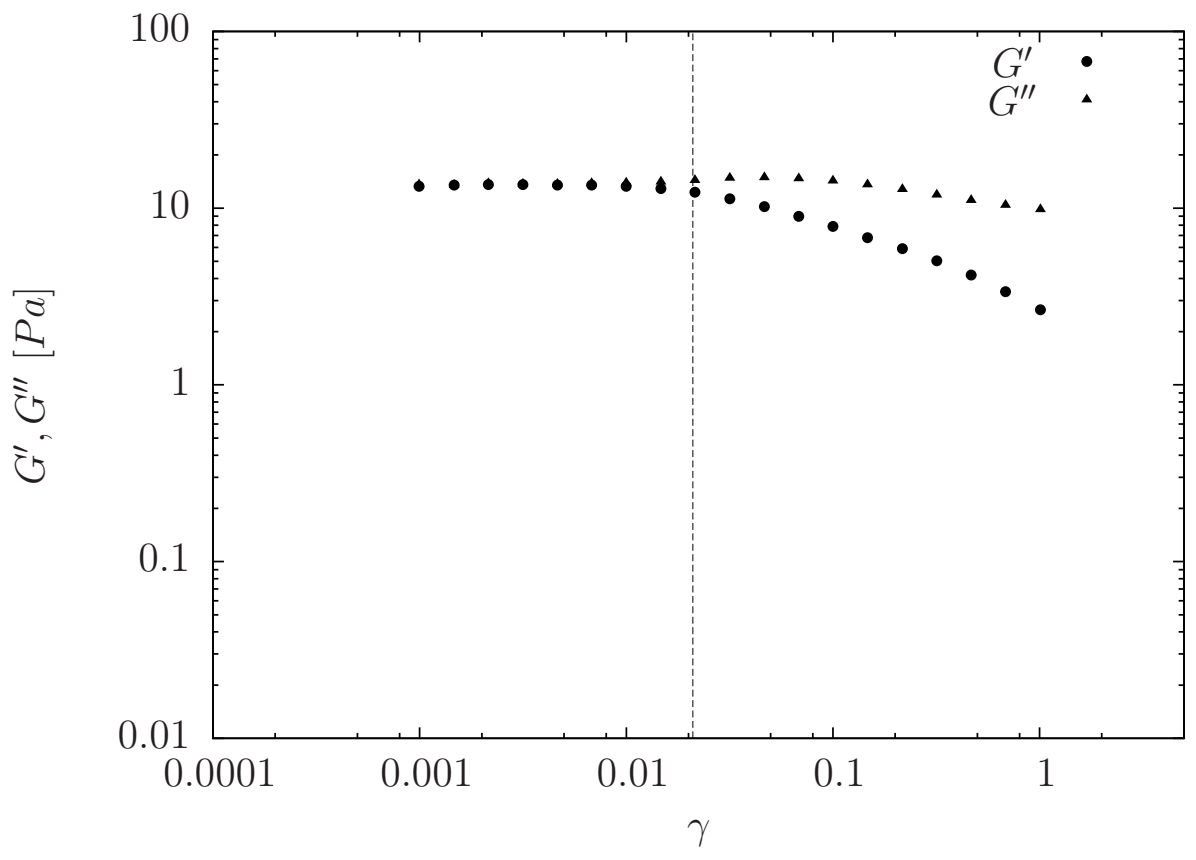

Figura 9.4: Variação dos módulos viscoelásticos $\left(G^{\prime}, G^{\prime \prime}\right)$ em função da deformação $(\gamma)$ da emulsão de $\phi=70 \%$ e $\lambda=10 \mathrm{com} \omega=5 \mathrm{rad} / \mathrm{s} . \quad \gamma<0,02$ : Regime de Viscoelasticidade Linear. $\gamma \geq 0,02$ : Regime de Viscoelasticidade Não-Linear.

A fig. 9.5 mostra a variação dos módulos viscoelásticos em função da deformação para a emulsão de fração volumétrica $70 \%$ e razão de viscosidade 20. Observa-se que para deformações menores o fluido apresenta uma característica de sólido $\left(G^{\prime \prime}<G^{\prime}\right)$. Comparando a fig. 9.4 com a fig. 9.5 observa-se que $G^{\prime \prime}$ diminuiu em relação a $G^{\prime}$ indicando que o aumento da razão de viscosidade aumenta a característica sólida da emulsão em baixas deformações. Para as maiores deformações a emulsão apresenta um comportamento semelhante as demais já analisadas.

A razão de viscosidade está associada com a propriedade elástica das gotas. Desta forma, as gotas de emulsões de maior razão de viscosidade apresentam menores deformações. Por outro lado, a polidispersidade e a formação de aglomerados de gotas são características da emulsão que afetam a reologia. A queda mais acentuada dos módulos 
de viscoelasticidade com aumento da razão de viscosidade está associada com a deformação das gotas, com a interação gota-gota e com a separação das gotas presentes nos aglomerados. Esses conjunto de efeitos propiciam o aparecimento de maiores efeitos não lineares em emulsões de maior fração volumétrica.

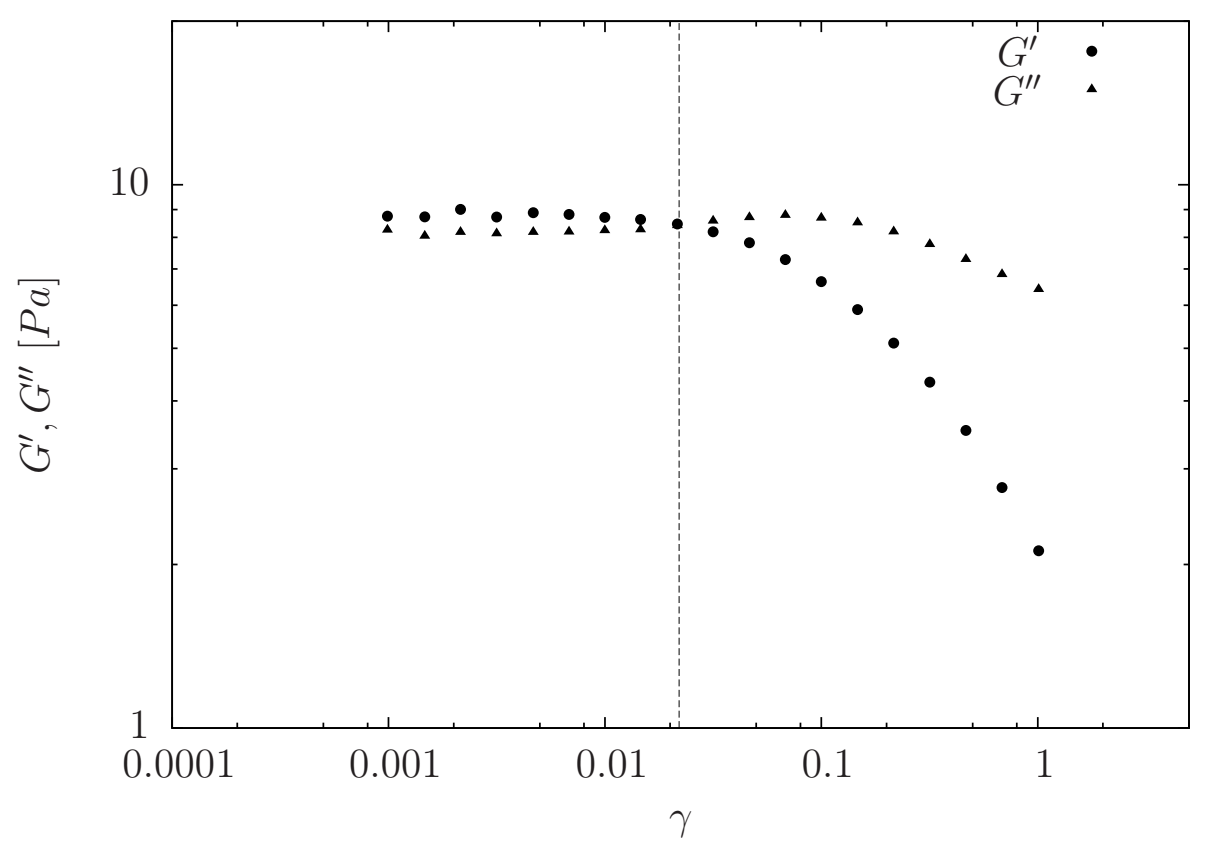

Figura 9.5: Variação dos módulos viscoelásticos $\left(G^{\prime}, G^{\prime \prime}\right)$ em função da deformação $(\gamma)$ da emulsão de $\phi=70 \%$ e $\lambda=20 \mathrm{com} \omega=5 \mathrm{rad} / \mathrm{s} . \quad \gamma<0,022$ : Regime de Viscoelasticidade Linear. $\gamma \geq 0,022$ : Regime de Viscoelasticidade Não-Linear.

O comportamento das emulsões por cisalhamento oscilatório foi analisado para uma deformação constante de 0,006, que é inferior a 0,01, com o aumento da frequência. Ou seja, em termos da deformação os experimentos foram realizados no regime de viscoelasticidade linear. A fig. 9.6 apresenta um gráfico típico desses experimentos. Nestes testes é de interesse avaliar para que frequência os módulos de viscoelasticidade são iguais, representando o ponto a partir do qual existe uma queda da característica elástica da emulsão. A tab. 9.1 apresenta para as emulsões analisadas a frequência onde os módulos elásticos são iguais.

Tabela 9.1: Ponto crítico $\left(G^{\prime}=G^{\prime \prime}\right)$ para as emulsões analisadas.

\begin{tabular}{|c|c|c|c|}
\hline$\phi(\%)$ & $\lambda$ & $G^{\prime}=G^{\prime \prime}[\mathrm{Pa}]$ & $f[\mathrm{~Hz}]$ \\
\hline 50 & 10 & 10,80 & 14,10 \\
60 & 10 & 11,72 & 7,46 \\
70 & 10 & 11,6 & 2,11 \\
70 & 20 & 3,42 & 0,17 \\
\hline
\end{tabular}




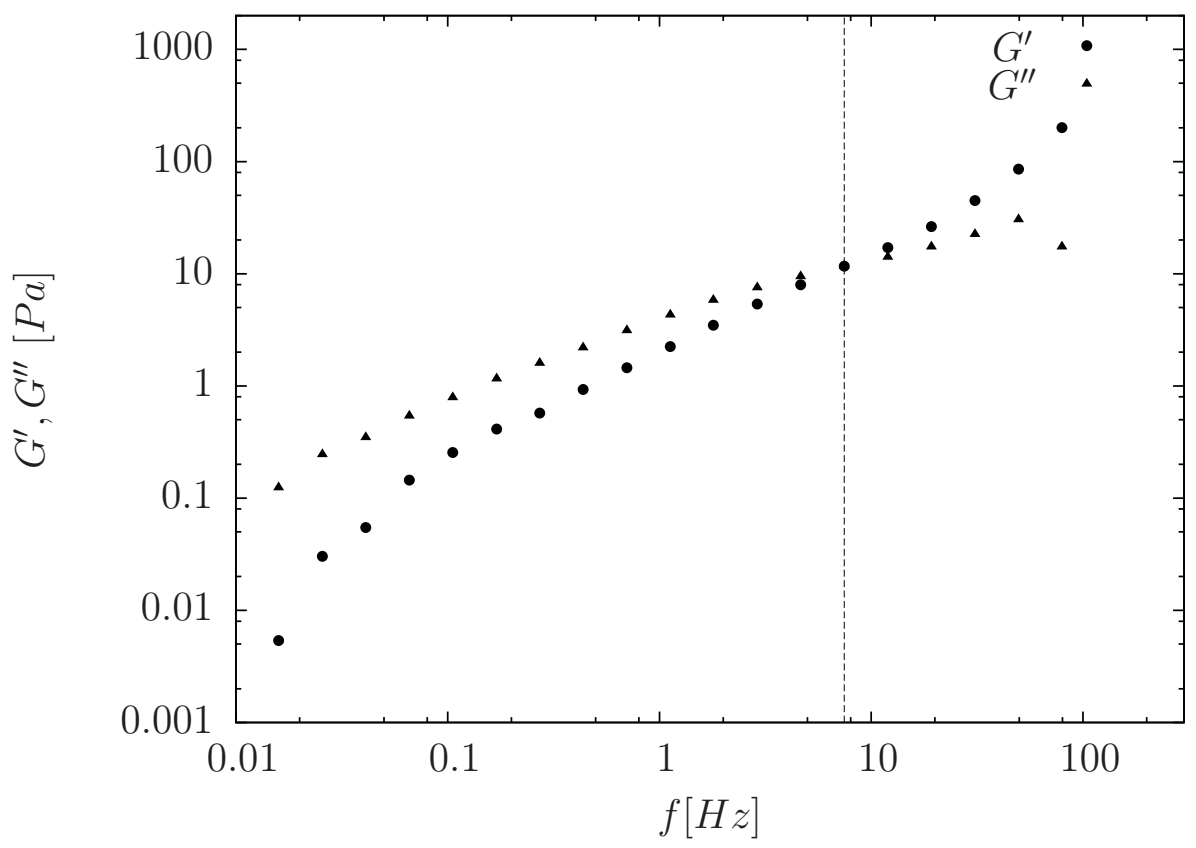

Figura 9.6: Módulos viscoelásticos $\left(G^{\prime}, G^{\prime \prime}\right)$ em função da frequência $(\gamma)$ no regime linear $(\gamma=0,006)$ para a emulsão de fração volumétrica $\phi=60 \%$ e $\lambda=10$.

Nesta seção analisou-se o comportamento viscoelástico de emulsões de altas frações volumétricas e de altas razões de viscosidade por experimentos em cisalhamento oscilatório transiente. Observou-se que o módulo elástico $G^{\prime}$ é mais sensível a variações de $\gamma$. Este acontecimento está associado com a deformação de gotas e à deformação induzida pela interação gota-gota. Isso é um efeito que afeta mais a propriedade elástica da emulsão do que a viscosa. Verificou-se que para frações volumétricas menores que $70 \%$ a emulsão se comporta mais como um líquido viscoso $\left(G^{\prime \prime}>G^{\prime}\right)$ em toda a faixa de deformação $(\gamma)$. Para as emulsões de fração volumétrica $70 \%$ o comportamento como característica de sólido em baixas deformações começa a estar presente. Para esta fração volumétrica verificou-se que o aumento da razão de viscosidade de 10 para 20 acentuou o comportamento de sólido em baixas deformações (diminuição de $G^{\prime \prime}$ em relação a $G^{\prime}$ ). Em altas deformações todas as emulsões apresentaram um decréscimo de $G^{\prime \prime}$ e $G^{\prime}$ associado a uma queda de viscosidade (efeito pseudo-plástico) devido à deformação das gotas e como consequência uma diminuição da característica elástica do fluido devido à deformação e orientação das gotas além da deformação induzida por interação gota-gota. É de notar que a transição de comportamento sólido-líquido nas emulsões de $70 \%$ foi verificado nas proximidades de $\gamma=0,01$. O mesmo foi detectado por outros autores em experimentos de emulsões concentradas (Masalov (2011)). 


\section{REOLOGIA DE FLUIDOS MAGNÉTICOS EM CISALHAMENTO PERMANENTE E TRANSIENTE}

O interesse pelo estudo de fluidos magnéticos foi abordado na Secção 1.2.3. Na próxima seção é obtida a equação governante para o movimento destes fluidos em cisalhamento.

\subsection{Fundamentação Teórica}

A área que estuda o escoamento de um fluido magnético na presença de um campo magnético é designada por Ferrohidrodinâmica. Para descrever o escoamento destes fluidos é necessário acoplar as equações de Maxwell do electromagnetismo às equações da hidrodinâmica de fluidos incompressíveis dada pela equação de Cauchy que estabelece o balanço de forças que rege o movimento de um meio contínuo (Batchelor (1970), Happel e Brenner (1965)).

$$
\rho \frac{D \boldsymbol{u}}{D t}=\nabla \cdot \boldsymbol{\Sigma}+\rho \boldsymbol{b}
$$

em que $\boldsymbol{u}$ é o vetor campo velocidade, $\rho$ é a massa específica, $\boldsymbol{b}$ é a força de campo por unidade de massa e $\boldsymbol{\Sigma}$ é o tensor de tensões de $2^{\mathrm{a}}$ ordem. Devido as interações de partícula-partícula, partícula-campo e partícula-fluido surgem tensões extras. Estas tensões surgem da anisotropia microestrutural do fluido magnético devido à orientação preferencial das partículas na direção do campo. Assim o tensor de tensões de um fluido magnético incorpora a contribuição magnética $\left(\boldsymbol{\Sigma}_{m}\right)$ à contribuição puramente hidrodinâmica $\left(\boldsymbol{\Sigma}_{h}\right)$ :

$$
\Sigma=\Sigma_{h}+\Sigma_{m}
$$

em que $\boldsymbol{\Sigma}_{h}=\mathcal{F}(\boldsymbol{I}, \boldsymbol{D})$ onde $\boldsymbol{I}$ é o tensor identidade e $\boldsymbol{D}$ é o tensor taxa de deformação, e $\boldsymbol{\Sigma}_{m}=\mathcal{G}\left(\boldsymbol{I}, \boldsymbol{H} \boldsymbol{B}_{m}\right)$ onde $\boldsymbol{H}$ é o vetor intensidade campo magnético e $\boldsymbol{B}_{m}$ é o vetor indução magnética os quais formam um tensor de segunda ordem $H_{i} B_{j}$ que em geral não é simétrico. 
Com o intuito de se obter uma equação constitutiva para o tensor magnético apresentamse as equações de Maxwell para o electromagnetismo. A lei de Gauss relaciona a taxa líquida de um vetor campo elétrico $\boldsymbol{E}_{e}$ com a carga $q$ no interior de uma superfície fechada $S$ pertencente a um volume $V$. Integrando a Lei de Gauss em toda a superfície e usando o Teorema da Divergência, obtém-se que:

$$
\int_{S} \boldsymbol{E}_{e} \cdot \boldsymbol{n} d S=\int_{V} \nabla \cdot \boldsymbol{E}_{e} d V=\frac{q}{\epsilon_{0}}
$$

em que $\boldsymbol{E}_{e} \cdot \boldsymbol{n} d S$ é o fluxo de campo elétrico e $\epsilon_{0}$ é a permissividade do vácuo $(8,854 \times$ $10^{-12}$ coulomb $\left.^{2} /\left(\mathrm{Nm}^{2}\right)\right)$. No contexto da Mecânica dos Meios Contínuos, a aplicação do Teorema da Localização permite transformar uma formulação integral para uma diferencial resultando na validade da Lei de Gauss em qualquer escala da região contínua $V$. Daqui resulta que:

$$
\nabla \cdot \boldsymbol{E}_{e}=\frac{\rho_{q}}{\epsilon_{0}}
$$

Para dielétricos, $\rho_{q}=\rho_{l}+\rho_{p}$, em que $\rho_{l}$ é a densidade de cargas livres e $\rho_{p}=\nabla \cdot \mathcal{P}$ é a densidade de cargas polarizadas em que $\mathcal{P}$ é o vetor de polarização do dielétrico. Portanto:

$$
\nabla \cdot\left(\epsilon_{0} \boldsymbol{E}_{e}+\mathcal{P}\right)=\rho_{l}
$$

Define-se que o vetor fluxo de deslocamento elétrico é $\mathcal{D}=\epsilon_{0} \boldsymbol{E}_{e}+\mathcal{P}$,

$$
\nabla \cdot \mathcal{D}=\rho_{l}
$$

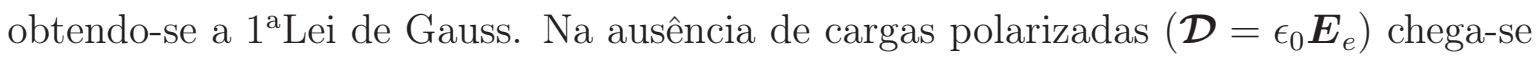
a $1^{\text {a} E q u a c ̧ a ̃ o ~ d e ~ M a x w e l l ~}$

$$
\nabla \cdot \mathcal{D}=\epsilon_{0} \nabla \cdot \boldsymbol{E}_{e}=\rho_{q}
$$

O vetor indução magnética ou densidade de fluxo magnético $\left(\boldsymbol{B}_{m}\right)$ é conhecido como Lei de Biot-Savart (Landau e Lifshitz,(1984), Grant e Philips (1990)):

$$
\boldsymbol{B}_{m}=\frac{\mu_{0}}{4 \pi} I \int_{C} \frac{d l \times \hat{\boldsymbol{r}}}{r^{2}} d C
$$

em que $\boldsymbol{B}_{m}$ é medido em Tesla no sistema internacional de unidades (S.I.) ou Gauss no sistema CGS que corresponde a $10^{-4} \mathrm{~T}$. O elemento de campo induzido pela corrente 
$d I=\boldsymbol{J} \cdot \boldsymbol{n} d S=\boldsymbol{J} \cdot d \boldsymbol{S}$ é escrito como:

$$
\boldsymbol{B}_{m}=\frac{\mu_{0}}{4 \pi} \boldsymbol{J}(d \boldsymbol{S} \cdot d l) \times \frac{\hat{\boldsymbol{r}}}{r^{2}} .
$$

Integrando em todo o volume resulta na representação integral de campo induzido em um dado espaço localizado pelo vetor $\boldsymbol{r}=r \hat{\boldsymbol{r}}$

$$
\boldsymbol{B}_{m}=\frac{\mu_{0}}{4 \pi} \int_{V} \frac{\boldsymbol{J} \times \hat{\boldsymbol{r}}}{r^{2}} d V
$$

O decaimento lento $\left(1 / r^{2}\right)$ indica que o campo $\boldsymbol{B}_{m}$ é de longo alcance. É possível

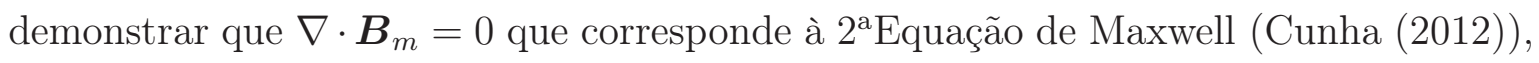
significando que não existes fontes ou sumidouros de indução magnética que leve a uma divergente de $\boldsymbol{B}_{m}$ não nulo. Integrando a $2^{\text {a} E q u a c ̧ a ̃ o ~ d e ~ M a x w e l l ~ e m ~ u m ~ v o l u m e ~}$ material contínuo $V$ limitado pela superfície $S$ :

$$
\int_{V} \nabla \cdot \boldsymbol{B}_{m} d V=\int_{S} \boldsymbol{B}_{m} \cdot \boldsymbol{n} d S=0
$$

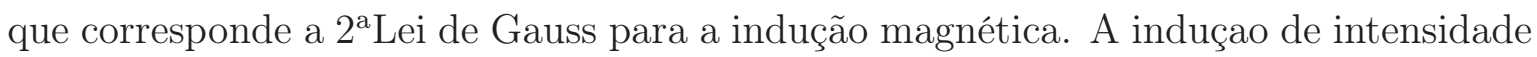
de campo $\boldsymbol{H}$ vem da Lei de Gauss aplicada a pólos magnéticos puntiformes (Grant e Philips (1990)):

$$
\boldsymbol{H}=\frac{\mathcal{P} \hat{\boldsymbol{r}}}{4 \pi \mu_{0} r^{2}}
$$

em que $\boldsymbol{H}$ no S.I. é medido em $\mathrm{A} / \mathrm{m}$ (ampere por metro). No vácuo:

$$
\boldsymbol{H}=\frac{\mathcal{P} \hat{\boldsymbol{r}}}{4 \pi \mu_{0} r^{2}}
$$

No vácuo

$$
\boldsymbol{B}_{m}=\mu_{0} \boldsymbol{H}
$$

assim:

$$
\boldsymbol{B}_{m}=\frac{\mathcal{P} \hat{\boldsymbol{r}}}{4 \pi r^{2}}
$$

que é o campo magnético induzido nas vizinhanças de um pólo de intensidade $\mathcal{P}$. O campo $\boldsymbol{H}$ em uma posição do espaço $\boldsymbol{r}$ produzido por uma distribuição de $N_{p}$ 
singularidades ou pólos puntiformes $\mathcal{P}_{k}$ localizados nas posições $\boldsymbol{r}_{k}$ é:

$$
\boldsymbol{H}=\sum_{i=1}^{N_{p}} \frac{\mathcal{P}_{k}}{4 \pi \mu_{0}} \frac{\left(\boldsymbol{r}-\boldsymbol{r}_{k}\right)}{\left|\boldsymbol{r}-\boldsymbol{r}_{k}\right|^{3}}
$$

Calculando o rotacional de $\boldsymbol{H}$ é possível mostrar que (Cunha (2012)) :

$$
\nabla \times \boldsymbol{H}=0
$$

A Lei de Faraday relaciona a circulação do vetor campo elétrico em um circuito fechado $C$ com a variação temporal da densidade de fluxo magnético que atravessa a superfície $A$ limitada por $C$ :

$$
\int_{C} \boldsymbol{E}_{e} \cdot d l=-\frac{D}{D t} \int_{A} \boldsymbol{B}_{m} \cdot n d A
$$

Do Teorema de Leibniz (Aris (1962)) tem-se que:

$$
\frac{D}{D t} \int_{A} \boldsymbol{B}_{m} \cdot d A=\int_{A}\left(\frac{\partial \boldsymbol{B}_{m}}{\partial t}+\nabla \cdot \boldsymbol{v} \boldsymbol{B}_{m}\right) \cdot \boldsymbol{n} d A-\int_{A} \boldsymbol{B}_{m} \boldsymbol{n}: \nabla^{T} \boldsymbol{v} d A
$$

Considerando a superfície $A$ fixa no espaço, ou seja, $\boldsymbol{v}=\mathbf{0}$, obtém-se que:

$$
\frac{D}{D t} \int_{A} \boldsymbol{B}_{m} \cdot \boldsymbol{n} d A=\int_{A} \frac{\partial \boldsymbol{B}_{m}}{\partial t} \cdot \boldsymbol{n} d A
$$

e como tal:

$$
\int_{C} \boldsymbol{E}_{e} \cdot d l=-\int_{A} \frac{\partial \boldsymbol{B}_{m}}{\partial t} \cdot \boldsymbol{n} d A .
$$

Desde que o domínio em análise seja regular pode-se aplicar o Teorema de Stokes à integral do lado esquerdo:

$$
\int_{A}\left(\nabla \times \boldsymbol{E}_{e}+\frac{\partial \boldsymbol{B}_{m}}{\partial t}\right) \cdot \boldsymbol{n} d A=0
$$

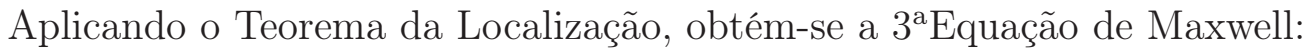

$$
\nabla \times \boldsymbol{E}_{e}=\frac{\partial \boldsymbol{B}_{m}}{\partial t}
$$

que representa a Lei de Indução de Faraday na escala do domínio contínuo. 
A Lei de Ampére postula que a circulação do vetor intensidade de campo em torno de um circuito fechado $C$ é igual a taxa do vetor densidade de corrente através da área $A$ limitada por $C$ :

$$
\int_{C} \boldsymbol{H} \cdot d l=\int_{A} \boldsymbol{J} \cdot \boldsymbol{n} d A=I_{h}
$$

Tratando-se de uma região regular o Teorema de Stokes pode ser aplicado à integral do lado esquerdo:

$$
\int_{A}(\nabla \times \boldsymbol{H}-\boldsymbol{J}) d A=0 .
$$

Aplicando o Teorema da Localização para qualquer área contínua;

$$
\nabla \times \boldsymbol{H}=\boldsymbol{J}
$$

que corresponde à $4^{\mathrm{a}}$ Equação de Maxwell para o caso de regime permanente do deslocamento de corrente $(\partial / \partial t=\mathbf{0})$. Para aplicações em $F H D$ considera-se o limite magnetoestático que corresponde em desprezar os efeitos do fluxo de corrente elétrica e de campo elétrico $\left(\boldsymbol{J}=\mathbf{0}, \boldsymbol{E}_{e}=\mathbf{0}\right)$ obtendo-se um regime de indução magnética $\partial \boldsymbol{B}_{m} / \partial t=0, \mathrm{e}:$

$$
\nabla \cdot \boldsymbol{B}_{m}=0 ; \nabla \times \boldsymbol{H}=0
$$

Voltando à Eq. (10.1) obtida pela 2a Lei de Newton, escreve-se que:

$$
\rho\left(\frac{\partial \boldsymbol{u}}{\partial t}+\boldsymbol{u} \cdot \nabla \boldsymbol{u}\right)=\nabla \cdot \boldsymbol{\Sigma}+\rho \boldsymbol{b}
$$

Por definição a pressão mecânica do escoamento é:

$$
P=-\frac{1}{3} \operatorname{tr}(\boldsymbol{\Sigma})
$$

Pela Mecânica dos Meios Contínuos um tensor de 2aardem pode ser decomposto por uma parte isotrópica $(P \boldsymbol{I})$ e uma parte deviatória $\boldsymbol{\Sigma}^{d}$, cujo traço é identicamente nulo (Aris (1962)). Assim:

$$
\boldsymbol{\Sigma}=-P \boldsymbol{I}+\boldsymbol{\Sigma}^{d}=-P \boldsymbol{I}+2 \eta \boldsymbol{D}+\boldsymbol{\Sigma}_{m}
$$

em que $\boldsymbol{\Sigma}_{m}$ é o tensor associado com a contribuição magnética. A generalização deste 
tensor de tensões é dado por (Gontijo e Cunha (2014)):

$$
\boldsymbol{\Sigma}_{m}=-p_{m} \boldsymbol{I}+\boldsymbol{H} \boldsymbol{B}_{m}
$$

em que $p_{m}$ é a pressão magnética, dada por:

$$
p_{m}=\frac{\mu_{0}}{2}(\boldsymbol{H} \cdot \boldsymbol{H})
$$

Após o calculo do divergente do tensor de tensões, a eq. 10.28 fica sendo (Rosa (2014)):

$$
\rho \frac{D \boldsymbol{u}}{D t}=-\nabla P+\eta \nabla^{2} \boldsymbol{u}+\mu_{0} \boldsymbol{M} \cdot \nabla \boldsymbol{H}+\frac{1}{2} \mu_{0} \nabla \times(\boldsymbol{M} \times \boldsymbol{H})+\rho \boldsymbol{g} .
$$

Esta equação recupera os casos particulares de campo uniforme, ou fluido supermagnético, ou fluido polar assimétrico em campo uniforme. Na eq. $10.33 \boldsymbol{M}$ é o vetor de magnetização. No caso de materiais paramagnéticos a permeabilidade magnética é constante. O termo $\mu_{0} \boldsymbol{M} \cdot \nabla \boldsymbol{H}$ corresponde ao divergente da parte simétrica do tensor $\boldsymbol{H} \boldsymbol{B}_{m}$. Este termo representa as forças devido ao gradiente de campo $\boldsymbol{H}$, e é nulo quando o campo magnético é uniforme. Este é o caso quando se mede as propriedades reológicas de um fluido magnético no reômetro descrito neste trabalho. O segundo termo surge do divergente da parte anti-simétrica do tensor $\boldsymbol{H} \boldsymbol{B}_{m}$. Este termo não é nulo mesmo quando o campo é uniforme, contabilizando os efeitos magnetoviscosos. Este termo representa a força extra necessária para desalinhar as partículas que se encontram alinhadas com o campo magnético.

\subsection{Resultados Experimentais}

Os testes foram realizados em um reômetro, modelo MCR301 da Anton-Paar. Para realizar experimentos com campo magnético é necessário acoplar uma base (ver fig. 10.1) que é constituída por bobinas capazes de produzir um campo magnético de até 1 Tesla (que corresponde a uma corrente máxima de $5 \mathrm{~A}$ ). A cápsula magnética que cobre a base assegura um campo homogêneo e perpendicular com relação à base. A cápsula é capaz de garantir a temperatura constante do fluido magnético de até $70^{\circ} \mathrm{C}$. 


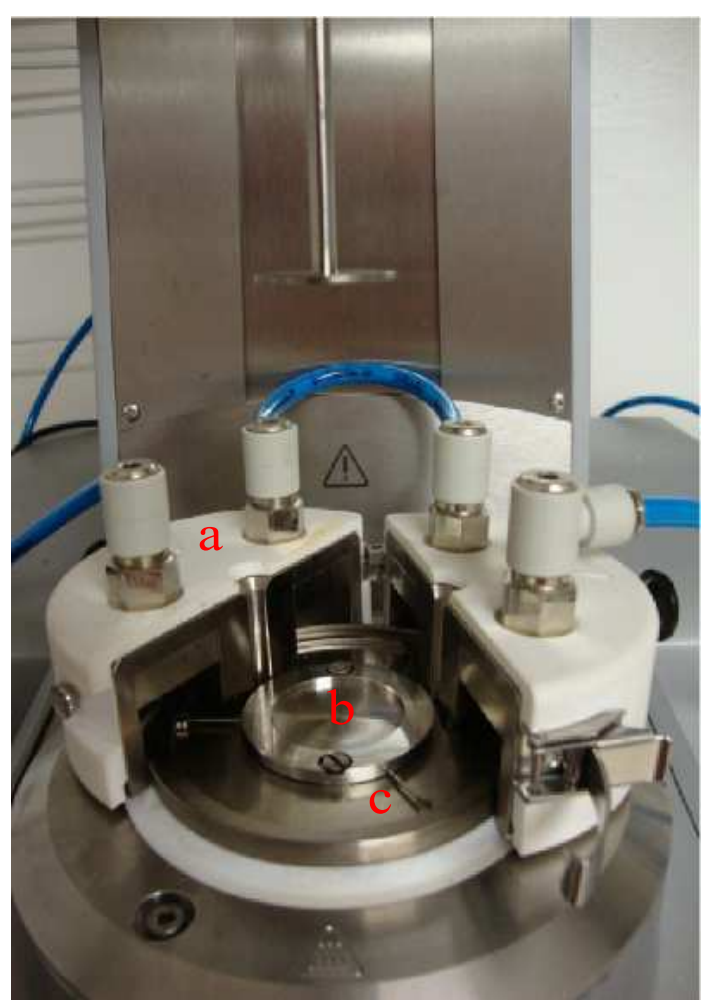

Figura 10.1: Reômetro equipado com os acessórios apropriados para a realização de experimentos com campo magnético. a) Cápsula Magnética. b) Base. c) Bobinas.

Os resultados experimentais são apresentados com quantidades dimensionais e adimensionais. Os modelos teóricos que se apresentam com quantidades adimensionais possibilitam o estudo do escoamento de fluidos em função de parâmetros físicos que caracterizam o escoamento. Para um material ferromagnético é válido escrever o vetor densidade de fluxo magnético como:

$$
\boldsymbol{B}_{m}=\mu_{0}(\boldsymbol{H}+\boldsymbol{M}) .
$$

Pela expressão anterior pode-se inferir que as unidades de $\boldsymbol{H}$ são as mesmas de $\boldsymbol{M}$, ou seja:

$$
\frac{\boldsymbol{B}_{m}}{\mu_{0}}
$$

O fabricante do fluido fornece o campo magnético de saturação $B_{s}$ na unidade Gauss $(G)$ que corresponde a $10^{-4}$ Tesla $(T)$. Para o ferrofluido APG1134 da Ferrotec $B=$ $220 \times 10^{-4}$ T. É de se referir que neste fluido a fração volumétrica de nanopartículas 
de magnetita é de 3,9\% V/V. A magnetização de saturação é calculada por:

$$
M_{s}=\frac{B_{s}}{\mu_{0}}=\frac{220 \times 10^{-4}}{4 \pi \times 10^{-7}}[\mathrm{~A} / \mathrm{m}] .
$$

É de notar que a unidade da permeabilidade no vácuo $\left(\mu_{0}\right)$ é Henry/metro. Esta unidade é igual a Weber/(Ampere metro). Sabendo que Tesla pode ser expressa por Weber $/$ metro $^{2}$ conclui-se que $M_{s}$ tem unidade de $\boldsymbol{H}$ que é Ampere/metro. Assim é possível adimensionalizar a intensidade do campo magnético $(\boldsymbol{H})$ como:

$$
\tilde{H}=\frac{H}{M_{s}}
$$

É sabido que o número de capilaridade é um parâmetro adimensional que expressa o balanço entre a escala de tempo de deformação da gota, devido à existência de uma tensão interfacial, e a escala de tempo do escoamento. Nesse sentido é necessário definir um parâmetro para adimensionalizar a taxa de cisalhamento aplicada pelo escoamento em um ferrofluido sujeito a um campo magnético externo. No entanto, não se conhece a tensão que está associada com a escala de tempo de deformação dos agregados de nanopartículas formados devido à aplicação de um campo magnético externo ao ferrofluido. Contudo, é sabido que quanto maior é o campo magnético aplicado mais numerosos são os agregados formados e de maior dimensão. Tais agregados exercem uma resistência adicional ao escoamento do ferrofluido. A resistência total, maior devido ao efeito dos agregados formados, pode ser mensurada pela existência de uma tensão crítica $\left(\tau_{0}\right)$ com o mesmo significado da tensão crítica de fluidos do tipo Bingham. Neste tipo de fluidos existe um valor de tensão de cisalhamento acima da qual o fluido apresenta uma resposta ao cisalhamento, devido às alterações na sua microestrutura. Assim é possível definir um novo parâmetro designado por número de capilaridade magnético que depende da tensão crítica associada à magnitude do campo magnético aplicado.

$$
C a_{M}=\frac{\eta \dot{\gamma}}{\tau_{0}}
$$

O número de capilaridade magnético $\left(C a_{M}\right)$ é entendido como a razão entre a força de quebra da estrutura de partículas $\left(\eta \dot{\gamma} a^{2}\right)$ formadas pelo campo magnético e a força de 
resistência ao escoamento $\left(\tau_{0} a^{2}\right)$, em que $a$ é o raio da partícula ou da estrutura formada por partículas e $\tau_{0}$ é a tensão a partir da qual o fluido deixa de ter características de sólido.

\subsubsection{Experimentos de Cisalhamento Permanente de Fluido Magnético}

A caracterização reológica de fluidos é feita avaliando primeiro a resposta da viscosidade do fluido em diferentes taxas de cisalhamento. Para fluidos magnéticos existe um parâmetro adicional para ser variado, que é a intensidade de campo magnético $(H)$. Nesta secção apresentam-se os resultados obtidos para cisalhamento permanente em diferentes campos magnéticos para averiguar a variação da viscosidade com o aumento da intensidade de $H$. Um segundo teste é apresentado para verificar o efeito da variação da taxa de cisalhamento para diferentes intensidades de campo magnético constante com o intuito de observar as alterações na viscosidade do fluido magnético.

Segundo o fabricante a viscosidade sem influência de campo magnético do fluido APG1134, com fração volumétrica de nanopartículas de $3,9 \% \mathrm{~V} / \mathrm{V}$, à $\mathrm{T}=27^{\circ} \mathrm{C}$ é de $1000 \mathrm{cP}$. Do experimento realizado com uma amostra de fluido de volume $0,75 \mathrm{ml}$ à temperatura de $25^{\circ} \mathrm{C}$ sujeito a uma intensidade de campo magnético nula, obteve-se uma viscosidade de $1100 c P$ (ver encarte da fig. 10.2). No encarte observa-se que o fluido não apresenta alterações da viscosidade com o tempo de experimento para uma taxa de cisalhamento constante. Indicando que o fluido não tem propriedades tixotrópicas e nem reopéticas. No entanto a viscosidade do fluido aumenta com a intensidade de campo magnético. Esse comportamento é chamado de magnetoviscoso (Shahnazian e Odenbach, (2014)). Cada ponto experimental da fig. 10.2 representa a viscosidade do fluido após 120 segundos sujeito a uma taxa de cisalhamento constante de $10 \mathrm{~s}^{-1}$, para diferentes intensidades de campo magnético. Quando a intensidade de campo magnético aumenta, a viscosidade aumenta devido à formação de agregados em maior número e tamanho, conferindo uma maior resistência ao escoamento. Este fato está também relacionado com o maior esforço que o escoamento tem que efetuar para desalinhar os agregados com o campo magnético. 


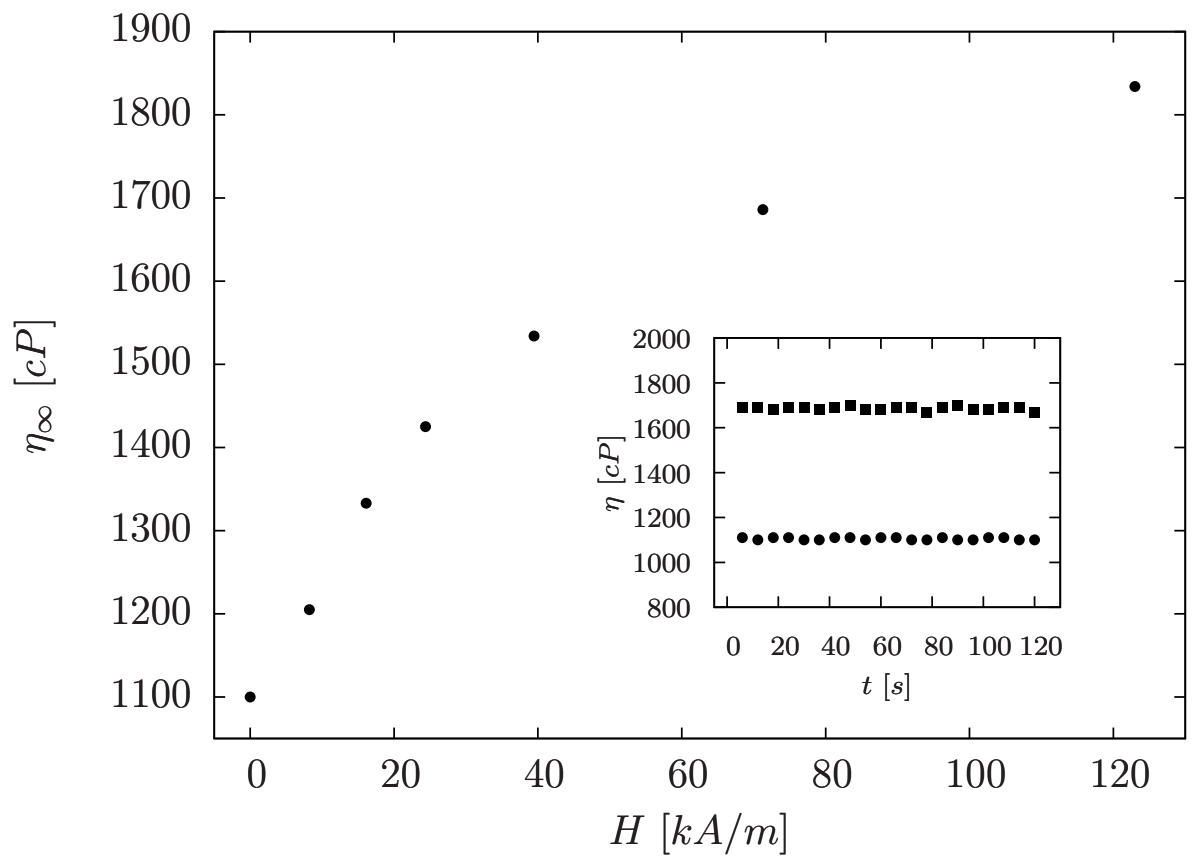

Figura 10.2: Influência do campo magnético na viscosidade para uma taxa de cisalhamento constante $\left(10 \mathrm{~s}^{-1}\right)$. Encarte: $\bullet H=0.0 ; \boldsymbol{\square} H=71,28 \mathrm{kA} / \mathrm{m}$. Teste de cisalhamento permanente mostrando o efeito magnetoviscoso do ferrofluido.

O encarte da fig. 10.3 mostra um comportamento típico pseudo-plástico (perda da viscosidade com o aumento da taxa de cisalhamento) do fluido magnético para intensidades de campo magnético diferente de zero. Com o aumento da taxa de cisalhamento as estruturas são desalinhadas com a direção do campo magnético e os agregados inicialmente formados são continuamente quebrados até que a configuração da microestrutura atinge a sua saturação, levando a que o ferrofluido alcance o seu platô newtoniano em altas taxas de cisalhamento. Observou-se ainda que em baixas taxas de cisalhamento existe um pico de viscosidade. Esse pico é tanto maior quanto maior for a intensidade de campo magnético aplicado. Isto é devido ao maior número de agregados de múltiplas partículas formados induzido pela ação de maiores campos magnéticos. É de se referir que as forças magnéticas atrativas entre as partículas devido ao campo magnético aplicado formam grandes agregados e cadeias longas distribuídas em todo o fluido. É de notar que esses agregados e cadeias estão alinhados com o campo e interagem magneticamente. Também se observou que na região de saturação da viscosidade em altas taxas de cisalhamento houve um aumento da viscosidade com o aumento do campo magnético. Isso se deve à presença de maior quantidade de estruturas de maiores dimensões que o diâmetro de uma partícula ou de um agregado de poucas partículas. Os 
pontos da fig. 10.3 representam a saturação da viscosidade para cada intensidade de campo magnético. A saturação da viscosidade é a região em que a microestrutura do fluido atingiu o seu regime permanente, ou seja, a microestrutura não se altera com o aumento da taxa de cisalhamento, tendo em vista que não existirá mais quebra ou ruptura da mesma pelo cisalhamento.

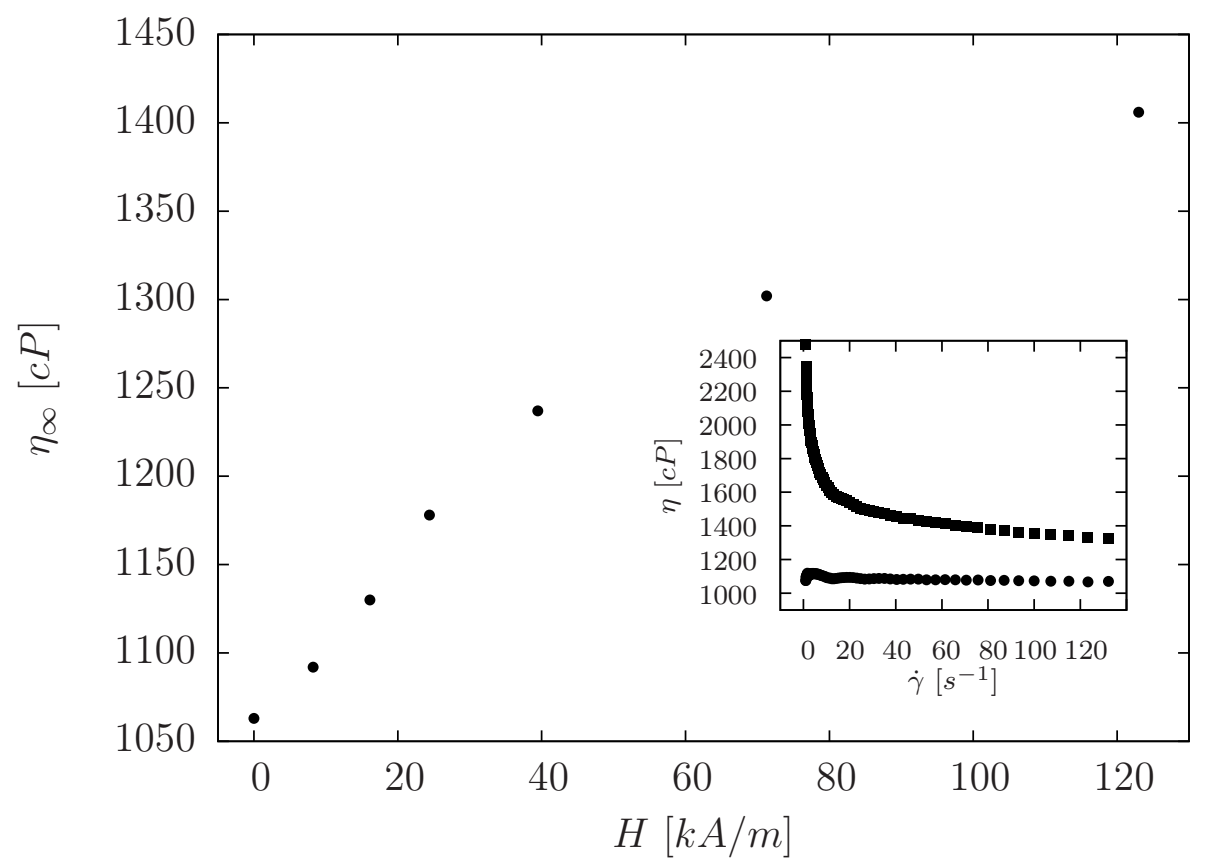

Figura 10.3: Variação da viscosidade em altas taxas de cisalhamento $\left(\eta_{\infty}\right)$ devido ao aumento da intensidade do campo magnético. Encarte: Perfil de viscosidade com o aumento da taxa de cisalhamento quando a intensidade de campo magnético é constante. $\bullet H=0.0 ; \boldsymbol{\square} H=71,28 \mathrm{k} / \mathrm{Am}$. A taxa de cisalhamento de saturação da viscosidade foi considerada a mesma para todas as intensidades de campos magnéticos $\left(\dot{\gamma}=120 \mathrm{~s}^{-1}\right)$.

A Fig. 10.4 mostra a influência do campo magnético na viscosidade para diferentes taxas de cisalhamento. Observa-se um decréscimo da viscosidade com o aumento da taxa de cisalhamento para um campo constante. Essa configuração deve-se ao fato que com o aumento da taxa de cisalhamento a microestrutura sofre rupturas continuamente e com uma maior frequência com o aumento da taxa de cisalhamento até que a configuração atinge agregados de poucas partículas e a viscosidade satura (ver fig. 10.5). No encarte da fig. 10.4 observa-se o comportamento típico da variação da viscosidade em função do aumento da intensidade do campo magnético para uma taxa de cisalhamento constante $\left(\dot{\gamma}=50 \mathrm{~s}^{-1}\right)$. Isso se deve à formação constante de novos e maiores agregados com o aumento do campo magnético. 


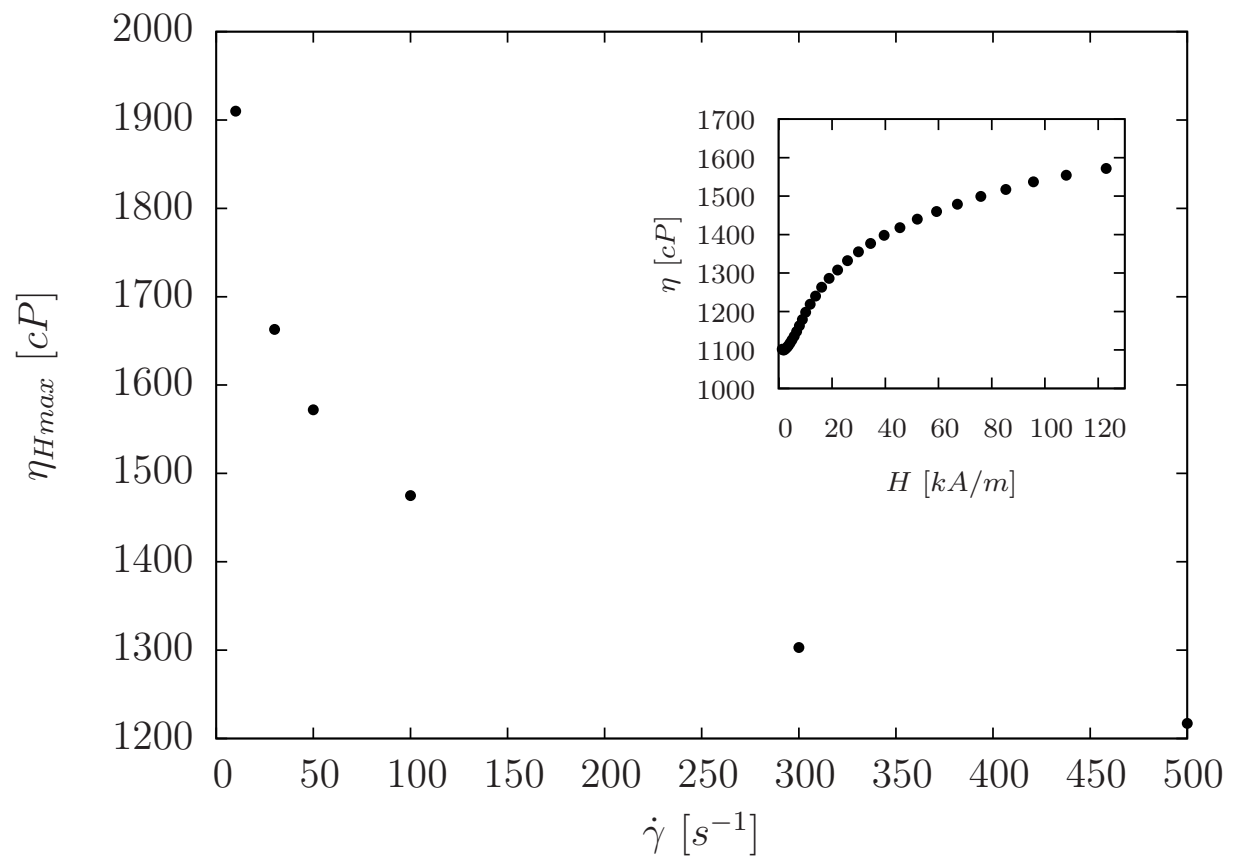

Figura 10.4: Influência do aumento da taxa de cisalhamento para uma intensidade constante de campo magnético $(H=123 \mathrm{kA} / \mathrm{m})$. Encarte: Aumento da viscosidade em função do aumento contínuo da intensidade do campo magnético. $\bullet \dot{\gamma}=5 \mathrm{~s}^{-1}$.

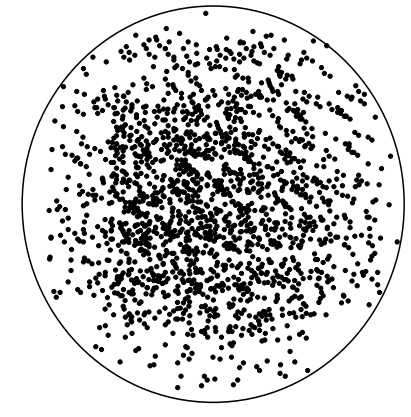

a

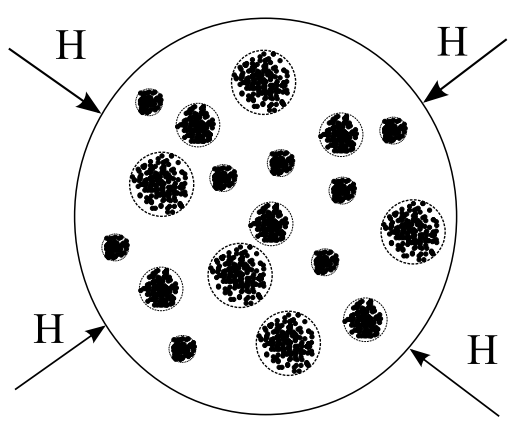

$\mathrm{b}$

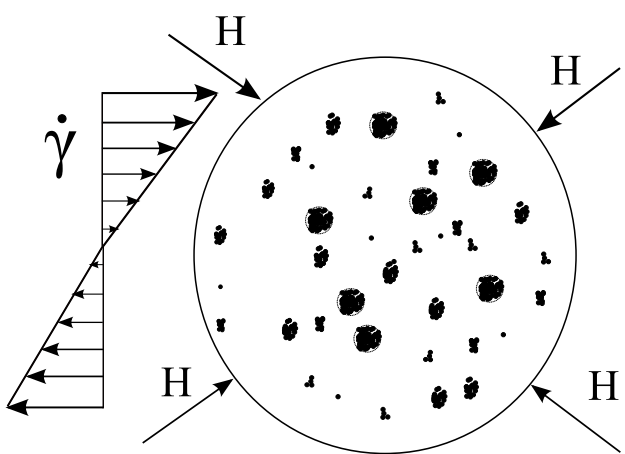

C

Figura 10.5: Configurações da microestrutura de um volume típico de fluido magnético com partículas de magnetite: a) Distribuição de partículas na ausência de campo magnético. b) Formação de estruturas de partículas com a aplicação de campo magnético. c) Quebra das estruturas devido ao cisalhamento simples aplicado.

\subsubsection{Experimentos de Cisalhamento Transiente de Fluido Magnético}

As propriedades viscoelásticas do fluido magnético foram determinadas experimentalmente aplicando cisalhamento oscilatório no fluido magnético. O volume de fluido magnético utilizado na realização dos experimentos foi de $0,75 \mathrm{ml}$. 
10.2.2.1 Experimento de Viscoelásticidade, $G^{\prime}$ e $G^{\prime \prime}$

Os módulos elásticos do fluido magnético para várias intensidades de campo magnético foram obtidos para uma faixa de valores de deformação com frequência constante de $0,16 \mathrm{~Hz}$, equivalente a $w=1 \mathrm{rad} / \mathrm{s}$. A propriedade $G^{\prime}$ mostrada na Fig. 10.6 é designada por módulo de armazenamento que está associado ao carácter elástico do fluido, enquanto que $G^{\prime \prime}$ (Fig. 10.7) está associado com a viscosidade do fluido magnético. No caso de $G^{\prime \prime}>G^{\prime}$ diz-se que o fluido se comporta com características de um líquido viscoso. Observou-se para $H=71,28 \mathrm{kA} / \mathrm{m}$ que o fluido magnético responde com comportamento de sólido, não havendo movimento relativo entre a microestrutura e o fluido base, para deformações $(\gamma)$ menores que 0,1 . Este resultado é devido as estruturas de maior tamanho serem formadas para maiores campos magnéticos e em baixas deformações a estrutura não tem movimento relativo. Para menores campos magnéticos o fluido apresenta características de líquido em toda a faixa de deformação. Para maiores deformações o comportamento é não-linear. Quanto ao $G^{\prime \prime}$ observa-se uma convergência para altas deformações. Em baixas deformações (até $\gamma=0,1$ ) um regime linear viscoelástico pode ser identificado para os maiores campos magnéticos.

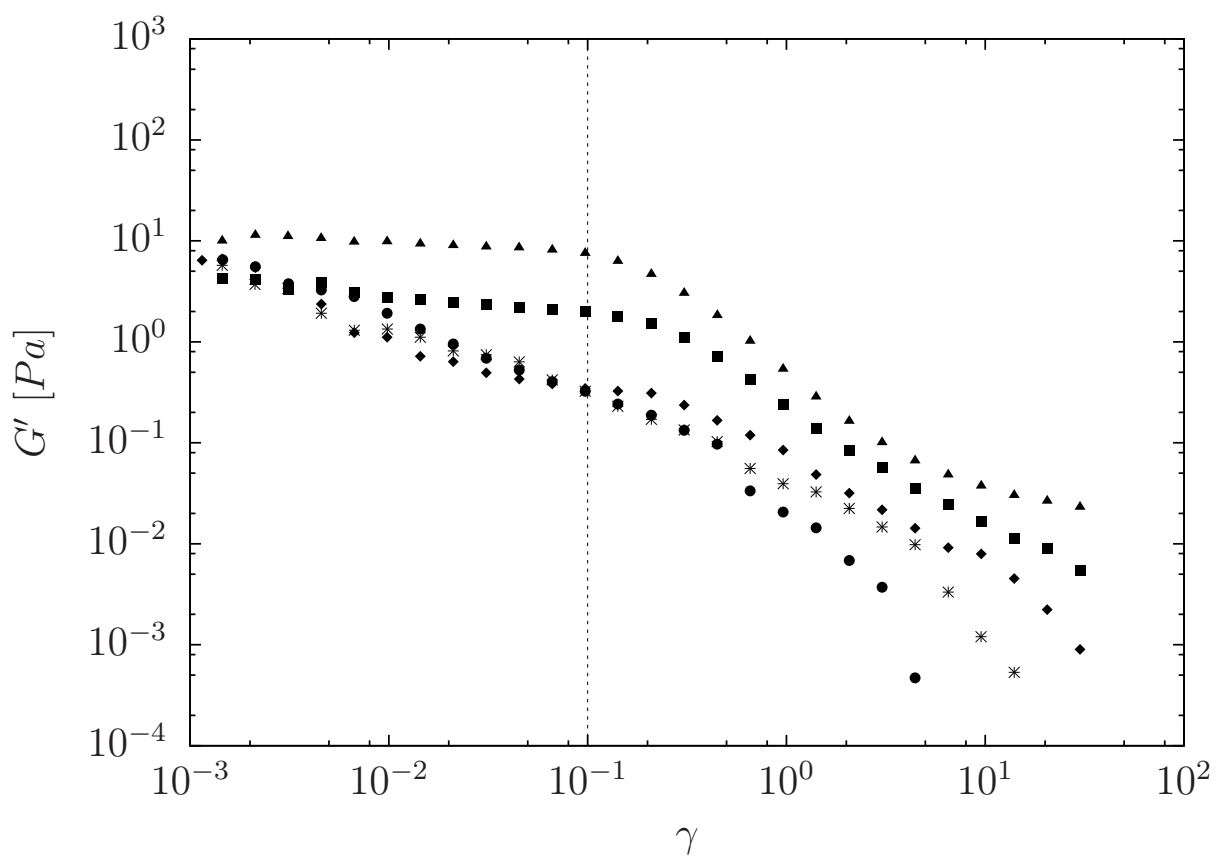

Figura 10.6: Influência da deformação $(\gamma)$ no módulo de armazenamento para diferentes intensidades de campo magnético. $\bullet H=0.0 \mathrm{kA} / \mathrm{m} ; * H=8.22 \mathrm{kA} / \mathrm{m}$; $16,13 \mathrm{kA} / \mathrm{m}$; $39,47 \mathrm{kA} / \mathrm{m} ; \boldsymbol{\Delta} 71,28 \mathrm{kA} / \mathrm{m}$. 


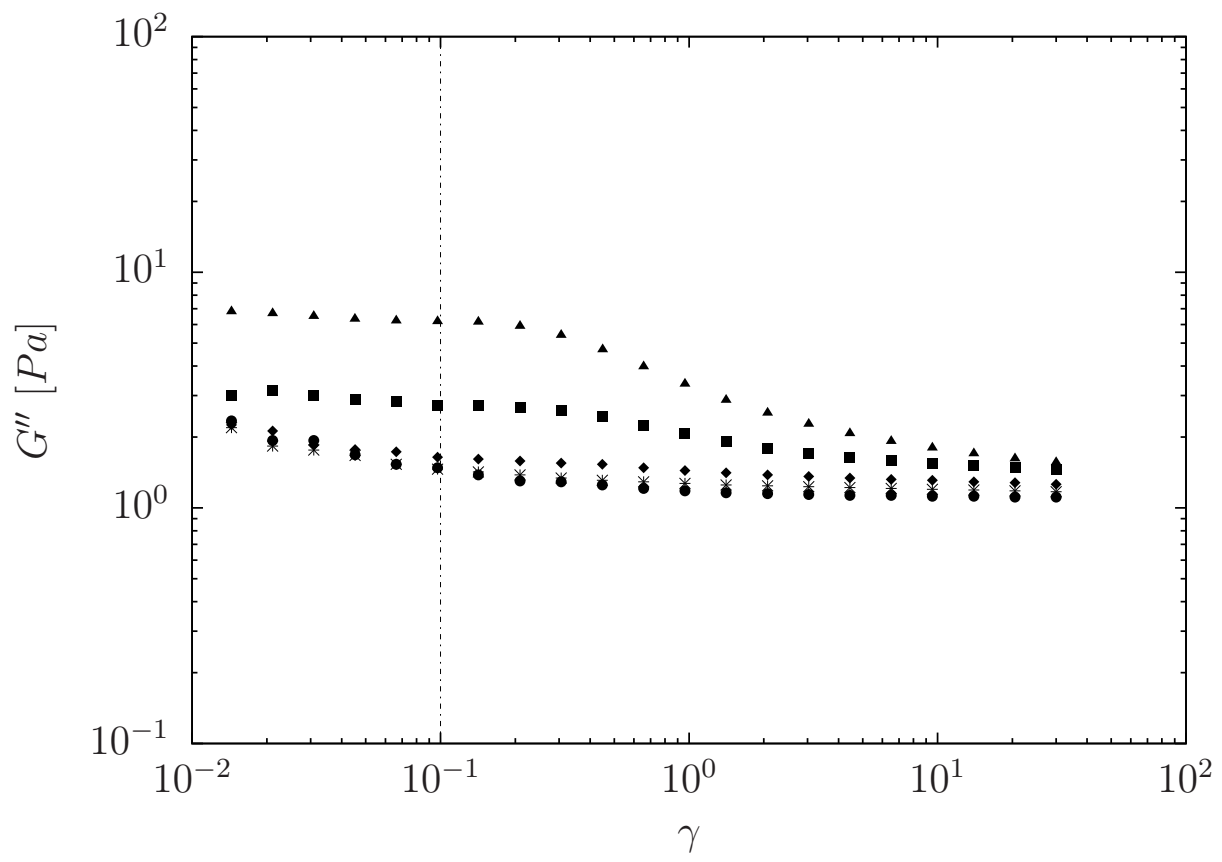

Figura 10.7: Influência da deformação $(\gamma) \mathrm{em} G^{\prime \prime}$ para diferentes intensidades de campo magnético. • $H=0.0 \mathrm{kA} / \mathrm{m} ; * H=8.22 \mathrm{kA} / \mathrm{m} ; 16,13 \mathrm{kA} / \mathrm{m} ; \mathbf{\square} 39,47 \mathrm{kA} / \mathrm{m}$; $71,28 \mathrm{kA} / \mathrm{m}$.

10.2.2.2 Medidas da função de relaxação, $\Phi(t)$

A Fig. 10.8 mostra a variação da função de relaxação, $\Phi(t)$, com o tempo, $t$ para diferentes deformações $(\gamma)$ para um campo magnético constante de $71,28 \mathrm{~A} / \mathrm{m}$ e frequência $0,79 \mathrm{~Hz}(w=5 \mathrm{rad} / \mathrm{s})$. O software Reoplus que acompanha o reômetro extrai a função de relaxação do fluido magnético após a interrupção da deformação (step strain). Observa-se que para uma deformação maior que 0,1 as estruturas do fluido magnéticas sofrem rupturas resultando em um decréscimo da tensão entre 1 a 10 segundos para $\gamma=0,2$ e entre 1 a 100 segundos para $\gamma=0,4$. Observou-se que com o aumento da deformação o tempo de relaxação $\left(t_{\infty}\right)$ da tensão para atingir o seu valor de saturação aumenta de forma visível. A fig. 10.9 mostra que quanto maior for a deformação maior é o tempo para que a tensão atinja o seu valor de equilíbrio (regime permanente). Para $\gamma=0,01$ o fluido magnético necessitou de cerca de $28 s$ para atingir o valor de saturação da tensão que foi de $\Phi(t)=1,448 \pm 0.016 P a$. Para $\gamma=0,05$ o fluido necessitou de 40 segundos para atingir o valor de saturação da tensão que foi de $\Phi(t)=0,548 \pm 0.034 P a$. Para $\gamma=0,1$ o fluido necessitou de 50 segundos para atingir o valor de saturação da tensão que foi de $\Phi(t)=0,276 \pm 0.009 P a$. 


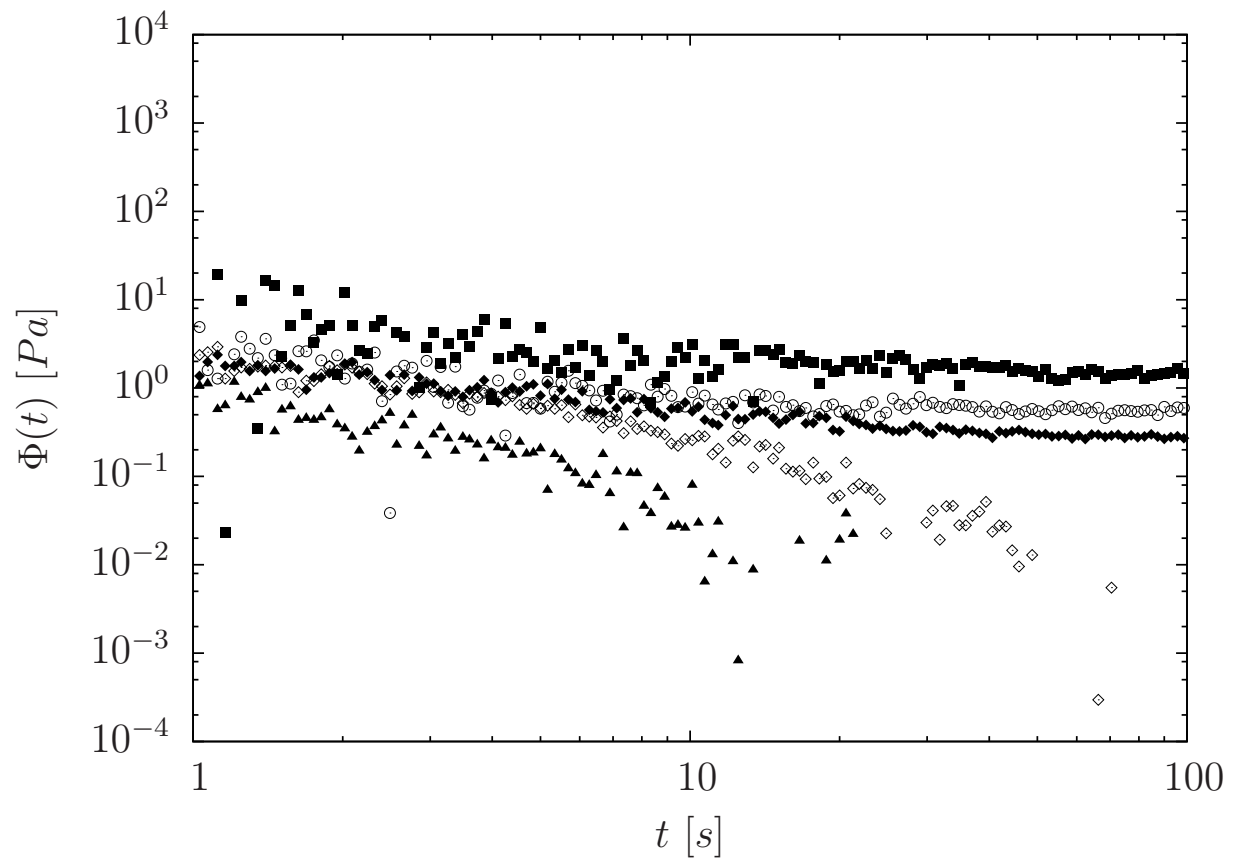

Figura 10.8: Função de Relaxação em função do tempo para diferentes degraus de deformação para $H=71,28 \mathrm{~A} / \mathrm{m}$ e $f=0,79 \mathrm{~Hz}(w=5 \mathrm{rad} / \mathrm{s})$. $\boldsymbol{\square} \gamma=0,01, \mathrm{o}$ $\gamma=0,05, \nabla \gamma=0,1, \diamond \gamma=0,2, \boldsymbol{\Delta} \gamma=0,4$.

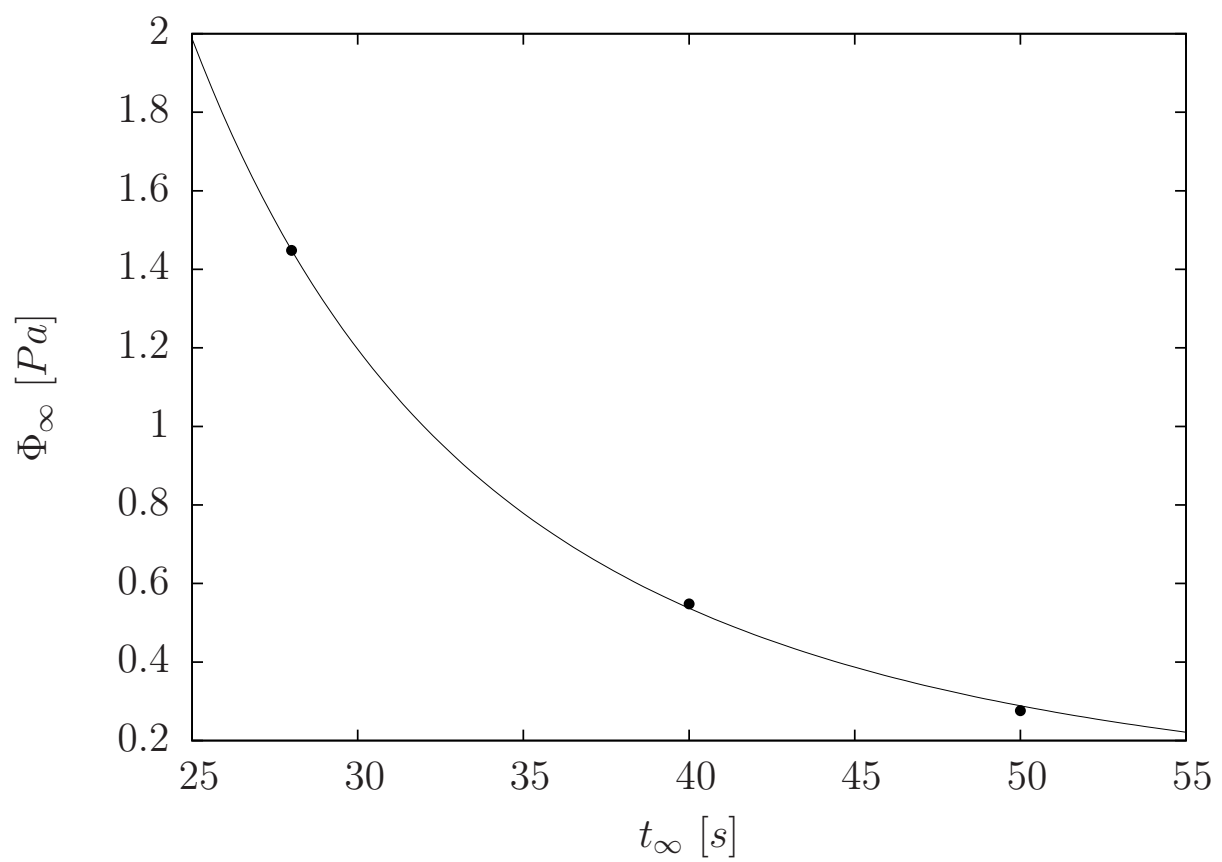

Figura 10.9: Variação da função de relaxação de equilíbrio com o tempo. Dados ajustados com a função $\Phi_{\infty}=C t^{\alpha}$ em que $k$ e $\alpha$ são constantes de ajuste. 
10.2.2.3 Medidas da tensão residual, $\tau_{r}$

A tensão de equilíbrio é entendida como sendo o valor da tensão em regime permanente. Essa tensão será designada como tensão residual, $\tau_{r}$. Para medir a tensão residual do fluido magnético optou-se por realizar experimentos em 4 estágios de tempo. No primeiro estágio de tempo o fluido sob a influência de um campo magnético devido à corrente de $1 A$ é pré-cisalhado com uma taxa de cisalhamento de $1 s^{-1}$ por um tempo de $100 \mathrm{~s}$. Este procedimento é realizado para que as estruturas de partículas sejam retiradas da sua configuração original. No segundo estágio de tempo o fluido permanece em repouso por $100 \mathrm{~s}$. Tempo este que é sempre muito maior que o tempo característico do escoamento $(1 / \dot{\gamma})$. No terceiro estágio de tempo é aplicada uma segunda pré-taxa de cisalhamento por um tempo dez vezes maior que o tempo do escoamento. A tensão residual é estudada em função da variação dessa pré-taxa de cisalhamento. No quarto estágio de tempo a taxa de cisalhamento é interrompida e o decaimento da tensão é medido ao longo do tempo até atingir um regime de equilíbrio permanente. O tempo experimental foi de $10^{3} \mathrm{~s}$. No entanto, é suficiente apenas mostrar os resultados até $600 s$ uma vez que neste tempo já foi atingida a tensão residual de equilíbrio.

Na fig. 10.11 destaca-se que a tensão residual aumenta com a diminuição da prétaxa de cisalhamento. Isto se deve ao fato que para pequenas taxas de cisalhamento as estruturas não se rompem e após a paragem instantânea da taxa de cisalhamento facilmente as partículas se reagrupam resultando em uma maior tensão (ver fig. 10.10 ). Para altas taxas de cisalhamento os agregados tiveram uma maior ruptura e como tal as partículas se encontram mais separadas inibindo a relaxação da estrutura dos agregados. As linhas pontilhadas da fig. 10.11 referem-se ao valor da tensão residual. 


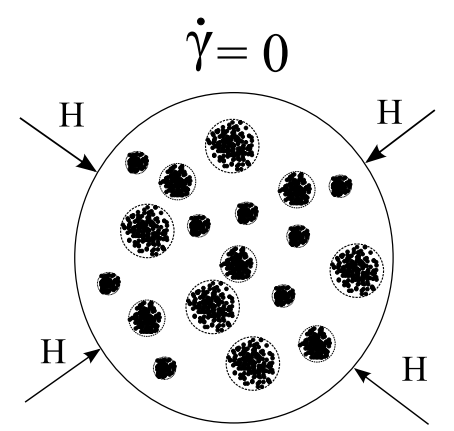

a

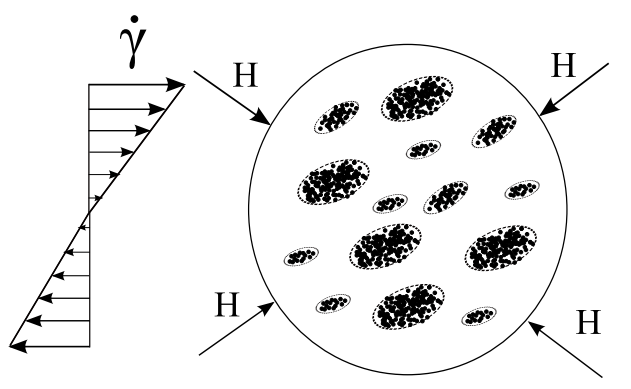

b

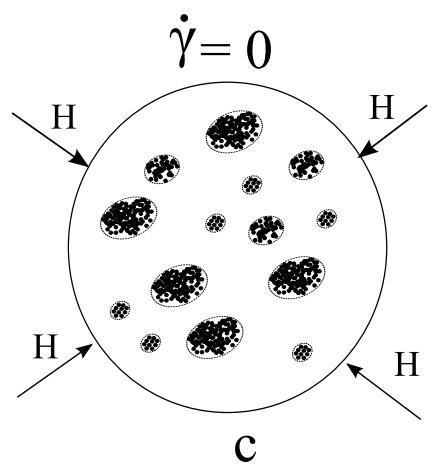

Figura 10.10: Configurações da microestrutura de um volume típico de fluido magnético com partículas de magnetite: a) Formação de agregados devido a aplicação de um campo magnético. b) Deformação dos agregados em uma baixa taxa de cisalhamento. c) Relaxação dos agregados após a retirada instantânea da taxa de cisalhamento.

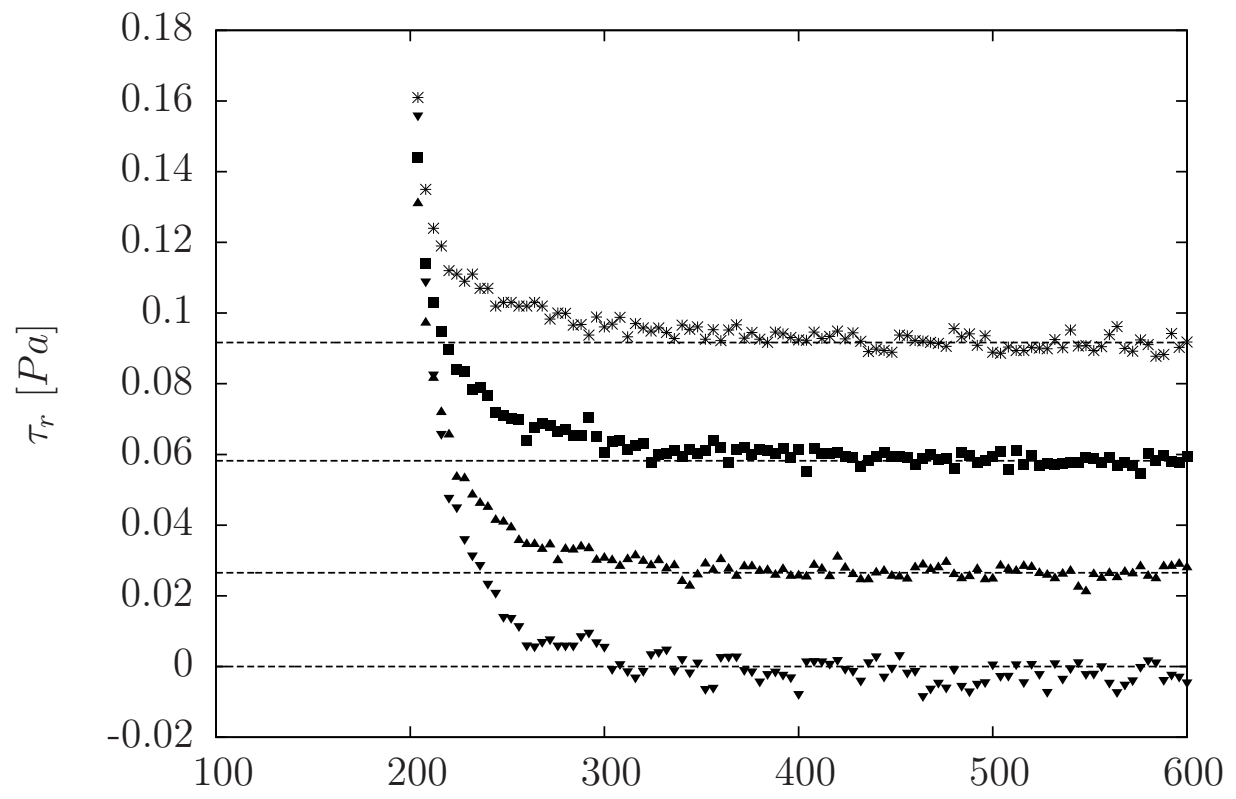

Figura 10.11: Influência da pré-taxa de cisalhamento $\left(\dot{\gamma}_{p}\right)$ na tensão residual $\left(\tau_{r}\right)$ com campo magnético constante de 71,28 kA/m. * $\dot{\gamma}_{p}=0,2 \mathrm{~s}^{-1}, \tau_{r}=0,0916 \mathrm{~Pa} ; \mathbf{\square} \dot{\gamma}_{p}=$ $0,4 s^{-1}, \tau_{r}=0,0582 \mathrm{~Pa} ; \boldsymbol{\Delta} \dot{\gamma}_{p}=0,5 s^{-1}, \tau_{r}=0,0265 \mathrm{~Pa} ; \boldsymbol{\nabla} \dot{\gamma}_{p}=1,0 \mathrm{~s}^{-1}, \tau_{r}=0,0 \mathrm{~Pa}$. - - - Tensão residual.

Na fig. 10.12 destaca-se o tempo necessário para que a tensão atinja o seu valor de saturação. Observa-se que, quanto maior é a pré-taxa de cisalhamento aplicada maior é o tempo necessário para que a tensão atinja o seu valor de equilíbrio. Este resultado é consistente com a explicação de que para maiores taxas de cisalhamento mais o fluido se afasta de uma configuração de equilíbrio. As linhas pontilhadas da fig. 10.12 destacam o tempo no qual foi obtida a tensão residual. Pela fig. 10.13 observa-se que 
o tempo de relaxação aumenta com a pré-taxa de cisalhamento aplicada devido ao aumento da desordem da microestrutura do fluido magnético em relação ao equilíbrio. É de se referir que o tempo de relaxação foi considerado pelo ajuste entre os dados experimentais e a curva $\tau=A \exp (-t / \alpha)$ em que $\alpha$ é designado como sendo um tempo de relaxação. A fig. 10.14 mostra o resultado típico experimental com o ajuste da tensão apresentando um comportamento equivalente a um fluido de Maxwell com o tempo de relaxação.

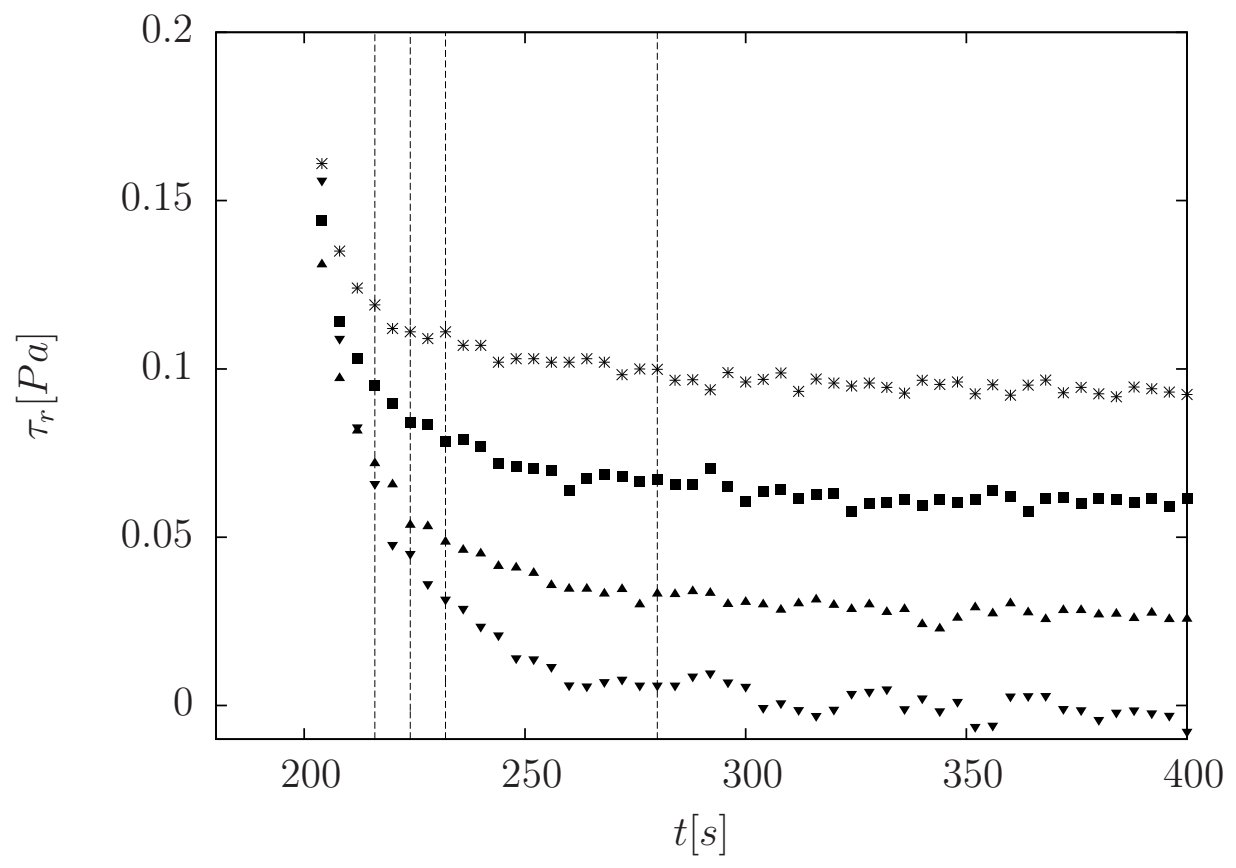

Figura 10.12: Influência da pré taxa de cisalhamento $\left(\dot{\gamma}_{p}\right)$ no tempo de relaxação $\left(t_{r}\right)$ para um campo magnético constante de $71,28 \mathrm{kA} / \mathrm{m} . * \dot{\gamma}_{p}=0.2 \mathrm{~s}^{-1}, t_{r}=216 \mathrm{~s}$; - $\dot{\gamma}_{p}=0.4 \mathrm{~s}^{-1}, t_{r}=224 \mathrm{~s} ; \boldsymbol{\Delta} \dot{\gamma}_{p}=0.5 \mathrm{~s}^{-1}, t_{r}=232 \mathrm{~s} ; \boldsymbol{\nabla} \dot{\gamma}_{p}=1.0 \mathrm{~s}^{-1}, t_{r}=280 \mathrm{~s}$. - - - Tempo para o qual a tensão entra em regime permanente. 


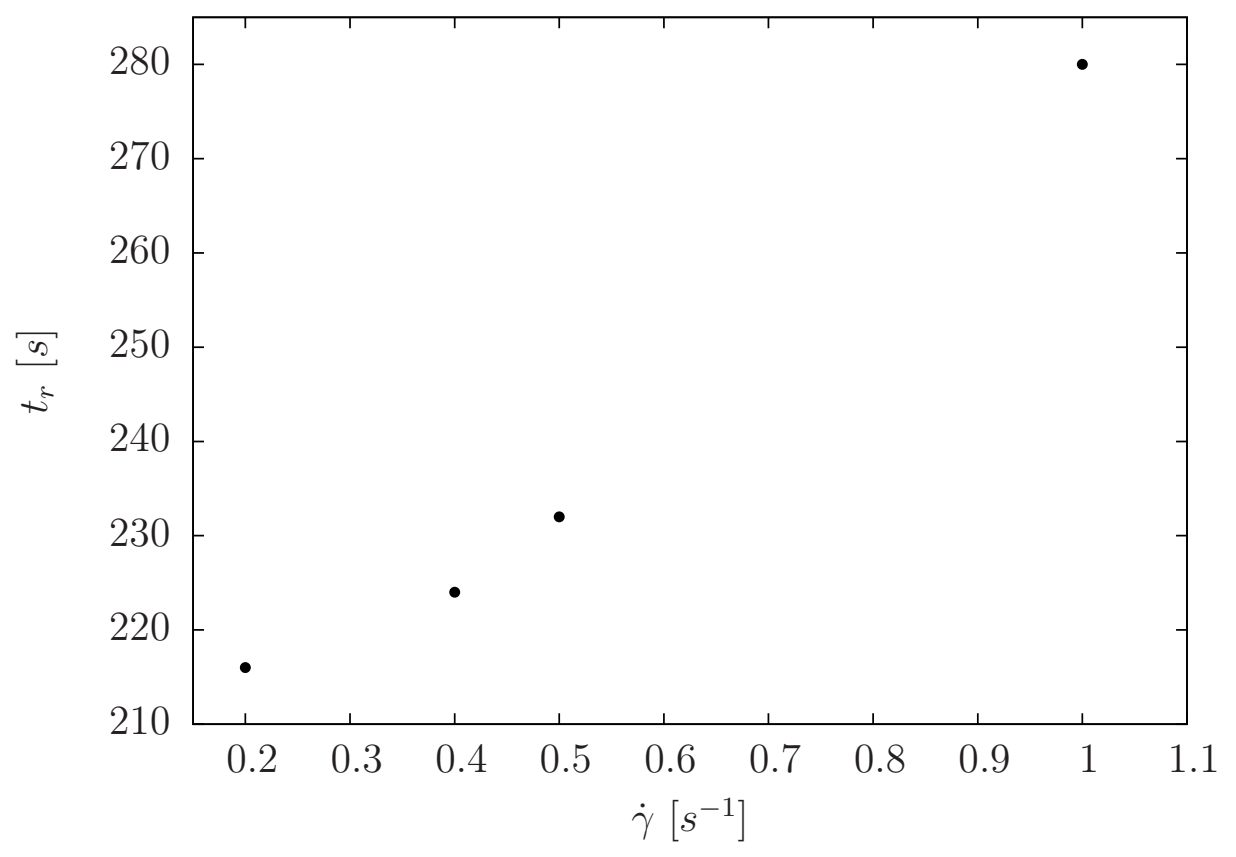

Figura 10.13: Tempo de relaxação em função da pré-taxa de cisalhamento.

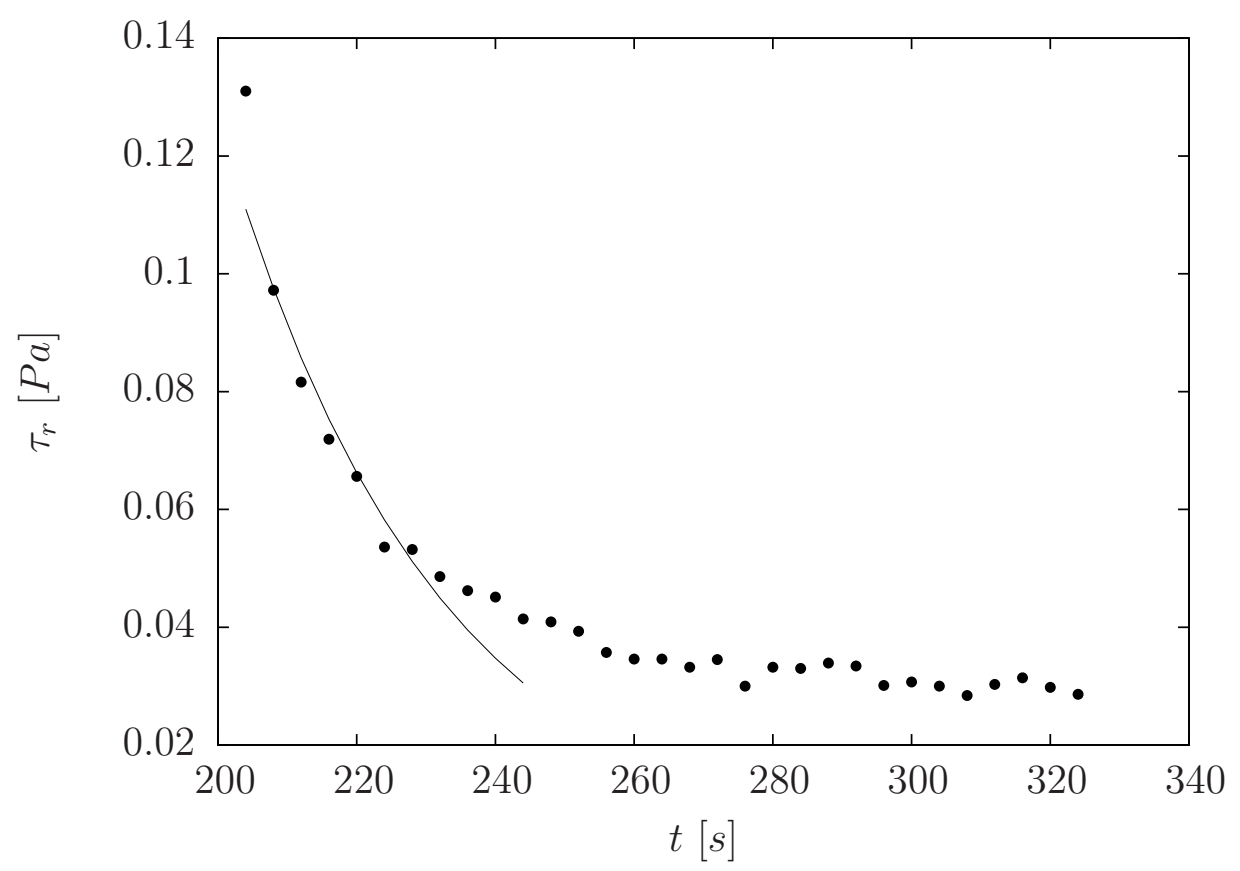

Figura 10.14: Tensão de relaxação em função do tempo de relaxação, para uma pré taxa de cisalhamento $\dot{\gamma}=0,5 \mathrm{~s}^{-1}$ com um campo magnético constante de $71,28 \mathrm{kA} / \mathrm{m}$. -Dados Experimentais, -Ajuste $\tau=A \exp (-t / \alpha)(A=80, \alpha=31)$. 
10.2.2.4 Medidas de tensão crítica em fluido magnético, $\tau_{0}$

Na Fig. 10.15 avalia-se a tensão crítica e a correspondente viscosidade em função da intensidade do campo magnético. A tensão crítica foi avaliada pelo software Rheoplus, que acompanha o reômetro, através do gráfico deformação $(\gamma)$ com tensão de cisalhamento $(\tau)$. A amostra de ferrofluido foi primeiramente sujeita a uma taxa de cisalhamento de $5 s^{-1}$ por 1 minuto. Após essa taxa de cisalhamento sujeita-se o ferrofluido a uma intensidade de campo magnético por 1 minuto. Em seguida, o ferrofluido é cisalhado com uma taxa de cisalhamento de $0,1 \leq \dot{\gamma} \leq 100 \mathrm{~s}^{-1}$. O gráfico adimensional correspondente é representado pela fig. 10.16. A tensão crítica é entendida como sendo a tensão de cisalhamento a partir da qual acontece o escoamento, ou seja o movimento relativo das partículas promovendo a deformação dos agregados. Observa-se um aumento linear da tensão crítica com o campo magnético a partir de $H \approx 24 \mathrm{kA} / \mathrm{m}$. Para intensidades de campo inferior a $H \approx 24 k A / m$ verificou-se que a tensão crítica apresenta uma saturação no valor de $\tau_{0}^{L}=38 \mathrm{~Pa}$. Contudo a viscosidade apresenta um aumento não-linear. A explicação é baseada no fato que para intensidades de campo em torno de $25 \mathrm{kA} / \mathrm{m}$ não existe movimento relativo de partículas/agregados. Mas com o aumento do campo esses agregados podem ser formados no fluido magnético em maior número e maior tamanho, traduzindo-se em um aumento da viscosidade efetiva. Com a tensão crítica obtida é possível calcular o número de capilaridade magnético pela eq. 10.38. A fig. 10.17 mostra a fig. 10.3 em termos de quantidades adimensionais. 


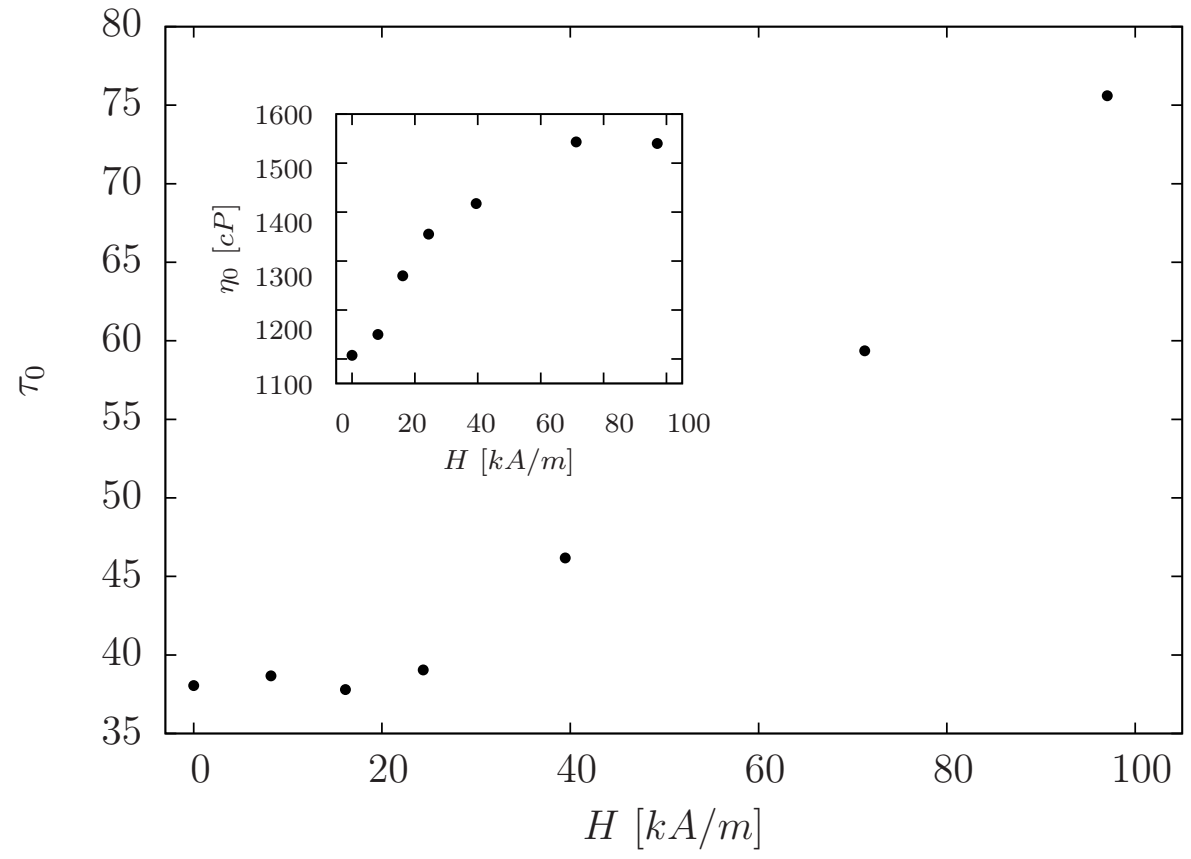

Figura 10.15: Aumento linear da tensão crítica com o campo magnético. Encarte: Aumento não linear da viscosidade com o campo magnético refletindo a formação de agregados mesmo nas menores intensidades de campo magnético.

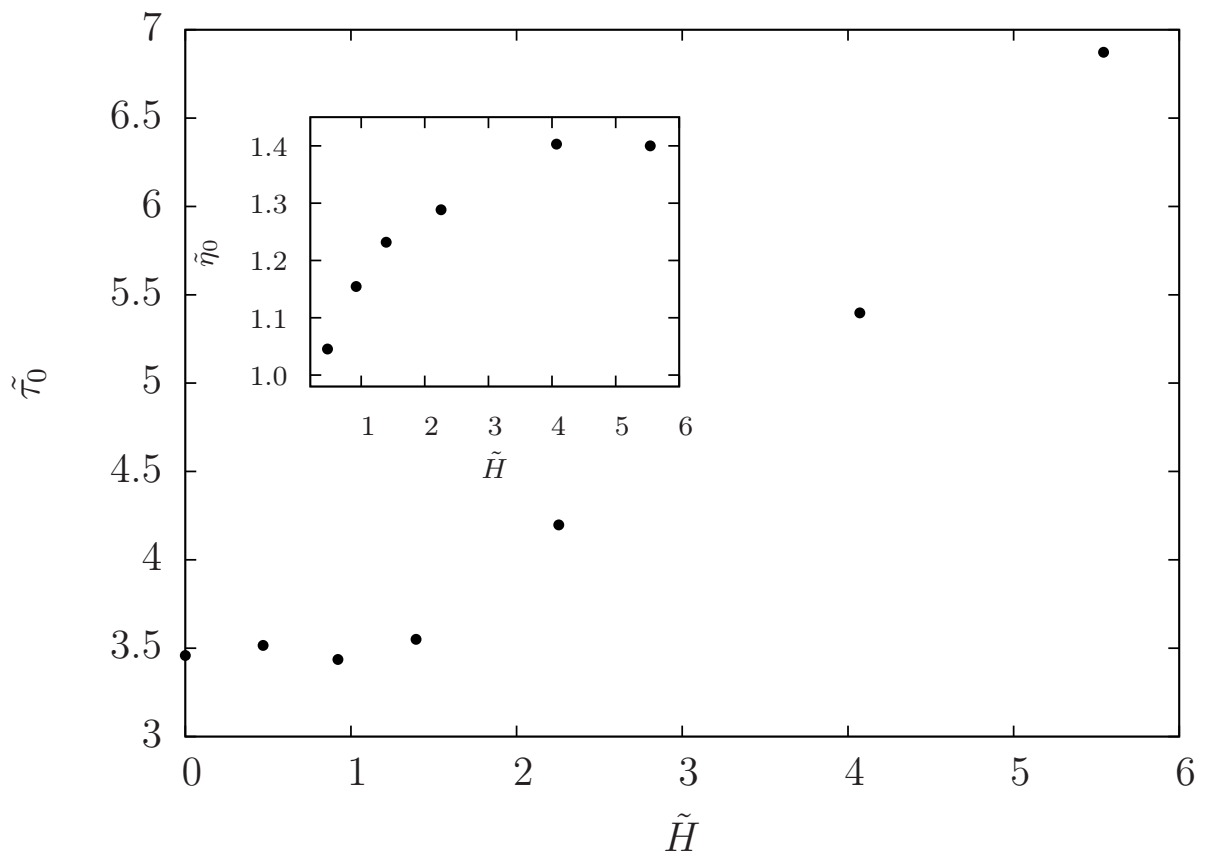

Figura 10.16: Tensão crítica adimensional pela tensão de cisalhamento quando $H=$ $0.0 \mathrm{kA} / \mathrm{m}$ com o aumento da intensidade do campo magnético adimensional. Encarte: Aumento da viscosidade crítica adimensional $\left(\tilde{\eta}_{0}=\eta_{0} / \eta_{H=0}\right)$ com o aumento da intensidade do campo magnético adimensional. 


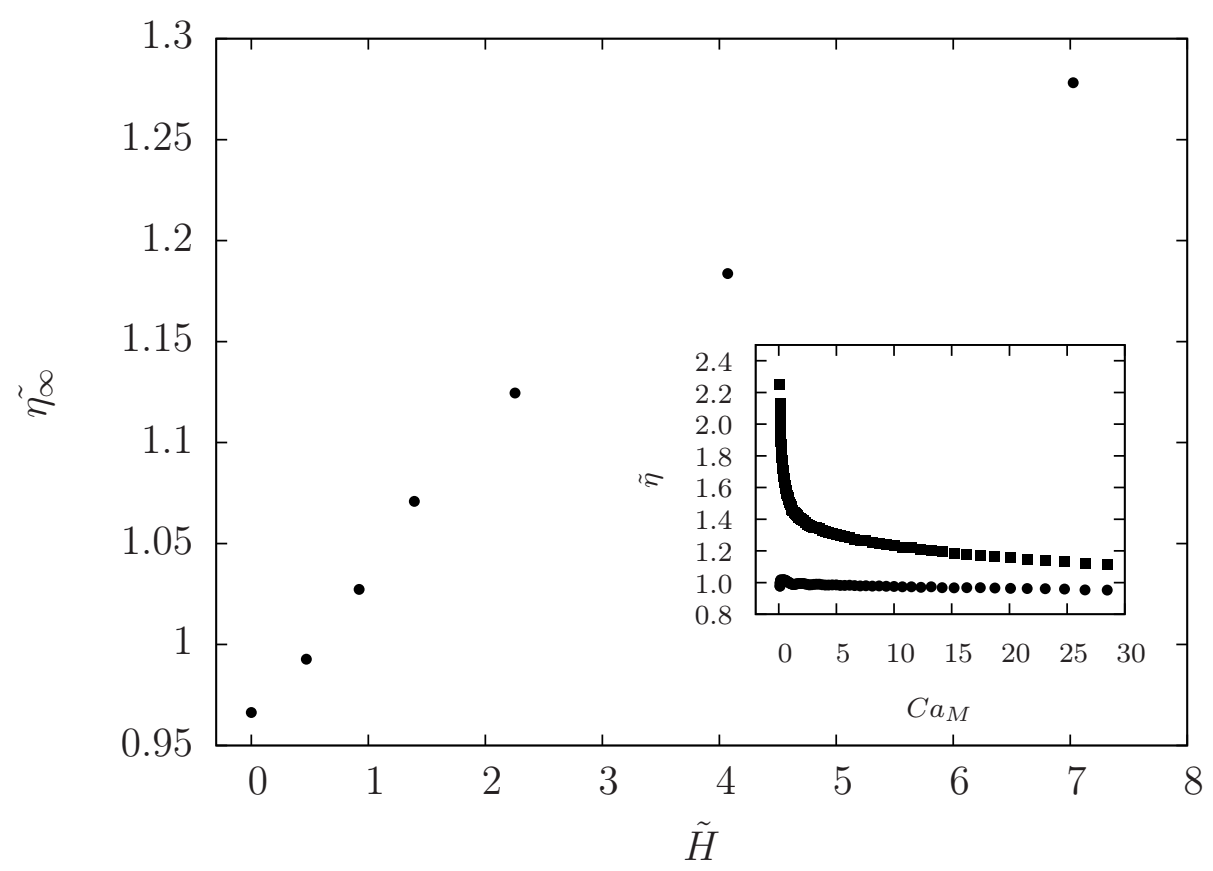

Figura 10.17: Variação da saturação da viscosidade adimensional $\left(\tilde{\eta}_{\infty}=\eta_{\infty} / \eta_{H=0}\right)$ em altos números de capilaridade magnético em função da intensidade do campo magnético adimensional. Encarte: Perfil de viscosidade adimensional $\left(\tilde{\eta}=\eta / \eta_{H=0}\right)$ com o aumento do número de capilaridade magnético para constantes campos magnéticos adimensionais. $\bullet H=0.0 ; \square H=4,07 \mathrm{k} / \mathrm{Am}$. 


\section{CONCLUSÕES}

No presente trabalhou foi realizado um estudo experimental do comportamento reológico de emulsões de diferentes frações volumétricas com diferentes razões de viscosidade e de um ferrofluido. Para esse propósito foi usada uma bancada de teste de escoamento em tubo capilar, em que os transdutores de pressão foram calibrados com um manômetro digital e um reômetro de disco rotativo que possibilita o estudo de fluidos magnéticos devido ao uso de célula magnética. Para a preparação de emulsões foi utilizado um homogenizador e surfactantes que evitam a separação de fases entre os líquidos da emulsão

A presente tese realçou que existem diferenças quando se avalia o comportamento de um fluido não-newtoniano em cisalhamento linear e em tubo capilar. Verificouse que na literaturas existem poucos trabalhos que utilizam o escoamento em tubo como um escoamento de análise das características reológicas de fluidos. Neste sentido, caracterizou-se emulsões de várias frações volumétricas e razões de viscosidade para observar os efeitos destes parâmetros na reologia e comparar os resultados com teorias de pequena deformação (altas razões de viscosidade) em emulsões diluídas (baixas frações volumétricas). A presente tese também conseguiu relacionar o comportamento pseudo-plástico com a distribuição de tamanho de gota (não coloidal).

O estudo teórico teve inicio com o escoamento de emulsões em tubo capilar. Neste tipo de escoamento considerou-se que a emulsão se concentra na região de menor taxa de cisalhamento, promovendo o desenvolvimento de uma camada livre de gotas adjacente à parede do tubo. A viscosidade do fluido foi tratada por um modelo típico de fluido newtoniano generalizado. Foi obtida uma expressão para a viscosidade intrínseca adimensionalizada pela viscosidade do fluido base, que é o fluido que se encontra na região de parede. Foi verificado um aumento da viscosidade com o aumento do raio do tubo capilar até $R \approx 200 \mu m$, situação idêntica ao da microcirculação. Para maiores 
raios a viscosidade diminuiu devido ao efeito de lubrificação da camada livre de gotas. Verificou-se também que para razões de viscosidade superior a 5 as gotas podem ser consideradas sistemas de pequena deformação. Com este tipo de modelo estimou-se a espessura da camada livre de gotas no qual a viscosidade intrínseca foi calculada com dados experimentais de escoamento em tubo capilar de emulsões de baixa fração volumétrica e alta razão de viscosidade.

Com o intuito de entender, do ponto de vista físico, a formação da camada livre de gotas foi proposto um modelo baseado na equação de transporte para a fração volumétrica de gotas. O problema foi tratado como um problema semi-infinito. Este modelo foi proposto com o intuito de identificar os parâmetros físicos responsáveis pelo surgimento da camada livre e gotas. Neste modelo considerou-se o desenvolvimento da camada na região de parede, considerando interações hidrodinâmicas entre gotas e entre gota e parede em emulsões de baixa fração volumétrica e alta razão de viscosidade. A equação de transporte para a fração volumétrica é constituída por um termo transiente, que considera a variação da espessura da camada com o tempo, um termo de velocidade do escoamento, um termo de velocidade de advecção na direção normal à parede e um termo de difusão hidrodinâmica para regimes diluídos e de pequenas deformações. Como uma primeira aproximação considerou-se que a camada livre de gotas está completamente desenvolvida e que a componente do vector de velocidade na direção do escoamento tem uma menor influência para o desenvolvimento da camada livre de gotas em comparação com a velocidade de advecção na direção normal do escoamento. Com estas considerações obtém-se uma expressão para a espessura da camada livre de gotas. Pela solução da equação resultante observou-se que a formação da camada livre de gotas é função do número de Peclet $(P e)$ e do número de capilaridade $(\mathrm{Ca})$. Para a predição da camada livre de gotas calculou-se o $\mathrm{Pe}$ e a $\mathrm{Ca}$ com dados dos experimentos de escoamento em cisalhamento simples de emulsões de baixa fração volumétrica e alta razão de viscosidade. A espessura da camada livre de gotas predita por este modelo está de acordo com o modelo do escoamento da emulsão pela região central do tubo capilar.

Para trabalhos futuros sugere-se resolver a equação difusão-convecção completa e em regime transiente do problema da camada livre de partículas, incluindo uma formulação 
do problema com gradientes de taxa de cisalhamento como ocorre em escoamentos em tubos. O gradiente de taxa de cisalhamento vai induzir um mecanismo de migração extra das partículas da parede para o centro do tubo.

As medidas da tensão interfacial por meio de um tensiômetro de gota se mostraram importantes para o cálculo do número de capilaridade $\left(C a=\eta \dot{\gamma} R / \tau_{s}\right)$ e para o conhecimento da fração volumétrica de surfactante adequada para garantir a estabilização da emulsão durante a realização dos experimentos. Os resultados obtidos mostraram que a tensão interfacial entre o óleo mineral e as misturas de água destilada e glicerina (fluido base) diminui com o aumento da fração volumétrica de glicerina. Os resultados da variação da tensão interfacial, adimensionalizada, pela tensão interfacial entre o óleo mineral e a água destilada, com a fração volumétrica de glicerina e com a razão de viscosidade foram bem ajustados pela Equação de Szyszkowski. Observou-se uma queda da tensão interfacial com o tempo de formação da gota para várias concentrações de surfactante (Tween80 e Span80). Este resultado mostrou que a tensão interfacial necessita de um tempo para estabilizar devido à reorganização das moléculas de surfactante na superfície da gota. Os resultados deste experimento foram bem ajustados pelo pelo modelo empírico de Huan e Rosen (1988) que nada mais é que o modelo de Cross (Cross (1967)) utilizado na Mecânica dos Fluidos para descrever o comportamento de fluidos newtonianos generalizados. Analisou-se a influência da fração volumétrica de surfactante no tempo de equilíbrio da tensão interfacial. Verificou-se que o tempo de equilíbrio diminui com o aumento da concentração. Os dados experimentais foram ajustados de forma razoável pelo modelo de Sisko. A tensão interfacial correspondente à concentração micelar crítica $\left(\phi_{c}\right)$ também foi obtida. Verificou-se uma diminuição da tensão interfacial com o aumento da concentração de surfactante. A utilização do surfactante Tween80 apresentou maior eficiência na redução da tensão interfacial, necessitando de menores concentrações, enquanto que o surfactante Span80 apresentou uma vantagem do ponto de vista de redução da tensão interfacial devido à menor tensão interfacial alcançada. Para trabalhos futuros sugere-se:

- estudar o efeito na tensão interfacial da adição de Span80 na fase oleosa e da adição de Tween80 na fase aquosa para várias concentrações;

- estudar o efeito da temperatura na tensão interfacial na presença de surfactantes. 
A microestrutura é um parâmetro que influencia a reologia das emulsões. Por microscopia óptica verificou-se que as emulsões sintetizadas por agitação mecânica têm características polidispersas. As emulsões de maior porcentagem de gotas de menor tamanho apresentaram um menor efeito pseudo-plástico. Pela literatura, as gotas de maior tamanho são mais propensas à deformação devido à menor pressão de Laplace ( Saiki et al., (2008)). Os resultados do escoamento em tubo e de cisalhamento linear mostraram indícios de um comportamento pseudo-plástico mais acentuado em emulsões de gotas de maior tamanho.

Os experimentos em cisalhamento simples foram realizados por um reômetro de discos paralelos onde $\dot{\gamma}=\dot{\gamma}(r)$. As emulsões estudadas foram as de fração volumétrica 2, 5, 20 e 40 de razões de viscosidade 2, 5, 10 e 20. Observou-se que o efeito pseudo-plástico é mais evidente em emulsões com fração volumétrica superior a 20\%. Nestas emulsões existe uma maior interação entre gotas que contribui para o surgimento de efeitos nãolineares no escoamento. Como era esperado, verificou-se que, a viscosidade aumenta com o aumento da fração volumétrica. Em relação à viscosidade adimensional $\left(\eta / \eta_{b}\right)$ foi observado um aumento com a razão de viscosidade, isto porque as gotas apresentam menores deformações. Por outro lado, a viscosidade aumenta com a diminuição da razão de viscosidade devido ao aumento da viscosidade do fluido base. Também se verificou que a viscosidade adimensional se aproxima da viscosidade do fluido base com a diminuição da fração volumétrica.

As propriedades reológicas das emulsões foram também analisadas pelo escoamento em tubo capilar. As emulsões estudadas foram as mesmas do cisalhamento simples. Observou-se que mesmo em baixas frações volumétricas $(\phi=2 \%)$ foi detectada uma diminuição da viscosidade com o aumento do número de capilaridade. Nessa situação, as gotas com menor razão de viscosidade apresentaram uma rápida deformação resultando em uma saturação da viscosidade para menores números de capilaridade. Foi observado o aumento da viscosidade adimensional com a fração volumétrica e a tendência do aumento da viscosidade adimensional com a razão de viscosidade $(\lambda)$ para a emulsão de $\phi=40 \%$. Quando se analisa a viscosidade aparente não adimensionalizada observa-se que esta aumenta com a diminuição da razão de viscosidade devido ao aumento da viscosidade do fluido base, tal como se observou no cisalhamento linear. 
Comparando os dois tipos de escoamento, observou-se que a viscosidade aparente da emulsão em tubo capilar foi maior que a viscosidade em cisalhamento linear. Para o escoamento em tubo capilar a viscosidade foi calculada na região de parede. Por outro lado, a viscosidade no reômetro, que está relacionada com a resistência ao movimento do disco, é capturada pela superfície em movimento. É de se destacar que existem diferenças na configuração da microestrutura da emulsão quando esta escoa pelo interior do tubo capilar e entre os discos do reômetro, devido às diferenças no perfil de velocidade.

Os resultados experimentais foram comparados com teorias de pequenas deformações (altas razões de viscosidade) para emulsões diluídas (baixa fração volumétrica). Para o cisalhamento simples, foi observada uma maior concordância entre os resultados experimentais e as predições teóricas com o aumento da razão de viscosidade para emulsões de até $20 \%$ de fração volumétrica. Isto porque em altos $\lambda$ as emulsões com fração volumétrica da ordem de $20 \%$ podem ser consideradas diluídas devido às pequenas deformações das gotas pelo cisalhamento. No cisalhamento quadrático as previsões teóricas também se mostraram satisfatórias com os resultados experimentais, mostrando que em altas razões de viscosidade a previsão é mais próxima dos resultados experimentais.

Analisou-se o comportamento reológico de emulsões de alta fração volumétrica (50, 60 e 70\%) com razão de viscosidade 10 e 20 em cisalhamento simples e oscilatório. Em cisalhamento simples a viscosidade das emulsões diminuiu com o aumento da taxa de cisalhamento devido a deformação e reorganização da microestrutura e da interação entre gotas. A emulsão de $70 \%$ e razão de viscosidade 10 apresentou um maior efeito pseudo-plástico com relação às emulsões 50 e $60 \%$ da mesma razão de viscosidade. A análise dos módulos de viscoelasticidade por cisalhamento oscilatório das emulsões de 50 e $60 \%$ não apresentaram nenhum comportamento elástico típico de sólido $\left(G^{\prime \prime}<G^{\prime}\right)$. Os módulos de viscosidade apresentaram um regime linear até $\gamma=0,01$. Com o aumento da magnitude da deformação surgiu o regime não-linear representado pela diminuição dos módulos viscoelásticos. Este comportamento é o reflexo da deformação e reorganização da microestrutura com o aumento da deformação. Da análise dos módulos viscoelásticos observou-se que o aumento da razão de viscosidade de 10 para 20, para as emulsões de 70\%, originou um comportamento elástico típico de sólido mais 
evidente. Isso está relacionado com a menor deformação das gotas devido ao aumento da razão de viscosidade. O comportamento elástico típico de sólido também foi mais pronunciado com o aumento da fração volumétrica.

Para trabalhos futuros sugere-se:

- estudar a influência da concentração de surfactante na reologia das emulsões e a sua influência na deformação de gotas relacionando com os módulos de viscoelasticidade;

- analisar o comportamento viscoelástico em emulsões com fração volumétrica acima de $60 \%$ em função da razão de viscosidade;

- analisar a deformação da gota em baixas taxas de cisalhamento por microscopia óptica interligada ao reômetro para diferentes razões de viscosidade em baixas e moderadas frações volumétricas;

- analisar os efeitos para a reologia de emulsões polidispersas e monodispersas com a mesma fração volumétrica e razão de viscosidade.

Foi estudado o comportamento reológico de um fluido magnético em função da intensidade de campo externo aplicado. Observou-se que o ferrofluido tem um comportamento Newtoniano quando a taxa de cisalhamento $(\dot{\gamma})$ é constante. Com o aumento da intensidade do campo magnético verificou-se um aumento da viscosidade (efeito magnetoviscoso). Isso se deve à formação de agregados de maior tamanho. A formação de agregados em maior número e de maior tamanho foi confirmada pelo resultado do aumento da viscosidade de saturação $\left(\eta_{\infty}\right)$ com o aumento da intensidade do campo magnético. Verificou-se também um aumento do pico de viscosidade com o aumento da intensidade do campo magnético devido ao maior número de estruturas formadas de maior tamanho. Foi observada a diminuição da viscosidade com o aumento da taxa de cisalhamento, quando a intensidade de campo magnético é diferente de zero. Isso se deve à quebra sucessiva dos aglomerados de partículas, formados pela presença do campo magnético, com o aumento da taxa de cisalhamento. 
Da análise das propriedades viscoelásticas, por cisalhamento oscilatório, do fluido magnético verificou-se que com o aumento da intensidade de campo magnético o ferrofluido apresenta um comportamento elástico típico de sólido, para deformações $(\gamma)$ menores que 0,1. Para maiores deformações o módulo viscoelástico associado com a propriedade elástica do fluido decai. O módulo associado com a a viscosidade apresenta um regime linear em toda a faixa de deformação para baixas intensidades de campo magnético. Porém, para a maior intensidade de campo magnético observa-se um regime linear seguido de um decaimento que é seguido de um regime linear. Esse comportamento está associado às mudanças na microestrutura devido ao aumento de $\gamma$. Em baixas deformações a estrutura do fluido não interage com o escoamento, mas com o aumento da deformação existe uma quebra da microestrutura (diminuição do módulo de G") até atingir uma saturação.

Analisou-se a função de relaxação, $\Phi(t)$, do fluido magnético. A função de relaxação foi obtida para diferentes valores de deformação $(\gamma)$ para uma intensidade de campo magnético constante. Observou-se que para deformações maiores do que 0,1 os aglomerados formados pela intensidade do campo magnético são quebrados. Vale notar que nos experimentos que avaliam os módulos de viscoelasticidade foi verificado que o regime não-linear se tornou presente para $\gamma>0,1$. Verificou-se que com o aumento da deformação $(\gamma \geq 0,1)$ o tempo para que o módulo de relaxação atinja o seu valor de equilíbrio aumenta. Isso indica que o aumento da deformação cria uma maior desordem na microestrutura.

A tensão residual, $\tau_{r}$, do fluido magnético foi medida em função de uma pré-taxa de cisalhamento. Verificou-se que a tensão residual aumenta com a diminuição da prétaxa de cisalhamento. Isto se deve ao fato que para baixas pré-taxas de cisalhamento as estruturas pouco se rompem ou se deformam. Ou seja, pouco se afastam do seu estado de equilíbrio e como consequência facilmente se reagrupam após a interrupção da pré-taxa de cisalhamento resultando em uma maior tensão. O tempo para que a tensão residual atinja o seu valor de equilíbrio aumenta com a pré-taxa de cisalhamento devido ao maior grau de afastamento da microestrutura com relação à sua configuração inicial. 
Por último, analisou-se o comportamento da tensão crítica, $\tau_{0}$, do fluido magnético com o aumento da intensidade do campo magnético. A tensão crítica é a tensão a partir da qual existe movimento relativo entre as partículas. Observou-se um platô da tensão crítica para as menores intensidade de campo magnético. Após esse platô a tensão crítica aumentou linearmente com a intensidade do campo magnético. Porém a viscosidade apresentou um aumento não-linear até atingir um platô para as maiores intensidades de campo magnético. A explicação pode ser que na região de platô da tensão crítica a formação de agregados é mais intensa refletindo em um aumento de viscosidade.

Para trabalhos futuros com ferrofluidos sugere-se:

- estudar a reologia destes fluidos em função da fração volumétrica de partículas;

- estudar a reologia de fluidos magnéticos de diferentes propriedades de magnetização de saturação;

- observar os efeitos reológicos da adição de micropartículas do mesmo material que as nanopartículas já presentes nos ferrofluidos;

- implementar uma bancada para estudar o escoamento de fluidos magnéticos em tubos capilares, na presença de um gradiente longitudinal de campo magnético (ao longo do tubo).

- estudar a reologia de emulsões magnéticas de alta razão de viscosidade em baixas/moderadas frações volumétricas, em cisalhamento simples e oscilatório e em tubo capilar. 


\section{REFERÊNCIAS BIBLIOGRÁFICAS}

Alexiou C., Jurgons R., Seliger C., Brunke O., Iro H., Odenbach S., 2006, Anticancer Research at press.

Aggarwal N., Sarkar K., 2008, Rheology of an emulsion of viscoelastic drops in steady shear ,Journal of Non-Newtonian Fluid Mechanics, 15, 19-31.

Arditty, S., Whitby, C.P., Binks, B.P.,Schmitt, V., Leal-Calderon, F., 2003: Some general features of limited coalescence in solid-stabilized emulsions, The European Physics Journal, vol. 11, 273-281.

Aris, R., 1962, Vectores, tensors and the basic equations of fluid mechanics, Dover Publications, New York.

Barthes-Biesel, D., Acrivos, A. 1973a, Deformation and burst of a liquid droplet linear shear flow, Journal of Fluid Mechanics, vol. 61, 1-21.

Bayareh M., 2012,Numerical Simulation of the Motion of a Drop in PLane Poiseuille Flow: Density Ratio Effects, International Journal Of Computational Engineering Research, 1, pp. 81-85.

Batchelor G. K., 1967, The stress system in a suspension of force-free particles, Journal of Fluid Mechanics 41, pp. 545-570.

Batchelor G. K., 1970, An Introduction to Fluid Dynamics, Cambridge University Press.

Barnes H. A., 1994, Rheology of emulsions - a review, Colloids and Surfaces A: Physicochemical and Engineering Aspects, 91, pp. 89-95. 
Bird. R.,Amstrong R. C., Hassanger O., 1987, Dynamics of Polymeric Liquids, Volume 1: Fluid Mechanics, Second Edition, John Wiley \& Sons, Inc.

Borin D. Y. ,Zubarev A. Y. ,Chirikov D. N. ,Odenbach S., 2014, Stress relaxation in a ferrofluid with clustered nanoparticles, Journal of Physical of Condensate Matter, 26 , pp. $1-10$.

Bossis G, Volkova O, Lacis S and Meunier A, 2002, Magnetorheology: Fluids, structures and Rheology. In: Ferrofluids (Odenbach, S., Ed.), p. 202, Berlin Springer.

Butler, J.A.V., 1932, The Thermodynamics of the Surfaces of Solutions, Proceedings of the Royal Society of London. Series A, 827, 348-375.

Brunke O., Odenbach S., Jurgons R., Alexiou C., Hilger I., Beckmann F., 2006, Determination of the magnetic particle distribution in tumour tissue bymeans of $\mathrm{x}$-ray tomography Journal of Physics: Condensed Matter, 18, S2903-S2917.

Carvalho J. A. A., Oliveira T. F., Cunha F. R., 2007 A core flow model of a high viscosity emulsion to describe the blood in the microcirculation, 19th International Congress of Mechanical Engineering

Carvalho, J A. A., 2008, Hidrodinâmica do Escoamento do Sangue em Microvasos, Dissertação de Mestrado, Programa de Pós-Graduação de Ciências Mecânicas, Universidade de Brasília, p. 196.

Chan, P. C.H., Leal, L. G., 1979, The motion of a deformable drop in a second-order fluid, Journal of Fluid Mechanics, vol 92, pg. 131-170.

Cunha, F. R., 2012, Fundamentals of Magnetic Fluid Hydrodynamics, in Turbulence (Book Chapter), ISBN: 978-85-85769-49-9, Poli-USP-ABCM, São Paulo, vol $8,257-339$.

Cross, M.M., 1967, Rheologia of non-Newtonian fluids: a new flow-equation for pseudo-plastic systems, Journal of Colloid Science,20, 417-437.

Cunha F. R., Hinch E. J., 1996, Shear-induced dispersion in a dilute suspension of rough spheres, Journal of Fluid Mechanics, Vol. 309, pp. 211-223. 
Cunha F. R., M Lowenberg M., 1999, Normal and pathological distribution of blood flow in the microcirculation, Proceedings of biomedical engineering research conference Vol 1, p. 119, 1999, New York, USA.

Cunha F. R., 2003, Projeto de pesquisa: Reologia e microhidrodinâmica de células, Relatório de projeto CNPq, 475201/2003-5, CNPq.

Cunha F. R., Loewenberg M., 2003, A study of emulsion expansion by a boundary integral method, Mechanics Research Communications, 30. pp. 639-649.

Cunha F.R.,Oliveira T.F., 2014, An Investigation of Micromechanics and Rheology of High Viscosity Drop Emulsion Flows by Boundary Integral Simulations, Rheological Acta, Vol (Under Review), 44 p.

Danov, K., D., 2001, On the viscosity of dilute emulsions, Journal of Colloid and Interface Science, 235, 144-149.

Davis H. T., 1994, Factors determining emulsion type: hydrophile-lipophile and beyond balance, 1994, Colloids and Surfaces A: Physicochemical and Engineering Aspects, 91, 9-24.

Rheology of emulsions, 2009, Advances in Colloid and Interface Science, 151, 1-23.

Einstein A., 1985, Investigations on the Theory of the Brownian Movement, Published by Dover Publications.

Frankel, N. A., Acrivos, A., 1970, The consitutive equation for a dilute emulsion, Journal of Fluid Mechanics, Vol. 44, pp. 65-78.

Furtado, A. and Batista, E. and Spohr, I. and Filipe, E., 2009, Measurement of density using oscillation-type density meters. Calibration, traceability and uncertainties, Proceedings of the 14ème Congrès International de Métrologie.

Physical Properties of Glycerine and Its Solutions, Glycerine Producers' Association, pp. $1-27$.

Glöckl, G., Hergt, R., Zeisberger, M., Dutz, S., Nagel, S., Weitschies, W., 2006, The effect of field parameters, nanoparticle properties and immobilization on the specific 
heating power in magnetic particle hyperthermia, Journal of Physics: Condensed Matter, 18, S2935-S2949.

Grandchamp, X., Coupier, G., Srivastav A.; et al., 2013, Lift and Down-Gradient Shear-Induced Diffusion in Red Blood Cell Suspensions Physical Review Letters vol. 110, pp. 108101-1081015.

Grant, I. S., Philips, W. R., 1990, Eletromagnetism, 2nd ed., John Wiley \& Sounds, New York.

Greenwald H.L., 1955, Theory of Emulsion Stability, Soc. Cosmetic Chemists, 6, pp. $164-177$

Gontijo R. G., Cunha F. R.,2012, Experimental investigation on thermo-magnetic convection inside cavities, Journal of Nanoscience and Nanotechnology, Vol 12, pp. 9198-9207.

Gontijo R. G., 2013, Micromecânica e Microhidrodinâmica de Suspensões Magnéticas, Tese de Doutorado, Programa de Pós-Graduação de Ciências Mecânicas, Universidade de Brasilia, pp. 262.

Gontijo, R. G., Cunha F. R.,2014, The influence of magnetic effects on a ferrofluid meniscus shape, SIAM - Applied Mathematics Journal (Under Review).

Guido S., Preziosi V., 2012, Droplet deformation under confined Poiseuille flow, Advances in Colloid and Interface Science, vol. 161,89-101.

Guldbakke, J. M., Hesselbach J., 2006, Development of bearings and a damper based on magnetically controllable fluids, Journal of Physics: Condensed Matter, 18, S2959-S2972.

Happel, J., Brenner, H., 1965, Low Reynolds Number Hydrodynamics, Prentice Hall.

Hariprasad D. S., Secomb T. W., 2014 Two-dimensional simulation of red blood cell motion near a wall under a lateral force, Physical Review, 90, pp. 1-7.

Hezaveha H. ,Fazlali A. ,Noshadi I., 2012 Synthesis, rheological properties and magnetoviscos effect of Fe2O3/paraffin ferrofluids Journal of the Taiwan Institute of Chemical Engineers, 43, pp. 159-164. 
Hollingsworth K.G., Johns M.L., 2006, Droplet migration in emulsion systems measured using MR methods, Journal of Colloid and Interface Science, 296, pp. 700-709.

Hua, X. Y., Rosen, M. J, 1988, Dynamic Surface Tension of Aqueous Surfactant Solutions: I. Basic paremeters, Journal of Colloid and Interface Science, 124, pp. $652-659$.

Ilg P., Coquelle E., Hess S., 2006, Structure and rheology of ferrofluids: simulation results and kinetic models, Journal of Physics: Condensed Matter, 18, S2757-S2770.

James F. D., Boger Fluids, 2009, Annual Review of Fluid Mechanics, 41, pp. 129-142.

Jayasuriya, D. S., Varanasi, P. P.,Tcheurekdjian, N.,1986, Viscoelastic properties of concentrated oil-in-water emulsions stabilized by mixed non-ionic surfactants, Colloids and Surfaces,21, pp. 371-391.

Jiao J., Burgess D. J., 2003, Rheology and Stability of Water-in-Oil-in-Water Multiple Emulsions Containing Span 83 and Tween 80, AAPS PharmSci, 5, pp. 1-12.

Jurgons R., Seliger C., Hilpert A.,Trahms L., Odenbach S., Alexiou C., 2006, Drug loaded magnetic nanoparticles for cancer therapy, Journal of Physics: Condensate Matter 18, S2893-S2902.

Kamiyama S., Satoh A., 1989, Rheological Properties of Magnetic Fluids with the Formation of Clusters: Analysis of Simple Shear Flow in a Strong Magnetic Field Journal of Colloid and Interface Science, Vol. 127, No. 1., pp. 173-188.

Karins A., Mason, S. G., 1967, Particle Motions in Sheared Suspensions: XXIII. Wall Migration of Fluid Drops, Journal of Colloid And Interface Science, vol. 169, pp. $164-169$.

Kim S., Karrila S. J., 1989, Microhydrodinamics: Principles and Select Applications.

Kim J., Leal L. G., 2006, Interactions for Dispersed Systems in Newtonian and Viscoelastic Fluids, Physics of Fluids, Volume 18, pp. 1-9. Issue 12.

King R. P.,2002, Introduction to Practical Fluid Flow, Elsevier Science. 
Kiss, N., Brenn, G., Pucher, H., Wieser, J., Scheler, S., Jennewein, H., Suzzi, D., Khinast, J., 2011, Formation of $\mathrm{O} / \mathrm{W}$ emulsions by static mixers for pharmaceutical applications, Chemical Engineering Science 66 , pp. 5084-5094.

Klingenberg, D. J., 2001, Magnetorheology: Applications and Challenges, AIChE Journal, 47,2 .

Laboratorio de Formulación, Interfases, Reología y Proceso.

Landau, L. D., Lifshitz, E. M., 1984, Electrodynamics of continuous media, Pergamon, Press, Oxford.

Lautrup B., 2011, Physics of Continuous Matter, Second Edition: Exotic and Everyday Phenomena in the Macroscopic World, Taylor Francis.

Leal-Calderon, F., Schmitt, V., Bibette, J., 2007, Emulsion Science: Basic Principles - Second Edition, 2007 Springer Science.

Liu T.,Gu R., Gong X., Xuan S., Wu H., Zhang Z., 2010, Strutural and Rheological Study of Magnetic Fluids using Molecular Dynamics, Magnetohydrodynamics, 46, 3, pp. $257-269$.

Liu, X. H., Jin, L.,2011, Effect of the Volume of Magneto-rheological Fluid on Shear Performance, Measurement Science Review, vol 11,pp. 54-57.

Loewenberg, M., Hinch, E. J., 1996 Numerical simulation of a concentrated emulsion in shear flow, Journal of Fluid Mechanics, vol. 321, pp.395-419.

Leal,G., 1980, Particle Motions in a Viscous Fluid, Annual Review of Fluid Mechanics, vol.12, 432-476.

López-López, M. T., Kuzhir, P., Lacis, S., Bossis, G., González-Caballero, F., Durán, J. D. G., 2006, Magnetorheology for suspensions of solid particles dispersed in ferrofluid, Journal of Physics: Condensed Matter, 18, S2803-S2813.

Lowenberg M., Hinch J. E. , 1997, Collision of two deformable drops in shear flow, Journal of Fluid Mechanics, Vol. 338, pp. 299. 
G. Magnac, P. Meneroud, M.F. Six, G. Patient, R. Leletty, F. Claeyssen, 2006 Characterisation of Magneto-Rheological Fluids for actuators applications Actuator 2006, 10th International Conference on New Actuators, pp. 856-859.

Mason, T. G., 1999, New Fundamental Concepts in Emulsion Rheology, Current Opinion in Colloid 8 Interface Science 4, pp. 231-238.

Masalova, I., Foudazi, R., Malkin, A. Ya., 2011, The rheology of highly concentrated emulsions stabilized with different surfactants, Colloids and Surfaces A: Physicochemical and Engineering Aspects, vol. 375, pp. 76-86.

Mortzavi, S., Tryggvason, G., 2000, A numerical study of the motion of drops in Poiseuille flow. Part 1. Lateral migration of one drop, Journal of Fluid Mechanics, vol. 411 , pag. $325-350$.

Morrison, F. A.,2001, Understanding Rheology, Oxford University Press.

Motozawaa, M., Changa, J., Sawadac, T., Kawaguchia, Y., 2010, Effect of Magnetic Field on Heat Transfer in Rectangular Duct Flow of a Magnetic Fluids 12th International Conference on Magnetic Fluids, Physics Procedia vol. 9, pp. 190-193.

Muller RH, Jakobs C , Kayser, 2001, Nanosuspensions as particulate drug formulations in therapy Rational for development and what we can expect for the future, Advanced Drug Delivery Reviews, vol. 47, pp. 3-19.

Vivek Narsimhan, Hong Zhao, and Eric S. G. Shaqfeh, 2013, Coarse-grained theory to predict the concentration distribution of red blood cells in wall-bounded Couette flow at zero Reynolds number, Physics of Fluids, 25, 061901, pp. 1-21.

Nethe, A., Scholz, Th., Stahlmann, H-D, 2006, Improving the efficiency of electric machines using ferrofluids Journal of Physics: Condensed Matter, 18, S2985-S2998.

Nourbakhsh A. , Mortazavi S. 2010, A three- dimensional study of the motion of a drop in plane Poiseuille flow at finite Reynolds number, Iranian Journal of Science \& Technology, Transaction B: Engineering, Vol. 34, No. B2, pp. 179-196.

Odenbach, S., Ferrofluids, Springer-Verlag, Berlin, 2002. 
Odenbach, S., 2003, Ferrofluids-magnetically controlled suspensions, Colloids and Surfaces A: Physicochem. Eng. Aspects, 217, pp. 171-178.

Oldroyd, J. G., 1964, Nonlinear stress, rate of strain relations at finite rates of shear in so-classed linear elastico-viscous liquids in "Second-order effects in Elasticity, Plasticity and Fluid Dynamics", Ed. Abir, Pergamon, pp. 520-529.

Oliveira T. F., 2007, Microhidrodinâmica e Reologia de Emulsões, Tese de Doutorado, Pontifícia Universidade Católica do Rio de Janeiro.

Oliveira T.F., Cunha F.R., 2011, A theoretical description of a dilute emulsion of very viscous drops undergoing unsteady simple shear, Journal of Fluids Engineering, Vol 133 (10), 101208 (8p).

Otsubo Y., Prud'homme, R. K., 1994, Rheology of oil-in-water emulsions, Rheologica Acta, 33, pp. 29-37.

Pal R., 1992, Rheological behaviour of concentrated surfactant solutions and emulsions, Colloids and Surfaces, 64, pp. 207-215.

Pal R., 1996, Multiple O / W / O Emulsion Rheology, Journal of Colloid and Interface Science, Langmuir, 12, pp. 2220-2225.

Pal,R., 2000, Relative Viscosity of Non-Newtonian Concentrated Emulsions of Noncolloidal Droplets, Industrial Engineering Chemistry Research, 39:12, pp. 4933-4943.

Pal, R., 2000, Shear Viscosity Behavior of Emulsions of Two Immiscible Liquids, Journal of Colloid and Interface Science, 225, pp. 359-366.

Pal, R.,2001, Evaluation of theoretical viscosity models for concentrated emulsions at low capillary numbers, Chemical Engineering Journal, 81, 15-21.

Pal, R., 2003, Viscous behavior of concentrated emulsions of two immiscible Newtonian fluids with interfacial tension, Journal of Colloid and Interface Science, 263, pp. $296-305$.

Pal, R., 2011, Rheology of simple and multiple emulsions, Current Opinion in Colloid ES Interface Science,16, pp. 41-60. 
Patty P. J., Frisken B. J., 2006, Direct determination of the number-weighted mean radius and polydispersity from dynamic light scattering data, Optical Society of America, Applied Optics, vol 45, no. 10, pp. 1-22.

Pérez M., Zambrano N., Ramirez M., Tyrode E., Salager J., Surfactant-Oil-Water Systems Near the Affinity Inversion. XII: Emulsion Drop Size Versus Formulation and Composition, Journal of Dispersion Science and Technology, 23, pp. 55-63.

Pouliquen D., Perdrisot R., Ermias A., Akoda S., Jallet P., Jeune J. J., 1989, Superparamagnetic iron oxide nanoparticles as a liver MRI contrast agent: contribution of microencapsulation to improved biodistribution, Magnetic Resonance Imaging, 7, pp. $619-27$.

Pranay P., Henríquez-Rivera R. G., Graham M. D., 2012, Depletion layer formation in suspensions of elastic capsules in Newtonian and viscoelastic fluids, Physics of Fluids, 24, 061902, pp. 1-30.

Pries, A. R., Secomb, T. W., Gessner, T., Sperandio, M. B., Gross, J. F., e Gaehtgens, P., 1994, Resistence to blood ${ }^{\circ}$ ow in microvessels in vivo, "Circulation Research", Vol. 75 , pp. $904-915$.

Prinderre P., Piccerelle Ph., Cauture E., Kalantzis G., Reynier J.P., Joachim J., 1998, Formulation and evaluation of $\mathrm{o} / \mathrm{w}$ emulsions using experimental design, International Journal of Pharmaceutics, Vol. 163, pp. 73-79.

Prista, L. N., Alves, A.C., Morgado, R.M.R., 1991, Técnica farmacêutica e farmácia galênica, 1 volume, $4^{\mathrm{a}}$ edição

Press W. H., Teukolsjy S. A., Vetterling W., Flannery B. P., 1992 Numerical Recipes in Fortran, Cambdridge University Press.

Qiang Li, Yimin Xuan, Jian Wang, 2005, Experimental investigations on transport properties of magnetic fluid, Experimental Thermal and Fluid Science, 30, pp. 109-116.

Rallison, J. M., 1984, The Deformation of Small Viscous Drops and Bubbles in Shear Flows, Annual Review of Fluid Mechanics, vol 16, pp. 45-66. 
Rodriguez-Arco L., López-López M. T., Zubarev A. Y., Gdulac K., Durán J. D. G., 2014, Inverse magnetorheological fluids, Soft Matter Advance Article, DOI: $10.1039 / \mathrm{c} 4 \mathrm{sm} 01103 \mathrm{a}$.

Rosa, A., P., 2014, Análise Numérical e Experimental da Reologia e Microestrutura de Suspensões Magnéticas, Dissertação de Mestrado, Programa de Pós-Graduação em Ciências Mecânicas, Universidade de Brasília, p.148.

Rosen, M.J., 2004, Surfactants and Interfacial Phenomena, Wiley \& Sons.

Rosensweig, R. E., 1988, An introduction to ferrohydrodynamics, Chemical Engineering Communications, 67, pp. 1-18.

Safarik, I., Safarikova, M., 1999, Use ofmagnetic techniques for the isolation of cells, Journal of Chromatography B, 722, pp. 33-35.

Schowalter W. R., Chaffey C. E., Brenner H., 1968, Rheological Behavior of a Dilute Emulsion, Journal of Colloid and Interface Science, 26, pp. 152-160.

Saiki Y., Prestidge C. A., Horn R. G., 2007, Effects of droplet deformability on emulsion rheology, Colloids and Surfaces A: Physicochem. Eng. Aspects, 299, pp. 65-72.

Saiki Y., Horn R. G. , Prestidge C. A. , 2008, Droplet structure instability in concentrated emulsions, Journal of Colloid and Interface Science 320, pp.569-574.

Skartlien R., Sollum E., Akselsen A., Meakin P., 2012, Direct numerical simulation of surfactant-stabilized emulsions: Morphology and shear viscosity in starting shear flow, Rheology Acta, 51, pp. 649-673.

Shauly A., Wachs A., Nir A., 1998, Shear-induced particle migration in a polydisperse concentrated suspension, Journal of Rheology, pp. 1329-1348.

Sagitani, H., 1981, Making Homogeneous and Fine Droplet O / W Emulsions Using Nonionic Surfactants, Journal of the American Oil Chemists' Society June, pp. $740-743$.

Salager J. L., Ramirez Gouveia M., Bullon J., 1995, Properties of emulsion mixtures, Progress in Colloid and Polymer Science, 98, pp. 173-176. 
Smart J. R., Leighton D. T., 1991, Measurement of the drift of a droplet due to the presence of a plane, Physics of Fluids, 3, pp. 21-28.

Shahnazian, H., Odenbach, S., 2008, Rheological investigations of ferrofluids with a shear stress controlled rheometer, Journal of Physics: Condensed Matter, 20, pp. $1-4$.

Shin S. J., Sung H. J., 2011, Inertial migration of an elastic capsule in a Poiseuille flow, Physical Review E, 83, 046321, pp. 1-13.

Shi L., Pan T-W, Glowinski R., 2012, Numerical simulation of lateral migration of red blood cells in Poiseuille flows, International Journal fot Numerical Methods in Fluids, 68, pp. 1393-1408.

Sisko, A.W., 1958, The flow of lubricating gases Ind. Eng. Chem., 50, pp. 1789-1792.

Tadros, T. F., 1994, Fundamental principles of emulsion rheology and their applications, Colloids and Surfaces: Phsysicochemical and Engineering Aspects, 91, pp. $39-55$.

Taylor, G., I., 1932, The Viscosity of a Fluid Containing Small Drops of Another Fluid, Proceedings of the Royal Society of London, Series A, Containing Papers of Mathematical and Psysical Character, vol 138, no 834, pp. 41-88.

W. M. Wan Rusmawati, K. Dzulkefly, W. H. Lim, Hamdan, 2002 Emulsion Properties of Mixed Tween20-Span20 in Non-Aqueous System, Journal of Science and Technology, 10, pp. 153-160 .

Walstra P.,2005 ,Emulsions, Fundamentals of Interface and Colloid Science, Volume V, Elsevier Ltd. All.

Whitby C. P., Djerdjev A. M., Beattie J. K.,Warr G. G., 2007 In Situ Determination of the sixe and Polydispersity of Concentrated Emulsions, American Chemical Society, Languir, 23, pp. 1694-1700.

Zubarev, A. Y., Iskakova,L. Y., 2006, Rheological properties of ferrofluids with microstructures, Journal of Physics: Condensed Matter, 18, S2771-S2784. 
APÊNDICES 
Apêndice A MICROESTRUTURA DAS EMULSÕES A.1 Emulsões $\lambda=2$

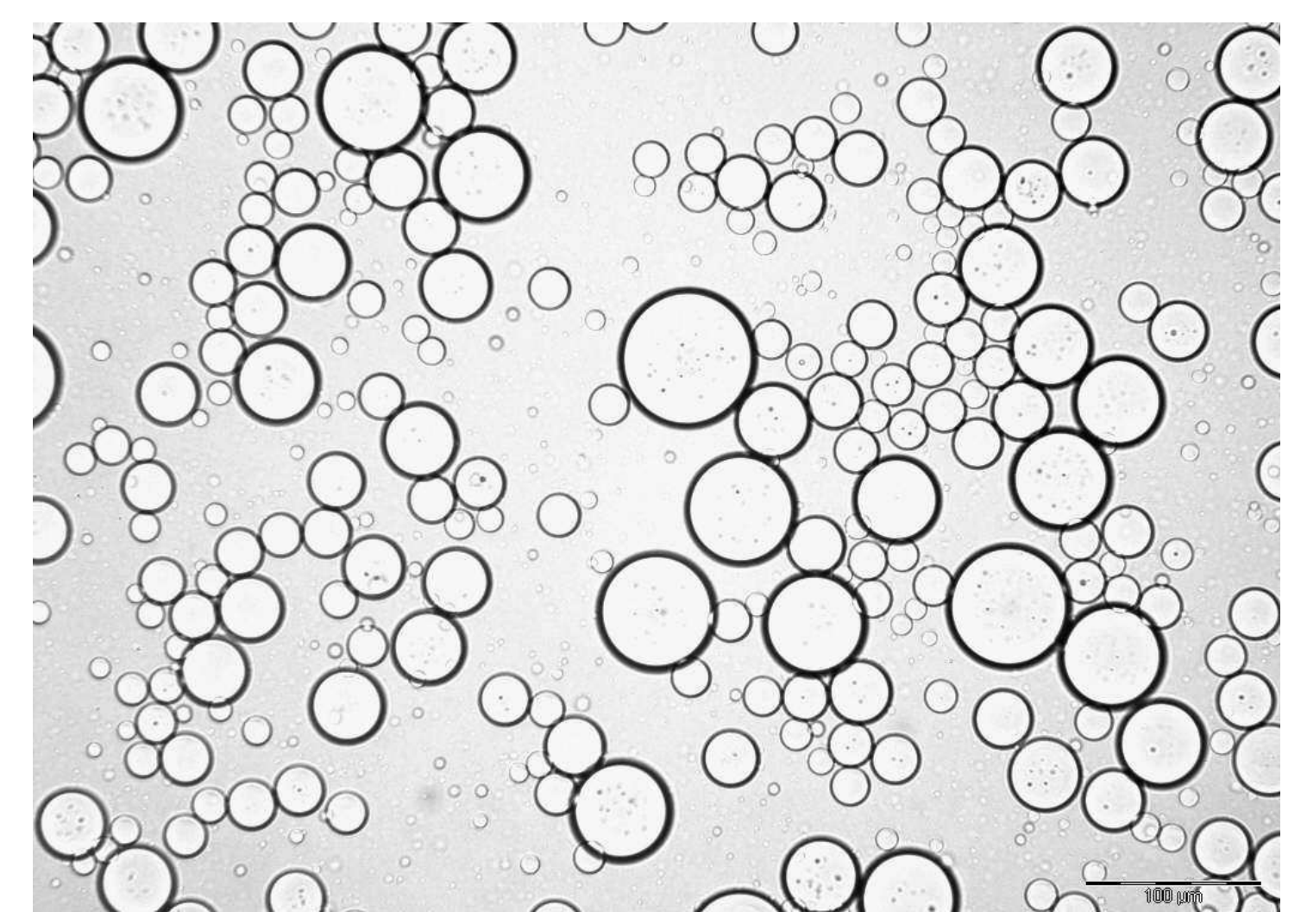

Figura A.1: Imagem da Microestrutura da Emulsão $\lambda=2$ e $\phi=2 \%$ 


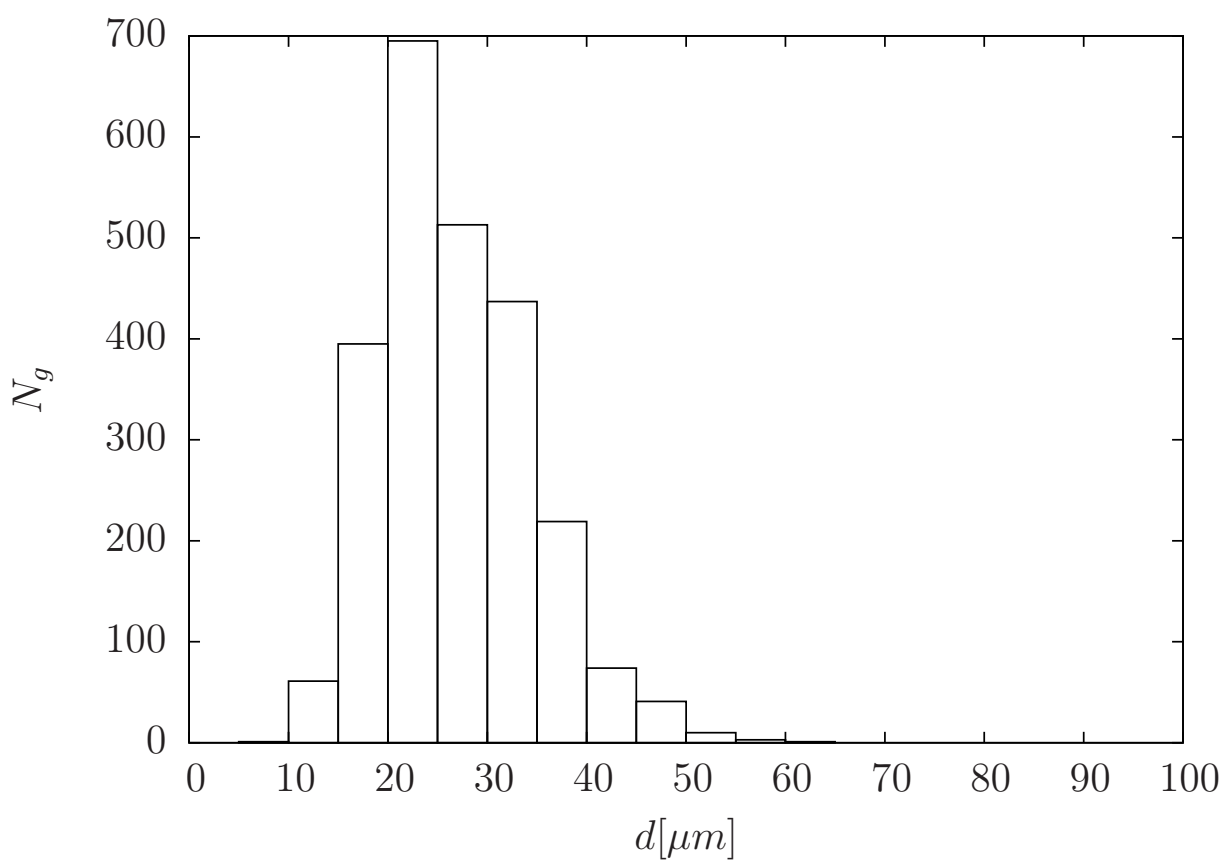

Figura A.2: Distribuição de Tamanho de gota para a emulsão $\lambda=2$ e $\phi=2 \%$. Características da microestrutura: $N_{g}=2450, \bar{a}=13,37 \mu m, p=0,286$

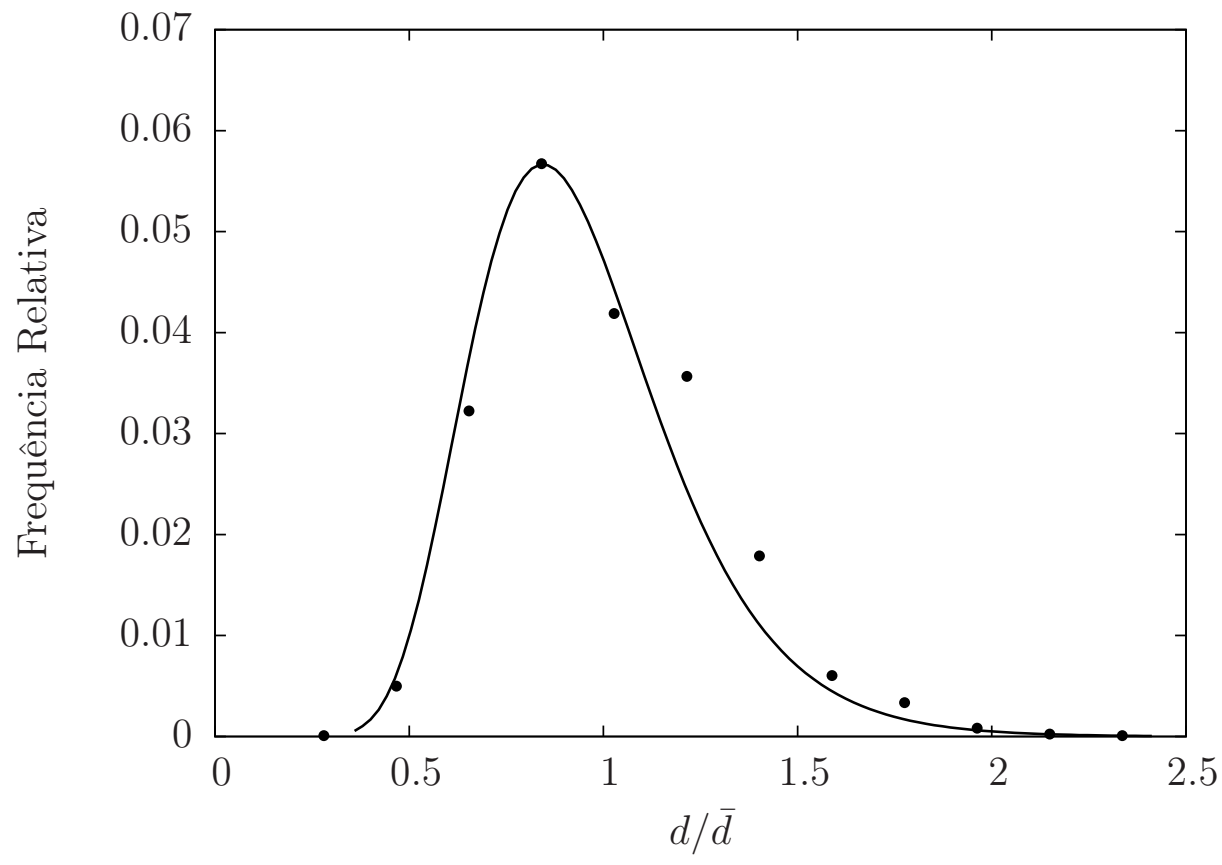

Figura A.3: Frequência Relativa $\left(N_{\text {gint }} /\left(\operatorname{Dim}_{\text {int }} \times N_{\text {gtot }}\right)\right.$ para a emulsão $\lambda=2$ e $\phi=2 \%$. Constantes da Log-Normal: $C_{1}=0,035, C_{2}=0,95$ 


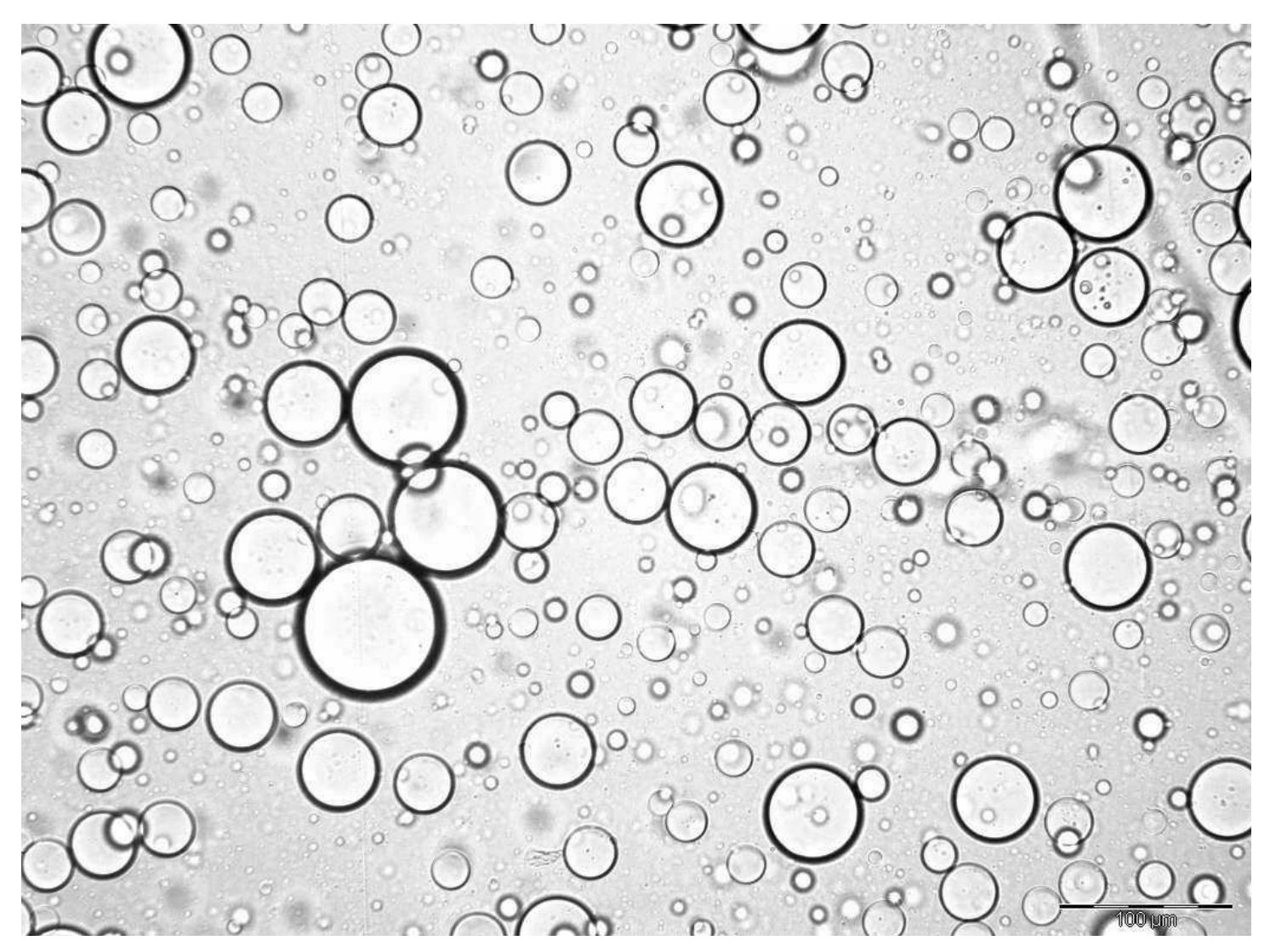

Figura A.4: Imagem da Microestrutura da Emulsão $\lambda=2$ e $\phi=5 \%$

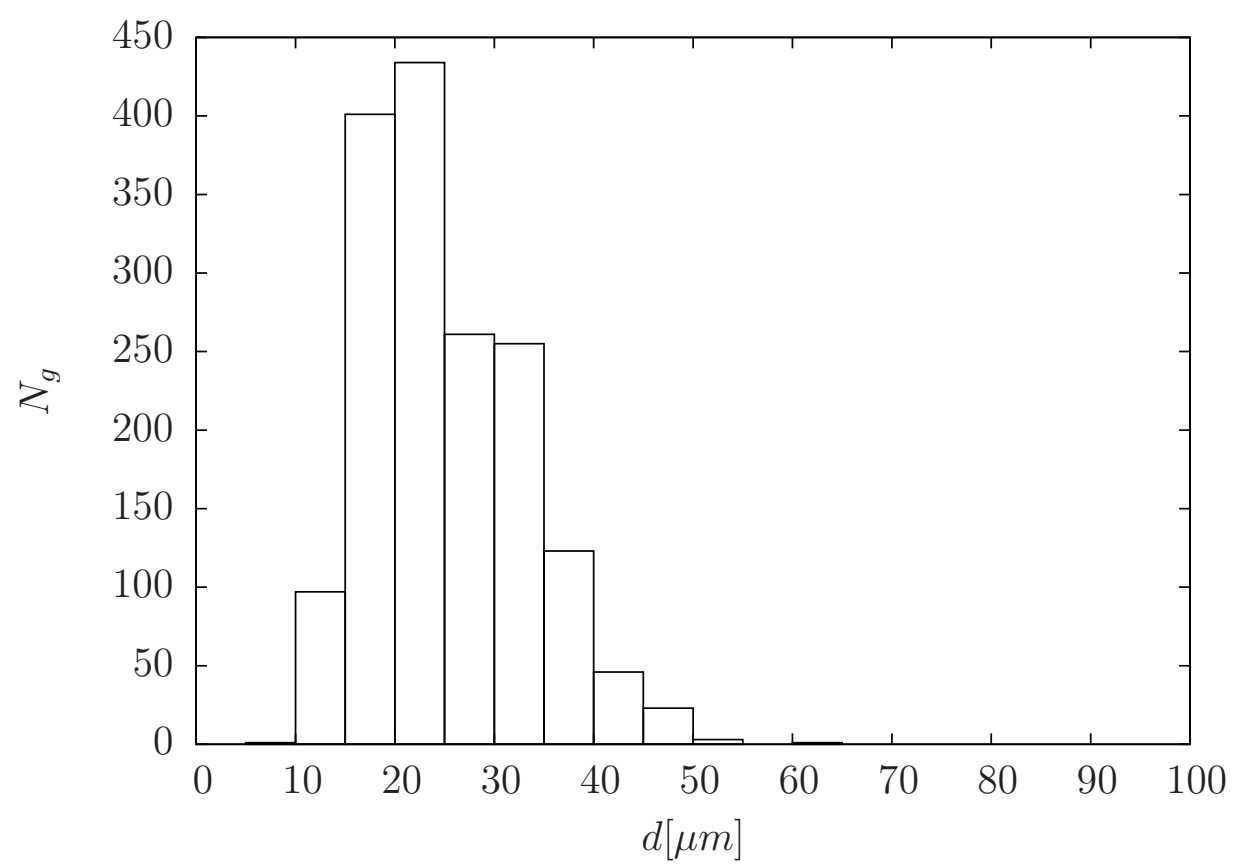

Figura A.5: Distribuição de Tamanho de gota para a emulsão $\lambda=2$ e $\phi=5 \%$. Características da microestrutura: $N_{g}=1650, \bar{a}=12,49 \mu m, p=0,321$ 


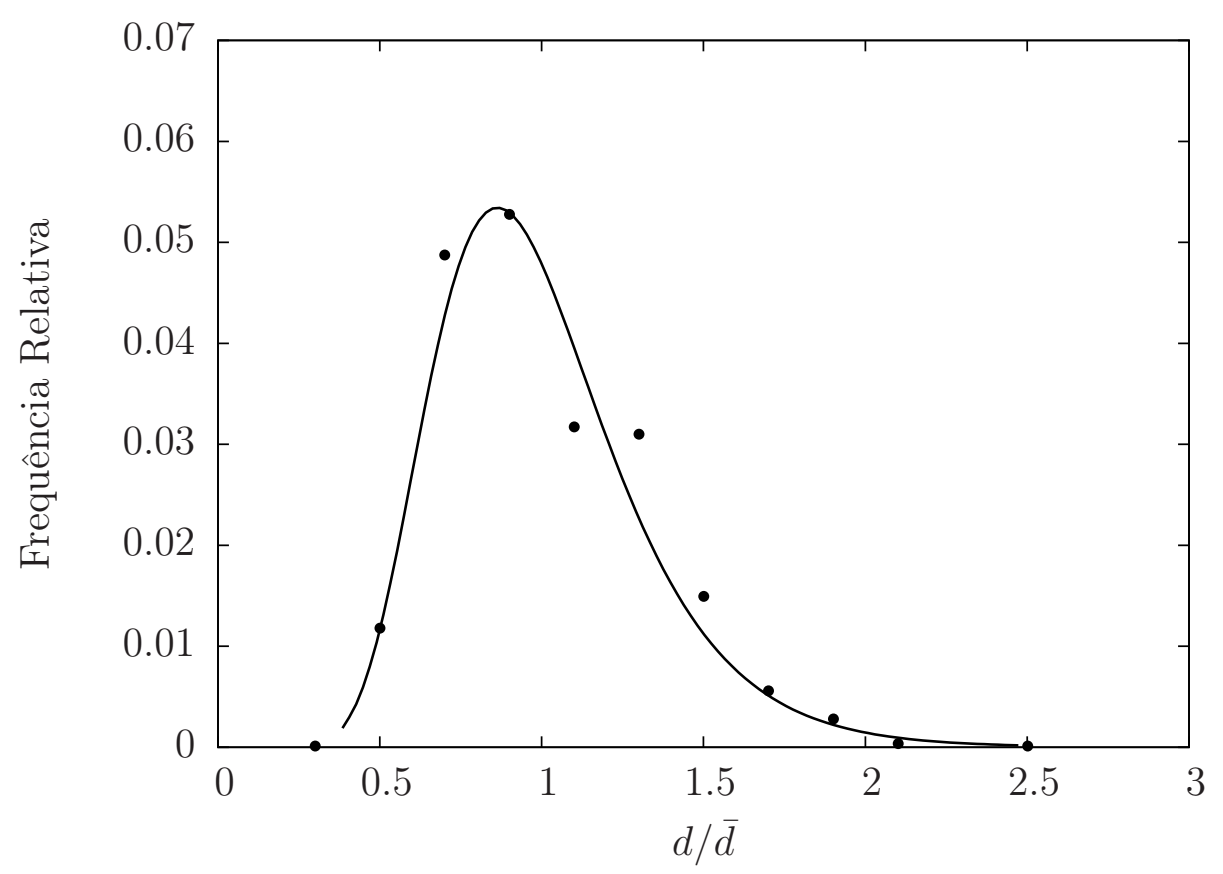

Figura A.6: Frequência Relativa $\left(N_{\text {gint }} /\left(\operatorname{Dim}_{\text {int }} \times N_{\text {gtot }}\right)\right.$ para a emulsão $\lambda=2 \mathrm{e}$ $\phi=5 \%$. Constantes da Log-Normal: $C_{1}=0,038, C_{2}=1,0$

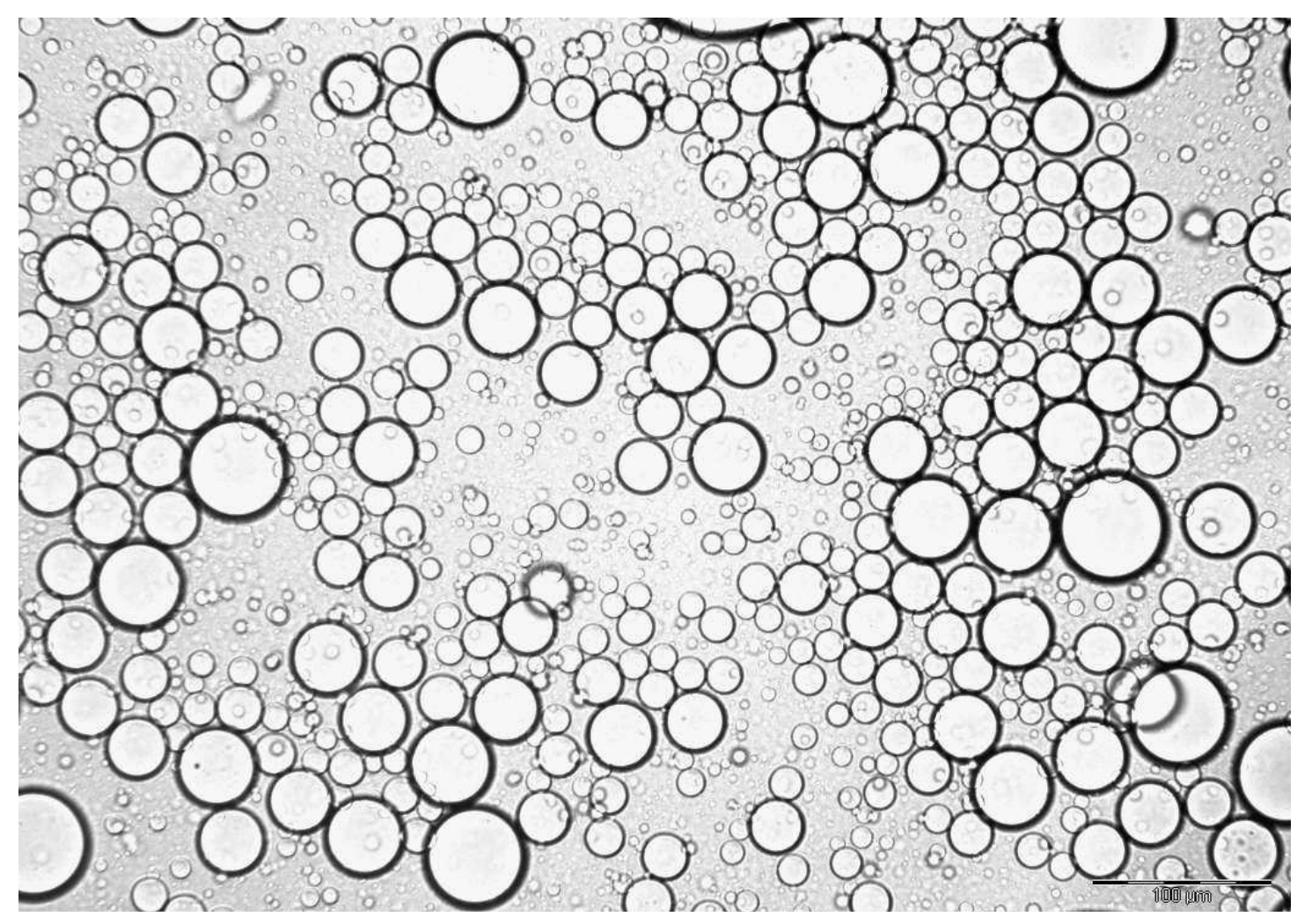

Figura A.7: Imagem da Microestrutura da Emulsão $\lambda=2$ e $\phi=20 \%$ 


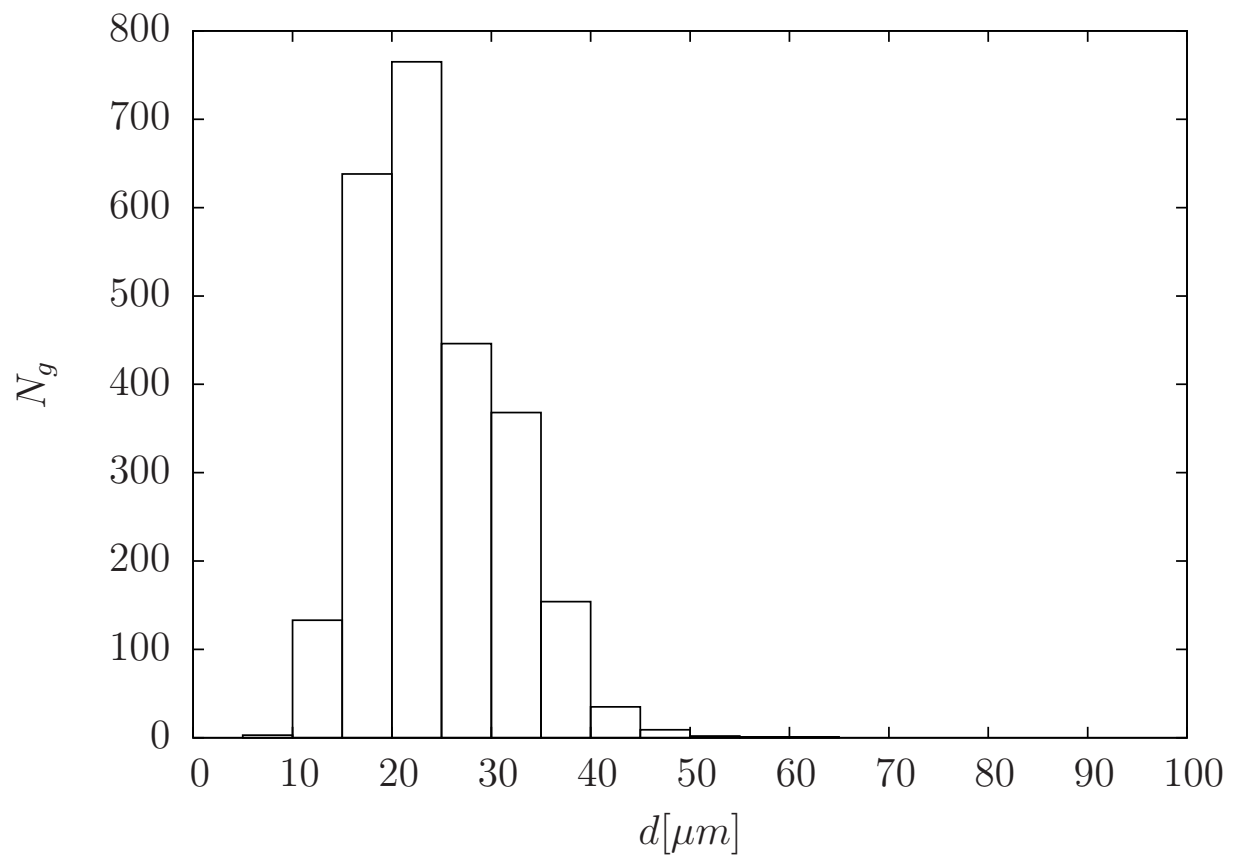

Figura A.8: Distribuição de Tamanho de gota para a emulsão $\lambda=2$ e $\phi=20 \%$. Características da microestrutura: $N_{g}=2555, \bar{a}=12,14 \mu \mathrm{m}, p=0,290$

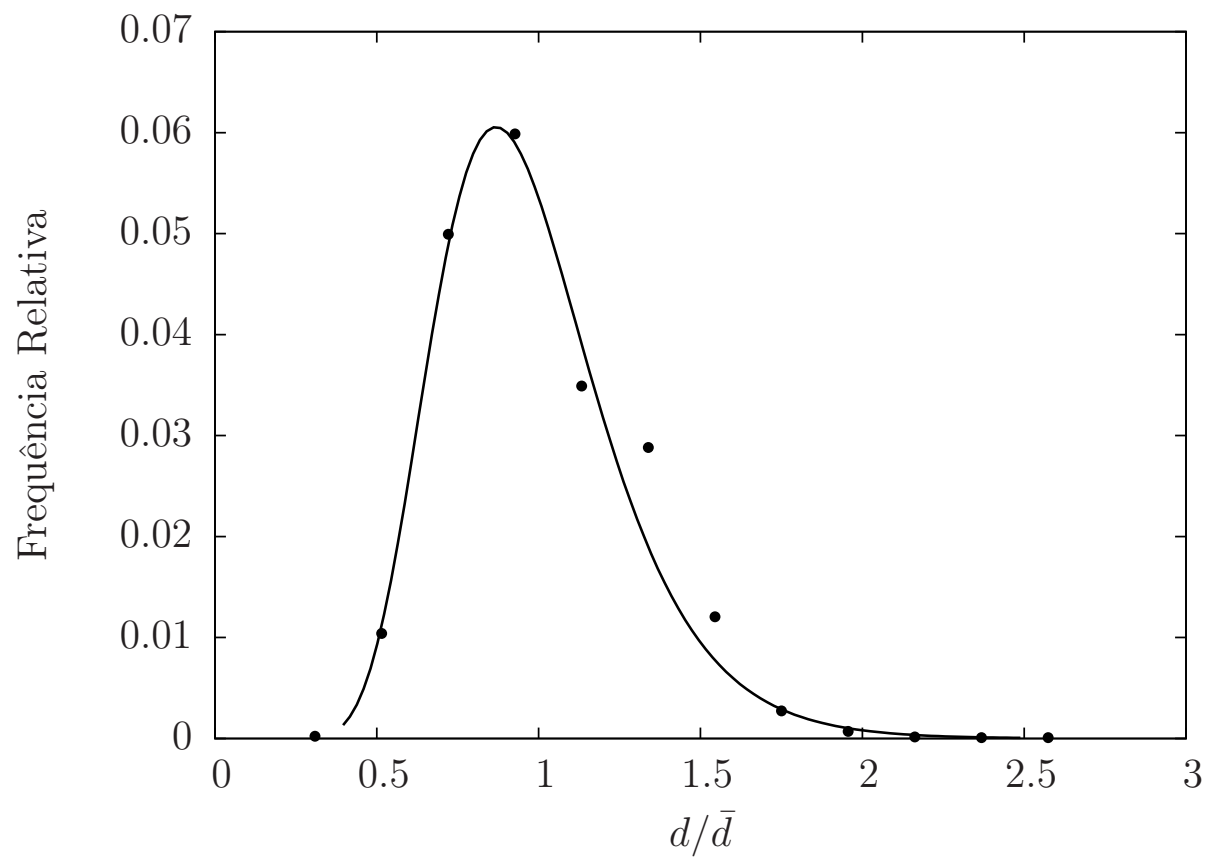

Figura A.9: Frequência Relativa $\left(N_{\text {gint }} /\left(\operatorname{Dim}_{\text {int }} \times N_{\text {gtot }}\right)\right.$ para a emulsão $\lambda=2 \mathrm{e}$ $\phi=20 \%$. Constantes da Log-Normal: $C_{1}=0,039, C_{2}=0,98$ 


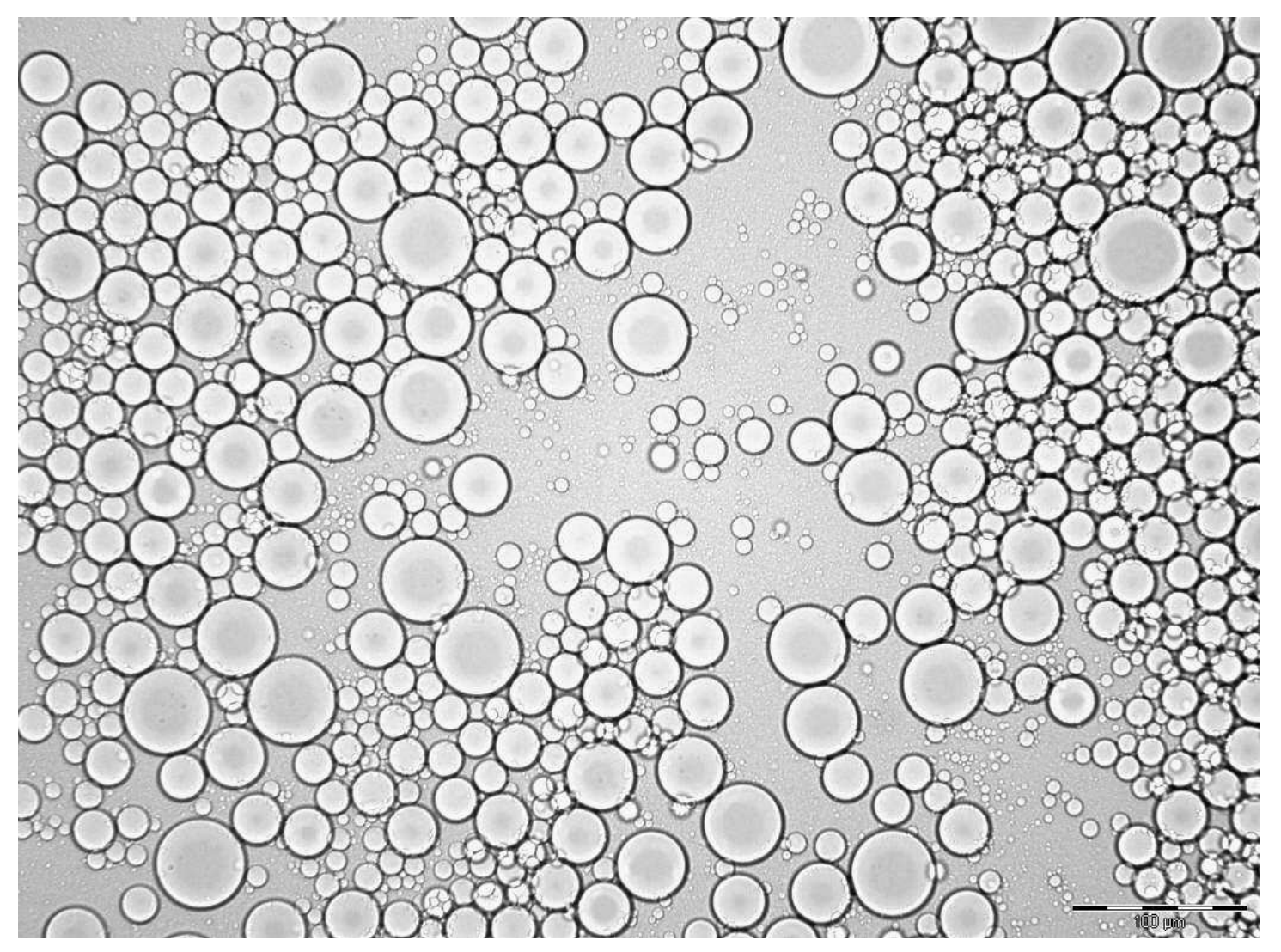

Figura A.10: Imagem da Microestrutura da Emulsão $\lambda=2$ e $\phi=40 \%$

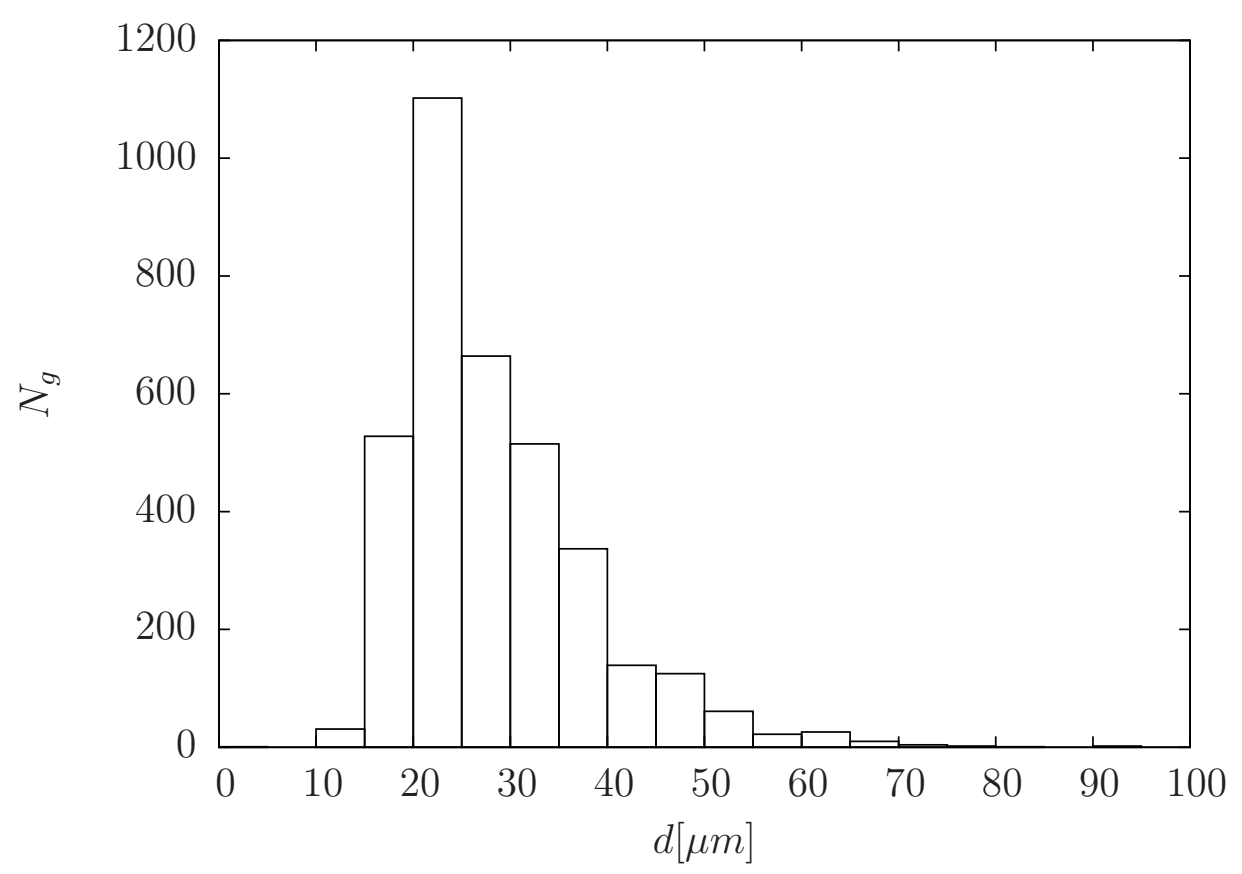

Figura A.11: Distribuição de Tamanho de gota para a emulsão $\lambda=2$ e $\phi=40 \%$. Características da microestrutura: $N_{g}=3570, \bar{a}=14,22 \mu \mathrm{m}, p=0,345$ 


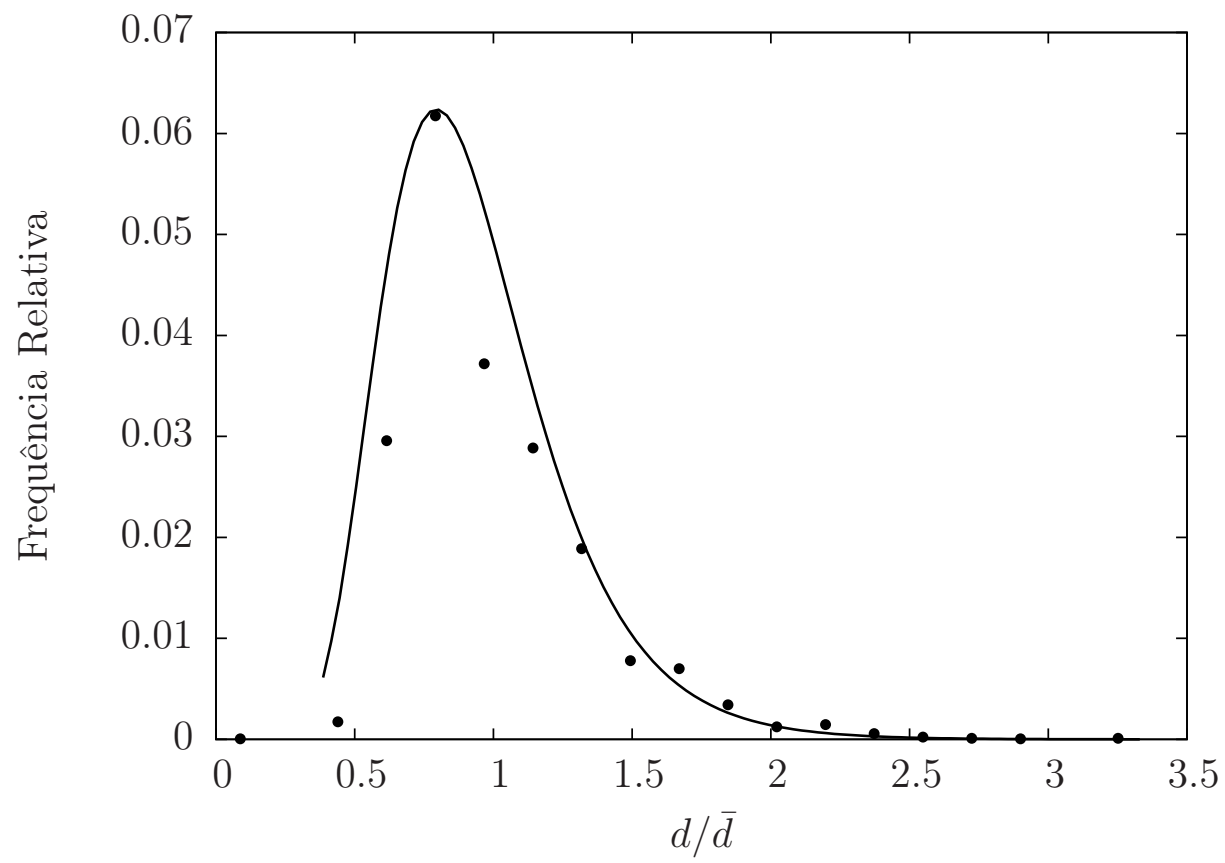

Figura A.12: Frequência Relativa $\left(N_{\text {gint }} /\left(\operatorname{Dim}_{\text {int }} \times N_{\text {gtot }}\right)\right.$ para a emulsão $\lambda=2$ e $\phi=40 \%$. Constantes da Log-Normal: $C_{1}=0,044, C_{2}=0,948$ 
A.2 Emulsões $\lambda=5$

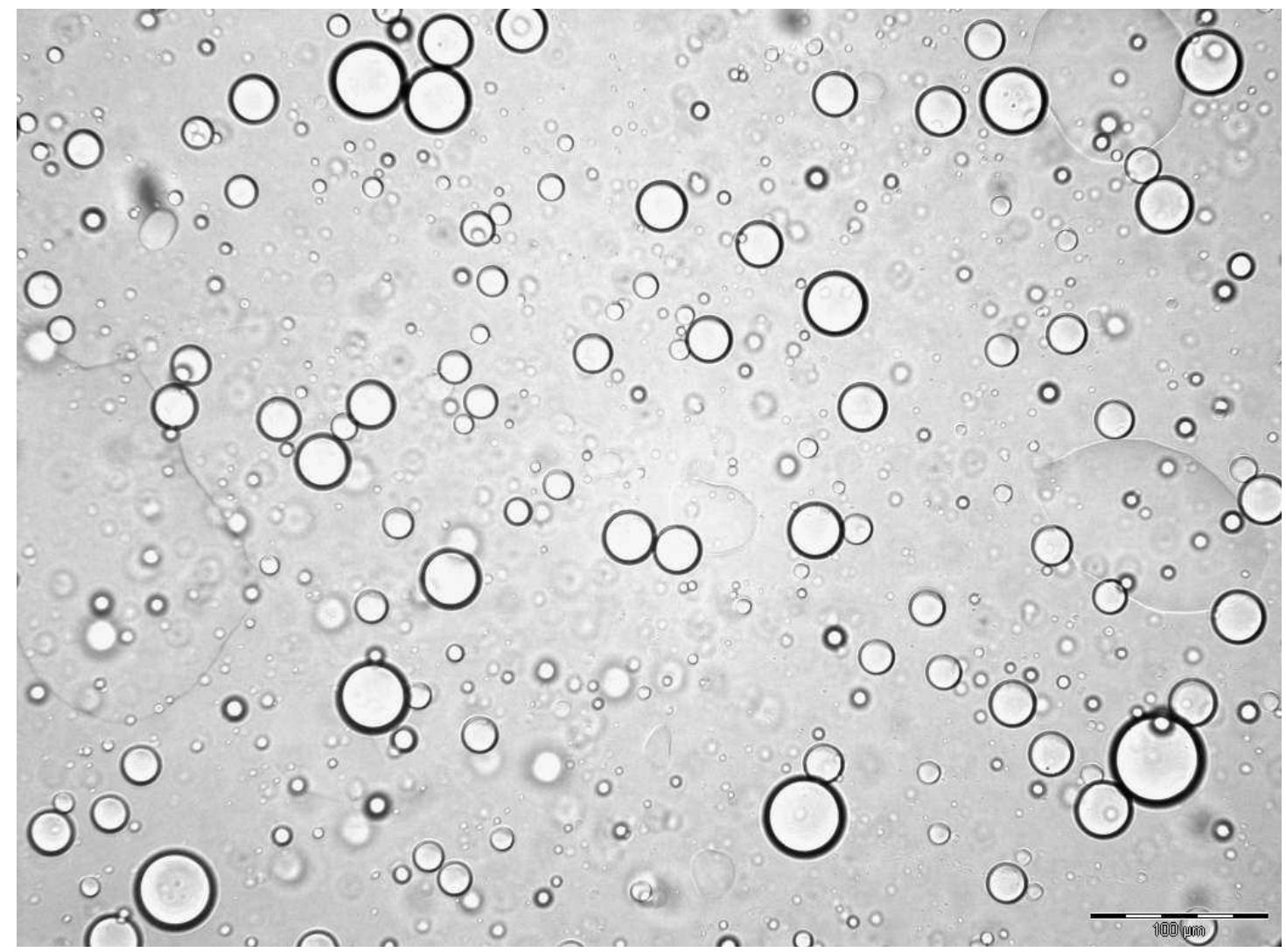

Figura A.13: Imagem da Microestrutura da Emulsão $\lambda=5$ e $\phi=2 \%$

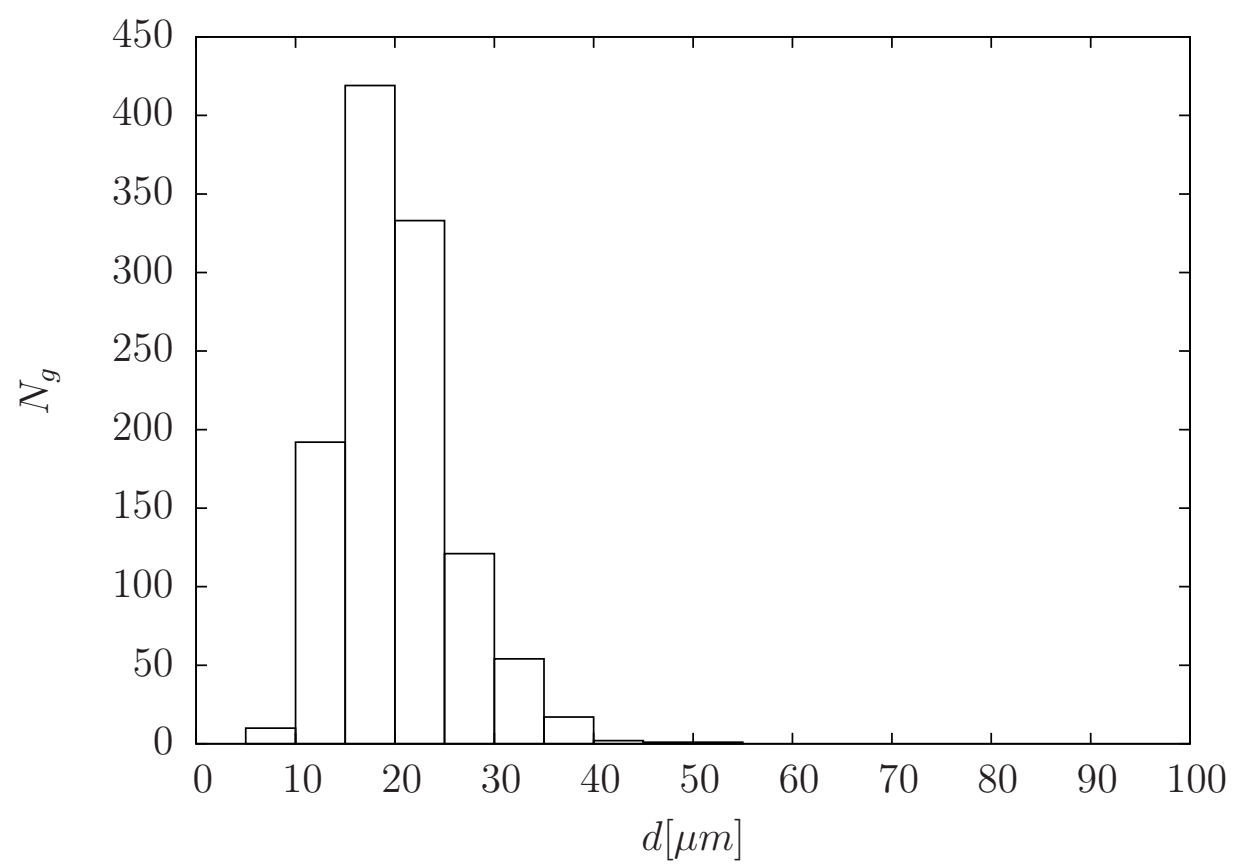

Figura A.14: Distribuição de Tamanho de gota para a emulsão $\lambda=5$ e $\phi=2 \%$. Características da microestrutura: $N_{g}=1150, \bar{a}=10,00 \mu \mathrm{m}, p=0,2987$ 


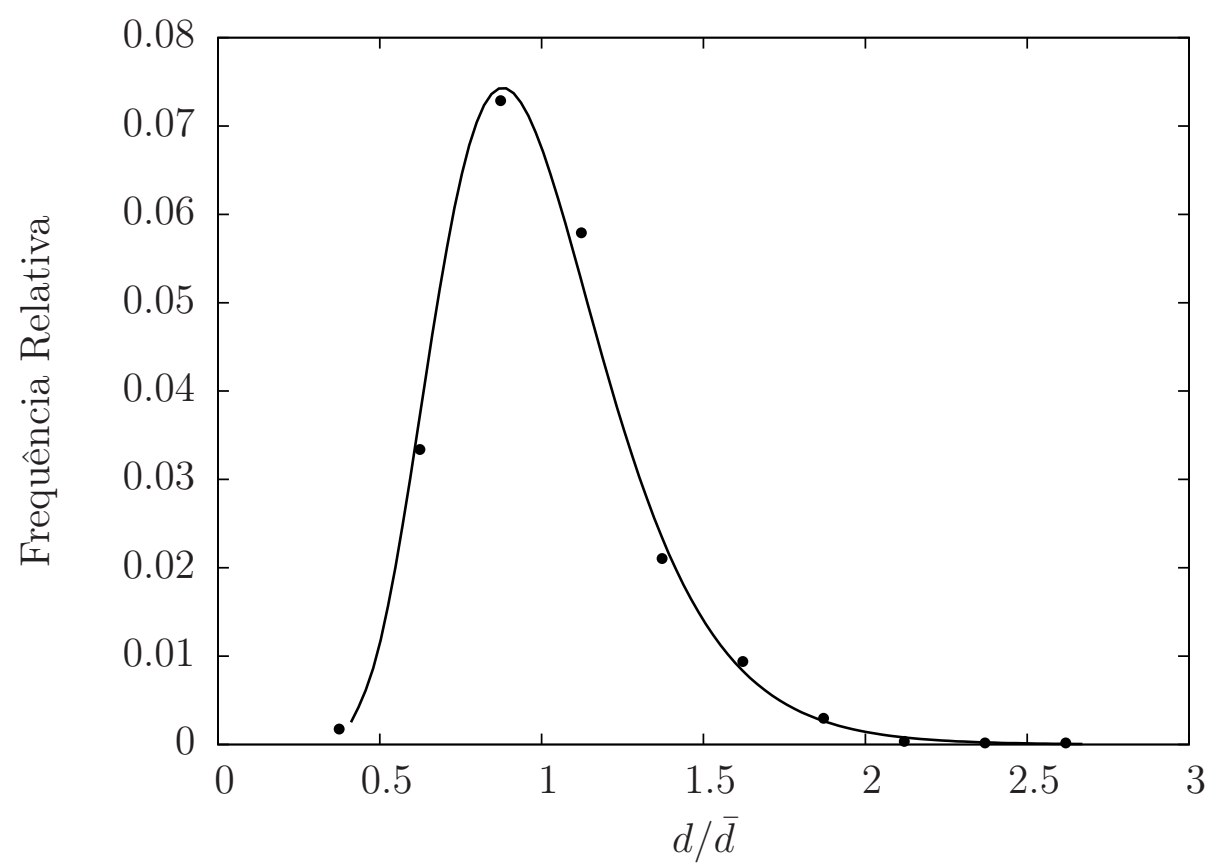

Figura A.15: Frequência Relativa $\left(N_{\text {gint }} /\left(\operatorname{Dim}_{\text {int }} \times N_{\text {gtot }}\right)\right.$ para a emulsão $\lambda=5 \mathrm{e}$ $\phi=2 \%$. Constantes da Log-Normal: $C_{1}=0,05, C_{2}=1,0$

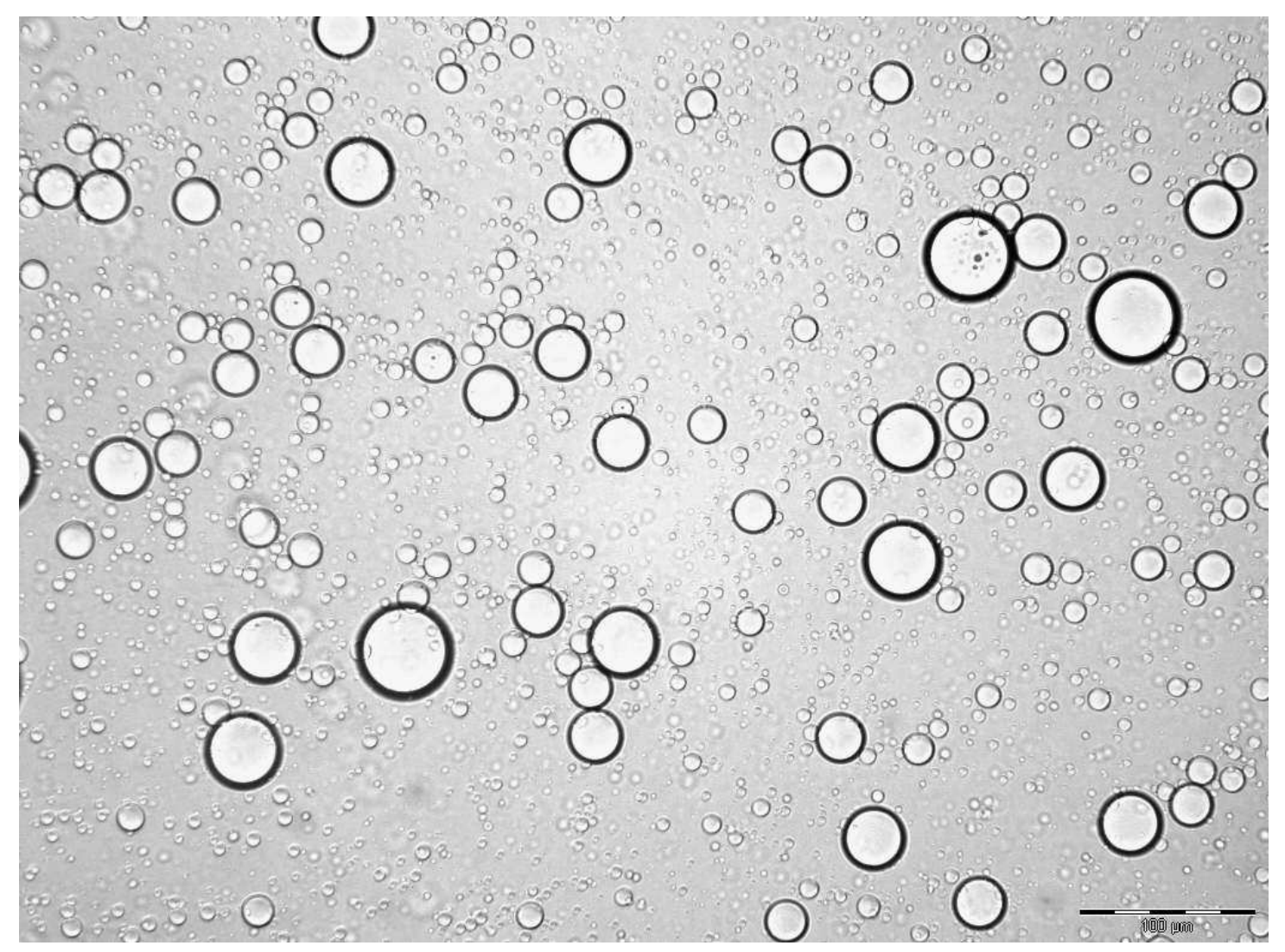

Figura A.16: Imagem da Microestrutura da Emulsão $\lambda=5$ e $\phi=5 \%$ 


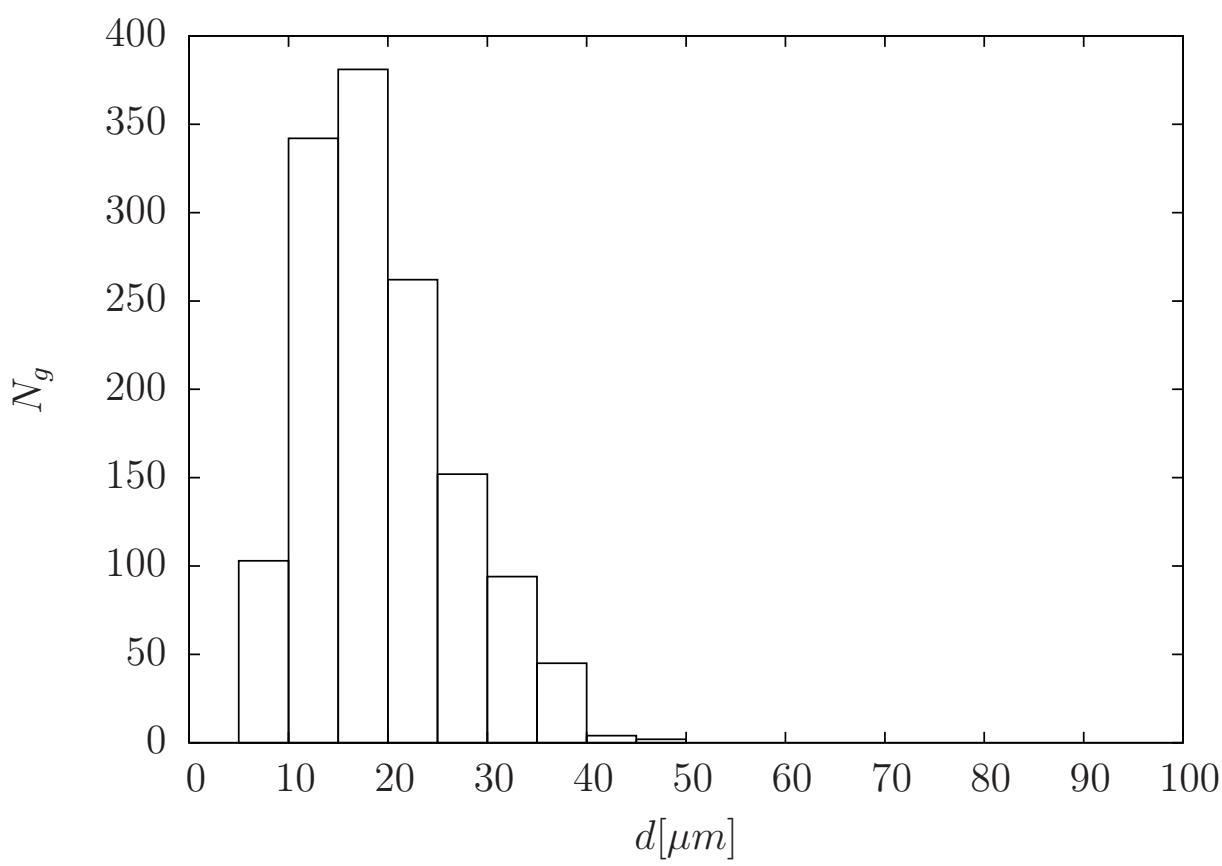

Figura A.17: Distribuição de Tamanho de gota para a emulsão $\lambda=5$ e $\phi=5 \%$. Características da microestrutura: $N_{g}=1385, \bar{a}=9,61 \mu m, p=0,386$

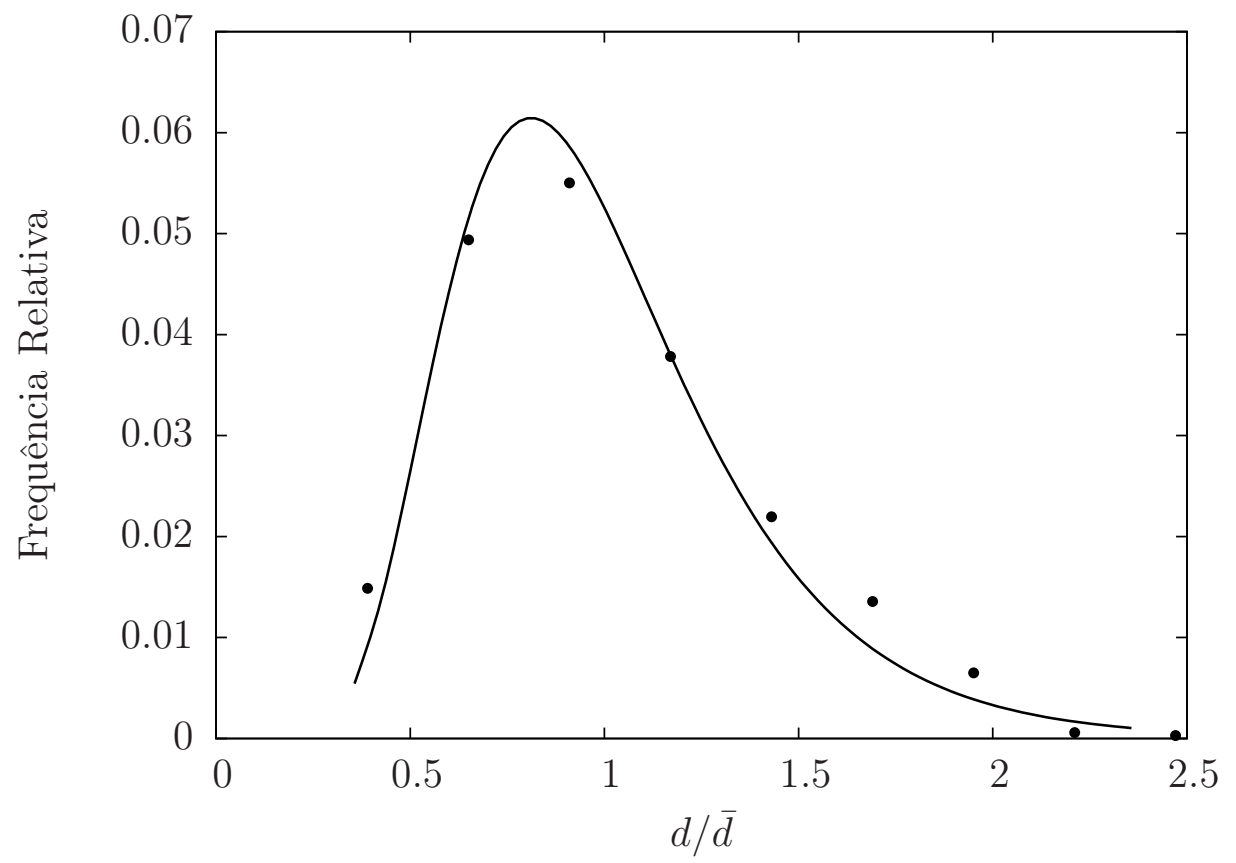

Figura A.18: Frequência Relativa $\left(N_{\text {gint }} /\left(\operatorname{Dim}_{\text {int }} \times N_{\text {gtot }}\right)\right.$ para a emulsão $\lambda=5 \mathrm{e}$ $\phi=5 \%$. Constantes da Log-Normal: $C_{1}=0,05, C_{2}=1,0$ 


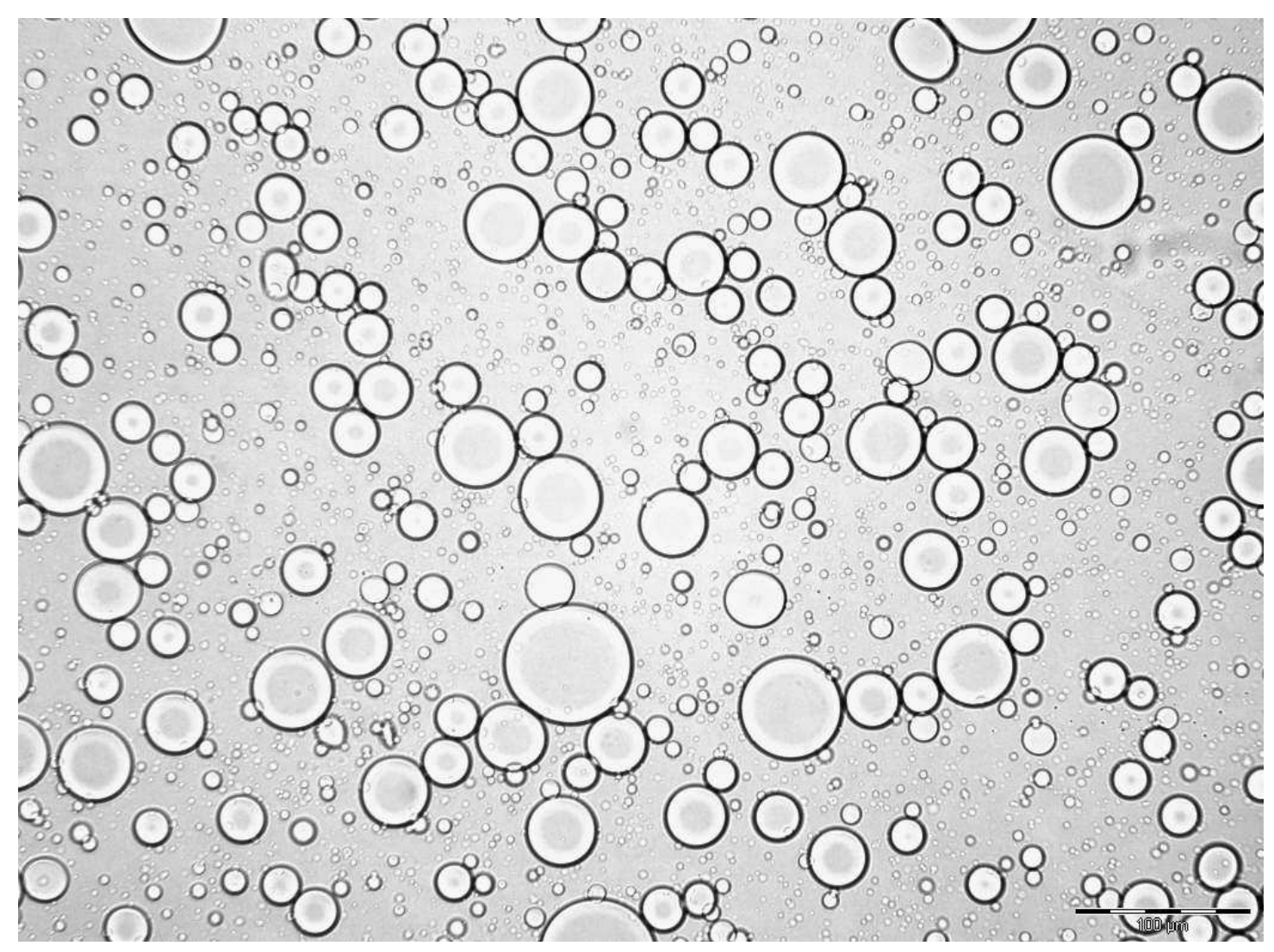

Figura A.19: Imagem da Microestrutura da Emulsão $\lambda=5$ e $\phi=20 \%$

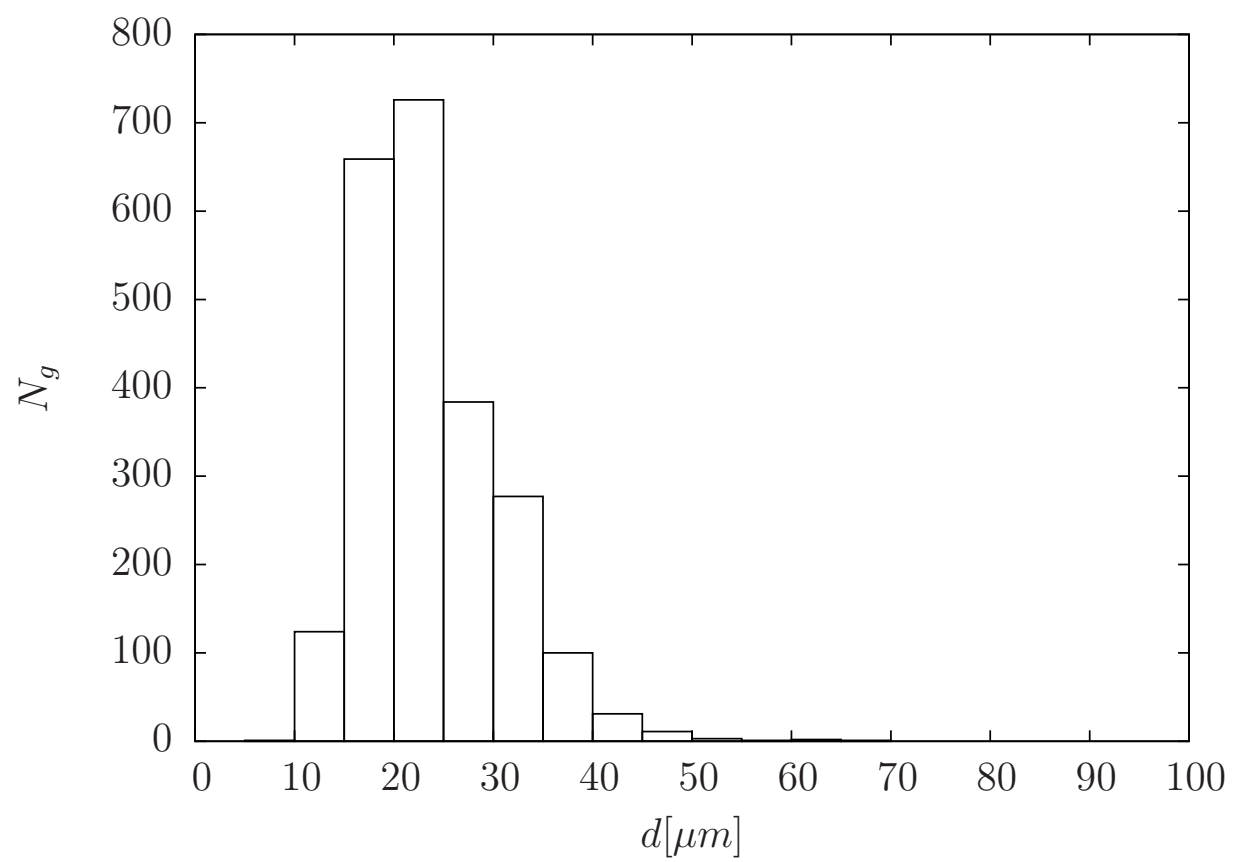

Figura A.20: Distribuição de Tamanho de gota para a emulsão $\lambda=5$ e $\phi=20 \%$. Características da microestrutura: $N_{g}=2320, \bar{a}=11,78 \mu \mathrm{m}, p=0,2961$ 


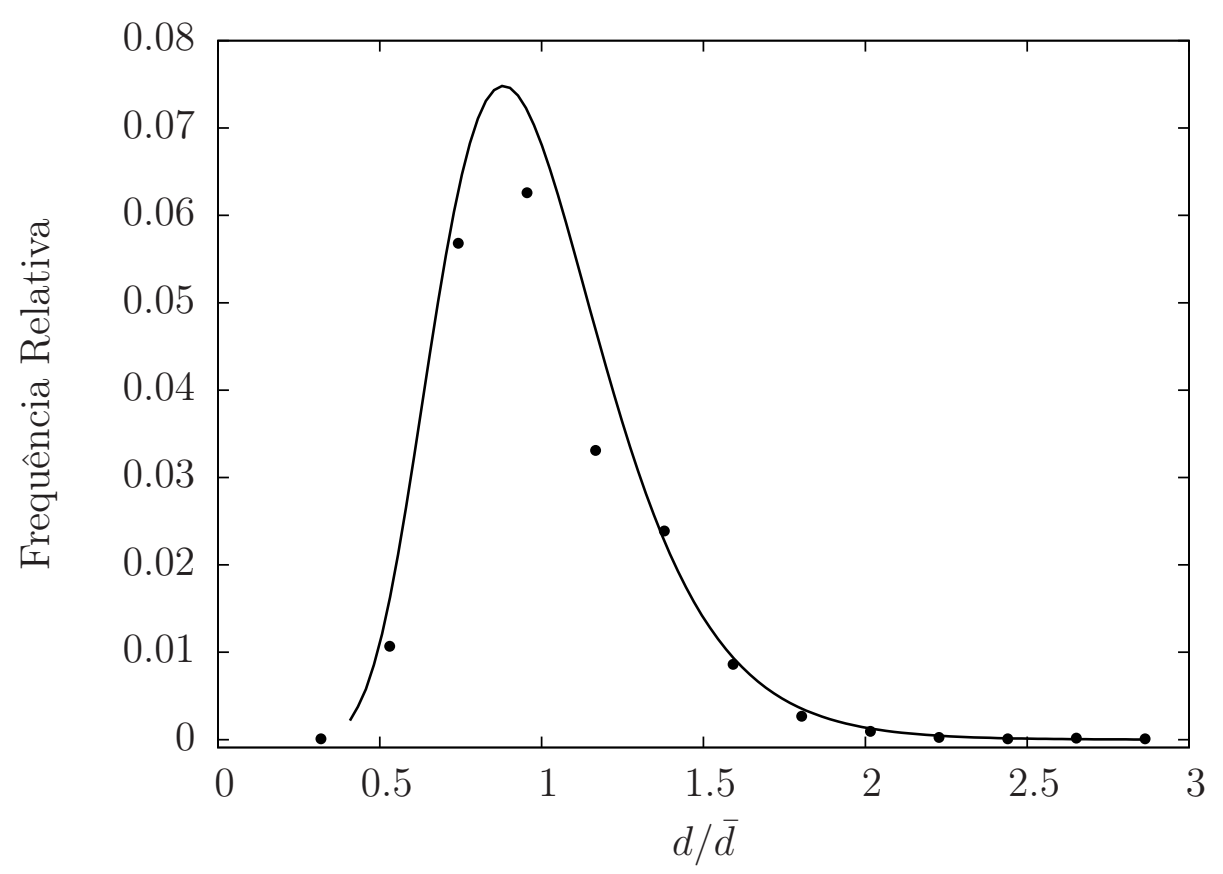

Figura A.21: Frequência Relativa $\left(N_{\text {gint }} /\left(\right.\right.$ Dim $\left._{\text {int }} \times N_{\text {gtot }}\right)$ para a emulsão $\lambda=5 \mathrm{e}$ $\phi=20 \%$. Constantes da Log-Normal: $C_{1}=0,05, C_{2}=1,0$

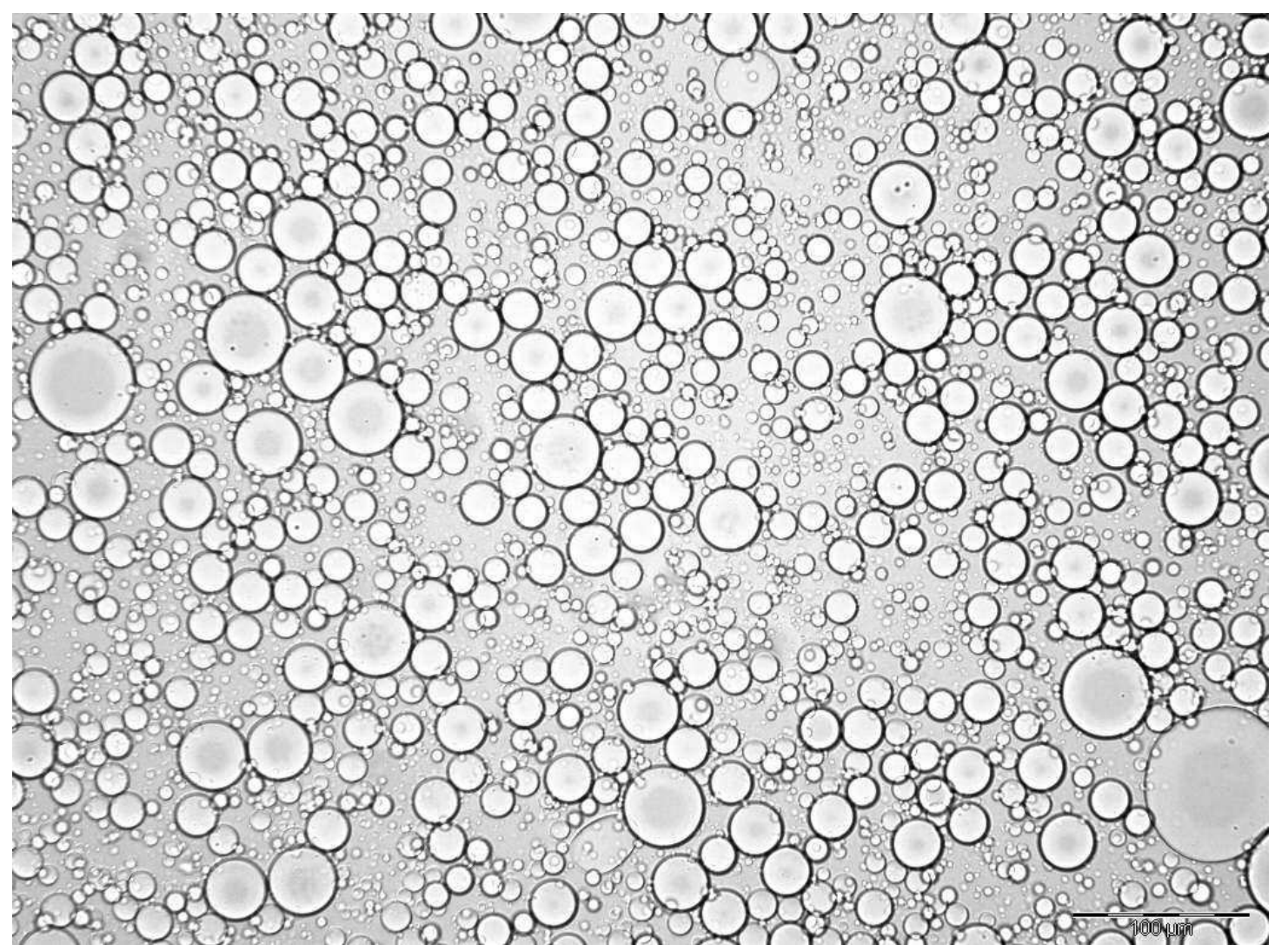

Figura A.22: Imagem da Microestrutura da Emulsão $\lambda=5$ e $\phi=40 \%$ 


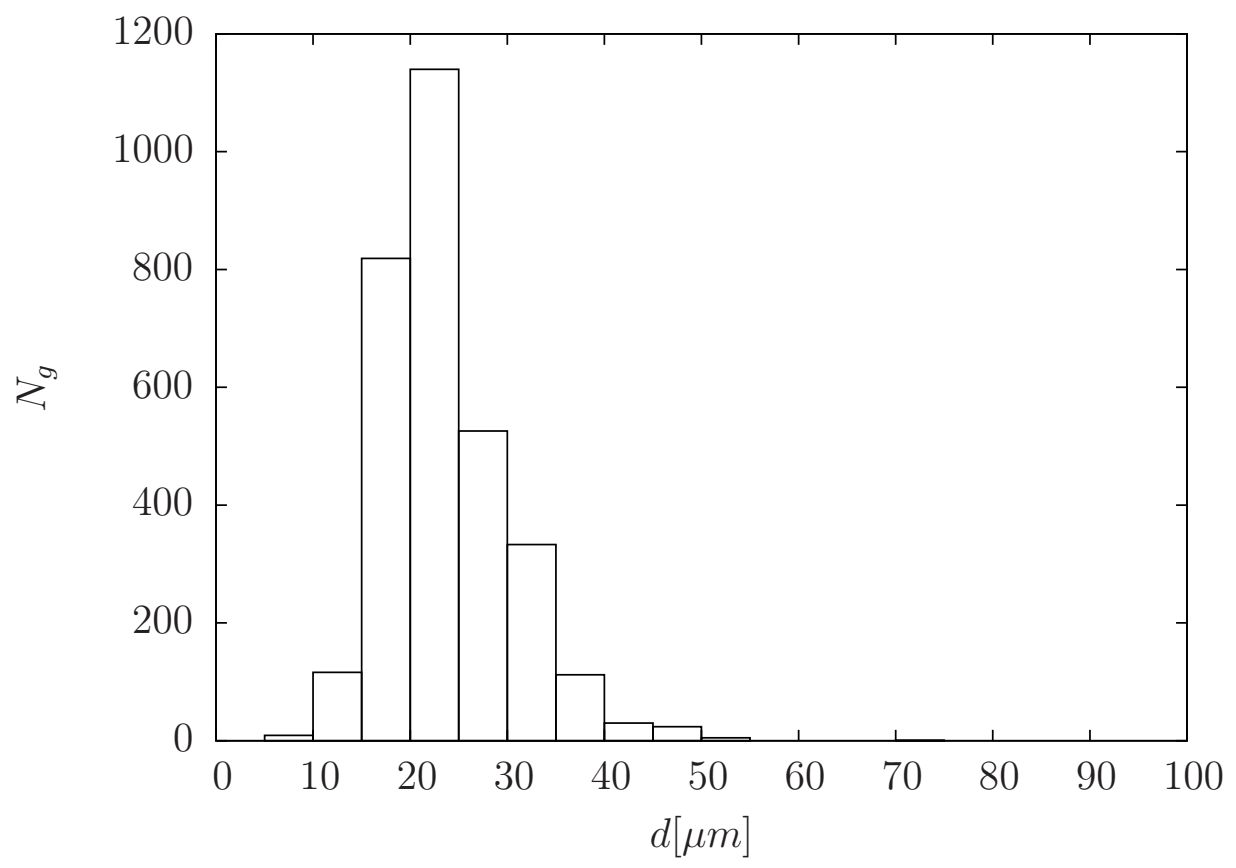

Figura A.23: Distribuição de Tamanho de gota para a emulsão $\lambda=5$ e $\phi=40 \%$. Características da microestrutura: $N_{g}=3115, \bar{a}=11,81 \mu \mathrm{m}, p=0,2762$

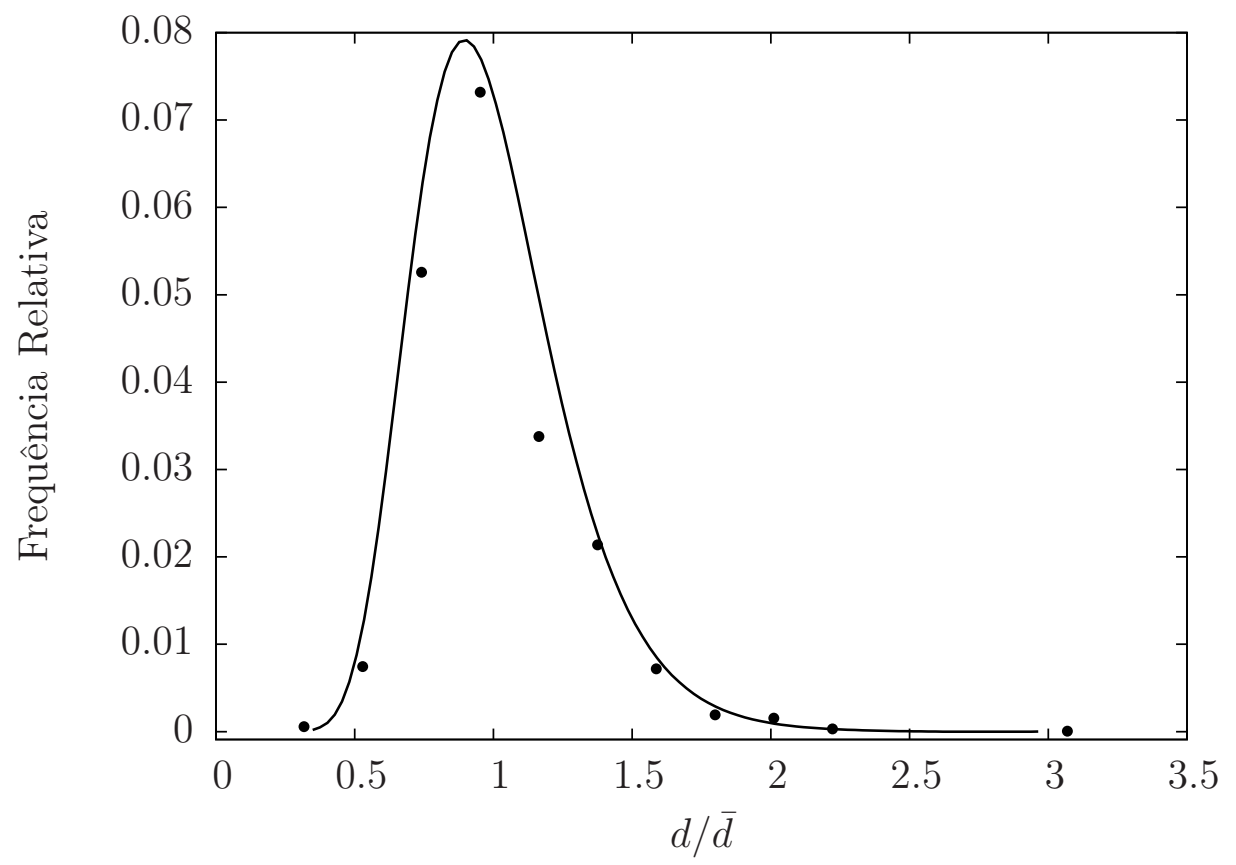

Figura A.24: Frequência Relativa $\left(N_{\text {gint }} /\left(\operatorname{Dim}_{\text {int }} \times N_{\text {gtot }}\right)\right.$ para a emulsão $\lambda=5 \mathrm{e}$ $\phi=40 \%$. Constantes da Log-Normal: $C_{1}=0,05, C_{2}=1,0$ 


\section{A.3 Emulsões $\lambda=10$}

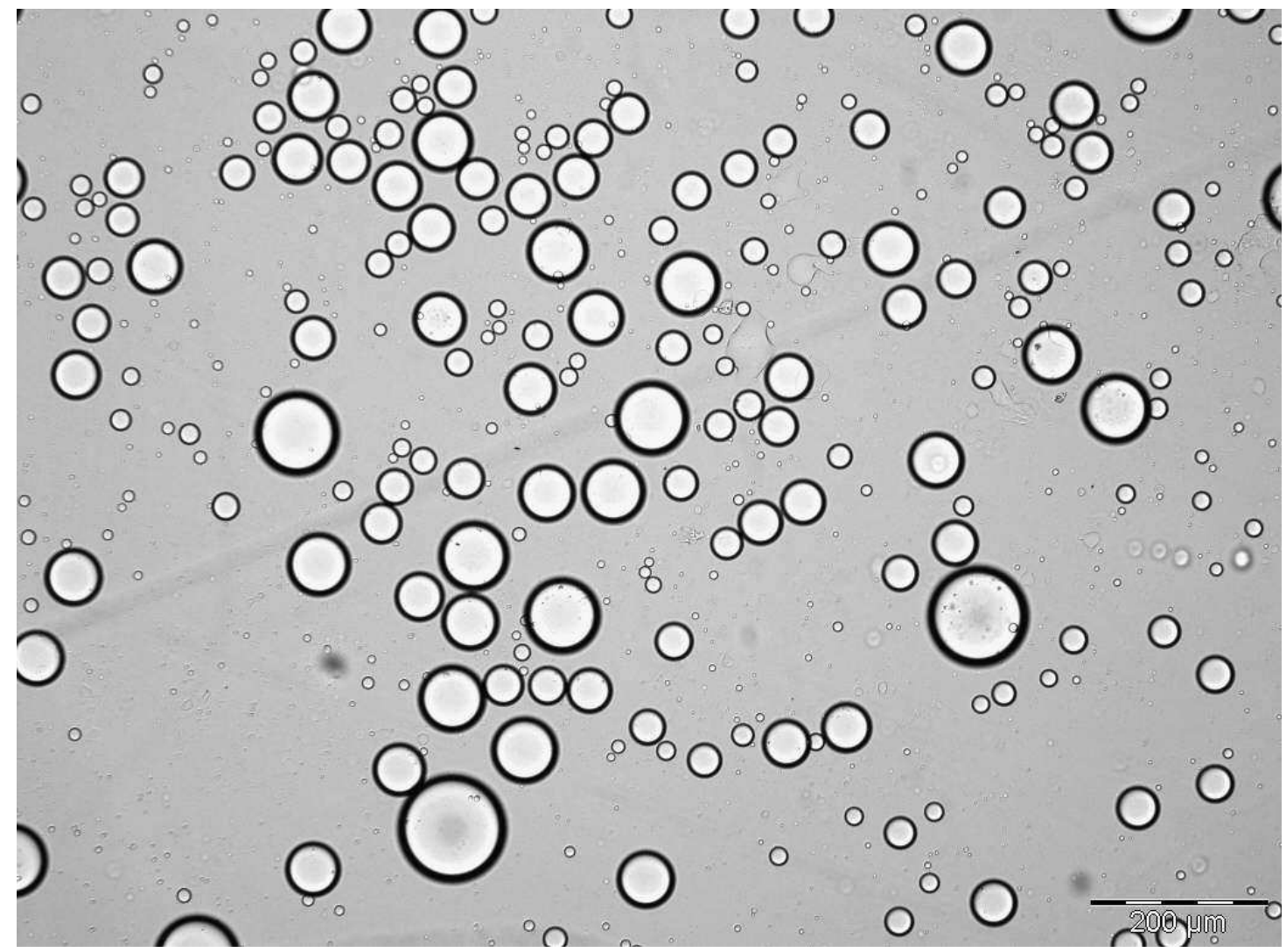

Figura A.25: Imagem da Microestrutura da Emulsão $\lambda=10$ e $\phi=2 \%$

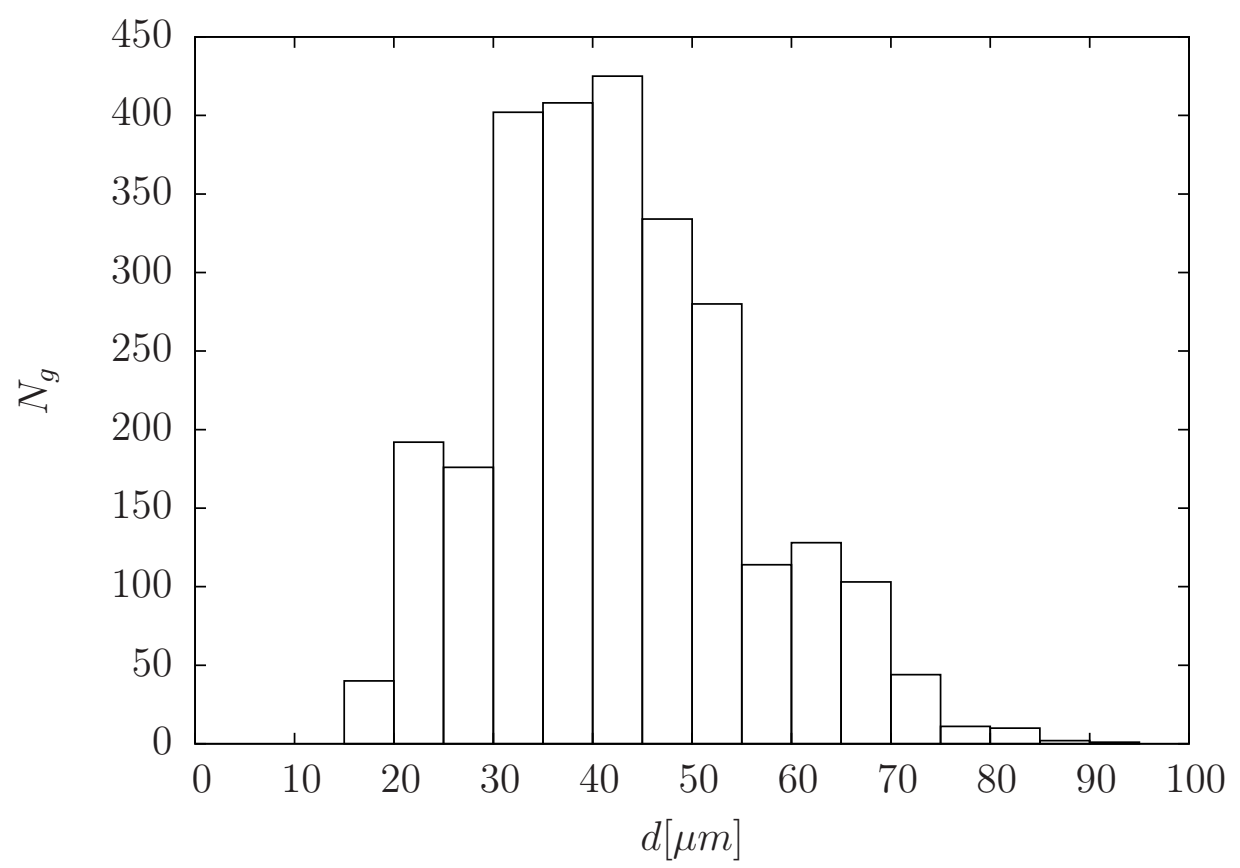

Figura A.26: Distribuição de Tamanho de gota para a emulsão $\lambda=10$ e $\phi=2 \%$. Características da microestrutura: $N_{g}=2670, \bar{a}=21,00 \mu m, p=0,30$ 


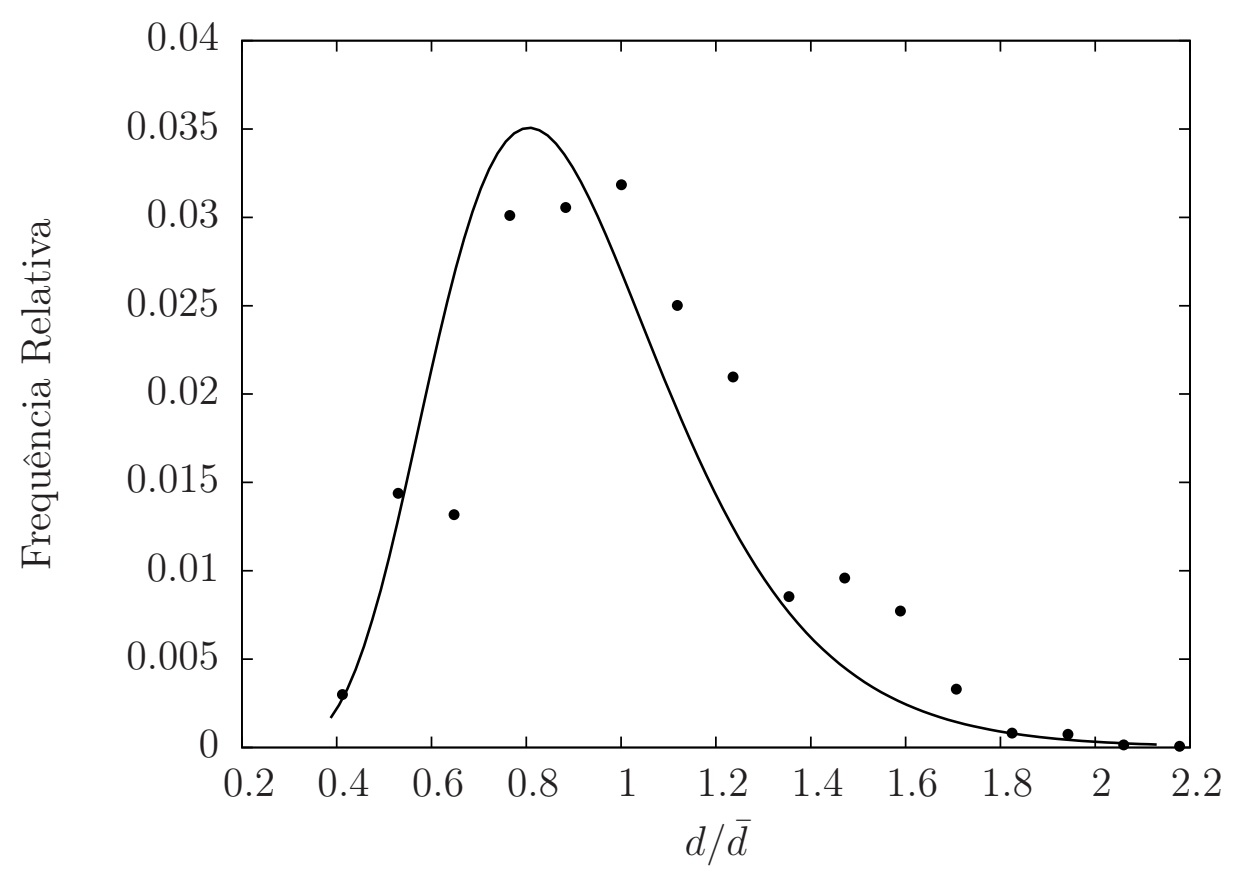

Figura A.27: Frequência Relativa $\left(N_{\text {gint }} /\left(\operatorname{Dim}_{\text {int }} \times N_{\text {gtot }}\right)\right.$ para a emulsão $\lambda=10 \mathrm{e}$ $\phi=2 \%$. Constantes da Log-Normal: $C_{1}=0,022, C_{2}=0,92$

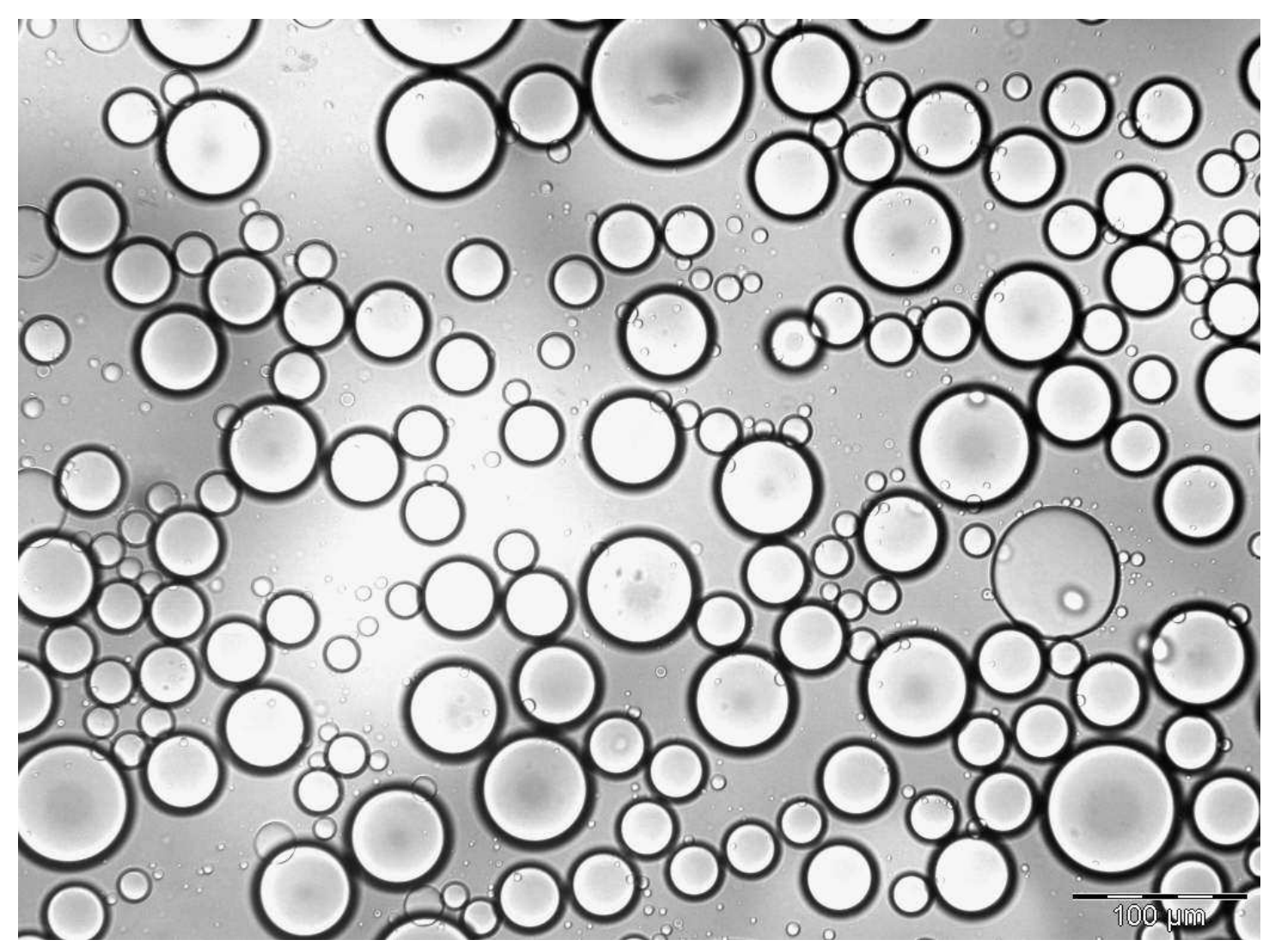

Figura A.28: Imagem da Microestrutura da Emulsão $\lambda=10$ e $\phi=5 \%$ 


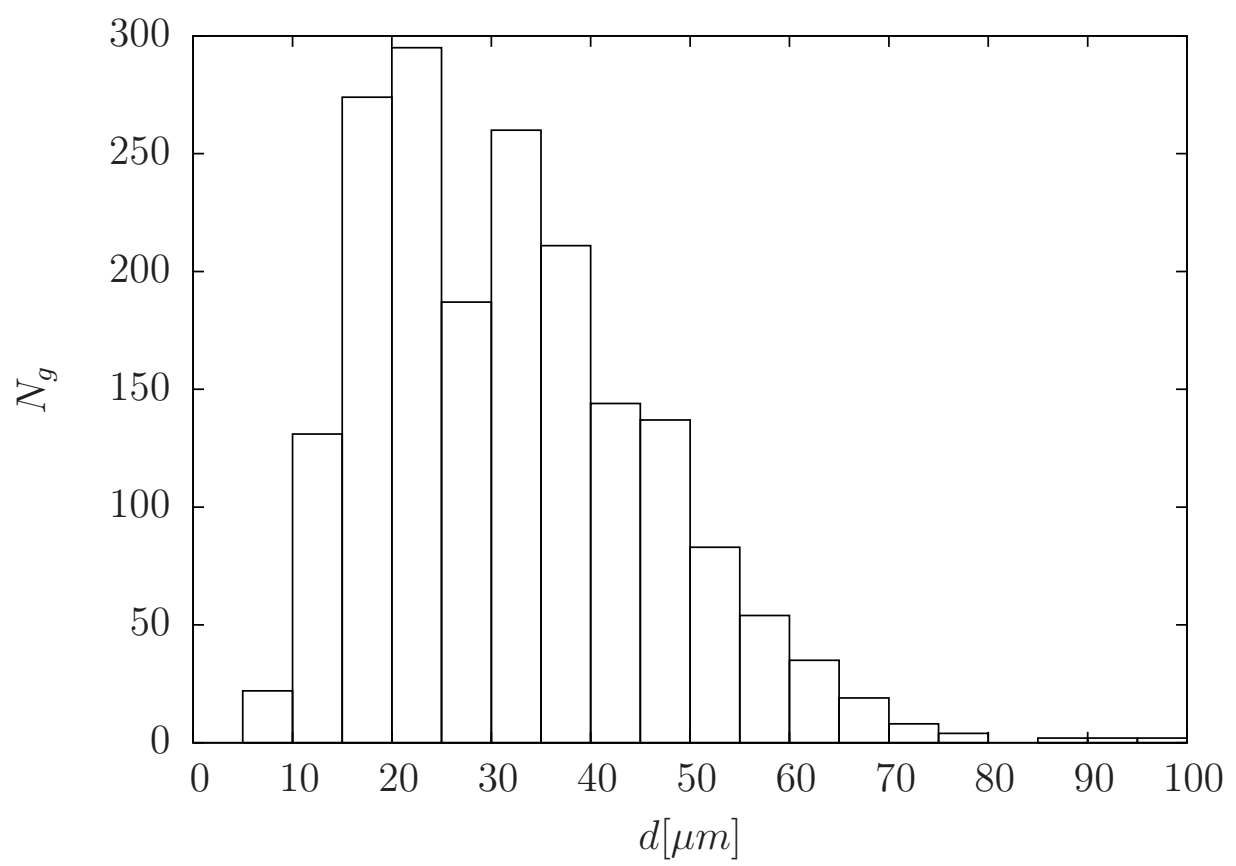

Figura A.29: Distribuição de Tamanho de gota para a emulsão $\lambda=10$ e $\phi=5 \%$. Características da microestrutura: $N_{g}=1870, \bar{a}=16,00 \mu m, p=0,44$

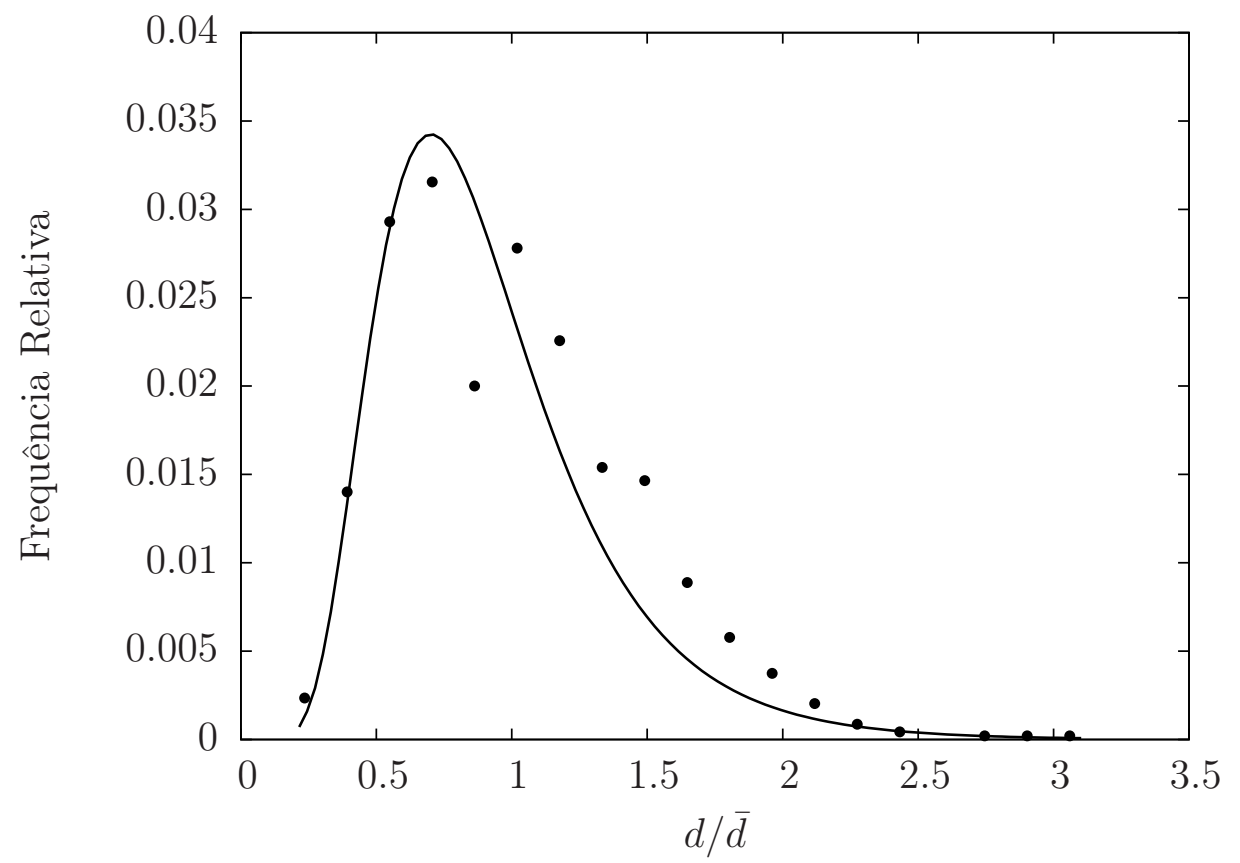

Figura A.30: Frequência Relativa $\left(N_{\text {gint }} /\left(\operatorname{Dim}_{\text {int }} \times N_{\text {gtot }}\right)\right.$ para a emulsão $\lambda=10 \mathrm{e}$ $\phi=5 \%$. Constantes da Log-Normal: $C_{1}=0,028, C_{2}=0,92$ 


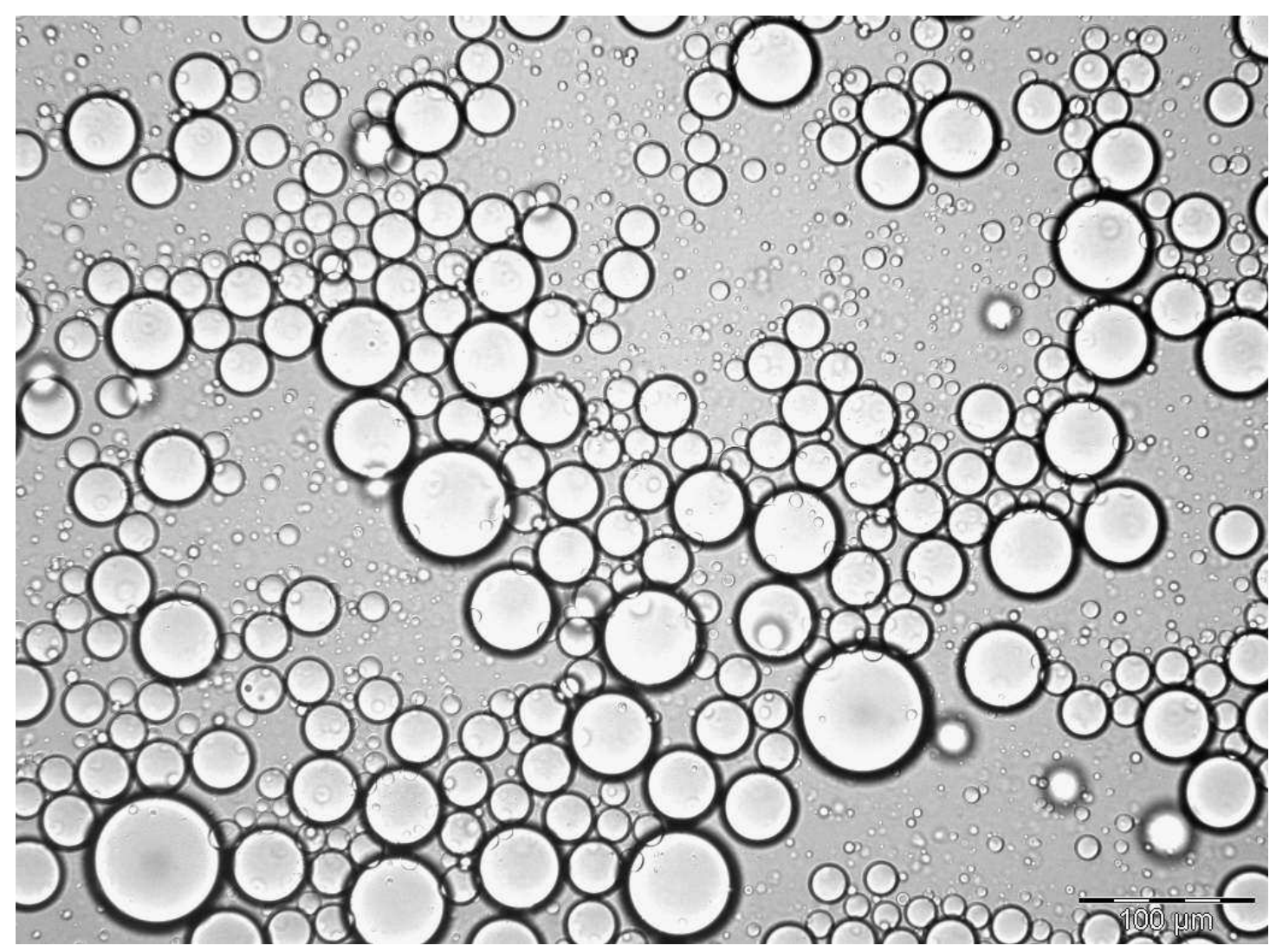

Figura A.31: Imagem da Microestrutura da Emulsão $\lambda=10$ e $\phi=20 \%$

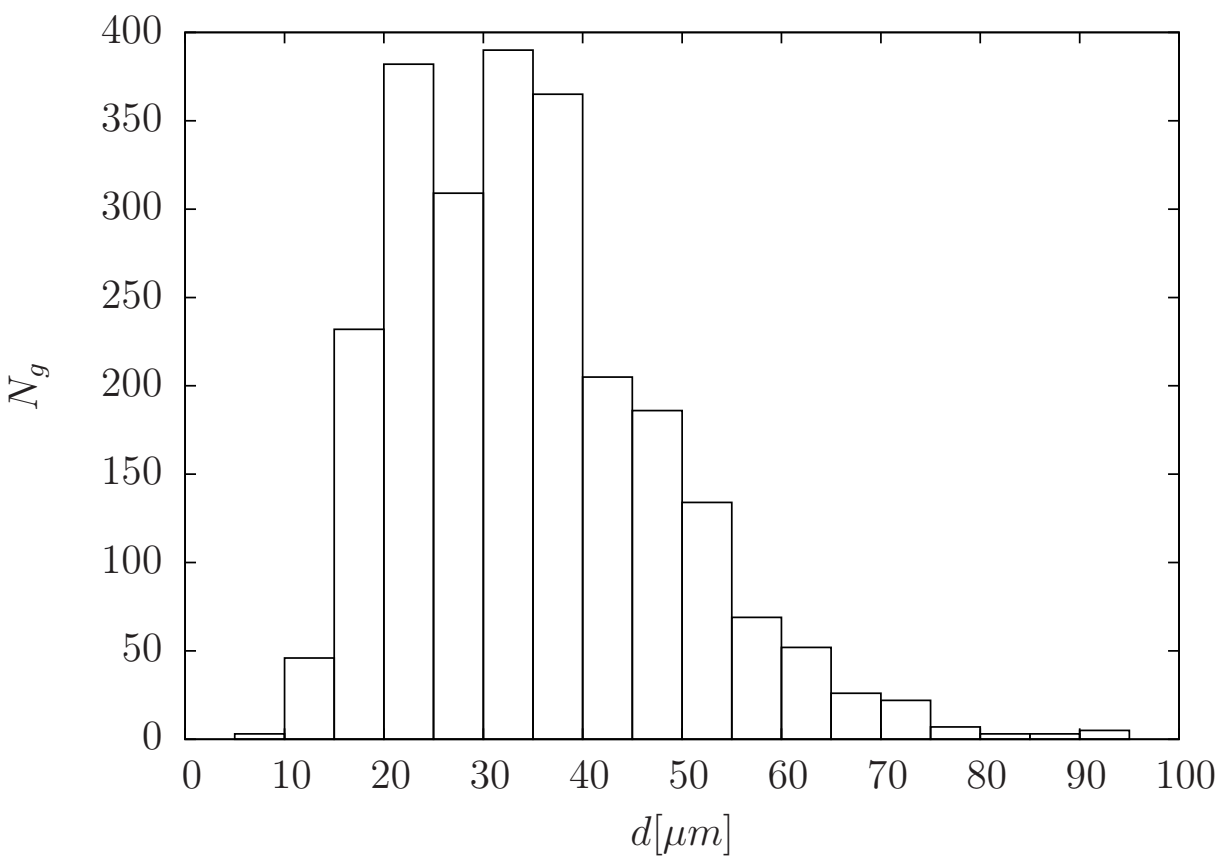

Figura A.32: Distribuição de Tamanho de gota para a emulsão $\lambda=10$ e $\phi=20 \%$. Características da microestrutura: $N_{g}=2440, \bar{a}=17,40 \mu m, p=0,39$ 


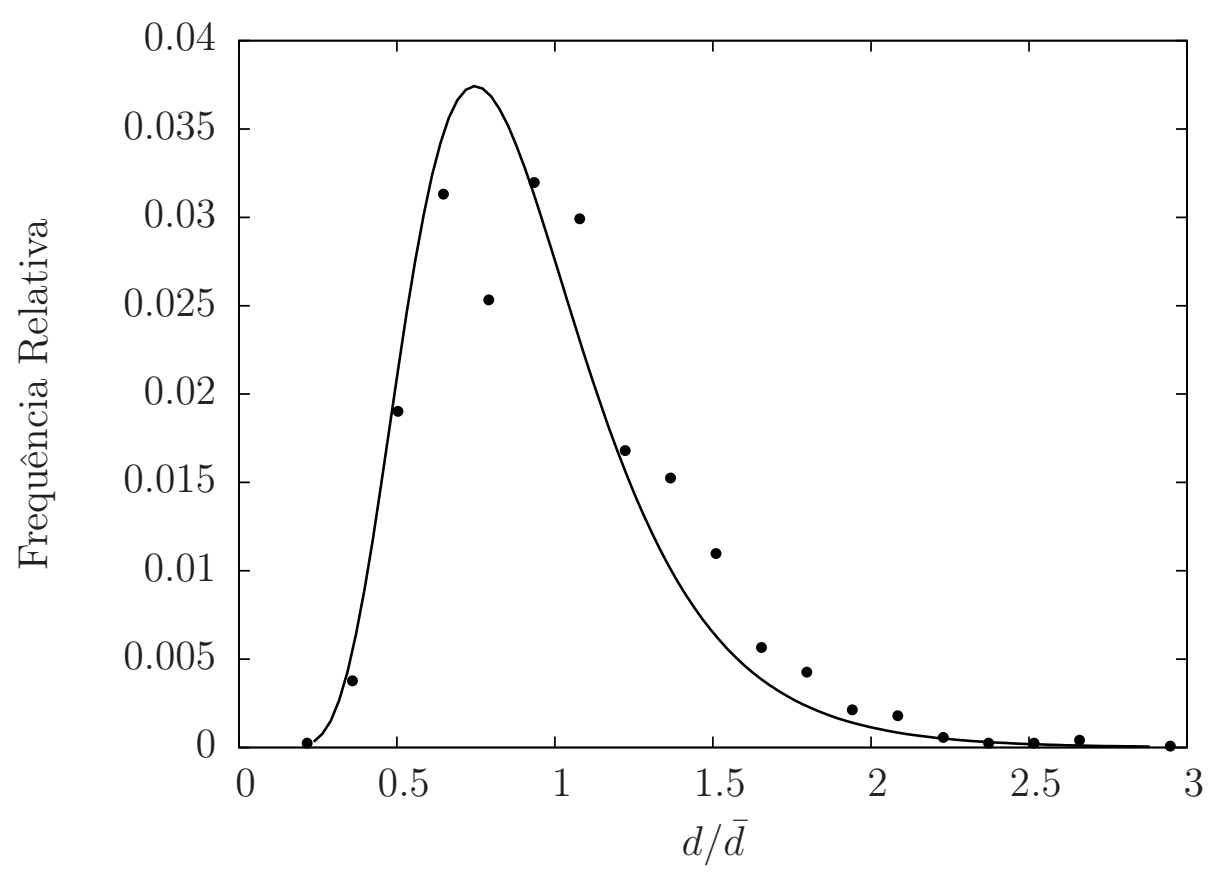

Figura A.33: Frequência Relativa $\left(N_{\text {gint }} /\left(\operatorname{Dim}_{\text {int }} \times N_{\text {gtot }}\right)\right.$ para a emulsão $\lambda=10$ e $\phi=20 \%$. Constantes da Log-Normal: $C_{1}=0,028, C_{2}=0,92$

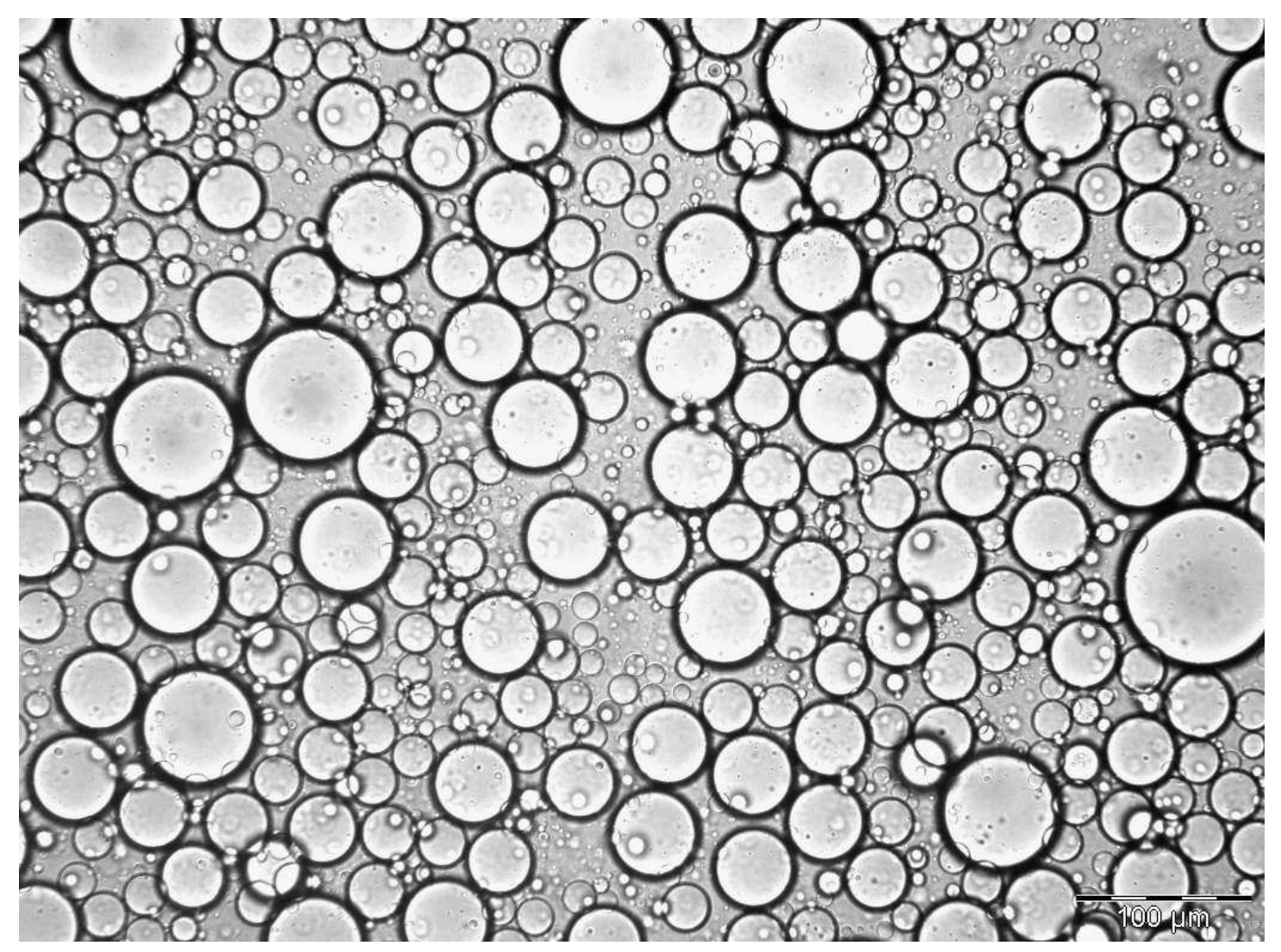

Figura A.34: Imagem da Microestrutura da Emulsão $\lambda=10$ e $\phi=40 \%$ 


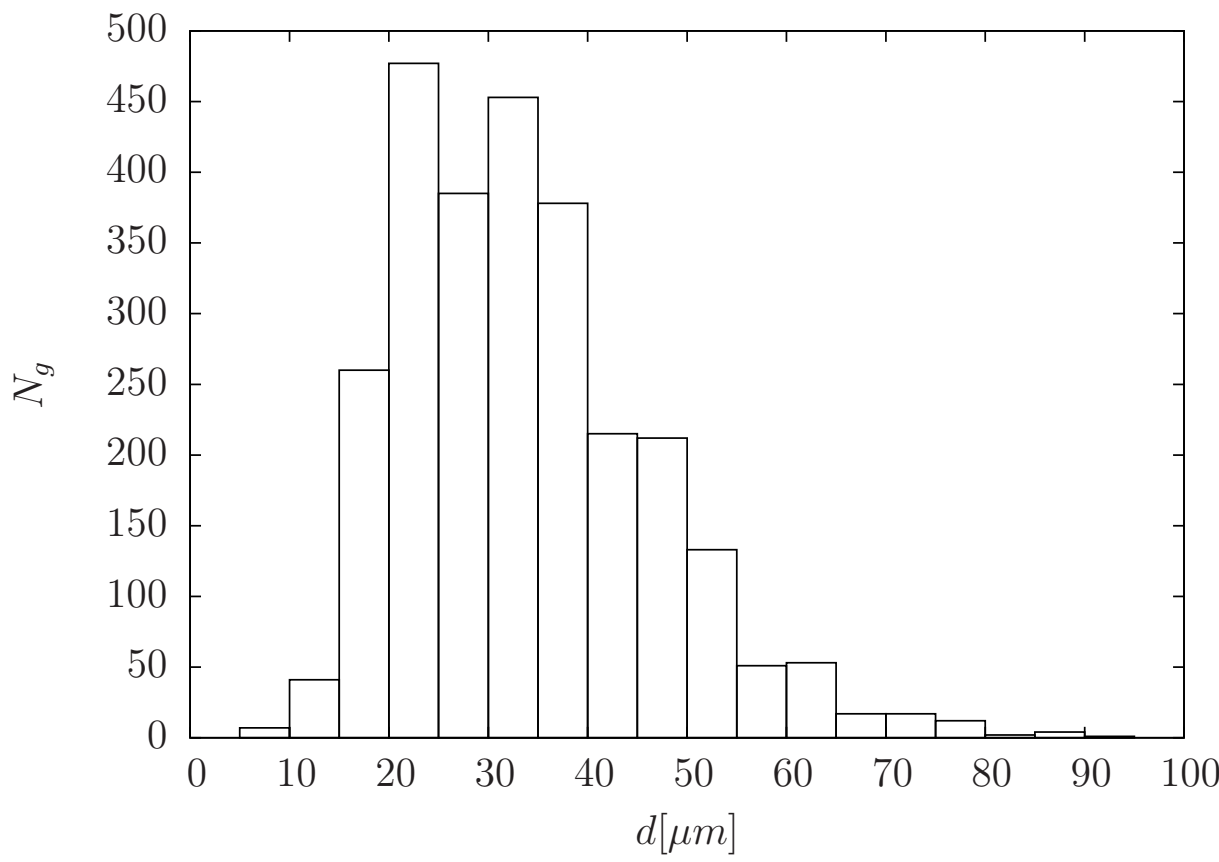

Figura A.35: Distribuição de Tamanho de gota para a emulsão $\lambda=10$ e $\phi=40 \%$. Características da microestrutura: $N_{g}=2720, \bar{a}=17,00 \mu m, p=0,38$

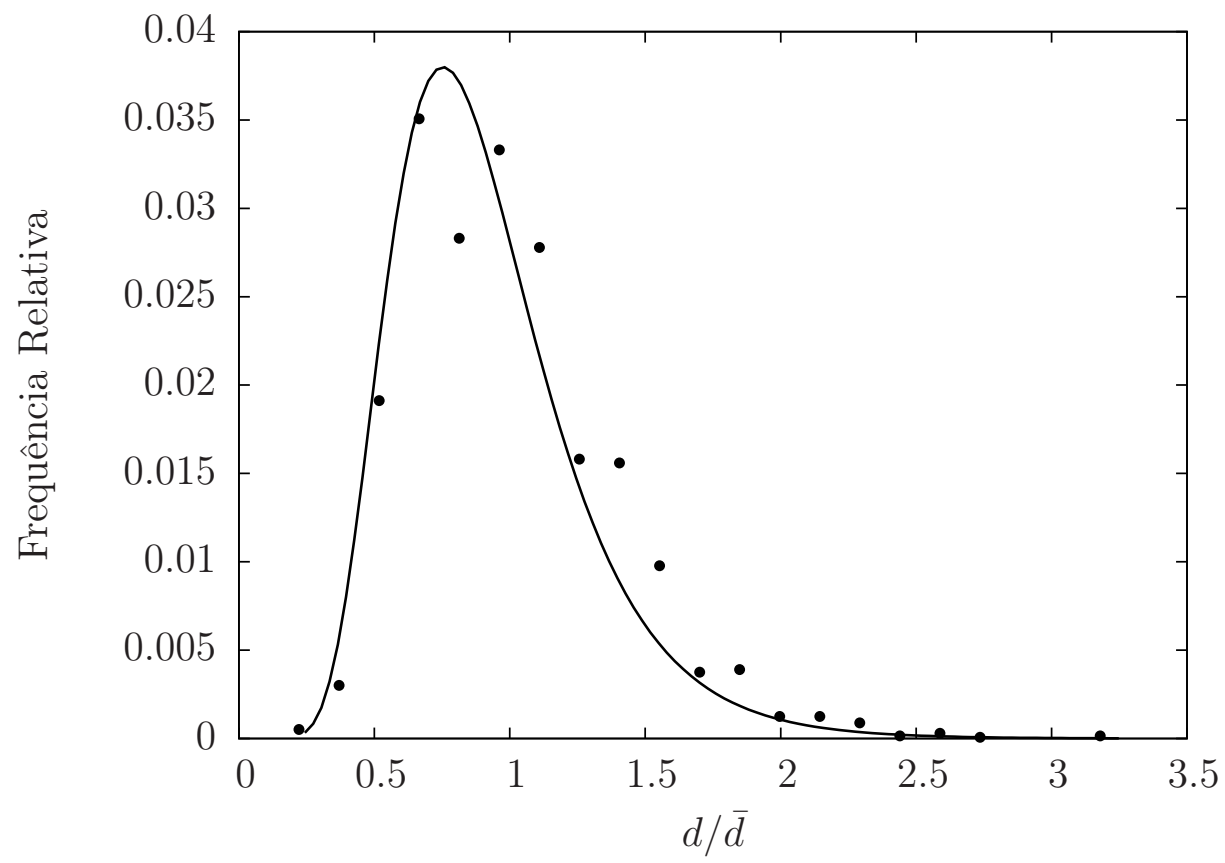

Figura A.36: Frequência Relativa $\left(N_{\text {gint }} /\left(\operatorname{Dim}_{\text {int }} \times N_{\text {gtot }}\right)\right.$ para a emulsão $\lambda=10 \mathrm{e}$ $\phi=40 \%$. Constantes da Log-Normal: $C_{1}=0,028, C_{2}=0,92$ 


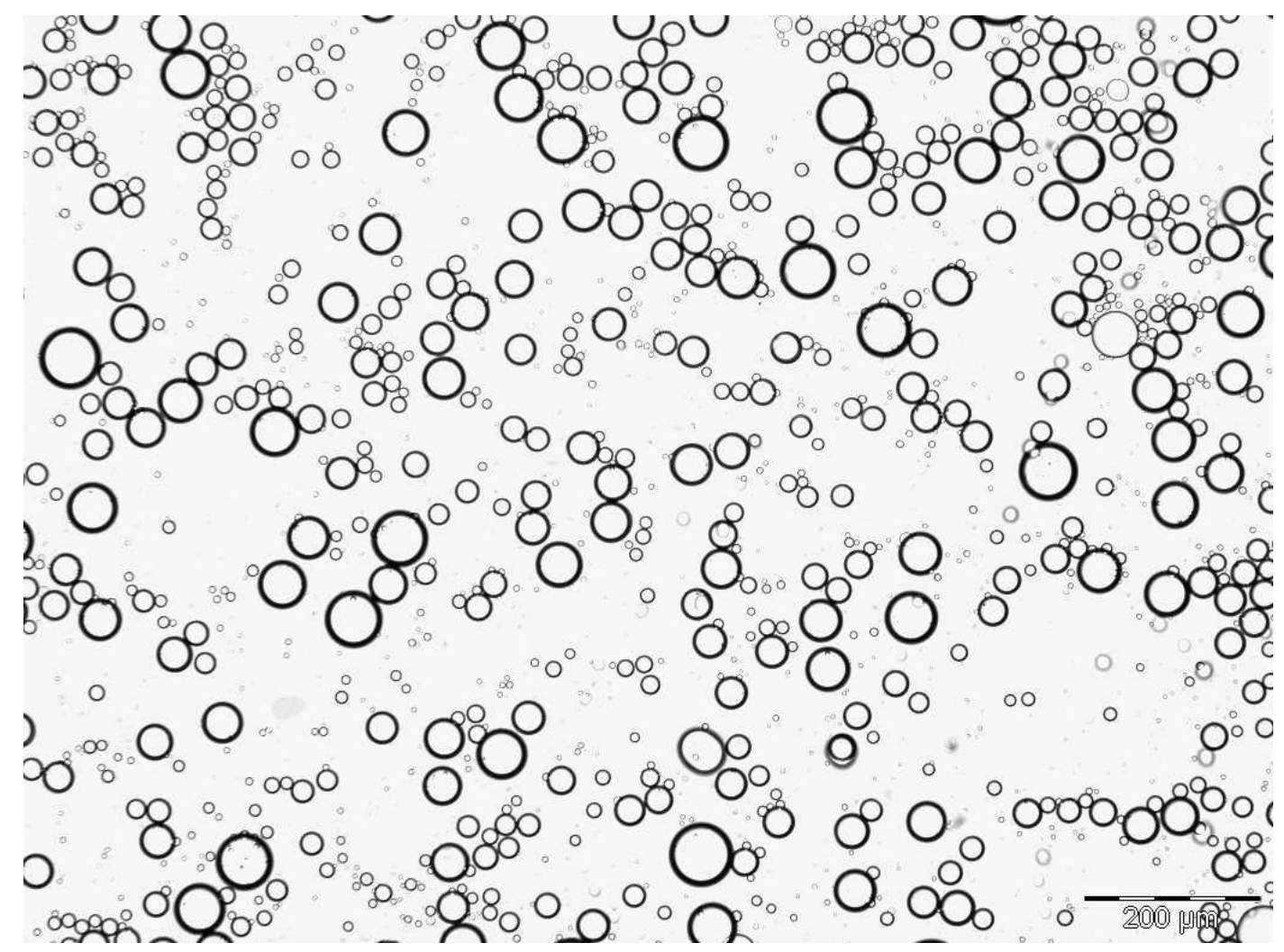

Figura A.37: Imagem da Microestrutura da Emulsão $\lambda=20$ e $\phi=2 \%$

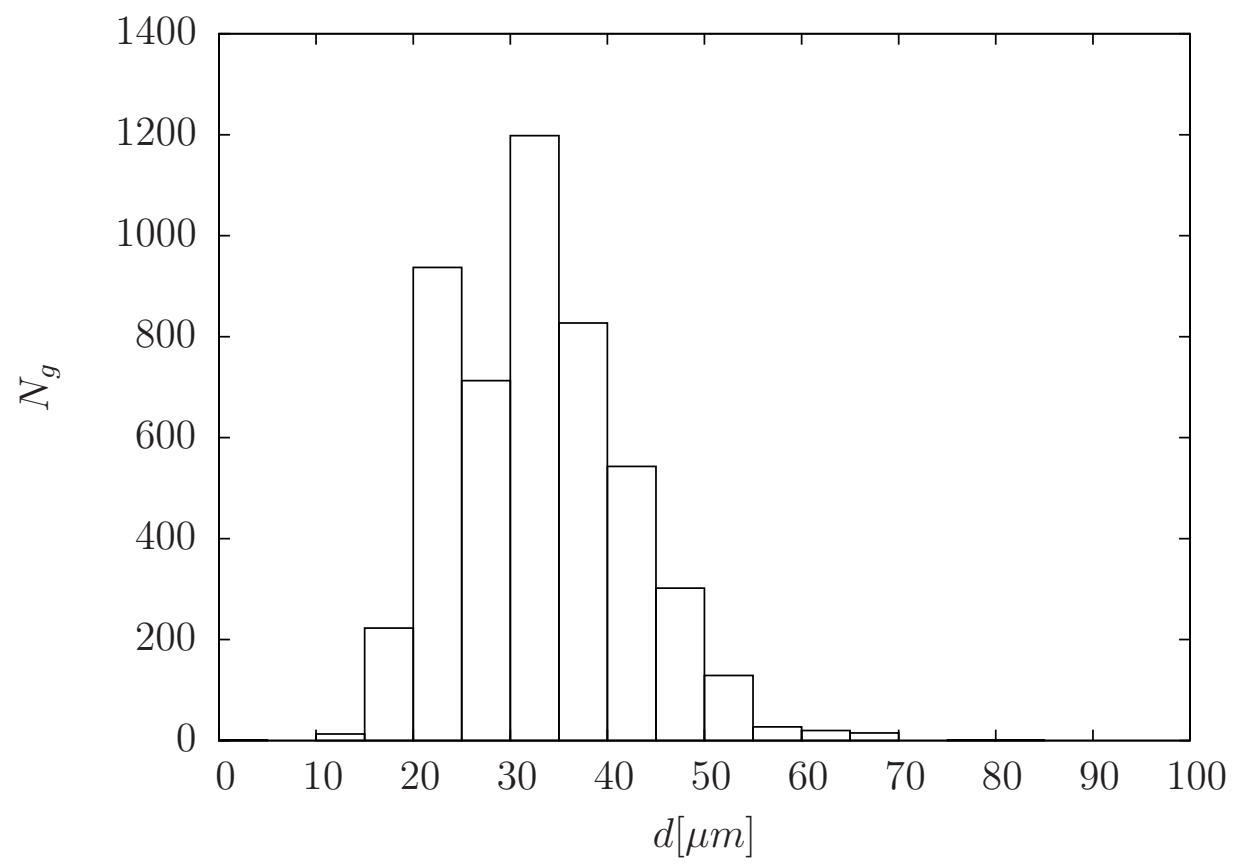

Figura A.38: Distribuição de Tamanho de gota para a emulsão $\lambda=20$ e $\phi=2 \%$. Características da microestrutura: $N_{g}=4950, \bar{a}=16,39 \mu \mathrm{m}, p=0,274$ 


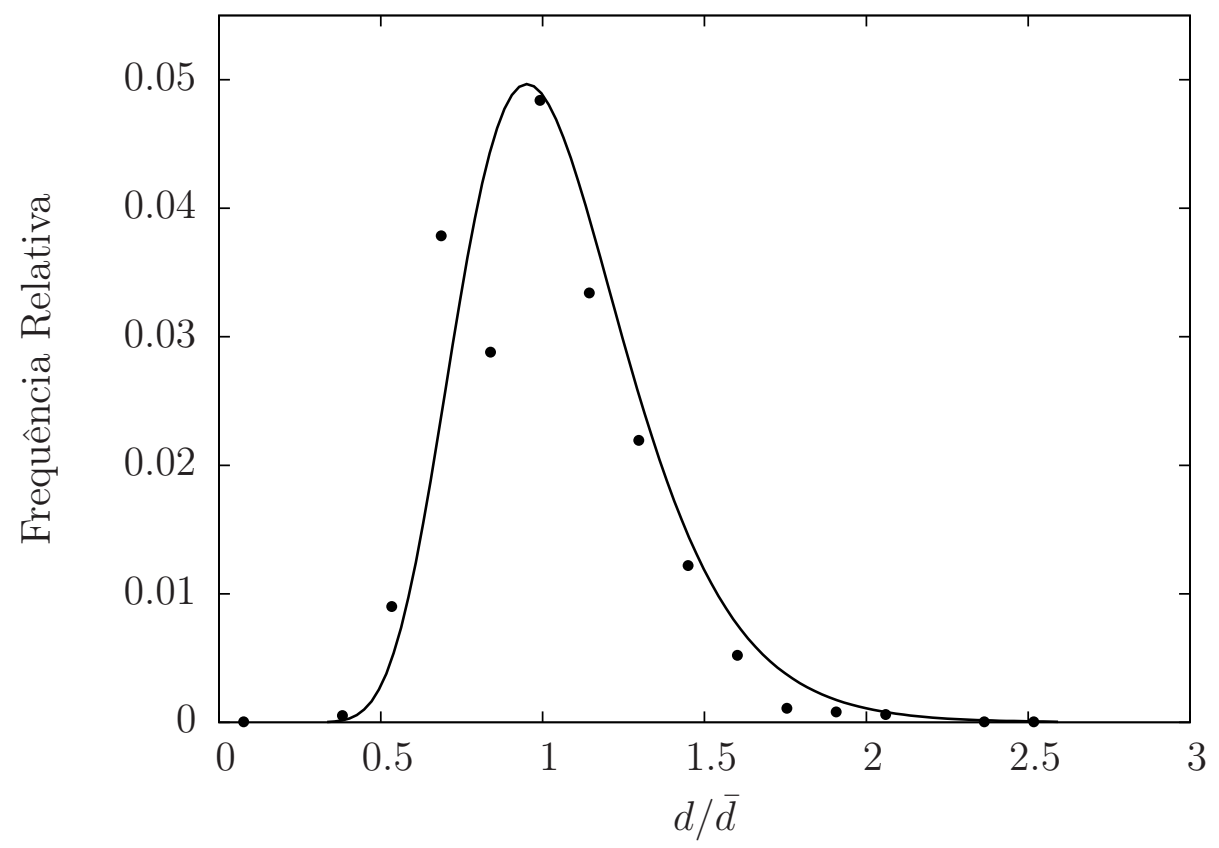

Figura A.39: Frequência Relativa $\left(N_{\text {gint }} /\left(\right.\right.$ Dim $\left._{\text {int }} \times N_{\text {gtot }}\right)$ para a emulsão $\lambda=20$ e $\phi=2 \%$. Constantes da Log-Normal: $C_{1}=0,033, C_{2}=1,06$

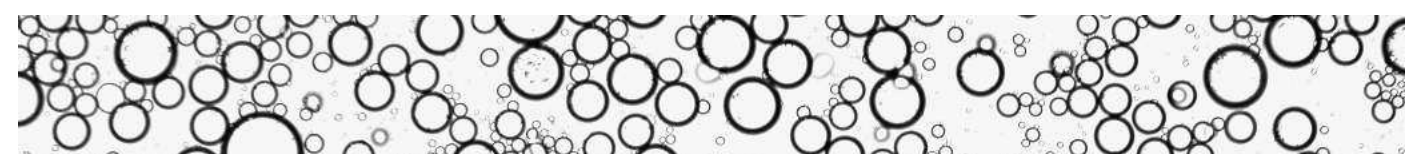
Jol

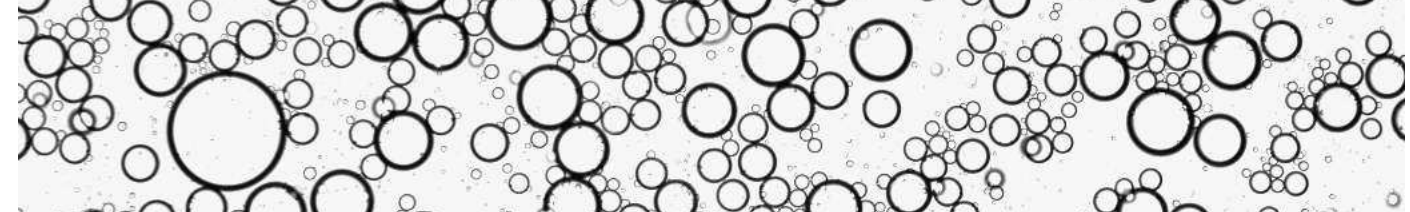

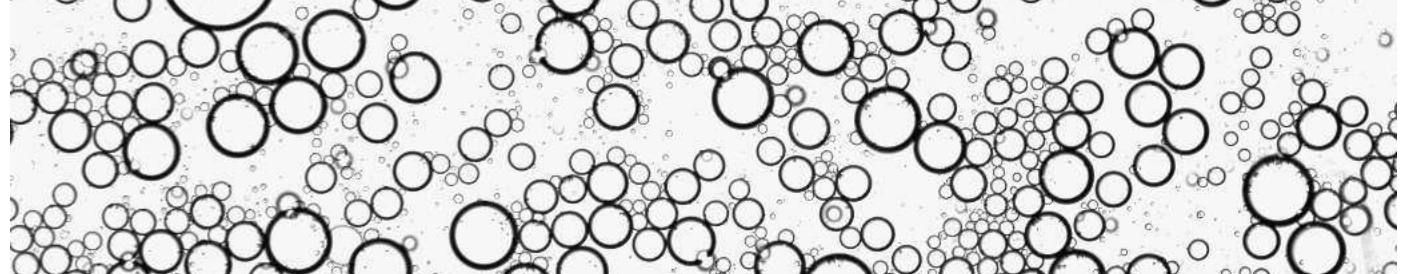

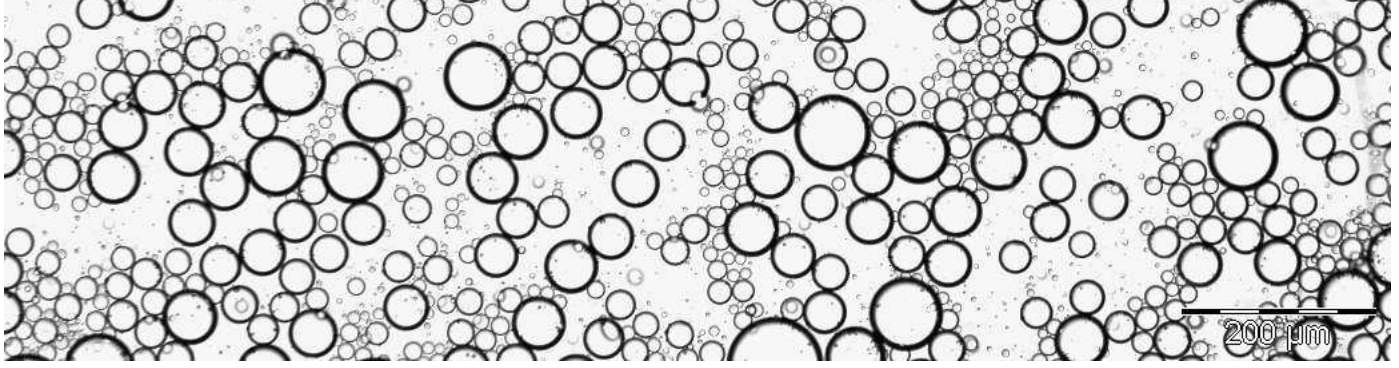

Figura A.40: Imagem da Microestrutura da Emulsão $\lambda=20$ e $\phi=5 \%$ 


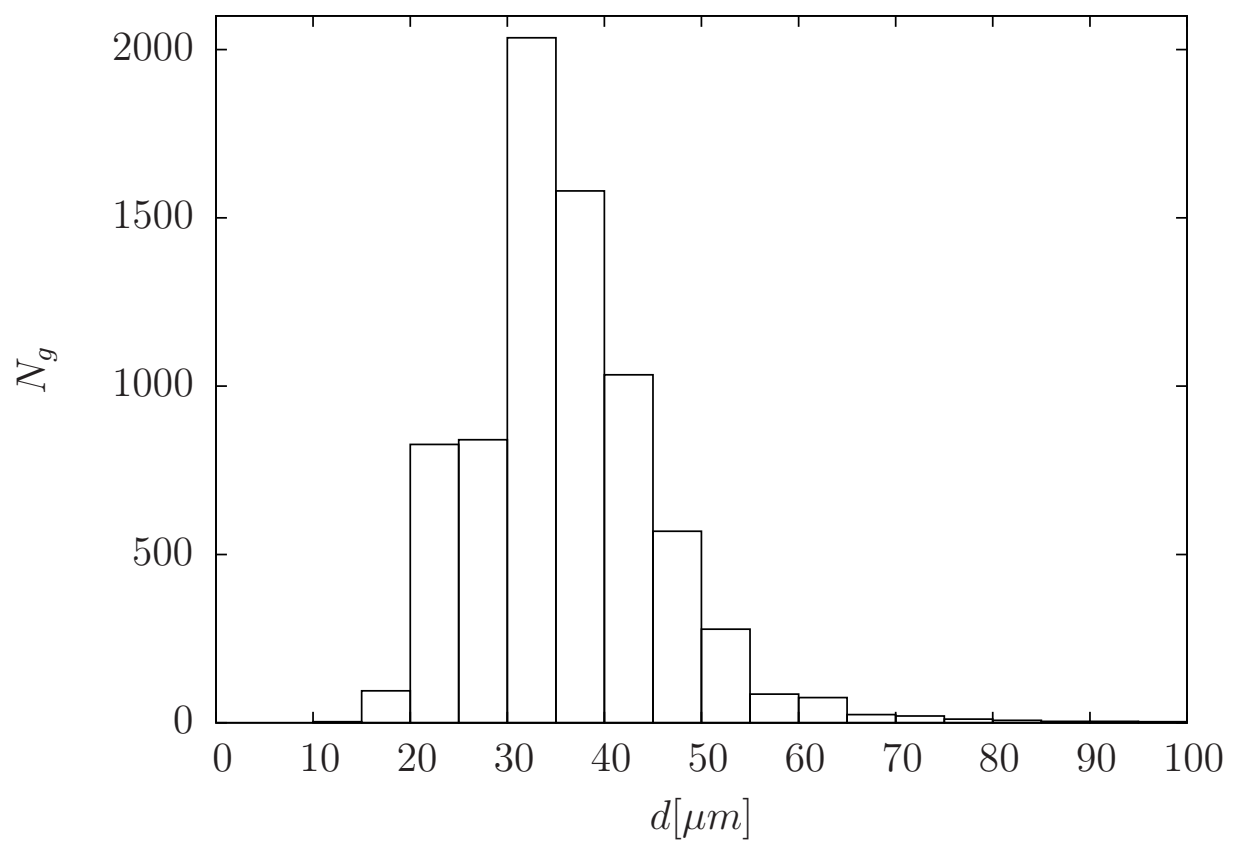

Figura A.41: Distribuição de Tamanho de gota para a emulsão $\lambda=20$ e $\phi=5 \%$. Características da microestrutura: $N_{g}=7500, \bar{a}=17,88 \mu \mathrm{m}, p=0,270$

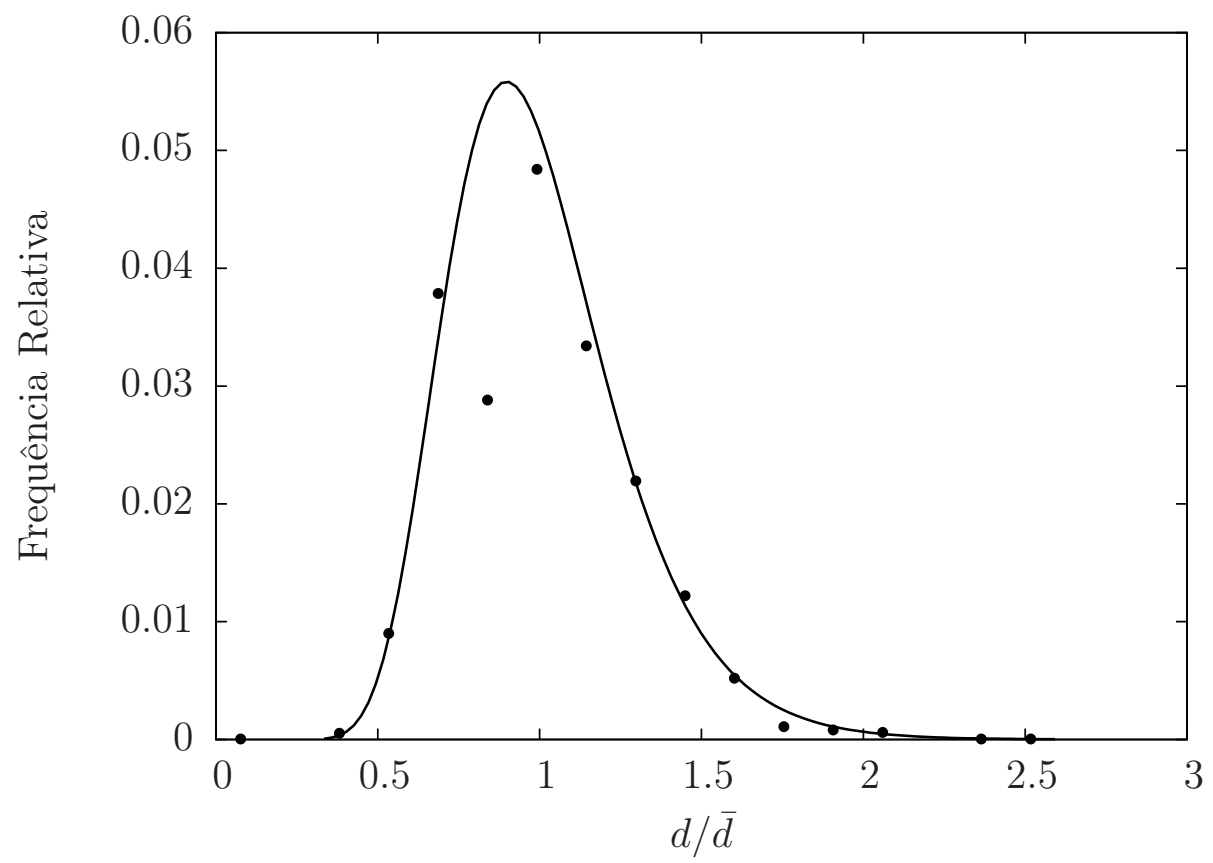

Figura A.42: Frequência Relativa $\left(N_{\text {gint }} /\left(\operatorname{Dim}_{\text {int }} \times N_{\text {gtot }}\right)\right.$ para a emulsão $\lambda=20 \mathrm{e}$ $\phi=5 \%$. Constantes da Log-Normal: $C_{1}=0,035, C_{2}=1,0$ 


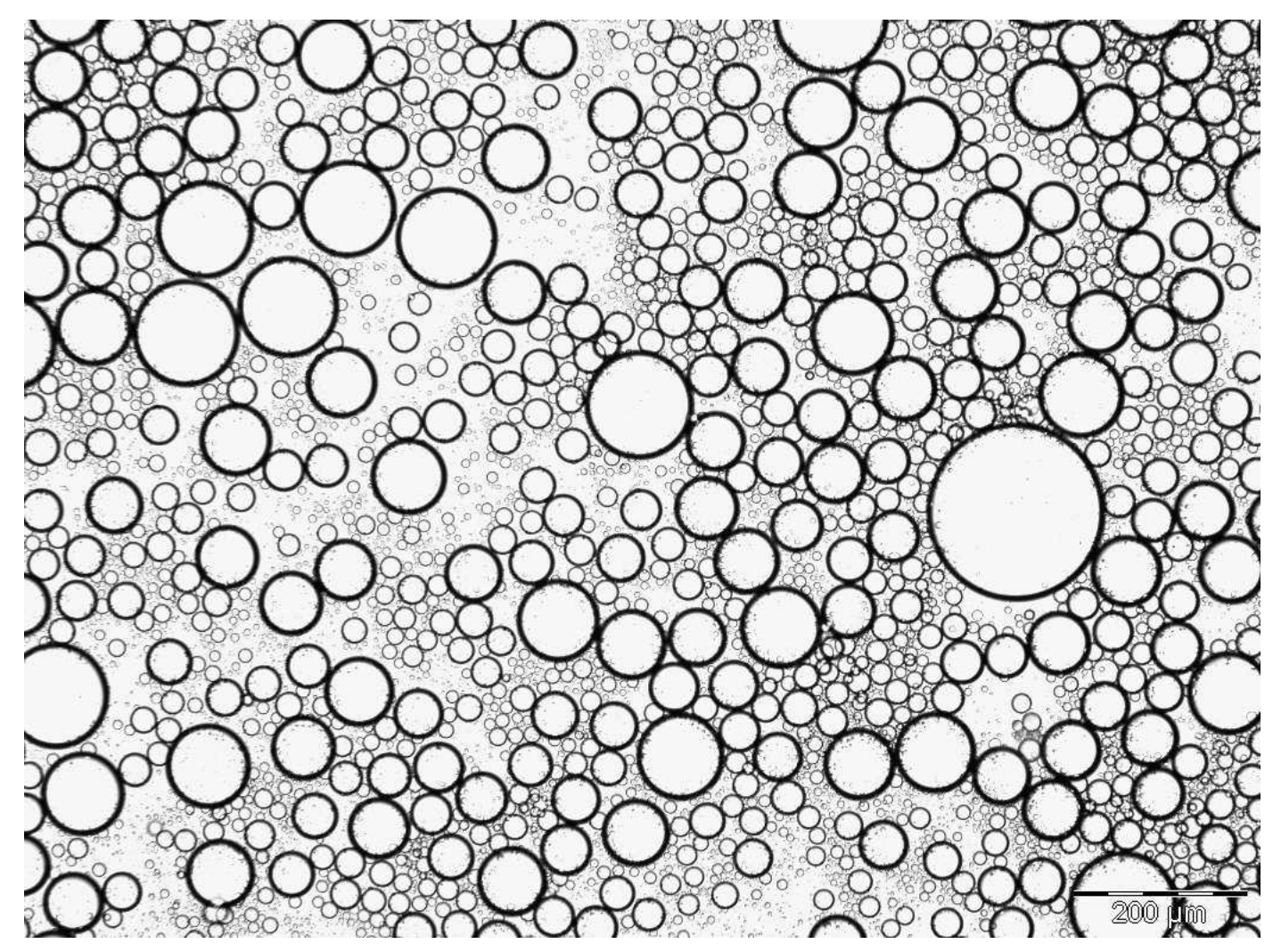

Figura A.43: Imagem da Microestrutura da Emulsão $\lambda=20$ e $\phi=20 \%$

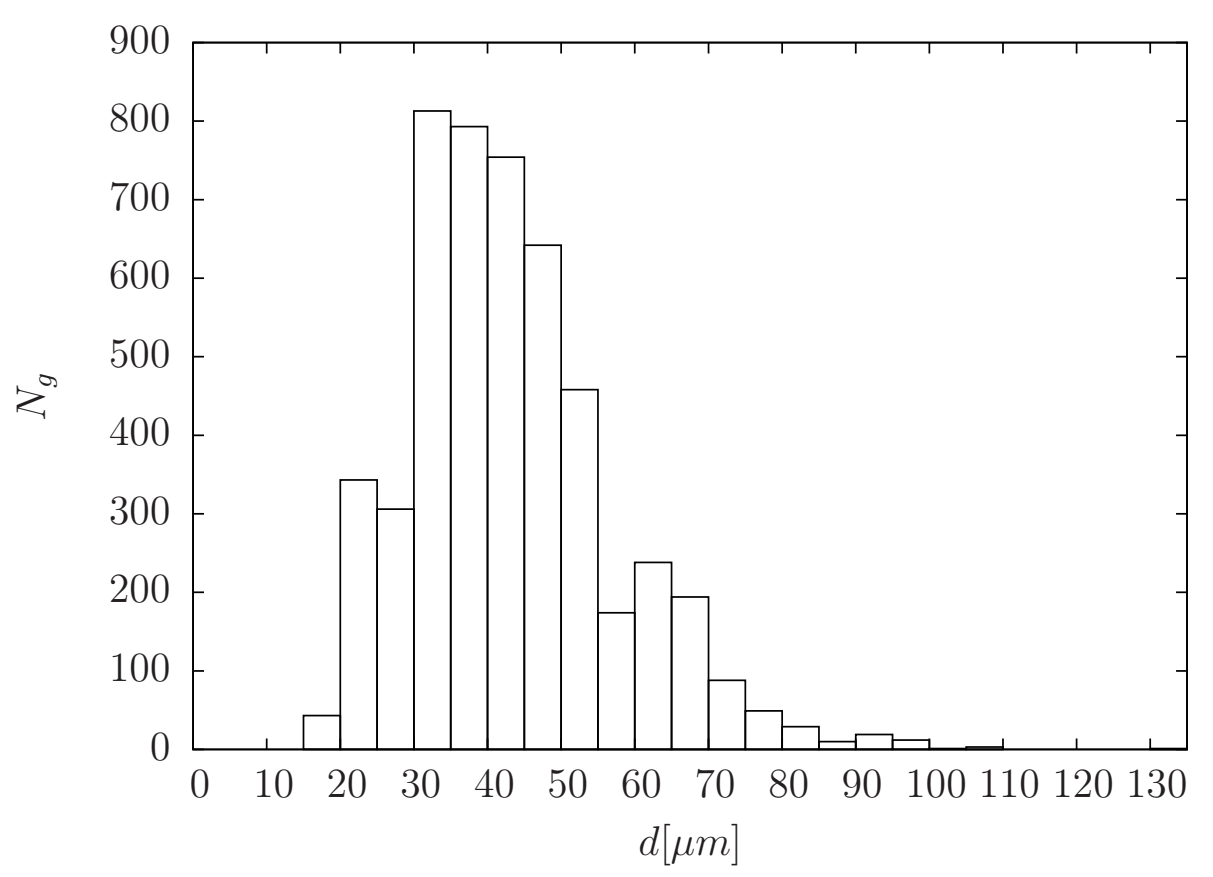

Figura A.44: Distribuição de Tamanho de gota para a emulsão $\lambda=20$ e $\phi=20 \%$. Características da microestrutura: $N_{g}=4970, \bar{a}=21,53 \mu \mathrm{m}, p=0,324$ 


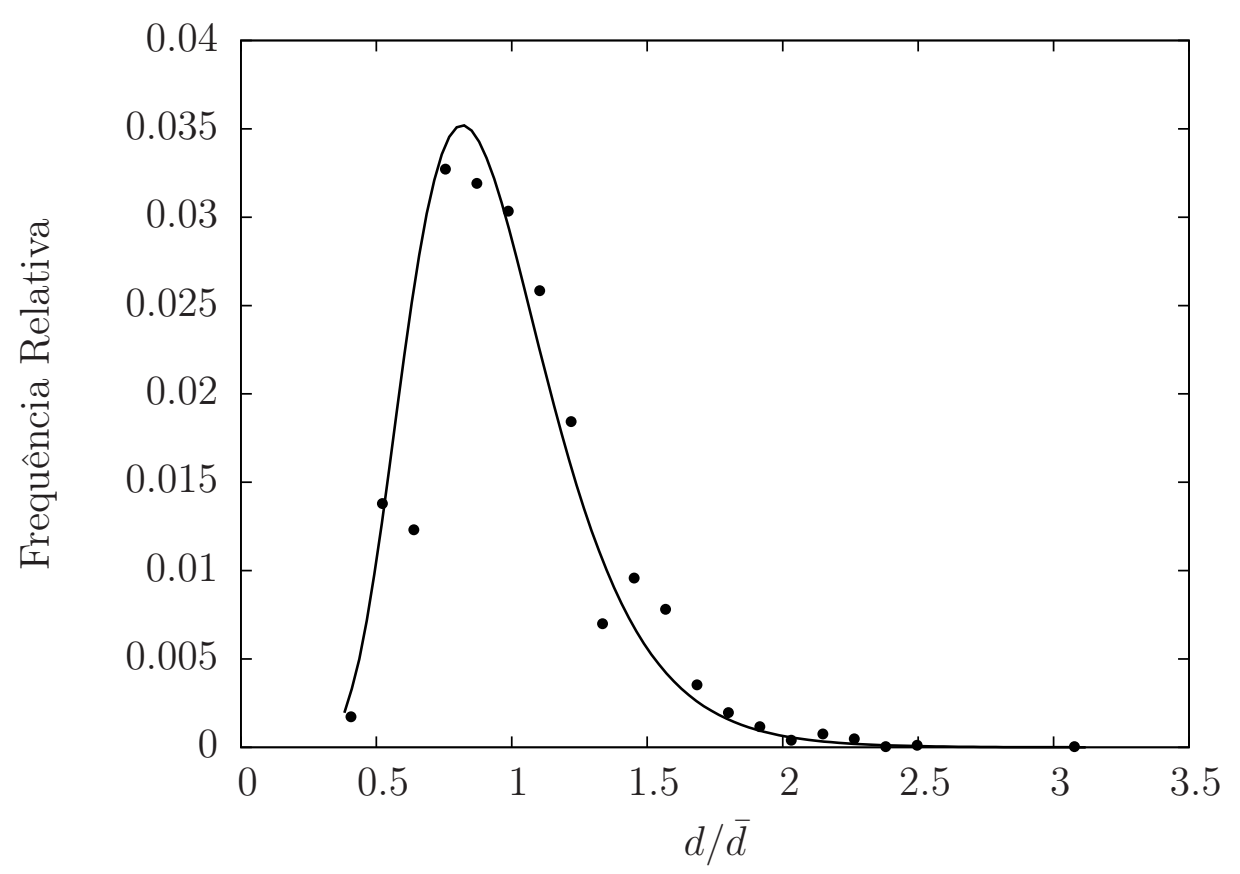

Figura A.45: Frequência Relativa $\left(N_{\text {gint }} /\left(\operatorname{Dim}_{\text {int }} \times N_{\text {gtot }}\right)\right.$ para a emulsão $\lambda=20$ e $\phi=20 \%$. Constantes da Log-Normal: $C_{1}=0,024, C_{2}=0,95$

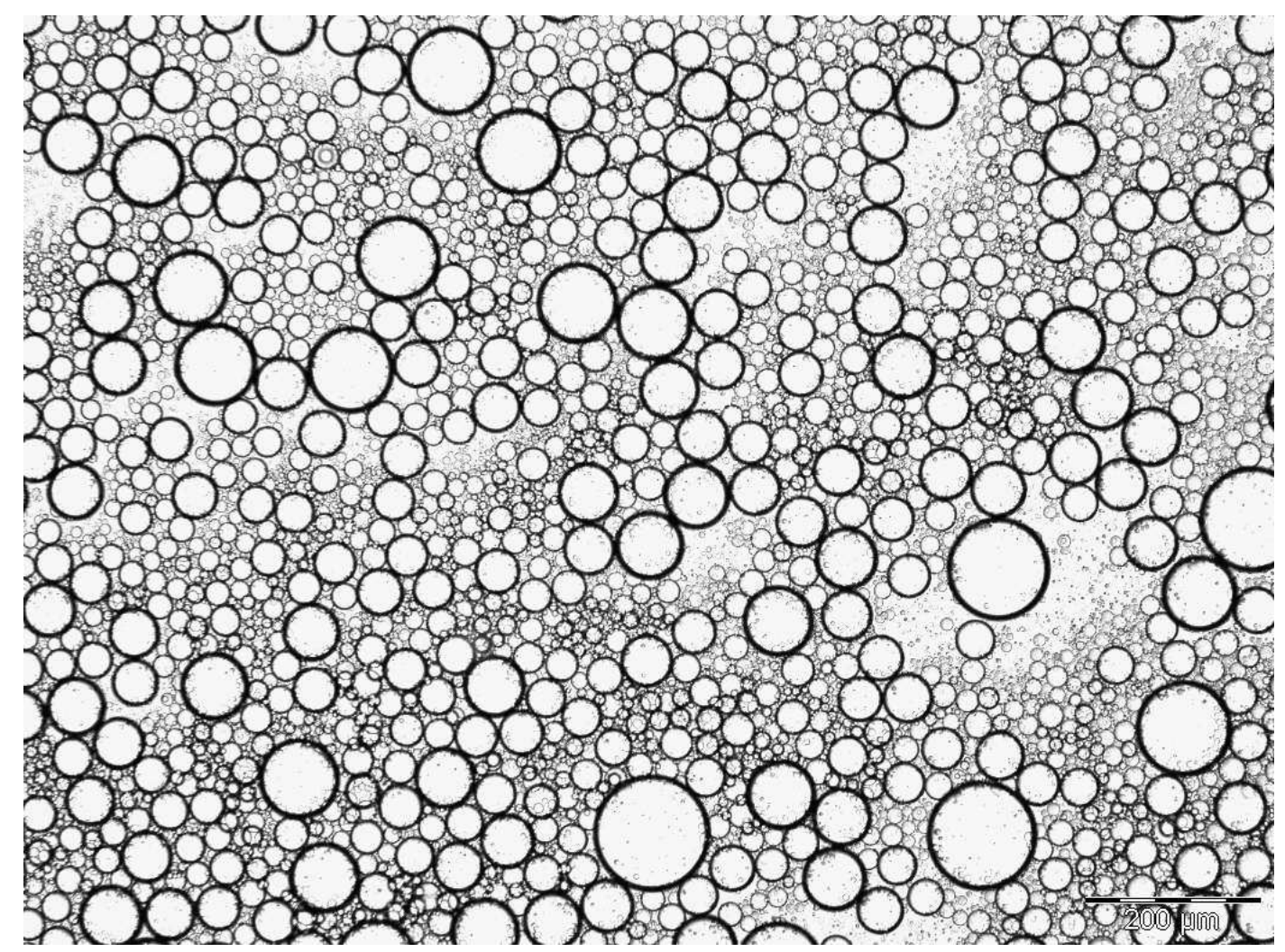

Figura A.46: Imagem da Microestrutura da Emulsão $\lambda=20$ e $\phi=40 \%$ 


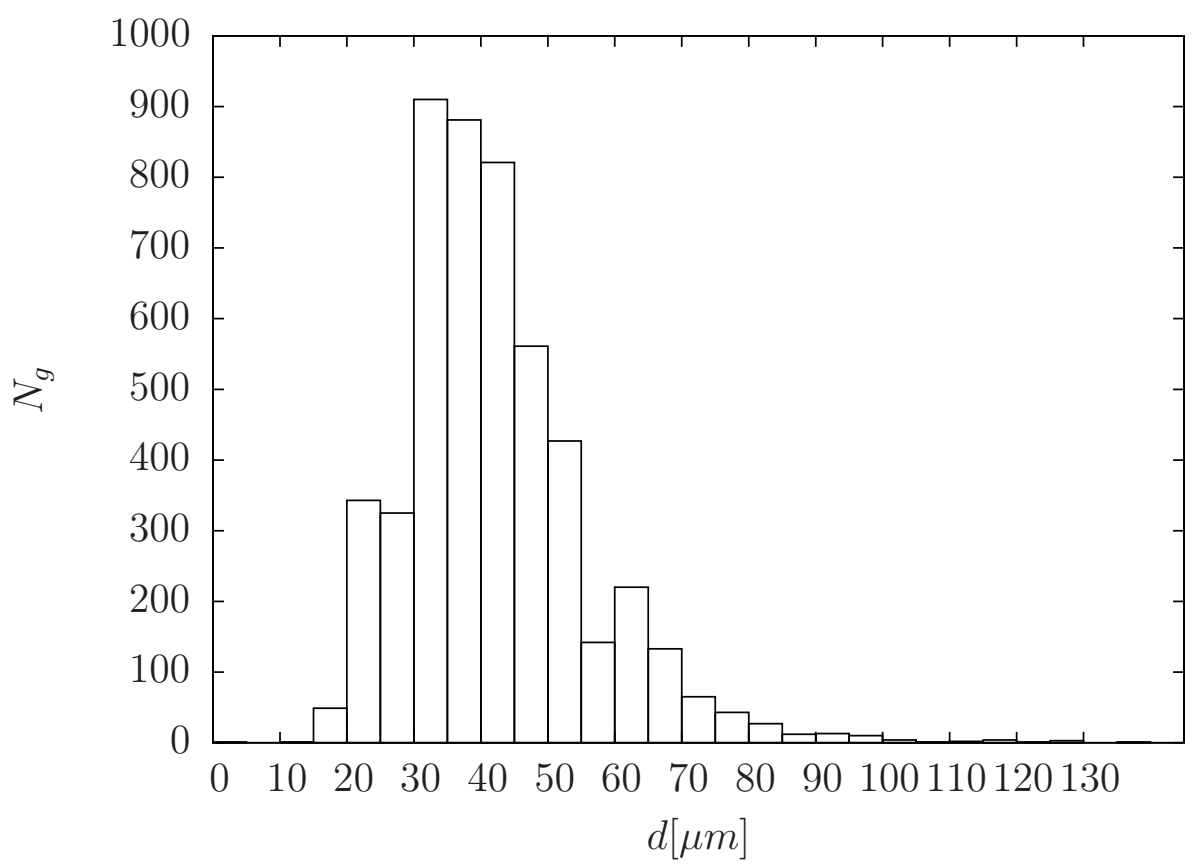

Figura A.47: Distribuição de Tamanho de gota para a emulsão $\lambda=20$ e $\phi=40 \%$. Características da microestrutura: $N_{g}=5000, \bar{a}=21,00 \mu m, p=0,33$

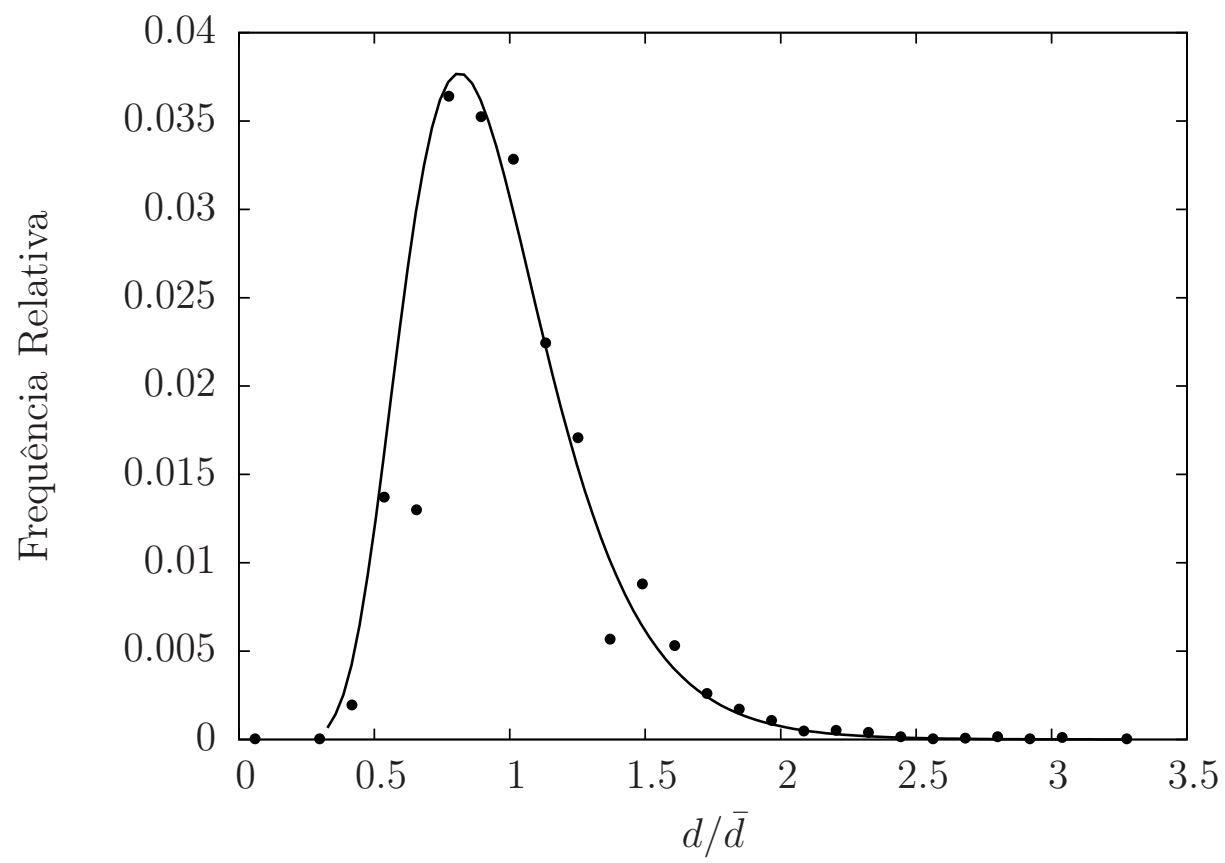

Figura A.48: Frequência Relativa $\left(N_{\text {gint }} /\left(\operatorname{Dim}_{\text {int }} \times N_{\text {gtot }}\right)\right.$ para a emulsão $\lambda=20 \mathrm{e}$ $\phi=40 \%$. Constantes da Log-Normal: $C_{1}=0,026, C_{2}=0,96$ 


\section{Apêndice B Teoria de Escoamento de Emulsão de Alta Razão de Viscosidade em Tubos}

A equação da evolução da forma da superfície da gota adimensionalizada é dada por:

$$
\frac{d \boldsymbol{A}}{d t}=\widehat{C a}\left[\boldsymbol{W} \cdot \boldsymbol{A}-\boldsymbol{A} \cdot \boldsymbol{W}+\frac{5}{2 \lambda} \boldsymbol{D}\right]-c \boldsymbol{A} .
$$

Considerando o regime permanente de deformação da gota:

$$
0=\widehat{C a}\left[\boldsymbol{W} \cdot \boldsymbol{A}-\boldsymbol{A} \cdot \boldsymbol{W}+\frac{5}{2 \lambda} \boldsymbol{D}\right]-c \boldsymbol{A} .
$$

Expandindo a eq. B.2, tem-se que:

$$
0=\frac{1}{2} \dot{\gamma} \widehat{C a}\left[\begin{array}{cc}
-A_{z r} & -A_{z z} \\
A_{r r} & A_{r z}
\end{array}\right]-\frac{1}{2} \dot{\gamma} \widehat{C a}\left[\begin{array}{cc}
A_{r z} & -A_{r r} \\
A_{z z} & -A_{z r}
\end{array}\right]+\frac{5}{4 \lambda} \dot{\gamma} \widehat{C a}\left[\begin{array}{cc}
0 & 1 \\
1 & 0
\end{array}\right]-c\left[\begin{array}{cc}
A_{r r} & A_{r z} \\
A_{z r} & A_{z z}
\end{array}\right]
$$

Da solução do sistema de equações da eq. B.3, resulta que:

$$
\left\{\begin{array}{l}
A_{r z}=\frac{5}{4 \lambda} \sqrt{\epsilon} \dot{\gamma}\left(\epsilon \dot{\gamma}^{2}+1\right)^{-1} \\
A_{z z}=\frac{5}{4 \lambda} \epsilon \dot{\gamma}^{2}\left(\epsilon \dot{\gamma}^{2}+1\right)^{-1} \\
A_{r r}=-\frac{5}{4 \lambda} \epsilon \dot{\gamma}^{2}\left(\epsilon \dot{\gamma}^{2}+1\right)^{-1}
\end{array}\right.
$$

em que $\dot{\gamma}=d u_{z} / d r, \epsilon=(\widehat{C a} / c)^{2}$ e $c=20 / 19$ 


\section{Apêndice C Teoria de Escoamento de Emulsões de Alta Razão de Viscosidade em Cisalhamento Simples}

Nesta seção o objetivo é prever a evolução da forma da superfície da gota no escoamento de cisalhamento simples. A equação da deformação da gota é dada pela expressão:

$$
\frac{d \boldsymbol{A}}{d t}=\boldsymbol{W} \cdot \boldsymbol{A}-\boldsymbol{A} \cdot \boldsymbol{W}+\frac{5}{2 \lambda} \boldsymbol{E}-\frac{\sigma_{s}}{\lambda \mu a}-c \boldsymbol{A},
$$

em que, $\boldsymbol{W}$ está associado com a rotação da gota e é a parte anti-simétrica do tensor gradiente de velocidade, $\sigma_{s}$ é a tensão superficial entre a gota e o fluido da fase contínua, $c=20 / 19$ e $a$ é o raio da gota. Neste caso $\boldsymbol{D}=1 / 2\left(\boldsymbol{e}_{1} \boldsymbol{e}_{2}+\boldsymbol{e}_{2} \boldsymbol{e}_{1}\right)$ e $\boldsymbol{W}=1 / 2\left(\boldsymbol{e}_{1} \boldsymbol{e}_{2}-\right.$ $\left.\boldsymbol{e}_{2} \boldsymbol{e}_{1}\right)$. Para simplificar a notação toma-se a igualdade de $d \boldsymbol{A} / d t=\dot{\boldsymbol{A}}$. O sistema de equações resultante da C.1 para o escoamento de cisalhamento simples é:

$$
\left\{\begin{array}{l}
\dot{A}_{11}=\dot{\gamma} A_{12}-K A_{11} \\
\dot{A}_{12}=\dot{\gamma}\left(A_{22}-A_{11}\right)+J-K A_{12} \\
\dot{A}_{22}=\dot{\gamma} A_{12}-K A_{11}
\end{array}\right.
$$

em que $J=5 \dot{\gamma} / 4 \lambda, K=\tau_{s} c / \lambda \eta a(c=20 / 19)$ e que $\dot{A}_{12}=\dot{A}_{21}$. Pode-se escrever o sistema de equações C.2 na forma compacta $\dot{\boldsymbol{A}}=\boldsymbol{T} . \boldsymbol{A}+\boldsymbol{R}$ que representa a seguinte igualdade:

$$
\left[\begin{array}{c}
\dot{A}_{11} \\
\dot{A}_{12} \\
\dot{A}_{22}
\end{array}\right]=\left[\begin{array}{ccc}
-K & \dot{\gamma} & 0 \\
-\dot{\gamma} / 2 & -K & \dot{\gamma} / 2 \\
0 & -\dot{\gamma} & -K
\end{array}\right]\left[\begin{array}{l}
A_{11} \\
A_{12} \\
A_{22}
\end{array}\right]+\left[\begin{array}{l}
0 \\
J \\
0
\end{array}\right]
$$

Para resolver o sistema de equações é necessário proceder ao seu desacoplamento. O procedimento de desacoplamento passa por montar uma matriz $(\boldsymbol{M})$ em que as suas colunas representam os autovalores de $\boldsymbol{A}$ e $\boldsymbol{M}^{-1}$ representa a matriz inversa de $\boldsymbol{M}$. A matriz $\boldsymbol{M}$ e a sua inversa foram obtidas pelo programa Maple13. Com estas matrizes 
pode-se escrever na forma compacta:

$$
M^{-1} \cdot \dot{A}=M^{-1} \cdot T \cdot M \cdot M^{-1} \cdot A+M^{-1} \cdot R
$$

Definindo $\dot{\boldsymbol{s}}=\boldsymbol{M}^{-1} . \dot{\boldsymbol{A}}, G=\boldsymbol{M}^{-1} \cdot \boldsymbol{T} \cdot \boldsymbol{M}, \boldsymbol{s}=\boldsymbol{M}^{-1} . \boldsymbol{A}$ e $z=\boldsymbol{M}^{-1} . \boldsymbol{R}$ e efetuando-se as operações nas igualdades enunciadas escreve-se:

$$
\left\{\begin{array}{l}
\dot{s}_{1}=-K s_{1} \\
\dot{s}_{2}=(-K+i \dot{\gamma}) s_{2}+i J / 2 \\
\dot{s}_{3}=(-K-i \dot{\gamma}) s_{3}+i J / 2
\end{array}\right.
$$

Para resolver este sistema aplica-se a condição inicial da forma da gota. Antes de a gota estar sujeita às tensões oriundas do escoamento a sua superfície se encontra no estado inicial esférico, $s(t=0)=0$. A solução deste sistema de equações é:

$$
\left\{\begin{array}{l}
\dot{s}_{1}(t)=0 \\
\dot{s}_{2}(t)=-\frac{1}{2} \frac{J(i K-\dot{\gamma})\left[-1+e^{-(K-i \dot{\gamma}) t}\right]}{K^{2}+\dot{\gamma}^{2}} \\
\dot{s}_{3}(t)=\frac{1}{2} \frac{J(i K+\dot{\gamma})\left[-1+e^{-(K+i \dot{\gamma}) t}\right]}{K^{2}+\dot{\gamma}^{2}}
\end{array}\right.
$$

Definiu-se que $\boldsymbol{s}=\boldsymbol{M}^{-1} . \boldsymbol{A}, \log \boldsymbol{A}=\boldsymbol{M} . \boldsymbol{s}$, que da forma expandida fica:

$$
\left[\begin{array}{l}
A_{11} \\
A_{12} \\
A_{22}
\end{array}\right]=\left[\begin{array}{ccc}
1 & 1 & -1 \\
0 & -i & i \\
1 & 1 & 1
\end{array}\right] \cdot\left[\begin{array}{l}
s_{1} \\
s_{2} \\
s_{3}
\end{array}\right]
$$

Desta forma obtém-se as seguintes igualdades:

$$
\left\{\begin{array}{l}
A_{11}=s_{1}-s_{2}-s_{3} \\
A_{12}=-i s_{2}-i s_{3} \\
A_{22}=s_{1}+s_{2}+s_{3}
\end{array}\right.
$$


Assim obtém-se as expressões para as componentes do tensor de evolução da forma da superfície da gota, lembrando que $A_{22}=-A_{11}$ :

$$
\begin{aligned}
& A_{11}=\frac{J \dot{\gamma}}{K^{2}+\dot{\gamma}^{2}}\left[1-e^{-K t} \cos (\dot{\gamma} t)-\frac{K}{\dot{\gamma}} e^{-K t} \operatorname{sen}(\dot{\gamma} t)\right] \\
& A_{12}=\frac{J \dot{\gamma}}{K^{2}+\dot{\gamma}^{2}}\left[1-e^{-K t} \cos (\dot{\gamma} t)+\frac{\dot{\gamma}}{K} e^{-K t} \operatorname{sen}(\dot{\gamma} t)\right]
\end{aligned}
$$

A adimensionalização das expressões de $A_{11}$ e de $A_{12}$ são baseadas no número de capilaridade $\left(C a=\dot{\gamma} a \mu / \tau_{s}\right)$. As expressões de $A_{11}$ e de $A_{12}$ adimensionalizadas são:

$$
\begin{aligned}
& A_{11}=\frac{5}{4 \lambda} \frac{1}{P^{2}+1}\left[1-e^{-P C a t} \cos (C a t)-P e^{-P C a t} \operatorname{sen}(C a t)\right] \\
& A_{12}=\frac{5}{4 \lambda} \frac{P}{P^{2}+1}\left[1-e^{-P C a t} \cos (C a t)+\frac{1}{P} e^{-P C a t} \operatorname{sen}(C a t)\right]
\end{aligned}
$$

em que $P=c / \lambda C a$. Se assumirmos que a evolução da forma da superfície da gota atingiu o seu regime permanente resolve-se o sistema de equações anterior tal que $\frac{{ }_{d} \boldsymbol{A}}{d t}=0$ obtendo-se a solução para as expressões para as componentes do tensor $\boldsymbol{A}$ para o caso particular de $\frac{d \boldsymbol{A}}{d t} \neq 0$ quando o tempo tende para infinito. Desta forma as componentes de interesse do tensor $\boldsymbol{A}$ :

$$
\left\{\begin{array}{l}
A_{11}=\frac{J \dot{\gamma}}{J^{2}+\dot{\gamma}^{2}} \\
A_{12}=\frac{J K}{J^{2}+\dot{\gamma}^{2}}
\end{array}\right.
$$

Na forma adimensional:

$$
\left\{\begin{array}{l}
A_{11}=\frac{5}{4 \lambda} \frac{1}{P^{2}+1} \\
A_{12}=\frac{5}{4 \lambda} \frac{P}{P^{2}+1}
\end{array}\right.
$$

Partindo da eq. 3.2, escreve-se que:

$$
\overline{\boldsymbol{S}}=\frac{1}{N} \sum_{\alpha=1}^{N}-2 \eta v_{p} \boldsymbol{B}
$$

em que $\mathrm{N}$ é a quantidade total de gotas, $n=N / V$ definido como sendo o número de densidade e $v_{p}$ é o volume da gota. Multiplicando a eq. C.13 pelo número de densidade, 
fica:

$$
<\overline{\boldsymbol{S}}>=-2 \eta \phi \boldsymbol{B}
$$

em que $\phi$ é a razão entre o volume de todas as gotas e o volume total da emulsão. Ou seja, é a razão entre o volume de óleo e o volume total que é igual ao volume de óleo mais o volume de água. Fazendo uma análise de dimensões constata-se que $\langle\boldsymbol{S}\rangle$ tem unidades de tensão $\left[N / m^{2}\right]$. Desta forma para obtermos unidades de viscosidade divide-se os dois termos da expressão por $\dot{\gamma}_{0}$ que é a taxa de cisalhamento típica do escoamento, obtendo-se:

$$
\frac{\eta_{e f}}{\eta}=-2 \phi \frac{\boldsymbol{B}}{\dot{\gamma}_{0}}
$$

A componente de interesse para a dedução de uma expressão prognóstica da viscosidade é a componente 12 devido às tensões de cisalhamento resultantes do escoamento. $\mathrm{O}$ tensor de segunda ordem $\boldsymbol{B}$ é dado por (Frankel e Acrivos (1970)):

$$
\boldsymbol{B}=-\frac{5(\lambda-1)}{2 \lambda+3} \boldsymbol{D}-\frac{4}{2 \lambda+3} \frac{\tau_{s}}{\mu a} \boldsymbol{A}-\frac{30(\lambda-1)^{2}}{7(2 \lambda+3)^{2}} L(\boldsymbol{A}, \boldsymbol{D})
$$

em que:

$$
L(\boldsymbol{A}, \boldsymbol{D})=\boldsymbol{A} \cdot \boldsymbol{D}+\boldsymbol{D} \cdot \boldsymbol{A}-\frac{2}{3}(\boldsymbol{A}: \boldsymbol{D}) \boldsymbol{I}
$$

É de notar que para o caso de escoamento de cisalhamento simples a componente 12 da função $L(\boldsymbol{A}, \boldsymbol{D})$ é nula. Para o caso de qualquer razão de viscosidade a expressão da viscosidade de uma emulsão infinitamente diluída é:

$$
\frac{\eta_{e f}}{\eta}=\phi\left[\frac{5(\lambda+1)}{2 \lambda+3}+\frac{8}{C a(2 \lambda+3)} A_{12}\right]
$$

Fazendo a aproximação para altos $\lambda$ :

$$
\boldsymbol{B}=-\left(\frac{5}{2}-\frac{25}{4 \lambda}\right) \boldsymbol{D}-\frac{2}{\lambda} \frac{\tau_{s}}{\mu a} \boldsymbol{A}-\frac{15}{14} L(\boldsymbol{A}, \boldsymbol{D})
$$

Desta forma para o caso de altos $\lambda$ a expressão da viscosidade é:

$$
\frac{\eta_{e f}}{\eta}=\phi\left[\left(\frac{5}{2}-\frac{25}{4 \lambda}\right)+\frac{4}{\lambda C a} A_{12}\right]
$$




\section{Apêndice D Cálculo de Incertezas}

\section{D.1 Incerteza da Viscosidade obtida em Cisalhamento Linear}

A incerteza da medição da viscosidade apurada pelo reômetro foi considerada o máximo entre o desvio padrão da viscosidade obtida em cinco medições para cada taxa de cisalhamento e a calculada através da expressão do torque do reômetro (eq. 2.38):

$$
\operatorname{In}(\eta)=\left|\frac{\partial \eta}{\partial \mathcal{T}}\right||\operatorname{In}(\mathcal{T})|+\left|\frac{\partial \eta}{\partial \dot{\gamma}(R)}\right||\operatorname{In}(\dot{\gamma}(R))|+\left|\frac{\partial \eta}{\partial R}\right||\operatorname{In}(R)|
$$

Segundo o fabricante do reômetro, a resolução do torque é $0,2 \mu m N$. A incerteza do raio do disco usado no experimento é de $10 \times 10^{-6} \mathrm{~m}$. É de notar que a taxa de cisalhamento é um valor de entrada para iniciar o experimento.

\section{D.2 Incerteza da Viscosidade obtida no Escoamento em Tubo Capilar}

A viscosidade intrínseca pode ser calculada através da equação de Poiseuille:

$$
\eta=\frac{\pi R^{4} \Delta P}{8 Q L}
$$

A incerteza da viscosidade calculada pela equação de Poiseuille é calculada pela expressão:

$$
\operatorname{In}(\eta)=\left|\frac{\partial \eta}{\partial R}\right||\operatorname{In}(R)|+\left|\frac{\partial \eta}{\partial \Delta P}\right||\operatorname{In}(\Delta P)|+\left|\frac{\partial \eta}{\partial Q}\right||\operatorname{In}(Q)|+\left|\frac{\partial \eta}{\partial L}\right||\operatorname{In}(L)|
$$

A incerteza da vazão é o menor valor da vazão possível de ser inserido na bomba de seringa, $\operatorname{In}(Q)=5,5 \times 10^{-3} \mathrm{~m}^{3} / \mathrm{s}$. A incerteza do manômetro de pressão fornecido pelo fabricante é $0,1 \%$ do fundo de escala, $\operatorname{In}(\Delta P)=37,33 \mathrm{~Pa}$. Quanto ao tubo de capilar a 
incerteza fornecida pelo fabricante em relação ao comprimento é, $\operatorname{In}(L)=5 \times 10^{-} 4 \mathrm{~m}$, e em relação ao raio é $\operatorname{In}(R)=0,02 \times 10^{-} 3 \mathrm{~m}$.

No caso da viscosidade ser calculada pela equação:

$$
\eta_{w}=\tau_{w} / \dot{\gamma}_{w}
$$

é necessário calcular a incerteza de $\tau_{w}$ (eq. 2.56) e de $\dot{\gamma}_{w}$ (eq. 2.62). A incerteza da tensão de cisalhamento na região de parede é calculada como:

$$
\operatorname{In}\left(\tau_{w}\right)=\left|\frac{\partial \tau_{w}}{\partial \Delta P}\right||\operatorname{In}(\Delta P)|+\left|\frac{\partial \tau_{w}}{\partial R}\right||\operatorname{In}(R)|+\left|\frac{\partial \tau_{w}}{\partial L}\right||\operatorname{In}(L)|
$$

A incerteza da taxa de cisalhamento na região de parede é calculada como:

$$
\operatorname{In}\left(\dot{\gamma}_{w}\right)=\left|\frac{\partial \dot{\gamma}_{w}}{\partial Q}\right||\operatorname{In}(Q)|+\left|\frac{\partial \dot{\gamma}_{w}}{\partial R}\right||\operatorname{In}(R)|+\left|\frac{\partial \dot{\gamma}_{w}}{\partial \Delta P}\right||\operatorname{In}(\Delta P)|
$$

A incerteza da viscosidade calculada na região de parede é obtida pela expressão:

$$
\operatorname{In}\left(\eta_{w}\right)=\left|\frac{\partial \eta_{w}}{\partial \tau_{w}}\right|\left|\operatorname{In}\left(\tau_{w}\right)\right|+\left|\frac{\partial \eta_{w}}{\partial \dot{\gamma}_{w}}\right|\left|\operatorname{In}\left(\dot{\gamma}_{w}\right)\right|
$$

